\title{
Platinum Complexes of Bicyclopropylidene and Related Ligands
}

by

Sarah Amy Hoyte

\section{Victoria \\ UNIVERSITY OF WELLINGTON \\ Te Whare Wānanga \\ o te Ūpoko o te Ika a Māui}

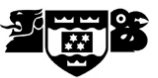

\author{
A thesis \\ submitted to the Victoria University of Wellington \\ in fulfilment of the requirements for the degree of \\ Doctor of Philosophy \\ in Chemistry
}

Victoria University of Wellington

2014 


\section{Abstract}

The coordination chemistry of the cyclopropyl-substituted alkenes, bicyclopropylidene $(\mathrm{BCP})$ and methylenecyclopropane $(\mathrm{MCP})$, with platinum was explored. A range of complexes with $\eta^{2}$-alkene ligands were synthesised by the displacement of a ligand, typically ethene, from a precursor complex. These complexes are $[\mathrm{Pt}(\mathrm{L})(\mathrm{P}-\mathrm{P})] \quad\left(\mathrm{L}=\mathrm{BCP}, \quad \mathrm{MCP} ; \mathrm{P}-\mathrm{P}=\mathrm{Ph}_{2} \mathrm{P}\left(\mathrm{CH}_{2}\right)_{3} \mathrm{PPh}_{2}, \quad \mathrm{Cy}_{2} \mathrm{P}\left(\mathrm{CH}_{2}\right)_{2} \mathrm{PCy}_{2}\right.$, $\left.{ }^{t} \mathrm{Bu}_{2} \mathrm{P}\left(\mathrm{CH}_{2}\right)_{2} \mathrm{P}^{t} \mathrm{Bu}_{2},{ }^{t} \mathrm{Bu}_{2} \mathrm{PCH}_{2}\left(o-\mathrm{C}_{6} \mathrm{H}_{4}\right) \mathrm{CH}_{2} \mathrm{P}^{t} \mathrm{Bu}_{2}\right), \quad[\mathrm{Pt}(\mathrm{L})(\mathrm{P}-\mathrm{S})]$ (L = BCP, MCP; $\left.\mathrm{P}-\mathrm{S}={ }^{t} \mathrm{Bu}_{2} \mathrm{PCH}_{2}\left(o-\mathrm{C}_{6} \mathrm{H}_{4}\right) \mathrm{CH}_{2} \mathrm{~S}^{t} \mathrm{Bu}\right),\left[\mathrm{Pt}\left(\mathrm{C}_{2} \mathrm{H}_{4}\right)(\mathrm{L})\left(\mathrm{PR}_{3}\right)\right]\left(\mathrm{L}=\mathrm{BCP}, \mathrm{MCP} ; \mathrm{PR}_{3}=\right.$ $\left.\mathrm{PPh}_{3}, \mathrm{PCy}_{3}\right),\left[\mathrm{Pt}(\mathrm{MCP})_{2}\left(\mathrm{PR}_{3}\right)\right]\left(\mathrm{PR}_{3}=\mathrm{PPh}_{3}, \mathrm{PCy}_{3}\right)$ and $\left[\mathrm{PtCl}_{2}(\mathrm{~L})\left(\mathrm{L}^{\prime}\right)\right](\mathrm{L}=\mathrm{BCP}$, MCP; $\left.\mathrm{L}^{\prime}=\mathrm{Py}, \mathrm{DMSO}\right)$. These were the first examples of platinum complexes with $\eta^{2}$-BCP ligands, and the first bis-MCP Pt complexes.

$\mathrm{BCP}$ underwent ring-opening reactions with both $\mathrm{Pt}(0)$ and $\mathrm{Pt}(\mathrm{II})$ complexes to form the 1,3-diene allylidenecyclopropane (ACP). The first transition metal complexes of ACP $[\mathrm{Pt}(\mathrm{ACP})(\mathrm{P}-\mathrm{P})]\left(\mathrm{P}-\mathrm{P}=\mathrm{Ph}_{2} \mathrm{P}\left(\mathrm{CH}_{2}\right)_{3} \mathrm{PPh}_{2}, \mathrm{Cy}_{2} \mathrm{P}\left(\mathrm{CH}_{2}\right)_{2} \mathrm{PCy}_{2},{ }^{t} \mathrm{Bu}{ }_{2} \mathrm{P}\left(\mathrm{CH}_{2}\right)_{2} \mathrm{P}^{t} \mathrm{Bu}_{2}\right)$

were synthesised. Some of these complexes rearranged to form $\eta^{2}: \sigma^{2}$-metallacyclopentene complexes, the first instances of the formation of $\eta^{2}: \sigma^{2}$-metallacyclopentene complexes from $\eta^{2}: \pi$-diene complexes. With MCP, the ring-opening reaction only occurred with $\left[\mathrm{PtEt}_{2}(\mathrm{COD})\right]$, as a result of the anti-Markovnikov addition of $\mathrm{Pt}-\mathrm{H}$, generated by the $\beta$-hydride elimination of an Et group, across the double-bond. The major products of this reaction were the 1-methylcyclopropyl complexes $\left.\left[\mathrm{Pt}\left(\mathrm{C}_{\left(\mathrm{CH}_{2}\right.}\right)_{2} \mathrm{CH}_{3}\right) \mathrm{Et}(\mathrm{COD})\right]$ and $\left[\mathrm{Pt}\left(\mathrm{C}\left(\mathrm{CH}_{2}\right)_{2} \mathrm{CH}_{3}\right)_{2}(\mathrm{COD})\right]$, the first examples of such complexes.

Protonation of $[\mathrm{Pt}(\mathrm{L})(\mathrm{P}-\mathrm{P})]$ resulted in a ring-opening reaction to form both the 2-substituted and 1-methyl allyl complexes, $\left[\mathrm{Pt}\left(\eta^{3}-\mathrm{CH}_{2} \mathrm{CRCH}_{2}\right)(\mathrm{P}-\mathrm{P})\right]^{+}$ 
$\left(\mathrm{R}={ }^{c} \mathrm{Pr}, \quad \mathrm{Me} ; \quad \mathrm{P}-\mathrm{P}=\mathrm{Ph}_{2} \mathrm{P}\left(\mathrm{CH}_{2}\right)_{3} \mathrm{PPh}_{2}, \quad{ }^{t} \mathrm{Bu}_{2} \mathrm{PCH}_{2}\left(o-\mathrm{C}_{6} \mathrm{H}_{4}\right) \mathrm{CH}_{2} \mathrm{P}^{t} \mathrm{Bu}_{2}\right)$ and $\left[\mathrm{Pt}\left(\eta^{3}-\mathrm{CR}_{2} \mathrm{CHCHMe}\right)(\mathrm{P}-\mathrm{P})\right]^{+}\left(\mathrm{R}={ }^{c} \mathrm{Pr}, \quad \mathrm{Me} ; \mathrm{P}-\mathrm{P}=\mathrm{Ph}_{2} \mathrm{P}\left(\mathrm{CH}_{2}\right)_{3} \mathrm{PPh}_{2}\right.$, $\left.{ }^{t} \mathrm{Bu}_{2} \mathrm{PCH}_{2}\left(o-\mathrm{C}_{6} \mathrm{H}_{4}\right) \mathrm{CH}_{2} \mathrm{P}^{t} \mathrm{Bu}_{2}\right)$. The analogous 1-methyl complexes were also formed from $[\mathrm{Pt}(\mathrm{L})(\mathrm{P}-\mathrm{S})]$, wherein the alkene reacted with a hydride formed by the orthometallation of the $\mathrm{P}-\mathrm{S}$ ligand. Computational models were used to investigate the formation of the allyl structures and it was found that the activation energy had a more significant effect than complex stability on product distributions.

Complexes with $\beta$-chloroalkyl ligands $\left[\mathrm{Pt}\left(\mathrm{C}\left(\mathrm{CH}_{2}\right)_{2} \mathrm{CR}_{2} \mathrm{Cl}\right) \mathrm{Cl}(\mathrm{L})_{2}\right]\left(\mathrm{R}=\mathrm{CH}_{2}, \mathrm{H}, \mathrm{L}\right.$ $\left.=\mathrm{SEt}_{2}, \mathrm{NC}^{t} \mathrm{Bu}, \mathrm{Py}\right)$ were formed by the addition of $\mathrm{Pt}-\mathrm{Cl}$ across the alkene double bond. Phosphine complexes were formed by the displacement of a ligand from cis$\left[\mathrm{Pt}\left(\mathrm{C}\left(\mathrm{CH}_{2}\right)_{2} \mathrm{CR}_{2} \mathrm{Cl}\right) \mathrm{Cl}(\mathrm{Py})_{2}\right]\left(\mathrm{R}=\mathrm{CH}_{2}, \mathrm{H}\right)$. These are the first examples of stable $\mathrm{Pt}(\mathrm{II})$ $\beta$-haloalkyl complexes. It was found using computational models that the presence of cyclopropyl rings had a stabilising effect on these complexes. 


\section{Acknowledgments}

Writing the acknowledgments section has turned out to be a difficult task. There are so many people who have helped and supported me over the years, I'm sure I'll miss some. The most important person to thank would have to be my supervisor Prof. John L. Spencer, for all of the support and guidance over the years.

I would like to thank the members of my research group, both past and present - Kathryn, Teresa, Melanie, Brad, Chris, Rosie, Almas, David and Jacqui. Climbing Mount $\mathrm{PhD}$ with you has been exhilarating, heartbreaking and everywhere in between, but ultimately rewarding. Thank you for all of your support, ideas, proofreading and the myriad of other ways you have helped me.

I am grateful for the help and support that numerous other people at SCPS have provided me with. Dr. Joanne Harvey, my second supervisor; Dr. Matthias Lein, for the computational chemistry guidance; Ian Vorster, Dr. John Ryan, Dr. Jono Singh and Assoc. Prof. Peter Northcote, for NMR-related assistance; Helen, Jaime-Anne, Jackie, Teresa, Gordon, Sally, Lisa, Kara, Dan and other general staff, for all manner of things. Also thank you to Dr. Jan Wikaira at the University of Canterbury for collection of the single-crystal X-ray data.

Thank you to both my chemistry and non-chemistry friends for all of the support, distraction, entertainment and sanity. Thank you to my family, particularly my Grandad, for help and support over the years. A huge thank you to Mel Abbott of Empower Therapies for teaching me how to be healthy again.

Lastly, thank you to the Curtis-Gordon Research Scholarship in Chemistry and the Victoria University Doctoral Scholarship/Assistantship for funding. 


\section{Contents}

Abstract $\quad$ ii

Acknowledgments $\quad$ iv

Table of Contents $\quad$ v

List of Figures $\quad$ vii

List of Schemes $\quad$ ix

List of Tables $\quad$ xi

$\begin{array}{ll}\text { Glossary } & 1\end{array}$

1 Introduction 3

1.1 Transition Metal Chemistry of Alkenes . . . . . . . . . . . . . . 3

1.1.1 Introduction . . . . . . . . . . . . . . . . . . 3

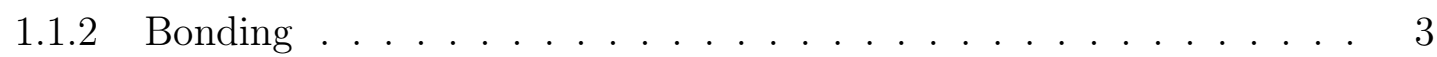

1.1.3 Group 10 Alkene Complexes . . . . . . . . . . . . . . . . . 5

1.2 Methylenecyclopropane . . . . . . . . . . . . . . . . 7

1.2.1 Synthesis and Properties . . . . . . . . . . . . . . . 7

1.2 .2 Organometallic Chemistry . . . . . . . . . . . . . . . . 10

1.3 Bicyclopropylidene . . . . . . . . . . . . . . . . . . 18

1.3.1 Synthesis of Bicyclopropylidene . . . . . . . . . . . . . . 18

1.3.2 Properties of Bicyclopropylidene . . . . . . . . . . . . . . 20

1.3.3 Organometallic Chemistry . . . . . . . . . . . . . 22

2 Platinum(0) Phosphine Complexes $\quad 35$

$2.1[\mathrm{Pt}(\mathrm{L})(\mathrm{P}-\mathrm{P})]$ Complexes $\ldots \ldots \ldots \ldots \ldots \ldots \ldots$

2.1.1 NMR Characterisation . . . . . . . . . . . . . . . . 41

2.2 Allylidenecyclopropane . . . . . . . . . . . . . . . . . . . . . . . . . . . . . . . . . 45

2.2.1 NMR Characterisation . . . . . . . . . . . . . . . 48

$2.3\left[\mathrm{Pt}(\mathrm{L})_{2}\left(\mathrm{PR}_{3}\right)\right]$ Complexes . . . . . . . . . . . . . . . 50

2.3.1 NMR Characterisation . . . . . . . . . . . . . . . 54

3 Phosphine-Thioether and Allyl Complexes $\quad 57$

$3.1[\mathrm{Pt}(\mathrm{L})(\mathrm{P}-\mathrm{S})]$ Complexes . . . . . . . . . . . . . . . . . 57

3.1.1 NMR Characterisation . . . . . . . . . . . . . . . . . 59

3.2 Allyl Complexes . . . . . . . . . . . . . . . . . . . . . . 61

3.2.1 Complexes Formed By Hydride Transfer . . . . . . . . . . . . . . . 61 
3.2.2 Complexes Formed By Protonation . . . . . . . . . . . . . . . . 69

3.2 .3 Computational Studies . . . . . . . . . . . . . . . . . 80

4 Platinum(II) Chemistry $\quad 95$

4.1 Introduction . . . . . . . . . . . . . . . . . . . . 95

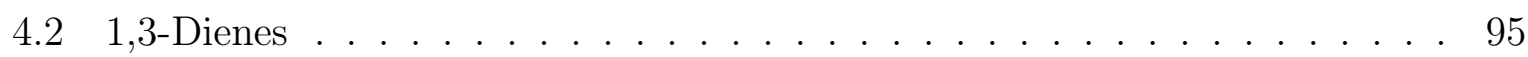

4.2.1 NMR Characterisation . . . . . . . . . . . . . . . . 97

$4.3 \eta^{2}$-Alkene Complexes . . . . . . . . . . . . . . . . . . . . 97

4.3.1 NMR Characterisation . . . . . . . . . . . . . . . . . . 101

$4.4 \boldsymbol{\beta}$-Chloroalkyl Complexes . . . . . . . . . . . . . . . . . . . . . 102

4.4.1 Synthesis From Dichloro Complexes . . . . . . . . . . . . . . . . . 104

4.4.2 Synthesis of Phosphine Complexes . . . . . . . . . . . . . . 106

4.4 .3 NMR Characterisation . . . . . . . . . . . . . . . . . . 112

4.4 .4 Computational Studies . . . . . . . . . . . . . . . . 117

5 Conclusion $\quad 124$

6 Experimental $\quad 130$

6.1 General Considerations . . . . . . . . . . . . . . . . . . . . 130

6.2 Chapter Two Experimental . . . . . . . . . . . . . . . . . . . . 131

6.3 Chapter Three Experimental . . . . . . . . . . . . . . . . . . . . . . 142

6.4 Chapter Four Experimental . . . . . . . . . . . . . . . . . 151

$\begin{array}{lr}\text { A NMR Spectra } & 160\end{array}$

A.1 Chapter Two . . . . . . . . . . . . . . . . . . . . . . 160

A.2 Chapter Three. . . . . . . . . . . . . . . . . . 183

A.3 Chapter Four . . . . . . . . . . . . . . . . . . 226

$\begin{array}{ll}\text { References } & 259\end{array}$ 


\section{List of Figures}

1.1 Schematic of the synergistic bonding between a metal atom and an alkene ligand. . . . . . . . . . . . . . . . . 4

1.2 X-ray crystal structures of some metal-alkene complexes. . . . . . . . . . 8

1.3 Methylenecyclopropane. . . . . . . . . . . . . . . . . . 9

1.4 X-ray crystal structure of $\left[\mathrm{Rh}(\mathrm{acac})(\mathrm{MCP})_{2}\right] \ldots \ldots \ldots \ldots \ldots$

1.5 X-ray crystal structure of BCP at 173 K. . . . . . . . . . . . . . . 20

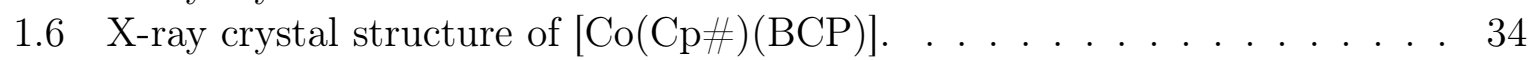

2.1 Structures and properties of diphosphine ligands. . . . . . . . . . . . . 36

2.2 ORTEP diagram of $[\mathrm{Pt}(\mathrm{BCP})(\mathrm{dppp})]$ (1a) showing $50 \%$ probability thermal ellipsoids. . . . . . . . . . . . . . . . . . . . . . 40

2.3 (i) ${ }^{31} \mathrm{P}\left\{{ }^{1} \mathrm{H}\right\}$ NMR spectrum of $[\mathrm{Pt}(\mathrm{MCP})(\mathrm{dppp})]$ (2a). (ii) ${ }^{13} \mathrm{C}\left\{{ }^{1} \mathrm{H}\right\} \mathrm{NMR}$

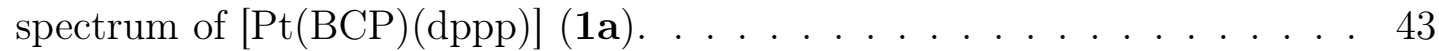

2.4 Geometry of the endo/exo protons in $[\mathrm{Pt}(\mathrm{BCP})(\mathrm{P}-\mathrm{P})](\mathbf{1}) \ldots \ldots . . .2 . \quad 45$

2.5 Structures and properties of monophosphine ligands. . . . . . . . . . . . 52

2.6 ORTEP diagram of $\left[\mathrm{Pt}(\mathrm{MCP})_{2}\left(\mathrm{PPh}_{3}\right)\right]$ (6a) showing $50 \%$ probability thermal ellipsoids. . . . . . . . . . . . . . . . 53

3.1 Geometry of allyl systems with anti and syn methyl groups. . . . . . . . . 65

$3.2{ }^{1} \mathrm{H} \quad \mathrm{NMR}$ resonances of the central allyl proton in $\left[\operatorname{Pt}\left(\eta^{3}\right.\right.$ $\left.\left.\mathrm{CH}_{2} \mathrm{CHCHMe}\right)(\mathrm{dppp})\right]\left[\mathrm{PhC}\left(\mathrm{SO}_{2} \mathrm{CF}_{3}\right)_{2}\right] \quad \mathbf{1 6 a}\left[\mathrm{PhC}\left(\mathrm{SO}_{2} \mathrm{CF}_{3}\right)_{2}\right] \quad$ (anti) and $16 \mathrm{~b}\left[\mathrm{PhC}\left(\mathrm{SO}_{2} \mathrm{CF}_{3}\right)_{2}\right]($ syn) . . . . . . . . . . . . . . 73

3.3 Possible conformations of $\left[\mathrm{Pt}\left(\eta^{3}-\mathrm{CH}_{2} \mathrm{C}^{c} \mathrm{PrCH}_{2}\right)(\mathrm{dbpx})\right]^{+}(\mathbf{1 7}) \ldots \ldots . . . \quad 75$

3.4 Temperature-dependent ${ }^{31} \mathrm{P}\left\{{ }^{1} \mathrm{H}\right\}$ NMR spectra of $\left[\mathrm{Pt}\left(\eta^{3}-\mathrm{CH}_{2} \mathrm{C}^{c} \mathrm{PrCH}_{2}\right)(\mathrm{dbpx})\right]^{+}$

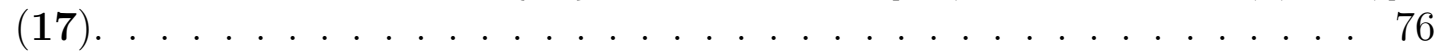

3.5 Temperature-dependent ${ }^{1} \mathrm{H}$ NMR spectra of $\left[\mathrm{Pt}\left(\eta^{3}-\mathrm{CH}_{2} \mathrm{C}^{c} \mathrm{PrCH}_{2}\right)(\mathrm{dbpx})\right]^{+}$

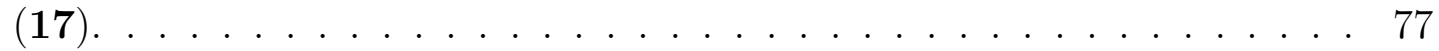

3.6 Temperature-dependent ${ }^{1} \mathrm{H}$ NMR spectra of $\left[\mathrm{Pt}\left(\eta^{3}-\mathrm{CH}_{2} \mathrm{C}^{c} \mathrm{PrCH}_{2}\right)(\mathrm{dbpx})\right]^{+}$

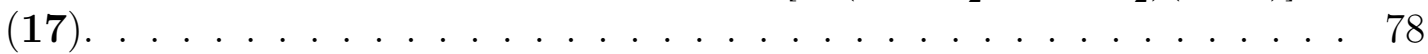

3.7 Allyl structural motifs derived from $[\mathrm{Pt}(\mathrm{BCP})(\mathrm{P}-\mathrm{S})](\mathbf{8}) . \ldots \ldots$. . . . . 82

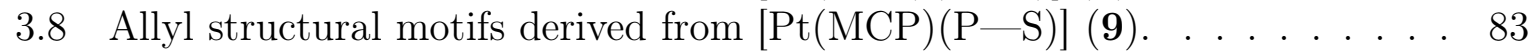

3.9 Allyl structural motifs derived from $[\mathrm{Pt}(\mathrm{BCP})(\mathrm{dppp})](\mathbf{1 a}) \ldots \ldots . . . . .8 .84$

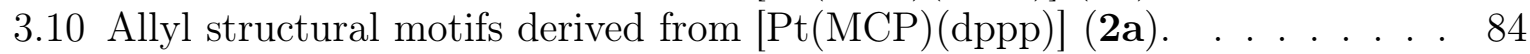

3.11 Allyl structural motifs derived from $[\mathrm{Pt}(\mathrm{BCP})(\mathrm{dbpx})](\mathbf{1 d}) \ldots \ldots$. . . . . . 85

3.12 Allyl structural motifs derived from $[\mathrm{Pt}(\mathrm{MCP})(\mathrm{dbpx})](\mathbf{2 d}) . \ldots . . . . \quad 85$

3.13 Reaction $\Delta H$ for the formation of allyl complexes from $[\mathrm{Pt}(\mathrm{L})(\mathrm{P}-\mathrm{S})] \ldots$. . 88

3.14 Reaction $\Delta H$ for the formation of allyl complexes from $[\mathrm{Pt}(\mathrm{L})(\mathrm{dppp})] \ldots$. . 89

3.15 Reaction $\Delta H$ for the formation of allyl complexes from $[\mathrm{Pt}(\mathrm{L})(\mathrm{dbpx})]$. . . 89

3.16 Structures of $[\mathrm{PtH}(\mathrm{L})(\mathrm{P}-\mathrm{C})]$ complexes. . . . . . . . . . . . . . . 92 
4.1 ORTEP diagram of $\left[\mathrm{Pt}(\mathrm{dppp})_{2}\right] \mathrm{Cl}_{2} \cdot 6 \mathrm{CDCl}_{3}(\mathbf{3 5 a})$ showing $50 \%$ probability thermal ellipsoids. . . . . . . . . . . . . . . . . . . . 108

4.2 Layered packing of $\left[\mathrm{Pt}(\mathrm{dppp})_{2}\right] \mathrm{Cl}_{2} \cdot 6 \mathrm{CDCl}_{3}(\mathbf{3 5 a}) \ldots \ldots \ldots$. . . . . . 109

$4.3{ }^{1} \mathrm{H}$ NMR spectra showing the cyclopropyl peaks for

(i) trans $-\left[\mathrm{Pt}\left(\mathrm{C}\left(\mathrm{CH}_{2}\right)_{2} \mathrm{C}\left(\mathrm{CH}_{2}\right)_{2} \mathrm{Cl}\right) \mathrm{Cl}\left(\mathrm{SEt}_{2}\right)_{2}\right]$ (32),

(ii) cis $-\left[\mathrm{Pt}\left(\mathrm{C}\left(\mathrm{CH}_{2}\right)_{2} \mathrm{C}\left(\mathrm{CH}_{2}\right)_{2} \mathrm{Cl}\right) \mathrm{Cl}(\mathrm{Py})_{2}\right](34 \mathrm{~b})$ and

(iii) trans $-\left[\mathrm{Pt}\left(\mathrm{C}\left(\mathrm{CH}_{2}\right)_{2} \mathrm{C}\left(\mathrm{CH}_{2}\right)_{2} \mathrm{Cl}\right) \mathrm{Cl}(\mathrm{PTA})_{2}\right](\mathbf{3 6 a}) \ldots \ldots . . . \ldots 115$

4.4 Geometry of the endo/exo protons in $\beta$-haloalkyl complexes. . . . . . . . 116

4.5 Structures of $\beta$-chloroalkyl complexes. . . . . . . . . . . . . . . 118

4.6 Reaction $\Delta H$ for the formation of $\beta$-chloroalkyl complexes From $\left[\mathrm{PtCl}_{2}\left(\mathrm{NC}^{t} \mathrm{Bu}\right)_{2}\right] \ldots \ldots \ldots \ldots . \ldots \ldots \ldots$

4.7 Reaction $\Delta H$ for the formation of $\left[\mathrm{PtCl}_{2}(\mathrm{~L})\left(\mathrm{NC}^{t} \mathrm{Bu}\right)\right]$ through $\beta$-chloride elimination. . . . . . . . . . . . . . . . . 120

4.8 Energy diagram for the formation of $\left[\mathrm{PtCl}_{2}(\mathrm{~L})\left(\mathrm{NC}^{t} \mathrm{Bu}\right)\right]$ from $\left[\mathrm{PtCl}_{2}\left(\mathrm{NC}^{t} \mathrm{Bu}\right)_{2}\right]$ via $\beta$-chloroalkyl complexes. . . . . . . . . . . . . 121

5.1 Biologically active molecules containing cyclopropyl rings. . . . . . . . . . . 124 


\section{List of Schemes}

1.1 Synthesis of alkene-transition metal complexes. . . . . . . . . . . . . . . 6

1.2 Methods of synthesising methylenecyclopropane. . . . . . . . . . . . . 9

1.3 The four reaction modes of methylenecyclopropanes with transition metals. 11

1.4 TM catalysed [3+2] cycloaddition of MCP involving distal bond cleavage. . 12

1.5 TM catalysed [3+2] cycloaddition of MCP involving proximal bond cleavage. 12

1.6 Palladium-catalysed Heck-type reaction with MCP. . . . . . . . . . . . . 13

1.7 Palladium-catalysed addition of metal hydrides to MCP. . . . . . . . . . . 14

1.8 Palladium-catalysed addition of pronucleophiles to MCP. . . . . . . . . . 15

1.9 Possible mechanisms for the metal-catalysed silaboration of MCP. . . . . . 16

1.10 Synthesis of $\mathrm{Ni}$ and $\mathrm{Pt}$ complexes of MCP . . . . . . . . . . . . . . . 17

1.11 Synthesis of a Co-MCP complex. . . . . . . . . . . . . . . 18

1.12 First syntheses of bicyclopropylidene. . . . . . . . . . . . . . . . . . . 19

1.13 Highest yielding synthesis of bicyclopropylidene. . . . . . . . . . . . . . 19

$1.14 \mathrm{Pd}$-catalysed reactions of BCP with electron-deficient alkenes. . . . . . . . 22

$1.15 \mathrm{Pd}$-catalysed reactions of BCP with diethyl fumarate . . . . . . . . . . . 23

1.16 Mechanisms for the formation of [3+2] cycloaddition products of BCP. . . 24

$1.17 \mathrm{Pd}(0)$-catalysed cyclodimerisation of $\mathrm{BCP}$ with norbornene and norbornadiene. . . . . . . . . . . . . . . . . . 25

$1.18 \mathrm{Pd}(0)$-catalysed cyclodimerisation of bicyclopropylidene. . . . . . . . 25

$1.19 \mathrm{Ni}(0)$-catalysed cycloaddition of bicyclopropylidene with diethyl fumarate. 25

$1.20 \mathrm{Ni}(0)$-catalysed $[2+2]$ cycloaddition of BCP with cyclobutene. . . . . . . 26

1.21 The reaction of BCP with Heck-type reagents. . . . . . . . . . . . . . 26

1.22 Domino Heck-Diels-Alder reactions of BCP. . . . . . . . . . . . . . 27

1.23 Domino Heck-Diels-Alder reaction of BCP with iodoethene and dienophiles. 27

1.24 Multicomponent domino reactions of BCP. . . . . . . . . . . . 28

1.25 Domino reaction of BCP involving a homoallyl- to $\pi$-allyl-palladium rearrangement. . . . . . . . . . . . . . . . . 29

1.26 Domino reaction of BCP involving a homoallyl- to $\pi$-allyl-palladium rearrangement. . . . . . . . . . . . . . . 30

1.27 Palladium-catalysed isomerisation of BCP. . . . . . . . . . . . . 30

1.28 Inter- and intra-molecular examples of the addition of a disilane to BCP with retention of both ${ }^{c}$ Pr rings. . . . . . . . . . . . . . . . . 31

1.29 Pd-catalysed addition of silylstannanes to BCP. . . . . . . . . . . 31

1.30 Mechanism for the Pd catalysed bismetallation of BCP. . . . . . . . . . . . 32

1.31 Synthesis of the first Ti complex of BCP. . . . . . . . . . . . . 33

1.32 Synthesis of the first Co complex of BCP . . . . . . . . . . . . . . 33

2.1 Synthesis of carbon-13 enriched bicyclopropylidene. . . . . . . . . . . . . 38

2.2 Synthesis of $[\mathrm{Pt}(\mathrm{BCP})(\mathrm{P}-\mathrm{P})](\mathbf{1})$ and $[\mathrm{Pt}(\mathrm{MCP})(\mathrm{P}-\mathrm{P})](\mathbf{2}) . \ldots . . . \quad . \quad 39$ 
2.3 Synthesis of allylidenecyclopropane from bicyclopropylidene. . . . . . . . . 46

2.4 Synthesis of $[\mathrm{Pt}(\mathrm{ACP})(\mathrm{P}-\mathrm{P})](\mathbf{3}) \ldots \ldots \ldots \ldots \ldots$

2.5 Synthesis of $[\mathrm{Pt}(\mathrm{ACP})(\mathrm{dbpe})](\mathbf{3 c}) \ldots \ldots \ldots \ldots . \ldots \ldots$

2.6 Rearrangement of $[\mathrm{Pt}(\mathrm{ACP})(\mathrm{P}-\mathrm{P})](\mathbf{3 a})$ to form metallocyclopentene

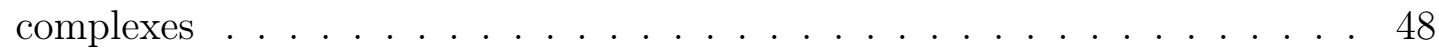

2.7 Synthesis of $\left[\mathrm{Pt}(\mathrm{MCP})\left(\mathrm{C}_{2} \mathrm{H}_{4}\right)\left(\mathrm{PR}_{3}\right)\right](\mathbf{6})$ and $\left[\mathrm{Pt}(\mathrm{MCP})_{2}\left(\mathrm{PR}_{3}\right)\right](\mathbf{7}) \ldots \ldots . \quad 51$

2.8 Synthesis of $\left[\mathrm{Pt}(\mathrm{BCP})\left(\mathrm{C}_{2} \mathrm{H}_{4}\right)\left(\mathrm{PR}_{3}\right)\right](\mathbf{5}) \ldots \ldots \ldots \ldots$

3.1 Synthesis of $\left[\mathrm{Pt}(\mathrm{BCP})\left({ }^{t} \mathrm{Bu}_{2} \mathrm{PCH}_{2}\left({ }^{o}-\mathrm{C}_{6} \mathrm{H}_{4}\right) \mathrm{CH}_{2} \mathrm{~S}{ }^{t} \mathrm{Bu}\right)\right](8) \ldots \ldots \ldots$. . . . . 58

3.2 Synthesis of $\left[\mathrm{Pt}(\mathrm{MCP})\left({ }^{t} \mathrm{Bu}_{2} \mathrm{PCH}_{2}\left(o-\mathrm{C}_{6} \mathrm{H}_{4}\right) \mathrm{CH}_{2} \mathrm{~S}^{t} \mathrm{Bu}\right)\right](\mathbf{9}) \ldots \ldots \ldots . . \quad \ldots . \quad \ldots 8$

3.3 Reaction of $\left[\mathrm{Pt}(\mathrm{nb})\left({ }^{t} \mathrm{Bu}_{2} \mathrm{PCH}_{2}\left(o-\mathrm{C}_{6} \mathrm{H}_{4}\right) \mathrm{CH}_{2} \mathrm{~S}{ }^{t} \mathrm{Bu}\right)\right]$ with an excess of MCP. $\quad 59$

3.4 Formation of allyl complexes from $[\mathrm{Pt}(\mathrm{BCP})(\mathrm{P}-\mathrm{S})](\mathbf{8}) \ldots \ldots . . . .62$

3.5 Formation of allyl complexes from $[\mathrm{Pt}(\mathrm{MCP})(\mathrm{P}-\mathrm{S})](\mathbf{9}) \ldots \ldots . . . . .6 .62$

3.6 Mechanism for the formation of allyl complexes from MCP. . . . . . . . . . 64

3.7 Formation of allyl complexes by protonation of $[\mathrm{Pt}(\mathrm{BCP})(\mathrm{dppp})](\mathbf{1 a}) . \quad$. 70

3.8 Formation of allyl complexes by protonation of $[\mathrm{Pt}(\mathrm{MCP})(\mathrm{dppp})](\mathbf{2 a})$. . . 71

3.9 Formation of an allyl complex by protonation of $[\mathrm{Pt}(\mathrm{BCP})(\mathrm{dbpx})](\mathbf{1 d})$. . 71

3.10 Formation of allyl complexes by protonation of $[\mathrm{Pt}(\mathrm{MCP})(\mathrm{dbpx})](\mathbf{1 d}) . \quad$. 72

3.11 Formation of $\mathrm{P}-\mathrm{C}$ allyl complexes from $[\mathrm{Pt}(\mathrm{L})(\mathrm{P}-\mathrm{S})] \ldots \ldots$. . . . . . . 87

3.12 Formation of $\mathrm{P}-\mathrm{P}$ allyl complexes from $[\mathrm{Pt}(\mathrm{L})(\mathrm{P}-\mathrm{P})] \ldots \ldots 7$

4.1 Formation of allylidenecyclopropane from Pt(II) alkyl complexes. . . . . . 96

4.2 Reaction of $\left[\mathrm{PtEt}_{2}(\mathrm{COD})\right]$ with MCP. . . . . . . . . . . . . . . . 96

4.3 Formation of butadiene from $\left[\mathrm{PtEt}_{2}(\mathrm{COD})\right] \ldots \ldots \ldots$

4.4 Formation of ACP from $\left[\mathrm{PtEt}_{2}(\mathrm{COD})\right] \ldots \ldots \ldots \ldots$

4.5 Synthesis of trans- $\left[\mathrm{PtCl}_{2}(\mathrm{~L})(\mathrm{Py})\right] \quad(\mathbf{2 8}$ and 29) from trans-

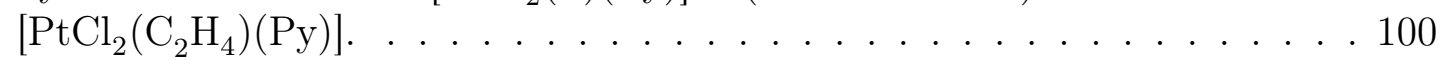

4.6 Synthesis of $c i s-\left[\mathrm{PtCl}_{2}(\mathrm{~L})(\mathrm{DMSO})\right]$ (30 and 31) from cis $^{-}\left[\mathrm{PtCl}_{2}(\mathrm{DMSO})_{2}\right] .100$

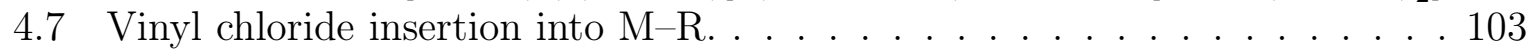

4.8 Synthesis of trans $-\left[\mathrm{Pt}\left(\mathrm{C}\left(\mathrm{CH}_{2}\right)_{2} \mathrm{C}\left(\mathrm{CH}_{2}\right)_{2} \mathrm{Cl}\right) \mathrm{Cl}(\mathrm{L})_{2}\right] \quad(\mathbf{3 2}-\mathbf{3 4 a})$ from

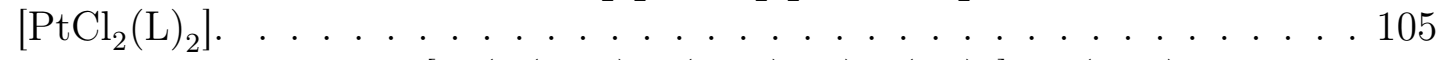

4.9 Synthesis of cis- $-\left[\mathrm{Pt}\left(\mathrm{C}\left(\mathrm{CH}_{2}\right)_{2} \mathrm{C}\left(\mathrm{CH}_{2}\right)_{2} \mathrm{Cl}\right) \mathrm{Cl}(\mathrm{Py})_{2}\right] \quad$ (34b) from

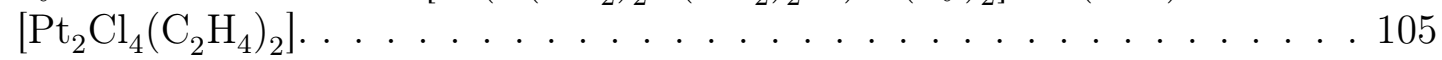

4.10 Synthesis of cis- $\left[\mathrm{Pt}\left(\mathrm{C}\left(\mathrm{CH}_{2}\right)_{2} \mathrm{CH}_{2} \mathrm{Cl}\right) \mathrm{Cl}(\mathrm{Py})_{2}\right]$ from $\left[\mathrm{Pt}_{2} \mathrm{Cl}_{4}\left(\mathrm{C}_{2} \mathrm{H}_{4}\right)_{2}\right](\mathbf{3 4 c})$. 106

4.11 Synthesis of trans- $\left.\mathrm{Pt}\left(\mathrm{C}\left(\mathrm{CH}_{2}\right)_{2} \mathrm{C}\left(\mathrm{CH}_{2}\right)_{2} \mathrm{Cl}\right) \mathrm{Cl}(\mathrm{PTA})_{2}\right]$ (36a) from trans$\left[\mathrm{Pt}\left(\mathrm{C}\left(\mathrm{CH}_{2}\right)_{2} \mathrm{C}\left(\mathrm{CH}_{2}\right)_{2} \mathrm{Cl}\right) \mathrm{Cl}(\mathrm{L})_{2}\right](32$ and 33) . . . . . . . . . 110

4.12 Synthesis of cis $-\left[\mathrm{Pt}\left(\mathrm{C}\left(\mathrm{CH}_{2}\right)_{2} \mathrm{C}\left(\mathrm{CH}_{2}\right)_{2} \mathrm{Cl}\right) \mathrm{Cl}(\mathrm{P})_{2}\right]$ from

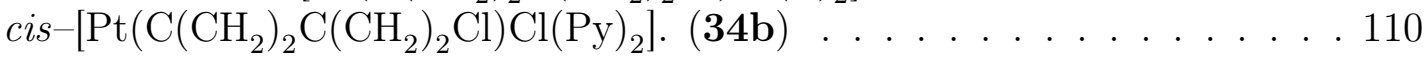

4.13 Synthesis of cis $-\left[\mathrm{Pt}\left(\mathrm{C}\left(\mathrm{CH}_{2}\right)_{2} \mathrm{CH}_{2} \mathrm{Cl}\right) \mathrm{Cl}(\mathrm{P})_{2}\right]$ from cis-[Pt $\left.\left(\mathrm{C}\left(\mathrm{CH}_{2}\right)_{2} \mathrm{CH}_{2} \mathrm{Cl}\right) \mathrm{Cl}(\mathrm{Py})_{2}\right] .(\mathbf{3 4 b}) \ldots \ldots . \ldots . . \ldots 111$

4.14 Synthesis of $\left[\mathrm{Pt}\left(\mathrm{C}\left(\mathrm{CH}_{2}\right)_{2} \mathrm{CH}_{2} \mathrm{Cl}\right) \mathrm{Cl}(\mathrm{Py})\left(\mathrm{PPh}_{3}\right)\right](\mathbf{3 8 c})$ from cis- $\left[\mathrm{Pt}\left(\mathrm{C}\left(\mathrm{CH}_{2}\right)_{2} \mathrm{CH}_{2} \mathrm{Cl}\right) \mathrm{Cl}(\mathrm{Py})_{2}\right] .(34 \mathbf{b}) \ldots \ldots . . \ldots . . . \ldots 112$

4.15 Formation of $\beta$-chloroalkyl complexes from trans $-\left[\mathrm{PtCl}_{2}\left(\mathrm{NC}^{t} \mathrm{Bu}\right)_{2}\right]$. . . . 119

4.16 Formation of $\left[\mathrm{PtCl}_{2}(\mathrm{~L})\left(\mathrm{NC}^{t} \mathrm{Bu}\right)\right]$ via $\beta$-chloride elimination. . . . . . . . 120 


\section{List of Tables}

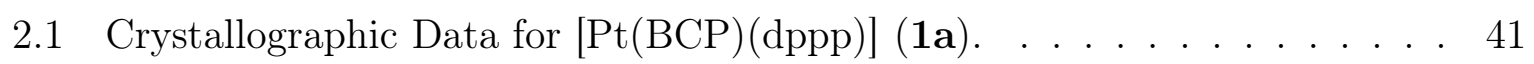

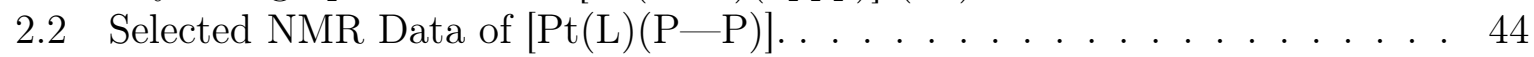

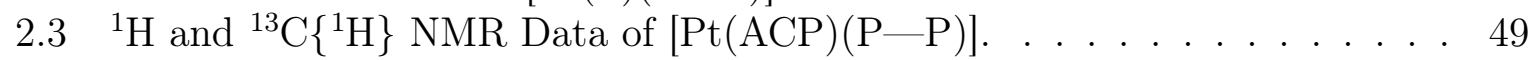

2.4 Crystallographic Data for $\left[\mathrm{Pt}(\mathrm{MCP})_{2}\left(\mathrm{PPh}_{3}\right)\right](6 \mathrm{a}) . \ldots \ldots \ldots \ldots$

2.5 Selected NMR Data of $\left[\mathrm{Pt}(\mathrm{L})_{2}\left(\mathrm{PR}_{3}\right)\right] \ldots \ldots \ldots \ldots \ldots$

3.1 Selected ${ }^{31} \mathrm{P}\left\{{ }^{1} \mathrm{H}\right\}$ and ${ }^{1} \mathrm{H}$ NMR Data of Allyl Complexes. . . . . . . . . . . 66

3.2 Selected ${ }^{13} \mathrm{C}\left\{{ }^{1} \mathrm{H}\right\}$ NMR Data of Allyl Complexes. . . . . . . . . . . . . . . 67

3.3 Reaction $\Delta H$ for the Formation of Allyl Complexes from $\eta^{2}$-BCP Complexes. 87

3.4 Reaction $\Delta H$ for the Formation of Allyl Complexes from $\eta^{2}$-MCP Complexes. 88

3.5 Atomic Charges on the Double-Bond and Hydride Atoms of Alkene

Complexes. . . . . . . . . . . . . . . . . . . 93

4.1 Selected ${ }^{1} \mathrm{H}$ NMR Data for $\left[\mathrm{Pt}(\mathrm{L})_{2}(\mathrm{COD})\right] \ldots \ldots \ldots$. . . . . . . . . . . . . . 99

4.2 Selected ${ }^{13} \mathrm{C}\left\{{ }^{1} \mathrm{H}\right\}$ NMR Data for $\left[\mathrm{Pt}(\mathrm{L})_{2}(\mathrm{COD})\right] \ldots \ldots \ldots$. . . . . . . . . . . . 99

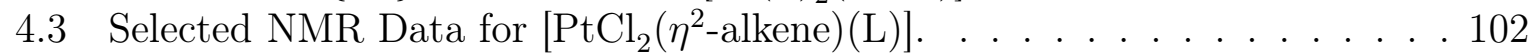

4.4 Crystallographic Data for $\left[\mathrm{Pt}(\mathrm{dppp})_{2}\right] \mathrm{Cl}_{2} \cdot 6 \mathrm{CDCl}_{3}(\mathbf{3 5 a}) \ldots \ldots$. . . . . . 109

4.5 Selected NMR Data of $\left[\mathrm{Pt}\left(\mathrm{C}\left(\mathrm{CH}_{2}\right)_{2} \mathrm{CR}_{2} \mathrm{Cl}\right) \mathrm{Cl}(\mathrm{L})_{2}\right] \ldots \ldots \ldots . . \ldots . . \ldots 113$

4.6 Reaction $\Delta H$ for the Formation of $\beta$-Chloroalkyl Complexes. . . . . . . . . 119

4.7 Reaction $\Delta H$ for the Formation of $\left[\mathrm{PtCl}_{2}(\mathrm{~L})\left(\mathrm{NC}^{t} \mathrm{Bu}\right)\right]$ Through $\beta$-Chloride Elimination. . . . . . . . . . . . . . . . 120 


\section{Glossary}

$\begin{array}{ll}\text { acac } & \text { acetylacetonate } \\ \text { ACP } & \text { allylidenecyclopropane } \\ \text { BCP } & \text { bicyclopropylidene (cyclopropylidenecyclopropane) } \\ \text { br } & \text { broad } \\ \text { COD } & \text { cycloocta-1,5-diene } \\ \text { Cp } & \text { cyclopentadiene } \\ \text { Cp\# } & \text { 2-(di-tert-butylphosphanyl)-P-ethyl)cyclopentadienyl } \\ \text { cPr } & \text { cyclopropyl }\left(\mathrm{C}_{3} \mathrm{H}_{5}\right) \\ \text { Cy } & \text { cyclohexyl }\left(\mathrm{C}_{6} \mathrm{H}_{11}\right) \\ \text { cyp } & \text { cyclopentyl }\left(\mathrm{C}_{5} \mathrm{H}_{9}\right) \\ \text { d } & \text { doublet } \\ \text { dbpe } & \text { 1,2-bis }(\text { di-tert-butylphosphino)ethane } \\ \text { dbpx } & \text { 1,2-bis[(di-tert-butylphosphino)methyl]benzene } \\ \text { DBU } & \text { 1,8-Diazabicycloundec-7-ene } \\ \text { dcyppe } & \text { 1,2-bis }(\text { dicyclopentylphosphino)ethane } \\ \text { DMSO } & \text { dimethylsulfoxide } \\ \text { dppe } & \text { 1,2-bis }(\text { diphenylphosphino)ethane } \\ \text { Et } & \text { info-bis }(\text { diphenylphosphino)propane } \\ \text { EW } & \text { Elhyl }\left(\mathrm{C}_{2} \mathrm{H}_{5}\right) \\ \text { Hoctron-Withdrawing Group }\end{array}$




\begin{tabular}{|c|c|}
\hline${ }^{i} \operatorname{Pr}$ & iso-propyl $\left(\mathrm{HC}\left(\mathrm{CH}_{3}\right)_{2}\right)$ \\
\hline LUMO & Lowest Unoccupied Molecular Orbital \\
\hline $\mathrm{m}$ & multiplet \\
\hline M & metal \\
\hline $\mathrm{MCP}$ & methylenecyclopropane \\
\hline $\mathrm{Me}$ & methyl $\left(\mathrm{CH}_{3}\right)$ \\
\hline $\mathrm{nb}$ & norbornene (dicyclo[2.2.1]hept-2-ene) \\
\hline NMR & Nuclear Magnetic Resonance \\
\hline $\mathrm{Nu}$ & nucleophile \\
\hline $\mathrm{Ph}$ & phenyl $\left(\mathrm{C}_{6} \mathrm{H}_{5}\right)$ \\
\hline $\mathrm{P}-\mathrm{C}$ & $\mathrm{C}_{6} \mathrm{H}_{3}-o-\mathrm{CH}_{2} \mathrm{P}^{t} \mathrm{Bu}_{2}-m-\mathrm{CH}_{2} \mathrm{~S}^{t} \mathrm{Bu}$ \\
\hline $\mathrm{P}-\mathrm{S}$ & ${ }^{t} \mathrm{Bu}_{2} \mathrm{PCH}_{2}\left(o-\mathrm{C}_{6} \mathrm{H}_{4}\right) \mathrm{CH}_{2} \mathrm{~S}{ }^{t} \mathrm{Bu}$ \\
\hline PTA & 1,3,5-triaza-7-phosphaadamantane \\
\hline $4-\mathrm{Py}$ & 4 -pyridyl $\left(4-\mathrm{C}_{5} \mathrm{H}_{5} \mathrm{~N}\right)$ \\
\hline $\mathrm{Py}$ & pyridine $\left(\mathrm{C}_{5} \mathrm{H}_{5} \mathrm{~N}\right)$ \\
\hline q & quartet \\
\hline quint & quintet \\
\hline $\mathrm{s}$ & singlet \\
\hline $\mathrm{t}$ & triplet \\
\hline${ }^{t} \mathrm{Bu}$ & tert-butyl $\left(\mathrm{C}\left(\mathrm{CH}_{3}\right)_{3}\right)$ \\
\hline TFP & trifurylphosphine \\
\hline $\mathrm{TM}$ & transition metal \\
\hline 4-Tol & 4-tolyl $\left(4-\mathrm{C}_{6} \mathrm{H}_{4} \mathrm{CH}_{3}\right)$ \\
\hline
\end{tabular}




\section{Chapter 1}

\section{Introduction}

\subsection{Transition Metal Chemistry of Alkenes}

\subsubsection{Introduction}

Alkene complexes of transition metals, particularly platinum, are among the most extensively studied organometallic compounds. ${ }^{1}$ The first transition metal-alkene complex was $\mathrm{K}\left[\mathrm{PtCl}_{3}\left(\mathrm{C}_{2} \mathrm{H}_{4}\right)\right] \cdot \mathrm{H}_{2} \mathrm{O}$, or Zeise's salt, which was synthesised in $1830 .^{2}$ Alkene complexes are common intermediates in catalytic cycles, and several model complexes have been synthesised over the years in order to lend insight into the processes that occur during catalysis. ${ }^{1}$

\subsubsection{Bonding}

When the X-ray crystal structure of Zeise's salt was solved in 1953, it was found that the alkene ligand was bound to the metal via the $\pi$ electrons, rather than by a $\sigma$-bond to just one of the carbon atoms, an arrangement now known to be typical of transition metalalkene complexes. ${ }^{3}$ The currently accepted model for the bonding between alkene ligands and transition metal complexes is the Dewar-Chatt-Duncanson model. This was first proposed by Dewar in relation to silver-ethene complexes ${ }^{4}$ and later applied to platinumethene complexes by Chatt and Duncanson. ${ }^{5}$ In this model, there is a synergistic bond between the metal and the ligand, involving the donation of electron density from the 
highest occupied molecular orbital (HOMO) of the ligand, the $\pi$-orbital, into an empty metal orbital with $\sigma$-type symmetry, coupled with the back-donation from a filled $\pi$-type metal d-orbital into the lowest unoccupied molecular orbital (LUMO) of the ligand, the $\pi^{*}$-orbital (Figure 1.1). ${ }^{5-8}$ As a result of the back-donation, the double-bond is weakened and lengthened, and there is a partial rehybridisation of the carbon centres, with the $\mathrm{sp}^{2}$ carbon atoms becoming more $\mathrm{sp}^{3}$-like. ${ }^{8}$ With the change in hybridisation, the substituents on the double-bond carbon atoms are bent away from the bond, with the angle increasing with the degree of back-bonding. ${ }^{8}$ The effect of back-donation can be seen in the infrared spectra of the complexes, with the coordinated alkene having a $\mathrm{C}=\mathrm{C}$ bond stretch at lower wavenumber. ${ }^{5}$

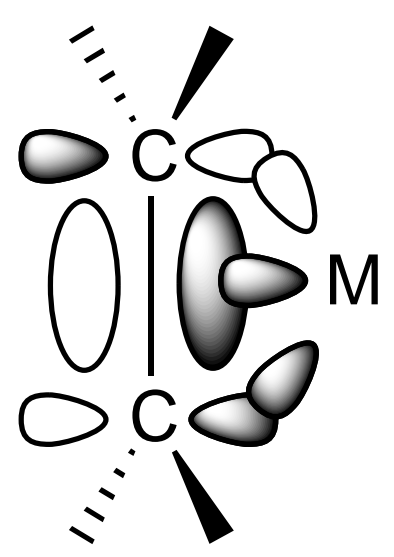

Figure 1.1. Schematic of the synergistic bonding between a metal atom and an alkene ligand. ${ }^{5-8}$

In general, the attenuation of the bond strength, and therefore the increase in bond length is correlated to the extent of back-bonding. In the case of a weak $\pi$-base, such as the $\mathrm{Pt}(\mathrm{II})$ in Zeise's salt, the back-bonding is minimal. The ethene $\mathrm{C}=\mathrm{C}$ bond length is similar to that in free ethene, and it can therefore be described as a simple $\pi$-complex. This is typical of alkene complexes with the metal in a high oxidation state. ${ }^{8}$ Conversely, when an electron-deficient alkene is coordinated to a strongly $\pi$-basic metal, as in the formally $\mathrm{Pt}(0)$ complex $\left[\mathrm{Pt}\left(\mathrm{C}_{2}(\mathrm{CN})_{4}\right)\left(\mathrm{PPh}_{3}\right)_{2}\right]$, the back-bonding is maximised. The alkene double-bond is significantly lengthened, and the complex can best be described as a metallacyclopropane species. ${ }^{8}$ Most transition metal-alkene complexes fall between the above extremes. 
As late transition metals have more filled orbitals than the earlier ones, the ability of the alkene ligand to act as a $\pi$-acceptor determines the strength of the binding to the metal, and stronger complexes are therefore formed with electron-deficient alkenes. ${ }^{8-10}$ Early transition metals, on the other hand, tend to have more empty orbitals, so it is the ability of the ligand to act as a $\sigma$-donor that predominantly affects the binding strength, and stronger complexes are formed with electron-rich alkenes. ${ }^{8,11-13}$ In general, alkenes are weak $\sigma$-donors but very good $\pi$-acceptors. ${ }^{8}$

The high $\pi$-accepting ability of alkene ligands mean that they have a strong transeffect. ${ }^{2}$ Electron deficient alkenes, which have lower LUMOs, have stronger trans-effects. ${ }^{8}$ The trans-influence of the alkene ligand, however, is highly dependent on the nature of the ligand trans to the alkene. ${ }^{2}$

The coordination strength of an alkene ligand is not just dependent on the electronic properties of the ligand. The structure of the alkene also plays a significant role in determining the stability of a complex. In general, the stability decreases with the number of substituents on the alkene, and cis isomers tend to be more tightly bound than the corresponding trans isomer. ${ }^{8,9,14,15}$ Ring strain is also a very important factor in complex stability. Strained alkenes such as norbornene (nb) form particularly stable complexes as coordination and the subsequent rehybridisation of the carbon atoms alleviates the strain. ${ }^{8,15}$ Strained alkenes also have a lower $\pi^{*}$-molecular orbital and a higher $\pi$-orbital than unstrained alkenes, which leads to a more favourable overlap with metal d-orbitals and therefore more stable complexes. ${ }^{16}$

\subsubsection{Group 10 Alkene Complexes}

By far the most common class of alkene complexes are those of the Group 10 metals nickel, palladium and platinum. These range from monoalkene complexes with a variety of auxiliary ligands, to complexes with three alkene ligands. There are several ways of synthesising Group 10 alkene complexes. Complexes with the metal in the +2 oxidation state can be made either by reacting a metal salt directly with an alkene (Scheme 1.1 (i)), ${ }^{17}$ or by displacing a ligand such as another alkene (Scheme 1.1 (ii)). ${ }^{2,18}$ Complexes 
(i)

$$
\left[\begin{array}{l}
\mathrm{Cl} \\
\mathrm{Cl}-\underset{\mathrm{Pt}}{\mathrm{l}}-\mathrm{Cl} \\
\mathrm{Cl}
\end{array}\right]_{\mathrm{NH}_{2}}^{\left(\mathrm{NH}_{4}\right)_{2}}+\left.\right|_{\mathrm{NH}_{2}}
$$

(ii)<smiles></smiles>

(iii)

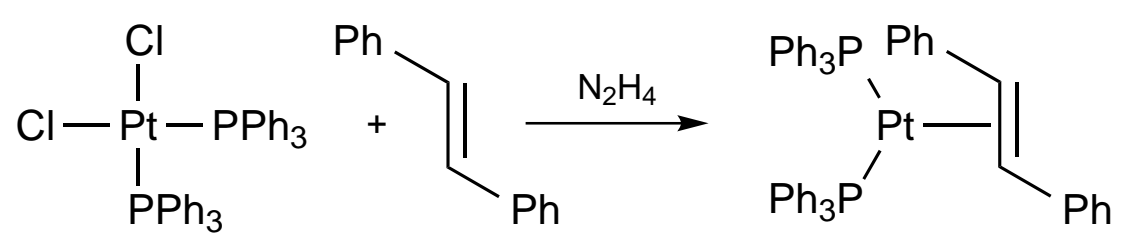

(iv)

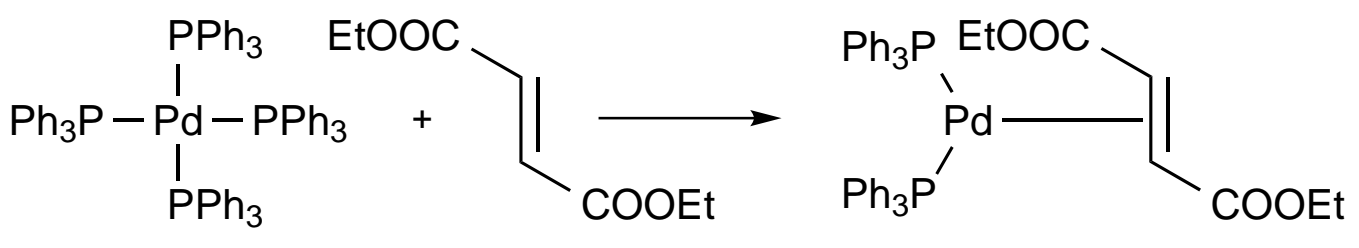

(v)

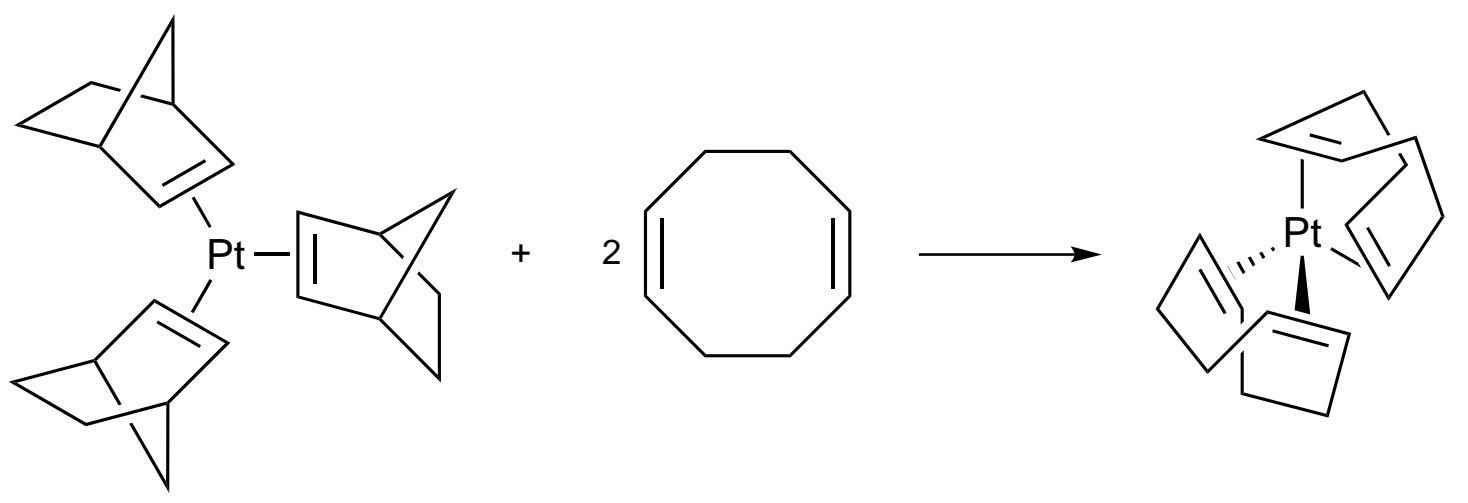

Scheme 1.1. Synthesis of alkene-transition metal complexes. ${ }^{17-21}$ 
with the metal in the zero oxidation state can be synthesised by the reduction of a $\mathrm{M}(\mathrm{II})$ complex in the presence of an alkene (Scheme 1.1 (iii)), ${ }^{19}$ or by the displacement of other ligands such as phosphines or other alkenes (Scheme 1.1 (iv) and (v)). ${ }^{2,20,21}$

The first complexes containing purely alkene ligands were made with nickel, $\left[\mathrm{Ni}(\text { cycloocta-1,5-diene })_{2}\right]$ and $[\mathrm{Ni}$ (trans,trans,trans-cyclododeca-1,5,9-triene $\left.)\right] .{ }^{16}$ Pure alkene complexes of platinum and palladium have also been synthesised. These are commonly used as precursors in the synthesis of other complexes, as alkenes are relatively easily displaced by other ligands. They are also used as catalysts and pre-catalysts.

The orientation of the coordinated alkene ligands is dependent on the oxidation state of the metal. In M(II) complexes, the alkene ligand usually sits perpendicular to the metal coordination plane (Figure $1.2(\mathrm{i})$ ), ${ }^{2,22}$ while in $\mathrm{M}(0)$ complexes, the alkene usually lies parallel to the coordination plane (Figure 1.2 (ii)). ${ }^{2,23}$ In cases where the ligands are constrained, the geometry of the complex differs from the ideal. The coordination geometry means that a maximum of three monoalkenes can coordinate to the metal in pure alkene complexes, although it is possible for four individual double-bonds to coordinate. ${ }^{16}$ Bis(cycloocta-1,5-diene)platinum, for example, has four coordinated double-bonds and a $\operatorname{Pt}(0)$ metal centre, and is almost tetrahedral at the metal. ${ }^{24}$

\subsection{Methylenecyclopropane}

\subsubsection{Synthesis and Properties}

Methylenecyclopropane (MCP) (Figure 1.3) is a four-carbon molecule that contains a cyclopropane ring with an external double-bond. It is a gas at room temperature, with a boiling point of $10^{\circ} \mathrm{C}$. As cyclopropane rings have some analogous reactivities to double-bonds, ${ }^{25} \mathrm{MCP}$ can be considered analogous to allene. Methylenecyclopropane was first synthesised in 1952 from 3-chloro-2-(chloromethyl)-1-propene using magnesium (Scheme 1.2 (i)). ${ }^{26}$ In this synthesis, the 3-chloro-2-(chloromethyl)-1-propene first had to be prepared by the chlorination of 3-chloro-2-methyl-1-propene (methallyl chloride). A second synthetic method enabled the transformation of methallyl chloride directly into 


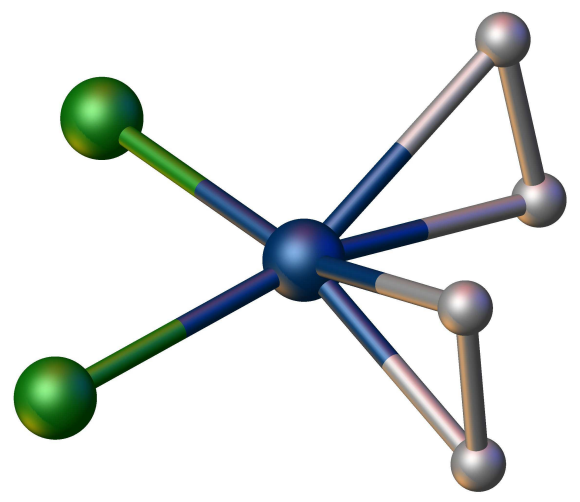

(i)

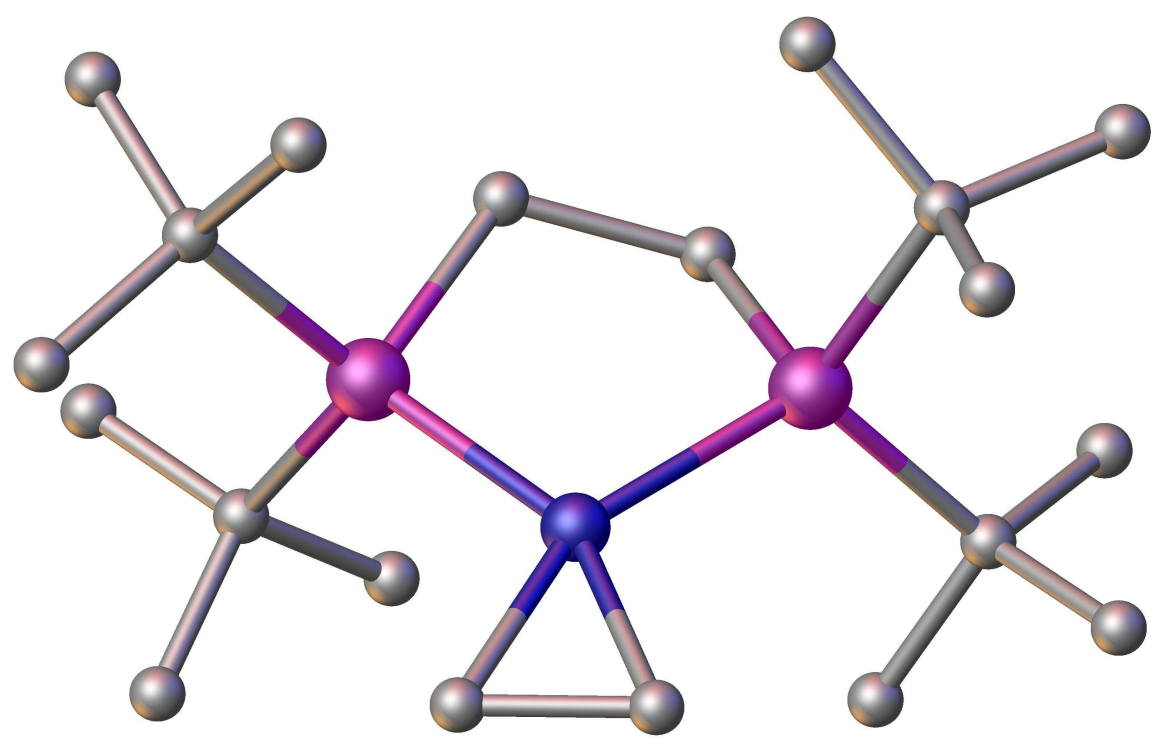

(ii)

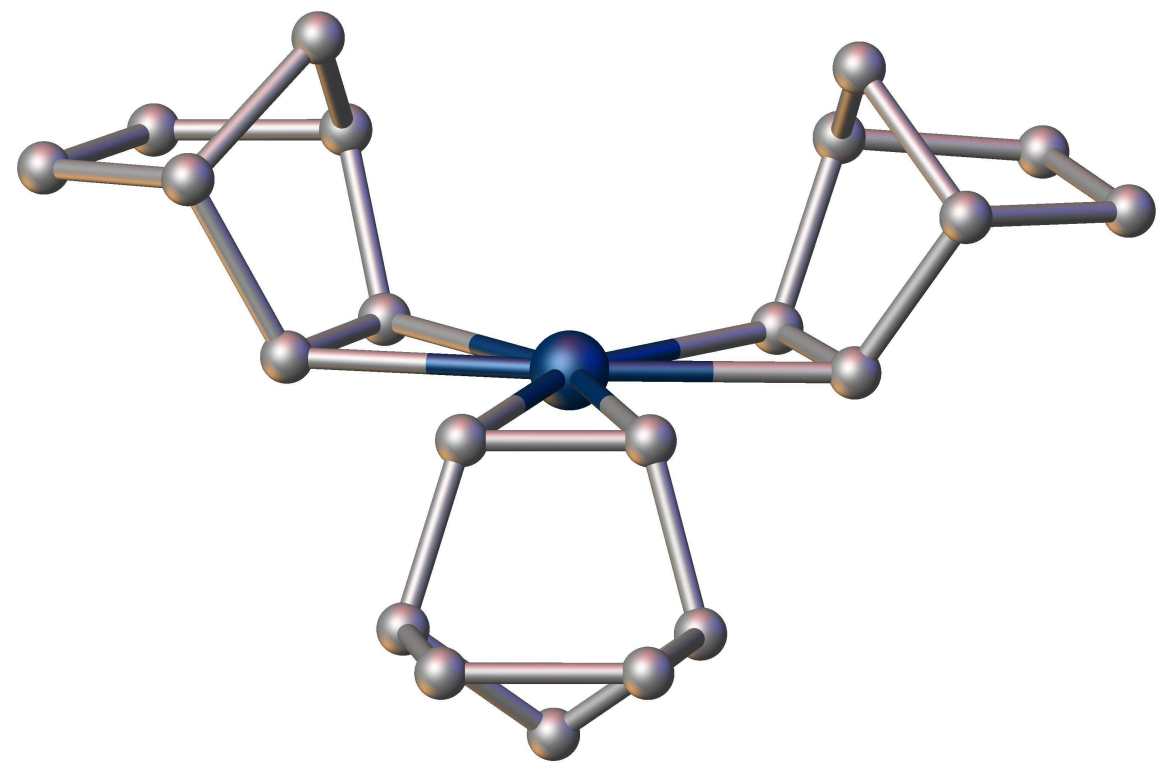

(iii)

Figure 1.2. X-ray crystal structures of some metal-alkene complexes: (i) $\left[\mathrm{PtCl}_{2}\left(\mathrm{C}_{2} \mathrm{H}_{4}\right)_{2}\right],{ }^{22}$ (ii) $\left[\mathrm{Ni}\left(\mathrm{C}_{2} \mathrm{H}_{4}\right)\left({ }^{t} \mathrm{Bu}_{2} \mathrm{P}\left(\mathrm{C}_{2} \mathrm{H}_{4}\right) \mathrm{P}^{t} \mathrm{Bu}_{2}\right)\right]^{23}$ and (iii) $\left[\mathrm{Pt}(\mathrm{nb})_{3}\right]{ }^{16}$ 
MCP using potassium amide (Scheme 1.2 (ii)). ${ }^{27}$ The equivalent reaction with sodium amide produced 1-methylcyclopropene, which means that the choice of base is important. This method was further modified to use a $\mathrm{KO}^{t} \mathrm{Bu} / \mathrm{NaNH}_{2}$ base system. ${ }^{28}$

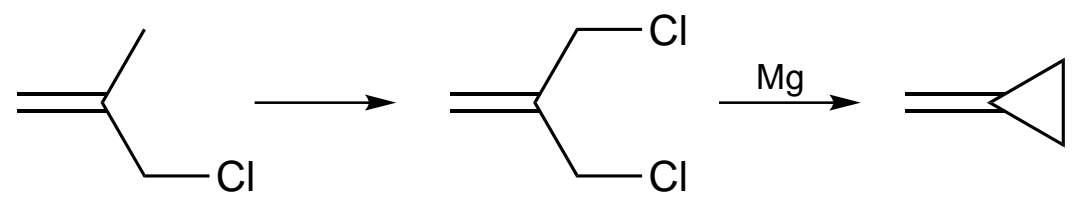

(i)

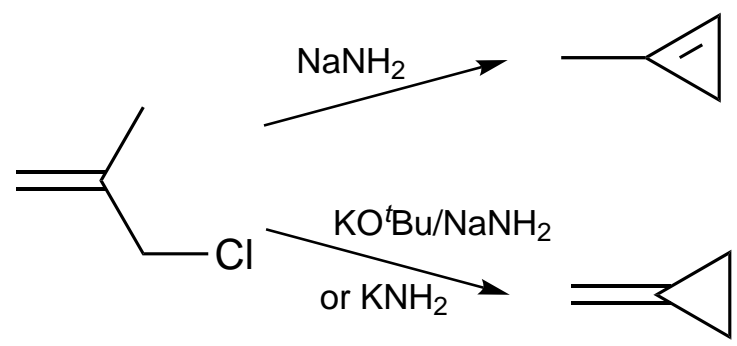

(ii)

Scheme 1.2. Methods of synthesising methylenecyclopropane. ${ }^{26,27}$

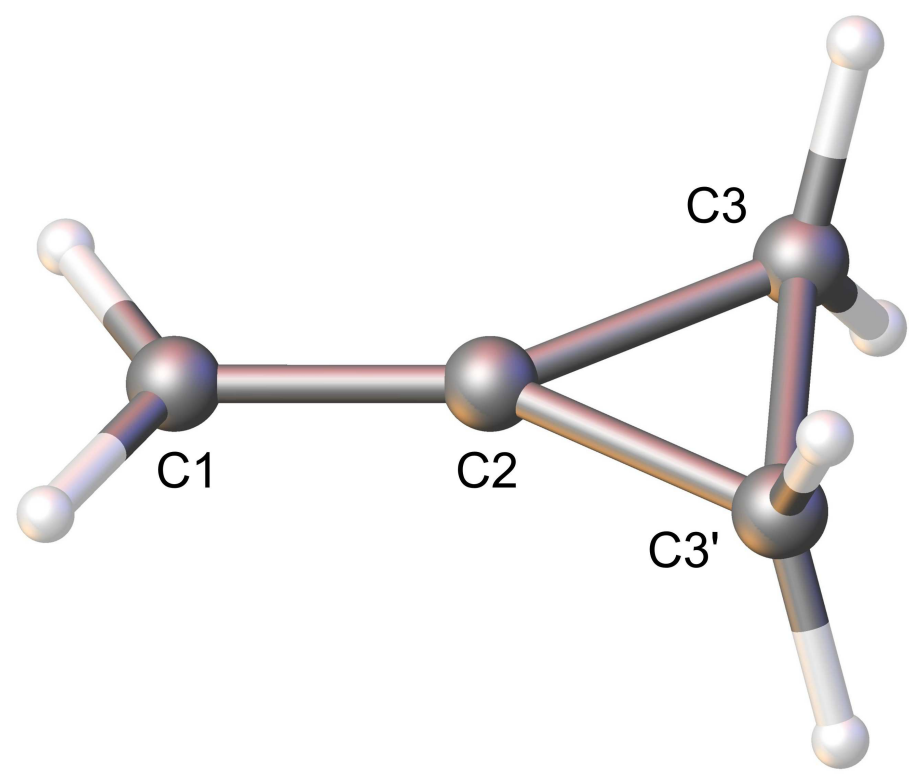

Figure 1.3. Methylenecyclopropane. ${ }^{29}$

While a crystal structure of MCP has not been obtained, the structural properties have been calculated from the microwave spectrum. ${ }^{29}$ The length of the double-bond $(1.332 \AA)$ is comparable to that of ethene $(1.330 \AA)^{30}$ and 2-methylpropene $(1.330 \AA) .{ }^{29}$ The 
proximal (C2-C3) bond lengths $(1.457 \AA)$ are shortened relative to the ideal cyclopropane bond lengths of $1.514 \AA,{ }^{29}$ while the distal bond length $(1.542 \AA)$ is lengthened. The proximal bond shortening is due to the fact that the bonding is between formally $\mathrm{sp}^{3}$ and $\mathrm{sp}^{2}$ carbon atoms, which typically means a shorter bond length than that of a bond between two $\mathrm{sp}^{3}$ carbon atoms. ${ }^{29}$ This trend can also be observed in 2-methylpropene and cyclopropanone, with proximal bonds shortened to 1.507 and $1.475 \AA$ respectively, while in methylcyclopropane the bond lengths are $1.517 \AA$, closer to the ideal. ${ }^{29,31}$ The $\mathrm{C} 3-\mathrm{C} 2-\mathrm{C} 3^{\prime}$ angle is larger than that of cyclopropane $\left(60^{\circ}\right)^{32}$ at $63.9^{\circ}$, while the remaining angles in the ${ }^{c} \operatorname{Pr}$ ring are $58.0^{\circ} .{ }^{29}$

The first ionisation energy of methylenecyclopropane is $9.6 \mathrm{eV}$, similar to 2-methylpropene $(9.2 \mathrm{eV})$, but significantly less than ethene $(10.5 \mathrm{eV}) .{ }^{33} \mathrm{MCP}$ shows a strong $\mathrm{C}=\mathrm{C}$ stretch at $1742 \mathrm{~cm}^{-1}$ in the infrared spectrum, which is at a higher wavenumber than that of ethene, $1623 \mathrm{~cm}^{-1} \cdot 34,35$ In the NMR spectra, there are three different carbon and two proton environments. ${ }^{28,36}$ The double-bond methylene carbon has a proton resonance at $5.35 \mathrm{ppm}$ and a carbon resonance at $103.0 \mathrm{ppm}$, while the ring methylenes have resonances at 1.00 and $2.6 \mathrm{ppm}$ in the ${ }^{1} \mathrm{H}$ NMR and ${ }^{13} \mathrm{C}$ NMR spectra respectively $\left(\mathrm{CDCl}_{3}\right)$. The ring $\mathrm{sp}^{2}$ carbon has a signal at $130.7 \mathrm{ppm}$. The ${ }^{13} \mathrm{C}-{ }^{1} \mathrm{H}$ coupling constant of the ring carbons, $162 \mathrm{~Hz}$, is indicative of the long-range effect of the increased s-character of the double-bond relative to cyclopropane, which has a coupling constant of $160.3 \mathrm{~Hz} \cdot{ }^{36,37}$

\subsubsection{Organometallic Chemistry}

\subsubsection{Transition Metal-Catalysed Reactions}

The transition metal chemistry of methylenecyclopropane and its derivatives has been explored since the 1970s. There are four different ways that MCPs react with transition metal species (Scheme 1.3). ${ }^{38}$ When the metal reacts with the cyclopropane ring, there can be insertion into either the distal (Scheme 1.3 (i)) or the proximal bonds (Scheme 1.3 (ii)) of the ring. When the double-bond reacts with an organotransition metal species $\left(\mathrm{R}-\mathrm{ML}_{n}\right)$, this can yield either the Markovnikov product (Scheme 1.3 (iii)), with the metal 
bound to the ${ }^{c} \operatorname{Pr}$ carbon atom, or the anti-Markovnikov product (Scheme 1.3 (iv)), with the metal bound to the methylene carbon atom.

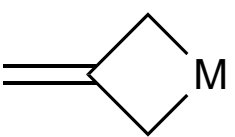

(i)

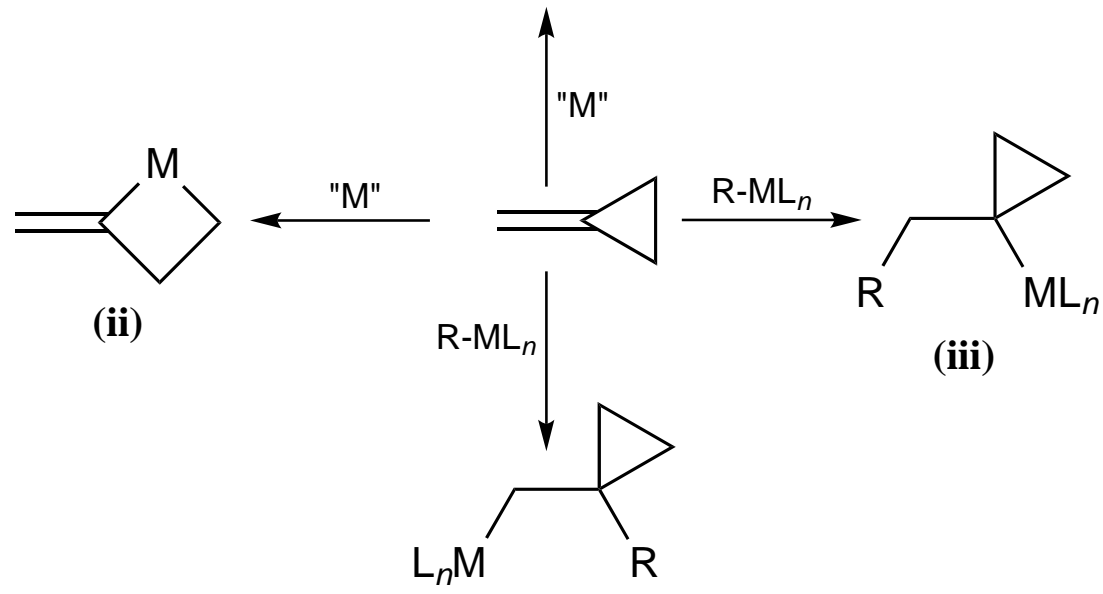

(iv)

Scheme 1.3. The four reaction modes of methylenecyclopropanes with transition metals. ${ }^{38}$

The transition metal-catalysed reactions of MCPs which have been previously studied can be divided into four types, which involve at least one of the above transformations: Transition metal-catalysed $[3+2]$ cycloadditions, Heck-type reactions with organopalladium species, additions of metal hydrides $(\mathrm{M}-\mathrm{H})$ and pronucleophiles $(\mathrm{Nu}-\mathrm{H})$, and the addition of bis-metallic species. ${ }^{38}$

\subsubsection{Transition Metal-Catalysed [3+2] Cycloadditions}

Methylenecyclopropane can act as a three-carbon unit in transition metal catalysed [3+2] cycloadditions. ${ }^{38-40}$ These reactions always involve the cleavage of one of the bonds in the ${ }^{c} \mathrm{Pr}$ ring. In the case of distal bond cleavage (Scheme 1.4), the reaction proceeds via the formation of a metallacyclobutane species, followed by the insertion of an $\mathrm{X}=\mathrm{Y}$ multiple bonded species. This forms a 5-membered carbo- or hetero-cycle, depending on the nature of $\mathrm{X}=\mathrm{Y} \cdot{ }^{38,41}$

Alternatively, in the case of proximal bond cleavage, the reaction can proceed via one 


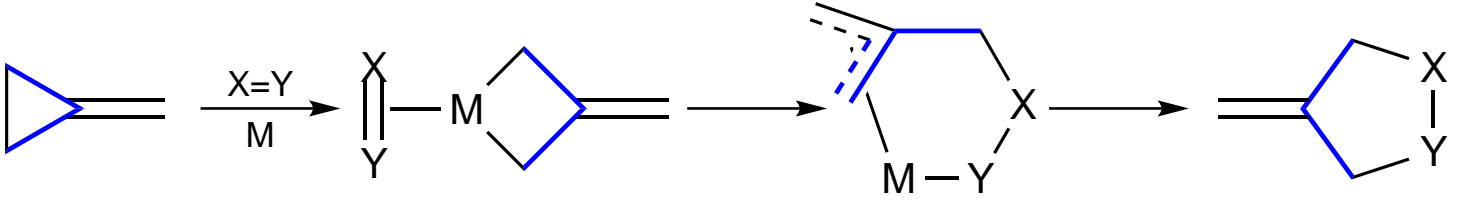

Scheme 1.4. TM catalysed $[3+2]$ cycloaddition of MCP involving distal bond cleavage. ${ }^{38}$

of two routes. (Scheme 1.5). The first, the direct attack of the catalyst on the proximal bond, is similar to distal bond cleavage, involving a metallacyclobutane intermediate. In the second route, a metallacyclopentane species is formed, incorporating $\mathrm{X}=\mathrm{Y}$. This then undergoes a cyclopropyl to homoallyl rearrangement, yielding 5-membered carboor hetero-cycles with different regiochemistry to the distal bond cleavage product. The mode of ring opening is catalyst dependent. ${ }^{38,41}$

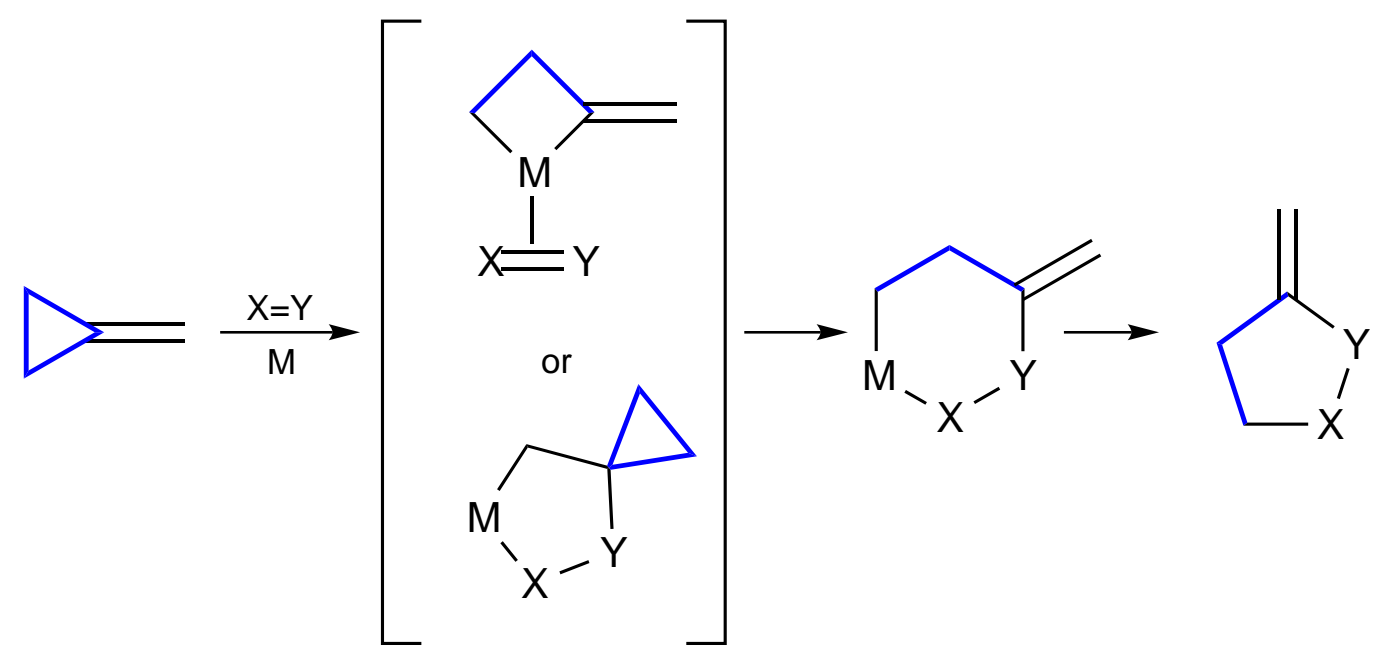

Scheme 1.5. TM catalysed [3+2] cycloaddition of MCP involving proximal bond cleavage. ${ }^{38}$

There are several species that can behave as $\mathrm{X}=\mathrm{Y}$ in these $[3+2]$ cycloadditions. Reactions where $\mathrm{X}=\mathrm{Y}$ is a carbon-carbon multiple bond have been extensively investigated, particularly for nickel- and palladium-catalysed reactions. ${ }^{38-40}$ A variety of MCP derivatives have been utilised as the three-carbon component, and the reaction has been extended to intramolecular versions. ${ }^{42-44}$

Reactions with carbon-heteroatom bonds have been successful with heterocumulenes such as carbon dioxide and ketenimines, producing lactones and pyrrolidine derivatives 
respectively. ${ }^{41,45}$ MCPs can also be reacted with aldehydes to produce substituted tetrahydrofurans, ${ }^{46}$ and with imines to produce 3 -methylenepyrrolidine derivatives. ${ }^{47}$ These reactions are reasonably high yielding, ranging from $38 \%$ to $94 \%$, depending on the nature of both the MCP derivative and the carbon-heteroatom species. ${ }^{38}$

\subsubsection{Heck-Type Reactions}

Methylenecyclopropanes can undergo palladium-catalysed Heck-type reactions with alkyl or aryl halides (Scheme 1.6). ${ }^{38}$ These reactions predominantly involve the cleavage of one of the proximal bonds of the ${ }^{c} \mathrm{Pr}$ ring. ${ }^{38,48,49}$ Initially, a previously formed $\mathrm{R}-\mathrm{Pd}-\mathrm{X}$ species adds across the double-bond in an anti-Markovnikov fashion. The proximal bond is then cleaved in a cyclopropyl to homoallyl rearrangement, generating a homoallylpalladium species. When this undergoes $\beta$-hydride elimination, the product is a 2 -alkylated 1,3-diene. However, in some cases the homoallylpalladium species rearranges to a $\pi$ allylpalladium intermediate, which can then be trapped by an appropriate nucleophile. ${ }^{38}$

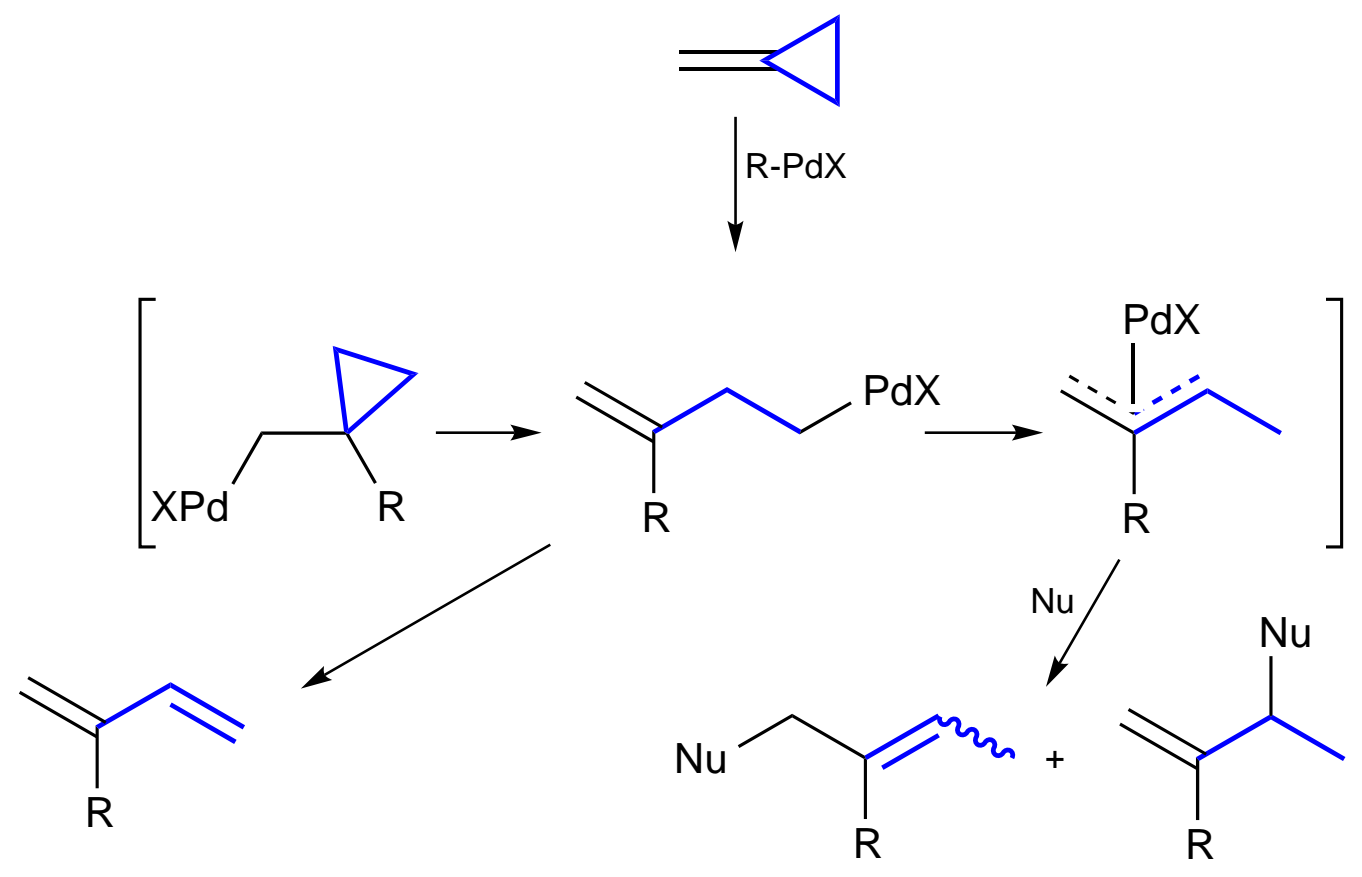

Scheme 1.6. Palladium-catalysed Heck-type reaction with MCP. ${ }^{38}$ 


\subsubsection{Addition of Metal Hydrides and Pronucleophiles}

The palladium-catalysed reactions of methylenecyclopropanes with either metal hydrides $(\mathrm{M}-\mathrm{H})$ or pronucleophiles $(\mathrm{Nu}-\mathrm{H})$ are of considerable use, as this can introduce a functional group into unsaturated molecules in an atom-economical manner. ${ }^{38}$ These reactions involve the cleavage of one of the ${ }^{c} \operatorname{Pr}$ bonds. The type of bond cleaved is dependent upon the substrate. ${ }^{38}$ In the reaction with metal hydrides such as stannyl hydrides $\left(\mathrm{HSnR}_{3}\right)$ and hydrosilanes $\left(\mathrm{HSiR}_{3}\right)$, it is usually one of the proximal bonds that is cleaved. ${ }^{38,50}$ First, the palladium atom inserts into the $\mathrm{M}-\mathrm{H}$ bond, and then, as with the Heck-type reactions, the resulting $\mathrm{H}-\mathrm{Pd}-\mathrm{M}$ species undergoes anti-Markovnikov addition across the MCP double-bond. The proximal bond is cleaved, forming a homoallylpalladium species. The product is formed by reductive elimination from the palladium (Scheme 1.7). Proximal bond cleavage also occurs in the addition of a boronboron bond. ${ }^{38}$

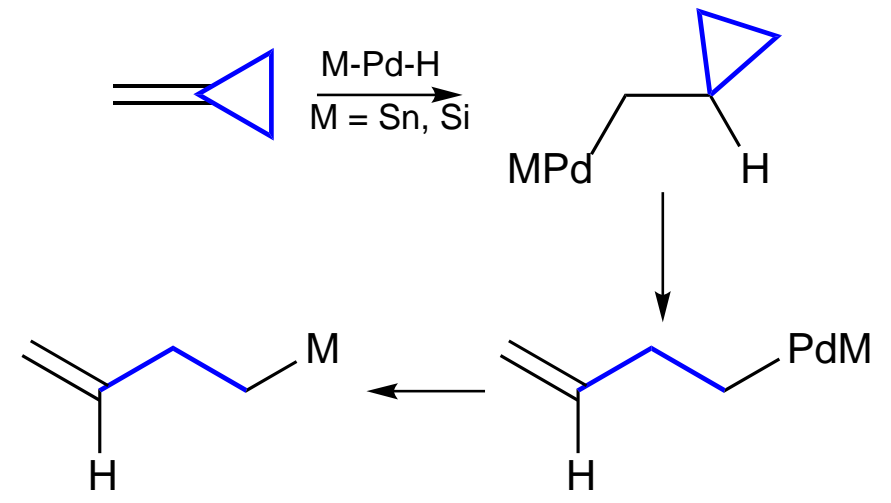

Scheme 1.7. Palladium-catalysed addition of metal hydrides to MCP. ${ }^{38}$

In the reaction with pronucleophiles such as carbo-pronucleophiles $\left(\mathrm{HC}(\mathrm{EWG})_{n} \mathrm{R}_{3-n}\right)$, amines $\left(\mathrm{HNR}_{2}\right)$ and alcohols (HOR), it is mainly the distal bond that is cleaved. ${ }^{38}$ There are two mechanistic possibilities in this reaction. The palladium atom could first insert into the $\mathrm{Nu}-\mathrm{H}$ bond, generating a $\mathrm{H}-\mathrm{Pd}-\mathrm{Nu}$ species, which then adds across the doublebond in a Markovnikov fashion. The cyclopropylpalladium species undergoes $\beta$-carbon palladium elimination to give a $\pi$-allylpalladium intermediate that is attacked by the nucleophile to yield the product (Scheme 1.8). Alternatively, the Pd can insert into the distal ${ }^{c} \operatorname{Pr}$ bond, forming a metallacyclobutane. This then reacts with the pronuclophile 
to give the same $\pi$-allylpalladium species as before.

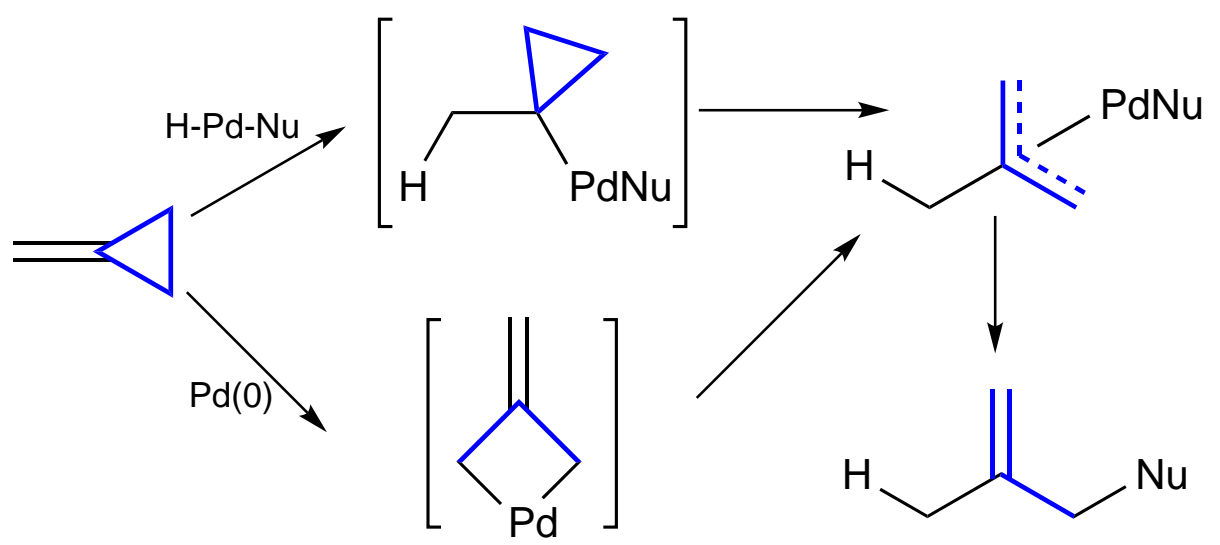

Scheme 1.8. Palladium-catalysed addition of pronucleophiles to MCP. ${ }^{38}$

\subsubsection{Bismetallation}

Catalytic bismetallation is an attractive methodology to introduce two metal atoms into a carbon framework by directly adding the metals across a carbon-carbon multiple bond. This chemistry has previously been demonstrated using alkenes, alkynes, 1,3-dienes and allenes. More recently, methylenecyclopropanes have been used as acceptors as they impart unique structural properties to the products. ${ }^{38}$

The palladium- and nickel-catalysed bismetallation of substituted MCPs has been achieved using trimethylsilyl cyanide. ${ }^{51}$ This can be done either with retention of the ring, or with cleavage of the distal bond. Unsubstituted MCP has been bismetallated by a diborane using a platinum catalyst, with cleavage of the proximal ring bond to yield a ring-opened product. ${ }^{52}$ Most extensively studied has been the palladium- and platinum-catalysed silaboration of MCPs. ${ }^{53}$ These reactions can involve either distal or proximal bond cleavage. The mechanism of the silaboration reaction has not been fully explored, and there are several possible reaction pathways (Scheme 1.9). ${ }^{38,53}$ Firstly, there is the possibility that it proceeds similar to the Heck type reactions and $\mathrm{Nu}-\mathrm{H}$ additions, with the addition of a $\mathrm{R}_{2} \mathrm{~B}-\mathrm{M}-\mathrm{SiR}_{3}^{\prime}$ species across the double-bond, followed by a rearrangement to yield a homoallyl product. However, this does not completely explain the product distribution. An alternative mechanism is possible, with the oxidative 
addition of the proximal bond onto the metal forming a metallacyclobutane, followed by reductive elimination of the borane and the double-bonded carbon atom to generate the same homoallyl species. The metallacyclobutane mechanism can also be applied to the case of distal bond cleavage.

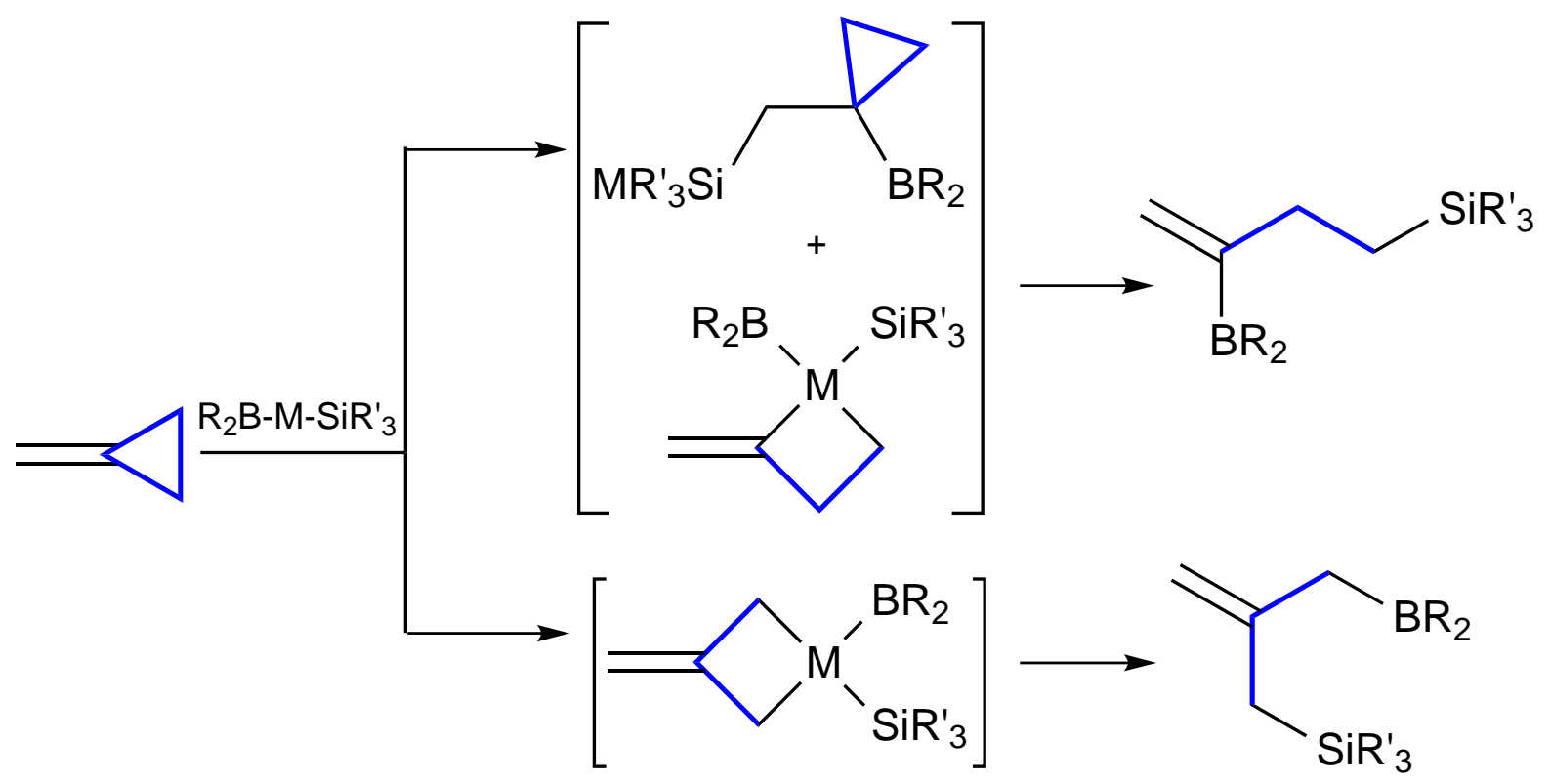

Scheme 1.9. Possible mechanisms for the metal-catalysed silaboration of MCP. ${ }^{38,53}$

\subsubsection{Transition Metal Complexes}

The transition metal chemistry of methylenecyclopropane is dominated by ring opening reactions, which has somewhat limited the isolation of $\eta^{2}$-methylenecyclopropane complexes. A common occurrence upon the coordination of $\mathrm{MCP}$ is the ring-opening of the distal ${ }^{c} \mathrm{Pr}$ bond to form $\eta^{4}$-trimethylenemethane complexes. Complexes of this ligand formed from MCP have been isolated for molybdenum, ${ }^{54}$ iron, ${ }^{39}$ nickel ${ }^{39,55}$ and palladium. ${ }^{56,57}$ Despite this propensity to ring-open, there are several instances of transition metal-catalysed reactions of MCP in which the ring is retained, and as such there have been a few $\eta^{2}$ methylenecyclopropane complexes isolated. As MCP has a high HOMO compared to other alkenes such as ethene, and is highly strained, it should be able to both effectively donate electron density into empty metal orbitals and accept back donation. ${ }^{58,59}$ Due to the sensitivity of MCP to ring-opening reactions, the precursor complexes and the 
ancillary ligands need to be carefully chosen. Complexes of nickel and platinum with phosphine ligands have been successfully synthesised by starting from the equivalent ethene complexes. In the presence of an excess of MCP, the ethene is displaced to yield $\left[\mathrm{Ni}\left(\eta^{2}-\mathrm{MCP}\right)\left(\mathrm{PPh}_{3}\right)_{2}\right]^{60}$ and $\left[\mathrm{Pt}\left(\eta^{2}-\mathrm{MCP}\right)\left(\mathrm{PPh}_{3}\right)_{2}\right]{ }^{61}$ (Scheme 1.10).
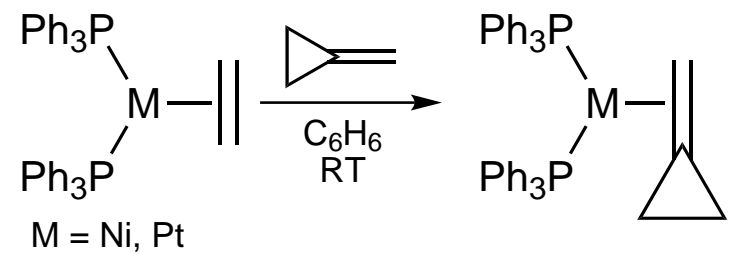

Scheme 1.10. Synthesis of Ni and Pt complexes of MCP. ${ }^{60,61}$

A rhodium-bis-MCP complex has also been isolated by the displacement of ethene from $\left[\mathrm{Rh}(\mathrm{acac})\left(\mathrm{C}_{2} \mathrm{H}_{4}\right)_{2}\right] .{ }^{61}$ The variable temperature NMR data of this complex shows that the MCP ligands undergo rapid propeller rotation at room temperature. ${ }^{61}$ Also, the NMR data showed that coupling to ${ }^{103} \mathrm{Rh}$ only occurs to the olefinic carbon atoms and protons, not to those in the ${ }^{c} \mathrm{Pr}$ ring. This is also the case for the above Pt complex. An X-ray crystal structure of $\left[\mathrm{Rh}(\mathrm{acac})(\mathrm{MCP})_{2}\right]$ was obtained (Figure 1.4). ${ }^{61}$ This shows that the coordination geometry of the rhodium atom is almost perfectly square planar. The two MCP ligands are anti-parallel to each other, and perpendicular to the metal coordination plane. The double-bond ring carbon is closer to the metal than the double-bond methylene carbon atom carbon atom (2.07 and $2.13 \AA$ respectively), and the coordination plane intersects the double-bond closer to the ring carbon atom. This can also be inferred from the ${ }^{103} \mathrm{Rh}-{ }^{13} \mathrm{C}$ coupling constants, with that of the ring carbon atom larger than that of the methylene carbon atom $(20 \mathrm{~Hz}$ vs. $14 \mathrm{~Hz})$. The plane of the ${ }^{c} \operatorname{Pr}$ ring is bent away from that of the double-bond by $23^{\circ}$, indicative of back bonding from the metal. The double-bond itself is at an angle of $80^{\circ}$ relative to the metal plane. This distortion is similar to that observed in allene complexes. ${ }^{61,62}$

MCP complexes can be synthesised by methods other than the displacement of an ethene ligand. The above nickel-phosphine complex $\left(\left[\mathrm{Ni}(\mathrm{MCP})\left(\mathrm{PPh}_{3}\right)_{2}\right]\right)$ can also be synthesised from $[\mathrm{Ni}(\mathrm{acac})], \mathrm{Et}_{2} \mathrm{Al}(\mathrm{OEt}), \mathrm{PPh}_{3}$ and $\mathrm{MCP} .{ }^{60} \mathrm{~A}$ cobalt complex has been synthesised by reductive complexation from a chloro complex. The $\mathrm{Co}$ (II) complex 


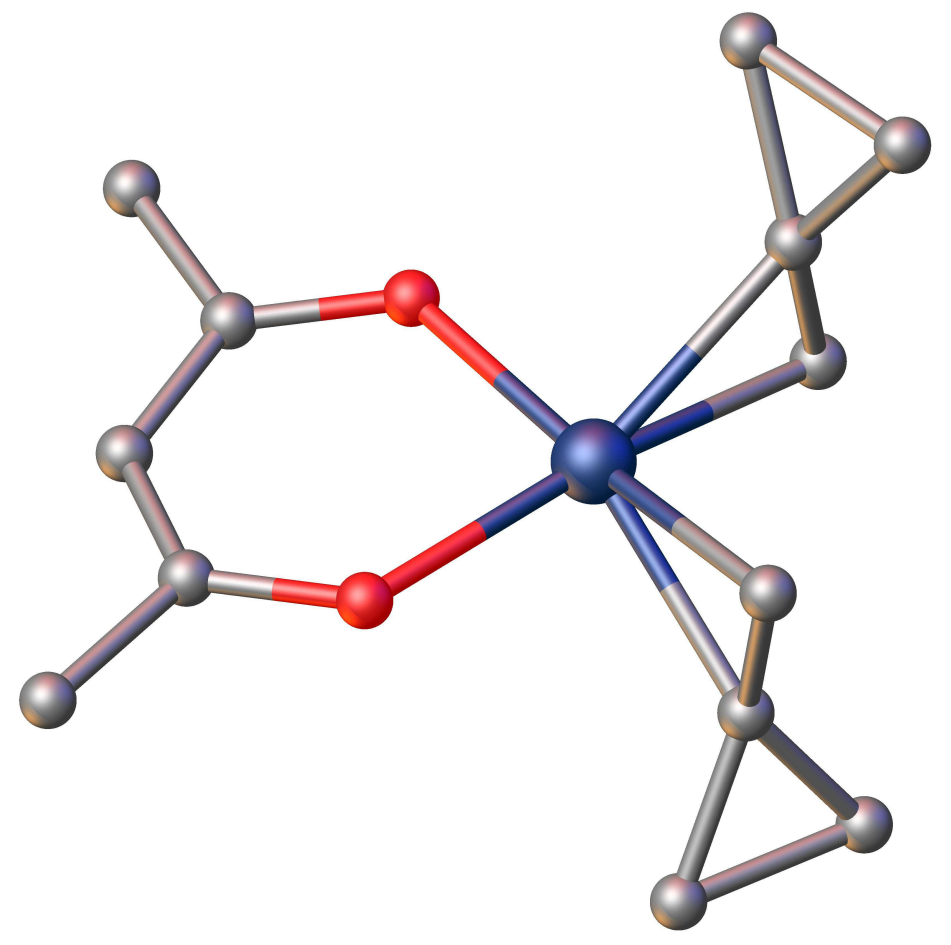

Figure 1.4. X-ray crystal structure of $\left[\operatorname{Rh}(\operatorname{acac})(\mathrm{MCP})_{2}\right] \cdot{ }^{61}$

((2-(di-tert-butylphosphanyl)-P-ethyl)cyclopentadienyl)chlorocobalt(II) ([CoCl(Cp\#)]) was treated with sodium amalgam and $\mathrm{MCP}$ at $-50^{\circ} \mathrm{C}$ to yield $[\mathrm{Co}(\mathrm{Cp} \#)(\mathrm{MCP})]$ (Scheme 1.11). ${ }^{58,59}$
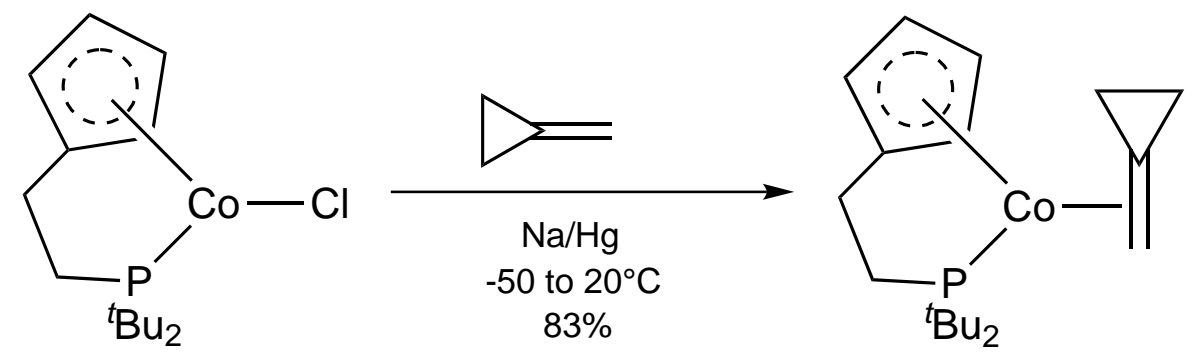

Scheme 1.11. Synthesis of a Co-MCP complex. ${ }^{58,59}$

\subsection{Bicyclopropylidene}

\subsubsection{Synthesis of Bicyclopropylidene}

Bicyclopropylidene (BCP) is a unique tetra-substituted alkene, consisting of two cyclopropylidene units joined by a common double-bond. It was originally conceived 


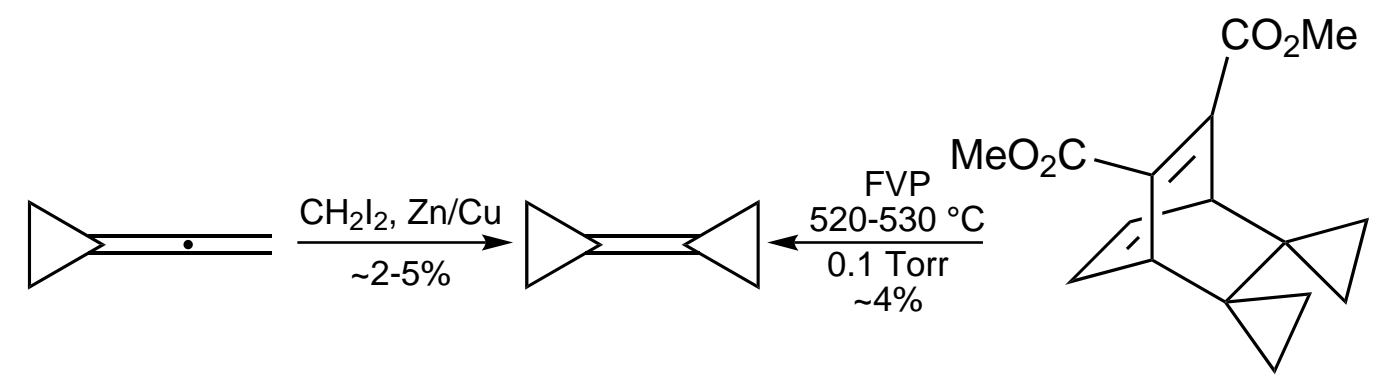

Scheme 1.12. First syntheses of bicyclopropylidene. ${ }^{63}$

by two independent groups as a molecule of mainly theoretical interest. ${ }^{37}$ The first syntheses (Scheme 1.12), either a Simmons-Smith-type monocyclopropanation of the terminal double-bond in ethenylidenecyclopropane ${ }^{64}$ or a retro-Diels-Alder cleavage of dispiro[cyclopropane-1,2'-bicyclo[2.2.2] octa[5,7]diene-3', $1^{\prime \prime}$-cyclopropane]-5', $6^{\prime}$-dimethyl ester, ${ }^{65}$ did not yield enough compound to perform a full structural and spectroscopic characterisation. Later syntheses were higher yielding, but still too convoluted to be synthetically useful. ${ }^{63}$ It was not until the Kulinkovich reaction enabled the transformation of an ester to a cyclopropanol group using an ethylmagnesium bromide/titanium tetraisopropoxide reagent that $\mathrm{BCP}$ could be easily made in useful quantities. ${ }^{63}$ This enabled the transformation of methyl cyclopropanecarboxylate to 1-cyclopropylcyclopropanol quantitatively, which could then be simply converted to the bromide followed by dehydrobromination to form the double-bond (Scheme 1.13). ${ }^{66,67}$ This efficient synthesis method allowed the properties and chemistry of BCP to be studied extensively.

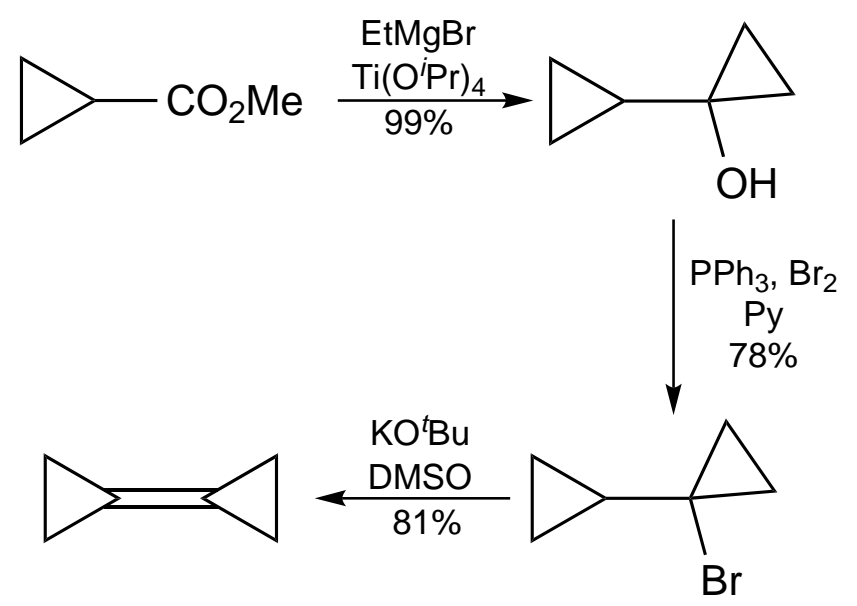

Scheme 1.13. Highest yielding synthesis of bicyclopropylidene. ${ }^{66,67}$ 


\subsubsection{Properties of Bicyclopropylidene}

\subsubsection{Structural Properties}

Bicyclopropylidene can be thought of as comprising two joined methylenecyclopropane units. The double-bond has increased s-character due to the presence of the ${ }^{c} \mathrm{Pr}$ rings and the carbon atoms are therefore close to sp-hybridised. ${ }^{29,32,68}$ As a result of this, in the Xray crystal structure the length of the double-bond is $1.304 \AA$ (Figure 1.5), ${ }^{30}$ shorter than the double-bonds in ethene $(1.330 \AA)^{30}$ and MCP $(1.332 \AA) .{ }^{29}$ It is noteworthy that the presence of one terminal ${ }^{c} \mathrm{Pr}$ on a double-bond does not make much of a difference to the bond length, as in the case of MCP, while the presence of two significantly shortens the bond. The double-bond in BCP is comparable to the central bond in butatriene, and has properties approaching those of an acetylenic triple bond. ${ }^{63}$ The length of the bonds in the ${ }^{c}$ Pr rings, 1.472 and $1.549 \AA$ for proximal (C1-C2, C1-C3) and distal (C2-C3) respectively, are comparative to the equivalent bonds in MCP, 1.457 and $1.542 \AA$, although the BCP proximal bond is somewhat longer. ${ }^{30}$ As with MCP, the shortening of the proximal bonds relative to the bonds in cyclopropane $(1.541 \AA)^{29}$ has been attributed to the fact that these bonds are nominally $\mathrm{sp}^{2}-\mathrm{sp}^{3}$, which tend to be shorter than $\mathrm{sp}^{3}-\mathrm{sp}^{3}$ bonds. ${ }^{29}$

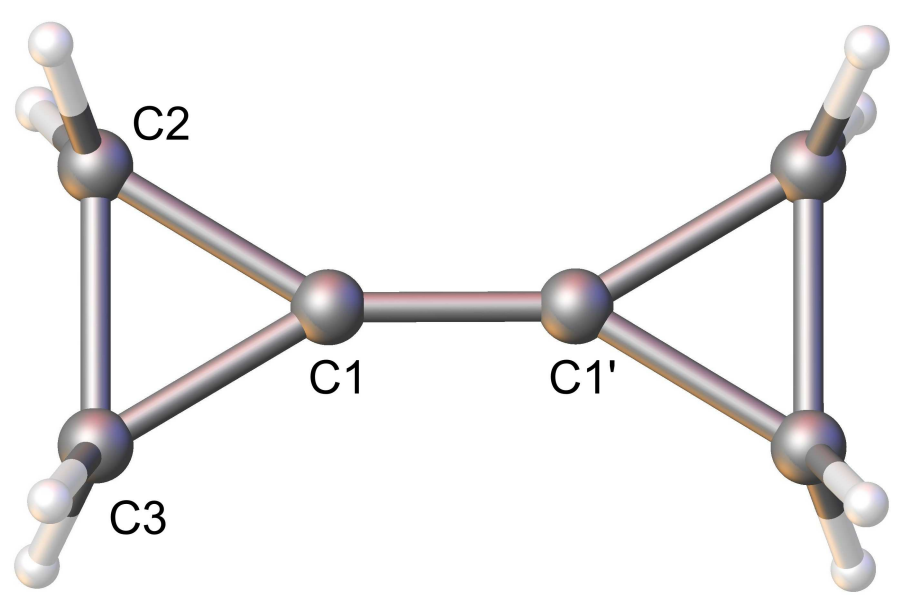

Figure 1.5. X-ray crystal structure of BCP at 173 K. ${ }^{30}$

The C2-C1-C3 angle is $63.1^{\circ},{ }^{30}$ approximately the same as that in $\operatorname{MCP}\left(63.9^{\circ}\right)^{29}$ and larger than that in cyclopropane $\left(60^{\circ}\right) .{ }^{32}$ Correspondingly, the $\mathrm{C} 1-\mathrm{C} 2-\mathrm{C} 3$ and $\mathrm{C} 1-\mathrm{C} 3-\mathrm{C} 2$ angles are smaller than those in cyclopropane at $58.4^{\circ}$. The two ${ }^{c} \operatorname{Pr}$ rings are coplanar 
with the double-bond to within $0.002^{\circ}{ }^{30}$

\subsubsection{Spectroscopic and Electronic Properties}

There have been several IR and Raman spectra of bicyclopropylidene reported by different groups, and not all are in agreement. ${ }^{37}$ The most relevant vibrational mode with respect to its bonding properties is the double-bond stretch, a weak band at $1836 \mathrm{~cm}^{-1}$ in the Raman. ${ }^{37}$ The NMR data show a peak at $1.16 \mathrm{ppm}$ in the ${ }^{1} \mathrm{H}$ NMR spectrum and peaks at 2.9 and $110.2 \mathrm{ppm}$ in the ${ }^{13} \mathrm{C}$ NMR spectrum $\left(\mathrm{CDCl}_{3}\right) \cdot{ }^{67}$ The ${ }^{13} \mathrm{C}-{ }^{1} \mathrm{H}$ coupling constant, $162.3 \mathrm{~Hz}$, is indicative of a slightly increased s character of the $\mathrm{C}-\mathrm{H}$ bonds relative to those in cyclopropane, which has a coupling constant of $160.3 \mathrm{~Hz} \cdot{ }^{37}$ Bicyclopropylidene has a relatively high-lying HOMO, $0.64 \mathrm{eV}$ higher than that of MCP. ${ }^{37}$ While the first ionisation energy of $\mathrm{BCP}(8.93 \mathrm{eV})^{68}$ is higher than that of tetramethylethene $(8.27 \mathrm{eV}),{ }^{69}$ $\mathrm{BCP}$ is significantly more reactive towards additions across the double-bond. ${ }^{63}$ This is in part due to the decreased steric bulk of the ${ }^{c} \mathrm{Pr}$ rings relative to the methyl groups, but mostly due to the difference in hybridisation of the double-bond carbon atoms. ${ }^{63}$ There is significant electronic interaction between the two ${ }^{c} \mathrm{Pr}$ rings, which can be approximated as double-bonds ${ }^{70}$ meaning that BCP has been described as a 'bishomobutatriene'. ${ }^{37}$ This, and the high $\mathrm{HOMO}$ mean that $\mathrm{BCP}$ has a uniquely enhanced reactivity towards a wide range of electrophiles and cycloaddends. ${ }^{37}$

\subsubsection{Reactivity}

$\mathrm{BCP}$ is reactive towards cycloadditions and additions across the double-bond. Due to the high HOMO, BCP is nucleophilic. ${ }^{32}$ While most monoalkenes are limited in their cycloadditions, the uniqueness of $\mathrm{BCP}$ is evident in the fact that it undergoes a wider range of reactions towards cycloaddends, comparable to cross-conjugated polyenes. ${ }^{71}$ For example, thermal cyclodimerisations of monoalkenes are rare, but BCP dimerises at high temperatures. ${ }^{64}$ Some of the chemistry of BCP is similar to that of cumulenes, namely that it undergoes high temperature dimerisations and $[2+2]$ cycloadditions with conjugated dienes. ${ }^{32}$ This is to be expected from the fact that it is a 'bishomobutatriene'. 
BCP can be deprotonated easily, leading to the formation of a wide range of substituted bicyclopropylidenes. ${ }^{37,63}$ This enhanced kinetic acidity is due not so much to the polarity of the $\mathrm{C}-\mathrm{H}$ bond, but rather to the stabilisation of the carbanion. ${ }^{37} \mathrm{BCP}$ can also undergo reactions in which either the proximal or distal bonds of the ${ }^{c} \operatorname{Pr}$ rings are cleaved. ${ }^{37,63}$

\subsubsection{Organometallic Chemistry}

\subsubsection{Transition Metal-Catalysed Reactions}

Bicyclopropylidene is active in several transition metal-catalysed reactions. These tend to be analogous to the transition metal-catalysed reactions of methylenecyclopropanes. To date, the bulk of the catalysis has involved the use of a palladium catalyst, although there are some examples of nickel-catalysis. ${ }^{37,63}$

\subsubsection{Transition Metal-Catalysed Cycloadditions}

As with other methylenecyclopropanes, BCP can undergo palladium-catalysed [3+2] cycloadditions as the $\mathrm{C}_{3}$-building block. ${ }^{72}$ When reacted with electron-deficient alkenes such as those in Scheme 1.14, two regioisomers that possess the 4-methylenespiro[2.4]heptane skeleton are produced.

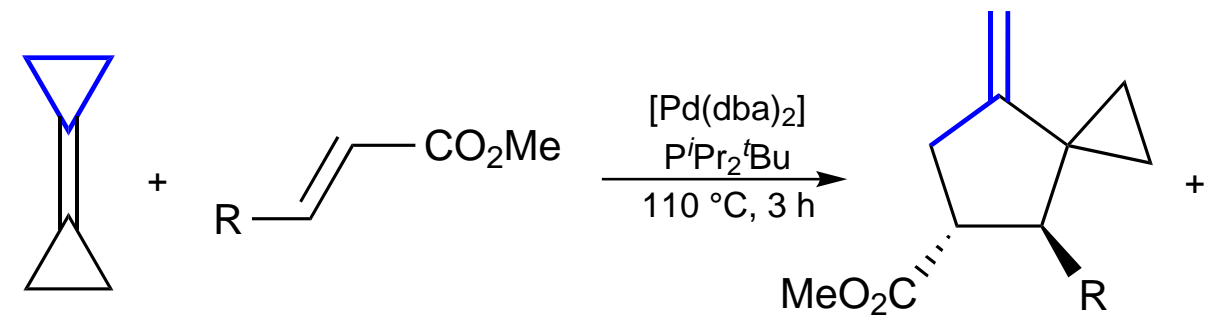

(i)

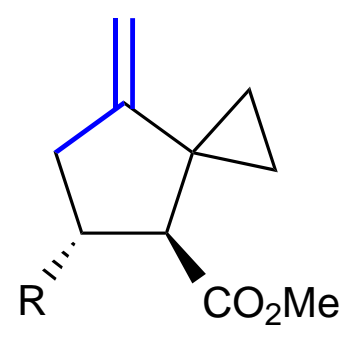

(ii)

\begin{tabular}{lrr}
\hline R & Yield \% & (i):(ii) \\
\hline $\mathrm{H}$ & 54 & $74: 26$ \\
$\mathrm{Me}$ & 58 & $90: 10$ \\
$\mathrm{Ph}$ & 81 & $89: 11$ \\
\hline
\end{tabular}

Scheme 1.14. Pd-catalysed reactions of BCP with electron-deficient alkenes. ${ }^{72}$ 


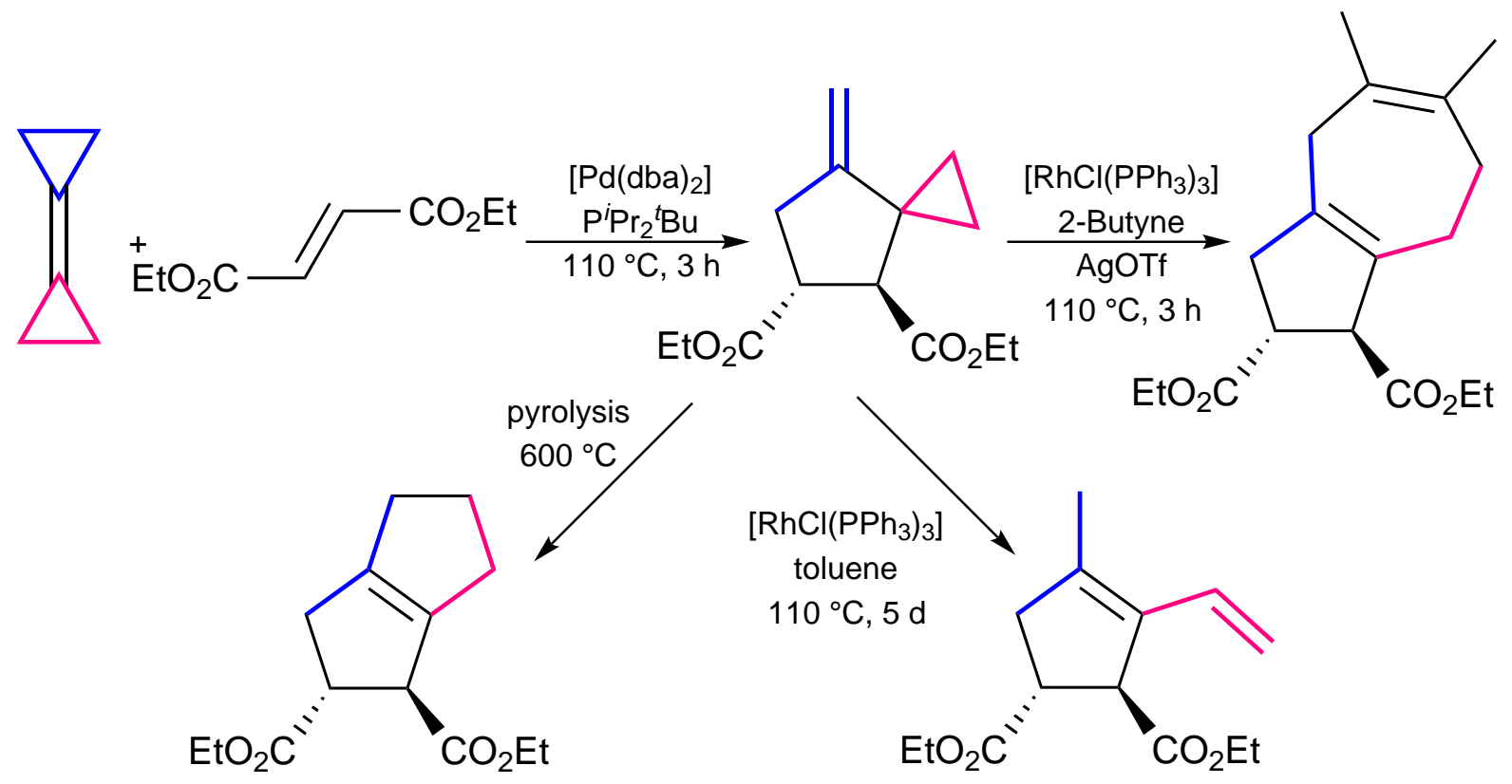

Scheme 1.15. Pd-catalysed reactions of BCP with diethyl fumarate. ${ }^{72}$

These reactions are regioselective, both with respect to BCP, in that only methylenespiro[2.4]heptane derivatives are produced, and with respect to the positioning of the carboxylate relative to the ${ }^{c} \operatorname{Pr}$ ring in the product, with $75-90 \%$ of the products having the carboxylate group in the $\gamma$-position (Scheme 1.14 (i)). In equivalent reactions with isopropylidene- and cyclopentylidene cyclopropane, the alkylidene group is retained, while $\operatorname{Pd}(0)$ catalysed reactions of 2-(1-trimethylsilyl-1-cyclopropyl)alkyl pivalate with electron deficient alkenes give a solvent-dependent distribution of products. Calculations involving $\mathrm{MCP}$ and ethene ${ }^{73}$ predict that the regioisomers with the carboxylate in the $\beta$-position (Scheme 1.14 (ii)) should be the sole products. ${ }^{72}$ However, these are the minor products, with the $\gamma$-carboxylate products being favoured. While the mechanism for the product formation is not completely understood, Scheme 1.16 shows the proposed mechanisms. ${ }^{72}$ Alternatively, a '(trimethylenemethane)palladium' intermediate with charge separation could account for the observed regiochemistry. ${ }^{72}$

In the case of the reaction of BCP with diethyl fumarate (Scheme 1.15), there is only one possible isomer formed. Several further reactions of this product have been explored, and the rhodium-catalysed cocyclisation with an alkyne yielding a further sevenmembered ring, the first intermolecular case of this reaction, may have applications in 


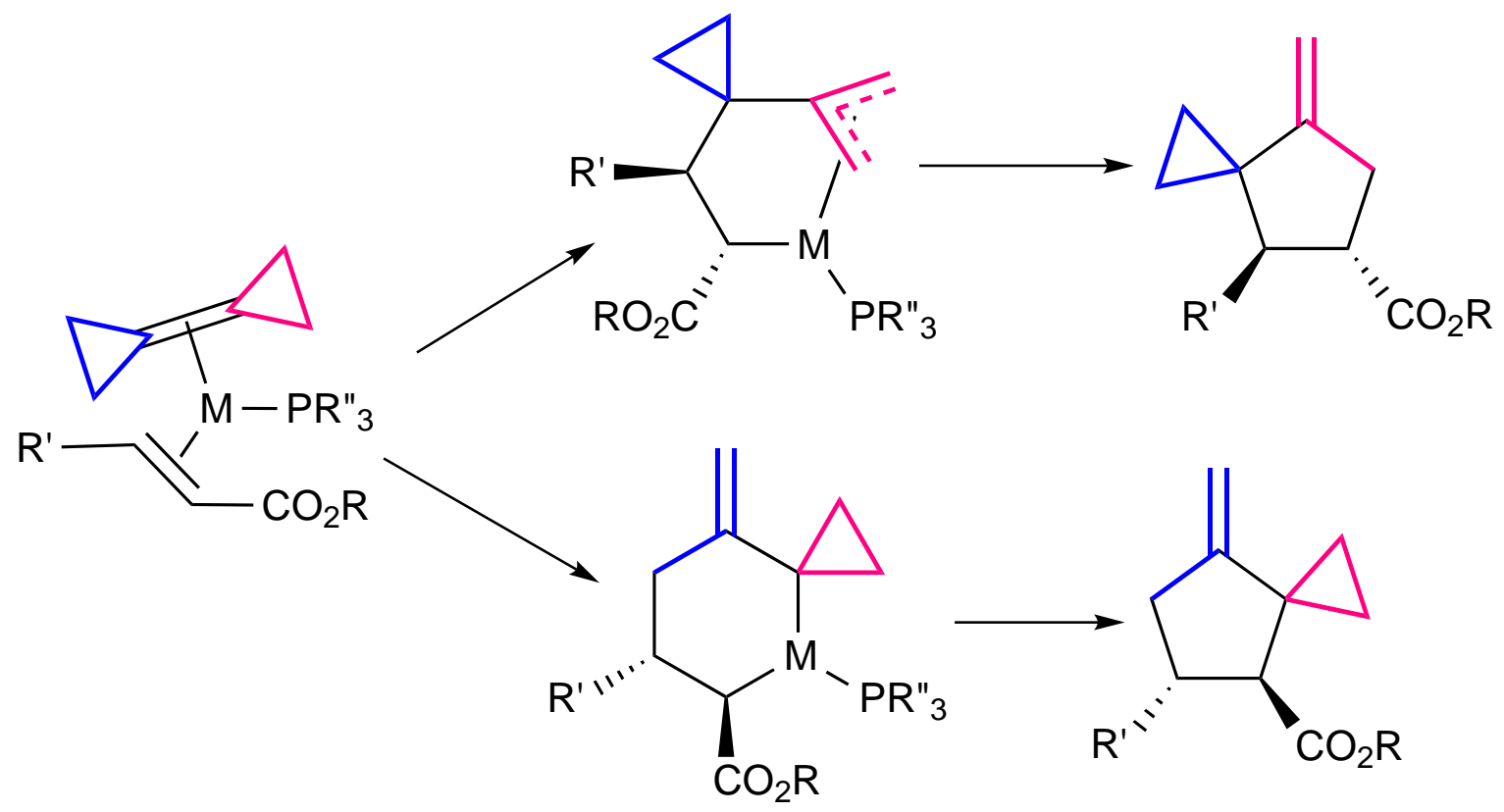

Scheme 1.16. Mechanisms for the formation of $[3+2]$ cycloaddition products of BCP. ${ }^{72}$ terpene total synthesis. ${ }^{72}$

BCP can also undergo palladium(0)-catalysed [3+2] cycloadditions with strained alkenes such as norbornene and norbornadiene to give products similar to those in Scheme 1.14 in good yields (Scheme 1.17). ${ }^{72}$ In the case of nb, there are also a number of 2:1 nb:BCP cotrimers formed. As BCP is itself a strained alkene, it can also can also undergo a $[3+2]$ cycloaddition to form a dimer. ${ }^{74}$ This involves the cleavage of a distal ring bond (Scheme 1.18).

When a nickel(0) rather than a palladium(0) catalyst is used, the reaction is no longer a simple $[3+2]$ cycloaddition. When $\mathrm{BCP}$ was reacted with diethyl fumarate under $\mathrm{Ni}(0)$-catalysis conditions, there were three products formed (Scheme 1.19). ${ }^{72}$ The major product was the $[2+2]$ cycloaddition product (Scheme 1.19 (i)), in 23-46\% yield, depending on the proportion of phosphine used in the catalyst mixture. ${ }^{72}$ The $[3+2]$ addition product (Scheme 1.19 (ii)), resulting from distal bond cleavage, was still produced in 10-25\% yield, and a cotrimer, generated by the [3+2] cycloaddition of two molecules of diethyl fumarate onto the two ${ }^{c} \operatorname{Pr}$ rings of $\mathrm{BCP}$, with proximal cleavage (Scheme 1.19 (iii)) was also produced. Nickel(0) can also catalyse the [2+2] cycloaddition between cyclobutene and BCP to give dispiro[cyclopropane-1,2'-bicyclo[2.2.0]hexane- $3^{\prime}, 1^{\prime \prime}$ - 


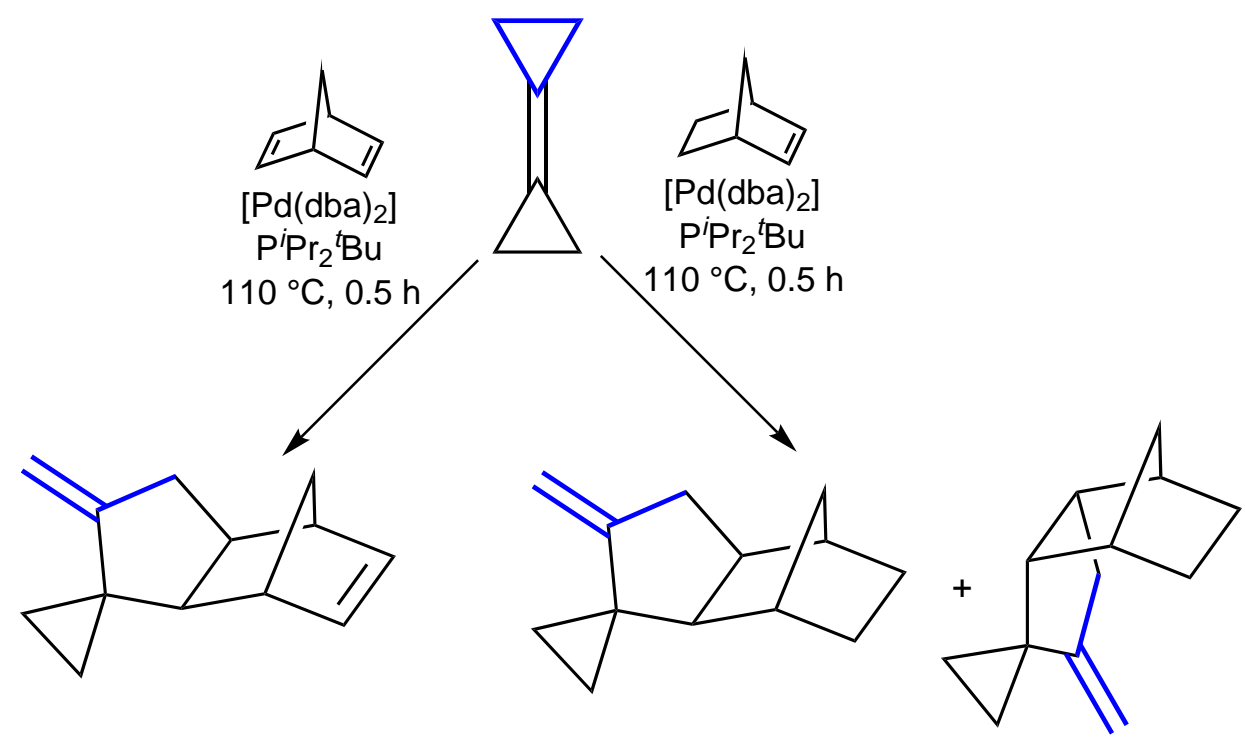

Scheme 1.17. $\operatorname{Pd}(0)$-catalysed cyclodimerisation of BCP with norbornene and norbornadiene. ${ }^{72}$

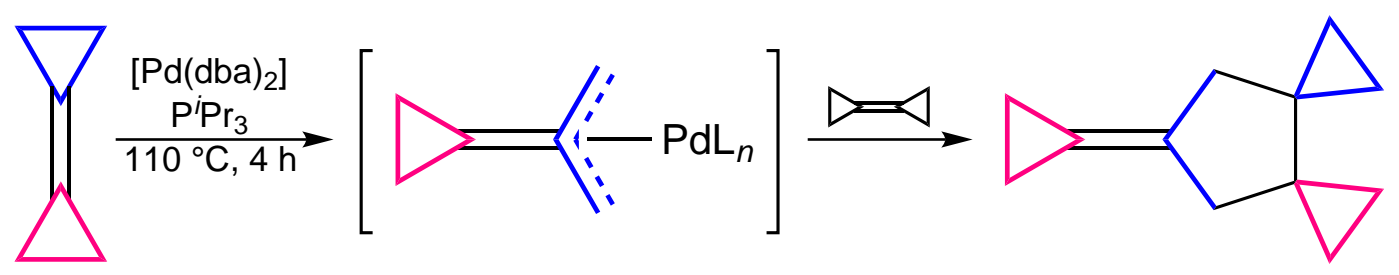

Scheme 1.18. $\operatorname{Pd}(0)$-catalysed cyclodimerisation of bicyclopropylidene. ${ }^{74}$
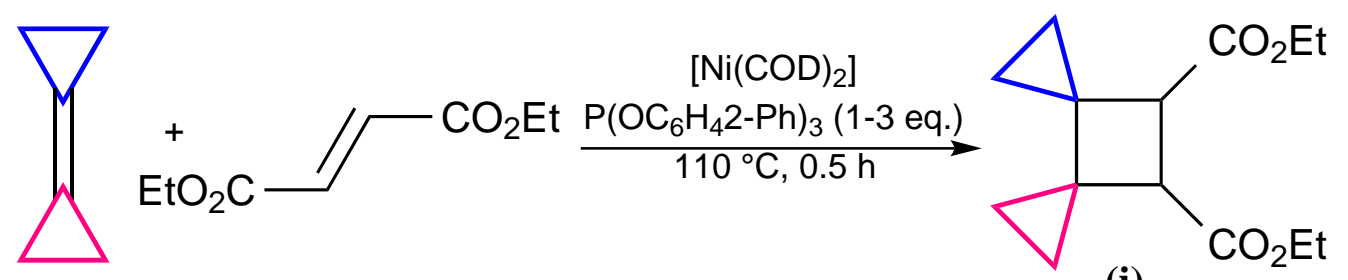

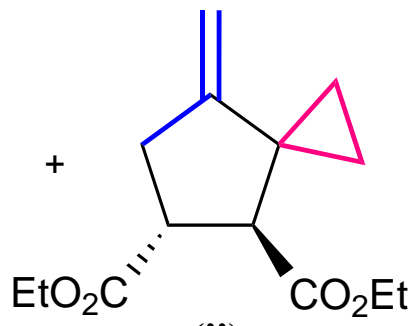

(ii)<smiles>CCOC(=O)C1CC(=C2CCC(C(=O)OCC)C2C(=O)OCC)CC1C(=O)OCC</smiles>

(iii)

Scheme 1.19. $\mathrm{Ni}(0)$-catalysed cycloaddition of bicyclopropylidene with diethyl fumarate. ${ }^{74}$ 
cyclopropane] (Scheme 1.20). ${ }^{37,75}$ This reaction also produces cycloocta-1,5-diene via the dimerisation of cyclobutene and subsequent rearrangement.

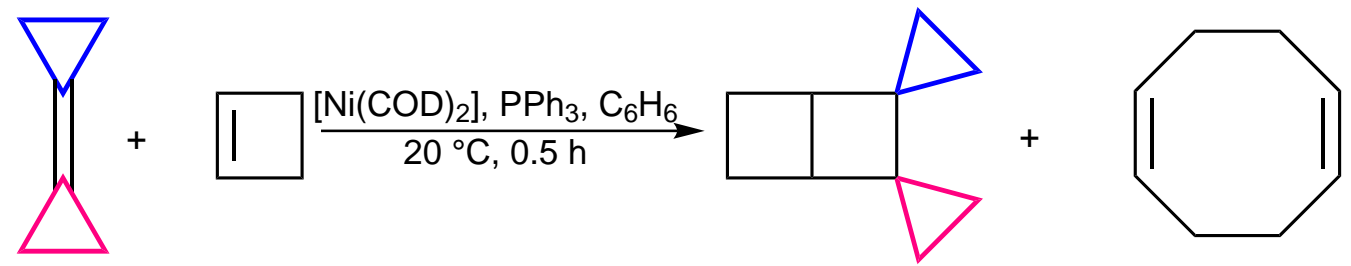

Scheme 1.20. $\mathrm{Ni}(0)$-catalysed $[2+2]$ cycloaddition of BCP with cyclobutene. ${ }^{37,75}$

\subsubsection{Heck-Type Reactions}

BCP undergoes reactions with Heck-type reagents in a similar fashion to methylenecyclopropanes. First an organopalladium species adds across the BCP double-bond, after which one of the ${ }^{c} \operatorname{Pr}$ rings opens up to a homoallylpalladium species. This then undergoes $\beta$-hydride elimination to yield a cross-conjugated diene (Scheme 1.21). ${ }^{74}$ While the resulting diene can be isolated, it is more often used in further reactions, usually DielsAlder reactions with a dieneophile. ${ }^{44,74,76}$ This can lead to a series of domino Heck-DielsAlder reactions, creating a range of spiro[2.5] octane derivatives. (Scheme 1.22). ${ }^{63,74}$ These reactions tend to be high yielding, and the reactions have been carried out on a robotic system to generate several small-molecule libraries of compounds. ${ }^{74}$

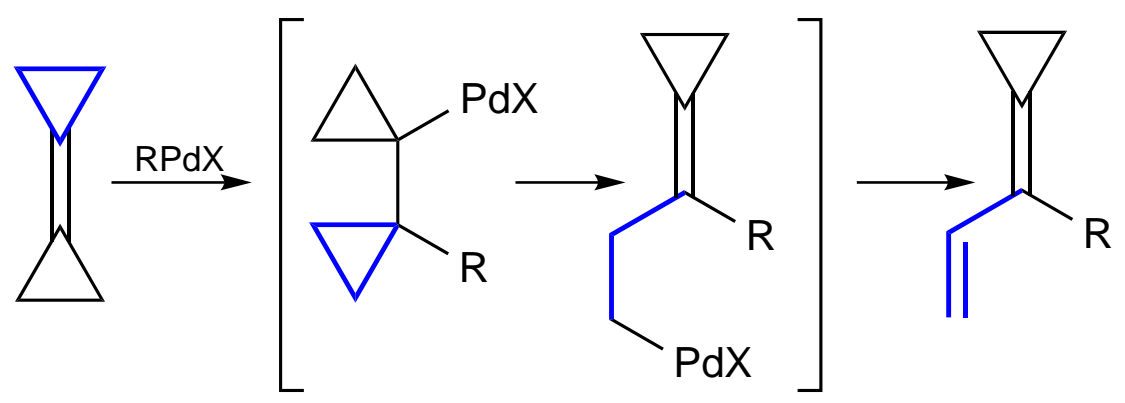

Scheme 1.21. The reaction of BCP with Heck-type reagents. ${ }^{74}$

The domino reaction can be extended to create a variety of carbon skeletons containing a cyclopropane ring. In the case of the reaction with iodoethene, the cross-conjugated triene product can undergo two sequential Diels-Alder reactions to give a tricyclic product 


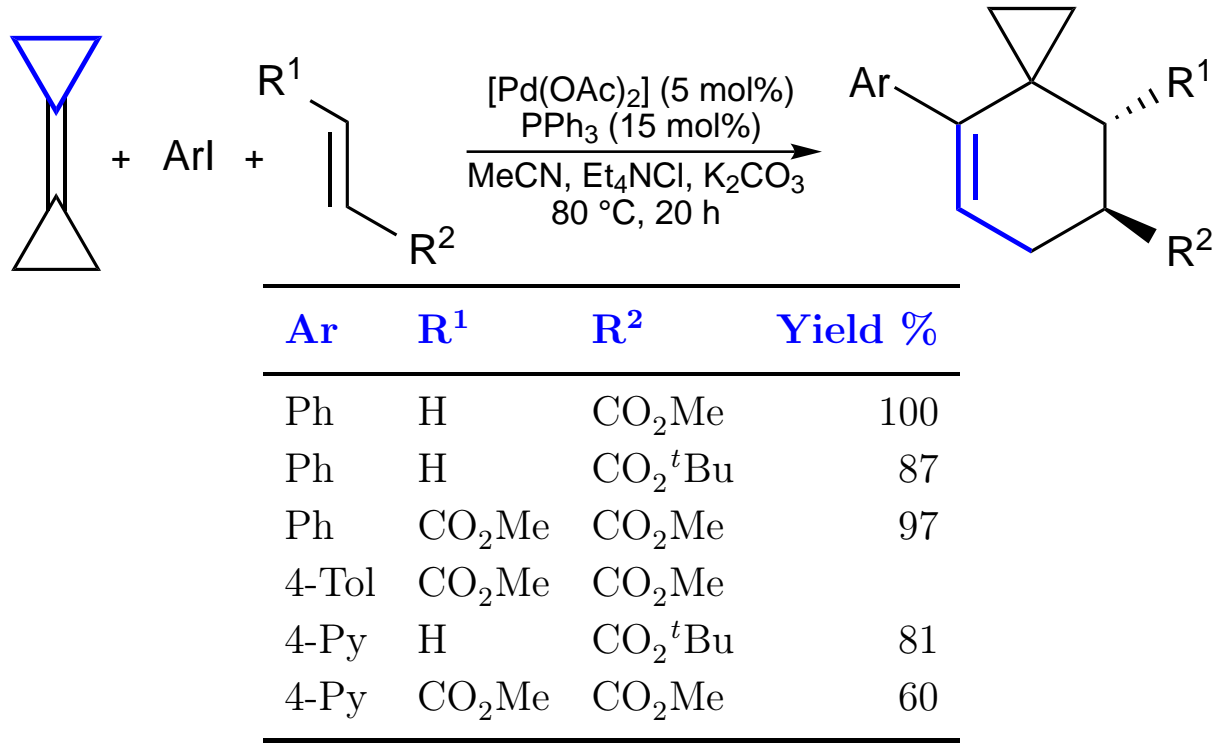

Scheme 1.22. Domino Heck-Diels-Alder reactions of BCP. ${ }^{63,74}$

(Scheme 1.23). ${ }^{74}$ When the reaction involves oligoiodoarenes, there is the possibility of creating up to 12 new $\mathrm{C}-\mathrm{C}$ bonds in a single synthetic operation in at least $47 \%$ yield (Scheme 1.24). ${ }^{74}$

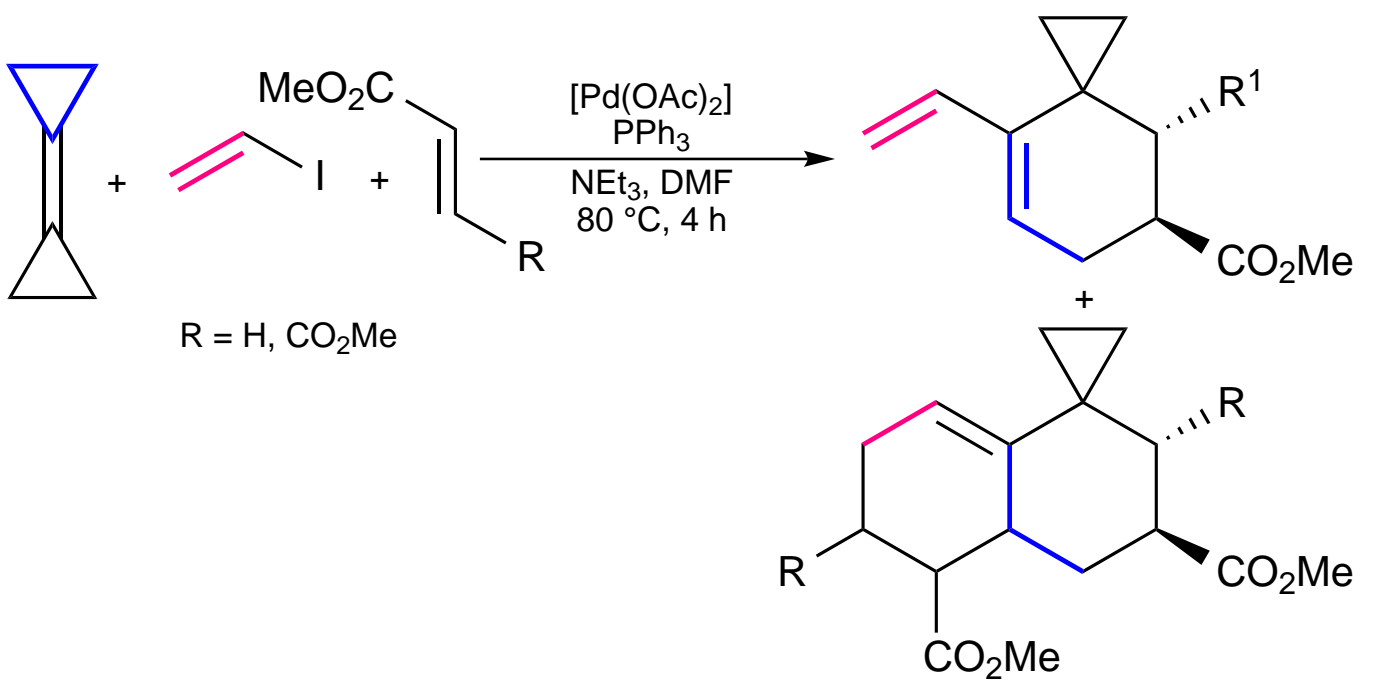

Scheme 1.23. Domino Heck-Diels-Alder reaction of BCP with iodoethene and dienophiles. ${ }^{37,75}$

An alternative sequence of reactions is observed when, instead of undergoing $\beta$-hydride elimination after the formation of the homoallylpalladium species, the intermediate rearranges to form a $\pi$-allylpalladium species. ${ }^{74}$ This is favoured by the use of electronrich ligands such as trifurylphosphine (TFP), which is known to retard $\beta$-hydride 


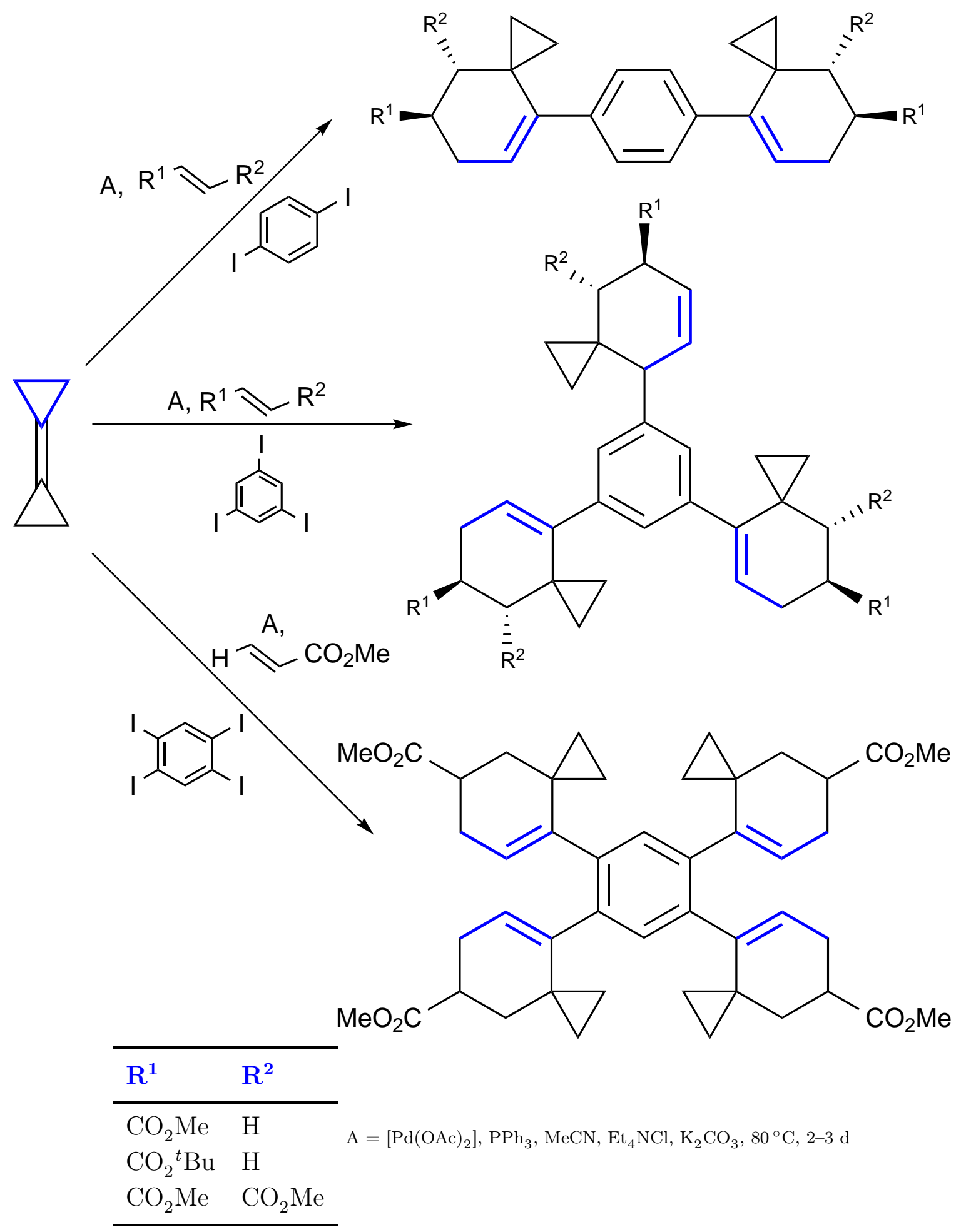

Scheme 1.24. Multicomponent domino reactions of BCP. ${ }^{74}$ 
elimination. ${ }^{63}$ The $\pi$-allylpalladium species can then undergo either inter- or intramolecular attack by a nucleophile (Schemes 1.25 and 1.26, c.f. Scheme 1.6). ${ }^{63}$

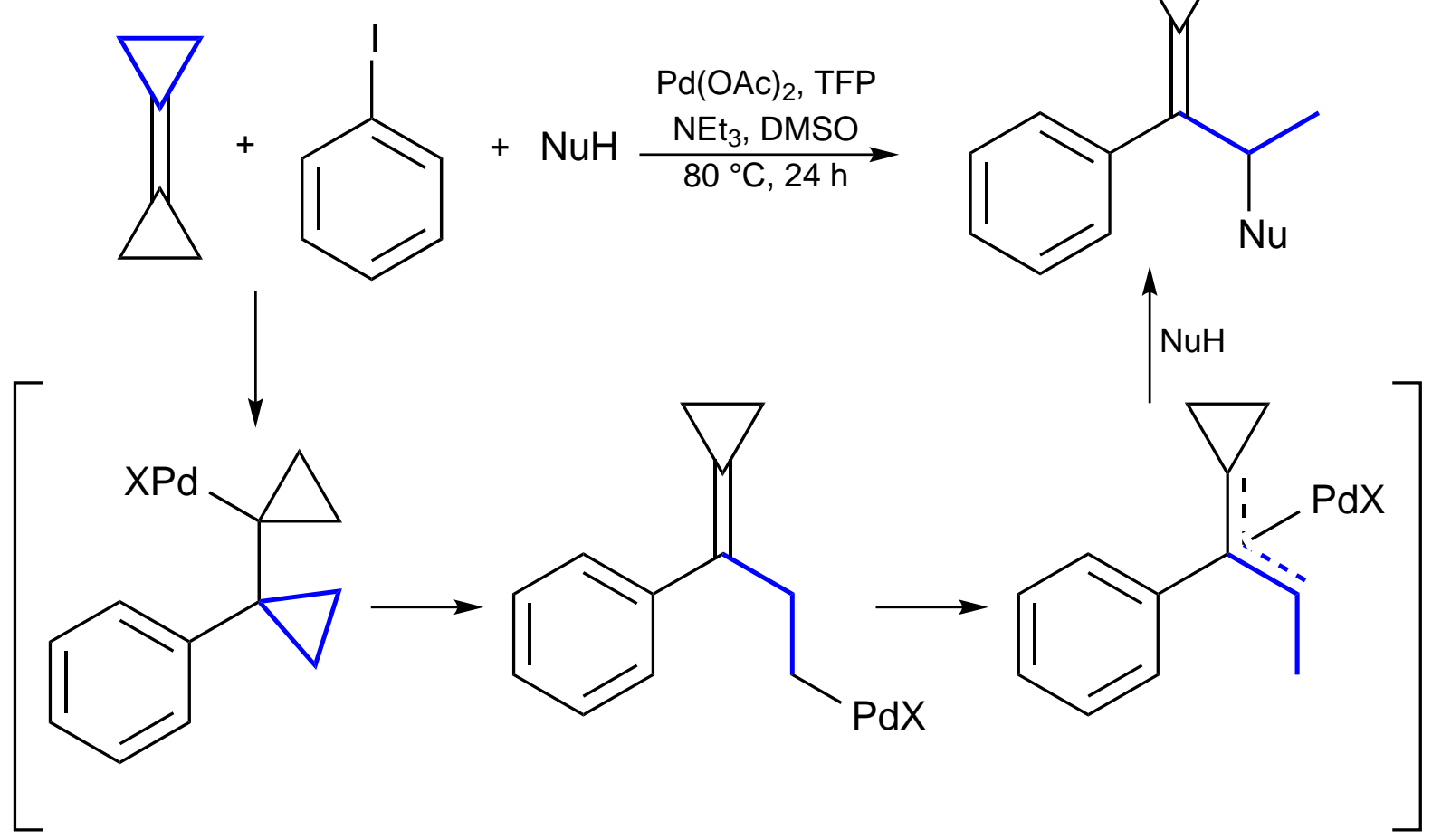

Scheme 1.25. Domino reaction of BCP involving a homoallyl- to $\pi$-allyl palladium rearrangement with an intermolecular nucleophile. ${ }^{63}$

When BCP is reacted with a Heck catalyst in the absence of another activated alkene, it undergoes $\mathrm{Pd}$-catalysed isomerisation to form allylidenecyclopropane (Scheme 1.21, $\mathrm{R}=\mathrm{H})$. This then slowly reacts further to form several different dimeric species (Scheme 1.27). ${ }^{74}$

\subsubsection{Bismetallation}

As is the case with methylenecyclopropane, bicyclopropylidene can undergo palladium catalysed bismetallations. In particular, the additions of silyl-containing species, such as disilanes, silylboranes and silylstannanes, have been studied. ${ }^{77}$ Disilanes, both intra- and inter-molecular, can be added across the bond with retention of both ${ }^{c}$ Pr rings (Scheme 1.28). ${ }^{77}$ The retention of both rings has also been achieved with silylstannanes (Scheme 1.29). ${ }^{77}$ Tributyl(trimethylsilyl)stannane adds directly across the 


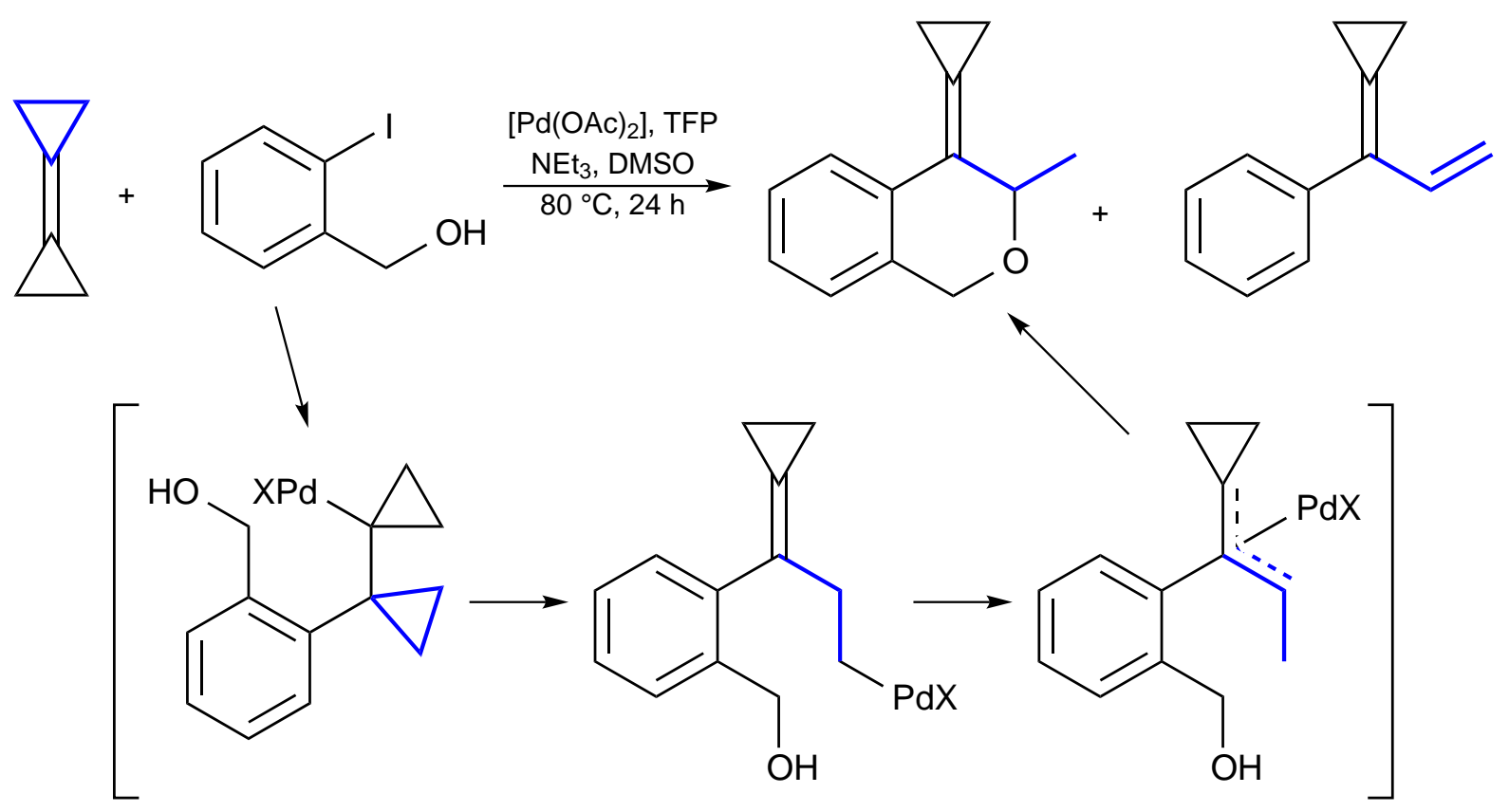

Scheme 1.26. Domino reaction of BCP involving a homoallyl- to $\pi$-allyl palladium rearrangement with an intramolecular nucleophile. ${ }^{63}$
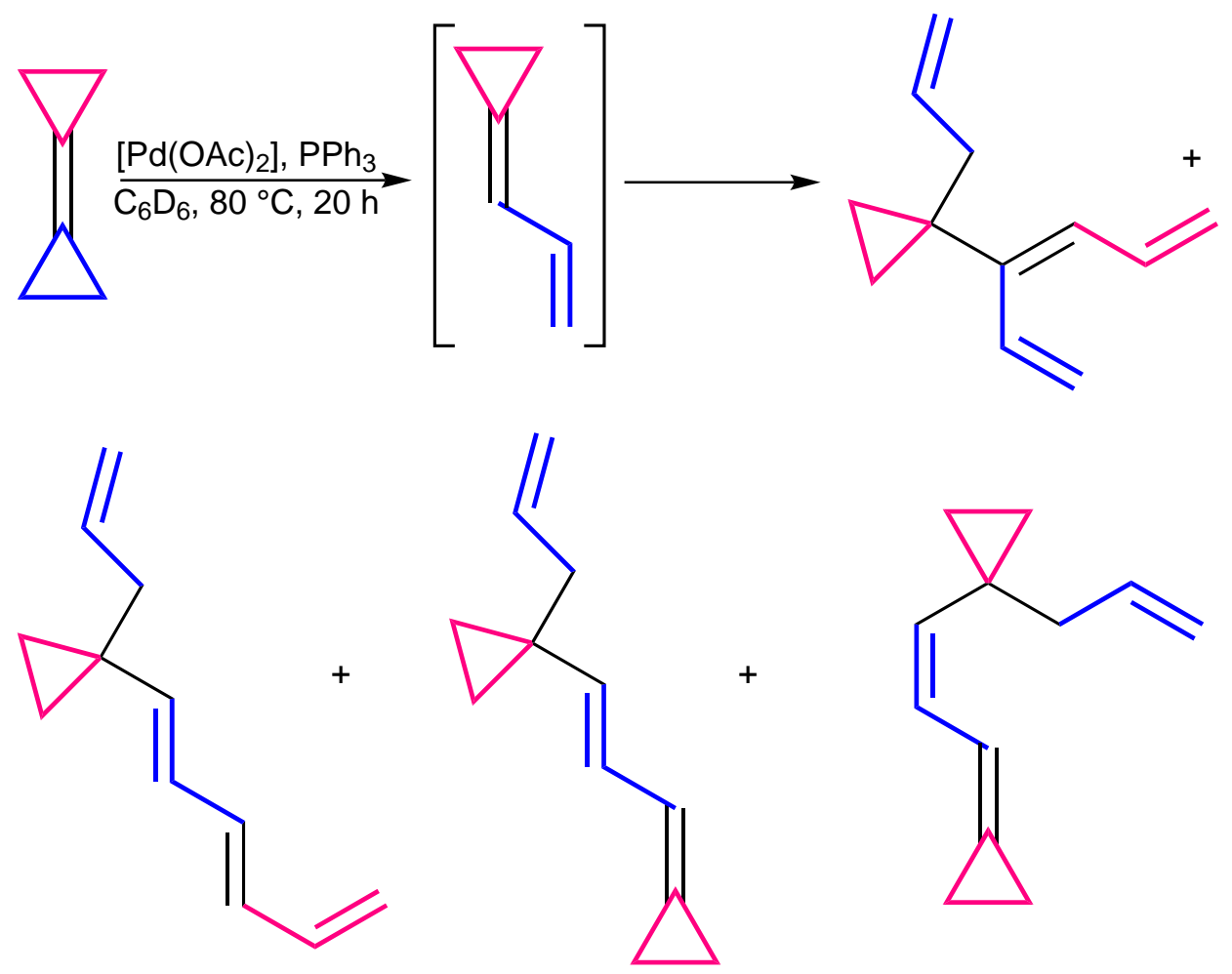

Scheme 1.27. Palladium-catalysed isomerisation of BCP. ${ }^{74}$ 
double-bond to give tributyl[1'-(trimethylsilyl)[1,1'-bicyclopropyl]-1-yl]-stannane. However, trimethyl(trimethylsilyl)stannane underwent Pd-catalysed disproportionation to form disilanes and distannanes, and the distannane subsequently added across the doublebond. ${ }^{77}$
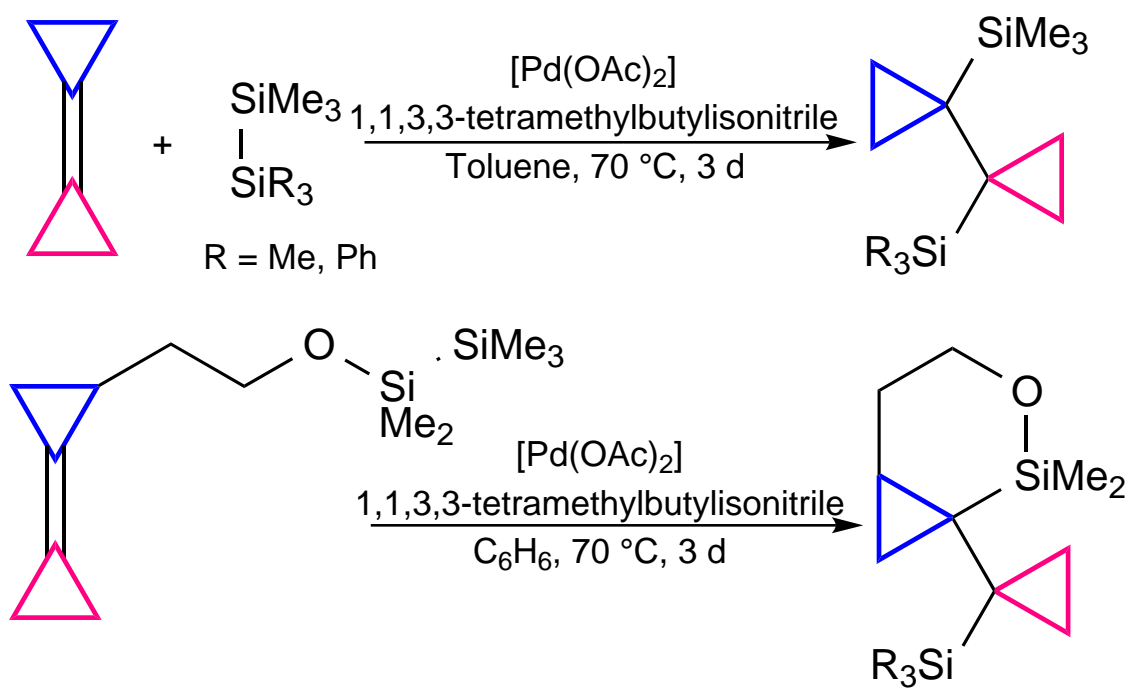

Scheme 1.28. Inter- and intra-molecular examples of the addition of a disilane to BCP with retention of both ${ }^{c} \operatorname{Pr}$ rings. ${ }^{77}$

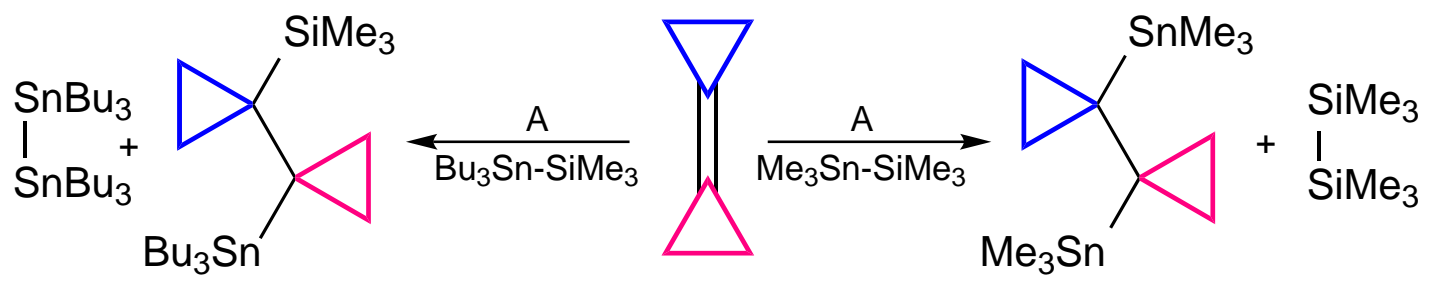

$\mathrm{A}=\left[\mathrm{Pd}(\mathrm{OAc})_{2}\right], 1,1,3,3$-tetramethylbutylisonitrile, pentane, $50^{\circ} \mathrm{C}, 7 \mathrm{~d}$

Scheme 1.29. Pd-catalysed addition of silylstannanes to BCP. ${ }^{77}$

Bismetallation reactions which involve the cleavage of one of the ${ }^{c} \operatorname{Pr}$ bonds can also occur. ${ }^{77}$ This occurs with disilanes for which at least one of the silanes is halogenated, as well as for silylboranes and silylstannanes. The reaction seems to initially proceed by the insertion of a palladium atom into the silyl-metal bond, then by the addition of this silylpalladium species across the BCP double-bond. In the case where the ${ }^{c} \mathrm{Pr}$ rings are retained, the next step is reductive elimination to form the bicyclopropyl products. However, in most cases, instead of a reductive elimination there is a rearrangement to 
generate a homoallylpalladium intermediate. This intermediate then undergoes reductive elimination to generate the ring-opened products (Scheme 1.30). It is thought that the deciding factor as to whether the product is the ring-opened or ring-retained product is the electrophilicity of the organopalladium species formed by the addition of the silylpalladium species across the double-bond (Scheme 1.30 (i)), with more electrophilic species favouring the ring-opened product. ${ }^{77}$

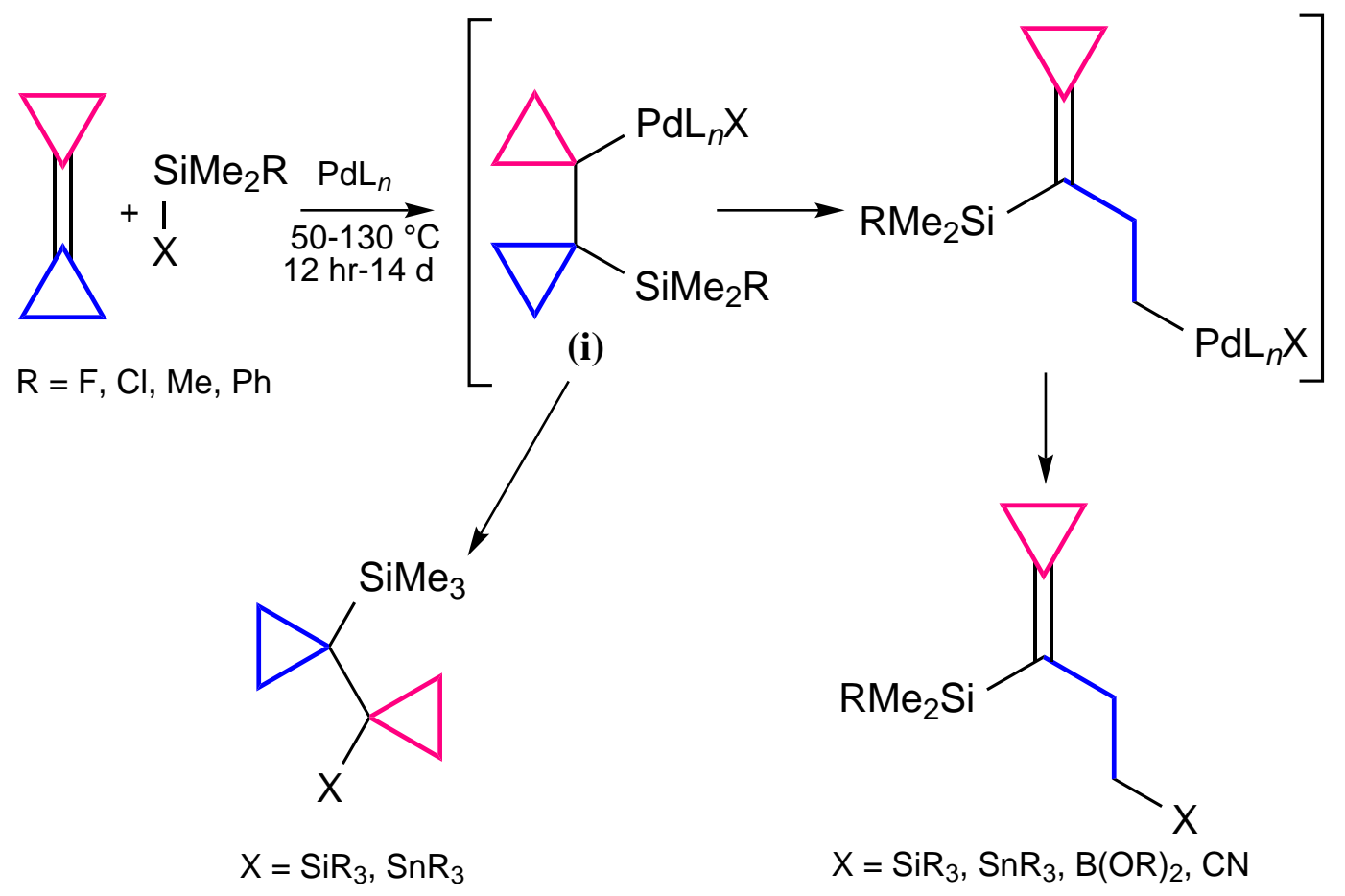

Scheme 1.30. Mechanism for the Pd catalysed bismetallation of BCP. ${ }^{77}$

\subsubsection{Transition Metal Complexes}

To date, there have been only two isolated transition metal complexes which have bicyclopropylidene as a ligand in $\eta^{2}$-coordination. ${ }^{58}$ Most of the organometallic research involving BCP thus far has been focused on its behaviour in metal-catalysed reactions, rather than on the organometallic intermediates themselves. $\mathrm{BCP}$ has the potential to be a good ligand towards transition metals for a number of reasons. The high-lying HOMO means that it should be able to effectively donate electron density into the empty metal orbitals. Also, as it is a highly strained system, it should be able to accept back-bonding, stabilising the system by alleviating ring strain upon complexation. 
The first transition metal complex of BCP was made from a bis(cyclopentadienyl)bis(trimethylphosphine)titanium(II) precursor by reaction with $\mathrm{BCP}$ in pentane (Scheme 1.31). ${ }^{58}$ The product with ligated BCP was obtained as a green solid in $79 \%$ yield. The precursor complex was chosen because titanocene complexes with alkene ligands are known 16-electron species. As such, if a BCP ligand was prone to ring-opening by oxidative addition, it would be likely to happen in this complex. ${ }^{58}$ The isolation of this BCP complex shows that this does not happen with titanium.
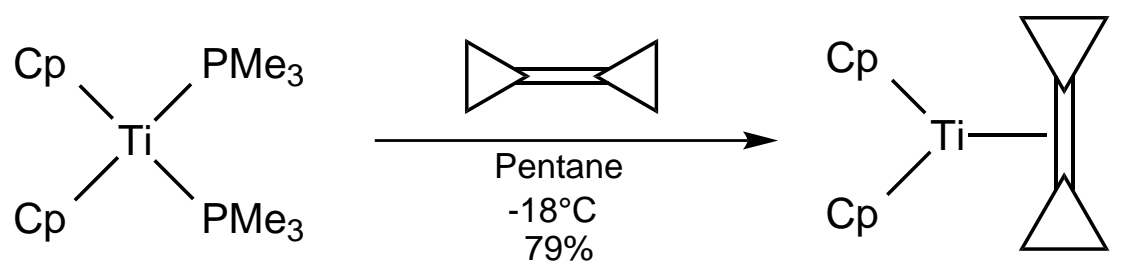

Scheme 1.31. Synthesis of the first Ti complex of BCP. ${ }^{58}$

The second BCP complex was made by reacting ((2-(di-tert-butylphosphanyl)-Pethyl)cyclopentadienyl)chlorocobalt(II) $([\mathrm{CoCl}(\mathrm{Cp} \#)])$ with sodium amalgam and BCP (Scheme 1.32). ${ }^{58,59}$ The Cp\# ligand prevents potential oligomerisation reactions because the phosphine arm wins competition for the coordination site, preventing the complexation of another ligand and therefore reaction with the existing BCP ligand. ${ }^{58}$

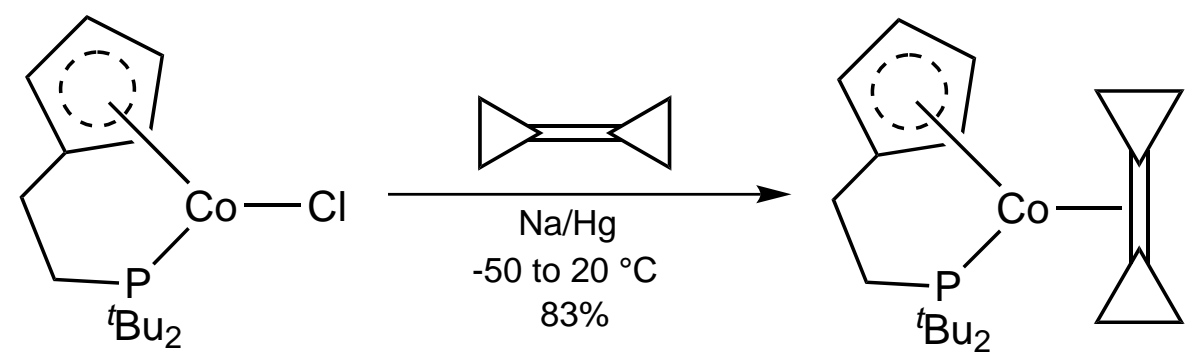

Scheme 1.32. Synthesis of the first Co complex of BCP. ${ }^{58,59}$

The X-ray crystal structure of the $[\mathrm{Co}(\mathrm{Cp} \#)(\mathrm{BCP})]$ complex (Figure 1.6 $)^{58}$ shows that the ${ }^{c}$ Pr rings of the BCP ligand are bent away from the double-bond by $40^{\circ}$. This and the increase of the length of the double-bond to $1.401 \AA$ indicate that there is a high degree of back bonding, as predicted. The percentage change in the bond length upon complexation is greater in the case of $\mathrm{BCP}(7.4 \%)$ than for free ethene $(5.0 \%)$, implying 
a greater degree of back bonding to $\mathrm{BCP}{ }^{78}$ As the character of the double-bond carbon atoms has become more $\mathrm{sp}^{3}$-like, the proximal bonds in the two ${ }^{c} \mathrm{Pr}$ rings have shortened from 1.544 to $1.499 \AA$.

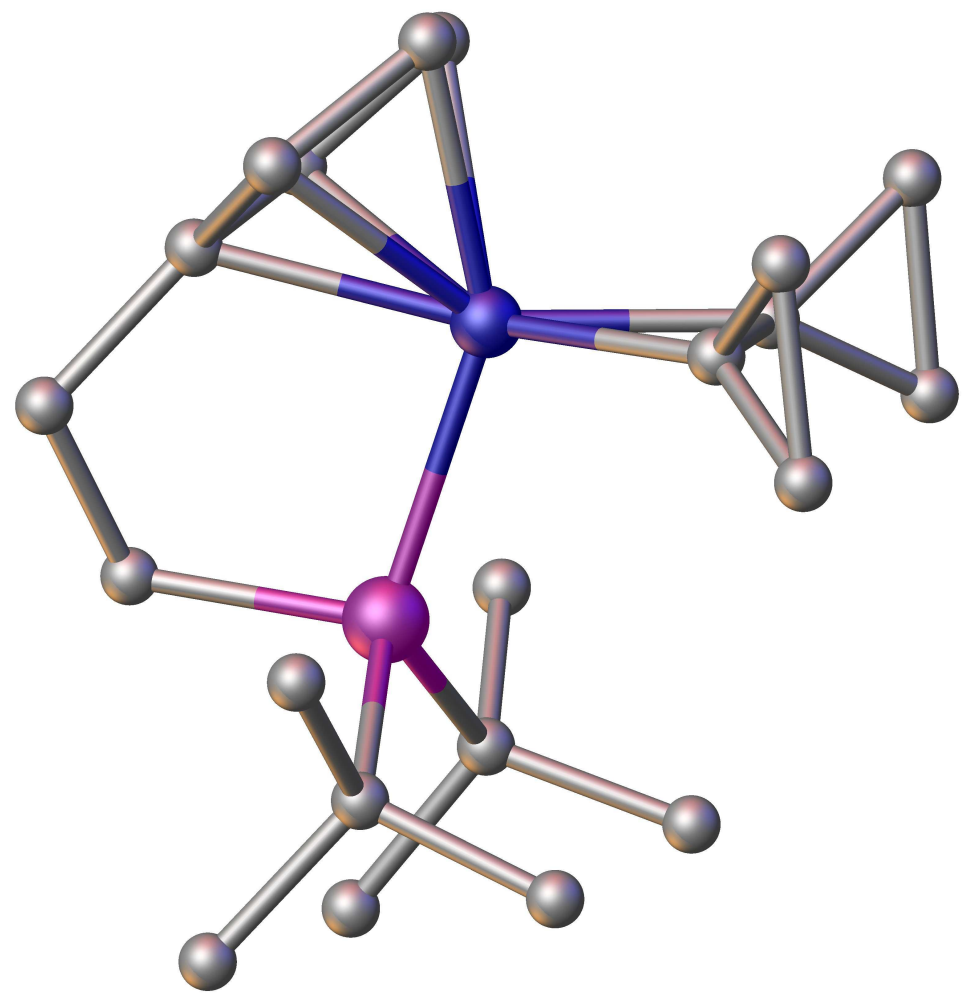

Figure 1.6. X-ray crystal structure of $[\mathrm{Co}(\mathrm{Cp} \#)(\mathrm{BCP})] .{ }^{58}$

These two complexes show that BCP is a good ligand toward transition metals. As such, there is much potential for the synthesis of complexes containing this ligand with other transition metals. As there is a dearth of isolated $\eta^{2}$-alkene complexes of both BCP and MCP, the initial focus of this project was on the synthesis of platinum complexes with these ligands. The reactivity of these complexes was then investigated. During the exploration of the reactivity of $\mathrm{BCP}$ and $\mathrm{MCP}$ towards platinum, a range of reactivity patterns were observed. Complexes with ligands derived from these reactions were also synthesised. 


\section{Chapter 2}

\section{Platinum(0) Phosphine Complexes}

The reactions of methylenecyclopropane and bicyclopropylidene with $\operatorname{Pt}(0)$ alkene complexes produced $\eta^{2}$-MCP and BCP complexes. Complexes with both mono- and di-phosphine auxillary ligands were synthesised. BCP underwent a ring-opening reaction to form the 1,3-diene allylidenecyclopropane, and the coordination chemistry of ACP was explored. ${ }^{79}$

\section{$2.1 \quad[\mathrm{Pt}(\mathrm{L})(\mathrm{P}-\mathrm{P})]$ Complexes}

A range of $\operatorname{Pt}(0)$ complexes containing chelating diphosphines as auxiliary ligands were chosen as precursors. These complexes were chosen because chelating phosphines not only stabilise transition metal complexes, particularly those in low oxidation states, but also allow the coordination of only one alkene ligand, thus preventing possible oligomerisation reactions. The diphosphines used in this research were 1,3-bis(diphenylphosphino)propane (dppp), 1,2-bis(dicyclopentylphosphino)ethane (dcyppe), 1,2-bis(di-tert-butylphosphino)ethane (dbpe) and 1,2-bis[(di-tertbutylphosphino)methyl]benzene $(\mathrm{dbpx})$, representing a variety of electronic properties and backbone sizes (Figure 2.1).

As discussed in Section 1.1.3, one of the ways of synthesising alkene complexes is by the displacement of another ligand such as another alkene. Ethene complexes were chosen as suitable precursors due to the ease of displacement of the ethene ligand as well 


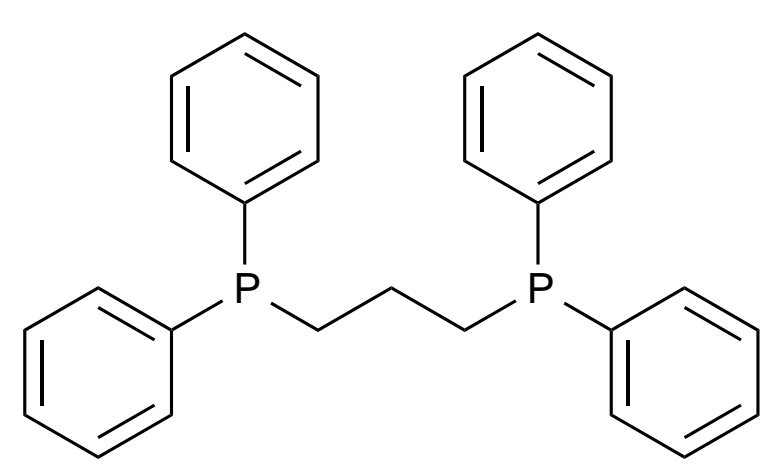

dppp

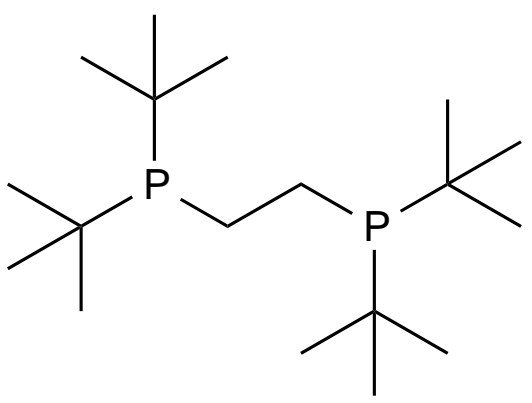

dbpe

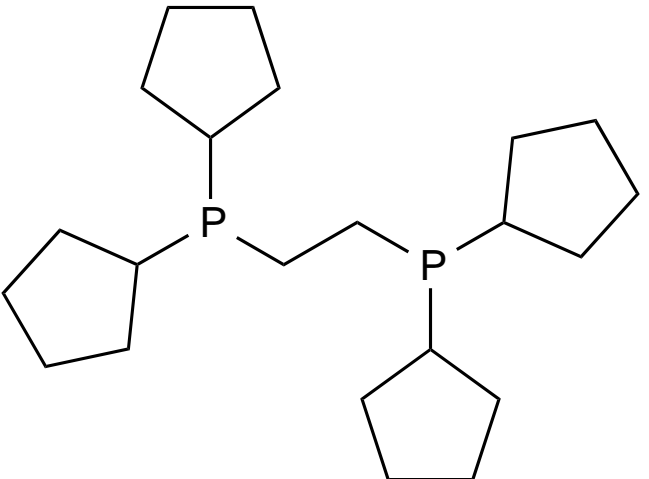

dcyppe

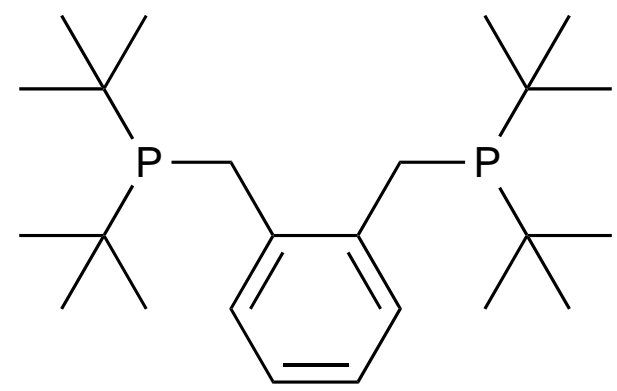

$\mathrm{dbpx}$

\begin{tabular}{lrr}
\hline Phosphine & $\boldsymbol{\theta}\left(^{\circ}\right)$ & $\boldsymbol{\nu}\left(\mathrm{cm}^{-1}\right)$ \\
\hline dppp & 127 & $2067\left(\mathrm{PPh}_{2} \mathrm{Et}\right)$ \\
dcyppe & $*$ & $*$ \\
dbpe & $115^{80}$ & $2058\left(\mathrm{PEt}^{t} \mathrm{Bu}_{2}\right)$ \\
dbpx & $138^{81}$ & $2060\left(\mathrm{P}(o \text {-tol })^{t} \mathrm{Bu}_{2}\right)$ \\
\hline
\end{tabular}

$\theta=$ Tolman cone angle. Calculated from the cone formed between the metal and the outer hydrogens of the ligand with an $\mathrm{M}-\mathrm{P}$ bond length of $2.28 \AA{ }^{82}$

$\nu=$ Tolman electronic parameter. Calculated from the $\mathrm{C} \equiv \mathrm{O}$ stretching frequency in $\left[\mathrm{Ni}\left(\mathrm{CO}_{3}\right)(\mathrm{L})\right]^{82}$

* No data available.

Figure 2.1. Structures and properties of diphosphine ligands. ${ }^{82}$ 
as the simplicity of the NMR spectra of both the free and the coordinated alkene, which facilitated the monitoring of the reactions. Free ethene is observed at $\delta_{\mathrm{H}} 5.2$ and $\delta_{\mathrm{C}}$ $123 \mathrm{ppm}$, while the resonances of coordinated ethene occur at approximately $\delta_{\mathrm{H}} 2-3 \mathrm{ppm}$ and $\delta_{\mathrm{C}} 20-30 \mathrm{ppm}$.

A range of methods were used to synthesise the various ethene complexes, with the choice of method dictated by the diphosphine ligand. The complexes $\left[\mathrm{Pt}\left(\mathrm{C}_{2} \mathrm{H}_{4}\right)(\mathrm{dbpe})\right]$ and $\left[\mathrm{Pt}\left(\mathrm{C}_{2} \mathrm{H}_{4}\right)(\mathrm{dbpx})\right]$ were synthesised by adding adding the appropriate diphosphine to $\left[\mathrm{Pt}\left(\mathrm{C}_{2} \mathrm{H}_{4}\right)_{3}\right]$, generated in situ from $\left[\mathrm{Pt}(\mathrm{COD})_{2}\right] .{ }^{83}$ This method was unsuitable for the synthesis of $\left[\mathrm{Pt}\left(\mathrm{C}_{2} \mathrm{H}_{4}\right)(\mathrm{dppp})\right]$, as the coordination of a second dppp ligand to form $\left[\mathrm{Pt}(\mathrm{dppp})_{2}\right]$ is very facile. Instead, the ethene complex was generated by the reduction of $\left[\mathrm{PtCl}_{2}(\mathrm{dppp})\right]$ under an ethene atmosphere using $\mathrm{NaBH}_{4}$.

While the reaction of dcyppe with $\left[\mathrm{Pt}\left(\mathrm{C}_{2} \mathrm{H}_{4}\right)_{3}\right]$ yielded $\left[\mathrm{Pt}\left(\mathrm{C}_{2} \mathrm{H}_{4}\right)(\right.$ dcyppe $\left.)\right]$, problems with purification meant that this was not a viable synthetic method. Reduction with $\mathrm{NaBH}_{4}$ was attempted, but was not successful. Instead, $\left[\mathrm{Pt}\left(\mathrm{C}_{2} \mathrm{H}_{4}\right)(\right.$ dcyppe$\left.)\right]$ was synthesised by the reduction of $\left[\mathrm{PtCl}_{2}(\right.$ dcyppe $\left.)\right]$ using sodium amalgam. Complexes of 1,2bis(diphenylphosphino)ethane (dppe) were considered, as these would have made a good comparison for the dppp complexes. However, $\left[\mathrm{Pt}\left(\mathrm{C}_{2} \mathrm{H}_{4}\right)(\mathrm{dppe})\right]$ could not be synthesised from $\left[\mathrm{Pt}\left(\mathrm{C}_{2} \mathrm{H}_{4}\right)_{3}\right]$ due to the facile formation of $\left[\mathrm{Pt}(\mathrm{dppe})_{2}\right]$, while reduction methods yielded only $\left[\mathrm{Pt}_{3} \mathrm{H}_{3}(\mathrm{dppe})_{3}\right]^{+} \cdot\left[\mathrm{Pt}_{3} \mathrm{H}_{3}(\mathrm{dppe})_{3}\right]^{+}$forms because the intermediate hydride complex in the reduction reaction is dimeric for dppe, rather than monomeric as for dppp. ${ }^{84,85}$ While the synthesis of $\left[\mathrm{Pt}\left(\mathrm{C}_{2} \mathrm{H}_{4}\right)\right.$ (dppe) $]$ using sodium naphthalenide has been reported, ${ }^{86}$ this method did not involve the isolation of the pure ethene complex, which meant that this synthesis was not suitable for the NMR-scale studies undertake here.

Methylenecyclopropane was made by the reaction of methallyl chloride with sodium amide and potassium tert-butoxide (Scheme 1.2 (ii)), ${ }^{28}$ while the synthesis of bicyclopropylidene made use of the Kulinkovich reaction to produce cyclopropylcyclopropanol from methyl cyclopropanecarboxylate, which was then converted to the bromide followed by dehydrobromination to produce the alkene (Scheme 1.13). ${ }^{67}$ Whereas BCP is an easily handled liquid, MCP is a gas at room temperature, with a boiling point of $10^{\circ} \mathrm{C}$. For this 
research, it was generally deemed most practical to use MCP by cooling a glass syringe in the freezer and then rapidly inject a small amount of the liquid alkene into the reaction vessel. However, standard solutions in both $\mathrm{C}_{6} \mathrm{D}_{6}$ and $\mathrm{CDCl}_{3}$ were occasionally used.

Carbon-13 enriched bicyclopropylidene was synthesised in order to increase the sensitivity of the double-bond carbons toward ${ }^{13} \mathrm{C}$ NMR spectroscopy (Scheme 2.1). First, cyclopropanecarboxylic acid was synthesised using a Grignard reagent formed from cyclopropyl bromide and $\mathrm{CO}_{2}$ generated from $\mathrm{BaCO}_{3}\left(70 \%{ }^{13} \mathrm{C}\right)$. This was then converted to methyl cyclopropanecarboxylate using methyl iodide and DBU. ${ }^{87}$ The ${ }^{c}$ PrCOOMe was then diluted with the carbon-12 variant to $12 \%$ enrichment of carbon-13, and the $\mathrm{BCP}$ synthesis continued as previously. The overall yield of this process was $0.8 \%$ based on $\mathrm{BaCO}_{3}$. This was both due to the small scale of the ${ }^{c} \mathrm{PrCOOMe}$ to BCP synthesis (the yield of this stage was $7 \%$, compared to $27 \%$ for larger scale) and to difficulties in the ${ }^{c} \mathrm{PrCOOH}$ synthesis. While the literature method reported yields of $82 \%$ for the synthesis of ${ }^{c} \mathrm{PrCOOH}$, it was not possible to obtain yields of greater than $30 \%$. ${ }^{88}$

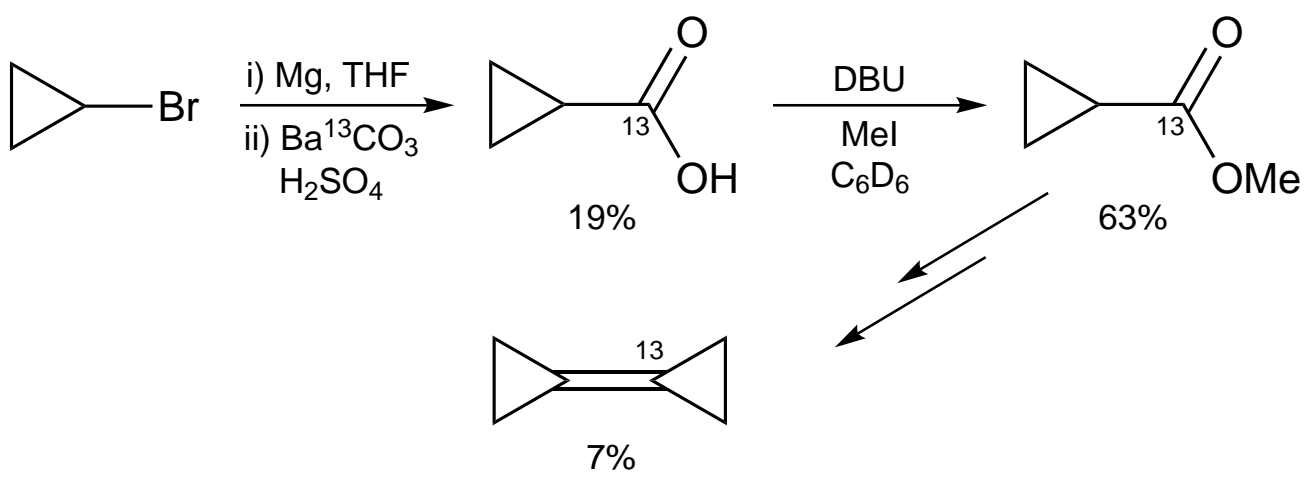

Scheme 2.1. Synthesis of carbon-13 enriched bicyclopropylidene.

$\mathrm{BCP}$ and MCP complexes were synthesised via the displacement of the ethene ligand from the precursor complexes. This was done by dissolving the ethene complex in either toluene or $d_{6}$-benzene and adding an excess of the appropriate alkene, producing the diphosphine complexes $[\mathrm{Pt}(\mathrm{BCP})(\mathrm{P}-\mathrm{P})](\mathrm{P}-\mathrm{P}=\operatorname{dppp}(\mathbf{1 a})$, dcyppe $(\mathbf{1 b})$, dbpe $(\mathbf{1} \mathbf{c})$ and $\operatorname{dbpx}(\mathbf{1 d}))$ and $[\mathrm{Pt}(\mathrm{MCP})(\mathrm{P}-\mathrm{P})](\mathrm{P}-\mathrm{P}=\operatorname{dppp}(\mathbf{2 a})$, dcyppe $(\mathbf{2 b})$, dbpe $(\mathbf{2 c})$ and $\operatorname{dbpx}(\mathbf{2 d}))$ (Scheme 2.2).

The formation rates of the complexes were found to depend on both the size of the 


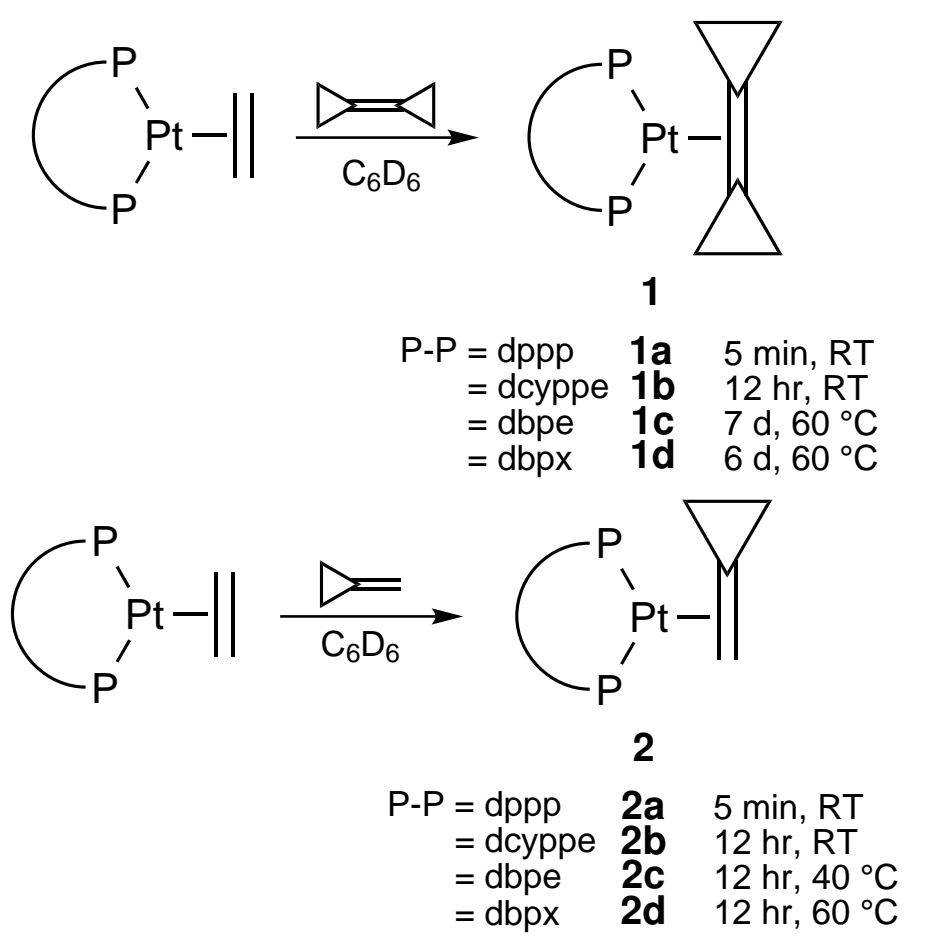

Scheme 2.2. Synthesis of $[\mathrm{Pt}(\mathrm{BCP})(\mathrm{P}-\mathrm{P})](\mathbf{1})$ and $[\mathrm{Pt}(\mathrm{MCP})(\mathrm{P}-\mathrm{P})](\mathbf{2})$.

alkene and the size of the diphosphine ligand. MCP, with only one ${ }^{c} \mathrm{Pr}$ ring, coordinated more rapidly than $\mathrm{BCP}$, with two rings. The steric bulk of the substituents on the phosphine ligands had a more significant effect on the formation rates. Complexes of dppp formed most rapidly, with the reaction occurring almost instantly at room temperature. Complexes of dcyppe reacted more slowly, forming overnight at room temperature. Both of the ${ }^{t} \mathrm{Bu}$ phosphine complexes required heating, at 40 and $60{ }^{\circ} \mathrm{C}$ overnight for $\mathbf{2 c}$ and $\mathbf{2 d}$, respectively, and for up to 7 days for $\mathbf{1 c}$ and $\mathbf{1 d}$. The dependence of reaction rate on steric bulk points to an associative rather than dissociative exchange mechanism.

X-ray quality crystals of $\mathbf{1 a}$ were grown by recrystallisation from hot toluene, and an X-ray crystal structure was obtained (Figure 2.2, Table 2.1). The $\mathrm{BCP} \mathrm{C}=\mathrm{C}$ bond length increased from 1.304(2) $\AA$ in the free alkene to $1.427(3) \AA$ in 1a, an increase of 9.4\%. ${ }^{30}$ This was greater than the $7.4 \%$ increase observed for $[\mathrm{Co}(\mathrm{Cp} \#)(\mathrm{BCP})]$, which had a $\mathrm{C}=\mathrm{C}$ bond length of 1.401(5) $\AA .59$ The bond length of $1 \mathbf{a}$ was closer to that of the comparable $\mathrm{C}-\mathrm{C}$ bond in bicyclopropyl (1.487(4) $\AA$, differing from 1a by $0.06 \AA$ ) than to the $\mathrm{C}=\mathrm{C}$ bond length of free $\mathrm{BCP}$ (differing from 1a by $0.123 \AA$ ). ${ }^{89}$ The two ${ }^{c} \operatorname{Pr}$ rings in $1 \mathbf{a}$ were bent by $36.02^{\circ}$ and $37.14^{\circ}$ away from the plane of the double-bond. The 
corresponding angles in the cobalt complex were $39.33^{\circ}$ and $41.04^{\circ}$, while in bicyclopropyl the rings were at $54.72^{\circ}$ to the central $\mathrm{C}-\mathrm{C}$ bond. There was a decrease in the ${ }^{c} \mathrm{Pr}$ ring angle centered on the double-bond carbon atom from $63.3(1)^{\circ}$ to $61.40(14)^{\circ}$ and $61.37(15)^{\circ}$ upon coordination and a concomitant shortening of the distal ring bond from 1.539(2) $\AA$ to $1.516(3)$ and 1.519(3) $\AA$. This effect was greater in the Co complex, with angles and distal bond lengths of $61.15^{\circ}$ and $1.499(12) \AA$, respectively. The increase in the $\mathrm{C}=\mathrm{C}$ bond length, the out-of-plane bend of the ${ }^{c} \operatorname{Pr}$ rings, and the shortening of the ring bond and angle were all indicative of the large degree of back-donation and subsequent rehybridisation of the double-bond carbon atoms upon coordination. ${ }^{8,59}$

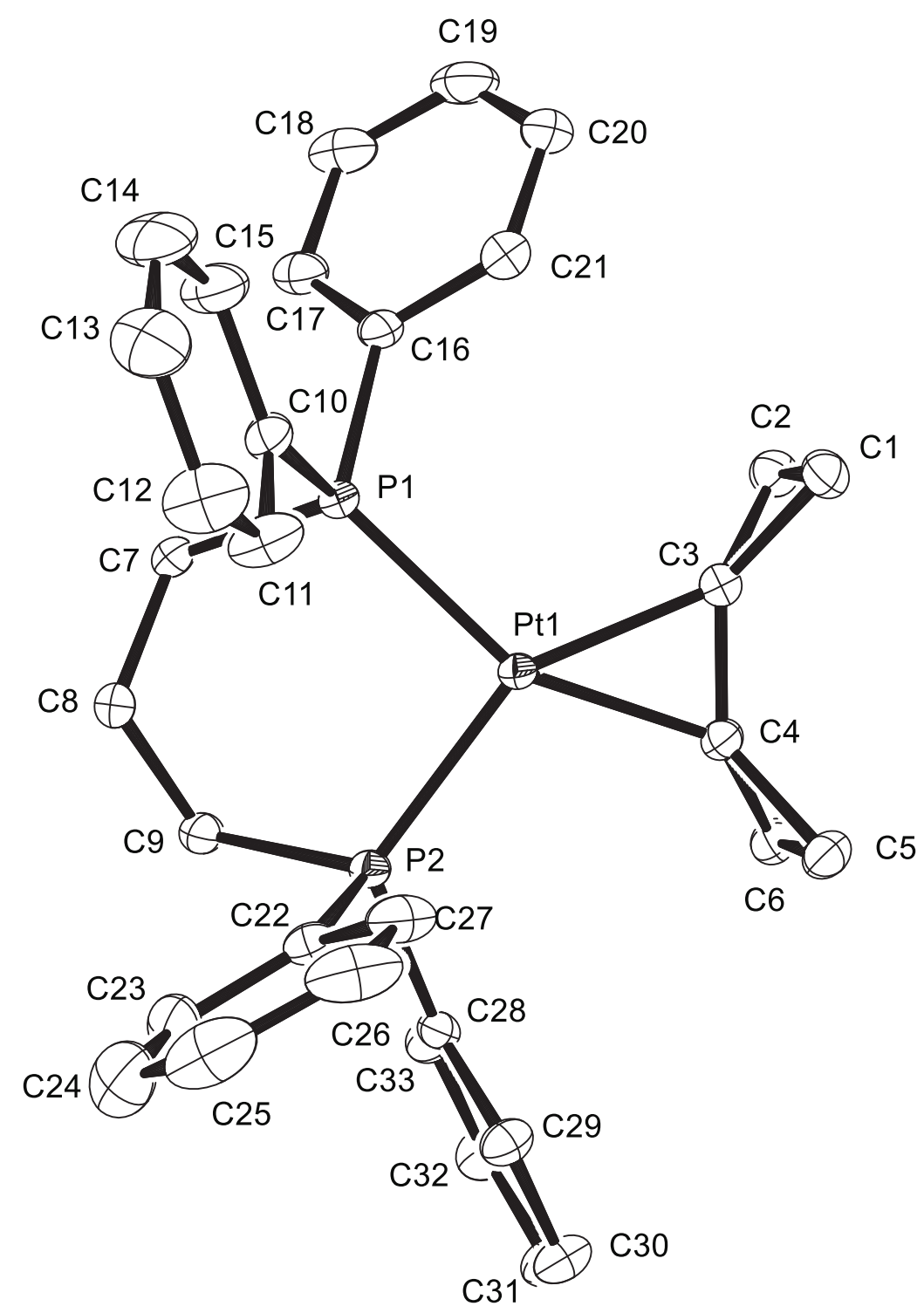

Figure 2.2. ORTEP diagram of $[\mathrm{Pt}(\mathrm{BCP})(\mathrm{dppp})]$ (1a) showing $50 \%$ probability thermal ellipsoids. $\mathrm{H}$ atoms have been omitted for clarity. 
Table 2.1. Crystallographic Data for $[\mathrm{Pt}(\mathrm{BCP})(\mathrm{dppp})]$ (1a).

\begin{tabular}{|c|c|}
\hline Chemical formula & $\mathrm{C}_{33} \mathrm{H}_{34} \mathrm{P}_{2} \mathrm{Pt}$ \\
\hline Formula weight & 687.63 \\
\hline $\mathrm{a}, \AA$ & $16.8042(6)$ \\
\hline $\mathrm{b}, \AA$ & $9.6338(3)$ \\
\hline c, $\AA$ & $17.7241(6)$ \\
\hline$\alpha, \operatorname{deg}$ & 90.00 \\
\hline$\beta, \operatorname{deg}$ & $106.904(2)$ \\
\hline$\gamma, \operatorname{deg}$ & 90.00 \\
\hline $\mathrm{V}, \AA^{3}$ & $2745.35(16)$ \\
\hline $\mathrm{Z}$ & 4 \\
\hline Space group & $P 2_{1} / \mathrm{n}$ \\
\hline $\mathrm{T}, \mathrm{K}$ & 119.0 \\
\hline$\lambda, \AA$ & 0.71073 \\
\hline $\mathrm{D}_{\text {calcd }}, \mathrm{g} \mathrm{cm}^{-3}$ & 1.664 \\
\hline$\mu, \mathrm{mm}^{-1}$ & 5.248 \\
\hline $\mathrm{R}_{1},[\mathrm{I}>2 \sigma(\mathrm{I})]^{a}$ & 0.0252 \\
\hline$w \mathrm{R}_{2}(\text { all data })^{a}$ & 0.0502 \\
\hline
\end{tabular}

The dppp backbone adopted a chair conformation, with a P-Pt-P angle of 96.762(19) ${ }^{\circ}$. A search of the Cambridge Crystallographic Database in March 2011 showed that of 81 dppp complexes with one or two platinum atoms, $86 \%$ adopted a chair and $9 \%$ adopted a boat conformation, while $5 \%$ were not sufficiently resolved to determine the conformation. Four of the 81 complexes were $\operatorname{Pt}(0)$ species, and of the four, three were trigonal planar complexes. All four $\operatorname{Pt}(0)$ complexes had dppp in a chair conformation. ${ }^{90-92}$ These complexes had P-Pt-P angles of $90.99-97.76^{\circ}$, with that of $\mathbf{1 a}$ falling at the top end of the range.

\subsubsection{NMR Characterisation}

For representative NMR spectra, see Figures A.1-A.11. The magnitude of the platinumphosphorus ${ }^{1} J_{\mathrm{Pt}-\mathrm{P}}$ coupling constants in the ${ }^{31} \mathrm{P}\left\{{ }^{1} \mathrm{H}\right\} \mathrm{NMR}$ spectra of $\mathbf{1}$ and $\mathbf{2}$ showed that 
the alkenes were in $\eta^{2}$-coordination. In the BCP complexes, ${ }^{1} J_{\mathrm{Pt}-\mathrm{P} \text { values were between }}$ 2731 and $2983 \mathrm{~Hz}$ (Table 2.2), $450 \mathrm{~Hz}$ less than those in the parent ethene complex. The ${ }^{31} \mathrm{P}\left\{{ }^{1} \mathrm{H}\right\}$ NMR spectra of $\mathbf{2}$ had second-order $\mathrm{ABX}\left(\mathrm{A}, \mathrm{B}={ }^{31} \mathrm{P}, \mathrm{X}={ }^{195} \mathrm{Pt}\right)$ peak patterns due to the unsymmetrical alkene and the rigid coordination geometry (Figure 2.3 (i)). The ${ }^{1} J_{\mathrm{Pt}-\mathrm{P}}$ values could be used to distinguish the $\mathrm{P}$ trans to the ${ }^{c} \mathrm{Pr}$ group from that of the $\mathrm{P}$ trans to the methylene in the MCP complexes, as the two coupling constants were comparable to those of $\mathbf{1}$ and the parent ethene complexes, respectively.

The ${ }^{13} \mathrm{C}\left\{{ }^{1} \mathrm{H}\right\}$ NMR spectra also clearly showed that the alkenes were in $\eta^{2}$ coordination. The cyclopropyl double-bond carbons showed large ${ }^{1} J_{\mathrm{Pt}-\mathrm{C}}$ values, 410-456 $\mathrm{Hz}$ for 1 and $455-538 \mathrm{~Hz}$ for $\mathbf{2}$ (Table 2.2), while the methylene carbon in 2 had ${ }^{1} J_{\mathrm{Pt}-\mathrm{C}}$ several hundred $\mathrm{Hz}$ less $(164-173 \mathrm{~Hz})$. There was also a large upfield shift of the ${ }^{c} \operatorname{Pr}$ double-bond carbon resonances upon coordination, from 110.6 to 29-34 ppm for 1 and from 131.0 to 33-43 ppm for 2 . The methylene carbon was typically $\sim 15 \mathrm{ppm}$ upfield of the ${ }^{c} \operatorname{Pr}$ carbon, expect for in $\mathbf{2 d}$, where the difference was only $5.8 \mathrm{ppm}$. For comparison, the methylene chemical shift differed from that of the parent ethene ligand by $0.6-6.6 \mathrm{ppm}$. A stronger $\mathrm{Pt}-\mathrm{C}$ bond is formed to the cyclopropyl carbons in $\mathbf{1}$ and $\mathbf{2}$ than to the methylene carbons in $\mathbf{2}$ and the parent ethene complexes. This is evidenced by the lower ${ }^{1} J_{\mathrm{Pt}-\mathrm{P}}$ of the $\mathrm{P}$ trans to the cyclopropyl carbons and the higher ${ }^{1} J_{\mathrm{Pt}-\mathrm{C}}$ coupling constants of these carbons and is a result of the decrease in strain energy of the ${ }^{c}$ Pr rings by rehybridisation upon coordination. ${ }^{8,93-97}$

For the double-bond carbons in $\mathbf{1}$, the line shape was characteristic of a "false $\mathrm{AA}^{\prime} \mathrm{X}$ " spin system $\left(\mathrm{A}, \mathrm{A}^{\prime}={ }^{31} \mathrm{P}, \mathrm{X}={ }^{13} \mathrm{C}\right)$ with ${ }^{195} \mathrm{Pt}$ satellites due to both the magnetic inequivalence of the two chemically equivalent carbons when one was ${ }^{13} \mathrm{C}$ and to the two ${ }^{31} \mathrm{P}$ atoms having the same chemical shift (Figure 2.3). ${ }^{98,99}$ The double-bond carbons in 2, however were ABX systems with ${ }^{195} \mathrm{Pt}$ satellites, as the two ${ }^{31} \mathrm{P}$ atoms were in different chemical environments. ${ }^{99}$ These ${ }^{13} \mathrm{C}$ NMR peaks, and the ${ }^{31} \mathrm{P}$ NMR spectra of $\mathbf{2}$, indicate that the alkene ligands do not rotate at room temperature when coordinated, as rotation would result in the two ${ }^{31} \mathrm{P}$ atoms becoming equivalent.

The endo/exo geometry of the ${ }^{c}$ Pr protons in $\mathbf{1 a}$ and 2a (Figure 2.4) was assigned 


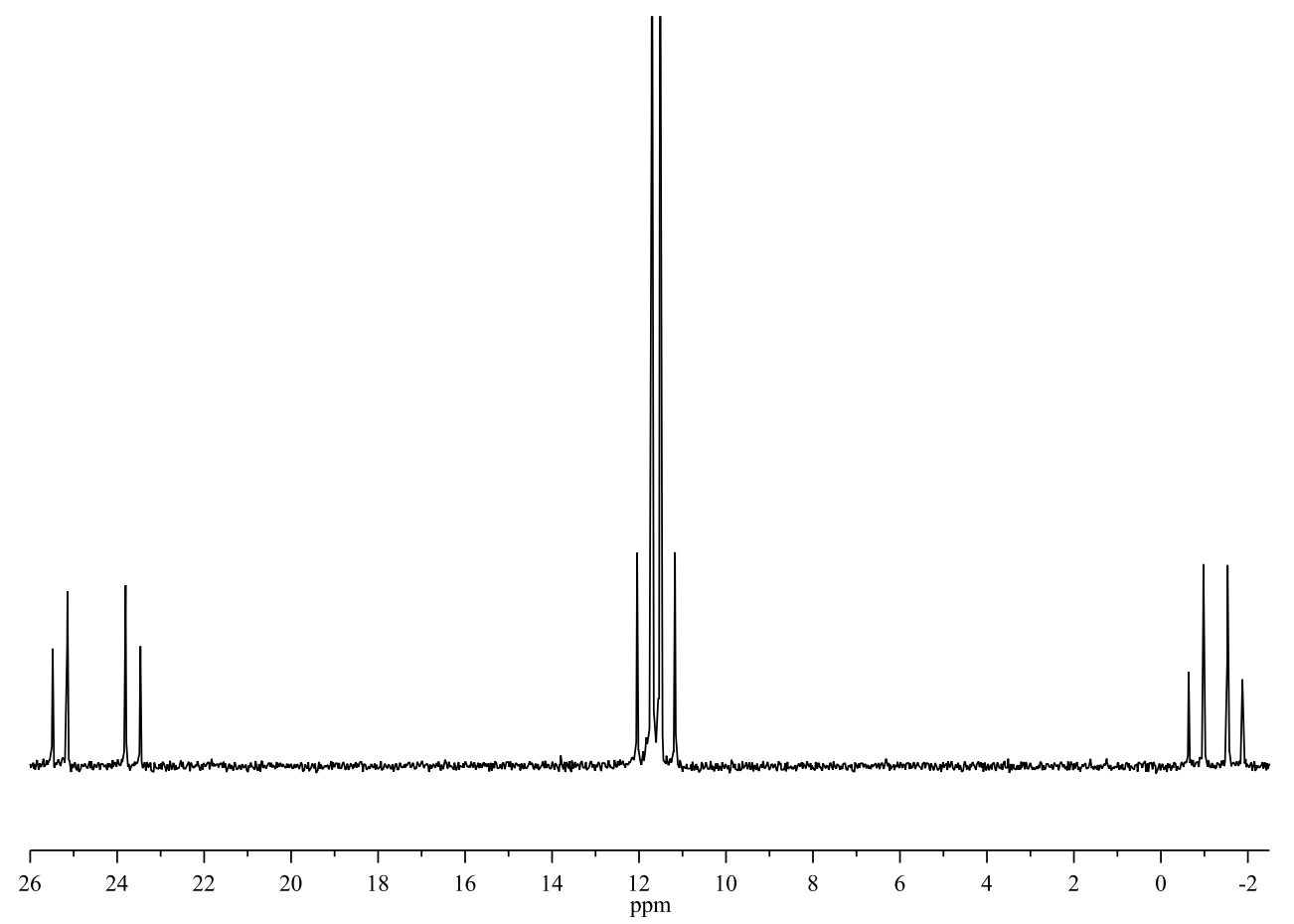

(i)

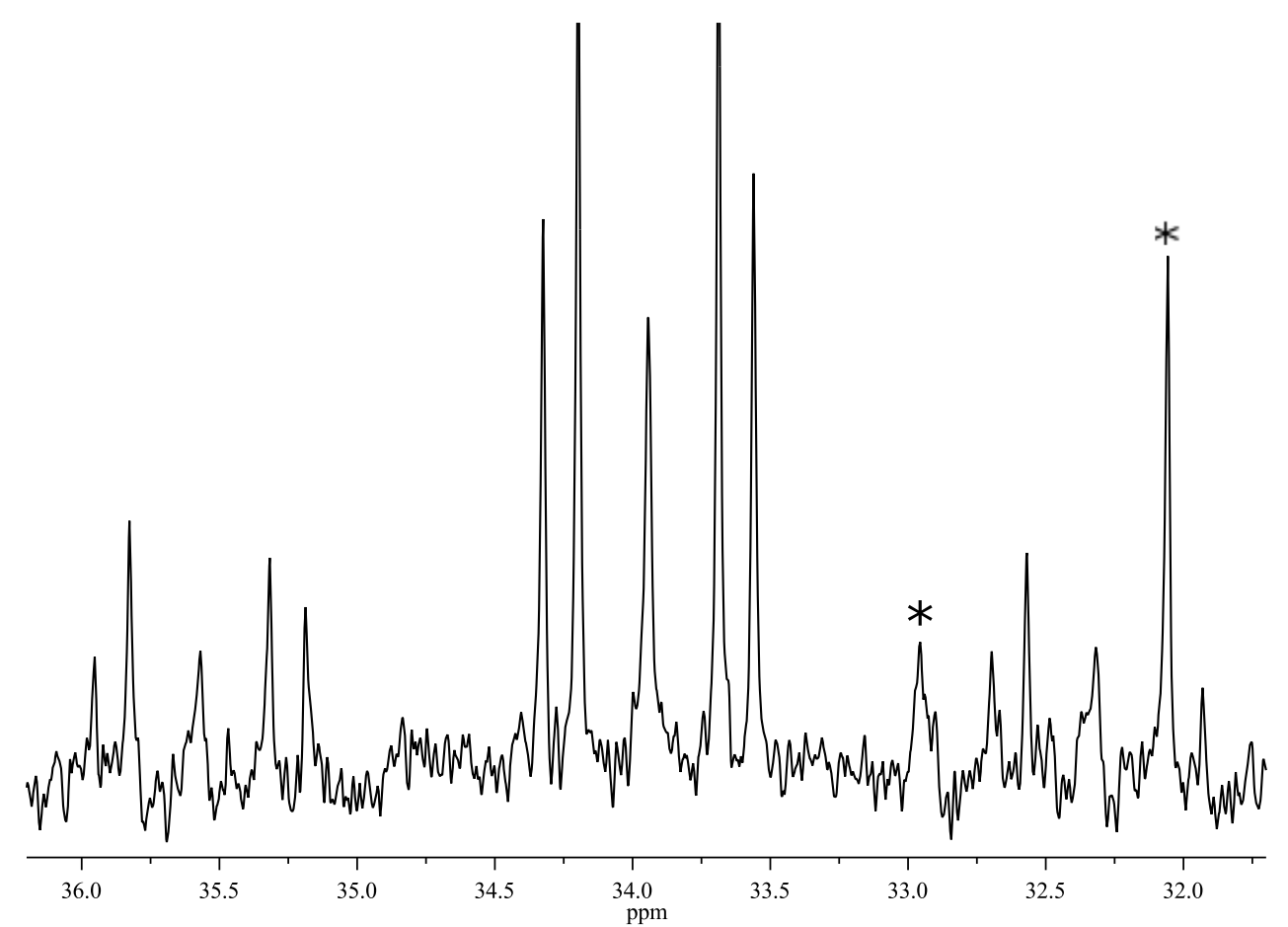

(ii)

Figure 2.3. (i) ${ }^{31} \mathrm{P}\left\{{ }^{1} \mathrm{H}\right\}$ NMR spectrum of $[\mathrm{Pt}(\mathrm{MCP})(\mathrm{dppp})]$ (2a) (125 MHz, RT, $40 \mathrm{mg} / \mathrm{mL}, \mathrm{C}_{6} \mathrm{D}_{6}$ ). (ii) ${ }^{13} \mathrm{C}\left\{{ }^{1} \mathrm{H}\right\}$ NMR spectrum of [Pt(BCP)(dppp)] (1a) $(150 \mathrm{MHz}$, $\left.\mathrm{RT}, 40 \mathrm{mg} / \mathrm{mL}, \mathrm{C}_{6} \mathrm{D}_{6}\right)$. ${ }^{*}$ signifies peaks belonging to other species. 
Table 2.2. Selected NMR Data of $[\mathrm{Pt}(\mathrm{L})(\mathrm{P}-\mathrm{P})]^{a}$

\begin{tabular}{|c|c|c|c|c|c|c|c|c|c|c|c|c|c|c|c|}
\hline \multirow{2}{*}{ Compound } & \multirow{2}{*}{\multicolumn{2}{|c|}{$\delta_{\mathrm{P}}$}} & \multirow{2}{*}{${ }^{1} J_{\mathrm{Pt}-\mathrm{P}}$} & \multirow{2}{*}{\multicolumn{2}{|c|}{${ }^{2} J_{\mathrm{Pt}-\mathrm{P}}$}} & \multicolumn{4}{|c|}{${ }^{c} \mathrm{Pr}$} & \multicolumn{4}{|c|}{$=\mathrm{CHR}$} & \multicolumn{2}{|c|}{$=\mathrm{CR}_{2}$} \\
\hline & & & & & & $\delta_{\mathrm{H}}$ & $J_{\mathrm{Pt}-\mathrm{H}}$ & $\delta_{\mathrm{C}}$ & $J_{\mathrm{Pt}-\mathrm{C}}$ & $\delta_{\mathrm{H}}$ & ${ }^{2} J_{\mathrm{Pt}-\mathrm{H}}$ & $\delta_{\mathrm{C}}$ & ${ }^{1} J_{\mathrm{Pt}-\mathrm{C}}$ & $\delta_{\mathrm{C}}$ & ${ }^{1} J_{\mathrm{Pt}-\mathrm{C}}$ \\
\hline$\overline{\mathrm{BCP}}$ & & & & & & 1.18 & & 3.3 & & & & & & 110.6 & \\
\hline MCP & & & & & & 0.90 & & 2.9 & & 5.46 & & 103.5 & & 131.1 & \\
\hline \multirow[t]{2}{*}{$\mathrm{ACP}$} & & & & & & 0.93 & & 2.6 & & 6.53 & & 136.9 & & 129.3 & \\
\hline & & & & & & 0.85 & & 2.3 & & & & & & & \\
\hline \multirow[t]{2}{*}[\mathrm{Pt}(\mathrm{BCP})(\mathrm{dppp})]{} & $1 \mathbf{a}$ & 9.3 & 2932 & & & 1.29 & 66.0 & 8.8 & 23.1 & & & & & 34.3 & 410.8 \\
\hline & & & & & & 1.18 & 37.7 & & & & & & & & \\
\hline$[\mathrm{Pt}(\mathrm{BCP})(\mathrm{dcyppe})]$ & $1 b$ & 70.8 & 2731 & & & $1.5-1.4$ & $b$ & 10.4 & 23.1 & & & & & 33.8 & 424.6 \\
\hline \multirow[t]{2}{*}[\mathrm{Pt}(\mathrm{BCP})(\mathrm{dbpe})]{} & $1 \mathrm{c}$ & 97.4 & 2798 & & & 1.57 & $b$ & 9.9 & 23.7 & & & & & 31.8 & 428.9 \\
\hline & & & & & & 1.31 & $b$ & & & & & & & & \\
\hline \multirow[t]{2}{*}[\mathrm{Pt}(\mathrm{BCP})(\mathrm{dbpx})]{} & $1 d$ & 43.3 & 2983 & & & 1.34 & 61.2 & 9.9 & 22.5 & & & & & 29.3 & 456.3 \\
\hline & & & & & & 0.99 & 32.0 & & & & & & & & \\
\hline \multirow[t]{2}{*}[\mathrm{Pt}(\mathrm{BCP})(\mathrm{P}-\mathrm{S})]{} & 8 & 54.9 & 3383 & & & $b$ & $b$ & 9.0 & & & & & trans $\mathrm{P}$ & 28.1 & 579.0 \\
\hline & & & & & & & & 8.7 & & & & & trans $\mathrm{S}$ & 25.2 & 656.6 \\
\hline \multirow[t]{2}{*}[\mathrm{Pt}(\mathrm{MCP})(\mathrm{dppp})]{} & $2 \mathbf{a}$ & 11.7 & 3275 & 42 & trans $=\mathrm{CH}_{2}$ & 1.65 & 33.0 & 10.1 & 25.9 & 2.63 & 65.3 & 25.3 & 173.4 & 42.7 & 455.4 \\
\hline & & 11.4 & 2975 & & trans $=\mathrm{CR}_{2}$ & 1.32 & 82.5 & & & & & & & & \\
\hline \multirow[t]{2}{*}{ [Pt(MCP)(dcyppe)] } & $2 \mathrm{~b}$ & 75.0 & 2751 & 63 & trans $=\mathrm{CR}_{2}$ & 1.95 & $b$ & 12.3 & 23.0 & 2.40 & 60.5 & 22.4 & 169.0 & 38.3 & 501.0 \\
\hline & & 70.8 & 3107 & & trans $=\mathrm{CH}_{2}$ & 1.80 & $b$ & & & & & & & & \\
\hline \multirow[t]{2}{*}[\mathrm{Pt}(\mathrm{MCP})(\mathrm{dbpe})]{} & $2 c$ & 100.8 & 2807 & 66 & trans $=\mathrm{CR}_{2}$ & 1.89 & 33.6 & 11.8 & 24.5 & 2.39 & 60.6 & 23.5 & 171.6 & 36.8 & 511.4 \\
\hline & & 99.2 & 3167 & & trans $=\mathrm{CH}_{2}$ & 1.79 & 60.0 & & & & & & & & \\
\hline \multirow{2}{*}[\mathrm{Pt}(\mathrm{MCP})(\mathrm{dbpx})]{} & $2 d$ & 49.3 & 3362 & 30 & trans $=\mathrm{CH}_{2}^{2}$ & 1.60 & $b$ & 11.4 & 25.0 & 2.12 & 56.2 & 27.8 & 164.2 & 33.6 & 537.6 \\
\hline & & 43.7 & 3025 & & trans $=\mathrm{CR}_{2}$ & 1.60 & $b$ & & & & & & & & \\
\hline \multirow[t]{2}{*}[\mathrm{Pt}(\mathrm{MCP})(\mathrm{P}-\mathrm{S})]{} & $9 \mathbf{a}$ & 58.8 & 3870 & & trans $=\mathrm{CH}_{2}$ & 1.45 & $b$ & 10.5 & 30.1 & 2.05 & 52.7 & 26.3 & 145.1 & $b$ & $b$ \\
\hline & & & & & & 1.37 & $b$ & & & & & & & & \\
\hline$[\mathrm{Pt}(\mathrm{MCP})(\mathrm{P}-\mathrm{S})]$ & $9 b$ & 55.3 & 3483 & & trans $=\mathrm{CR}_{2}$ & $\begin{array}{l}1.59 \\
1.50\end{array}$ & & 10.0 & 24.8 & 2.38 & 82.1 & 25.7 & 270.6 & $b$ & $b$ \\
\hline \multirow[t]{2}{*}[\mathrm{Pt}(\mathrm{ACP})(\mathrm{dppp})]{} & $\mathbf{3 a}$ & 10.3 & 3293 & 39 & trans $=\mathrm{CHR}$ & $1.3-0.8$ & $b$ & $b$ & $b$ & 3.78 & 67.8 & $b$ & $b$ & $b$ & $b$ \\
\hline & & 9.7 & 3003 & & trans $=\mathrm{CR}_{2}$ & & & & & & & & & & \\
\hline \multirow[t]{2}{*}[\mathrm{Pt}(\mathrm{ACP})(\mathrm{dcyppe})]{} & $3 b$ & 70.0 & 3153 & -59 & trans $=\mathrm{CHR}$ & $b$ & $b$ & $b$ & $b$ & 3.41 & 62.1 & $b$ & $b$ & $b$ & $b$ \\
\hline & & 68.6 & 2771 & & trans $=\mathrm{CR}_{2}$ & & & & & & & & & & \\
\hline \multirow[t]{2}{*}[\mathrm{Pt}(\mathrm{ACP})(\mathrm{dbpe})]{} & $3 \mathrm{c}$ & 96.4 & 2848 & 62 & trans $=\mathrm{CR}_{2}$ & 1.5 & $b$ & 10.6 & 17.7 & 3.43 & 62.0 & 44.7 & 165.5 & 41.4 & 533.1 \\
\hline & & 96.4 & 3196 & & trans $=\mathrm{CHR}$ & 1.0 & $b$ & 9.5 & 15.5 & & & & & & \\
\hline$\left[\mathrm{Pt}\left(\mathrm{C}_{2} \mathrm{H}_{4}\right)(\mathrm{dppp})\right]$ & & 13.8 & 3340 & & & & & & & 2.68 & 60.0 & 31.9 & 216.0 & & \\
\hline$\left[\mathrm{Pt}\left(\mathrm{C}_{2} \mathrm{H}_{4}\right)(\right.$ dcyppe $\left.)\right]$ & & 75.4 & 3170 & & & & & & & 2.38 & 58.0 & 23.2 & 227.4 & & \\
\hline$\left[\mathrm{Pt}\left(\mathrm{C}_{2} \mathrm{H}_{4}\right)(\mathrm{dbpe})\right]$ & & 102.5 & 3230 & & & & & & & 2.41 & 59.4 & 25.0 & 229.0 & & \\
\hline$\left[\mathrm{P}\left(\mathrm{C}_{2} \mathrm{H}_{4}\right)(\mathrm{dbpx})\right]$ & & 50.1 & 3493 & & & & & & & 2.20 & 57.3 & 27.2 & 217.0 & & \\
\hline
\end{tabular}

${ }^{a} \delta$ values are given in ppm and $J$ values in $\mathrm{Hz}$. All spectra were measured in $\mathrm{C}_{6} \mathrm{D}_{6}$ at room temperature with $40 \mathrm{mg} / \mathrm{mL}$ sample. ${ }^{b} \mathrm{NMR}$ data could not be obtained. 
using 1D NOESY correlations. When each proton resonance was selectively excited, those due to the endo protons showed correlations to the $o-\mathrm{C}_{6} \mathrm{H}_{5}$ protons on the phosphine substituents, as well as to the other ${ }^{c} \operatorname{Pr}$ protons, while the exo protons only correlated to the ${ }^{c}$ Pr protons. It was also found that the endo protons had significantly higher $J_{\mathrm{Pt}-\mathrm{H}}$ couplings $(\sim 60$ vs. $\sim 30 \mathrm{~Hz})$, allowing the geometry of other complexes to be assigned by analogy.

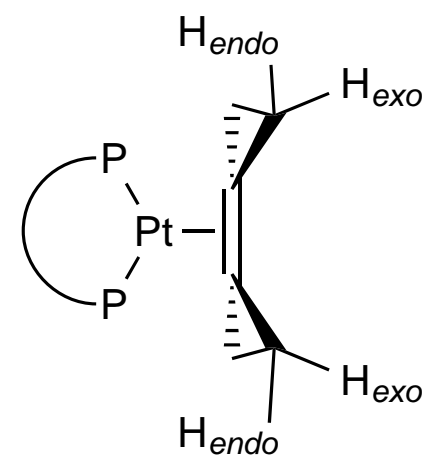

Figure 2.4. Geometry of the endo/exo protons in $[\mathrm{Pt}(\mathrm{BCP})(\mathrm{P}-\mathrm{P})](\mathbf{1})$.

Due to the complex nature of the ${ }^{31} \mathrm{P}$ NMR spectra of $\mathbf{2}$ and the ${ }^{13} \mathrm{C}$ NMR resonances of the double-bond carbons of $\mathbf{1}$, the NMR modelling program gNMR was used to obtain chemical shift and coupling constant data reported in Table 2.2.

\subsection{Allylidenecyclopropane}

It was found that when $\mathrm{BCP}$ reacted with $\left[\mathrm{Pt}\left(\mathrm{C}_{2} \mathrm{H}_{4}\right)_{3}\right]$, a ring-opening reaction occurred to form the 1,3-diene, allylidenecyclopropane (ACP) (Scheme 2.3). This reaction also occurred with $\left[\mathrm{Pt}(\mathrm{COD})_{2}\right],\left[\mathrm{Pt}(\mathrm{nb})_{3}\right],\left[\mathrm{PtMe}_{2}(1,5\right.$-hexadiene $\left.)\right]$ and $\left[\mathrm{PtEt}_{2}(\mathrm{COD})\right]$. One previous instance of the formation of $\mathrm{ACP}$ from $\mathrm{BCP}$ has been reported, occurring in the reaction of $\mathrm{BCP}$ with $\left[\mathrm{Pd}(\mathrm{OAc})_{2}\right]$ and $\mathrm{PPh}_{3} \cdot{ }^{74}$ The proposed mechanism for this reaction involved the addition of a palladium hydride across the BCP double-bond, followed by a cyclopropylmethyl to homoallyl rearrangement and terminated by $\beta$-hydride elimination. Under the reported conditions, ACP went on to react with another molecule of BCP to form various oligomers (see Scheme 1.21, $\mathrm{R}=\mathrm{H}$ ). However, no oligomerisation reactions were observed with the above Pt complexes, even after several days at $60{ }^{\circ} \mathrm{C}$. 


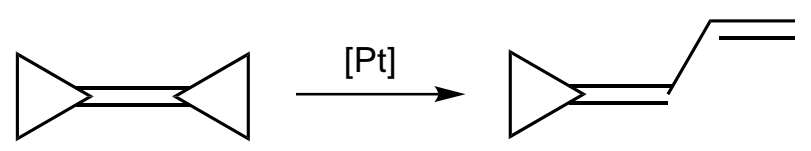

Scheme 2.3. Synthesis of allylidenecyclopropane from bicyclopropylidene.

As there were no published reports of any transition metal chemistry with ACP, the formation of Pt-diphosphine complexes containing ACP ligands was investigated. A solution of ACP was produced for these reactions by dissolving a few crystals of $\left[\mathrm{PtMe}_{2}(1,5\right.$-hexadiene) $]$ in either $\mathrm{CDCl}_{3}$ or $\mathrm{C}_{6} \mathrm{D}_{6}$ under inert atmosphere and adding a small amount of BCP. The reaction could then be monitored by NMR spectroscopy for completion, typically reaching $\sim 95 \%$ after 5 days. The solution was then used without further purification.

The first transition metal complexes of allylidenecyclopropane (3a and $\mathbf{3} \mathbf{b})$ formed immediately upon addition of the ACP solution to the parent ethene complex $\left[\mathrm{Pt}\left(\mathrm{C}_{2} \mathrm{H}_{4}\right)(\mathrm{P}-\mathrm{P})\right](\mathrm{P}-\mathrm{P}=\mathrm{dppp}$, dcyppe) (Scheme 2.4). ACP could also be generated in situ from small amounts of $\left[\mathrm{Pt}(\mathrm{COD})_{2}\right]$, and the addition of $\mathrm{BCP}$ and $\left[\mathrm{Pt}(\mathrm{COD})_{2}\right]$ to solutions of $\left[\mathrm{Pt}\left(\mathrm{C}_{2} \mathrm{H}_{4}\right)(\mathrm{dbpe})\right]$, followed by heating at $40^{\circ} \mathrm{C}$, was used to synthesise $\mathbf{3 c}$ (Scheme 2.5). With $10 \%\left[\mathrm{Pt}(\mathrm{COD})_{2}\right]$ present, the reaction reached $97 \%$ completion after heating overnight. The formation of $3 \mathbf{c}$ still occurred when no detectable $\left[\mathrm{Pt}(\mathrm{COD})_{2}\right]$ was present; however, this reaction only reached $88 \%$ completion after 13 days. $[\mathrm{Pt}(\mathrm{ACP})(\mathrm{dbpx})]$ could not be synthesised, likely due to the steric bulk of the phosphine ligand making coordination of the alkene unfavourable.

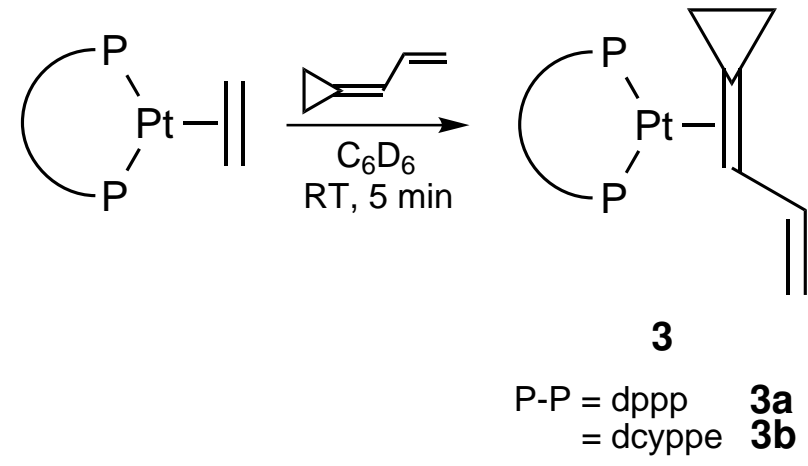

Scheme 2.4. Synthesis of $[\mathrm{Pt}(\mathrm{ACP})(\mathrm{P}-\mathrm{P})](\mathbf{3})$. 


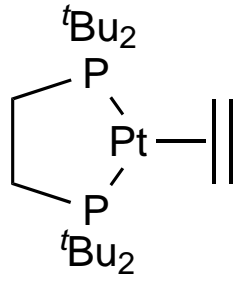

${ }^{t} \mathrm{Bu}_{2}$

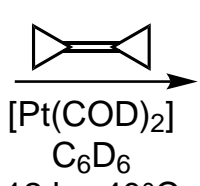

$12 \mathrm{hr}, 40^{\circ} \mathrm{C}$

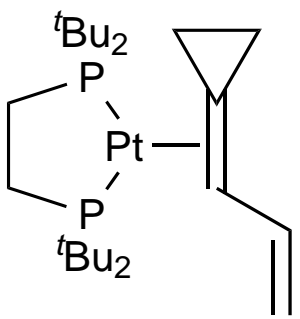

$3 c$

Scheme 2.5. Synthesis of $[\mathrm{Pt}(\mathrm{ACP})(\mathrm{dbpe})](\mathbf{3 c})$.

It was found that when both $\mathrm{ACP}$ and $\mathrm{BCP}$ were present in the reaction mixture, ACP complexes formed initially. However, the ACP ligand in $\mathbf{3 a}$ was slowly displaced by $\mathrm{BCP}$ over several hours at room temperature to form 1a. For the dbpe complexes, 3c was the only product at $40^{\circ} \mathrm{C}$, while at $60^{\circ} \mathrm{C}, 3 \mathbf{c}$ formed initially, before continued heating over several days produced 1c. It was unclear whether this would also happen for the dcyppe complexes, as $\mathbf{3 b}$ underwent a rearrangement that reached completion too rapidly for displacement to occur (see below), although it is considered likely. From this we infer that the complexes of the less bulky ACP were the kinetic products, while the BCP complexes, which had a degree of extra stabilisation afforded by alleviation of strain in the second cyclopropyl ring, were the thermodynamic products.

Complexes $\mathbf{3 a}$ and $\mathbf{3 b}$ were unstable in solution, undergoing a rearrangement to form the metallacyclic complexes $\mathbf{4 a}$ and $\mathbf{4 b}$ (Scheme 2.6). The rearrangement proceeded more rapidly for the dcyppe complex $\mathbf{3 b}$, with significant amounts of $\mathbf{4 b}$ present within 5 min of addition of the ACP solution and the reaction proceeding to completion after $3 \mathrm{hr}$. For the dppp complex 3a, the metallacycle appeared in the ${ }^{31} \mathrm{P}\left\{{ }^{1} \mathrm{H}\right\}$ NMR spectroscopy after $3 \mathrm{hr}$, reaching $96 \%$ completion after 7 days.

The formation of metallacyclo-3-pentenes from 1,3-dienes is well established. There are two possible binding modes for these ligands: the $\eta^{4}: \sigma^{2}, \pi$ mode, where the double-bond is also coordinated to the metal, common for early transition and actinide metals, ${ }^{100-102}$ and the planar $\eta^{2}: \sigma^{2}$ mode. Planar metallacyclopentene complexes are considered to be intermediates in ring-flipping mechanisms of $\eta^{4}$-diene complexes, ${ }^{103}$ and complexes with $\eta^{2}: \sigma^{2}$-metallacyclopentene ligands formed from various 1,3-dienes have been reported for 

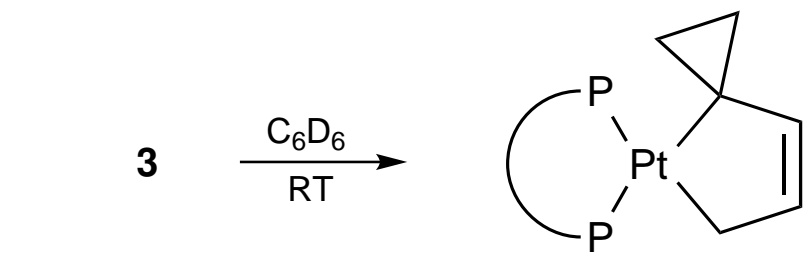

\section{4}

$\begin{aligned} P-P & =\text { dppp } \quad 3 \mathbf{a} \\ & =\text { dcyppe } \quad 3 \mathbf{b}\end{aligned}$

P-P $=$ dppp $\quad 4 a \quad 3 \mathrm{hr}$

$=$ dcyppe $4 \mathrm{~b} \quad 7 \mathrm{~d}$

Scheme 2.6. Rearrangement of $[\mathrm{Pt}(\mathrm{ACP})(\mathrm{P}-\mathrm{P})](\mathbf{3 a})$ to form metallocyclopentene complexes

Fe, ${ }^{104,105} \mathrm{Co},{ }^{106} \mathrm{Mo}^{107} \mathrm{~W},{ }^{107} \mathrm{Rh},{ }^{103,108-110} \mathrm{Ir},{ }^{111-114} \mathrm{Pt},{ }^{103,115} \mathrm{Ge},{ }^{116}$ and Mg. ${ }^{117}$

The rearrangements of $\mathbf{3}$ to $\mathbf{4}$ appear to be the first instances of the formation of $\eta^{2}: \sigma^{2}$-metallacyclopentene complexes from $\eta^{2}: \pi$-diene complexes. Previously reported $\eta^{2}: \sigma^{2}$-metallacyclopentenes were formed either directly upon addition of the 1,3-diene to a metal precursor ${ }^{103-105,108-110,115-117}$ or by rearrangement of an $\eta^{4}$ : $\pi$-diene complex, generally initiated by the addition of a species such as a Lewis base. ${ }^{106,107,113,114}$

\subsubsection{NMR Characterisation}

\subsubsection{Allylidenecyclopropane Complexes}

All ACP complexes exhibited second-order $\mathrm{ABX}{ }^{31} \mathrm{P}\left\{{ }^{1} \mathrm{H}\right\}$ NMR spectra similar to the corresponding MCP complexes, with ${ }^{1} J_{\mathrm{Pt}-\mathrm{P}}$ couplings for both phosphine environments within $40 \mathrm{~Hz}$ of those in $\mathbf{2}$ (Table 2.2). The ${ }^{1} \mathrm{H}$ NMR signal of the internal doublebond proton showed a large upfield shift from $6.6 \mathrm{ppm}$ in free ACP to $3.4-3.8 \mathrm{ppm}$ in 3 (Table 2.3). The magnitudes of the ${ }^{2} J_{\mathrm{Pt}-\mathrm{H}}$ coupling constants of these protons, $62-68 \mathrm{~Hz}$, were typical of coordination through this bond. The protons of the terminal double-bond have chemical shifts much closer to those in the free alkene. Both the ${ }^{1} \mathrm{H}$ and the ${ }^{31} \mathrm{P}$ NMR data indicated that ACP was coordinated via the internal rather than the terminal double-bond. This is to be expected given the stabilisation afforded by the alleviation of ring strain in the ${ }^{c} \operatorname{Pr}$ upon coordination.

The ${ }^{1} J_{\mathrm{Pt}-\mathrm{C}}$ coupling constants of the internal double-bond carbons of $\mathbf{3} \mathbf{c}$ further indicated that the alkene had coordinated via this bond. The coupling constant for 
Table 2.3. ${ }^{1} \mathrm{H}$ and ${ }^{13} \mathrm{C}\left\{{ }^{1} \mathrm{H}\right\}$ NMR Data of $[\mathrm{Pt}(\mathrm{ACP})(\mathrm{P}-\mathrm{P})] .{ }^{a}$

\begin{tabular}{|c|c|c|c|c|c|c|c|c|c|c|}
\hline \multirow{2}{*}{ Compound } & & \multicolumn{4}{|c|}{$\delta_{\mathrm{H}}$} & \multicolumn{5}{|c|}{$\overline{\delta_{\mathrm{C}}}$} \\
\hline & & ${ }^{c} \operatorname{Pr}$ & $=\mathrm{CH}_{2}$ & terminal $=\mathrm{CHR}$ & internal $=\mathbf{C H R}$ & ${ }^{c} \mathrm{Pr}$ & $=\mathrm{CH}_{2}$ & terminal $=\mathrm{CHR}$ & internal $=\mathrm{CHR}$ & $=\mathrm{CR}_{2}$ \\
\hline \multirow[t]{2}{*}{$\mathrm{ACP}$} & & 0.93 & 5.18 & 6.49 & 6.58 & 2.6 & 115.2 & 120.2 & 136.9 & 129.3 \\
\hline & & 0.85 & 5.05 & & & 2.3 & & & & \\
\hline \multirow{2}{*}[\mathrm{Pt}(\mathrm{ACP})(\mathrm{dppp})]{} & $3 \mathbf{a}$ & $1.3-0.8$ & 5.04 & 6.47 & 3.78 & $b$ & $b$ & $b$ & $b$ & $b$ \\
\hline & & & 4.69 & & ${ }^{2} J_{\mathrm{Pt}-\mathrm{H}}=67.8 \mathrm{~Hz}$ & & & & & \\
\hline \multirow[t]{2}{*}[\mathrm{Pt}(\mathrm{ACP})(\mathrm{dcyppe})]{} & $3 \mathrm{~b}$ & $b$ & 4.85 & 6.11 & 3.41 & $b$ & $b$ & $b$ & $b$ & $b$ \\
\hline & & & 4.37 & & ${ }^{2} J_{\mathrm{Pt}-\mathrm{H}}=62.1 \mathrm{~Hz}$ & & & & & \\
\hline \multirow[t]{2}{*}[\mathrm{Pt}(\mathrm{ACP})(\mathrm{dbpe})]{} & $3 c$ & 1.5 & 4.98 & 6.20 & 3.43 & 10.6 & 102.7 & 147.5 & 44.7 & 41.4 \\
\hline & & & 4.64 & & ${ }^{2} J_{\mathrm{Pt}-\mathrm{H}}=62.0 \mathrm{~Hz}$ & 9.5 & & & & \\
\hline
\end{tabular}

${ }^{a} \delta$ values are given in ppm and $J$ values in $\mathrm{Hz}$. All spectra were measured in $\mathrm{C}_{6} \mathrm{D}_{6}$ at room temperature with $40 \mathrm{mg} / \mathrm{mL}$ sample. ${ }^{b} \mathrm{NMR}$ data could not be obtained. 
the cyclopropyl carbon was $533 \mathrm{~Hz}$, while that of the methyne was $166 \mathrm{~Hz}$, both of which were within $20 \mathrm{~Hz}$ of the corresponding value for 2c (Table 2.2). The chemical shifts of the carbons of the terminal double-bond were also much closer to those of the free alkene than the internal double-bond carbons (Table 2.3). In 3c, the double-bond carbons had an $\mathrm{AA}^{\prime} \mathrm{X}$ coupling pattern with ${ }^{195} \mathrm{Pt}$ satellites similar to those of the $\mathrm{BCP}$ complexes. This was due to the two phosphorus atoms in this complex coincidentally having the same chemical shift. ${ }^{99}$ The effect could be seen throughout the carbon spectrum, with all of the resonances of the ACP ligands in $\mathbf{3 a}$ and $\mathbf{3} \mathbf{b}$ would have ABX spectra (with ${ }^{195} \mathrm{Pt}$ satellites) similar to the corresponding MCP complexes, as the phosphorus atoms have different chemical shifts. However, due to the short lifetimes of these complexes, ${ }^{13} \mathrm{C}$ NMR data could not be obtained.

\subsubsection{Metallocyclopentene Complexes}

For representative NMR spectra, see FIgures A.12-A.15. The NMR data of 4 were consistent with a planar $\eta^{2}: \sigma^{2}$-metallocyclopentene structure. The ${ }^{1} J_{\mathrm{Pt}-\mathrm{P}}$ coupling constants of $4(1784-1856 \mathrm{~Hz})$ were comparable to those of $\left[\mathrm{Pt}\left(\mathrm{CH}_{2} \mathrm{CPh}=\mathrm{CCHC}=\mathrm{CMe}_{2}\right)(\mathrm{dppe})\right](1818$ and $1842 \mathrm{~Hz}$ ), which showed that there were $\mathrm{Pt}-\mathrm{C} \sigma$-bonds in $4 .{ }^{103}$ In the previously reported $\mathrm{Pt}$ metallacycles, the $\mathrm{CH}_{2}$ groups directly bonded to the metal had $\delta_{\mathrm{H}}$ at

2.8-3.2 ppm with ${ }^{2} J_{\mathrm{Pt}-\mathrm{H}}=68-92 \mathrm{~Hz}$ and $\delta_{\mathrm{C}}$ at $31-41 \mathrm{ppm}$ with ${ }^{1} J_{\mathrm{Pt}-\mathrm{C}}=603-787 \mathrm{~Hz},{ }^{103,115}$ while the Ir metallacycles had 2.4-3.0 and $-2-13 \mathrm{ppm}$ for $\delta_{\mathrm{H}}$ and $\delta_{\mathrm{C}}$, respectively. ${ }^{113}$ The NMR data of both the Pt- $\mathrm{CH}_{2}$ groups $\left(\delta_{\mathrm{H}}=2.9-3.2 \mathrm{ppm},{ }^{2} J_{\mathrm{Pt}-\mathrm{H}}=62-73 \mathrm{~Hz}, \delta_{\mathrm{C}}=\right.$ 29-39 ppm, $\left.{ }^{1} J_{\mathrm{Pt}-\mathrm{C}}=297-450 \mathrm{~Hz}\right)$ and the $\mathrm{Pt}-\mathrm{CR}_{3} \operatorname{groups}\left(\delta_{\mathrm{C}}=32-33 \mathrm{ppm},{ }^{1} J_{\mathrm{Pt}-\mathrm{C}}=\right.$ $959 \mathrm{~Hz}$ for $\mathbf{4 b}$ ) in 4 agree well with the literature. The NMR data of the double-bond carbons and their attached protons $\left(\delta_{\mathrm{H}}=5.3-6.4\right.$ and $\left.\delta_{\mathrm{C}}=131-154 \mathrm{ppm}\right)$ also compared favourably to the literature values $\left(\delta_{\mathrm{H}}=5.0-5.6\right.$ and $\left.\delta_{\mathrm{C}}=135.9-151.3 \mathrm{ppm}\right) .{ }^{103,113,115}$

\section{$2.3\left[\mathrm{Pt}(\mathrm{L})_{2}\left(\mathrm{PR}_{3}\right)\right]$ Complexes}

Precursor complexes containing two ethene ligands and one phosphine ligand were also investigated. Bis-ethene complexes were chosen due to the possibility that oligomerisation 
or isomerisation reactions similar to the formation of $\mathrm{ACP}$ from $\mathrm{BCP}$ might occur. Complexes of the type $\left[\mathrm{M}(\mathrm{L})(\mathrm{BCP})\left(\mathrm{PR}_{3}\right)\right]\left(\mathrm{M}=\mathrm{Ni}, \mathrm{Pd}, \mathrm{L}=\right.$ electron-deficient alkene, $\mathrm{PR}_{3}$ $=$ tert-butyldiisopropylphosphine, tris(o-phenylphenyl)phosphite) have been proposed as intermediates in the palladium- and nickel catalysed $[3+2]$ co-cyclisation of BCP with various alkenes, but were not isolated (see Scheme 1.16). ${ }^{72}$ Bis-BCP complexes have also been postulated to be intermediates in nickel-catalysed $[3+2+2]$ co-cyclisations. ${ }^{118}$

Bis-ethene precursor complexes $\left[\mathrm{Pt}\left(\mathrm{C}_{2} \mathrm{H}_{4}\right)_{2}\left(\mathrm{PR}_{3}\right)\right]\left(\mathrm{PR}_{3}=\mathrm{PPh}_{3}, \mathrm{PCy}_{3}\right)$ were synthesised by addition of the appropriate phosphine (Figure 2.5) to $\left[\mathrm{Pt}\left(\mathrm{C}_{2} \mathrm{H}_{4}\right)_{3}\right] .{ }^{119}$ When BCP was added to $\left[\mathrm{Pt}\left(\mathrm{C}_{2} \mathrm{H}_{4}\right)_{2}\left(\mathrm{PR}_{3}\right)\right]$, the product was $\left[\mathrm{Pt}\left(\mathrm{C}_{2} \mathrm{H}_{4}\right)(\mathrm{BCP})\left(\mathrm{PR}_{3}\right)\right]\left(\mathrm{PR}_{3}=\mathrm{PPh}_{3}\right.$ (5a), $\left.\mathrm{PCy}_{3}(\mathbf{5 b})\right)$ (Scheme 2.8). For the bulkier $\mathrm{PCy}_{3}$, complex $5 \mathbf{b}$ was stable with an excess of BCP. However, 5a was stable in solution only when 1 equiv. of BCP was used. When more than 1 equiv. was used, $\left[\mathrm{Pt}(\mathrm{BCP})\left(\mathrm{PPh}_{3}\right)_{2}\right]$ began to form after $40 \mathrm{~min}$ and was the only phosphine-containing product after $24 \mathrm{hr}$. No other platinum-containing species were identified. The formation of a bis-BCP complex did not occur with either of the phosphines used in this work. This was likely due to the steric constraints of having the two alkenes in a planar coordination geometry as occurs with platinum(0). ${ }^{2}$

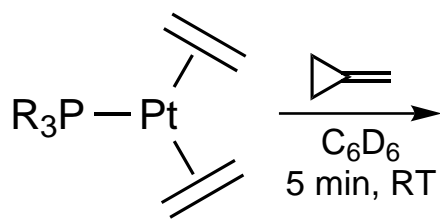

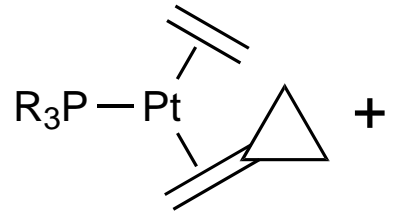

6

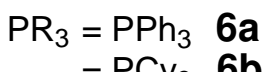

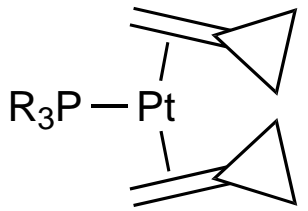

7

Scheme 2.7. Synthesis of $\left[\mathrm{Pt}(\mathrm{MCP})\left(\mathrm{C}_{2} \mathrm{H}_{4}\right)\left(\mathrm{PR}_{3}\right)\right](\mathbf{6})$ and $\left[\mathrm{Pt}(\mathrm{MCP})_{2}\left(\mathrm{PR}_{3}\right)\right](\mathbf{7})$.

Despite the large excesses of MCP used, both the mixed alkene $\left[\mathrm{Pt}\left(\mathrm{C}_{2} \mathrm{H}_{4}\right)(\mathrm{MCP})\left(\mathrm{PR}_{3}\right)\right]$ $\left(\mathrm{PR}_{3}=\mathrm{PPh}_{3}(\mathbf{6 a}), \mathrm{PCy}_{3}(\mathbf{6} \mathbf{b})\right)$ and the bis-MCP complexes $\left[\mathrm{Pt}(\mathrm{MCP})_{2}\left(\mathrm{PR}_{3}\right)\right]\left(\mathrm{PR}_{3}=\right.$ $\mathrm{PPh}_{3}(\mathbf{7 a}), \mathrm{PCy}_{3}(\mathbf{7 b})$ ) were always formed in a closed system (Scheme 2.7). The bisMCP complexes 7 are the first examples of Pt-MCP complexes with more than one MCP ligand. When $\mathrm{PPh}_{3}$ was used, the product ratio was 80:20 bis-MCP:mixed alkene. The ratio changed to 30:70 in favour of the mixed complex when $\mathrm{PCy}_{3}$ was used, with the 

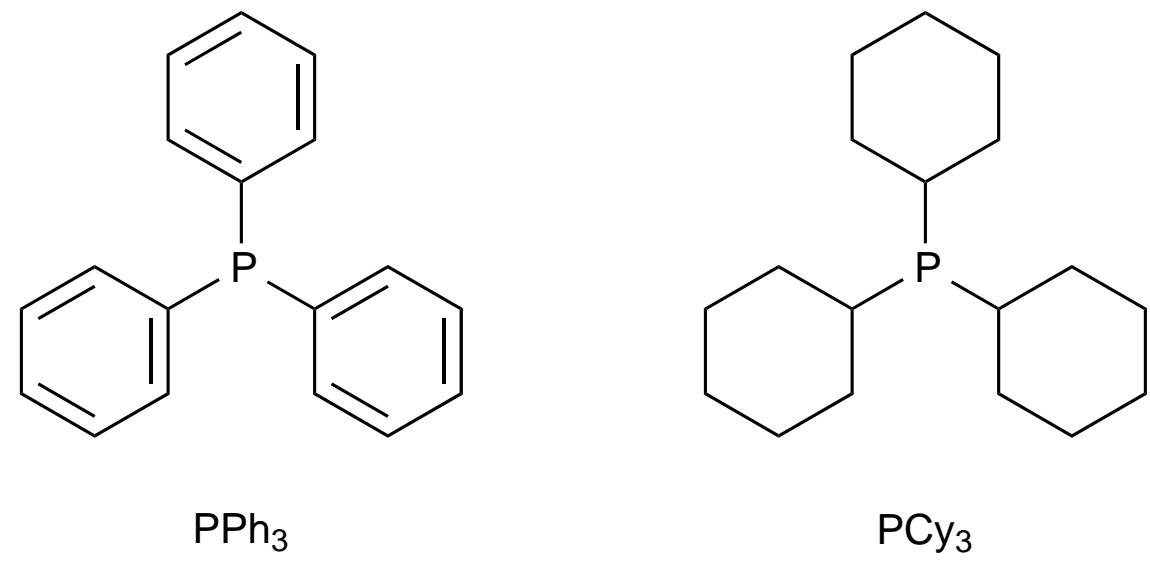

\begin{tabular}{lrr}
\hline Phosphine & $\boldsymbol{\theta}\left({ }^{\circ}\right)$ & $\boldsymbol{\nu}\left(\mathrm{cm}^{-1}\right)$ \\
\hline $\mathrm{PPh}_{3}$ & 145 & 2069 \\
$\mathrm{PCy}_{3}$ & 170 & 2056 \\
\hline
\end{tabular}

$\mathrm{PCy}_{3}$

$\theta=$ Tolman cone angle. Calculated from the cone formed between the metal and the outer hydrogens of the ligand with an M-P bond length of $2.28 \AA .{ }^{82}$

$\nu=$ Tolman electronic parameter. Calculated from the $\mathrm{C} \equiv \mathrm{O}$ stretching frequency in $\left[\mathrm{Ni}\left(\mathrm{CO}_{3}\right)(\mathrm{L})\right] .{ }^{82}$

Figure 2.5. Structures and properties of monophosphine ligands. ${ }^{82}$ 

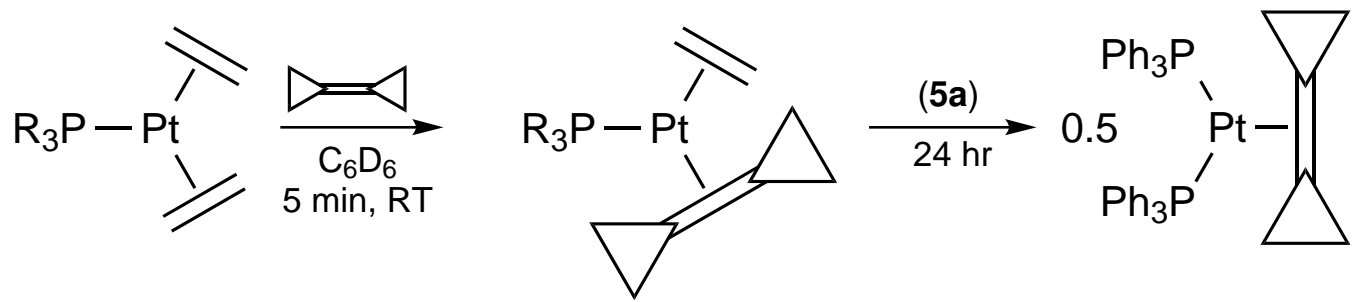

5

$$
\begin{aligned}
& \mathrm{PR}_{3}=\mathrm{PPh}_{3} \quad \mathbf{5 a} \\
& =\mathrm{PCy}_{3} \mathbf{5 b}
\end{aligned}
$$

Scheme 2.8. Synthesis of $\left[\mathrm{Pt}(\mathrm{BCP})\left(\mathrm{C}_{2} \mathrm{H}_{4}\right)\left(\mathrm{PR}_{3}\right)\right](\mathbf{5})$.

bulkier phosphine hindering but not preventing the coordination of the second MCP ligand. When ethene was allowed to diffuse out of the reaction, complex $\mathbf{7 a}$ was formed in $90 \%$ yield. Yields could be improved and complex $\mathbf{7 b}$ formed selectively when inert gas was bubbled through the reaction mixture. The mixed alkene complexes 6 became the major products when ethene was bubbled through the solution. However, the mixed alkene complexes were much less stable than the bis-MCP complexes, as large amounts of ethene regenerated the bis-ethene complexes, while in the presence of free MCP, 7 formed.

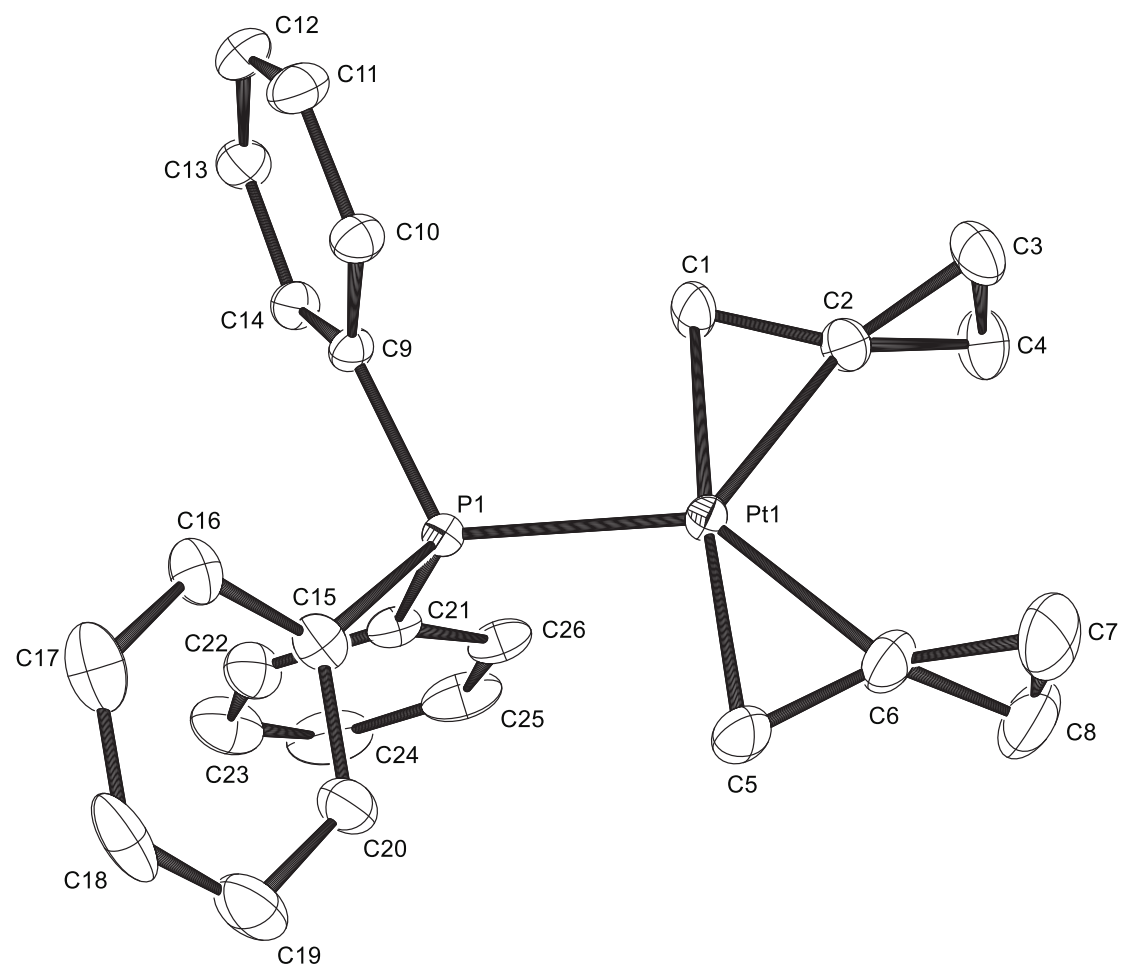

Figure 2.6. ORTEP diagram of $\left[\mathrm{Pt}(\mathrm{MCP})_{2}\left(\mathrm{PPh}_{3}\right)\right](6 \mathrm{a})$ showing $50 \%$ probability thermal ellipsoids. $\mathrm{H}$ atoms have been omitted for clarity. 
X-ray quality crystals of $\mathbf{7 a}$ were grown from cold hexane (Figure 2.6, Table 2.4). The MCP carbon-carbon double-bond length was increased by 5.7\% upon coordination, from $1.332(1) \AA$ in free $\mathrm{MCP}$ to $1.408(5) \AA$ in $7 \mathbf{a} .{ }^{29} \operatorname{In}\left[\operatorname{Rh}(\operatorname{acac})(\mathrm{MCP})_{2}\right]$, the only other MCP complex characterized by X-ray diffraction, the bond lengths were 1.405(19) and $1.440(19) \AA$, representing increases of $5.4 \%$ and $8.1 \%$, respectively. The increase in MCP bond length upon coordination was much greater than the $1.5 \%$ increase in ethene $\mathrm{C}=\mathrm{C}$ bond length in the related complex $\left[\mathrm{Pt}\left(\mathrm{C}_{2} \mathrm{H}_{4}\right)\left(\mathrm{C}_{2} \mathrm{~F}_{4}\right)\left(\mathrm{PCy}_{3}\right)\right]$, the only other $\left[\mathrm{Pt}(\text { alkene })_{2}\left(\mathrm{PR}_{3}\right)\right]$ complex with an X-ray crystal structure. ${ }^{120,121}$ The $\mathrm{C}_{2} \mathrm{~F}_{4}$ bond increased by $10.0 \%$ upon coordination. ${ }^{122}$ The cyclopropyl rings in $\mathbf{7 a}$ were bent by $35.49^{\circ}$ and $35.86^{\circ}$ away from the plane of the double-bond, a greater angle than those in the $\mathrm{Rh}$ complex $\left(26.48^{\circ}\right.$ and $\left.27.79^{\circ}\right)$. Given the strain of the ${ }^{c} \operatorname{Pr}$ ring, it would be expected that there was a stronger bond from the platinum to the ring double-bond carbon than to the methylene carbon. This was evidenced by the shorter Pt-C distance to the ${ }^{c} \mathrm{Pr}$ carbon (2.087(3) and 2.093(3) $\AA$ ) than to the methylene $(2.130(3)$ and $2.123(3) \AA)$. The Pt-P

bond length was 2.3028(7) $\AA$, shorter than that in $\left[\mathrm{Pt}\left(\mathrm{C}_{2} \mathrm{H}_{4}\right)\left(\mathrm{C}_{2} \mathrm{~F}_{4}\right)\left(\mathrm{PCy}_{3}\right)\right]$, which had a Pt-P distance of 2.343(2) $\AA$.

\subsubsection{NMR Characterisation}

For representative NMR spectra, see Figures A.20-A.25. The double-bond carbons of the BCP ligands in 5 had similar chemical shifts $(29-30 \mathrm{ppm})$ and ${ }^{1} J_{\mathrm{Pt}-\mathrm{C}}(431-483 \mathrm{~Hz})$ to those in $\mathbf{1}$, indicating that the ligands were in $\eta^{2}$-coordination (Table 2.5 ). The ${ }^{1} J_{\mathrm{Pt}-\mathrm{P}}$ coupling constants in both mixed alkene complexes were $\sim 330 \mathrm{~Hz}$ lower than those of the parent bis-ethene complexes, showing the same decrease in ${ }^{1} J_{\mathrm{Pt}-\mathrm{P}}$ upon coordination of $\mathrm{BCP}$ as was seen for the diphosphine complexes.

The mixed ethene-MCP complexes 6 had ${ }^{1} J_{\mathrm{Pt}-\mathrm{P}}$ couplings within $10 \mathrm{~Hz}$ of the etheneBCP complexes 5 (Table 2.5). ${ }^{13} \mathrm{C}$ NMR data could not be obtained for these complexes due to their instability. However, their ${ }^{1} \mathrm{H}$ NMR spectra showed similar chemical shifts and ${ }^{2} J_{\mathrm{Pt}-\mathrm{H}}$ for the ethene ligands to 5 . The bis-MCP complexes 7 had ${ }^{1} J_{\mathrm{Pt}-\mathrm{P}}$ several hundred $\mathrm{Hz}$ lower than the parent ethene complexes and more than $150 \mathrm{~Hz}$ lower than 
Table 2.4. Crystallographic Data for $\left[\mathrm{Pt}(\mathrm{MCP})_{2}\left(\mathrm{PPh}_{3}\right)\right](6 \mathrm{a})$.

\begin{tabular}{|c|c|}
\hline Chemical formula & $\mathrm{C}_{26} \mathrm{H}_{27} \mathrm{PPt}$ \\
\hline Formula weight & 565.54 \\
\hline $\mathrm{a}, \AA$ & $10.4179(4)$ \\
\hline $\mathrm{b}, \AA$ & $10.7385(4)$ \\
\hline $\mathrm{c}, \AA$ & $11.3770(4)$ \\
\hline$\alpha, \operatorname{deg}$ & $66.647(2)$ \\
\hline$\beta, \operatorname{deg}$ & $71.772(2)$ \\
\hline$\gamma, \operatorname{deg}$ & $70.542(2)$ \\
\hline $\mathrm{V}, \AA^{3}$ & $1077.48(7)$ \\
\hline Z & 2 \\
\hline Space group & $P-1$ \\
\hline $\mathrm{T}, \mathrm{K}$ & 119.0 \\
\hline$\lambda, \AA$ & 0.71073 \\
\hline $\mathrm{D}_{\text {calcd }}, \mathrm{g} \mathrm{cm}^{-3}$ & 1.743 \\
\hline$\mu, \mathrm{mm}^{-1}$ & 6.594 \\
\hline $\mathrm{R}_{1},[\mathrm{I}>2 \sigma(\mathrm{I})]^{a}$ & 0.0250 \\
\hline$w \mathrm{R}_{2}(\text { all data })^{a}$ & 0.0601 \\
\hline
\end{tabular}

the mixed alkene complex (Table 2.5). The MCP methylene resonances in the ${ }^{1} \mathrm{H}$ NMR were also at lower chemical shifts than in the mixed complex and had lower ${ }^{2} J_{\mathrm{Pt}-\mathrm{H}}(50-$ $55 \mathrm{~Hz}$ ), closer to those of the ethene rather than the MCP ligand in 6. Both the carbon and proton NMR data showed that the two MCP ligands were in the same chemical environment on the NMR time scale. While this could be due to rotation of the ligands, it was considered more likely that the ligands were arranged either head-to-head or tailto-tail. The X-ray crystal structure of $\mathbf{7 a}$ showed that in the solid state the two MCP ligands were tail-to-tail 
Table 2.5. Selected NMR Data of $\left[\mathrm{Pt}(\mathrm{L})_{2}\left(\mathrm{PR}_{3}\right)\right] .^{a}$

\begin{tabular}{|c|c|c|c|c|c|c|c|c|c|c|c|c|c|c|c|c|c|}
\hline \multirow{2}{*}{ Compound } & & \multirow{2}{*}{$\delta_{\mathrm{P}}$} & \multirow{2}{*}{${ }^{1} J_{\mathrm{Pt}-\mathrm{P}}$} & \multicolumn{4}{|c|}{${ }^{c} \mathrm{Pr}$} & \multicolumn{4}{|c|}{$\mathrm{MCP}=\mathrm{CH}_{2}$} & \multicolumn{4}{|c|}{$\mathrm{C}_{2} \mathrm{H}_{4}=\mathrm{CH}_{2}$} & \multicolumn{2}{|c|}{$=\mathrm{CR}_{2}$} \\
\hline & & & & $\delta_{\mathbf{H}}$ & $J_{\mathrm{Pt}-\mathrm{H}}$ & $\delta_{\mathrm{C}}$ & $J_{\mathrm{Pt}-\mathrm{C}}$ & $\delta_{\mathrm{H}}$ & ${ }^{2} J_{\mathrm{Pt}-\mathrm{H}}$ & $\delta_{\mathrm{C}}$ & ${ }^{1} J_{\mathrm{Pt}-\mathrm{C}}$ & $\delta_{\mathrm{H}}$ & ${ }^{2} J_{\mathrm{Pt}-\mathrm{H}}$ & $\delta_{\mathrm{C}}$ & ${ }^{1} J_{\mathrm{Pt}-\mathrm{C}}$ & $\delta_{\mathrm{C}}$ & ${ }^{1} J_{\mathrm{Pt}-\mathrm{C}}$ \\
\hline$\left[\mathrm{Pt}(\mathrm{BCP})\left(\mathrm{C}_{2} \mathrm{H}_{4}\right)\left(\mathrm{PPh}_{3}\right)\right]$ & $5 a$ & 23.2 & 3094 & $1.2-0.8$ & $b$ & $9.2-6.8$ & $b$ & & & & & 2.71 & 51.0 & 54.8 & 102.2 & 30.2 & 431.5 \\
\hline$\left[\mathrm{Pt}(\mathrm{BCP})\left(\mathrm{C}_{2} \mathrm{H}_{4}\right)\left(\mathrm{PCy}_{3}\right)\right]$ & $5 b$ & 25.3 & 2976 & $1.17-1.05$ & $b$ & 8.3 & 23.8 & & & & & 2.68 & 50.0 & 50.7 & 101.8 & 29.1 & 482.9 \\
\hline \multirow[t]{2}{*}[\mathrm{Pt}(\mathrm{MCP})(\mathrm{C}_{2}\mathrm{H}_{4})(\mathrm{PPh}_{3})]{} & $6 a$ & 23.6 & 3085 & 1.64 & 60.0 & $b$ & $b$ & 2.58 & 61.5 & $b$ & $b$ & 2.61 & 56.0 & $b$ & $b$ & $b$ & $b$ \\
\hline & & & & 1.55 & 34.0 & & & & & & & & & & & & \\
\hline$\left[\mathrm{Pt}(\mathrm{MCP})\left(\mathrm{C}_{2} \mathrm{H}_{4}\right)\left(\mathrm{PCy}_{3}\right)\right]$ & $6 \mathrm{~b}$ & 28.0 & 2978 & $1.5-0.9$ & $b$ & $b$ & $b$ & 2.52 & 61.2 & $b$ & $b$ & 2.49 & 48.1 & $b$ & $b$ & $b$ & $b$ \\
\hline$\left[\mathrm{Pt}(\mathrm{MCP})_{2}\left(\mathrm{PPh}_{3}\right)\right]$ & $7 a$ & 22.3 & 2932 & 1.31 & $b$ & 7.8 & 24.5 & 2.39 & 55.0 & 38.9 & 100.3 & & & & & 54.1 & 352.9 \\
\hline$\left[\mathrm{Pt}(\mathrm{MCP})_{2}\left(\mathrm{PCy}_{3}\right)\right]$ & $7 \mathrm{~b}$ & 23.2 & 2695 & $1.47-1.29$ & $b$ & 7.2 & 25.0 & 2.27 & 50.0 & 32.0 & $b$ & & & & & 48.5 & 385.6 \\
\hline$\left[\mathrm{Pt}(\mathrm{MCP})_{2}(\mathrm{P}-\mathrm{S})\right]$ & 10 & 40.6 & 2661 & $b$ & $b$ & 7.2 & 25.4 & 2.49 & 48.1 & 35.7 & 100.6 & & & & & 48.7 & 381.9 \\
\hline$\left[\mathrm{Pt}\left(\mathrm{C}_{2} \mathrm{H}_{4}\right)_{2}\left(\mathrm{PPh}_{3}\right)\right]$ & & 24.6 & 3426 & & & & & & & & & 2.82 & 57.8 & 42.3 & 146 & & \\
\hline$\left[\mathrm{Pt}\left(\mathrm{C}_{2} \mathrm{H}_{4}\right)_{2}\left(\mathrm{PCy}_{3}\right)\right]$ & & 29.2 & 3296 & & & & & & & & & 2.72 & 56.7 & 36.9 & 146 & & \\
\hline
\end{tabular}

${ }^{a} \delta$ values are given in ppm and $J$ values in $\mathrm{Hz}$. All spectra were measured in $\mathrm{C}_{6} \mathrm{D}_{6}$ at room temperature with $40 \mathrm{mg} / \mathrm{mL}$ sample. ${ }^{b}$ NMR data could not be obtained. 


\section{Chapter 3}

\section{Phosphine-Thioether and Allyl}

\section{Complexes}

Phosphine-thioether ( $\mathrm{P}-\mathrm{S}) \mathrm{Pt}(0)$ complexes with $\eta^{2}$-methylenecyclopropane and bicyclopropylidene ligands were synthesised by the displacement of the norbornene ligand from $[\mathrm{Pt}(\mathrm{nb})(\mathrm{P}-\mathrm{S})]$. These complexes rearranged to form allyl complexes through metallation of the $\mathrm{P}-\mathrm{S}$ backbone. Analogous allyl complexes were also synthesised by the protonation of diphosphine MCP and BCP complexes.

\section{$3.1 \quad[\mathrm{Pt}(\mathrm{L})(\mathrm{P}-\mathrm{S})]$ Complexes}

The novel complex $[\mathrm{Pt}(\mathrm{nb})(\mathrm{P}-\mathrm{S})] \quad\left(\mathrm{nb}=\right.$ norbornene, $\mathrm{P}-\mathrm{S}={ }^{t} \mathrm{Bu}_{2} \mathrm{PCH}_{2}(o-$ $\left.\left.\mathrm{C}_{6} \mathrm{H}_{4}\right) \mathrm{CH}_{2} \mathrm{~S}^{t} \mathrm{Bu}\right),{ }^{123}$ was used as a precursor complex because the $\mathrm{P}-\mathrm{S}$ ligand is an analogue of 1,2-bis[(di-tert-butylphosphino)methyl]benzene (dbpx). Dbpx is used in a number of catalytic systems, including the commercial synthesis of methyl methacrylate. ${ }^{124-128}$ The replacement of one of the phosphine groups with a thioether has the potential to affect the reactivity of complexes in catalysis, particularly as the sulfur is potentially hemilabile. ${ }^{129-132}$ The synthesis of BCP and MCP complexes was undertaken to give insight into the effect of the different donor atoms, as well as to compare the $\mathrm{P}-\mathrm{S}$ ligand to dbpx (see Section 2.1 for dbpx complexes).

$[\mathrm{Pt}(\mathrm{BCP})(\mathrm{P}-\mathrm{S})](8)$ was synthesised by the addition of a stoichiometric amount 
of $\mathrm{BCP}$ to $[\mathrm{Pt}(\mathrm{nb})(\mathrm{P}-\mathrm{S})]$ (Scheme 3.1). The formation of 8 was complete after one hour at room temperature. In the analogous reaction with MCP, two isomers of $[\mathrm{Pt}(\mathrm{MCP})(\mathrm{P}-\mathrm{S})]$ formed over an hour at room temperature. In this case, two isomers were formed. The major isomer $(\mathbf{9 a})$, which formed in a 62:38 ratio relative to the minor isomer, had the cyclopropyl ring trans to the sulfur, while the minor isomer $(\mathbf{9 b})$ had the cyclopropyl ring trans to the phosphorus (Scheme 3.2). When one equivalent of MCP was added to $[\mathrm{Pt}(\mathrm{nb})(\mathrm{P}-\mathrm{S})], \mathbf{9}$ formed in only $80 \%$ yield by ${ }^{31} \mathrm{P}\left\{{ }^{1} \mathrm{H}\right\} \mathrm{NMR}$. However, the $[\mathrm{Pt}(\mathrm{nb})(\mathrm{P}-\mathrm{S})]$ continued to react slowly, until it had reacted completely (see Section 3.2.1). When a large excess of MCP was used, all of the nb complex reacted immediately, and $\mathbf{9 a}, \mathbf{9 b}$ as well as a new complex $\mathbf{1 0}$ formed, initially in a 40:24:36 ratio. This new complex (10) was determined to be $\left[\mathrm{Pt}(\mathrm{MCP})_{2}(\mathrm{P}-\mathrm{S})\right]$ (Scheme 3.3).

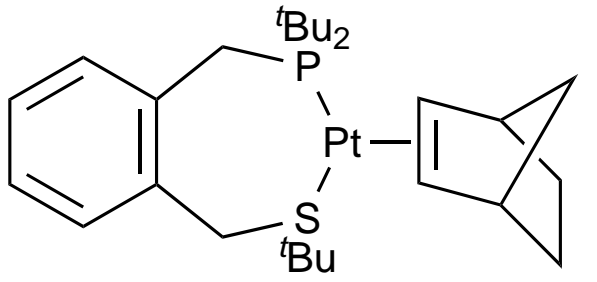

Scheme 3.1. Synthesis of $\left[\mathrm{Pt}(\mathrm{BCP})\left({ }^{t} \mathrm{Bu}_{2} \mathrm{PCH}_{2}\left(o-\mathrm{C}_{6} \mathrm{H}_{4}\right) \mathrm{CH}_{2} \mathrm{~S}^{t} \mathrm{Bu}\right)\right](8)$.
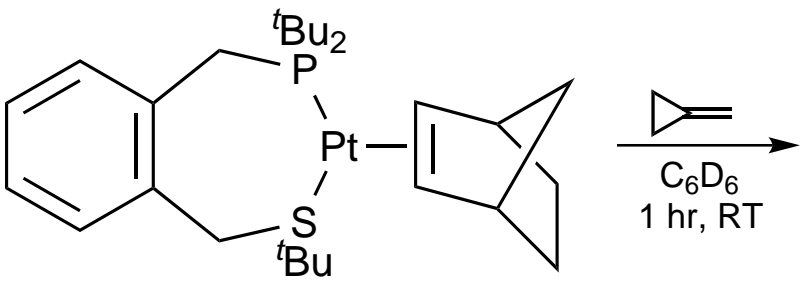

Scheme 3.2. Synthesis of $\left[\mathrm{Pt}(\mathrm{MCP})\left({ }^{t} \mathrm{Bu}_{2} \mathrm{PCH}_{2}\left(o-\mathrm{C}_{6} \mathrm{H}_{4}\right) \mathrm{CH}_{2} \mathrm{~S}^{t} \mathrm{Bu}\right)\right](\mathbf{9})$. 


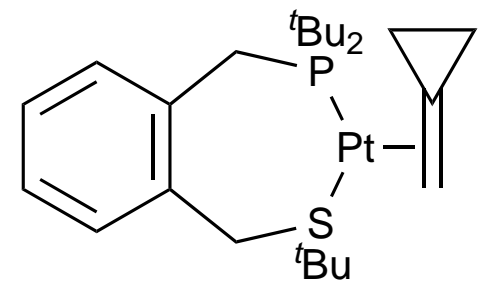

$9 a$

$40 \%$
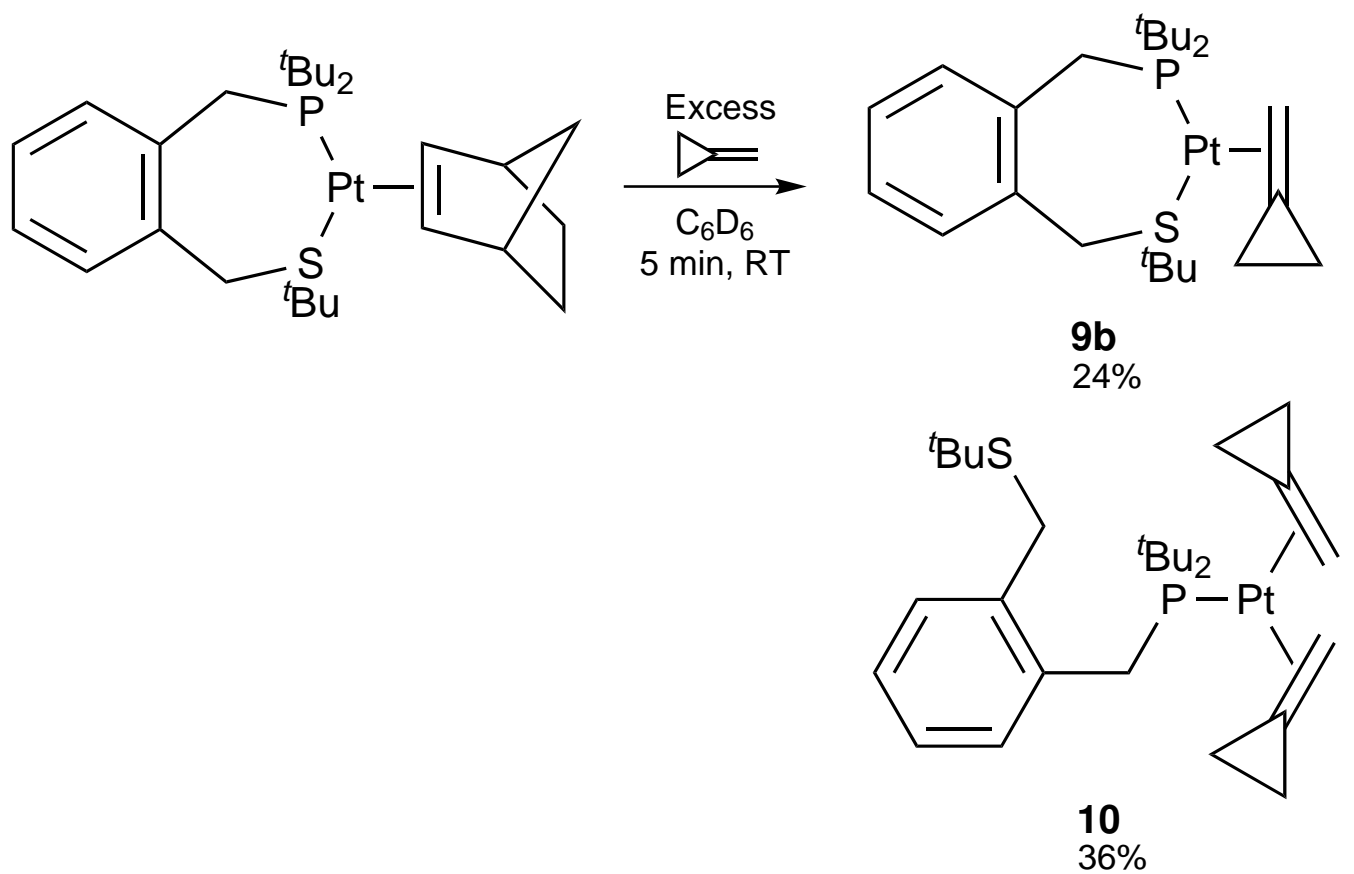

Scheme 3.3. Reaction of $\left[\mathrm{Pt}(\mathrm{nb})\left({ }^{t} \mathrm{Bu}_{2} \mathrm{PCH}_{2}\left(o-\mathrm{C}_{6} \mathrm{H}_{4}\right) \mathrm{CH}_{2} \mathrm{~S}{ }^{t} \mathrm{Bu}\right)\right]$ with an excess of $\mathrm{MCP}$.

\subsubsection{NMR Characterisation}

The $\eta^{2}$-BCP complex 8 formed from $[\mathrm{Pt}(\mathrm{nb})(\mathrm{P}-\mathrm{S})]$ had the highest ${ }^{1} J_{\mathrm{Pt}-\mathrm{P}}$ coupling constant of the BCP complexes synthesised in this study by a significant margin (3383 compared to $2983 \mathrm{~Hz}$ for $[\mathrm{Pt}(\mathrm{BCP})(\mathrm{dbpx})](\mathbf{1 d}))$; this was due to the nature of the $\mathrm{P}-\mathrm{S}$ ligand, rather than the BCP ligand (Table 2.2). The nb starting material had a significantly higher ${ }^{1} J_{\mathrm{Pt}-\mathrm{P}}$ coupling $(3868 \mathrm{~Hz})$ than both the ethene precursors used in Section $2.1(\sim 3300 \mathrm{~Hz})$ and $[\mathrm{Pt}(\mathrm{nb})(\mathrm{dbpx})](3331 \mathrm{~Hz}) .{ }^{133}$ The change in ${ }^{1} J_{\mathrm{Pt}-\mathrm{P}}$ upon coordination of $\mathrm{BCP}$ was $485 \mathrm{~Hz}$, similar to the average change of $\sim 450 \mathrm{~Hz}$ for $\mathbf{1}$, and therefore consistent with the formation of a BCP complex.

The two different isomers of $[\mathrm{Pt}(\mathrm{MCP})(\mathrm{P}-\mathrm{S})]$ could be easily distinguished by their 
${ }^{1} J_{\mathrm{Pt}-\mathrm{P}}$ coupling constants. For 9a ${ }^{1} J_{\mathrm{Pt}-\mathrm{P}}$ was $3870 \mathrm{~Hz}$, while for $9 \mathbf{b}^{1} J_{\mathrm{Pt}-\mathrm{P}}$ was $3483 \mathrm{~Hz}$. These coupling constants were both higher than those in $\mathbf{2 d}(3362 \mathrm{~Hz}$ for $\mathrm{P}$ trans to methylene, $3025 \mathrm{~Hz}$ for $\mathrm{P}$ trans to $\left.{ }^{c} \mathrm{Pr}\right)$. However, the relative changes in ${ }^{1} J_{\mathrm{Pt}-\mathrm{P}}$ upon coordination were similar enough to be consistent with the formation of MCP complexes (2 and $385 \mathrm{~Hz}$ for $\mathbf{9}, \sim 70$ and $\sim 425 \mathrm{~Hz}$ for $\mathbf{2}$ ), particularly given that nb complexes tend to have lower ${ }^{1} J_{\mathrm{Pt}-\mathrm{P}}$ than ethene complexes $(3331 \mathrm{~Hz}$ for $[\mathrm{Pt}(\mathrm{nb})(\mathrm{dbpx})]$ vs. $3493 \mathrm{~Hz}$ for $\left.\left[\mathrm{Pt}\left(\mathrm{C}_{2} \mathrm{H}_{4}\right)(\mathrm{dbpx})\right]\right)$. As with 2, the $\mathrm{P}$ trans to the ${ }^{c} \mathrm{Pr}$ carbon had a lower coupling constant due to the higher trans-influence of the $\mathrm{sp}^{2}$ carbon of the cyclopropyl ring.

The ${ }^{13} \mathrm{C}\left\{{ }^{1} \mathrm{H}\right\}$ NMR data for $\mathbf{8}, \mathbf{9 a}$ and $\mathbf{9 b}$ confirmed the formation of $\eta^{2}$-BCP and $\eta^{2}$ MCP complexes. In particular, the values of the ${ }^{1} J_{\mathrm{Pt}-\mathrm{C}}$ coupling constants were consistent with those of $\mathbf{1}$ and $\mathbf{2}$ (Table 2.2). These coupling constants showed the differing transinfluences of the two donor atoms of the $\mathrm{P}-\mathrm{S}$ ligand. For 8 , the carbon atom trans to $\mathrm{P}$ had a ${ }^{1} J_{\mathrm{Pt}-\mathrm{C}}$ of $579.0 \mathrm{~Hz}$, while that trans to $\mathrm{S}$ had a ${ }^{1} J_{\mathrm{Pt}-\mathrm{C}}$ of $656.6 \mathrm{~Hz}$. In 9, when the methylene was trans to $\mathrm{P},{ }^{1} J_{\mathrm{Pt}-\mathrm{C}}$ was $145.1 \mathrm{~Hz}$, while the ${ }^{1} J_{\mathrm{Pt}-\mathrm{C}}$ trans to $\mathrm{S}$ was $270.6 \mathrm{~Hz}$. The peak due to the ${ }^{c}$ Pr carbon in 9 could not be found due to its low intensity. The higher ${ }^{1} J_{\mathrm{Pt}-\mathrm{C}}$ coupling constant for the carbons trans to $\mathrm{S}$ demonstrates the weaker trans-influence of sulfur relative to phosphorus, resulting in a stronger $\mathrm{Pt}-\mathrm{C}$ bond trans to $\mathrm{S} .{ }^{93}$ This effect was also evident in the ${ }^{1} \mathrm{H}$ NMR spectra in the relative sizes of the ${ }^{2} J_{\mathrm{Pt}-\mathrm{H}}$ coupling constants of the methylene resonances in $\mathbf{9}$. For the methylene trans to the $\mathrm{P},{ }^{2} J_{\mathrm{Pt}-\mathrm{H}}$ was $52.7 \mathrm{~Hz}$, slightly lower than those in $\mathbf{2}(\sim 60 \mathrm{~Hz})$. The ${ }^{2} J_{\mathrm{Pt}-\mathrm{H}}$ of the methylene trans to S was significantly larger at $82.1 \mathrm{~Hz}$.

The NMR data for 10 were consistent with the other bis-MCP complexes $\mathbf{7}$ (Table 2.5). The ${ }^{1} J_{\mathrm{Pt}-\mathrm{P}}$ coupling constant $(2661 \mathrm{~Hz})$ was closer to that of $\left[\mathrm{Pt}(\mathrm{MCP})_{2}\left(\mathrm{PCy}_{3}\right)\right](\mathbf{7} \mathbf{b})$ $(2695 \mathrm{~Hz})$ than $\left[\mathrm{Pt}(\mathrm{MCP})_{2}\left(\mathrm{PPh}_{3}\right)\right](\mathbf{7 a})(2932 \mathrm{~Hz})$. This could be rationalised by the fact that the phosphine of the $\mathrm{P}-\mathrm{S}$ ligand was more similar both sterically and electronically to $\mathrm{PCy}_{3}$ than $\mathrm{PPh}_{3} .{ }^{82}$ For $\mathrm{PCy}_{3}$, the cone angle $\theta$ is $170^{\circ}$ and the Tolman electronic parameter $\nu$ is $2056 \mathrm{~cm}^{-1}$, while for $\mathrm{PPh}_{3}, \theta$ is $145^{\circ}$ and $\nu$ is $2069 \mathrm{~cm}^{-1}$. The cone angle of the $\mathrm{P}-\mathrm{S}$ ligand was calculated to be $180^{\circ}$ when in monodentate coordination through the $\mathrm{P}$ in trans $-\left[\mathrm{PtH}_{2}(\mathrm{P}-\mathrm{S})\right],{ }^{123}$ while the $\mathrm{P}(o \text {-tol })^{t} \mathrm{Bu}_{2}\left(\nu=2060 \mathrm{~cm}^{-1}\right)$ is a 
close analogue for the electronic parameter. These show more similarity to $\mathrm{PCy}_{3}$ than to $\mathrm{PPh}_{3}$.

The ${ }^{13} \mathrm{C}\left\{{ }^{1} \mathrm{H}\right\}$ NMR data for the MCP ligands of $\mathbf{1 0}$ were very similar to those of $\mathbf{7}$, particularly $\mathbf{7 b}$. The double-bond carbons had chemical shifts of 48.7 and $35.7 \mathrm{ppm}$ and ${ }^{1} J_{\mathrm{Pt}-\mathrm{C}}$ of 381.9 and $100.6 \mathrm{~Hz}$ for ${ }^{c} \mathrm{Pr}$ and methylene respectively, compared to $48.5-54.1$ and 32.0-38.9 ppm, and 352.9-385.6 and $100.3 \mathrm{~Hz}$ for 7 . The cyclopropyl methylene carbons appeared at $7.18 \mathrm{ppm}$ with $J_{\mathrm{Pt}-\mathrm{C}}$ coupling of $25.4 \mathrm{~Hz}$, compared to $7.20-7.70 \mathrm{ppm}$ and 24.5-25.0 Hz for 7. The ${ }^{1} \mathrm{H}$ NMR data of 10 was also in agreement with $\mathbf{7}$, with the methylene protons of $\mathbf{1 0}$ appearing at $2.49 \mathrm{ppm}$ with a ${ }^{2} J_{\mathrm{Pt}-\mathrm{H}}$ of $48.1 \mathrm{~Hz}$, compared to 2.27-2.39 ppm and 50.0-55.0 $\mathrm{Hz}$ for 7 .

\subsection{Allyl Complexes}

\subsubsection{Complexes Formed By Hydride Transfer}

Both $[\mathrm{Pt}(\mathrm{BCP})(\mathrm{P}-\mathrm{S})](\mathbf{8})$ and the two isomers of $[\mathrm{Pt}(\mathrm{MCP})(\mathrm{P}-\mathrm{S})](\mathbf{9 a}$ and $\mathbf{9 b})(\mathrm{P}-\mathrm{S}=$ $\left.{ }^{t} \mathrm{Bu}_{2} \mathrm{PCH}_{2}\left(o-\mathrm{C}_{6} \mathrm{H}_{4}\right) \mathrm{CH}_{2} \mathrm{~S}^{t} \mathrm{Bu}\right)$ proved to be unstable in solution. In the case of $\mathbf{8}$, two new complexes (11a and 11b) began to form after one hour. The formation of these complexes was $99 \%$ complete by ${ }^{31} \mathrm{P}$ NMR spectroscopy after eight days at room temperature. For $\mathbf{9 a}$ and $\mathbf{9 b}$, two new complexes (12a and $\mathbf{1 2} \mathbf{b})$ began to form overnight, reaching 91-95\% completion after three weeks. When 1 eq. of $\mathrm{MCP}$ was used, $20 \%[\mathrm{Pt}(\mathrm{nb})(\mathrm{P}-\mathrm{S})]$ was still present initially, as well as $\mathbf{9 a}, \mathbf{9 b}$ and free MCP. The $[\mathrm{Pt}(\mathrm{nb})(\mathrm{P}-\mathrm{S})]$ was the slowest of the three alkene species to react, and the conversion to $\mathbf{1 2 a}$ and $\mathbf{1 2} \mathbf{b}$ reached $95 \%$ completion after 21 days. When $\left[\mathrm{Pt}(\mathrm{MCP})_{2}(\mathrm{P}-\mathrm{S})\right](\mathbf{1 0})$ was present (excess of MCP used), all three MCP complexes rearranged to form $\mathbf{1 2 a}$ and $\mathbf{1 2 b}$. Complex 10 reacted more rapidly than $\mathbf{9 a}$ or $\mathbf{9 b}$ due to the sulfur already being displaced. The ratio of $\mathbf{9}$ to 10 changed from 64:36 to 78:22 after 10 days, all $\mathbf{1 0}$ had reacted after 13 days, and the reaction reached $91 \%$ completion after 21 days at room temperature.

The new complexes $\mathbf{1 1 a}, \mathbf{1 1} \mathbf{b}, \mathbf{1 2 a}$ and $\mathbf{1 2} \mathbf{b}$ were determined to be allyl complexes wherein the alkene ligand had undergone a reaction with a hydride, resulting in proximal 

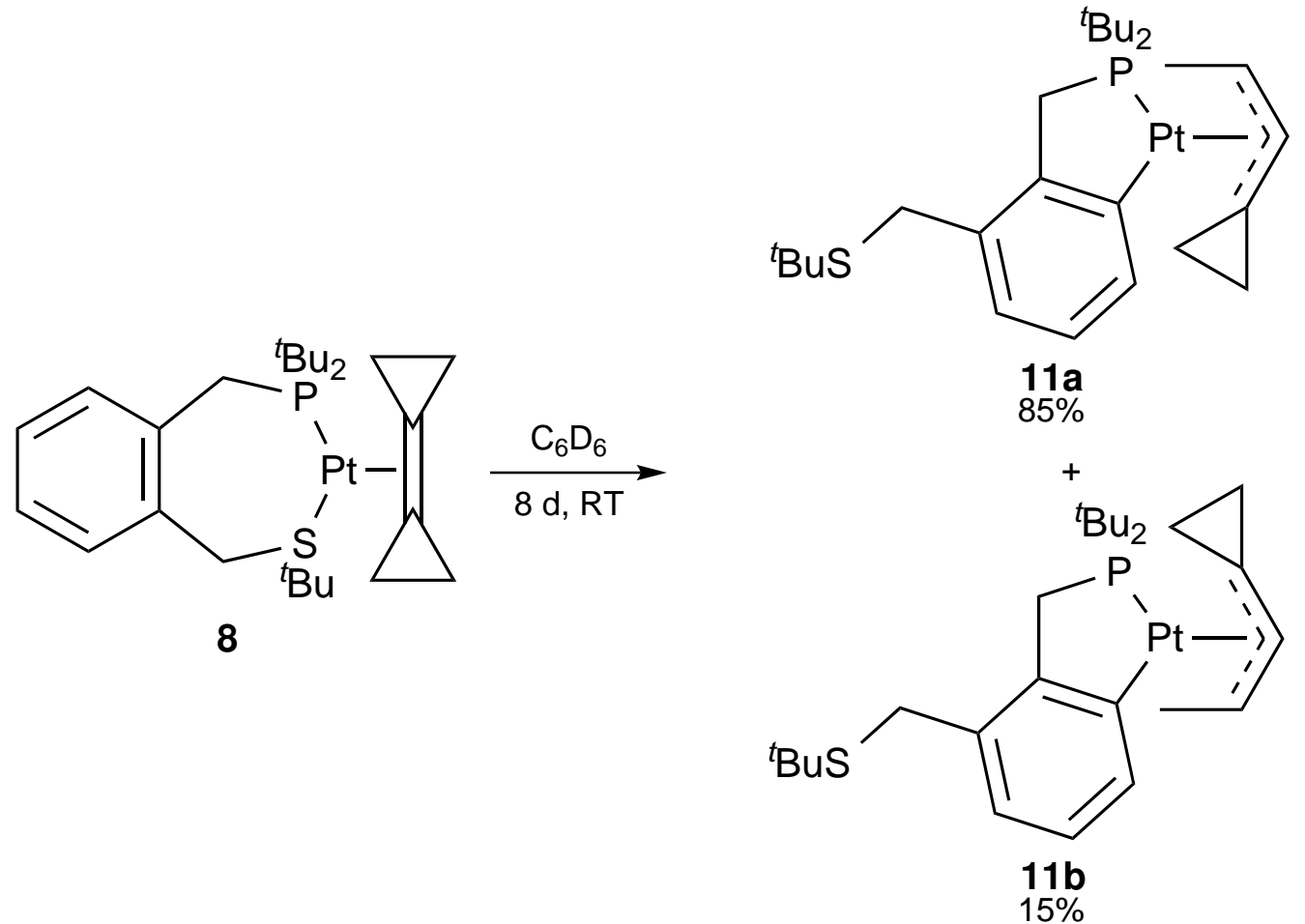

Scheme 3.4. Formation of allyl complexes from $[\mathrm{Pt}(\mathrm{BCP})(\mathrm{P}-\mathrm{S})](\mathbf{8})$.<smiles>C=C1CC1[Pb]1[Sb]Cc2ccccc2C[Pb]1C(=C)C</smiles>

9a<smiles>C=C(C1CC1)P1[Se]Cc2ccccc2C[R15]1(C)C</smiles>

$9 b$<smiles>C=C/C=C\Cc1cccc2c1CP(C(C)(C)C)P2c1ccccc1CSC(C)(C)C</smiles>

$\underset{21 \mathrm{~d}, \mathrm{RT}}{\stackrel{\mathrm{C}_{6} \mathrm{D}_{6}}{\longrightarrow}}$

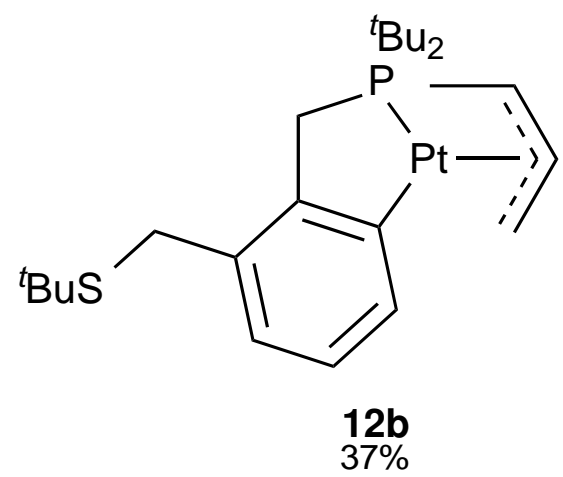

Scheme 3.5. Formation of allyl complexes from $[\mathrm{Pt}(\mathrm{MCP})(\mathrm{P}-\mathrm{S})](\mathbf{9})$. 
bond cleavage of one of the cyclopropyl rings (Schemes 3.4 and 3.5). The hydride was generated by ortho-metallation of the $\mathrm{P}-\mathrm{S}$ ligand, producing a $\mathrm{P}-\mathrm{C}$ chelate ring. The formation of allyl complexes from coordinated MCP has been observed previously in the reaction of MCP with trans- $\left[\mathrm{PtH}\left(\mathrm{NO}_{3}\right)(\mathrm{L})_{2}\right]\left(\mathrm{L}=\mathrm{PEt}_{3}, \mathrm{PMe}_{2} \mathrm{Ph}, \mathrm{PPh}_{3}\right)^{134,135}$ and with $\left[\mathrm{PdCl}_{2}(\mathrm{NCPh})_{2}\right] \cdot{ }^{136}$ The product of the reaction with trans- $\left[\mathrm{PtH}\left(\mathrm{NO}_{3}\right)(\mathrm{L})_{2}\right]$ was dependent on the phosphine ligand. When $\mathrm{L}=\mathrm{PEt}_{3}$ or $\mathrm{PMe}_{2} \mathrm{Ph}$, the product was entirely the 1-methylallyl complex. When $\mathrm{L}=\mathrm{PPh}_{3}$, an approximately 1:1 mixture of the 1-methylallyl and 2-methylallyl complexes was produced. With $\left[\mathrm{PdCl}_{2}(\mathrm{NCPh})_{2}\right]$, the product was the 1-methylallyl complex, with a $\mathrm{Cl}$ at the 2-position. Allyl complexes are also intermediates in several of the transition metal catalysed reactions of both MCP and BCP, most notably in Heck-type reactions (see Schemes 1.6 and 1.21). ${ }^{38,72,74,137,138}$

The proposed mechanism for the formation of the 1-methyl allyl complexes involves the anti-Markovnikov addition of $\mathrm{Pt}-\mathrm{H}$ across the double-bond, with the $\mathrm{H}$ attaching to the ${ }^{c} \operatorname{Pr}$ carbon. This was followed by the cleavage of the proximal ring bond to form an alkyl ligand, $\beta$-hydride elimination, then hydride attack at the methylene end of the coordinated double-bond (Scheme 3.6). This was supported by studies using trans- $\left[\mathrm{PtD}\left(\mathrm{NO}_{3}\right)(\mathrm{L})_{2}\right]$ and the reaction with $\left[\mathrm{PdCl}_{2}(\mathrm{NCPh})_{2}\right]$, with, respectively, the deuterium or the chloride ending up in the 2-position. The proposed mechanism for the formation of the 2-methyl allyl complexes also began with the addition of $\mathrm{Pt}-\mathrm{H}$ across the double-bond, except that in this case the $\mathrm{H}$ attached to the methylene carbon. The cleavage of the ring then occurred at the distal rather than the proximal bond, leading to the direct formation of the 2-methylallyl complex (Scheme 3.6). When trans- $\left[\mathrm{PtD}\left(\mathrm{NO}_{3}\right)\left(\mathrm{PPh}_{3}\right)_{2}\right]$ was used, the deuterium ended up on the methyl carbon in the 2 -substituted product. ${ }^{134}$

The $\mathrm{P}-\mathrm{S}$ complexes in this work formed exclusively 1-methylallyls. Due to the lack of symmetry in both the allyl and the $\mathrm{P}-\mathrm{C}$ ligand, in each case there were two possible isomers. The isomer which had the least substituted carbon trans to the $\mathrm{C}$ of the $\mathrm{P}-\mathrm{C}$ ring formed in the largest amounts $(\mathbf{1 1 a}$ and $\mathbf{1 2 a})$. For $\mathbf{1 1}$, there was a pronounced difference in the proportions of the two isomers, 85:15 11a to 11b. The isomer with the ${ }^{c}$ Pr ring trans to the $\mathrm{C}$ was disfavoured due to the high trans-influences of both the 


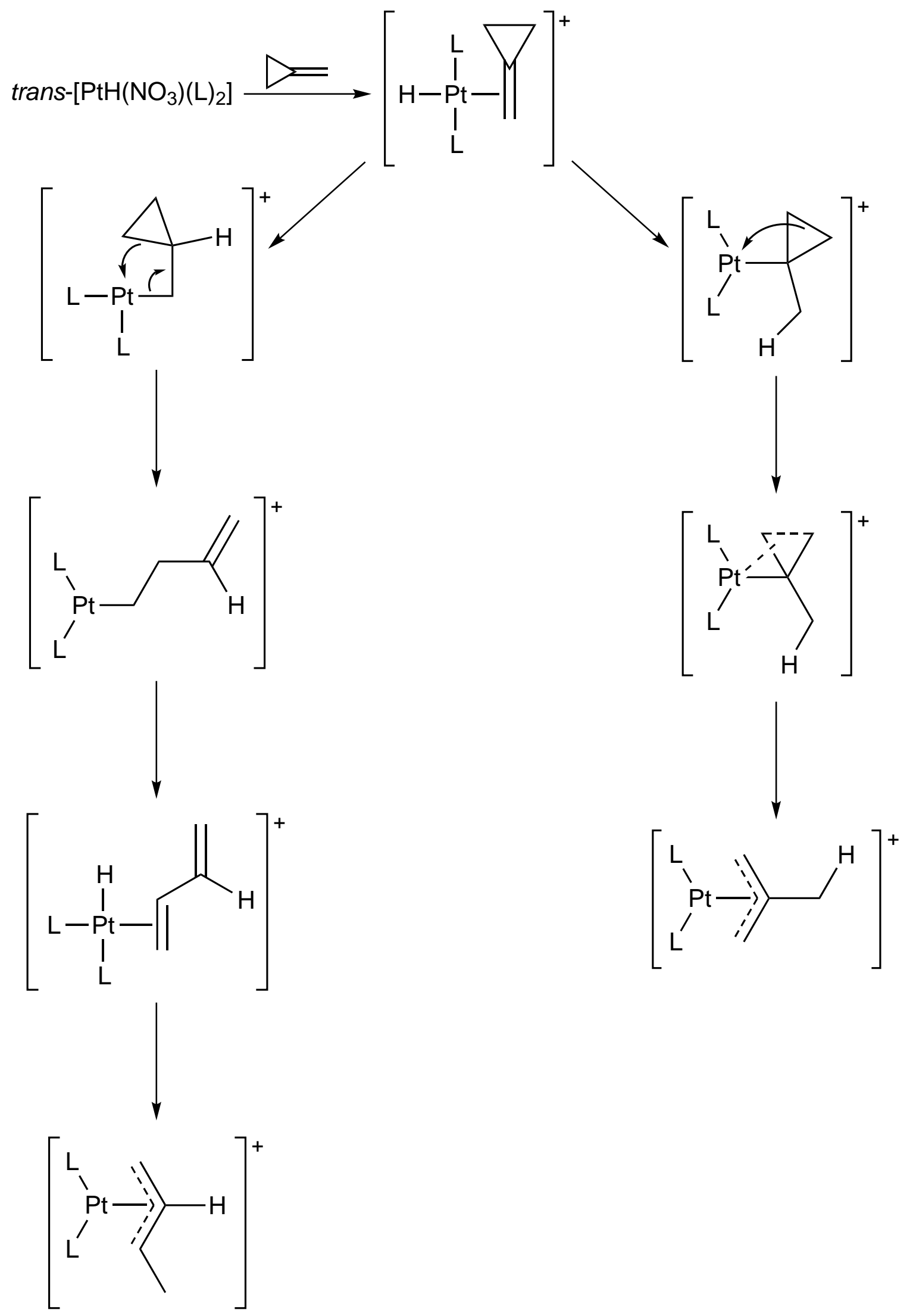

Scheme 3.6. Mechanism for the formation of allyl complexes from MCP. ${ }^{135}$ 
$\sigma$-bonded carbon and the ${ }^{c}$ Pr ring. ${ }^{93,139}$ The difference between the two isomers of $\mathbf{1 2}$ was less significant, 63:37 12a:12b. In this case, the proportions were more equal due to the steric and electronic similarity of the methylene to the CHMe group. ${ }^{140}$

The methyl groups in $\mathbf{1 1}$ and $\mathbf{1 2}$ were determined to be in the anti position based on ${ }^{1} \mathrm{H}$ NMR coupling constants (Section 3.2.1.1). In other systems, anti methyl groups were the kinetic products, while syn methyl groups were the thermodynamically stable isomer (Figure 3.1). ${ }^{141,142}$ No rearrangement to the syn-methyl isomer was observed for 11 and 12, even when the complexes were placed in $d_{6}$-acetone, which was found to facilitate the rearrangment of other allyl systems (Section 3.2.2).

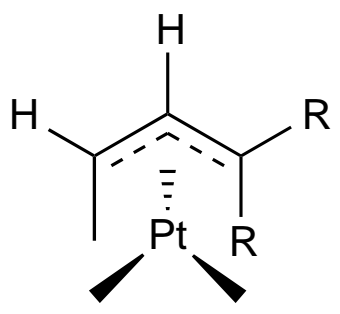

anti

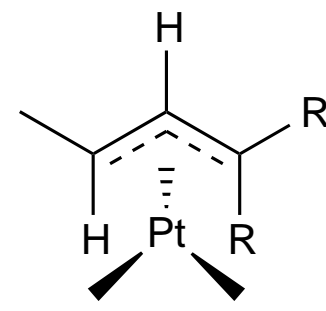

syn

Figure 3.1. Geometry of allyl systems with anti and syn methyl groups.

\subsubsection{NMR Characterisation}

For representative NMR spectra, see Figures A.26-Figure A.35. As with other complexes (see Table 2.2), it was possible to distinguish between the two isomers of $\mathbf{1 1}$ based on their ${ }^{1} J_{\mathrm{Pt}-\mathrm{P}}$ coupling constants (Table 3.1 ). The isomer with the $\mathrm{P}$ trans to the ${ }^{c} \mathrm{Pr}$ ring, 11a, had a ${ }^{1} J_{\mathrm{Pt}-\mathrm{P}}$ of $3141 \mathrm{~Hz}$, while $\mathbf{1 1} \mathbf{b}$, with $\mathrm{P}$ trans to the CHMe, had a ${ }^{1} J_{\mathrm{Pt}-\mathrm{P}}$ of $3893 \mathrm{~Hz}$. The two isomers of 12 had very similar coupling constants; 3560 and $3590 \mathrm{~Hz}$ for $\mathbf{1 2 a}$ and $\mathbf{1 2 b}$ respectively.

The orientation of the allyl relative to the $\mathrm{P}-\mathrm{C}$ chelate ring had an effect on the ${ }^{13} \mathrm{C}\left\{{ }^{1} \mathrm{H}\right\}$ NMR spectra. The most pronounced differences were in the resonances of the carbons of the allylic system (Table 3.2). The allyl carbon trans to the phosphorus donor had ${ }^{1} J_{\mathrm{Pt}-\mathrm{C}}$ and $J_{\mathrm{P}-\mathrm{C}}$ couplings typical of other alkene/allyl complexes (see Table 2.2). ${ }^{143}$ In $11 \mathbf{a}$, the quaternary ${ }^{c} \mathrm{Pr}$ carbon had a large trans $J_{\mathrm{P}-\mathrm{C}}$ coupling constant $(76.3 \mathrm{~Hz})$, 
Table 3.1. Selected ${ }^{31} \mathrm{P}\left\{{ }^{1} \mathrm{H}\right\}$ and ${ }^{1} \mathrm{H}$ NMR Data of Allyl Complexes. ${ }^{a}$

\begin{tabular}{|c|c|c|c|c|c|c|c|c|c|c|c|}
\hline \multirow{2}{*}{ Compound } & & \multirow{2}{*}{$\delta_{\mathrm{P}}$} & \multirow{2}{*}{${ }^{1} J_{\mathrm{Pt}-\mathrm{P}}$} & \multirow{2}{*}{$\frac{{ }^{c} \mathrm{Pr}}{\delta_{\mathrm{H}}}$} & \multicolumn{2}{|l|}{$\mathrm{CH}_{2}$} & \multicolumn{2}{|l|}{$\mathrm{CH}$} & \multicolumn{2}{|c|}{$\mathrm{CHMe}$} & \multirow{2}{*}{$\frac{\mathrm{CH}_{3}}{\delta_{\mathrm{H}}}$} \\
\hline & & & & & $\delta_{\mathrm{H}}$ & ${ }^{2} J_{\mathrm{Pt}-\mathrm{H}}$ & $\delta_{\mathrm{H}}$ & ${ }^{2} J_{\mathrm{Pt}-\mathrm{H}}$ & $\delta_{\mathrm{H}}$ & ${ }^{2} J_{\mathrm{Pt}-\mathrm{H}}$ & \\
\hline$\left[\mathrm{Pt}\left(\eta^{3}-\mathrm{C}\left(\mathrm{CH}_{2}\right)_{2} \mathrm{CHCHMe}\right)(\mathrm{P}-\mathrm{C})\right]^{b}$ & $11 a$ & 82.0 & 3141 & $\begin{array}{l}1.56 \\
1.26\end{array}$ & & & 4.54 & 39.0 & 4.85 & 13.0 & 1.63 \\
\hline$\left[\mathrm{Pt}\left(\eta^{3}-\mathrm{C}\left(\mathrm{CH}_{2}\right)_{2} \mathrm{CHCHMe}\right)(\mathrm{P}-\mathrm{C})\right]^{b}$ & $11 b$ & 80.1 & 3893 & $\begin{array}{r}1.38 \\
1.26 \\
1.1\end{array}$ & & & 4.82 & 41.6 & 4.57 & $c$ & 1.65 \\
\hline$\left[\mathrm{Pt}\left(\eta^{3}-\mathrm{CH}_{2} \mathrm{CHCHMe}\right)(\mathrm{P}-\mathrm{C})\right]^{b}$ & $12 a$ & 84.1 & 3560 & & $\begin{array}{l}3.57 \\
2.27\end{array}$ & $\begin{array}{r}(\text { syn }) \\
38.1(\text { anti })\end{array}$ & $4.61(13.3,7.7)$ & 41.9 & 4.34 & & 1.39 \\
\hline$\left[\mathrm{Pt}\left(\eta^{3}-\mathrm{CH}_{2} \mathrm{CHCHMe}\right)(\mathrm{P}-\mathrm{C})\right]^{b}$ & $12 b$ & 82.0 & 3590 & & $\begin{array}{r}3.6 \\
2.92\end{array}$ & $\begin{array}{r}(\text { syn }) \\
(\text { anti) }\end{array}$ & $4.61(13.3,7.7)$ & 41.9 & 4.39 & & 1.29 \\
\hline$\left[\mathrm{Pt}\left(\eta^{3}-\mathrm{C}\left(\mathrm{CH}_{2}\right)_{2} \mathrm{CHCHMe}\right)(\mathrm{dppp})\right]^{+}$ & $13 \mathbf{a}$ & $\begin{array}{r}1.4 \\
-2.8\end{array}$ & $\begin{array}{l}3852 \\
3259\end{array}$ & $\begin{array}{l}1.21 \\
0.86 \\
0.37\end{array}$ & & & $5.40(8.2)$ & 54.0 & 4.93 & & 0.88 \\
\hline$\left[\mathrm{Pt}\left(\eta^{3}-\mathrm{C}\left(\mathrm{CH}_{2}\right)_{2} \mathrm{CHCHMe}\right)(\mathrm{dppp})\right]^{+}$ & $13 b$ & $\begin{array}{r}1.0 \\
-0.4\end{array}$ & $\begin{array}{l}4042 \\
3267\end{array}$ & $\begin{array}{l}1.22 \\
0.65 \\
0.39 \\
0.14\end{array}$ & & & $5.39(12.5)$ & 51.0 & 4.14 & & 1.38 \\
\hline$\left[\mathrm{Pt}\left(\eta^{3}-\mathrm{CH}_{2} \mathrm{CHCHMe}\right)(\mathrm{dppp})\right]^{+}$ & $16 a$ & $\begin{array}{l}-1.2 \\
-1.2\end{array}$ & $\begin{array}{l}3569 \\
3625\end{array}$ & & $\begin{array}{l}3.94 \\
2.99\end{array}$ & $\begin{array}{r}(\text { syn }) \\
(\text { anti) }\end{array}$ & $5.32(14.1,7.6)$ & 53.4 & 4.62 & & 0.80 \\
\hline$\left[\mathrm{Pt}\left(\eta^{3}-\mathrm{CH}_{2} \mathrm{CHCHMe}\right)(\mathrm{dppp})\right]^{+}$ & $16 \mathrm{~b}$ & $\begin{array}{r}1.4 \\
-1.8\end{array}$ & $\begin{array}{l}3670 \\
3693\end{array}$ & & $\begin{array}{r}3.59 \\
2.54(12.7,10.0,2.7)\end{array}$ & $\begin{array}{r}(\text { syn }) \\
(\text { anti) }\end{array}$ & $5.23(12.7,7.3)$ & 51.5 & 3.68 & & 1.29 \\
\hline$\left[\mathrm{Pt}\left(\eta^{3}-\mathrm{CH}_{2} \mathrm{CHCHMe}\right)(\mathrm{dbpx})\right]^{+}$ & $18 \mathrm{~b}$ & 36.9 & 3844 & & $\begin{array}{r}4.53 \\
2.86(11.1,10.0,2.2)\end{array}$ & $\begin{array}{r}(\text { syn }) \\
34.4(\text { anti })\end{array}$ & $5.04(12.2,7.5)$ & 51.9 & 6.28 & & $c$ \\
\hline$\left[\mathrm{Pt}\left(\eta^{3}-\mathrm{CH}_{2} \mathrm{C}^{c} \mathrm{PrCH}_{2}\right)(\mathrm{dbpx})\right]^{+}$ & 17 & $\begin{array}{l}33.9 \\
32.1\end{array}$ & $\begin{array}{l}3632 \\
3647\end{array}$ & $\begin{array}{l}0.93 \\
0.87\end{array}$ & $\begin{array}{r}4.81 \\
2.74(8.1)\end{array}$ & $\begin{array}{r}(\text { syn }) \\
41.3(\text { anti })\end{array}$ & & & & & \\
\hline$\left[\mathrm{Pt}\left(\eta^{3}-\mathrm{CH}_{2} \mathrm{CMeCH}_{2}\right)(\mathrm{dppp})\right]^{+}$ & 15 & 0.1 & 3521 & & $\begin{array}{r}3.56 \\
2.95(8.5)\end{array}$ & $\begin{array}{r}(\text { syn }) \\
32.0(\text { anti })\end{array}$ & & & & & 1.96 \\
\hline$\left[\mathrm{Pt}\left(\eta^{3}-\mathrm{CH}_{2} \mathrm{CMeCH}_{2}\right)(\mathrm{dbpx})\right]^{+}$ & $18 \mathrm{a}$ & $\begin{array}{l}33.9 \\
32.4\end{array}$ & $\begin{array}{l}3572 \\
3641\end{array}$ & & $\begin{array}{r}4.88 \\
2.80(8.4)\end{array}$ & $\begin{array}{r}(\text { syn }) \\
39.4(\text { anti })\end{array}$ & & & & & $c$ \\
\hline
\end{tabular}

${ }^{a} \delta$ values are given in ppm and $J$ values in $\mathrm{Hz}$. Values in parentheses are $J_{\mathrm{H}-\mathrm{H}}$ couplings. All spectra were measured in $d_{6}$-acetone at room temperature with $40 \mathrm{mg} / \mathrm{mL}$ sample unless noted. ${ }^{b}$ Spectra collected in $\mathrm{C}_{6} \mathrm{D}_{6} .{ }^{c}$ NMR data could not be obtained. 
Table 3.2. Selected ${ }^{13} \mathrm{C}\left\{{ }^{1} \mathrm{H}\right\}$ NMR Data of Allyl Complexes. ${ }^{a}$

\begin{tabular}{|c|c|c|c|c|c|c|c|c|c|c|c|c|c|}
\hline \multicolumn{2}{|l|}{ Compound } & \multicolumn{2}{|c|}{$\mathrm{Pt}-\mathrm{C}$} & \multicolumn{2}{|c|}{${ }^{c} \mathrm{Pr}$} & \multicolumn{2}{|l|}{$\mathrm{CR}_{2}$} & \multicolumn{2}{|l|}{$\mathbf{C H}$} & \multicolumn{2}{|c|}{ CHMe } & \multicolumn{2}{|l|}{$\mathrm{CH}_{3}$} \\
\hline & & $\delta_{\mathrm{C}}$ & ${ }^{1} J_{\mathrm{Pt}-\mathrm{C}}$ & $\delta_{\mathrm{C}}$ & $J_{\mathrm{Pt}-\mathrm{C}}$ & $\delta_{\mathrm{C}}$ & ${ }^{1} J_{\mathrm{Pt}-\mathrm{C}}$ & $\delta_{\mathrm{C}}$ & ${ }^{1} J_{\mathrm{Pt}-\mathrm{C}}$ & $\delta_{\mathrm{C}}$ & ${ }^{1} J_{\mathrm{Pt}-\mathrm{C}}$ & $\delta_{\mathrm{C}}$ & ${ }^{2} J_{\mathrm{Pt}-\mathrm{C}}$ \\
\hline$\left[\mathrm{Pt}\left(\eta^{3}-\mathrm{C}\left(\mathrm{CH}_{2}\right)_{2} \mathrm{CHCHMe}\right)(\mathrm{P}-\mathrm{C})\right]^{b}$ & $11 \mathrm{a}$ & $152.9(2.4)$ & 1192.1 & $\begin{array}{r}7.7(4.3) \\
3.7\end{array}$ & $\begin{array}{l}25.9 \\
18.0\end{array}$ & $53.5(76.3)$ & 447.4 & $98.6(4.3)$ & 21.1 & 74.1 & 32.6 & 17.3 & 27.9 \\
\hline$\left[\mathrm{Pt}\left(\eta^{3}-\mathrm{C}\left(\mathrm{CH}_{2}\right)_{2} \mathrm{CHCHMe}\right)(\mathrm{P}-\mathrm{C})\right]^{b}$ & $11 b$ & $159.9(2.8)$ & 1043.3 & $\begin{array}{l}9.0 \\
6.6\end{array}$ & 15.0 & 48.1 & 202.3 & 102.8 & 7.18 & $84.3(30.1)$ & 130.6 & $16.8(4.6)$ & 41.6 \\
\hline$\left[\mathrm{Pt}\left(\eta^{3}-\mathrm{CH}_{2} \mathrm{CHCHMe}\right)(\mathrm{P}-\mathrm{C})\right]^{b}$ & $12 \mathrm{a}$ & $158.4(2.3)$ & 1142.7 & & & 42.5 & 52.0 & 108.2 & 8.47 & $73.4(37.0)$ & 173.4 & $15.3(5.2)$ & 39.9 \\
\hline$\left[\mathrm{Pt}\left(\eta^{3}-\mathrm{C}\left(\mathrm{CH}_{2}\right)_{2} \mathrm{CHCHMe}\right)(\mathrm{dppp})\right]^{+}$ & $13 \mathbf{a}$ & & & $\begin{array}{r}8.2(4.0) \\
4.4\end{array}$ & $\begin{array}{l}16.8 \\
15.6\end{array}$ & $66.7(54.4)$ & 252.6 & $6104.2(3.4,1.7)$ & & $91.2(22.6)$ & 65.9 & $15.5(4.1)$ & 33.2 \\
\hline$\left[\mathrm{Pt}\left(\eta^{3}-\mathrm{C}\left(\mathrm{CH}_{2}\right)_{2} \mathrm{CHCHMe}\right)(\mathrm{dppp})\right]^{+}$ & $13 b$ & & & $\begin{array}{r}8.6(4.0) \\
5.7\end{array}$ & 20.8 & $67.1(53.2)$ & 269.3 & $111.6(4.1,1.8)$ & & $92.6(21.9)$ & 29.0 & $15.9(2.4)$ & \\
\hline$\left[\mathrm{Pt}\left(\eta^{3}-\mathrm{CH}_{2} \mathrm{CHCHMe}\right)(\mathrm{dppp})\right]^{+}$ & $16 a$ & & & & & 60.2 & 88.0 & $113.9(3.2)$ & 16.5 & 83.4 & 83.7 & $14.1(2.8,1.1)$ & 23.1 \\
\hline$\left[\mathrm{Pt}\left(\eta^{3}-\mathrm{CH}_{2} \mathrm{CHCHMe}\right)(\mathrm{dppp})\right]^{+}$ & $16 \mathrm{~b}$ & & & & & 62.3 & 100.1 & $119.3(3.5)$ & 26.6 & 84.3 & 54.4 & $15.9(2.9)$ & 3.8 \\
\hline$\left[\mathrm{Pt}\left(\eta^{3}-\mathrm{CH}_{2} \mathrm{CHCHMe}\right)(\mathrm{dbpx})\right]^{+}$ & $18 \mathrm{~b}$ & & & & & 51.7 & 106.9 & 106.8 & & 84.6 & 63.7 & 16.5 & 14.5 \\
\hline$\left[\mathrm{Pt}\left(\eta^{3}-\mathrm{CH}_{2} \mathrm{C}^{c} \mathrm{PrCH}_{2}\right)(\mathrm{dbpx})\right]^{+}$ & 17 & & & 8.9 & & $59.1(30.2,-2.1)$ & 79.8 & 126.4 & 44.5 & & & & \\
\hline$\left[\mathrm{Pt}\left(\eta^{3}-\mathrm{CH}_{2} \mathrm{CMeCH}_{2}\right)(\mathrm{dppp})\right]^{+}$ & 15 & & & & & 66.4 & 85.0 & $135.9(3.2)$ & 24.8 & & & 24.8 & 30.0 \\
\hline
\end{tabular}

${ }^{a} \delta$ values are given in ppm and $J$ values in $\mathrm{Hz}$. Values in parenthesis are $J_{\mathrm{P}-\mathrm{C}}$. All spectra were measured in $d_{6}$-acetone at room temperature with $40 \mathrm{mg} / \mathrm{mL}$ sample unless noted. ${ }^{b}$ Spectra collected in $\mathrm{C}_{6} \mathrm{D}_{6}$. 
and a ${ }^{1} J_{\mathrm{Pt}-\mathrm{C}}$ of $447.4 \mathrm{~Hz}$, similar to those in the alkene complexes $\mathbf{1}$ and $\mathbf{2}$. For the allyl carbon attached to the methyl, when trans to the $\mathrm{P}$ in $\mathbf{1 1} \mathbf{b}$ and $\mathbf{1 2 a}{ }^{1} J_{\mathrm{Pt}-\mathrm{C}}$ was 130.6 and $173.4 \mathrm{~Hz}$, while $J_{\mathrm{P}-\mathrm{C}}$ was 30.1 and $37.0 \mathrm{~Hz}$ respectively. The methylene in $\mathbf{1 2} \mathbf{b}$ had a ${ }^{1} J_{\mathrm{Pt}-\mathrm{C}}$ of $182.6 \mathrm{~Hz}$ and a $J_{\mathrm{P}-\mathrm{C}}$ of $40.4 \mathrm{~Hz}$.

The ${ }^{1} J_{\mathrm{Pt}-\mathrm{C}}$ coupling constants for the allyl carbons dramatically decreased when trans to the carbon donor. For $\mathbf{1 1 b}$, the ${ }^{1} J_{\mathrm{Pt}-\mathrm{C}}$ coupling of the quaternary ${ }^{c} \mathrm{Pr}$ carbon was less than half that of $\mathbf{1 1 a}$ at $202.3 \mathrm{~Hz}$. The carbons attached to the methyls in $\mathbf{1 1 a}$ and $\mathbf{1 2} \mathbf{b}$ had couplings of 32.6 and $48.6 \mathrm{~Hz}$ respectively, 98-125 Hz less than their counterparts. In $\mathbf{1 2 a}$, the methylene carbon also had a significant decrease in ${ }^{1} J_{\mathrm{Pt}-\mathrm{C}}$ from $\mathbf{1 2} \mathbf{b}$, decreasing by $130 \mathrm{~Hz}$ to become $52.0 \mathrm{~Hz}$. The effect on the central carbon of the allyl was less significant, but was still evident. In $\mathbf{1 1} \mathbf{b}$ and $\mathbf{1 2 a}$, which had the methyls trans to the phosphorus, ${ }^{1} J_{\mathrm{Pt}-\mathrm{C}}$ was 7.1 and $8.4 \mathrm{~Hz}$ respectively, while in $11 \mathrm{a}$ and $12 \mathrm{~b}{ }^{1} J_{\mathrm{Pt}-\mathrm{C}}$ was 21.1 and $11.0 \mathrm{~Hz}$ respectively. There was also a decrease in the ${ }^{2} J_{\mathrm{Pt}-\mathrm{C}}$ coupling constants of the methyl carbons when they were trans to the C, from 41.6 and $39.9 \mathrm{~Hz}$ in $\mathbf{1 1 b}$ and $\mathbf{1 2 a}$ (trans $\mathrm{P}$ ) to 27.9 and 26.6 in $\mathbf{1 1 a}$ and $\mathbf{1 2 b}$ (trans $\mathrm{C}$ ). The low $J_{\mathrm{Pt}-\mathrm{C}}$ coupling constants for the carbons trans to the $\mathrm{C}$ of the $\mathrm{P}-\mathrm{C}$ chelate was due to the high transinfluence of the $\sigma$-bonded carbon. ${ }^{93}$ This lowering of ${ }^{1} J_{\mathrm{Pt}-\mathrm{C}}$ trans to a $\sigma$-bonded carbon has been reported for a range of $\eta^{3}$-allyl complexes, both with $\mathrm{P}-\mathrm{C}$ chelate rings and for $\left[\mathrm{Pt}\left(\eta^{3}-\mathrm{C}_{3} \mathrm{H}_{5}\right) \mathrm{Me}\left(\mathrm{PPh}_{3}\right)\right]$ complexes. ${ }^{144}$

The orientation of the allyl also had an effect on the chemical shift of the carbon resonances. There was some variation in the absolute chemical shift; when a particular carbon environment was trans to the phosphorus it had a shift 10.2-10.9 ppm higher than when it was trans to the carbon. The exceptions to this were the central allyl carbons, which did not sit trans to either donor and had differences of $0.5-4.2 \mathrm{ppm}$, and the ${ }^{c} \operatorname{Pr}$ $\mathrm{CH}_{2}$ carbons, which again did not sit directly trans, only differed by $5.5 \mathrm{ppm}$.

The metallation of the aromatic ring was evident in the high chemical shift $(152.9-159.9 \mathrm{ppm})$ and high ${ }^{1} J_{\mathrm{Pt}-\mathrm{C}}$ coupling constant $(1043.3-1192.1 \mathrm{~Hz})$ of one of the ring carbon atoms. The complex with the ${ }^{c} \mathrm{Pr}$ ring trans to the carbon, $\mathbf{1 1} \mathbf{b}$, had a ${ }^{1} J_{\mathrm{Pt}-\mathrm{C}}$ $100 \mathrm{~Hz}$ lower than the other complexes, signifying that the strong $\mathrm{Pt}-{ }^{c} \mathrm{Pr}$ bond caused 
a weakening of the $\mathrm{Pt}-\mathrm{C} \sigma$-bond. The shifts of both of the $\mathrm{S}-{ }^{t} \mathrm{Bu}$ carbons were very similar to those of the free ligand, and showed no platinum or phosphorus coupling, unlike in 8 and $\mathbf{9}$. This was consistent with the $\mathrm{S}$ no longer being coordinated.

The ${ }^{1} \mathrm{H}$ NMR spectra of $\mathbf{1 1 a} \mathbf{-} \mathbf{1 2} \mathbf{b}$ were typical of allyl complexes. ${ }^{141,142,144,145}$ It was possible to assign the syn and anti protons of the methylenes of $\mathbf{1 2 a}$ and $\mathbf{1 2} \mathbf{b}$ both from the chemical shift and from the $J_{\mathrm{H}-\mathrm{H}}$ couplings. The anti protons had lower chemical shifts (2.27 and $2.97 \mathrm{ppm})$ than the syn $(3.57$ and $3.6 \mathrm{ppm})$, while the $J_{\mathrm{H}-\mathrm{H}}$ coupling of the anti protons to the central allyl protons was higher $(\sim 13$ vs. $\sim 8 \mathrm{~Hz})$. It was also possible to determine the geometry at the CHMe carbon of $\mathbf{1 1}$ and 12 using $J_{\mathrm{H}-\mathrm{H}}$ couplings. The peak belonging to the central allyl proton in $\mathbf{1 1 a}$ was a doublet with coupling of $8.0 \mathrm{~Hz}$, while that of $\mathbf{1 1 b}$ was a doublet with coupling of $7.5 \mathrm{~Hz}$, corresponding to couplings to a proton in the syn position. The methyl groups were therefore in the anti position. In both 12a and $\mathbf{1 2 b}$, the central allyl proton was a doublet of triplets, with a doublet coupling of 13.3 $\mathrm{Hz}$ and a triplet coupling of $7.7 \mathrm{~Hz}$, indicating one proton in the anti position (from the $\mathrm{CH}_{2}$ ) and two in the syn position (from the $\mathrm{CH}_{2}$ and the CHMe). Again, the methyl groups were therefore in the anti position.

\subsubsection{Complexes Formed By Protonation}

The reactivity of a selection of $\eta^{2}$-alkene $\mathrm{P}-\mathrm{P}$ complexes $[\mathrm{Pt}(\mathrm{BCP})(\mathrm{P}-\mathrm{P})](\mathrm{P}-\mathrm{P}=$ $\operatorname{dppp}(\mathbf{1 a}), \operatorname{dbpx}(\mathbf{1 d}))$ and $[\mathrm{Pt}(\mathrm{MCP})(\mathrm{P}-\mathrm{P})](\mathrm{P}-\mathrm{P}=\operatorname{dppp}(\mathbf{2 a}), \operatorname{dbpx}(\mathbf{2 d}))$ with acids was explored. The acid predominantely used for these studies was $\mathrm{H}_{2} \mathrm{C}\left(\mathrm{SO}_{2} \mathrm{CF}_{3}\right)_{2}$ $(\mathrm{p} K \mathrm{a}=2.4$ in DMSO $) .{ }^{146}$ The reactions with dppp complexes were also performed using $\mathrm{HCPh}\left(\mathrm{SO}_{2} \mathrm{CF}_{3}\right)_{2}(\mathrm{pKa}=2.0 \text { in } \mathrm{DMSO})^{146}$ and $\mathrm{HBF}_{4}(\mathrm{pKa}=1.2$ in 1,2dichloroethane), ${ }^{147}$ with no difference in product distributions observed.

When $\mathrm{H}_{2} \mathrm{C}\left(\mathrm{SO}_{2} \mathrm{CF}_{3}\right)_{2}$ was added to a suspension of $\mathbf{1 a}$ in $d_{6}$-acetone, a reaction occurred immediately, resulting in the formation of two species in a approx. 75:25 ratio. The major product 13a proved to be a 1-methylallyl complex similar to $\mathbf{1 1}$, with the methyl in the anti position, formed by cleavage of the proximal ring bond, while the structure of the minor product $(\mathbf{1 4 a})$ could not be assigned. Overnight, 13a began to 
convert into the syn-methyl complex, 13b. The conversion continued slowly, eventually stabilising at 27:73 anti:syn after two months at room temperature.

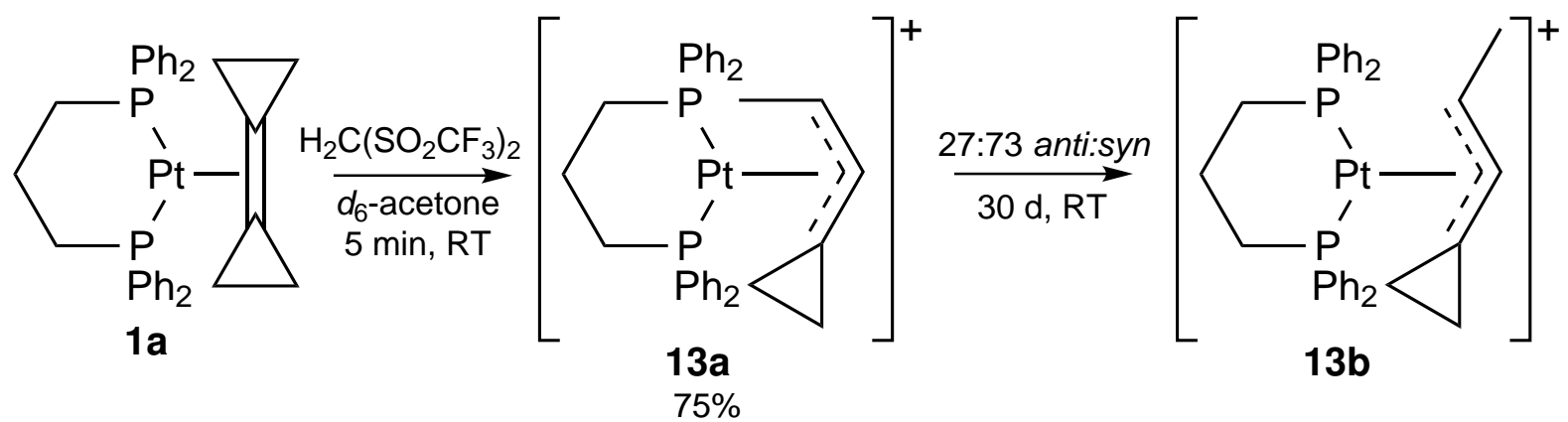

Scheme 3.7. Formation of allyl complexes by protonation of $[\mathrm{Pt}(\mathrm{BCP})(\mathrm{dppp})](\mathbf{1 a})$.

In the equivalent reactions with $\mathbf{2 a}$, there were two products formed initially (15 and $\mathbf{1 6 a}$ ), in a 68:32 ratio (Scheme 3.8). In this case, the major product 15 was a 2 -methylallyl complex, formed by the cleavage of the distal ring bond (Scheme 3.6). This complex had been synthesised previously by the addition of dppp to $\left[\mathrm{Pt}\left(\mathrm{CH}_{2} \mathrm{CMeCH}_{2}\right)(\text { acetone })_{2}\right]^{+} .{ }^{148}$ The minor product $\mathbf{1 6 a}$ was a 1 -methylallyl complex with the methyl in the anti position. As with 13, the conversion to the syn-methyl complex (16b) was evident within $12 \mathrm{hr}$, with the ratios stabilising at 16:84 anti:syn after 8 days. When the protonation reaction was done in $\mathrm{CD}_{2} \mathrm{Cl}_{2}$ rather than $d_{6}$-acetone, the ratio of 15 to 16 a was much higher in favour of the 2-methyl complex at 84:16. There was also no conversion of the anti 1-methyl complex into the syn form. This was ascribed to the ability of $d_{6}$-acetone to coordinate to the metal, filling a vacant coordination site while the allyl converted from $\eta^{3}$ (anti) to $\eta^{1}$ to $\eta^{3}$ (syn), which was not possible in non-coordinating $\mathrm{CD}_{2} \mathrm{Cl}_{2}$.

The reactivity of the dbpx complexes differed from that of the dppp complexes. The products of the reactions were again allyl complexes, but different isomers were favoured. In the reaction of $\mathbf{1 d}$ with $\mathrm{H}_{2} \mathrm{C}\left(\mathrm{SO}_{2} \mathrm{CF}_{3}\right)_{2}$, the only species produced (17) was an allyl substituted in the 2-position with a cyclopropyl ring (Scheme 3.9). This species was not observed with 1a, though the analogous 2-methylallyl complex was the major product with $\mathbf{2 a}$. The 2-methyl complex (18a) was also formed in the reaction with $\mathbf{2 d}$, as well as the 1-methylallyl complex with the methyl in the anti position (18b) (Scheme 3.10). Unlike the dppp complexes, in this case it was the 1-methylallyl complex that was the 


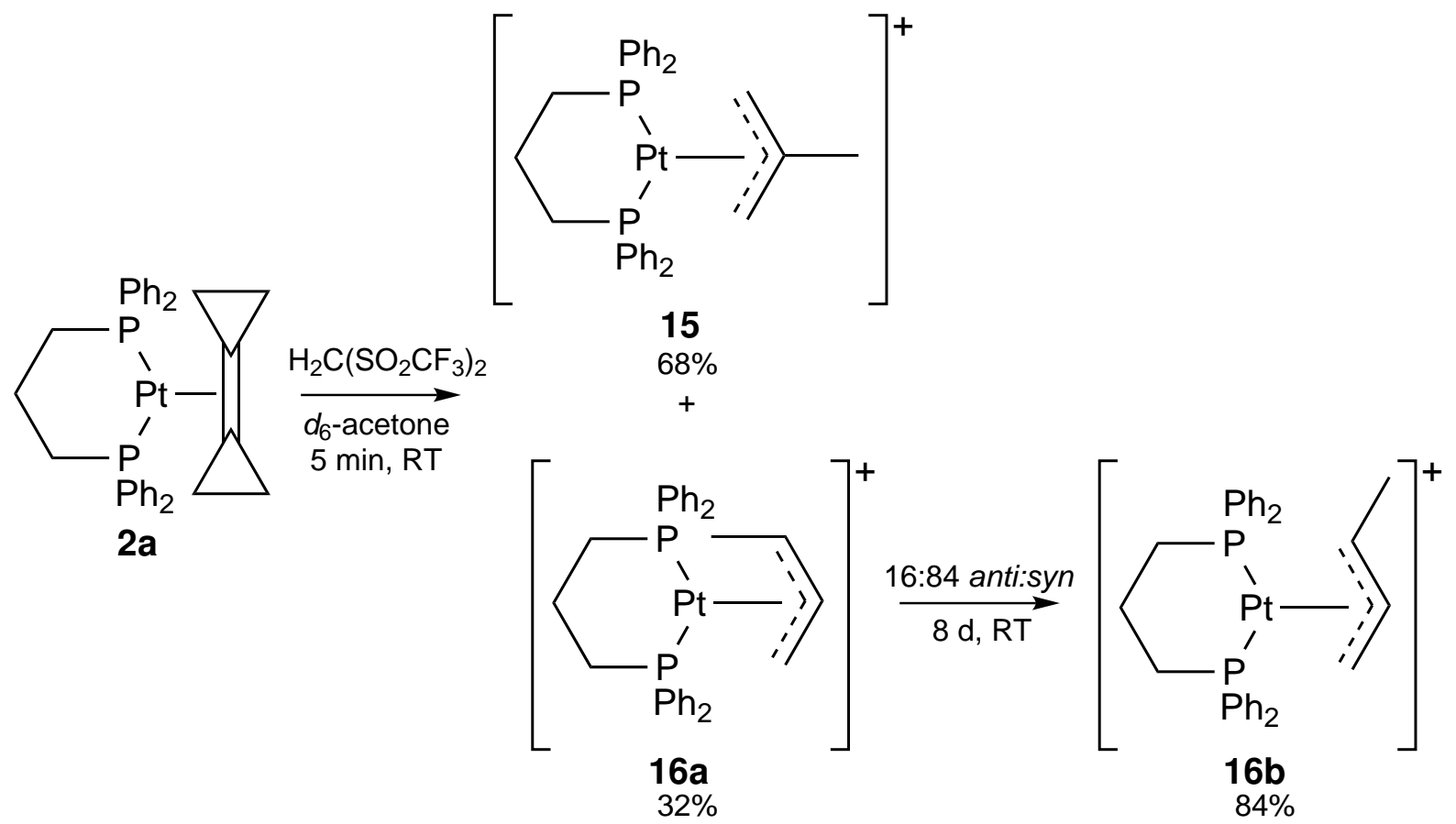

Scheme 3.8. Formation of allyl complexes by protonation of $[\mathrm{Pt}(\mathrm{MCP})(\mathrm{dppp})](\mathbf{2 a})$.

major isomer, with a ratio of 58:42 18a:18b. The dbpx complexes further differed from the dppp complexes with no rearrangement of the anti-methyl $\mathbf{1 8 b}$ to the syn-methyl complex.
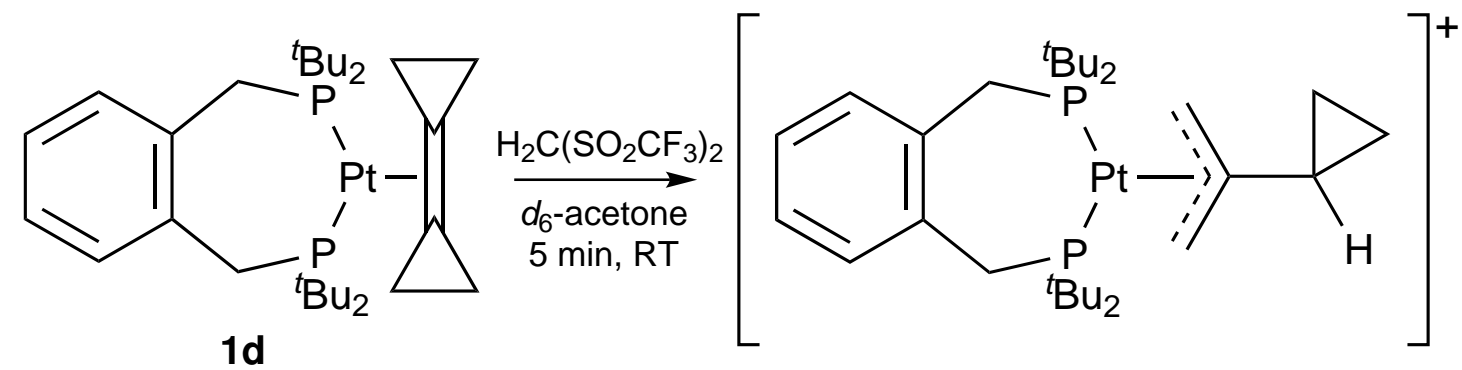

17

Scheme 3.9. Formation of an allyl complex by protonation of $[\mathrm{Pt}(\mathrm{BCP})(\mathrm{dbpx})](\mathbf{1 d})$.

\subsubsection{NMR Characterisation}

For representative NMR spectra see Figures A.36-A.70. The ${ }^{1} \mathrm{H}$ NMR resonances of the 1-methylallyl complexes as well as 1D NOESY correlations were used to assign the geometries of the allyl ligand. In $\mathbf{1 6 a}$ and $\mathbf{1 8 b}$, the peak due to the central allyl proton was a doublet of triplets with couplings of 14.1 and $7.6 \mathrm{~Hz}$ for $\mathbf{1 6 a}$ and 12.2 and $7.5 \mathrm{~Hz}$ 


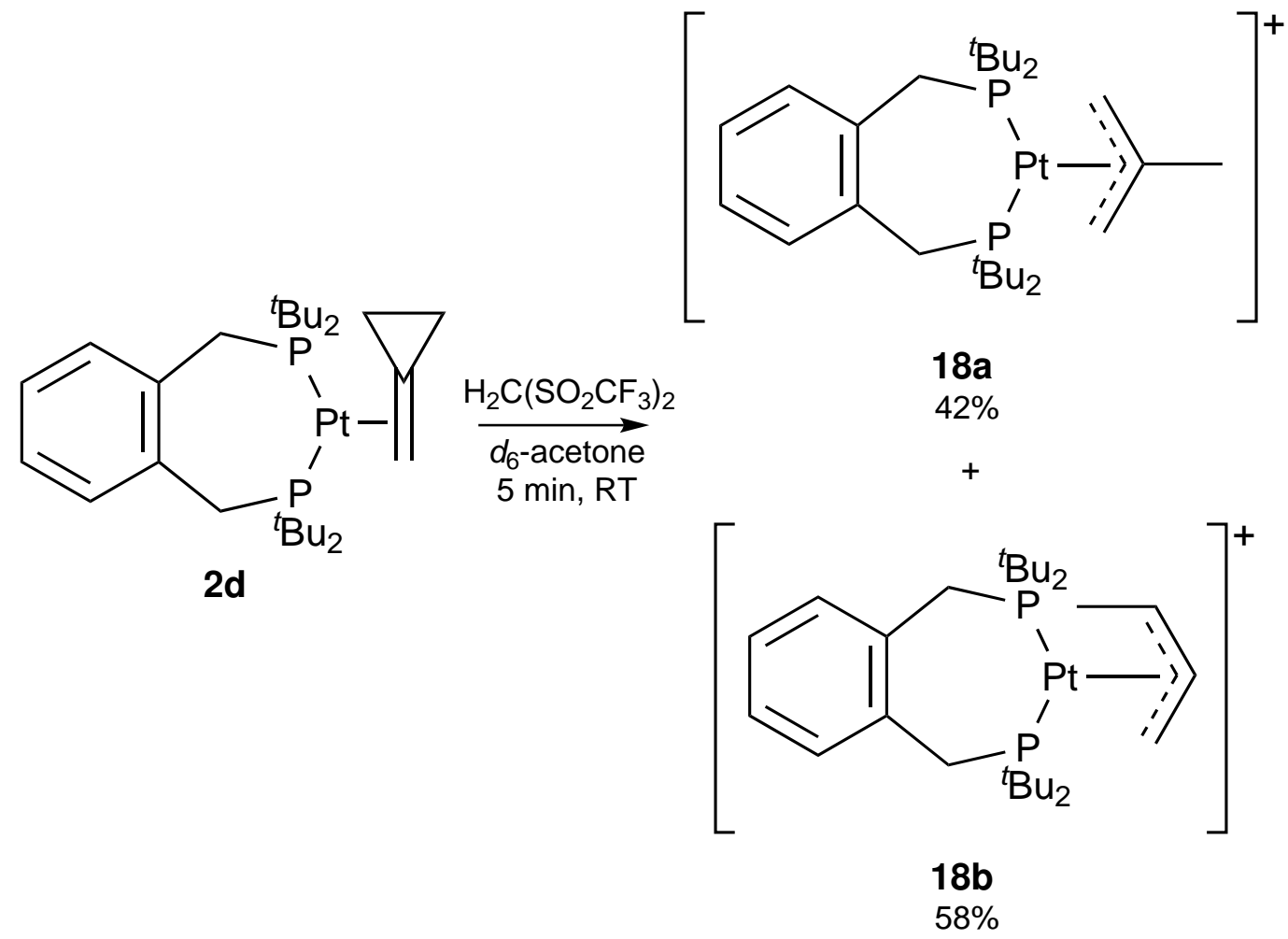

Scheme 3.10. Formation of allyl complexes by protonation of $[\mathrm{Pt}(\mathrm{MCP})(\mathrm{dbpx})](\mathbf{1 d})$.

for $\mathbf{1 8 b}$. This showed that there were two protons in the syn positions (from the CHMe and the $\mathrm{CH}_{2}$ ), and one in the anti (from the $\mathrm{CH}_{2}$ ), and that the methyl was therefore in the anti position (Figure 3.2). ${ }^{141,142,144,145}$ The peak due to the central allyl proton in 16b, however, was a triplet of doublets with couplings of 12.7 and $7.3 \mathrm{~Hz}$, showing that there were now two anti protons, and the methyl was therefore syn. The central allyl protons in $\mathbf{1 3 a}$ and $\mathbf{1 3} \mathbf{b}$ were also used to assign the allyl geometries. In $\mathbf{1 3 a}$, the peak had a $J_{\mathrm{H}-\mathrm{H}}$ coupling of $8.2 \mathrm{~Hz}$ to the CHMe proton, indicating that it was in the syn position, with the methyl group in the anti. The $J_{\mathrm{H}-\mathrm{H}}$ coupling in $\mathbf{1 3 a}$ was $12.5 \mathrm{~Hz}$, and the methyl group was therefore syn.

There were several other differences between the anti-and syn-methyl allyl complexes in the NMR spectra (Tables 3.1 and 3.2). In the ${ }^{1} \mathrm{H}$ NMR spectrum, the chemical shifts for the methyl protons appeared at lower chemical shifts for the anti methyl groups $(0.80$ and $0.88 \mathrm{ppm})$ than for the syn $(1.29$ and $1.38 \mathrm{ppm})$. This differed from the other protons, with the chemical shifts of the protons in the syn-methyl allyl lower than the equivalent anti-methyl allyl. The ${ }^{2} J_{\mathrm{Pt}-\mathrm{H}}$ couplings on the central proton were also slightly larger for 

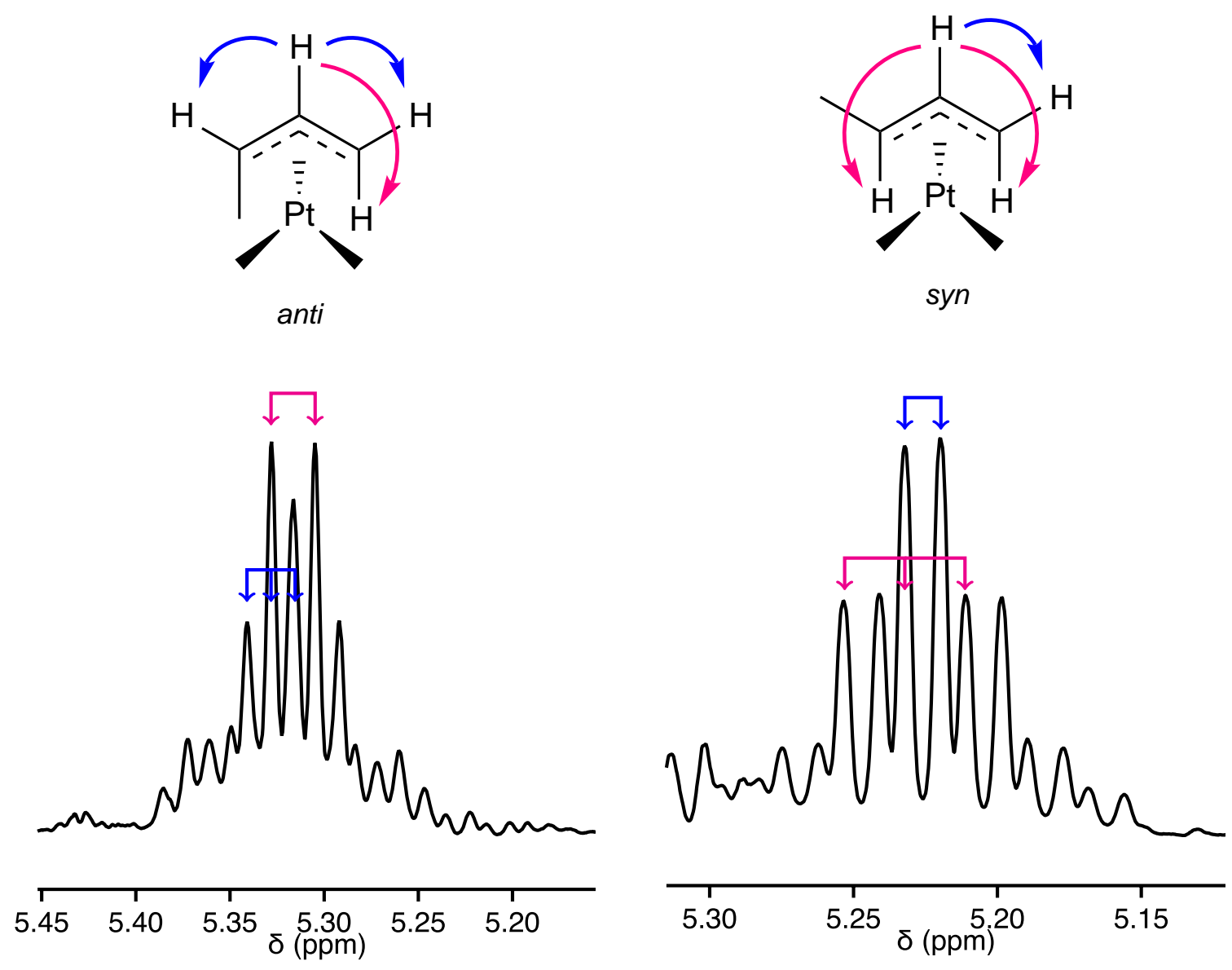

Figure 3.2. ${ }^{1} \mathrm{H}$ NMR resonances of the central allyl proton in $\left[\mathrm{Pt}\left(\eta^{3}-\mathrm{CH}_{2} \mathrm{CHCHMe}\right)(\mathrm{dppp})\right]\left[\mathrm{PhC}\left(\mathrm{SO}_{2} \mathrm{CF}_{3}\right)_{2}\right] \mathbf{1 6 a}\left[\mathrm{PhC}\left(\mathrm{SO}_{2} \mathrm{CF}_{3}\right)_{2}\right]$ (anti) and $\mathbf{1 6 b}\left[\mathrm{PhC}\left(\mathrm{SO}_{2} \mathrm{CF}_{3}\right)_{2}\right]($ syn $)$. 
the anti form $(53.4$ and $54.0 \mathrm{~Hz})$ than for the syn form $(51.0-51.9 \mathrm{~Hz})$.

In the ${ }^{13} \mathrm{C}\left\{{ }^{1} \mathrm{H}\right\}$ NMR spectrum (Table 3.2), the differences in chemical shift had the opposite trend, with those of the anti isomers typically being at lower ppm than the syn isomer, by $0.4-7.4 \mathrm{ppm}$. Most of the $J_{\mathrm{Pt}-\mathrm{C}}$ coupling constants were also lower in the anti isomer by $10-17 \mathrm{~Hz}$. The exception to this was the CHMe carbons, where the ${ }^{1} J_{\mathrm{Pt}-\mathrm{C}}$ coupling constants were higher in the anti case by $36.9 \mathrm{~Hz}$ for $\mathbf{1 3}$ and $29.3 \mathrm{~Hz}$ for $\mathbf{1 6}$. As with other complexes, the carbon with the cyclopropyl ring attached had a significantly higher ${ }^{1} J_{\mathrm{Pt}-\mathrm{C}}$ than the equivalent methylene carbon due to the higher trans-influence of the ${ }^{c} \operatorname{Pr}$ ring, 252.6 and 269.3 vs. $88.0-106.9 \mathrm{~Hz}$. However, the coupling constants of the ${ }^{c} \operatorname{Pr}$ allyl carbons in 13 were lower by $\sim 150 \mathrm{~Hz}$ than those in $\mathbf{1}$. This decrease was consistent with the metal in the allyl complexes being $\mathrm{Pt}(\mathrm{II})$ rather than $\mathrm{Pt}(0)$, with less electron-density being available and therefore weaker bonds to the allyl system than to the alkene ligands. ${ }^{140,149-151}$ In $\mathbf{1 1 a}$, which was also $\mathrm{Pt}(\mathrm{II})$ with the ${ }^{c} \mathrm{Pr}$ ring trans to $\mathrm{P}$, the ${ }^{1} J_{\mathrm{Pt}-\mathrm{C}}$ of the ${ }^{c} \mathrm{Pr}$ allyl carbon $(447.4 \mathrm{~Hz})$ was also larger than for $\mathbf{1 3}$, though that of $\mathbf{1 1 b}$, with the ${ }^{c} \mathrm{Pr}$ trans to $\mathrm{C}$, was lower $(202.3 \mathrm{~Hz})$. However, the $\mathrm{P}-\mathrm{P}$ complexes had a positive charge, again leading to a lower electron density. As well as this, the allyl system in the $\mathrm{P}-\mathrm{C}$ complexes would be affected by the significantly different strengths of the $\mathrm{Pt}-\mathrm{P}$ and $\mathrm{Pt}-\mathrm{C}$ bonds, leading to a comparatively stronger bond trans to the $\mathrm{P}$. The lower ${ }^{1} J_{\mathrm{Pt}-\mathrm{C}}$ coupling constants of the CHMe carbon compared to the $\mathrm{CH}_{2}$ carbon in 16 and $18 \mathrm{~b}$ indicated that there was a greater interaction with the metal for the $\mathrm{CH}_{2}$ group than for the CHMe, both in the $\mathrm{P}-\mathrm{P}$ and the $\mathrm{P}-\mathrm{C}$ complexes. ${ }^{93}$ The differences varied between $3.4 \mathrm{~Hz}$ when trans to $\mathrm{C}$ in $\mathbf{1 2}$ and $45.7 \mathrm{~Hz}$ for $\mathbf{1 6} \mathbf{b}$.

In the ${ }^{31} \mathrm{P}\left\{{ }^{1} \mathrm{H}\right\}$ NMR spectra of 13 , there was a large difference between ${ }^{1} J_{\mathrm{Pt}-\mathrm{P}}$ coupling constants, with that of the phosphorus trans to the ${ }^{c} \operatorname{Pr}$ ring significantly lower than the that of the $\mathrm{P}$ trans to CHMe at $3260 \mathrm{~Hz}$. There was a nearly $200 \mathrm{~Hz}$ difference in the ${ }^{1} J_{\mathrm{Pt}-\mathrm{P}}$ of the $\mathrm{P}$ trans to the CHMe group between the anti- and syn-methyl complexes, 3852 and $4042 \mathrm{~Hz}$ respectively. As with 11, the P trans to the CHMe had a significantly higher ${ }^{1} J_{\mathrm{Pt}-\mathrm{P}}$ in the complexes derived from BCP than from MCP. In 16, the ${ }^{1} J_{\mathrm{Pt}-\mathrm{P}}$ of the $\mathrm{P}$ trans to CHMe $(3625$ and $3695 \mathrm{~Hz})$ were within $60 \mathrm{~Hz}$ of the ${ }^{1} J_{\mathrm{Pt}-\mathrm{P}}$ of the $\mathrm{P}$ trans 
to $\mathrm{CH}_{2}(3569$ and $3670 \mathrm{~Hz})$.

The 2-substituted allyl complexes with dbpx (17 and 18a) both had NMR spectra that varied with temperature. At room temperature, the ${ }^{31} \mathrm{P}$ NMR spectra of both complexes showed two very broad peaks of uneven intensity, with the major peaks at 32.1 and $32.4 \mathrm{ppm}$ with ${ }^{1} J_{\mathrm{Pt}-\mathrm{P}}$ of 3647 and $3572 \mathrm{~Hz}$ and the minor peaks at 33.9 and $33.9 \mathrm{ppm}$ with ${ }^{1} J_{\mathrm{Pt}-\mathrm{P}}$ of 3632 and $3641 \mathrm{~Hz}$ for $\mathbf{1 7}$ and $\mathbf{1 8 a}$ respectively (Figure 3.4). When NMR spectra were run at higher temperatures, the peaks coalesced into a sharp singlet $\left(\mathbf{1 7} \delta_{\mathrm{P}}\right.$ $\left.=33.4 \mathrm{ppm},{ }^{1} J_{\mathrm{Pt}-\mathrm{P}}=3640 \mathrm{~Hz}, \mathbf{1 8 a} \delta_{\mathrm{P}}=32.3 \mathrm{ppm},{ }^{1} J_{\mathrm{Pt}-\mathrm{P}}=3598 \mathrm{~Hz}\right)$, beginning at $30^{\circ} \mathrm{C}$. This fluxional behaviour was due to flipping of the dbpx backbone. ${ }^{152,153}$ When the temperature of $\mathbf{1 7}$ was decreased, the two broad peaks became four sharp peaks, beginning at $0{ }^{\circ} \mathrm{C}\left(\delta_{\mathrm{P}}=34.2,33.0,31.0\right.$ and $30.7 \mathrm{ppm},{ }^{1} J_{\mathrm{Pt}-\mathrm{P}}=3650,3651,3639$ and $3642 \mathrm{~Hz}$, with 8:34:12:46 intensity). This was ascribed to a combination of flipping of the dbpx backbone and different orientations of the cyclopropyl substituent, prevented from free rotation due to the large steric bulk of the ${ }^{t} \mathrm{Bu}$ substituents (Figure 3.3).
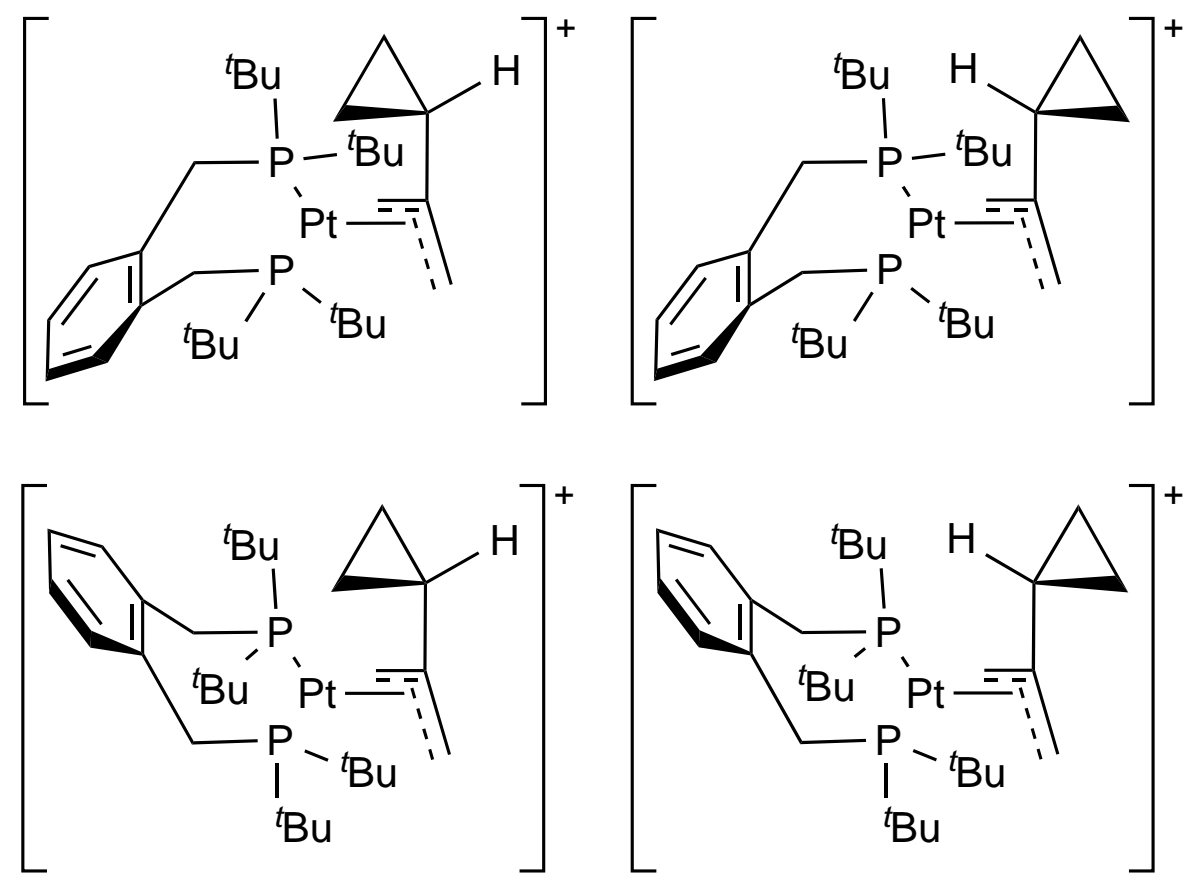

Figure 3.3. Possible conformations of $\left[\mathrm{Pt}\left(\eta^{3}-\mathrm{CH}_{2} \mathrm{C}^{c} \mathrm{PrCH}_{2}\right)(\mathrm{dbpx})\right]^{+}(\mathbf{1 7})$.

The coalescence temperature for the ${ }^{1} \mathrm{H}$ NMR of $\mathbf{1 7}$ was slightly lower than for the ${ }^{31} \mathrm{P}$ NMR, between 0 and $-10^{\circ} \mathrm{C}$. (Figures 3.5 and 3.6). The room temperature proton spectra 


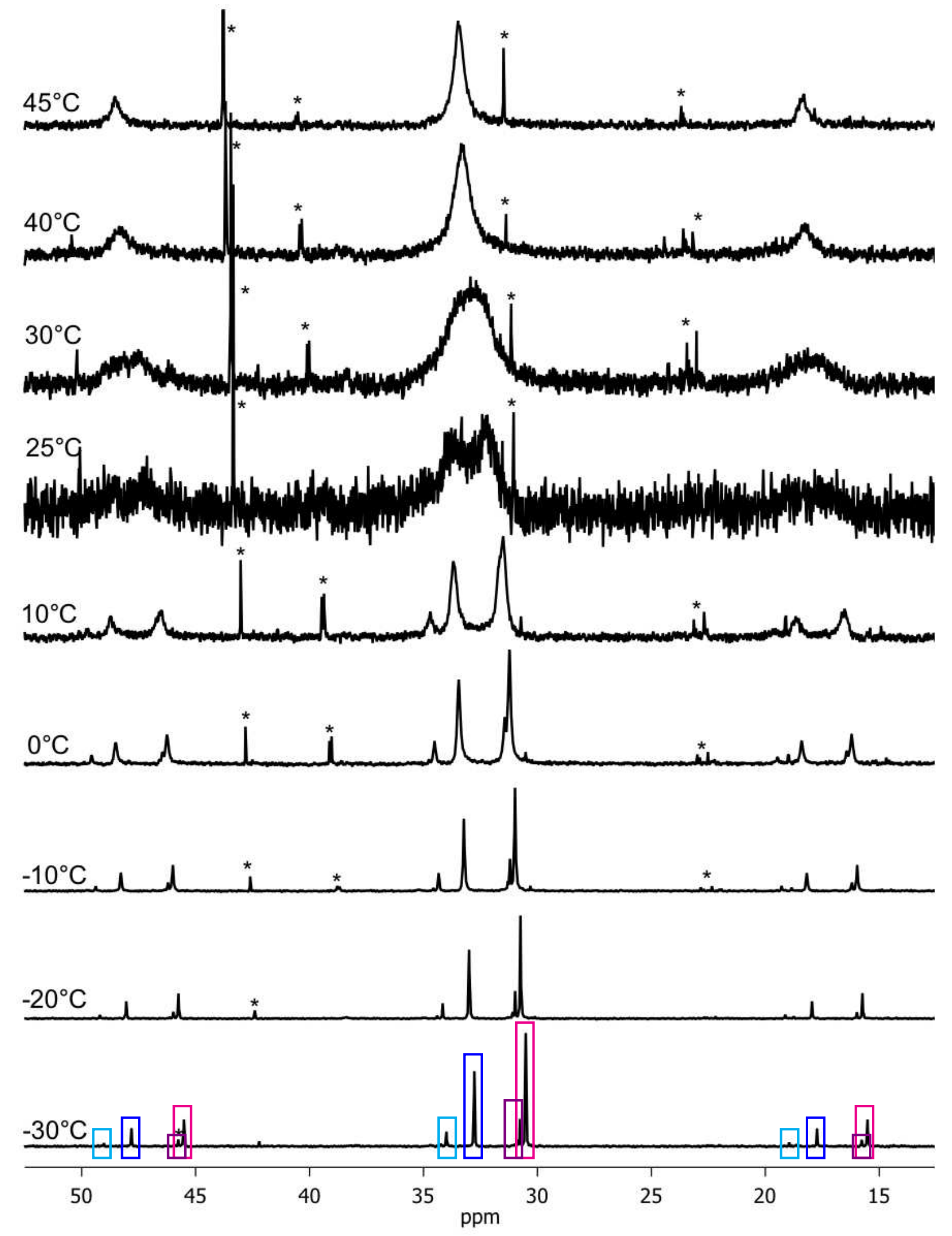

Figure 3.4. Temperature-dependent ${ }^{31} \mathrm{P}\left\{{ }^{1} \mathrm{H}\right\}$ NMR spectra of

$\left[\mathrm{Pt}\left(\eta^{3}-\mathrm{CH}_{2} \mathrm{C}^{c} \mathrm{PrCH}_{2}\right)(\mathrm{dbpx})\right]^{+}(\mathbf{1 7})\left(125 \mathrm{MHz}, 40 \mathrm{mg} / \mathrm{mL}, \mathrm{C}_{6} \mathrm{D}_{6}\right)$. * signifies peaks belonging to other species 


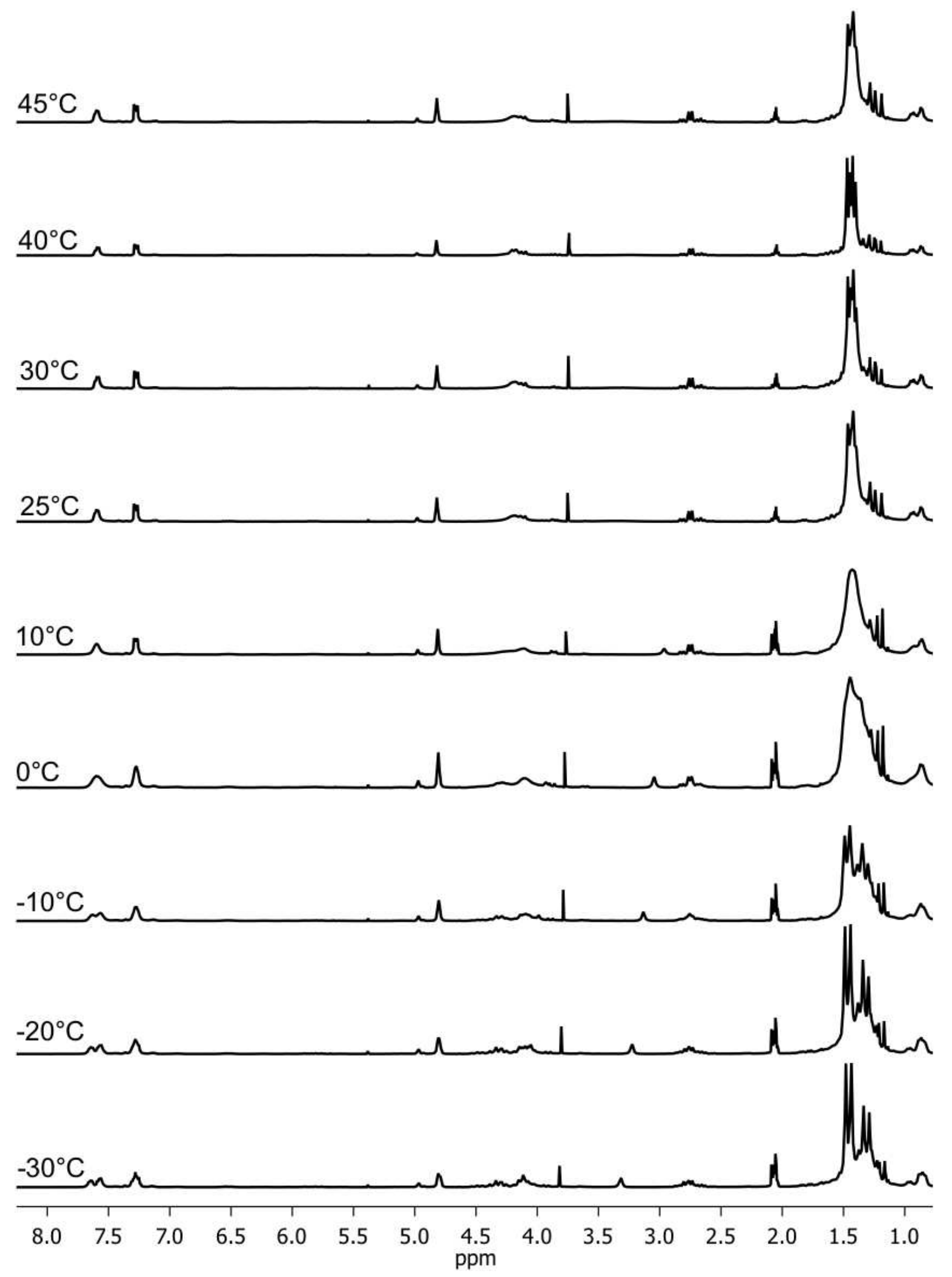

Figure 3.5. Temperature-dependent ${ }^{1} \mathrm{H}$ NMR spectra of $\left[\mathrm{Pt}\left(\eta^{3}-\mathrm{CH}_{2} \mathrm{C}^{c} \mathrm{PrCH}_{2}\right)(\mathrm{dbpx})\right]^{+}$ (17) $\left(300 \mathrm{MHz}, 40 \mathrm{mg} / \mathrm{mL}, \mathrm{C}_{6} \mathrm{D}_{6}\right)$. 

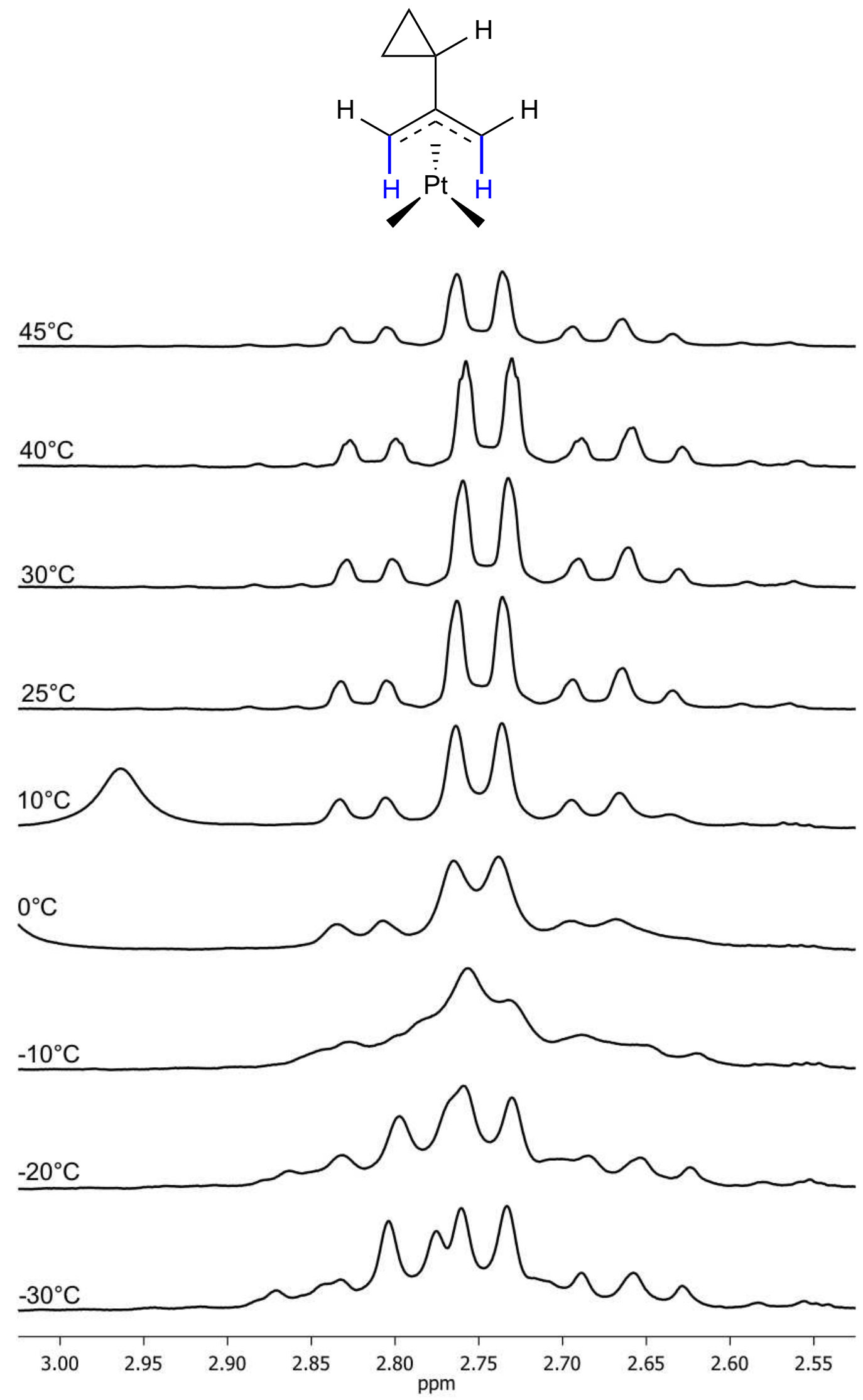

Figure 3.6. Temperature-dependent ${ }^{1} \mathrm{H}$ NMR spectra of the anti methylene proton of $\left[\mathrm{Pt}\left(\eta^{3}-\mathrm{CH}_{2} \mathrm{C}^{c} \mathrm{PrCH}_{2}\right)(\mathrm{dbpx})\right]^{+}(\mathbf{1 7})\left(300 \mathrm{MHz}, 40 \mathrm{mg} / \mathrm{mL}, \mathrm{C}_{6} \mathrm{D}_{6}\right)$. 
of the three 2-substituted allyl complexes 15, 17 and 18a showed good agreement. All three showed a broad singlet peak due to the syn $\mathrm{CH}_{2}$ allyl peaks between 3.56-4.88 ppm, with only $0.07 \mathrm{ppm}$ difference between the two dbpx complexes. The anti $\mathrm{CH}_{2}$ allyl peaks appeared between 2.74-2.95 ppm, with ${ }^{2} J_{\mathrm{Pt}-\mathrm{H}}$ between $32.0-41.3 \mathrm{~Hz}$. Due to the presence of the large ${ }^{t} \mathrm{Bu}$ peaks, the methyl protons for $\mathbf{1 8 a}$ could not be found, with those of $\mathbf{1 5}$ appearing at $1.96 \mathrm{ppm}$, higher than for the 1-methyl allyl complexes.

The room temperature ${ }^{13} \mathrm{C}\left\{{ }^{1} \mathrm{H}\right\}$ NMR spectra of $\mathbf{1 7}$ and $\mathbf{1 8 a}$ showed the same broadness as the ${ }^{31} \mathrm{P}$ NMR spectra, although there was only one set of peaks. The central allyl carbon peak appeared at higher chemical shifts (126.4-135.9 ppm) than the corresponding carbon in the 1-methyl allyl complexes (98.59-119.33 ppm). The peak due to the methylene carbon appeared at similar chemical shifts to the 1-methyl methylene carbons (51.7-66.4 ppm), with the methylene in the 2-methyl complex at higher shifts than in the 1-methyl complex with the same phosphine backbone. The methyl carbons also appeared at higher ppm than in the 1-methyl complexes, at 21.6 and $24.8 \mathrm{ppm}$. The ${ }^{1} J_{\mathrm{Pt}-\mathrm{C}}$ coupling constants of the 2-methyl complexes showed the same trends, with that of the methylene carbon of similar magnitude (79.8-85.0 c.f. 88.0-100.1 Hz) and that of the methyl carbon higher (28.4-30.0 c.f. 3.8-23.1 Hz) than for the 1-methyl allyl complexes.

The structure of the minor product in the protonation reaction of $\mathbf{1 a}$ could not be fully determined. The complex formed initially (14a) converted into a second complex overnight (14b), and remained unchanged over several months. The same complexes formed in the same ratios when either $\mathrm{H}_{2} \mathrm{C}\left(\mathrm{SO}_{2} \mathrm{CF}_{3}\right)_{3}, \mathrm{HCPh}\left(\mathrm{SO}_{2} \mathrm{CF}_{3}\right)_{3}$ or $\mathrm{HBF}_{4}$ was used. From the ${ }^{1} J_{\mathrm{Pt}-\mathrm{P}}$ coupling constants, 3439 and $3520 \mathrm{~Hz}$ for 14a, 3512 and $3592 \mathrm{~Hz}$ for 14b, both complexes had unsymmetrical allyl ligands, therefore were not the 2-substituted allyl similar to $\mathbf{1 7}$. The similar size of the coupling constants indicated that the end of the allyl was not substituted with a cyclopropyl ring, as with $\mathbf{1 1}$ and $\mathbf{1 6 .}$

The ${ }^{13} \mathrm{C}\left\{{ }^{1} \mathrm{H}\right\}$ NMR data for $\mathbf{1 4 b}$ suggested that it was a 2-substituted allyl, evidenced by the presence of a peak at $135.8 \mathrm{ppm}$, comparable to $\mathbf{1 5}, \mathbf{1 7}$ and $\mathbf{1 8 a}$. There were peaks at 84.7 and $76.3 \mathrm{ppm}$ with ${ }^{1} J_{\mathrm{Pt}-\mathrm{C}}$ of 123.7 and $56.6 \mathrm{~Hz}$ respectively. When carbon13 enriched BCP (enriched at the double-bond carbons) was used, it was the peak at 
$84 \mathrm{ppm}$ which was enhanced, as well as the peak at $135 \mathrm{ppm}$. The peak at $76 \mathrm{ppm}$ was at a much higher chemical shift and had a much smaller ${ }^{1} J_{\mathrm{Pt}-\mathrm{C}}$ coupling constant than the methylene resonances in the other allyl complexes (Table 3.2). Three other carbon resonances were identified, at 12.5, 27.4 and $30.6 \mathrm{ppm}$. None of these were in good agreement with the methyl peaks in either the 2-methyl (21.6 and $24.8 \mathrm{ppm}$ ) or 1-methyl (14.1-17.3 ppm) allyls. The presence of two phosphorus and three allyl carbon environments precludes a structure similar to 17. A structure similar to that of $\mathbf{1 1}$ and 16 with the methyl in the 2-position was ruled out due to the similarities of the ${ }^{1} J_{\mathrm{Pt}-\mathrm{P}}$ coupling constants and the small size of the allyl ${ }^{1} J_{\mathrm{Pt}-\mathrm{C}}$ couplings compared to those of the ${ }^{c} \operatorname{Pr}$ allyl carbons. While it was evident that the second cyclopropyl ring had opened, there was no sign of a double-bond, which which would result from the ring-opening when the number of protons was conserved. The possibility of ring-opening with the gain of deuterium from the NMR solvent ( $d_{6}$-acetone) was considered, but was deemed unlikely due to the lack of coupling to deuterium on any of the ${ }^{13} \mathrm{C}$ NMR peaks.

\subsubsection{Computational Studies}

Complexes with three allyl structural motifs were observed experimentally, with the proportions of these dependent on both the phosphine backbone and the solvent used. These were the allyl substituted in the 2-position, the 1-methyl allyl with the methyl in the anti position and the 1-methyl allyl with the methyl in the syn position. When formed from BCP, the 1-methyl allyls had a cyclopropyl ring in the 3-position. Computational models were used to investigate the formation of the allyl complexes. All structures were optimised and frequencies calculated using density functional theory calculations (B3LYP), ${ }^{154-157}$ optimised using the def2-TZVP basis set, ${ }^{158}$ of triple $\zeta$ quality.

Structures with a range of allyl systems were optimised for each of the three phosphine backbones used. The three phosphine backbones were the ortho-metallated phosphine-thioether ligand $\mathrm{C}_{6} \mathrm{H}_{3}-o-\mathrm{CH}_{2} \mathrm{P}^{t} \mathrm{Bu}_{2}-m-\mathrm{CH}_{2} \mathrm{~S}^{t} \mathrm{Bu}(\mathrm{P}-\mathrm{C})$, dppp and dbpx. Six allyl complexes were used for both dppp and dbpx (Figures 3.9, 3.10, 3.11 and 3.12). These were the 2-substituted allyl complexes $\left[\mathrm{Pt}\left(\eta^{3}-\mathrm{CH}_{2} \mathrm{C}^{c} \mathrm{PrCH}_{2}\right)(\mathrm{P}-\mathrm{P})\right]$ 
$(\mathrm{P}-\mathrm{P}=\operatorname{dppp}(\mathbf{1 9}), \operatorname{dbpx}(\mathbf{1 7}))$ and $\left[\mathrm{Pt}\left(\eta^{3}-\mathrm{CH}_{2} \mathrm{CMeCH}_{2}\right)(\mathrm{P}-\mathrm{P})\right](\mathrm{P}-\mathrm{P}=\mathrm{dppp}$ (15), dbpx (18a)), the 1-methyl allyl complexes with the the methyl in the anti position $\left[\mathrm{Pt}\left(\eta^{3}-\mathrm{C}\left(\mathrm{CH}_{2}\right)_{2} \mathrm{CHCHMe}\right)(\mathrm{P}-\mathrm{P})\right](\mathrm{P}-\mathrm{P}=\operatorname{dppp}(\mathbf{1 3 a}), \operatorname{dbpx}(\mathbf{2 0 a}))$ and $\left[\mathrm{Pt}\left(\eta^{3}-\mathrm{CH}_{2} \mathrm{CHCHMe}\right)(\mathrm{P}-\mathrm{P})\right](\mathrm{P}-\mathrm{P}=\operatorname{dppp}(\mathbf{1 6 a}), \operatorname{dbpx}(\mathbf{1 8 b}))$, and the 1-methyl complex with the methyl in the syn position $\left[\mathrm{Pt}\left(\eta^{3}-\mathrm{C}\left(\mathrm{CH}_{2}\right)_{2} \mathrm{CHCHMe}\right)(\mathrm{P}-\mathrm{P})\right](\mathrm{P}-\mathrm{P}$ $=\operatorname{dppp}(\mathbf{1 3 b}), \operatorname{dbpx}(\mathbf{2 0 b}))$ and $\left[\mathrm{Pt}\left(\eta^{3}-\mathrm{CH}_{2} \mathrm{CHCHMe}\right)(\mathrm{P}-\mathrm{P})\right](\mathrm{P}-\mathrm{P}=\operatorname{dppp}(\mathbf{1 6 a})$, $\operatorname{dbpx}(\mathbf{1 8 c}))$.

Due to the unsymmetrical phosphine ligand in the $\mathrm{P}-\mathrm{C}$ complexes, there were 10 possible allyl structures (Figures 3.7 and 3.8). The 2-substituted complexes were $\left[\mathrm{Pt}\left(\eta^{3}-\mathrm{CH}_{2} \mathrm{C}^{c} \mathrm{PrCH}_{2}\right)(\mathrm{P}-\mathrm{C})\right] \quad(\mathbf{2 1})$ and $\left[\mathrm{Pt}\left(\eta^{3}-\mathrm{CH}_{2} \mathrm{CMeCH}_{2}\right)(\mathrm{P}-\mathrm{C})\right] \quad(\mathbf{2 2})$. There were four 1-methyl allyl complexes with the methyl group in the anti position, $\left[\mathrm{Pt}\left(\eta^{3}-\mathrm{C}\left(\mathrm{CH}_{2}\right)_{2} \mathrm{CHCHMe}\right)(\mathrm{P}-\mathrm{C})\right] \quad(\mathrm{Me}$ trans $\mathrm{C}(\mathbf{1 1 a})$, Me trans $\mathrm{P}(\mathbf{1 1 b}))$ and $\left[\mathrm{Pt}\left(\eta^{3}-\mathrm{CH}_{2} \mathrm{CHCHMe}\right)(\mathrm{P}-\mathrm{C})\right]$ (Me trans $\mathrm{P}(\mathbf{1 2 a})$, Me trans $\left.\mathrm{C}(\mathbf{1 2 b})\right)$, and four 1methyl complexes with the methyl in the syn position, $\left[\mathrm{Pt}\left(\eta^{3}-\mathrm{C}\left(\mathrm{CH}_{2}\right)_{2} \mathrm{CHCHMe}\right)(\mathrm{P}-\mathrm{C})\right]$ (Me trans $\mathrm{C}(\mathbf{2 3 a})$, Me trans $\mathrm{P}(\mathbf{2 3} \mathbf{b}))$ and $\left[\mathrm{Pt}\left(\eta^{3}-\mathrm{CH}_{2} \mathrm{CHCHMe}\right)(\mathrm{P}-\mathrm{C})\right](\mathrm{Me}$ trans $\mathrm{P}$ (24a), Me trans $\mathrm{C}(\mathbf{2 4 b}))$. Structures for the parent alkene complexes $[\mathrm{Pt}(\mathrm{BCP})(\mathrm{P}-\mathrm{P})]$ $(\mathrm{P}-\mathrm{P}=\operatorname{dppp}(\mathbf{1 a}), \operatorname{dbpx}(\mathbf{1 d})),[\operatorname{Pt}(\mathrm{MCP})(\mathrm{P}-\mathrm{P})](\mathrm{P}-\mathrm{P}=\operatorname{dppp}(\mathbf{2 a}), \operatorname{dbpx}(\mathbf{2 d}))$, $[\mathrm{Pt}(\mathrm{BCP})(\mathrm{P}-\mathrm{S})](\mathbf{8}),[\mathrm{Pt}(\mathrm{MCP})(\mathrm{P}-\mathrm{S})]\left({ }^{c} \operatorname{Pr}\right.$ trans $\mathrm{S}(\mathbf{9 a}),{ }^{c} \operatorname{Pr}$ trans $\left.\mathrm{P}(\mathbf{9 b})\right)$, the acid used in the protonation reactions $\left(\mathrm{H}_{2} \mathrm{C}\left(\mathrm{SO}_{2} \mathrm{CF}_{3}\right)_{2}\right)$ and its counter ion $\left(\mathrm{HC}\left(\mathrm{SO}_{2} \mathrm{CF}_{3}\right)_{2}^{-}\right)$ were also optimised. 


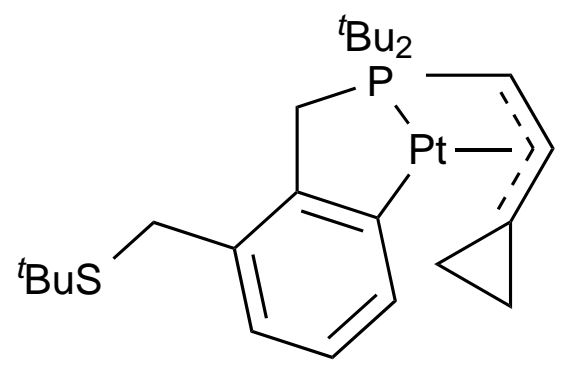

$11 \mathrm{a}$

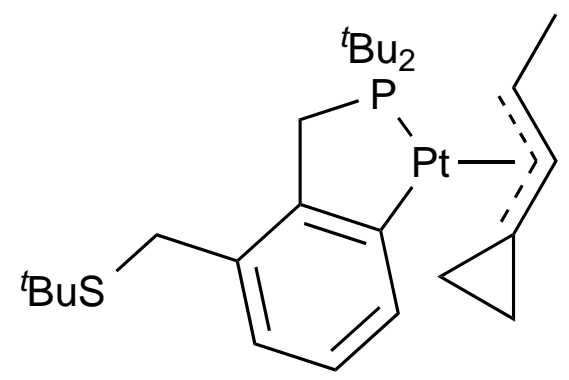

23a

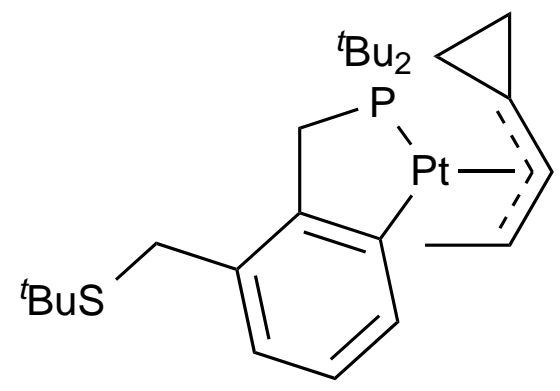

11b

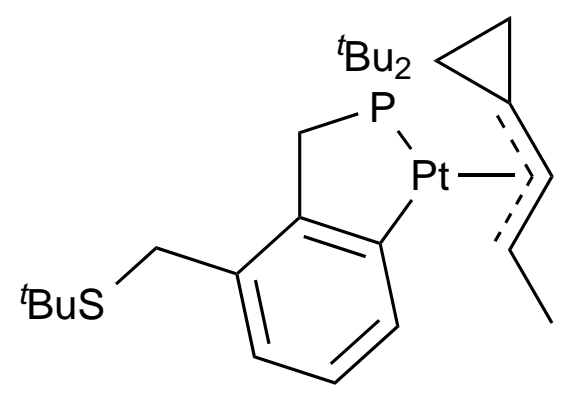

$23 b$

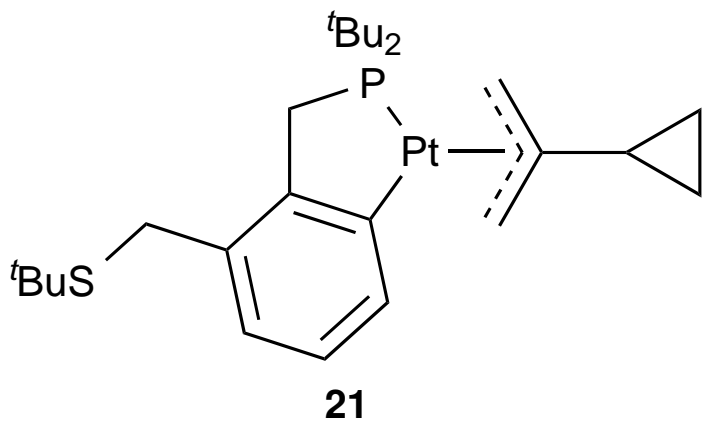

Figure 3.7. Allyl structural motifs derived from $[\mathrm{Pt}(\mathrm{BCP})(\mathrm{P}-\mathrm{S})](\mathbf{8})$. 


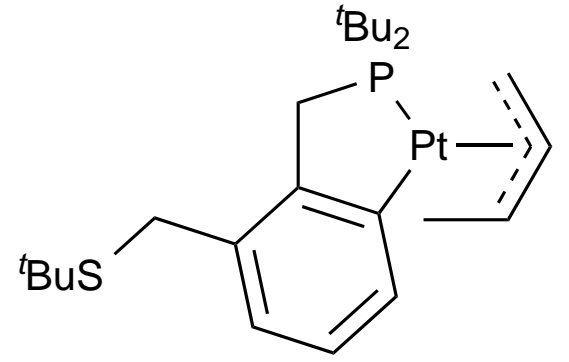

12a

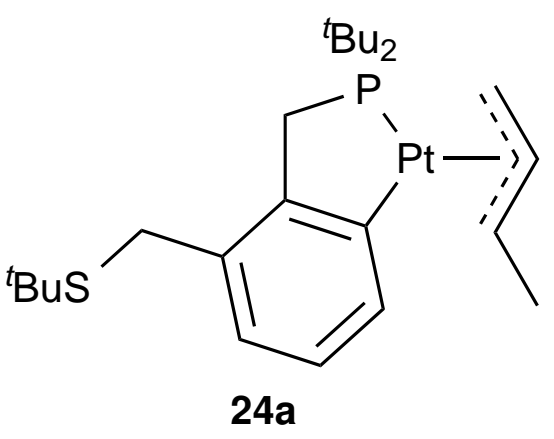

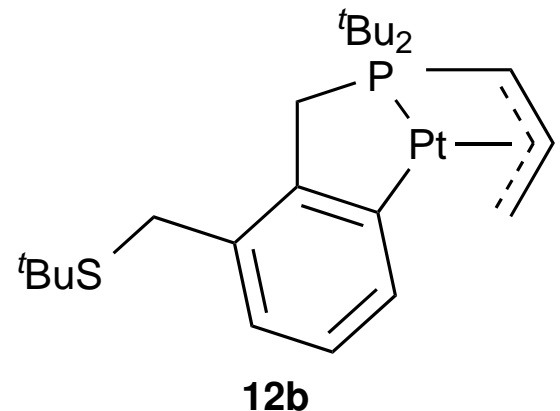

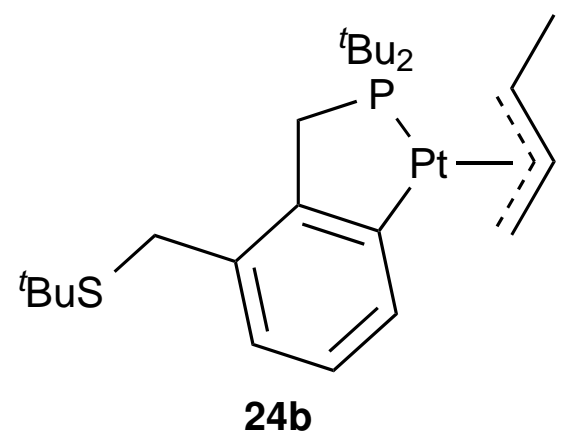

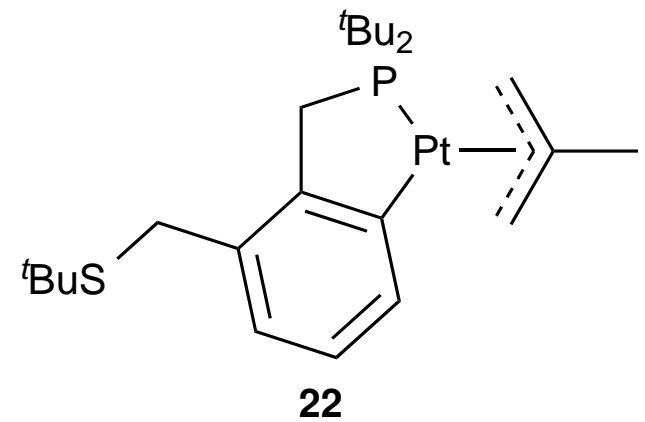

Figure 3.8. Allyl structural motifs derived from $[\mathrm{Pt}(\mathrm{MCP})(\mathrm{P}-\mathrm{S})](\mathbf{9})$. 


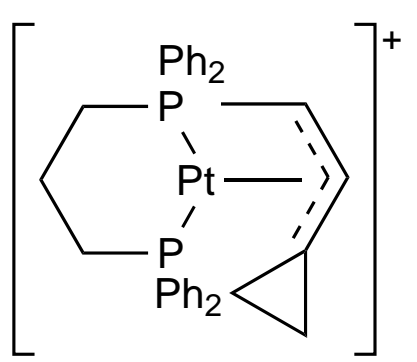

$13 a$

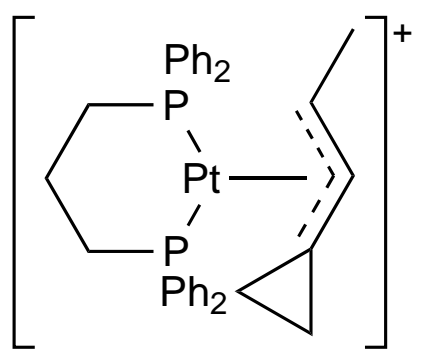

$13 b$

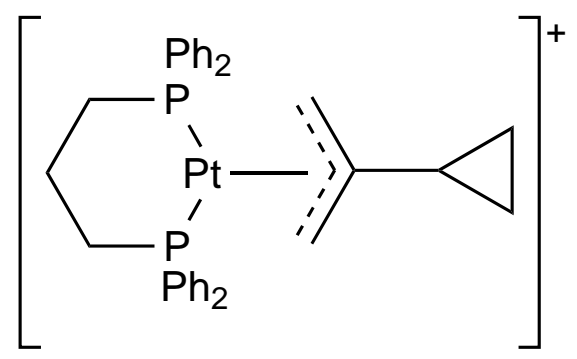

19

Figure 3.9. Allyl structural motifs derived from $[\mathrm{Pt}(\mathrm{BCP})(\mathrm{dppp})](\mathbf{1 a})$.

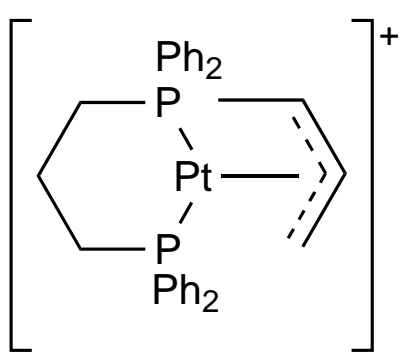

$16 a$

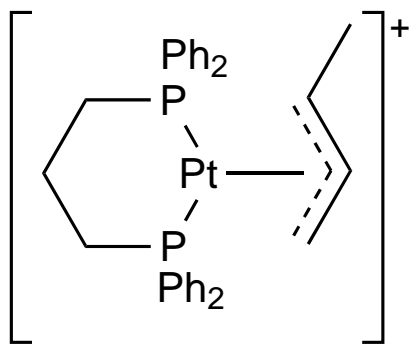

$16 b$<smiles>C=C([CH2+])P1P(c2ccccc2)CCC[Pb]1P</smiles>

15

Figure 3.10. Allyl structural motifs derived from [Pt(MCP)(dppp)] (2a). 


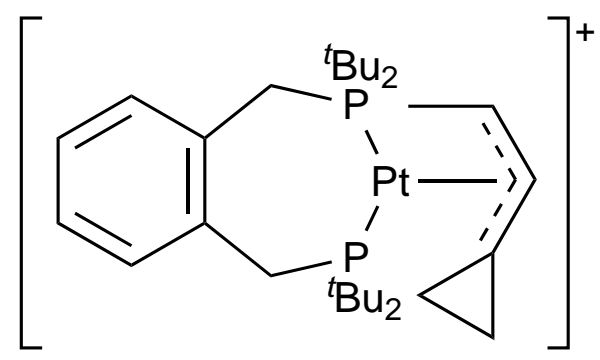

20a

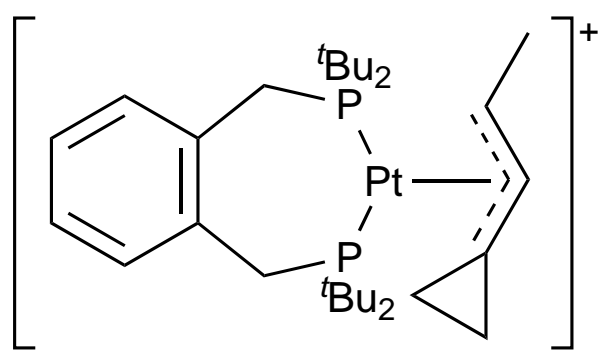

$20 b$

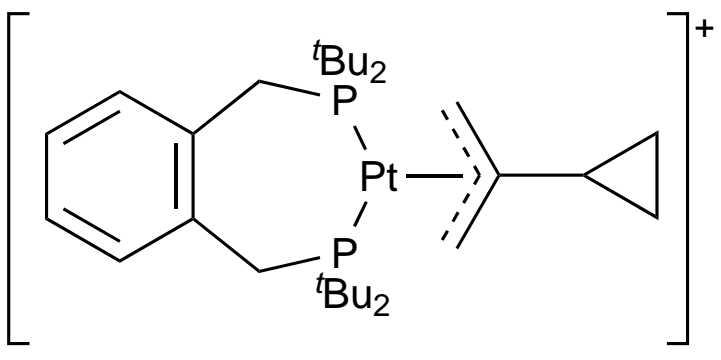

17

Figure 3.11. Allyl structural motifs derived from $[\mathrm{Pt}(\mathrm{BCP})(\mathrm{dbpx})](\mathbf{1 d})$.<smiles>C=C[Pb]1Cc2ccccc2CP1C(=C)C</smiles>

$18 b$

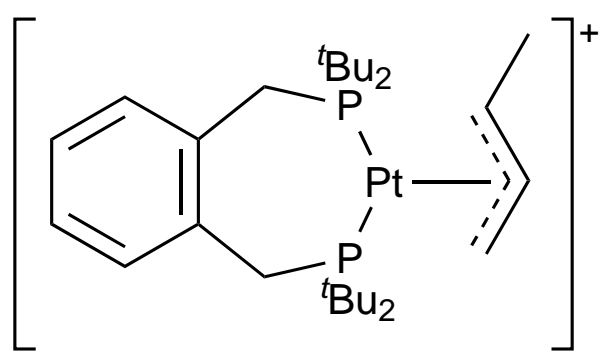

$18 c$<smiles>C=C(C)[Pb]1Cc2ccccc2CP1[18CH]</smiles>

$18 a$

Figure 3.12. Allyl structural motifs derived from $[\mathrm{Pt}(\mathrm{MCP})(\mathrm{dbpx})](\mathbf{2 d})$. 
The reaction $\Delta H$ values for the formation of the allyl complexes from the appropriate $\eta^{2}$-alkene complexes were calculated (Tables 3.3 and 3.4, Figures 3.13, 3.14 and 3.15). The reaction used for the $\mathrm{P}-\mathrm{C}$ complexes was the rearrangement of the parent $[\mathrm{Pt}(\mathrm{L})(\mathrm{P}-\mathrm{S})]$ complex to form the allyl complex (Scheme 3.11), with the isomers of $[\mathrm{Pt}(\mathrm{MCP})(\mathrm{P}-\mathrm{S})]$ leading to two reaction possibilities. For the diphosphine complexes, the reaction used was the addition of $\mathrm{H}_{2} \mathrm{C}\left(\mathrm{SO}_{2} \mathrm{CF}_{3}\right)_{2}$ to $[\mathrm{Pt}(\mathrm{L})(\mathrm{P}-\mathrm{P})]$, forming $[\mathrm{Pt}(\text { allyl })(\mathrm{P}-\mathrm{P})]^{+}$and $\mathrm{HC}\left(\mathrm{SO}_{2} \mathrm{CF}_{3}\right)_{2}^{-}$(Scheme 3.12). The species used in the calculations were isolated molecules in the gas phase, so the absolute values of $\Delta \mathrm{H}$ thus obtained were not necessarily those for the experimental systems. However, the calculated values of reaction $\Delta H$ were considered to be accurate indicators of the trends in stability of the complexes, within the limits of the theoretical description. Transition state structures were not calculated, so no kinetic information was obtained.

In all systems, the reaction $\Delta \mathrm{H}$ for the formation of the 2-substituted allyl complexes had the lowest value. The 2-cyclopropyl complexes with $\mathrm{P}-\mathrm{C}(\mathbf{2 1})$ and $\operatorname{dppp}(\mathbf{1 9})(\Delta \mathrm{H}$ $=-172.6$ and $46.7 \mathrm{~kJ} \mathrm{~mol}^{-1}$ respectively) were not observed experimentally, despite the lower $\Delta \mathrm{H}$ value indicating that these complexes were more stable than the corresponding 1-methyl complexes. The difference between $\Delta \mathrm{H}$ for the 2-substituted and 1-methyl complexes was similar for both backbones $\left(39.1-48.1 \mathrm{~kJ} \mathrm{~mol}^{-1}\right)$. The formation of the 2-substituted allyl complexes occurs via a different mechanism than for the formation of the 1-methyl allyls (Scheme 3.6). It is therefore likely that there was a larger activation energy for the formation of the 2-substituted complexes, leading to the formation of the 1methyl complexes being favoured kinetically. The 2-cyclopropyl complex 17 was the only protonated product observed experimentally with dbpx. In this case, $\Delta \mathrm{H}\left(56.3 \mathrm{~kJ} \mathrm{~mol}^{-1}\right)$ was significantly lower than for the 1-methyl complexes, with differences of 79.8 and $81.3 \mathrm{~kJ} \mathrm{~mol}^{-1}$ between the anti and syn methyl complexes respectively, nearly twice that of the $\mathrm{P}-\mathrm{C}$ and dppp systems.

The 2-methyl substituted complexes $\mathbf{1 5}, \mathbf{1 8} \mathbf{a}$ and $\mathbf{2 2}$ also had lower reaction $\Delta \mathrm{H}$ values than for the 1-methyl allyls, $69.0,97.9,-141.5$ and $-145.4 \mathrm{~kJ} \mathrm{~mol}^{-1}$ respectively. In this case, there were smaller differences between the 2-substituted and 1-methyl complexes 


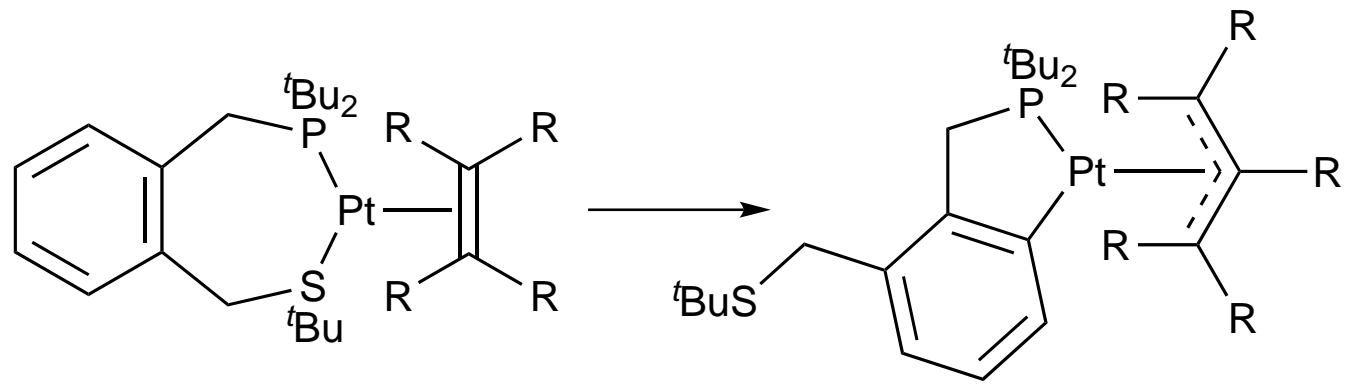

Scheme 3.11. Formation of $\mathrm{P}-\mathrm{C}$ allyl complexes from $[\mathrm{Pt}(\mathrm{L})(\mathrm{P}-\mathrm{S})]$.

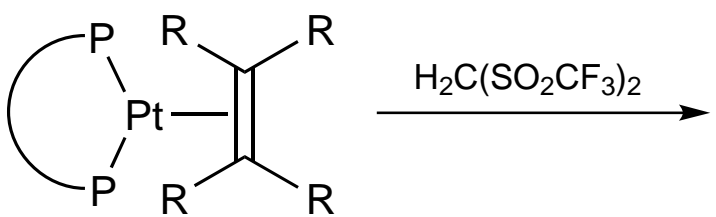<smiles>[R]C([R])=C([2H])PP1CPCCP1</smiles>

$\mathrm{HC}\left(\mathrm{SO}_{2} \mathrm{CF}_{3}\right)_{2}^{-}$

Scheme 3.12. Formation of $\mathrm{P}-\mathrm{P}$ allyl complexes from $[\mathrm{Pt}(\mathrm{L})(\mathrm{P}-\mathrm{P})]$.

Table 3.3. Reaction $\Delta H$ for the Formation of Allyl Complexes from $\eta^{2}$-BCP Complexes.

\begin{tabular}{|c|c|c|c|c|}
\hline Compound & & & \multicolumn{2}{|c|}{$\Delta H\left(\mathrm{~kJ} \mathrm{~mol}^{-1}\right)$} \\
\hline$\left[\mathrm{Pt}\left(\eta^{3}-\mathrm{CH}_{2} \mathrm{C}^{c} \mathrm{PrCH}_{2}\right)(\mathrm{P}-\mathrm{C})\right]$ & & & 21 & -172.6 \\
\hline$\left[\mathrm{Pt}\left(\eta^{3}-\mathrm{C}\left(\mathrm{CH}_{2}\right)_{2} \mathrm{CHCHMe}\right)(\mathrm{P}-\mathrm{C})\right]$ & Me trans $\mathrm{C}$ & anti & $11 \mathrm{a}$ & -126.9 \\
\hline$\left[\mathrm{Pt}\left(\eta^{3}-\mathrm{C}\left(\mathrm{CH}_{2}\right)_{2} \mathrm{CHCHMe}\right)(\mathrm{P}-\mathrm{C})\right]$ & Me trans $\mathrm{C}$ & syn & $23 a$ & -133.6 \\
\hline$\left[\mathrm{Pt}\left(\eta^{3}-\mathrm{C}\left(\mathrm{CH}_{2}\right)_{2} \mathrm{CHCHMe}\right)(\mathrm{P}-\mathrm{C})\right]$ & Me trans $\mathrm{P}$ & anti & $11 b$ & -124.6 \\
\hline$\left[\mathrm{Pt}\left(\eta^{3}-\mathrm{C}\left(\mathrm{CH}_{2}\right)_{2} \mathrm{CHCHMe}\right)(\mathrm{P}-\mathrm{C})\right]$ & Me trans $\mathrm{P}$ & syn & $23 b$ & -124.5 \\
\hline$\left[\mathrm{Pt}\left(\eta^{3}-\mathrm{CH}_{2} \mathrm{C}^{c} \mathrm{PrCH}_{2}\right)(\mathrm{dppp})\right]^{+}$ & & & 19 & 46.7 \\
\hline$\left[\mathrm{Pt}\left(\eta^{3}-\mathrm{C}\left(\mathrm{CH}_{2}\right)_{2} \mathrm{CHCHMe}\right)(\mathrm{dppp})\right]^{+}$ & & anti & $13 \mathbf{a}$ & 93.0 \\
\hline$\left[\mathrm{Pt}\left(\eta^{3}-\mathrm{C}\left(\mathrm{CH}_{2}\right)_{2} \mathrm{CHCHMe}\right)(\mathrm{dppp})\right]^{+}$ & & syn & $13 b$ & 86.2 \\
\hline$\left[\mathrm{Pt}\left(\eta^{3}-\mathrm{CH}_{2} \mathrm{C}^{c} \mathrm{PrCH}_{2}\right)(\mathrm{dbpx})\right]^{+}$ & & & 17 & 56.2 \\
\hline$\left[\mathrm{Pt}\left(\eta^{3}-\mathrm{C}\left(\mathrm{CH}_{2}\right){ }_{2} \mathrm{CHCHMe}\right)(\mathrm{dbpx})\right]^{+}$ & & anti & $20 a$ & 136.0 \\
\hline$\left[\mathrm{Pt}\left(\eta^{3}-\mathrm{C}\left(\mathrm{CH}_{2}\right)_{2} \mathrm{CHCHMe}\right)(\mathrm{dbpx})\right]^{+}$ & & syn & $20 \mathrm{~b}$ & 137.4 \\
\hline
\end{tabular}


Table 3.4. Reaction $\Delta H$ for the Formation of Allyl Complexes from $\eta^{2}$-MCP Complexes.

\begin{tabular}{|c|c|c|c|c|c|c|}
\hline \multirow{2}{*}{ Compound } & & & & \multicolumn{3}{|c|}{$\Delta H\left(\mathrm{~kJ} \mathrm{~mol}^{-1}\right)$} \\
\hline & & & & From 9a & From 9b & From 2 \\
\hline$\left[\mathrm{Pt}\left(\eta^{3}-\mathrm{CH}_{2} \mathrm{CMeCH}_{2}\right)(\mathrm{P}-\mathrm{C})\right]$ & & & 22 & -141.5 & -145.4 & \\
\hline$\left[\mathrm{Pt}\left(\eta^{3}-\mathrm{CH}_{2} \mathrm{CHCHMe}\right)(\mathrm{P}-\mathrm{C})\right]$ & Me trans $\mathrm{P}$ & anti & $12 \mathrm{a}$ & -124.9 & -128.7 & \\
\hline$\left[\mathrm{Pt}\left(\eta^{3}-\mathrm{CH}_{2} \mathrm{CHCHMe}\right)(\mathrm{P}-\mathrm{C})\right]$ & Me trans $\mathrm{P}$ & syn & $24 a$ & -125.3 & -129.2 & \\
\hline$\left[\mathrm{Pt}\left(\eta^{3}-\mathrm{CH}_{2} \mathrm{CHCHMe}\right)(\mathrm{P}-\mathrm{C})\right]$ & Me trans $\mathrm{C}$ & anti & $12 \mathrm{~b}$ & -119.7 & -123.6 & \\
\hline$\left[\mathrm{Pt}\left(\eta^{3}-\mathrm{CH}_{2} \mathrm{CHCHMe}\right)(\mathrm{P}-\mathrm{C})\right]$ & Me trans $\mathrm{C}$ & syn & $24 b$ & -125.4 & -129.3 & \\
\hline$\left[\mathrm{Pt}\left(\eta^{3}-\mathrm{CH}_{2} \mathrm{CMeCH}_{2}\right)(\mathrm{dppp})\right]^{+}$ & & & 15 & & & 69.0 \\
\hline$\left[\mathrm{Pt}\left(\eta^{3}-\mathrm{CH}_{2} \mathrm{CHCHMe}\right)(\mathrm{dppp})\right]^{+}$ & & anti & $16 \mathbf{a}$ & & & 86.0 \\
\hline$\left[\mathrm{Pt}\left(\eta^{3}-\mathrm{CH}_{2} \mathrm{CHCHMe}\right)(\mathrm{dppp})\right]^{+}$ & & syn & $16 \mathrm{~b}$ & & & 81.5 \\
\hline$\left[\mathrm{Pt}\left(\eta^{3}-\mathrm{CH}_{2} \mathrm{CMeCH}_{2}\right)(\mathrm{dbpx})\right]^{+}$ & & & $18 \mathbf{a}$ & & & 97.9 \\
\hline$\left[\mathrm{Pt}\left(\eta^{3}-\mathrm{CH}_{2} \mathrm{CHCHMe}\right)(\mathrm{dbpx})\right]^{+}$ & & anti & $18 \mathrm{~b}$ & & & 115.5 \\
\hline$\left[\mathrm{Pt}\left(\eta^{3}-\mathrm{CH}_{2} \mathrm{CHCHMe}\right)(\mathrm{dbpx})\right]^{+}$ & & syn & $18 \mathrm{c}$ & & & 118.7 \\
\hline
\end{tabular}

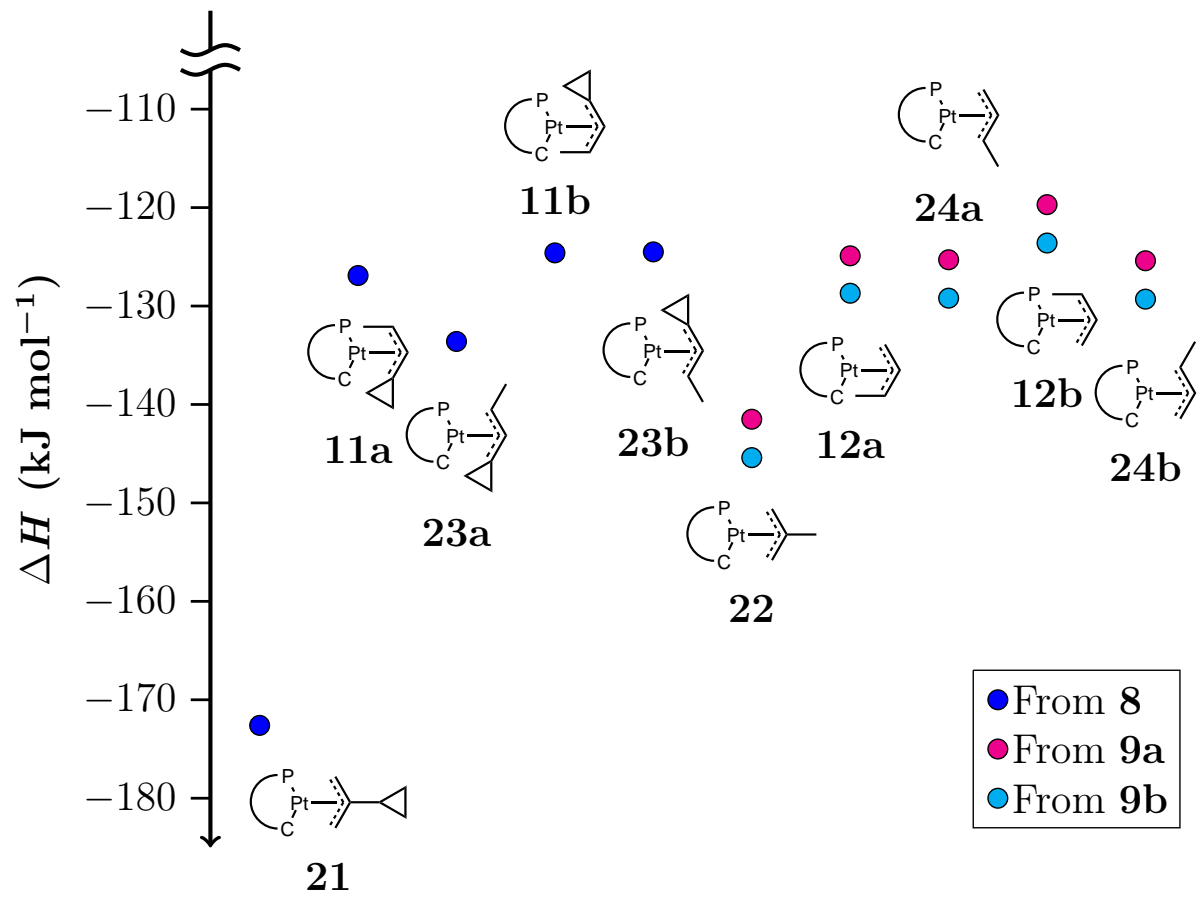

Figure 3.13. Reaction $\Delta H$ for the formation of allyl complexes from $[\mathrm{Pt}(\mathrm{L})(\mathrm{P}-\mathrm{S})]$. 


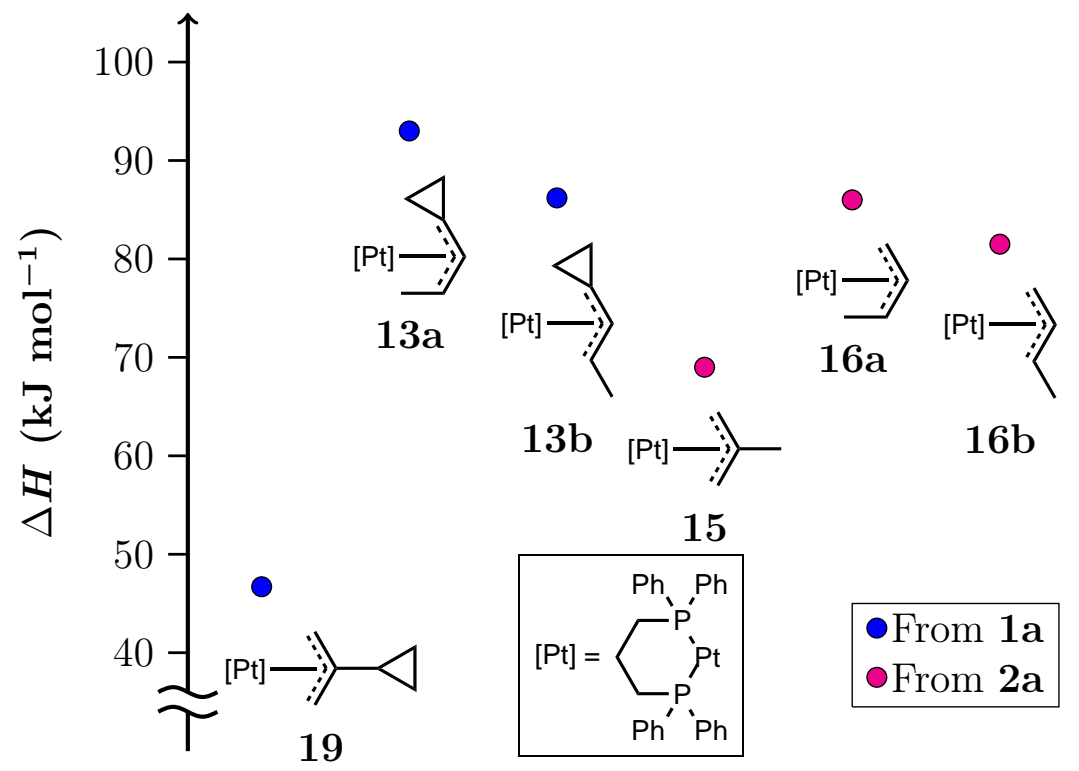

Figure 3.14. Reaction $\Delta H$ for the formation of allyl complexes from $[\mathrm{Pt}(\mathrm{L})(\mathrm{dppp})]$.

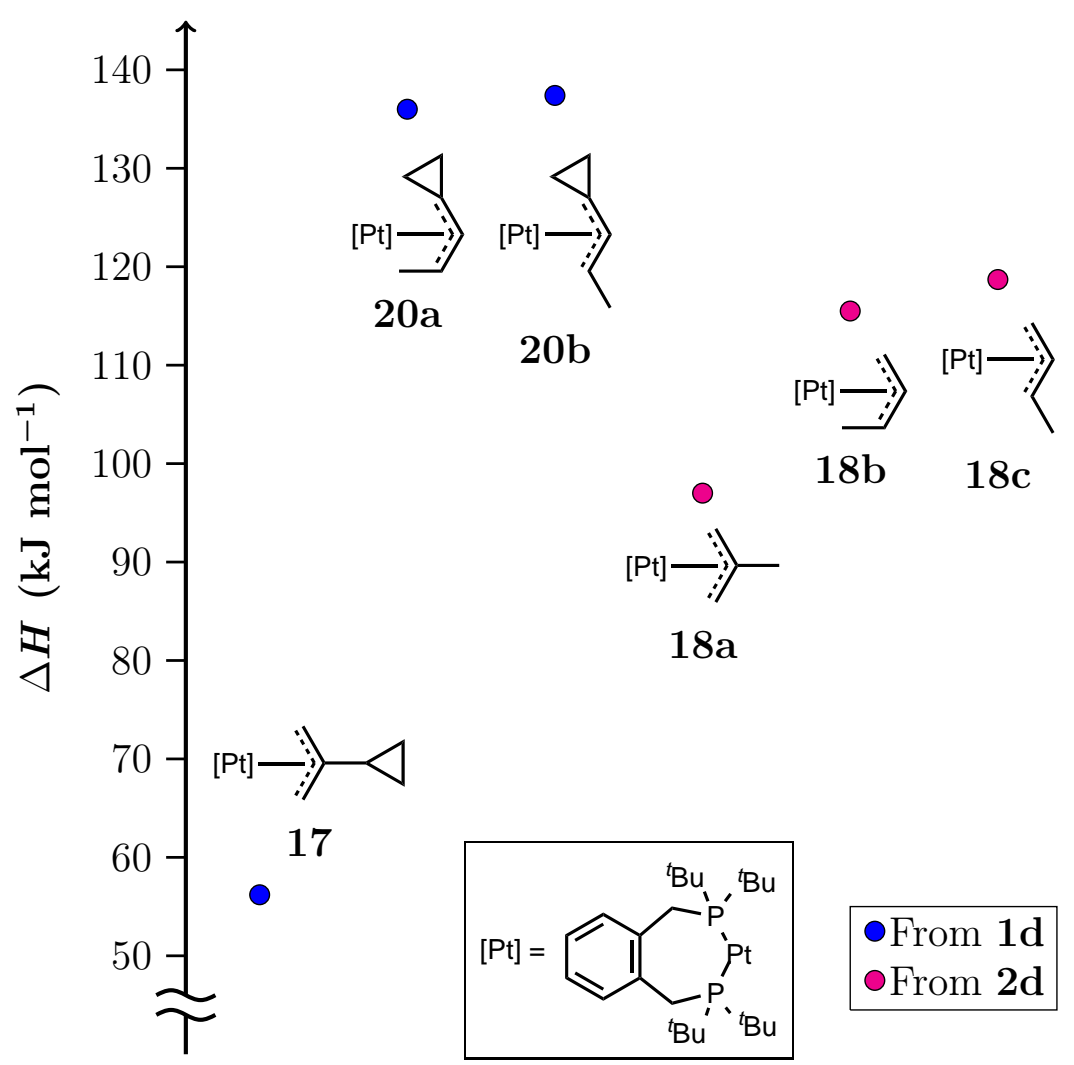

Figure 3.15. Reaction $\Delta H$ for the formation of allyl complexes from $[\mathrm{Pt}(\mathrm{L})(\mathrm{dbpx})]$. 
(12.6-21.8 $\left.\mathrm{kJ} \mathrm{mol}^{-\mathbf{1}}\right)$. Again, it was likely that the size of the activation barrier played a part in determining which isomers were formed. While the differences in $\Delta \mathrm{H}$ for the $\mathrm{P}-\mathrm{C}$ complexes $\left(16.1-21.8 \mathrm{~kJ} \mathrm{~mol}^{-\mathbf{1}}\right)$ was similar to those of the diphosphine complexes, 22 was not observed experimentally. A significantly larger proportion of $\mathbf{1 5}$ (68\%) was produced than 18a (42\%), despite the similarity in the differences of $\Delta \mathrm{H}(12.6-17.1$ and 17.6-20.9 $\mathrm{kJ} \mathrm{mol}^{-\mathbf{1}}$ respectively). It was found experimentally that the solvent used in the reaction had a large effect on the proportion of $\mathbf{1 5}$ formed, with $68 \% \mathbf{1 5}$ formed in $d_{6}$-acetone and $84 \% 15$ formed in $\mathrm{CD}_{2} \mathrm{Cl}_{2}$ (Section 3.2.2), indicating that more factors affected the reaction outcome than were considered in this computational study.

The majority of the 1-methyl complexes with the methyl group in the anti position had enthalpy values higher than the corresponding complexes with the methyl group in the syn position, indicating that the syn isomer was thermodynamically more stable. The dbpx complexes and the $\mathrm{P}-\mathrm{C}$ cyclopropyl allyl complexes with the methyl group trans to the $\mathrm{P}(\mathbf{1 1 b}$ and $\mathbf{2 3 b}$ ), which had lower values for the anti isomer, were the exception to this. The complexes of $\operatorname{dppp}\left(\Delta \mathrm{H}=93.0,86.0,86.0\right.$ and $81.5 \mathrm{~kJ} \mathrm{~mol}^{-\mathbf{1}}$ for $\mathbf{1 3 a}, \mathbf{1 3 b}$, $\mathbf{1 6 a}$ and $\mathbf{1 6} \mathbf{b}$ respectively) and $\mathrm{P}-\mathrm{C}$ with the methyl group trans to $\mathrm{C}(\Delta \mathrm{H}=-126.9$ for $\mathbf{1 1 a},-133.6$ for $\mathbf{2 3 a},-119.7$ and -125.4 for $\mathbf{1 2 b}$, and -123.6 and $-129.3 \mathrm{~kJ} \mathrm{~mol}^{-\mathbf{1}}$ for 24b) had the largest differences between the anti and syn isomers, $4.5-6.8 \mathrm{~kJ} \mathrm{~mol}^{-\mathbf{1}}$ in favour of the syn isomer. The $\mathrm{P}-\mathrm{C}$ complexes with the methyl group trans to $\mathrm{P}$ had only small differences between the isomers; $\Delta \mathrm{H}$ was -124.9 and $-128.7 \mathrm{~kJ} \mathrm{~mol}^{\mathbf{- 1}}$ for $\mathbf{1 2 a}$ and -125.3 and $-129.2 \mathrm{~kJ} \mathrm{~mol}^{\mathbf{- 1}}$ for $\mathbf{2 4 a}, 0.5 \mathrm{~kJ} \mathrm{~mol}^{-\mathbf{1}}$ in favour of the syn isomer, -124.6 and $-124.5 \mathrm{~kJ} \mathrm{~mol}^{-1}$ for $\mathbf{1 1 b}$ and $\mathbf{2 3 b}, 0.1 \mathrm{~kJ} \mathrm{~mol}^{-1}$ in favour of the anti isomer. The dbpx complexes $\left(\Delta \mathrm{H}=136.0,137.4,115.5\right.$ and $118.7 \mathrm{~kJ} \mathrm{~mol}^{-\mathbf{1}}$ for $\mathbf{2 0 a}, \mathbf{2 0 b}, \mathbf{1 8 b}$ and $\mathbf{1 8 c}$ respectively) had differences of 1.5 and $3.2 \mathrm{~kJ} \mathrm{~mol}^{-\mathbf{1}}$, in favour of the anti isomer.

Experimentally, it was the anti isomer that was formed initially, for all cases except for the protonation of $[\mathrm{Pt}(\mathrm{BCP})(\mathrm{dbpx})](\mathbf{1 d})$, where only the 2-substitiuted allyl $\mathbf{1 7}$ was observed. While this was consistent with the lower anti reaction $\Delta \mathrm{H}$ values for the dbpx complexes and $\mathbf{1 1 b} / \mathbf{2 3 b}$, for the other reactions it was the syn isomer which was thermodynamically the more stable. The anti isomer would therefore be the kinetic 
isomer, with a lower activation energy for formation (not calculated in this study). Rearrangement to the syn isomer was observed for the dppp complexes, with anti:syn ratios stabilising at 27:73 for $\mathbf{1 3}$ and 58:42 for $\mathbf{1 6}$. Other allyl systems showed similar reactivity, with the anti methyl isomers formed initially, followed by rearrangement to the syn isomer. ${ }^{141,142}$ No rearrangement was observed for the $\mathrm{P}-\mathrm{C}$ complexes, indicating that the energy barrier for rearrangement was higher in these systems.

In order to determine whether the atomic charges on the double-bond atoms had an effect on the site of protonation, NBO calculations were performed on the starting complexes (Table 3.5). For the $\mathrm{P}-\mathrm{S} / \mathrm{P}-\mathrm{C}$ complexes, the reaction was with an internal hydride formed by the ortho-metallation of the backbone aromatic ring, rather than a proton. Structures of the likely intermediate complexes $[\mathrm{PtH}(\mathrm{L})(\mathrm{P}-\mathrm{C})]$ were optimised, and the atomic charges calculated. A number of structures were possible due to the unsymmetrical backbone and the perpendicular coordination of the alkene (Figure 3.16), favoured in platinum(II) complexes. ${ }^{2,22}$ Two isomers of $[\mathrm{PtH}(\mathrm{BCP})(\mathrm{P}-\mathrm{C})]$ were used, with $\mathrm{H}$ trans to $\mathrm{P}(\mathbf{2 5 a})$ and with $\mathrm{H}$ trans to $\mathrm{C}(\mathbf{2 5 b})$. There were four isomers of $[\mathrm{PtH}(\mathrm{MCP})(\mathrm{P}-\mathrm{C})]$ used, $\mathrm{H}$ trans to $\mathrm{P}$ with the ${ }^{c} \mathrm{Pr}$ ring up according to the coordination plane as drawn (26a), $\mathrm{H}$ trans to $\mathrm{P}$ with the ${ }^{c} \mathrm{Pr}$ ring down $(\mathbf{2 6 b}), \mathrm{H}$ trans to $\mathrm{C}$ with the ${ }^{c}$ Pr ring down (26c) and $\mathrm{H}$ trans to $\mathrm{C}$ with the ${ }^{c} \mathrm{Pr}$ ring down $(\mathbf{2 6 d})$.

The atomic charges on the double-bond carbons in the dppp complexes $(-0.20 e$ for 1a, $-0.22\left(=\mathrm{CR}_{2}\right)$ and $-0.55 e\left(=\mathrm{CH}_{2}\right)$ for $\left.\mathbf{2 a}\right)$ were found to be the same as for the dbpx complexes $\left(-0.20 e\right.$ for $\mathbf{1 d},-0.22\left(=\mathrm{CR}_{2}\right)$ and $-0.55 e\left(=\mathrm{CH}_{2}\right)$ for $\left.\mathbf{2 d}\right)$. The double-bond carbons trans to $\mathrm{P}$ in the $\mathrm{P}-\mathrm{S}$ complexes had charges 0.2 e lower (more negative) than for the $\mathrm{P}-\mathrm{P}$ complexes, $-0.22 e$ for $\mathbf{8},-0.24 e\left(=\mathrm{CR}_{2}\right)$ for $\mathbf{9 b}$ and $-0.58 e\left(=\mathrm{CH}_{2}\right)$ for $\mathbf{9 a}$. When trans to S, the carbons had charges higher (more positive) by $0.6 e$ than when trans to $\mathrm{P},-0.16$ e for $\mathbf{8},-0.18$ e $\left(=\mathrm{CR}_{2}\right)$ for $\mathbf{9 a}$ and $-0.52 e\left(=\mathrm{CH}_{2}\right)$ for $\mathbf{9 b}$. For the hydride complexes, the atoms trans to $\mathrm{P}$ had higher charges. This difference was small for the double-bond carbons, 0.01-0.04 e, but larger for the hydride, 0.08-0.09 e. The methylene end of the MCP double-bond had a higher charge than the cyclopropyl end, -0.6 vs. $-0.2 \mathrm{e}$, which indicated that protonation of the $=\mathrm{CH}_{2}$ would be more likely. According 


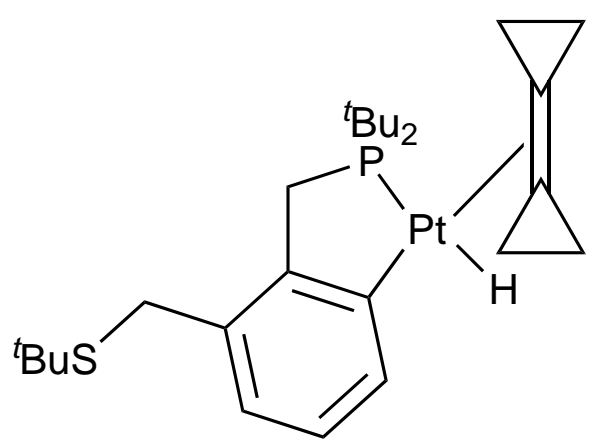

25a

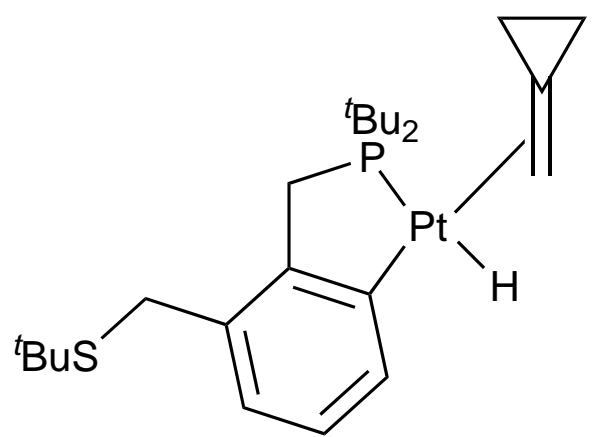

26a

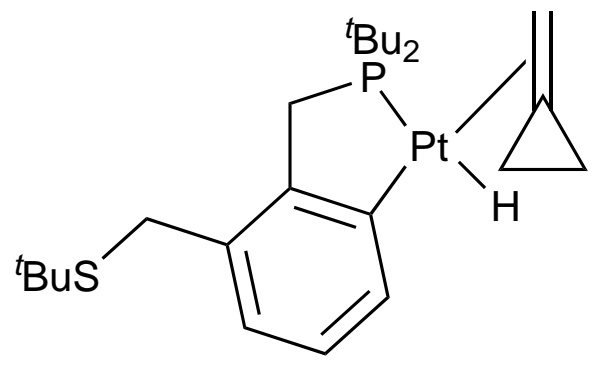

26b

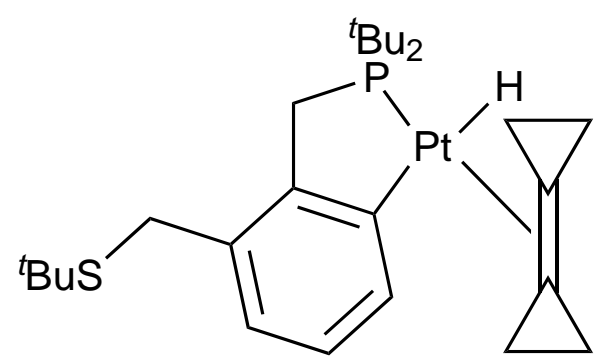

25b

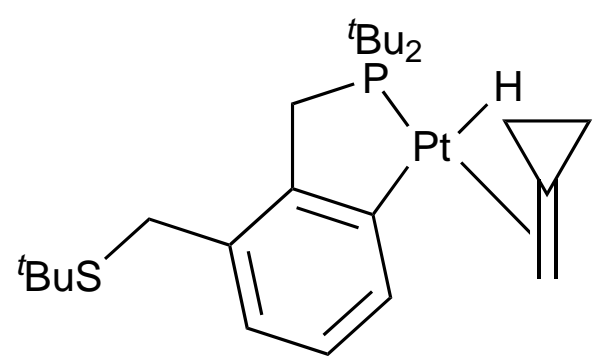

26c

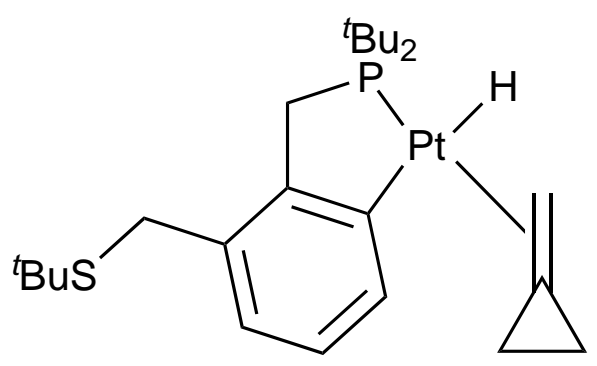

26d

Figure 3.16. Structures of $[\mathrm{PtH}(\mathrm{L})(\mathrm{P}-\mathrm{C})]$ complexes. 
Table 3.5. Atomic Charges on the Double-Bond and Hydride Atoms of Alkene Complexes.

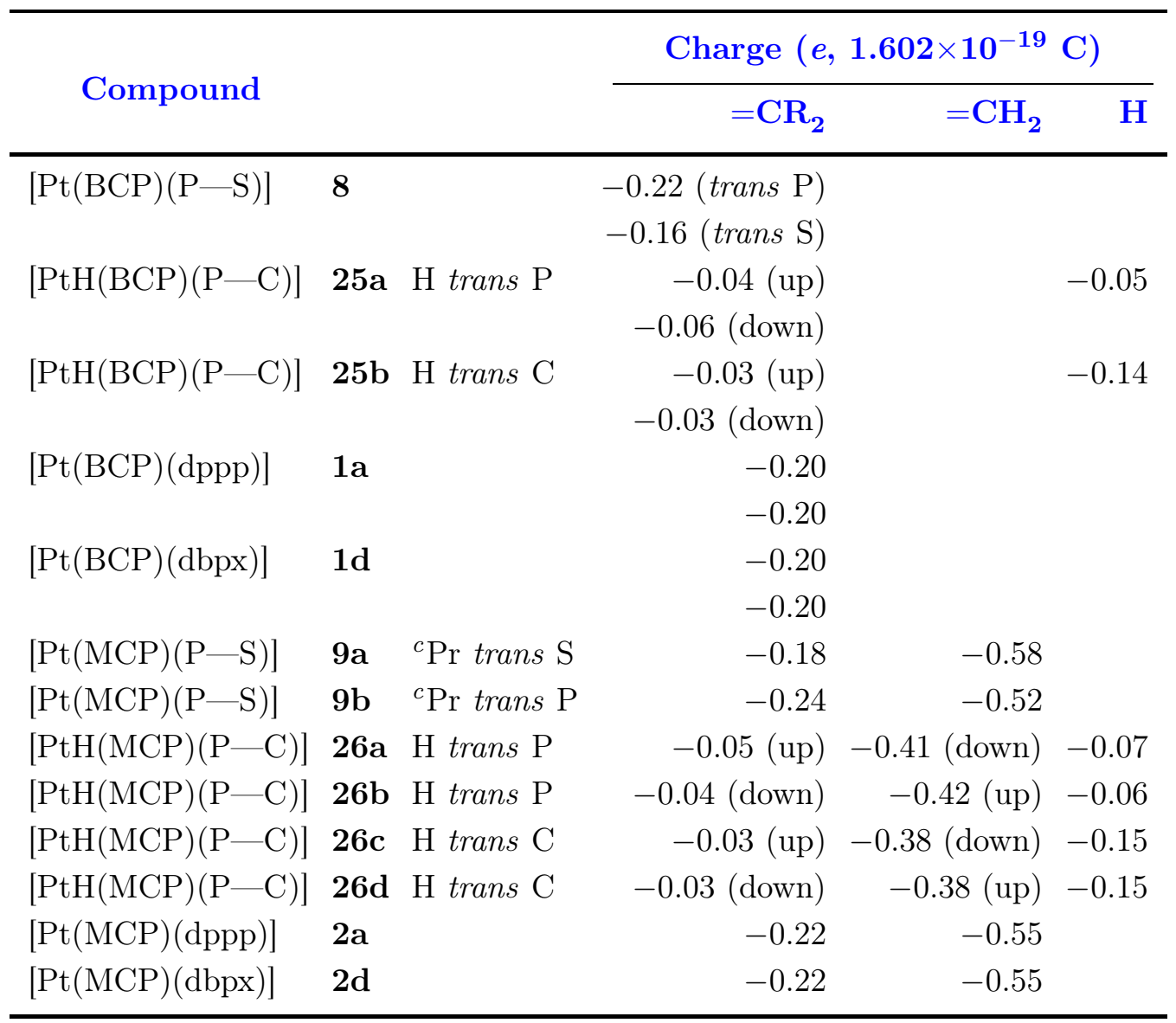

to the literature mechanism for the allyl formation (Scheme 3.6), attack on the methylene carbon results in the formation of 2-methyl allyl complexes. While these isomers were observed experimentally, the fact that the dbpx complex, which formed $42 \% \mathbf{1 8 a}$, had the same atomic charges as for the dppp complex, which formed $68 \% \mathbf{1 5}$, indicated that the factors affecting the product distribution were not simply electronic.

This is supported by the Tolman electronic parameters $\nu$ of the phosphines both in this study and in the reaction of trans- $\left[\mathrm{PtH}\left(\mathrm{NO}_{3}\right)(\mathrm{L})_{2}\right]\left(\mathrm{L}=\mathrm{PEt}_{3}\left(\nu=2062 \mathrm{~cm}^{-1}\right), \mathrm{PMe}_{2} \mathrm{Ph}\right.$ $\left.\left(\nu=2067 \mathrm{~cm}^{-1}\right), \mathrm{PPh}_{3}\left(\nu=2069 \mathrm{~cm}^{-1}\right)\right)$ with MCP. ${ }^{82,134,135}$ While there was no data available for dppp and dbpx, $\mathrm{PPh}_{2} \mathrm{Et}\left(\nu=2067 \mathrm{~cm}^{-1}\right)$ and $\mathrm{P}(o \text {-tol })^{t} \mathrm{Bu}_{2}\left(\nu=2060 \mathrm{~cm}^{-1}\right)$ were reasonable approximations. ${ }^{82}$ The electronic properties of the $\mathrm{P}-\mathrm{C}$ ligand were more complicated. No 2-substituted allyl complex was observed with $\mathrm{PEt}_{3}$ or $\mathrm{PMe}_{2} \mathrm{Ph}$, which were on the low and high end respectively of the range of electronic parameters. With 
$\mathrm{PPh}_{3}$, dppp and dbpx, 42-100\% of the products were 2-substituted, with the $\nu$ values again at both ends of the range. There was therefore no correlation between the value of $\nu$ and the product distribution.

There was a stronger correlation between the product distribution and the cone angle of the phosphine ligand. In the reaction of trans- $\left[\mathrm{PtH}\left(\mathrm{NO}_{3}\right)(\mathrm{L})_{2}\right]$ with $\mathrm{MCP}$, when the cone angle was small $\left(\mathrm{PEt}_{3} \theta=132^{\circ}, \mathrm{PMe}_{2} \mathrm{Ph} \theta=122^{\circ}\right)$, only 1-methyl allyl complexes were formed. ${ }^{82}$ With $\mathrm{PPh}_{3}$, which had a larger cone angle of $145^{\circ}$, the products were 50:50 1-methyl to 2-methyl allyls. A similar trend was seen in the protonation of the BCP complexes of $\operatorname{dppp}\left(\theta=127^{\circ}\right)$ and $\operatorname{dbpx}\left(\theta=138^{\circ}\right),{ }^{81,82}$ where no 2-substituted complex was observed for dppp, and 100\% 2-substituted was observed for dbpx. These trends indicated that steric factors had a significant effect on product distributions. The protonation of the MCP complexes did not fit this trend, with more 2-substituted complexes observed with dppp than with dbpx. This suggested that the factors affecting product distribution were more complicated than those discussed here, and it was likely that both steric and electronic factors played a part.

In summary, the reaction $\Delta H$ values indicated that the 2 -substituted complexes were more stable than the corresponding 1-methyl substituted complexes. In most cases, the 1-methyl complex with the methyl in the syn position was more stable than the anti isomer, although it was the anti isomer that was formed initially experimentally. This indicated that the activation energy had a significant effect on complex formation. 


\section{Chapter 4}

\section{Platinum(II) Chemistry}

\subsection{Introduction}

Three different types of reactivity were observed when bicyclopropylidene and methylenecyclopropane were reacted with platinum(II) complexes. These were (i) ring-opening reactions to form 1,3-dienes, (ii) the coordination of an alkene to form an $\eta^{2}$-alkene complex, and (iii) the formation of a $\beta$-chloroalkyl complex.

\section{$4.2 \quad 1,3$-Dienes}

Allylidenecyclopropane (ACP) is a 1,3-diene which has a cyclopropyl ring at the end of one of the double-bonds, and can be produced when bicyclopropylidene undergoes a single ring-opening reaction. As mentioned previously (Section 2.2), there has been one report of the formation of $\mathrm{ACP}$ from $\mathrm{BCP}$, occurring in the reaction of $\mathrm{BCP}$ with $\left[\mathrm{Pd}(\mathrm{OAc})_{2}\right]$ and $\mathrm{PPh}_{3} .{ }^{74}$ The proposed mechanism for this reaction involved the addition of a palladium hydride across the BCP double-bond, followed by a cyclopropylmethyl to homoallyl rearrangement and termination by $\beta$-hydride elimination. Under the reported conditions, ACP went on to react with another molecule of $\mathrm{BCP}$ to form various oligomers (see Scheme 1.27).

In the reactions of $\mathrm{BCP}$ with the alkyl complexes $\left[\mathrm{PtMe}_{2}(1,5\right.$-hexadiene $\left.)\right]$ and $\left[\mathrm{PtEt}_{2}(\mathrm{COD})\right], \mathrm{ACP}$ was produced (Scheme 4.1). This reaction was also observed with the 
$\operatorname{Pt}(0)$ complexes $\left[\mathrm{Pt}\left(\mathrm{C}_{2} \mathrm{H}_{4}\right)_{3}\right],\left[\mathrm{Pt}(\mathrm{COD})_{2}\right]$ and $\left[\mathrm{Pt}(\mathrm{nb})_{3}\right]$ (Section 2.2). With $\left[\mathrm{PtMe}_{2}(1,5-\right.$ hexadiene)] the reaction was catalytic, converting a $\sim 1000$ fold excess of BCP into ACP in three days at room temperature, although the $\left[\mathrm{PtMe}_{2}(1,5\right.$-hexadiene)] was largely unreacted. Only two equivalents of $\mathrm{BCP}$ were converted to $\mathrm{ACP}$ in the reaction with $\left[\mathrm{PtEt}_{2}(\mathrm{COD})\right]$. This occurred over one day at room temperature, with the reaction mixture unchanged over several weeks. While approximately half of the $\left[\mathrm{PtEt}_{2}(\mathrm{COD})\right]$ reacted with $\mathrm{BCP}$, no platinum-containing products could be characterised.

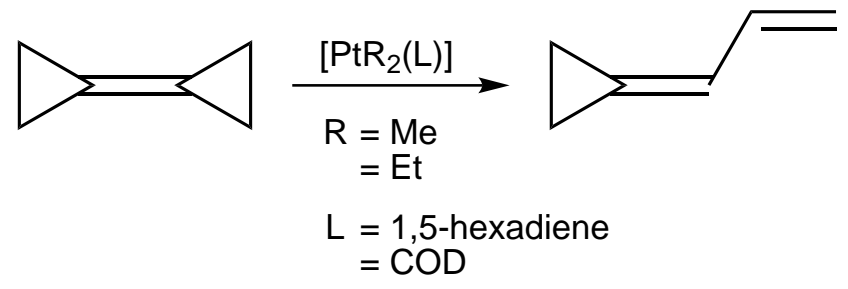

Scheme 4.1. Formation of allylidenecyclopropane from Pt(II) alkyl complexes.

The analogous ring-opening reaction of MCP would produce 1,3-butadiene. When MCP was combined with $\left[\mathrm{PtMe}_{2}(1,5\right.$-hexadiene) $\left.)\right]$ at room temperature no reaction occurred. With $\left[\mathrm{PtEt}_{2}(\mathrm{COD})\right]$, there was a small amount of 1,3-butadiene formed (10\% relative to the amount of $\left.\left[\mathrm{PtEt}_{2}(\mathrm{COD})\right]\right)$. However, this was not the major product. After one day, two new complexes $\left[\mathrm{PtEt}\left(\mathrm{C}\left(\mathrm{CH}_{2}\right)_{2} \mathrm{CH}_{3}\right)(\mathrm{COD})\right](\mathbf{2 7 a})$ and $\left[\mathrm{Pt}\left(\mathrm{C}\left(\mathrm{CH}_{2}\right)_{2} \mathrm{CH}_{3}\right)_{2}(\mathrm{COD})\right](\mathbf{2 7 b})$ formed in an approximately 2:1 ratio (Scheme 4.2), with about a third of the $\left[\mathrm{PtEt}_{2}(\mathrm{COD})\right]$ still unreacted. All of the $\left[\mathrm{PtEt}_{2}(\mathrm{COD})\right]$ had reacted after 2 days. The mono-ethyl complex $\mathbf{2 7 a}$ also continued to react with MCP, reaching a 15:85 27a:27b ratio after 30 days, even when 11 eq. of MCP was used.

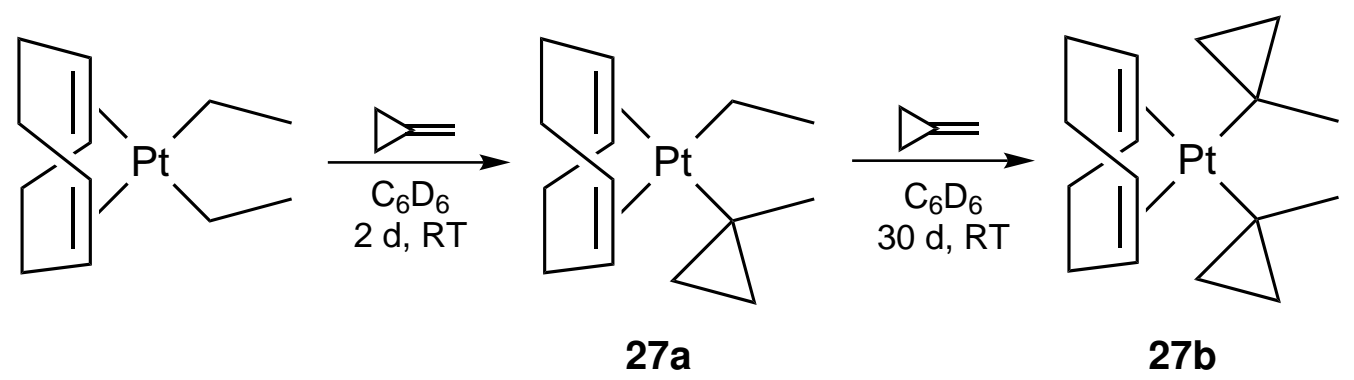

Scheme 4.2. Reaction of $\left[\mathrm{PtEt}_{2}(\mathrm{COD})\right]$ with MCP. 
While the cyclopropylmethyl motif is fairly common (see Sections 2.2 and 4.4 for examples from this work), these complexes are the first examples of complexes with stable, unsubstituted cyclopropylmethyl ligands. The ligands were formed by the Markovnikov addition of $\mathrm{Pt}-\mathrm{H}$ across the MCP double-bond, with $\mathbf{2 7 a}$ formed from one equivalent of MCP, and $\mathbf{2 7} \mathbf{b}$ formed from two equivalents (Scheme 4.2). The Pt-H was generated by the $\beta$-hydride elimination of an ethyl group, as evidenced by the presence of ethene in the reaction mixture. ${ }^{159}$ The small amount of butadiene resulted from the anti-Markovnikov addition of the $\mathrm{Pt}-\mathrm{H}$, followed by a cyclopropylmethyl to homoallyl rearrangement and $\beta$-hydride elimination (Scheme 4.3). Allylidenecyclopropane would be produced in the corresponding reaction from $\mathrm{BCP}$, with only one addition product possible due to the two identical ends of the double-bond (Scheme 4.4).

\subsubsection{NMR Characterisation}

For NMR spectra see Figures A.71-A.78. The peaks in the ${ }^{13} \mathrm{C}\left\{{ }^{1} \mathrm{H}\right\}$ NMR spectra of $\mathbf{2 7 a}$ and $\mathbf{2 7} \mathbf{b}$ due to the cyclopropyl carbon directly bound to the metal had very high ${ }^{1} J_{\mathrm{Pt}-\mathrm{C}}$ coupling constants $(1160.6$ and $1178.5 \mathrm{~Hz})$, characteristic of a $\mathrm{Pt}-\mathrm{C} \sigma$-bond (Table 4.2). ${ }^{93,139}$ These coupling constants were greater than those of the platinum-bound carbon of the ethyl ligands in $\left[\mathrm{PtEt}_{2}(\mathrm{COD})\right]$ and $\mathbf{2 7 a}$ (847.2 and $854.8 \mathrm{~Hz}$ respectively). This indicated that the interaction with the metal was stronger for the ${ }^{c} \mathrm{Pr}$ ring than for the $\mathrm{sp}^{3}$ methylene, which has also been observed previously in this work for $\mathrm{sp}^{2}$ cyclopropyl carbons (see Sections 2.1 and 3.2). The remaining ${ }^{13} \mathrm{C}$ and ${ }^{1} \mathrm{H}$ NMR data (Table 4.1) were consistent with the assigned structures.

\section{$4.3 \quad \eta^{2}$-Alkene Complexes}

Platinum(II) $\eta^{2}$-alkene complexes of BCP and MCP were synthesised by the displacement of a neutral ligand from a precursor complex, as with the platinum(0) complexes previously discussed (Chapter 2). For the $\mathrm{Pt}(0)$ complexes, it was an alkene ligand that was displaced. This was usually ethene, but in the case of the $\mathrm{P}-\mathrm{S}$ complexes, a norbornene precursor 

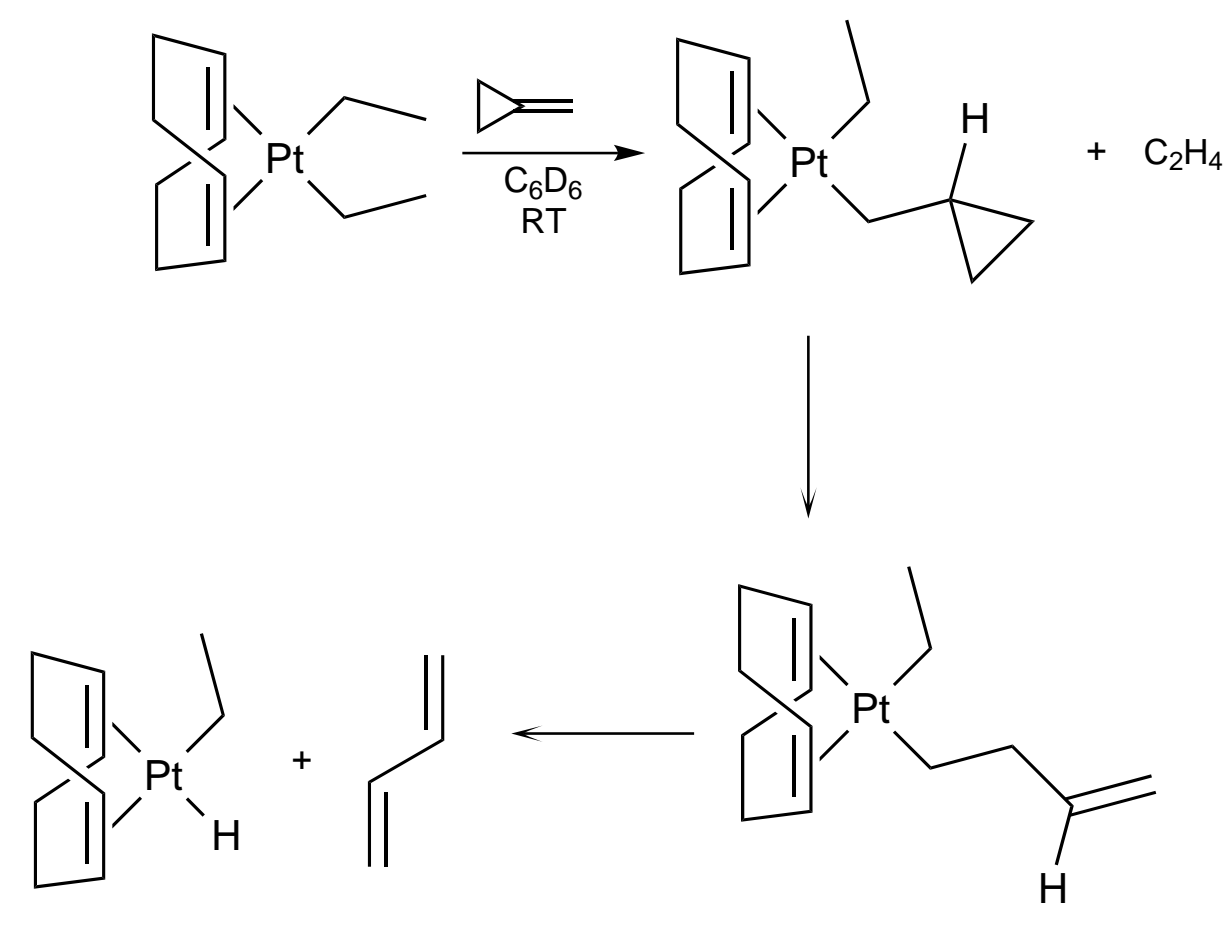

Scheme 4.3. Formation of butadiene from $\left[\mathrm{PtEt}_{2}(\mathrm{COD})\right]$.
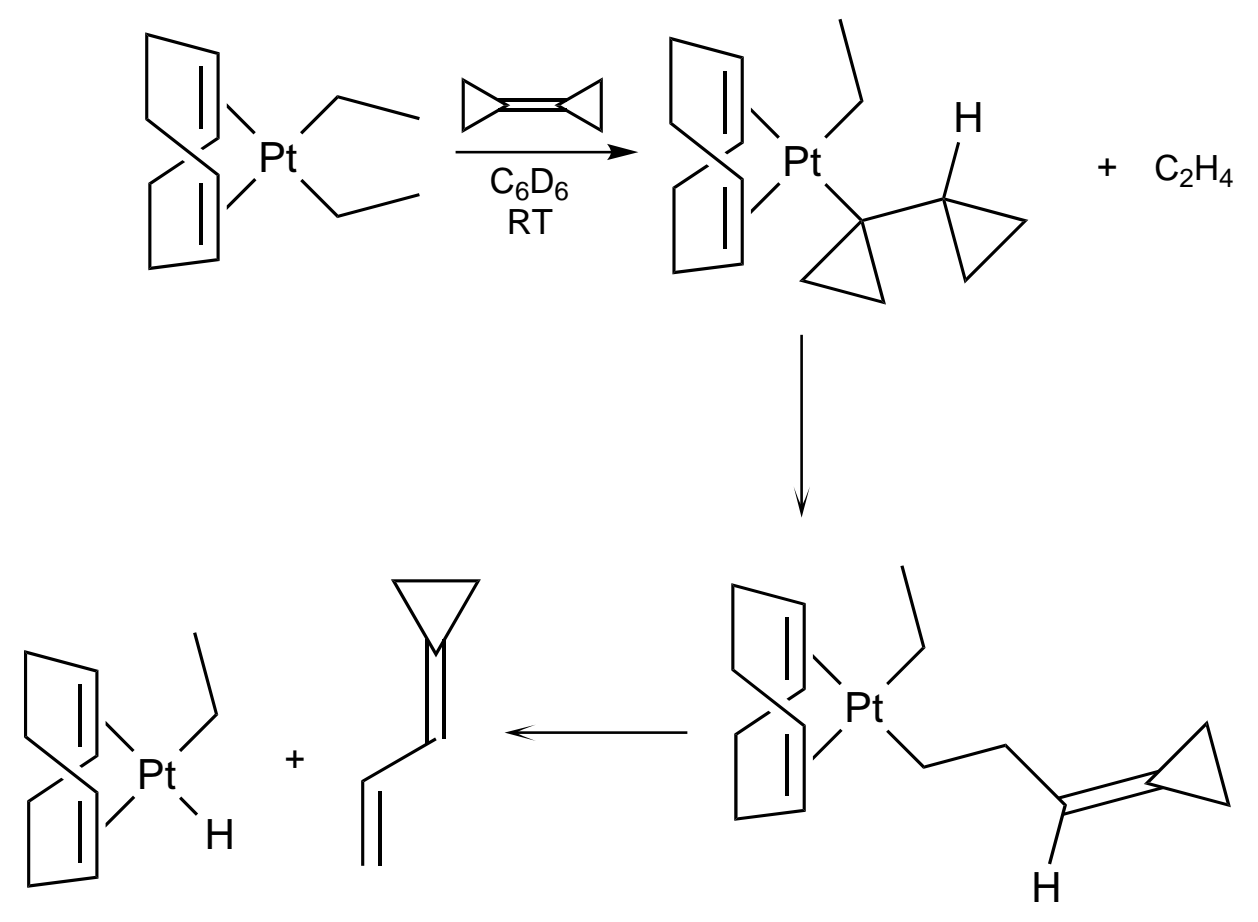

Scheme 4.4. Formation of ACP from $\left[\mathrm{PtEt}_{2}(\mathrm{COD})\right]$. 
Table 4.1. Selected ${ }^{1} \mathrm{H}$ NMR Data of $\left[\mathrm{Pt}(\mathrm{L})_{2}(\mathrm{COD})\right]^{a}$

\begin{tabular}{|c|c|c|c|c|c|}
\hline \multirow{2}{*}{ Compound } & & \multicolumn{4}{|c|}{$\delta_{\mathrm{H}}$} \\
\hline & & ${ }^{c} \mathrm{Pr}$ & $\mathrm{CH}_{3}$ & Et $\mathrm{CH}_{2}$ & Et $\mathrm{CH}_{3}$ \\
\hline$\left[\mathrm{PtEt}_{2}(\mathrm{COD})\right]$ & & & & $1.89(90.2)$ & $1.54(79.5)$ \\
\hline$\left[\mathrm{PtEt}\left(\mathrm{C}\left(\mathrm{CH}_{2}\right)_{2} \mathrm{CH}_{3}\right)(\mathrm{COD})\right]$ & $27 \mathrm{a}$ & $\begin{array}{l}0.73(66.2) \\
0.42(46.5)\end{array}$ & $1.35(55.9)$ & $1.96(91.8)$ & $1.51(74.4)$ \\
\hline$\left[\mathrm{Pt}\left(\mathrm{C}\left(\mathrm{CH}_{2}\right)_{2} \mathrm{CH}_{3}\right)_{2}(\mathrm{COD})\right]$ & $27 \mathrm{~b}$ & $\begin{array}{l}0.86 \\
0.41(66.2) \\
(44.4)\end{array}$ & $1.41(53.5)$ & & \\
\hline
\end{tabular}

${ }^{a} \delta$ values are given in ppm and $J$ values in $\mathrm{Hz}$. All spectra were measured in $\mathrm{C}_{6} \mathrm{D}_{6}$ at room temperature with $40 \mathrm{mg} / \mathrm{mL}$ sample. Values in parentheses are platinum couplings.

Table 4.2. Selected ${ }^{13} \mathrm{C}\left\{{ }^{1} \mathrm{H}\right\}$ NMR Data of $\left[\mathrm{Pt}(\mathrm{L})_{2}(\mathrm{COD})\right] .{ }^{a}$

\begin{tabular}{lccccccc}
\hline \multirow{2}{*}{ Compound } & \multicolumn{6}{c}{$\boldsymbol{\delta}_{\mathbf{C}}$} \\
\cline { 3 - 7 } & & $\mathbf{P t}-\mathbf{C}$ & ${ }^{c} \mathbf{P r}$ & $\mathbf{C H}_{\mathbf{3}}$ & $\mathbf{E t ~} \mathbf{C H}_{\mathbf{2}}$ & $\mathbf{E t} \mathbf{C H}_{\mathbf{3}}$ \\
\hline$\left[\mathrm{PtEt}_{2}(\mathrm{COD})\right]$ & & & & $20.4(847.2)$ & $16.6(32.9)$ \\
{$\left[\mathrm{PtEt}\left(\mathrm{C}\left(\mathrm{CH}_{2}\right)_{2} \mathrm{CH}_{3}\right)(\mathrm{COD})\right]$} & $\mathbf{2 7 a}$ & $17.4(1160.6)$ & 14.9 & $31.2(27.2)$ & $21.8(854.8)$ & $16.4(35.2)$ \\
{$\left[\mathrm{Pt}\left(\mathrm{C}\left(\mathrm{CH}_{2}\right)_{2} \mathrm{CH}_{3}\right)_{2}(\mathrm{COD})\right]$} & $\mathbf{2 7 b}$ & $17.2(1178.5)$ & 15.9 & $31.5(21.3)$ & & \\
\hline
\end{tabular}

${ }^{a} \delta$ values are given in ppm and $J$ values in $\mathrm{Hz}$. All spectra were measured in $\mathrm{C}_{6} \mathrm{D}_{6}$ at room temperature with $40 \mathrm{mg} / \mathrm{mL}$ sample. Values in parentheses are platinum couplings.

was used (Section 3.1). It was found that both BCP and MCP were able to displace ethene from the $\mathrm{Pt}(\mathrm{II})$ complex trans- $-\left[\mathrm{PtCl}_{2}\left(\mathrm{C}_{2} \mathrm{H}_{4}\right)(\mathrm{Py})\right]$ to form the $\eta^{2}$-alkene complexes trans $-\left[\mathrm{PtCl}_{2}(\mathrm{~L})(\mathrm{Py})\right](\mathrm{L}=\mathrm{BCP}(\mathbf{2 8}), \operatorname{MCP}(\mathbf{2 9}))$ (Scheme 4.5). The ethene complex was synthesised in situ by the addition of two equivalents (one per $\mathrm{Pt}$ ) of pyridine to Zeise's dimer $\left(\left[\mathrm{Pt}_{2} \mathrm{Cl}_{4}\left(\mathrm{C}_{2} \mathrm{H}_{4}\right)_{2}\right]\right)$. The formation of $\mathbf{2 8}$ and $\mathbf{2 9}$ occurred immediately upon the addition of the appropriate alkene to trans- $\left[\mathrm{PtCl}_{2}\left(\mathrm{C}_{2} \mathrm{H}_{4}\right)(\mathrm{Py})\right]$ at room temperature. Both of these complexes were unstable, decomposing after approximately 1 hour.

When cis $-\left[\mathrm{PtCl}_{2}(\mathrm{DMSO})_{2}\right]$ was used, it was one of the DMSO ligands that was displaced by the alkene to form cis $-\left[\mathrm{PtCl}_{2}(\mathrm{~L})(\mathrm{DMSO})\right](\mathrm{L}=\operatorname{BCP}(\mathbf{3 0}), \operatorname{MCP}(\mathbf{3 1}))$ (Scheme 4.6). The reactions occurred over the course of several hours, and did not go to completion. Unlike the pyridine complexes, these were stable for several days. 


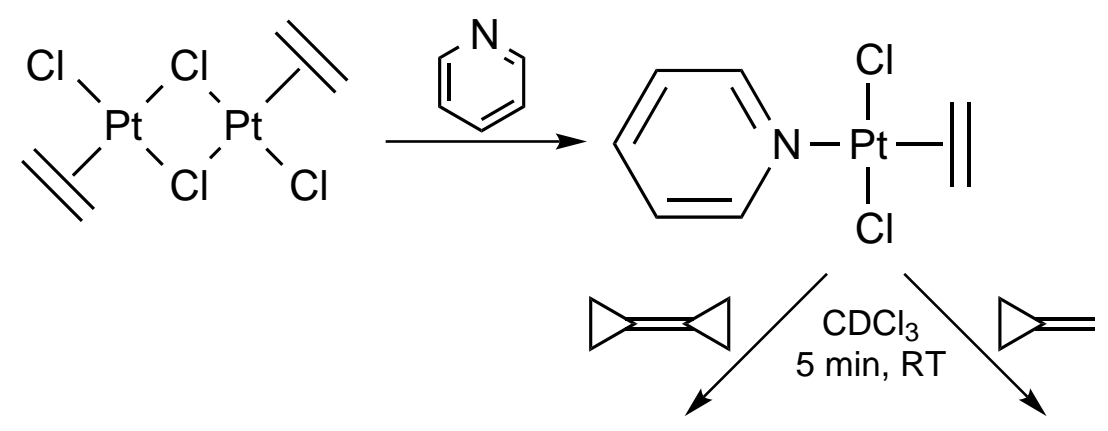

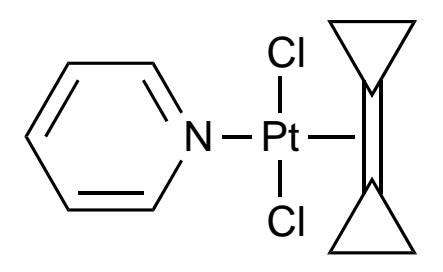

28

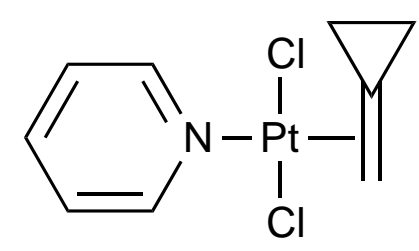

29

Scheme 4.5. Synthesis of trans $-\left[\mathrm{PtCl}_{2}(\mathrm{~L})(\mathrm{Py})\right]$ (28 and 29) from trans $-\left[\mathrm{PtCl}_{2}\left(\mathrm{C}_{2} \mathrm{H}_{4}\right)(\mathrm{Py})\right]$.

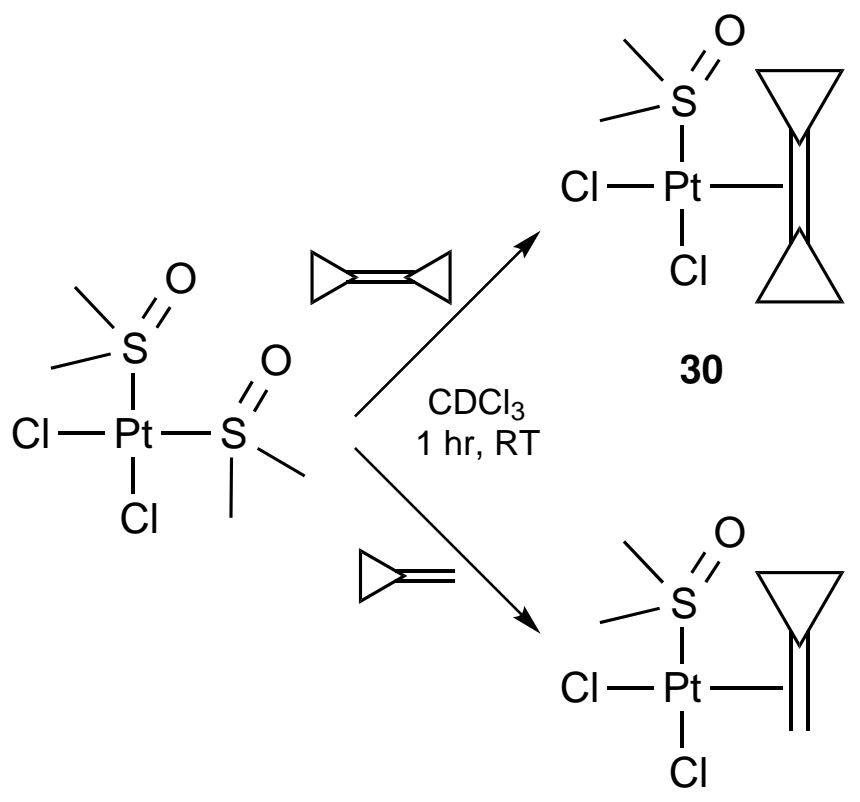

31

Scheme 4.6. Synthesis of cis $^{-}\left[\mathrm{PtCl}_{2}(\mathrm{~L})(\mathrm{DMSO})\right]$ (30 and 31) from cis- $-\left[\mathrm{PtCl}_{2}(\mathrm{DMSO})_{2}\right]$. 


\subsubsection{NMR Characterisation}

For representative NMR spectra, see FIgures A.79-A.81. Compared to the platinum(0) $\eta^{2}$-alkene complexes, the alkene carbons in the $\mathrm{Pt}(\mathrm{II})$ complexes had significantly higher chemical shifts in the ${ }^{13} \mathrm{C}\left\{{ }^{1} \mathrm{H}\right\}$ NMR spectra and therefore smaller changes in chemical shift $(\Delta \delta)$ between the free and coordinated alkene (Tables 2.2 and 4.3). In the BCP complexes $\mathbf{2 8}$ and $\mathbf{3 0}$, the chemical shifts of the double-bond carbons were 75.3 and $82.3 \mathrm{ppm}$ respectively, representing $\Delta \delta \mathrm{s}$ of 35.3 and $28.3 \mathrm{ppm}$. For $[\mathrm{Pt}(\mathrm{BCP})(\mathrm{P}-\mathrm{P})]$ (1), the chemical shifts were between 29-34 ppm, while in $[\mathrm{Pt}(\mathrm{BCP})(\mathrm{P}-\mathrm{S})](\mathbf{8})$, the two double-bond carbons had shifts at 25.2 and $28.1 \mathrm{ppm}$, with an average $\Delta \delta$ of $81 \mathrm{ppm}$. For the Pt(II) MCP complexes 29 and 31, the cyclopropyl double-bond chemical shifts (91.6 and $97.34 \mathrm{ppm}$ ) were $\sim 30 \mathrm{ppm}$ higher than the methylene double-bond carbons (59.8 and $67.5 \mathrm{ppm})$, twice the $\sim 15 \mathrm{ppm}$ difference in $[\mathrm{Pt}(\mathrm{MCP})(\mathrm{P}-\mathrm{P})](\mathbf{2})$. The ${ }^{c} \operatorname{Pr}$ carbons also had a lower $\Delta \delta$ (39.5 and $33.7 \mathrm{ppm})$ than the methylene carbons (43.7 and $36.0 \mathrm{ppm})$. Again, the same resonances in the $\mathrm{Pt}(0) \mathrm{MCP}$ complexes $\mathbf{2}$ and $[\mathrm{Pt}(\mathrm{MCP})(\mathrm{P}-\mathrm{S})](\mathbf{9})$ appeared at significantly lower shifts, 33-43 ppm for the ${ }^{c} \operatorname{Pr}$ double-bond carbon and 22-28 ppm for the methylene carbon (due to the low intensity of the signal, the NMR data for the ${ }^{c} \operatorname{Pr}$ carbon in $\mathbf{9}$ could not be obtained). The average $\Delta \delta$ was therefore $93 \mathrm{ppm}$ for the ${ }^{c} \operatorname{Pr}$ carbon and $78 \mathrm{ppm}$ for the methylene carbon.

The magnitude of $\Delta \delta$ gives a good estimate of the electron density around the alkene carbons, with a larger upfield shift of the resonance upon coordination (larger $\Delta \delta$ ) indicative of a greater electron density. ${ }^{140,149-151} \mathrm{~A}$ larger $\Delta \delta$ also indicates that there is a larger degree of $\pi$ back-bonding. Between the $\mathrm{Pt}(0)$ and $\mathrm{Pt}(\mathrm{II})$ complexes, there was a $\sim 50 \mathrm{ppm}$ difference in $\Delta \delta$ for the ${ }^{c} \operatorname{Pr}$ double-bond carbons and a $\sim 44 \mathrm{ppm}$ difference for the methylene double-bond carbons. This was consistent with there being a higher metal electron density to be shared through back-donation in $\mathrm{d}^{10} \mathrm{Pt}(0)$ complexes than in $\mathrm{d}^{8} \mathrm{Pt}(\mathrm{II})$ complexes.

There was a similar lowering of the magnitude of the ${ }^{1} J_{\mathrm{Pt}-\mathrm{C}}$ coupling constants in the $\mathrm{Pt}(\mathrm{II})$ complexes compared the the Pt(0) complexes. In the BCP complexes 28 and 30, ${ }^{1} J_{\mathrm{Pt}-\mathrm{C}}$ of the ${ }^{c} \mathrm{Pr}$ double-bond carbons were 248.5 and $251.8 \mathrm{~Hz}$ respectively. In $\mathbf{1}$, 
Table 4.3. Selected NMR Data of $\left[\mathrm{PtCl}_{2}\left(\eta^{2}\right.\right.$-alkene $\left.)(\mathrm{L})\right] .^{a}$

\begin{tabular}{|c|c|c|c|c|c|c|c|c|}
\hline \multirow{2}{*}{ Compound } & & \multicolumn{2}{|c|}{${ }^{c} \operatorname{Pr}$} & \multicolumn{3}{|c|}{$=\mathrm{CH}_{2}$} & \multicolumn{2}{|c|}{$=\mathrm{CR}_{2}$} \\
\hline & & $\delta_{\mathrm{H}}$ & $\delta_{\mathrm{C}}$ & $\delta_{\mathrm{H}}$ & $\delta_{\mathrm{C}}$ & ${ }^{1} J_{\mathrm{Pt}-\mathrm{C}}$ & $\delta_{\mathrm{C}}$ & ${ }^{1} J_{\mathrm{Pt}-\mathrm{C}}$ \\
\hline trans $-\left[\mathrm{PtCl}_{2}(\mathrm{BCP})(\mathrm{Py})\right]$ & 28 & $\begin{array}{l}1.58 \\
1.12\end{array}$ & 10.6 & & & & 75.3 & 248.5 \\
\hline$c i s-\left[\mathrm{PtCl}_{2}(\mathrm{BCP})(\mathrm{DMSO})\right]$ & 30 & $\begin{array}{l}1.25 \\
0.85\end{array}$ & $\begin{array}{l}12.5 \\
11.5\end{array}$ & & & & 82.3 & 251.8 \\
\hline trans $-\left[\mathrm{PtCl}_{2}(\mathrm{MCP})(\mathrm{Py})\right]$ & 29 & $\begin{array}{l}1.62 \\
1.32\end{array}$ & 10.2 & 5.02 & 59.8 & & 91.6 & \\
\hline$c i s-\left[\mathrm{PtCl}_{2}(\mathrm{MCP})(\mathrm{DMSO})\right]$ & 31 & $\begin{array}{l}1.88 \\
1.55 \\
1.38 \\
1.28\end{array}$ & 12.6 & $\begin{array}{l}4.81 \\
4.64\end{array}$ & 67.5 & 141.0 & 97.3 & 277.5 \\
\hline
\end{tabular}

${ }^{a} \delta$ values are given in ppm and $J$ values in Hz. All spectra were measured in $\mathrm{CDCl}_{3}$ at room temperature with $40 \mathrm{mg} / \mathrm{mL}$ sample.

${ }^{1} J_{\mathrm{Pt}-\mathrm{C}}$ was $410-456 \mathrm{~Hz}, \sim 200 \mathrm{~Hz}$ larger, while in $8{ }^{1} J_{\mathrm{Pt}-\mathrm{C}}$ was even higher $(579.0$ and 656.6 Hz), a difference of as much as $400 \mathrm{~Hz}$. For the ${ }^{c}$ Pr double-bond carbon in the MCP complex 31, ${ }^{1} J_{\mathrm{Pt}-\mathrm{C}}$ was slightly higher than in the BCP complexes, $277.5 \mathrm{~Hz}$, an average of $\sim 220 \mathrm{~Hz}$ lower than $\mathbf{2}$. Due to the broadness of the spectra of $\mathbf{2 9}$, no coupling data could be obtained. The ${ }^{1} J_{\mathrm{Pt}-\mathrm{C}}$ of the methylene carbon in $\mathbf{3 1}$ was also lower than those of 2 at $141.0 \mathrm{~Hz}$, a difference of $\sim 27 \mathrm{~Hz}$, a smaller difference than for the ${ }^{c} \mathrm{Pr}$ carbons.

\section{$4.4 \quad \beta$-Chloroalkyl Complexes}

The polymerisation of halogenated monomers such as vinyl chloride typically occurs through a radical mechanism. ${ }^{160-163}$ However, this method is problematic as it can lead to a range of "defect sites", which decrease the thermal stability of the resulting polymer. An alternative pathway involves insertion of the alkene monomer into a metal alkyl bond, forming a halogenated alkyl ligand. Chain propagation would then occur with the coordination of another monomer molecule, followed by another insertion step. It is thought that this mechanism would lead to a polymer that contains fewer defects, as well as allowing greater control over polymer structure by using tailored catalysts. ${ }^{160,162}$ 
When vinyl chloride was reacted with a variety of both early- and late-transition metal catalysts, it was found that the insertion step was followed by a rapid $\beta$-chloride elimination to form a $\mathrm{M}-\mathrm{Cl}$ bond. ${ }^{160-163}$ There are two possible modes of insertion of vinyl chloride into a $\mathrm{M}-\mathrm{R}$ bond (Scheme 4.7). For 2,1-insertion, the $\mathrm{R}$ group attaches to the methylene carbon, leading to an $\alpha$-chloroalkyl ligand. For 1,2-insertion, the $\mathrm{R}$ group attaches to the same carbon as the $\mathrm{Cl}$, and a $\beta$-chloroalkyl ligand is produced. While the 2,1-insertion is favoured theoretically, this product was never observed. Either the 1,2-insertion product was the only one that formed, or the 2,1-product underwent a facile isomerisation to form the 1,2-product. ${ }^{162,164,165} \mathrm{~A}$ very fast $\beta$-chloride elimination reaction then occurred. The elimination proceeded more rapidly than the coordination of a second monomer, preventing the propagation of the polymer chain. Complexes of the early transition metals are more prone to $\beta$-halogen elimination than those of the late transition metals due to the relative strengths of the $\mathrm{M}-\mathrm{X}$ and $\mathrm{M}-\mathrm{C}$ bonds. ${ }^{160,162}$ Calculations on a palladium phosphine species also showed that $\beta$-halide elimination is both thermodynamically and kinetically more favourable than $\beta$-hydride elimination. ${ }^{166}$

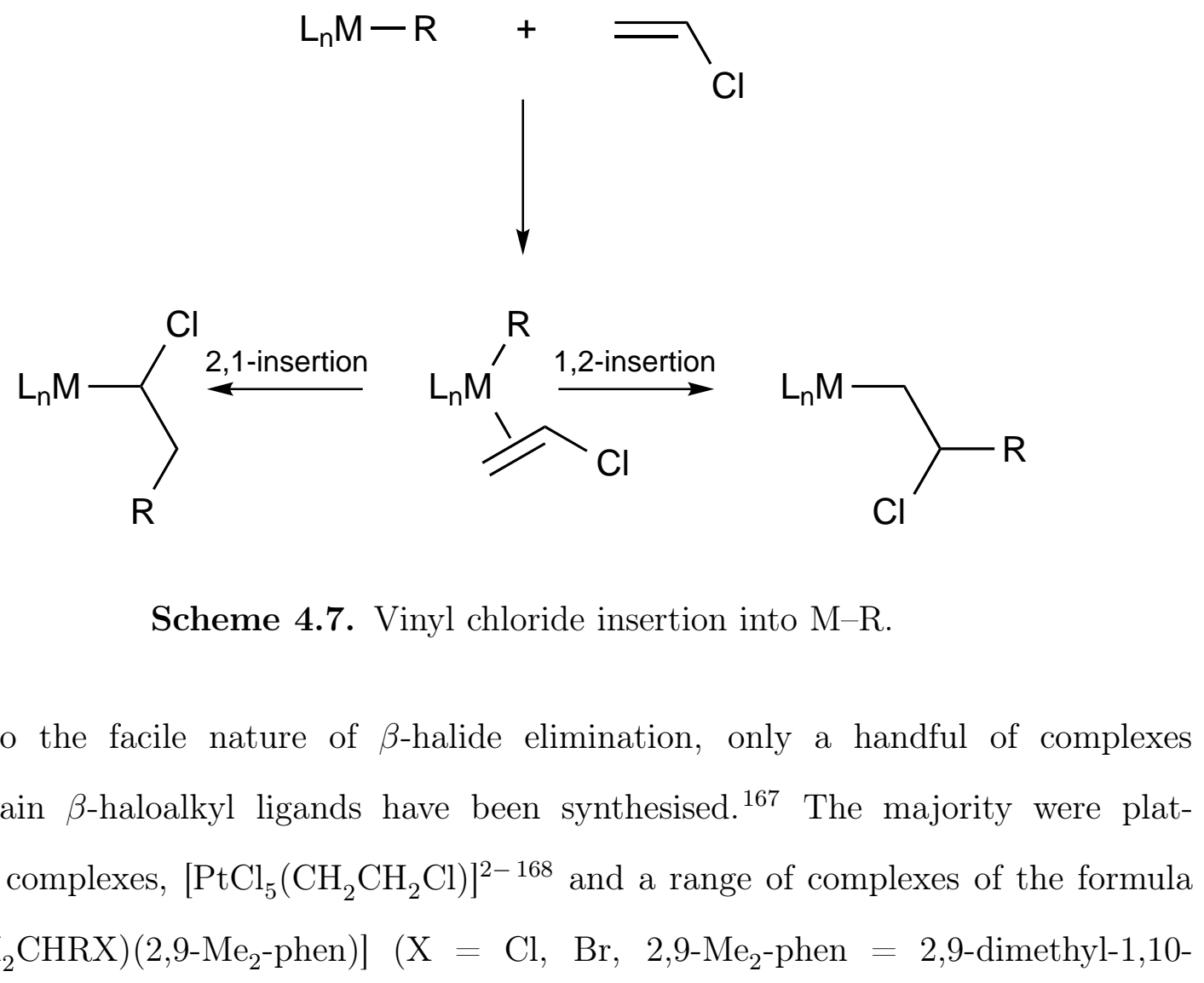


phenanthroline). ${ }^{169}$ An iridium complex, $\left[\mathrm{IrBr}_{2}\left(\mathrm{CH}_{2} \mathrm{CH}_{2} \mathrm{Br}\right)(\mathrm{CO})\left(\mathrm{PMe}_{2} \mathrm{Ph}\right)_{2}\right],{ }^{170}$ has also been synthesised, as well as complexes with ligands that contain multiple halogens, ${ }^{171}$ particularly perfluorinated ligands. ${ }^{172-177}$ Except for the perfluorinated complexes, these $\beta$-haloalkyl complexes were synthesised by the addition of $\mathrm{X}_{2}$ to an alkene complex.

\subsubsection{Synthesis From Dichloro Complexes}

It was found that when bicyclopropylidene was reacted with a range of platinum precursors that contained chloride ligands, $\mathrm{BCP}$ inserted into the $\mathrm{Pt}-\mathrm{Cl}$ bond to form complexes with stable $\beta$-chloroalkyl ligands. The reactions with $\left[\mathrm{PtCl}_{2}\left(\mathrm{SEt}_{2}\right)_{2}\right]$ (a mixture of isomers $),{ }^{178}$ trans $-\left[\mathrm{PtCl}_{2}\left(\mathrm{NC}^{t} \mathrm{Bu}\right)_{2}\right]$ and trans $-\left[\mathrm{PtCl}_{2}(\mathrm{Py})_{2}\right]$ yielded the complexes trans$\left[\mathrm{Pt}\left(\mathrm{C}\left(\mathrm{CH}_{2}\right)_{2} \mathrm{C}\left(\mathrm{CH}_{2}\right)_{2} \mathrm{Cl}\right) \mathrm{Cl}(\mathrm{L})_{2}\right]\left(\mathrm{L}=\mathrm{SEt}_{2}(\mathbf{3 2}), \mathrm{NC}^{t} \mathrm{Bu}(33)\right.$, Py (34a)) respectively (Scheme 4.8). The formation of $\mathbf{3 2}$ takes up to 5 days with an excess of BCP, while the formation of $\mathbf{3 3}$ takes 2 days with 1 eq. BCP. The formation of $\mathbf{3 4 a}$ occurred over 2 days. However, the reaction did not go to completion, with 34a making up $30 \%$ of the species in solution by ${ }^{1} \mathrm{H}$ NMR spectroscopy, and a large amount of undissolved solid remaining. After two weeks, a second new complex formed from the trans $-\left[\mathrm{PtCl}_{2}(\mathrm{Py})_{2}\right]$ in a 1:3 ratio relative to $\mathbf{3 4 a}$. This complex could not be characterised.

When cis- $\left[\mathrm{PtCl}_{2}\left(\mathrm{NC}^{t} \mathrm{Bu}\right)_{2}\right]$ and cis- $\left[\mathrm{PtCl}_{2}(\mathrm{Py})_{2}\right]$ were used, no reaction occurred. Given this, it is likely that only the trans form of $\left[\mathrm{PtCl}_{2}\left(\mathrm{SEt}_{2}\right)_{2}\right]$ undergoes a reaction with BCP. The cis and trans forms of $\left[\mathrm{PtCl}_{2}\left(\mathrm{SEt}_{2}\right)_{2}\right]$ can interconvert in the presence of $\mathrm{SEt}_{2}$, forming an equilibrium mixture. ${ }^{179}$ The need for the interconversion of the isomers could explain the long reaction time with BCP.

When two equivalents of BCP (one per Pt) was reacted with Zeise's dimer $\left(\left[\mathrm{Pt}_{2} \mathrm{Cl}_{4}\left(\mathrm{C}_{2} \mathrm{H}_{4}\right)_{2}\right]\right)$ and two equivalents pyridine (one per $\mathrm{Pt}$ ), initially an $\eta^{2}$-alkene complex, trans- $\left.\mathrm{PtCl}_{2}(\mathrm{BCP})(\mathrm{Py})\right]$ (28) was formed (Section 4.3). This complex was unstable, and decomposed after an hour. When a second equivalent of Py was added after the formation of $\mathbf{2 8}$, the alkene complex reacted immediately formed the $\beta$-chloroalkyl complex cis- $\left[\mathrm{Pt}\left(\mathrm{C}\left(\mathrm{CH}_{2}\right)_{2} \mathrm{C}\left(\mathrm{CH}_{2}\right)_{2} \mathrm{Cl}\right) \mathrm{Cl}(\mathrm{Py})_{2}\right](\mathbf{3 4 b})$. Complex 34b could also be synthesised directly by the addition of two equivalents of $\mathrm{BCP}$ (one per Pt) and 


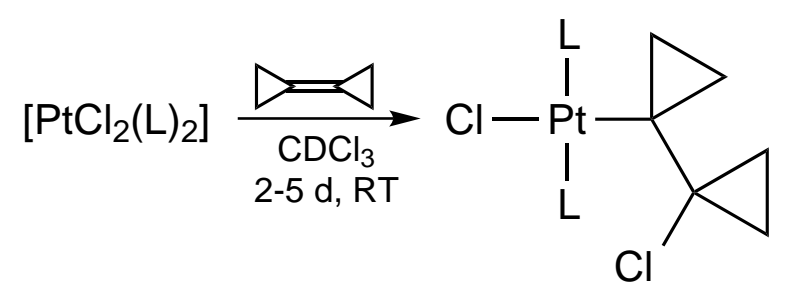

$$
\begin{array}{rlr}
\mathrm{L} & =\mathrm{SEt}_{2} & \mathbf{3 2} \\
& =\mathrm{NC}^{t} \mathrm{Bu}_{2} & \mathbf{3 3} \\
& =\mathrm{Py} & \mathbf{3 4 a}
\end{array}
$$

Scheme 4.8. Synthesis of trans $-\left[\mathrm{Pt}\left(\mathrm{C}\left(\mathrm{CH}_{2}\right)_{2} \mathrm{C}\left(\mathrm{CH}_{2}\right)_{2} \mathrm{Cl}\right) \mathrm{Cl}(\mathrm{L})_{2}\right]$ from $\left[\mathrm{PtCl}_{2}(\mathrm{~L})_{2}\right]$ $(32-34 a)$.

four equivalents of Py (two per Pt) to Zeise's dimer. This reaction occurred immediately upon the mixing of the reagents (Scheme 4.9).

Comparable reactivity was observed with MCP. Again, when only two equivalents of Py was used a $\eta^{2}$-alkene complex formed, trans- $\left[\mathrm{PtCl}_{2}(\mathrm{MCP})(\mathrm{Py})\right](\mathbf{2 9})$. When a further two equivalents of $\mathrm{Py}$ (one per $\mathrm{Pt}$ ) was added, cis- $\left[\mathrm{Pt}\left(\mathrm{C}\left(\mathrm{CH}_{2}\right)_{2} \mathrm{CH}_{2} \mathrm{Cl}\right) \mathrm{Cl}(\mathrm{Py})_{2}\right]$ (34c) was formed (Scheme 4.10). The corresponding reaction of $\left[\mathrm{Pt}_{2} \mathrm{Cl}_{4}\left(\mathrm{C}_{2} \mathrm{H}_{4}\right)_{2}\right]$ with two equivalents of MCP (one per Pt) and four equivalents of Py (two per Pt) also produced 34c). The analogous reactions of $\mathrm{MCP}$ with $\left[\mathrm{PtCl}_{2}\left(\mathrm{SEt}_{2}\right)_{2}\right]$, cis- and trans$\left[\mathrm{PtCl}_{2}\left(\mathrm{NC}^{t} \mathrm{Bu}\right)_{2}\right]$ and cis- and trans $-\left[\mathrm{PtCl}_{2}(\mathrm{Py})_{2}\right]$ did not occur.

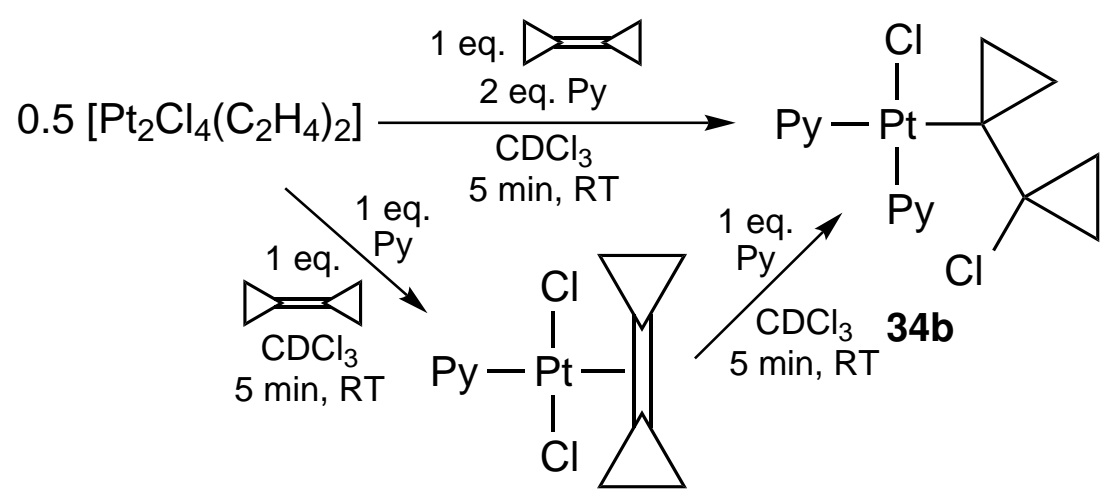

28

Scheme 4.9. Synthesis of cis- $\left[\mathrm{Pt}\left(\mathrm{C}\left(\mathrm{CH}_{2}\right)_{2} \mathrm{C}\left(\mathrm{CH}_{2}\right)_{2} \mathrm{Cl}\right) \mathrm{Cl}(\mathrm{Py})_{2}\right]$ (34b) from $\left[\mathrm{Pt}_{2} \mathrm{Cl}_{4}\left(\mathrm{C}_{2} \mathrm{H}_{4}\right)_{2}\right]$.

The ethene complex $\left[\mathrm{PtCl}_{2}\left(\mathrm{C}_{2} \mathrm{H}_{4}\right)(\mathrm{Py})\right]$ in the presence of pyridine is in equilibrium with the 5-coordinate complex $\left[\mathrm{PtCl}_{2}\left(\mathrm{C}_{2} \mathrm{H}_{4}\right)(\mathrm{Py})_{2}\right] .{ }^{180}$ The availability of the 5-coordinate 


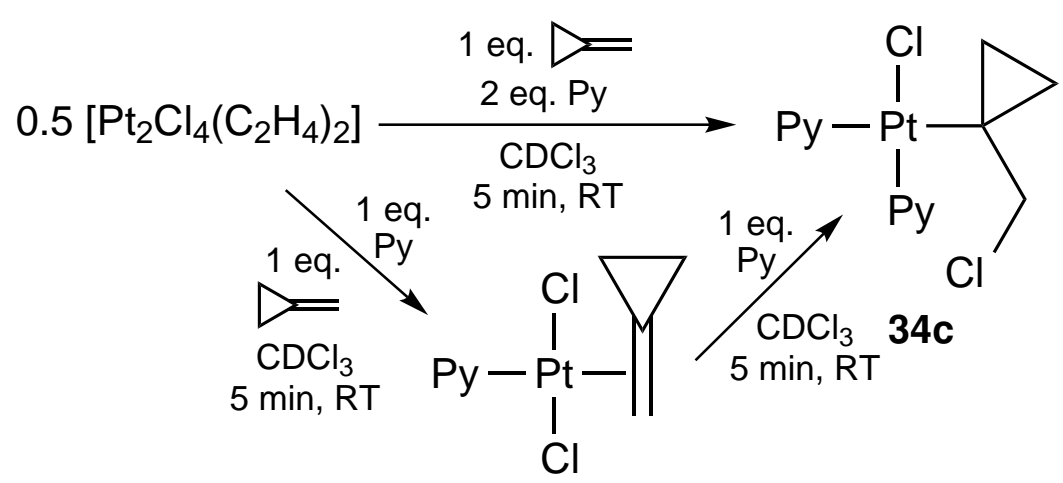

29

Scheme 4.10. Synthesis of cis- $\left[\mathrm{Pt}\left(\mathrm{C}\left(\mathrm{CH}_{2}\right)_{2} \mathrm{CH}_{2} \mathrm{Cl}\right) \mathrm{Cl}(\mathrm{Py})_{2}\right]$ from $\left[\mathrm{Pt}_{2} \mathrm{Cl}_{4}\left(\mathrm{C}_{2} \mathrm{H}_{4}\right)_{2}\right]$ $(34 \mathrm{c})$.

complex suggests that the mechanism for the formation of the $\beta$-chloroalkyl complexes would be associative, rather than dissociative. Initially, $\mathrm{BCP}$ or MCP would coordinate to form an intermediate $\eta^{2}$-alkene complex (as with $\mathbf{2 8}$ and $\mathbf{2 9}$ ). This would be followed by the addition of the second equivalent of pyridine and insertion of the alkene into the $\mathrm{Pt}-\mathrm{Cl}$ bond. The cis-pyridine complexes formed the most rapidly of the $\beta$-chloroalkyl complexes (by several days), and had isolatable alkene complex intermediates, $\mathbf{2 8}$ and $\mathbf{2 9}$, which were able to be converted to $\mathbf{3 4 b}$ and $\mathbf{3 4 c}$ by the addition of pyridine, supporting this mechanism.

\subsubsection{Synthesis of Phosphine Complexes}

The synthesis of a phosphine complex containing a $\beta$-chloroalkyl ligand was considered desirable due to the inclusion of another NMR-active nuclei, increasing the amount of characterisation data available. However, no reaction occurred when either $\mathrm{BCP}$ or MCP was combined with $\left[\mathrm{PtCl}_{2}\left(\mathrm{PR}_{3}\right)_{2}\right]$ complexes. Instead, phosphine complexes were synthesised by the addition of the phosphine to a complex with a $\beta$-chloroalkyl ligand already installed.

The thioether complex trans- $\left[\mathrm{Pt}\left(\mathrm{C}\left(\mathrm{CH}_{2}\right)_{2} \mathrm{C}\left(\mathrm{CH}_{2}\right)_{2} \mathrm{Cl}\right) \mathrm{Cl}\left(\mathrm{SEt}_{2}\right)_{2}\right]$ (32) was treated with a number of phosphines, both mono- and bi-dentate. When triphenylphosphine was used, the $\mathrm{SEt}_{2}$ was successfully displaced by the $\mathrm{PPh}_{3}$. However, a $\beta$-chloride elimination occurred, forming cis- $\left[\mathrm{PtCl}_{2}\left(\mathrm{PPh}_{3}\right)_{2}\right]$ as well as free BCP. The chelating phosphines 
1,3-bis(diphenylphosphino)propane (dppp) and 1,2-bis(diphenylphosphino)ethane (dppe) were also used. In these reactions, there was again a $\beta$-chloride elimination, producing the $\mathrm{Pt}(\mathrm{II})$ bis-diphosphine complexes $\left[\mathrm{Pt}(\mathrm{P}-\mathrm{P})_{2}\right] \mathrm{Cl}_{2}(\mathrm{P}-\mathrm{P}=\operatorname{dppp}(\mathbf{3 5 a})$, dppe (35b)) and free BCP. The phosphine-chloride complexes were identified by ${ }^{31} \mathrm{P}$ NMR data. ${ }^{181,182}$

Single crystals of $\mathbf{3 5 a}$ were grown by layering a frozen solution of $\mathbf{3 2}$ in $\mathrm{CDCl}_{3}$ with a solution of dppp in $\mathrm{CDCl}_{3}$ and allowing to warm to room temperature, and an X-ray crystal structure obtained (Figure 4.1, Table 4.4). ${ }^{183}$ The asymmetric unit contained only half of the molecule, consisting of a complete dppp ligand as well as one of the chloride counter ions and three of the six $\mathrm{CDCl}_{3}$ solvent molecules. The platinum coordination geometry was close to square planar, with a P1-Pt-P2 angle of $87.23(3)^{\circ}$. This is smaller than the corresponding angle in the quasi-tetrahedral $\mathrm{Pt}(0)$ complex $\left[\mathrm{Pt}^{0}(\mathrm{dppp})_{2}\right]$ $\left(97.76(4)^{\circ}\right) .{ }^{90}$ The Pt-P bond lengths in 35a were 2.3647(8) and 2.3790(8) $\AA$, longer than those in $\left[\mathrm{Pt}^{0}(\mathrm{dppp})_{2}\right](2.286(1) \AA)$. The chelate ring had a 'chair' conformation, typical for dppp complexes. In $\mathbf{3 5 a}$, the two chelate rings were rotated by $180^{\circ}$ relative to each other, while in $\left[\mathrm{Pt}^{0}(\mathrm{dppp})_{2}\right]$ the rings were rotated by $87.20(2)^{\circ}$, according to the P1-Pt-P2 planes. While 35a crystallised as a $\mathrm{CDCl}_{3}$ solvate in the orthorhombic Pccn space group, $\left[\mathrm{Pt}^{0}(\mathrm{dppp})_{2}\right]$ crystallised solvent-free in the monoclinic $C 2 / c$ space group. The $\mathrm{Cl}^{-}$counter ion was separated by $4.197 \AA$ from the Pt, indicating that it was not coordinated. The $\left[\mathrm{Pt}^{\mathrm{II}}(\mathrm{dppp})_{2}\right]^{2+}$ ions were arranged in $2 \mathrm{D}$ layers, with the $\mathrm{Cl}^{-}$anions and solvent between the layers (Figure 4.2).

When 1,3,5-triaza-7-phosphaadamantane (PTA) was added to 32, the $\mathrm{SEt}_{2}$ ligands were again successfully displaced by the phosphine. As with the other phosphines, cis- $-\left[\mathrm{PtCl}_{2}(\mathrm{PTA})_{2}\right]$ and free $\mathrm{BCP}$ were formed. ${ }^{184}$ However, in this case a short-lived (approx. $1 \mathrm{hr}$ ) complex formed inititally. This complex is believed to be trans$\left[\mathrm{Pt}\left(\mathrm{C}\left(\mathrm{CH}_{2}\right)_{2} \mathrm{C}\left(\mathrm{CH}_{2}\right)_{2} \mathrm{Cl}\right) \mathrm{Cl}(\mathrm{PTA})_{2}\right] \quad(\mathbf{3 6 a})$ (Scheme 4.11). The reaction of PTA with trans $-\left[\mathrm{Pt}\left(\mathrm{C}\left(\mathrm{CH}_{2}\right)_{2} \mathrm{C}\left(\mathrm{CH}_{2}\right)_{2} \mathrm{Cl}\right) \mathrm{Cl}\left(\mathrm{NC}^{t} \mathrm{Bu}\right)_{2}\right]$ (33) also resulted in the formation of $\mathbf{3 6 a}$ and subsequently cis- $\left.-\mathrm{PtCl}_{2}(\mathrm{PTA})_{2}\right]$.

The synthesis of cis-phosphine complexes proved to be more successful than trans-

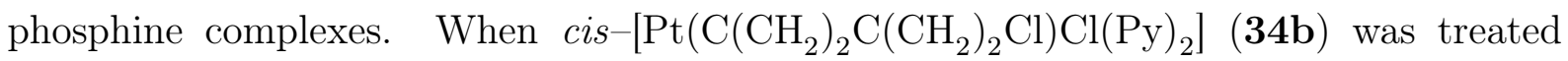




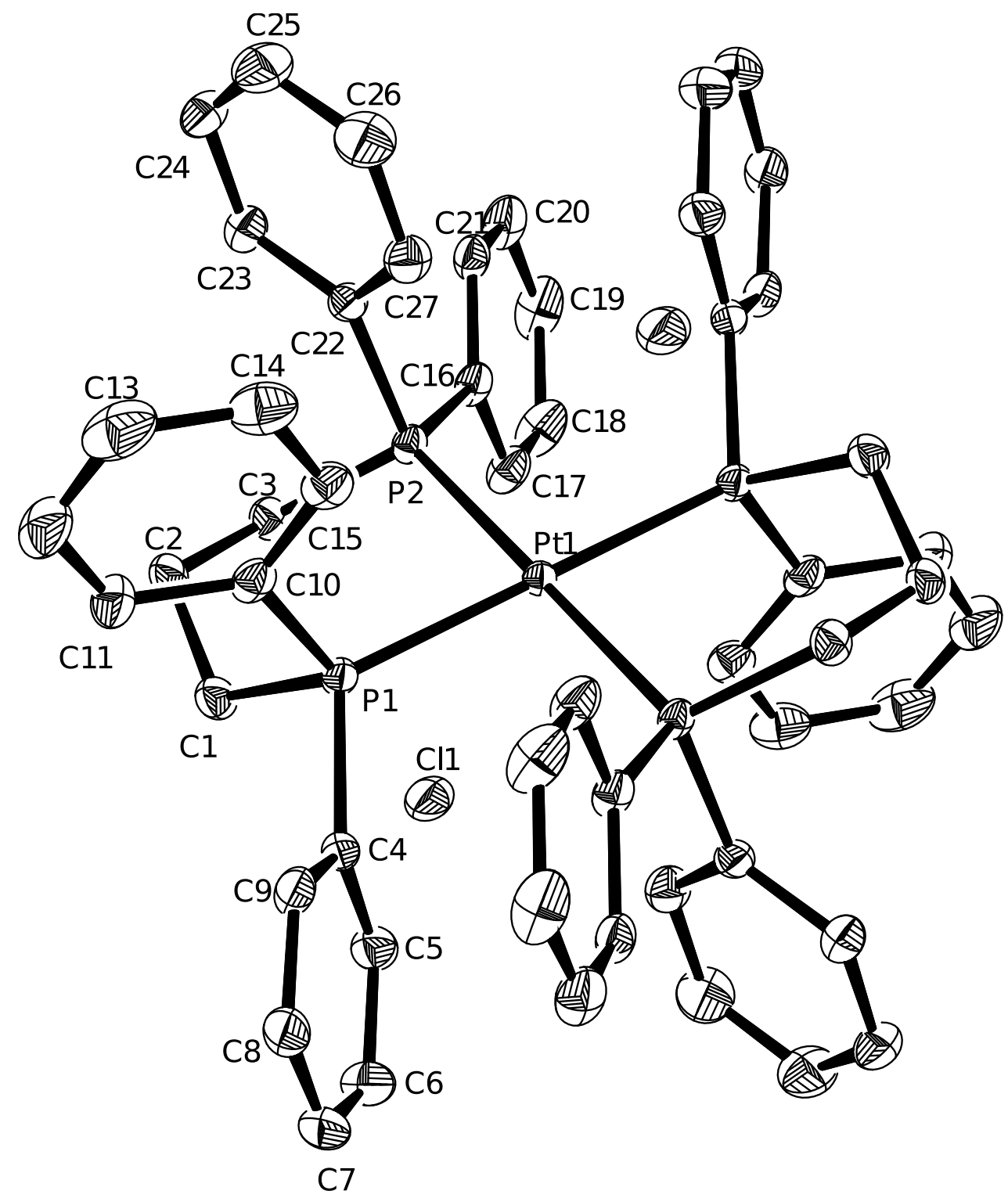

Figure 4.1. ORTEP diagram of $\left[\mathrm{Pt}(\mathrm{dppp})_{2}\right] \mathrm{Cl}_{2} \cdot 6 \mathrm{CDCl}_{3}$ (35a) showing $50 \%$ probability thermal ellipsoids. $\mathrm{H}$ atoms and $\mathrm{CDCl}_{3}$ solvent molecules have been omitted for clarity. 


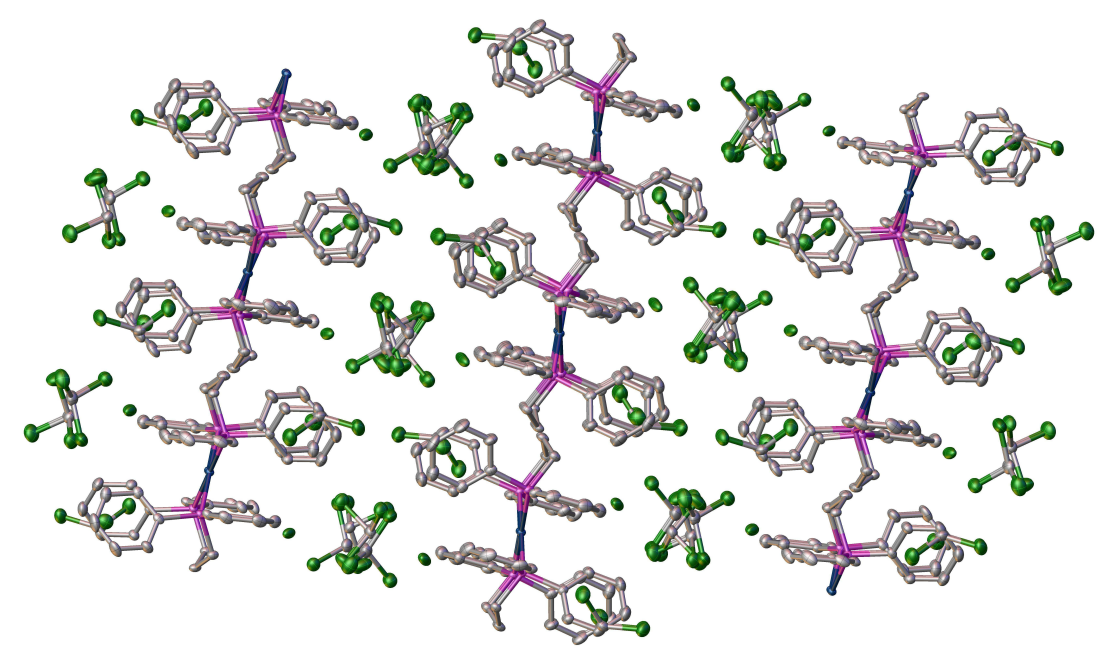

Figure 4.2. Layered packing of $\left[\mathrm{Pt}(\mathrm{dppp})_{2}\right] \mathrm{Cl}_{2} \cdot 6 \mathrm{CDCl}_{3}(\mathbf{3 5 a})$.

Table 4.4. Crystallographic Data for $\left[\mathrm{Pt}(\mathrm{dppp})_{2}\right] \mathrm{Cl}_{2} \cdot 6 \mathrm{CDCl}_{3}(\mathbf{3 5 a})$.

\begin{tabular}{|c|c|}
\hline Chemical formula & $\mathrm{C}_{60} \mathrm{H}_{58} \mathrm{Cl}_{20} \mathrm{P}_{4} \mathrm{Pt}$ \\
\hline Formula weight & 1687.77 \\
\hline $\mathrm{a}, \AA$ & $26.2042(9)$ \\
\hline $\mathrm{b}, \AA$ & $15.3120(5)$ \\
\hline c, $\AA$ & $16.7930(5)$ \\
\hline$\alpha, \operatorname{deg}$ & 90.00 \\
\hline$\beta, \operatorname{deg}$ & 90.00 \\
\hline$\gamma, \operatorname{deg}$ & 90.00 \\
\hline $\mathrm{V}, \AA^{3}$ & $6738.0(4)$ \\
\hline Z & 4 \\
\hline Space group & Pccn \\
\hline $\mathrm{T}, \mathrm{K}$ & 160 \\
\hline$\lambda, \AA$ & 0.71073 \\
\hline $\mathrm{D}_{\text {calcd }}, \mathrm{g} \mathrm{cm}^{-3}$ & 1.664 \\
\hline$\mu, \mathrm{mm}^{-1}$ & 2.890 \\
\hline $\mathrm{R}_{1},[\mathrm{I}>2 \sigma(\mathrm{I})]^{a}$ & 0.0373 \\
\hline$w \mathrm{R}_{2}(\text { all data })^{a}$ & 0.0745 \\
\hline
\end{tabular}


<smiles>CC(C)(Cl)C1([P](Cl)(Cl)I)CC1</smiles>

$\mathrm{L}=\mathrm{SEt}_{2}$ $=\mathrm{NC}{ }^{t} \mathrm{Bu}$

32

33

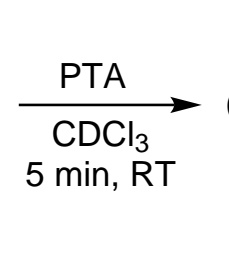

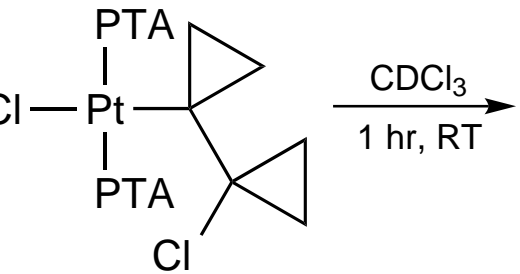

$36 \mathbf{a}$

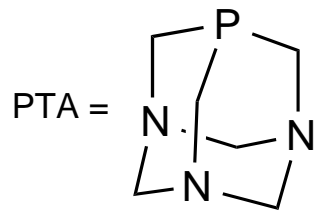

Scheme 4.11. Synthesis of trans $-\left[\mathrm{Pt}\left(\mathrm{C}\left(\mathrm{CH}_{2}\right)_{2} \mathrm{C}\left(\mathrm{CH}_{2}\right)_{2} \mathrm{Cl}\right) \mathrm{Cl}(\mathrm{PTA})_{2}\right]$ (36a) from trans $-\left[\mathrm{Pt}\left(\mathrm{C}\left(\mathrm{CH}_{2}\right)_{2} \mathrm{C}\left(\mathrm{CH}_{2}\right)_{2} \mathrm{Cl}\right) \mathrm{Cl}(\mathrm{L})_{2}\right](32$ and 33).

with either PTA, dppp or $\mathrm{PPh}_{3}$, the products were $\beta$-chloroalkyl complexes cis$\left[\mathrm{Pt}\left(\mathrm{C}\left(\mathrm{CH}_{2}\right)_{2} \mathrm{C}\left(\mathrm{CH}_{2}\right)_{2} \mathrm{Cl}\right) \mathrm{Cl}(\mathrm{P})_{2}\right] \quad\left((\mathrm{P})_{2}=(\mathrm{PTA})_{2} \quad(\mathbf{3 6} \mathbf{b}), \operatorname{dppp}(\mathbf{3 7 a}), \quad\left(\mathrm{PPh}_{3}\right)_{2} \quad(\mathbf{3 8 a})\right)$ which were stable in solution over several weeks (Scheme 4.12). The reactions also generated a small amount of $\operatorname{cis}-\left[\mathrm{PtCl}_{2}(\mathrm{P})_{2}\right]$. The amount of $c i s-\left[\mathrm{PtCl}_{2}(\mathrm{PTA})_{2}\right]$ produced was significantly greater than for the other phosphines. As cis- $\left[\mathrm{PtCl}_{2}(\mathrm{PTA})_{2}\right]$ was only partially soluble, the exact amount was not calculated, while there was $30 \%$ cis$\left[\mathrm{PtCl}_{2}\left(\mathrm{PPh}_{3}\right)_{2}\right]$ and $11 \%$ cis $-\left[\mathrm{PtCl}_{2}(\mathrm{dppp})_{2}\right]$.

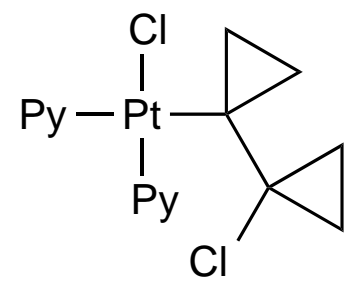

$34 b$

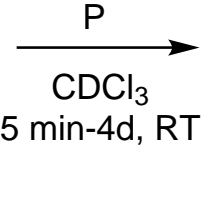

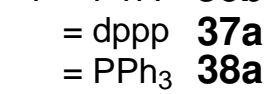

Scheme 4.12. Synthesis of cis- $\left[\mathrm{Pt}\left(\mathrm{C}\left(\mathrm{CH}_{2}\right)_{2} \mathrm{C}\left(\mathrm{CH}_{2}\right)_{2} \mathrm{Cl}\right) \mathrm{Cl}(\mathrm{P})_{2}\right]$ from cis $-\left[\mathrm{Pt}\left(\mathrm{C}\left(\mathrm{CH}_{2}\right)_{2} \mathrm{C}\left(\mathrm{CH}_{2}\right)_{2} \mathrm{Cl}\right) \mathrm{Cl}(\mathrm{Py})_{2}\right](\mathbf{3 4 b})$.

In the reaction of $\mathbf{3 4 a}$ with $\mathrm{PPh}_{3}$, a complex with only one phosphine ligand was formed initially (38b). The ${ }^{31} \mathrm{P}\left\{{ }^{1} \mathrm{H}\right\}$ and ${ }^{13} \mathrm{C}\left\{{ }^{1} \mathrm{H}\right\}$ NMR data (see below) indicated that it was the pyridine trans to the chloride that was displaced. The bis(phosphine) complex 
38a began to form after an hour. The reaction did not reach completion; after 4 days there was $53 \%$ 38a, 8.5\% monophosphine complex, 8.5\% $\mathrm{PPh}_{3}$ and $30 \%$ cis- $\left[\mathrm{PtCl}_{2}\left(\mathrm{PPh}_{3}\right)_{2}\right]$, with the ratios remaining stable over several weeks. With dppp, 37a formed initially, reaching $85 \%$ with $11 \%\left[\mathrm{PtCl}_{2}(\mathrm{dppp})\right]$ after 2 days.

The addition of phosphines to the $\beta$-chloroalkyl complex formed from MCP (cis$\left.\left[\mathrm{Pt}\left(\mathrm{C}\left(\mathrm{CH}_{2}\right)_{2} \mathrm{CH}_{2} \mathrm{Cl}\right) \mathrm{Cl}(\mathrm{Py})_{2}\right], 34 \mathbf{c}\right)$ also resulted in the formation of phosphine complexes cis- $-\left[\mathrm{Pt}\left(\mathrm{C}\left(\mathrm{CH}_{2}\right)_{2} \mathrm{CH}_{2} \mathrm{Cl}\right) \mathrm{Cl}(\mathrm{P})_{2}\right]\left((\mathrm{P})_{2}=(\mathrm{PTA})_{2}\right.$ (36c), dppp $\left.(37 \mathbf{b})\right)$, as well as cis$\left[\mathrm{PtCl}_{2}(\mathrm{P})_{2}\right]$ (Scheme 4.13). These complexes were all unstable, decomposing into the dichloride complexes over 1 (dppp) to 5 (PTA) days. Again, due to the insolubility of cis- $\left[\mathrm{PtCl}_{2}(\mathrm{PTA})_{2}\right]$, the exact amount formed was not calculated, with $\mathbf{3 6}$ comprising approximately $50 \%$ of the species in solution after 24 hrs. With dppp, the solution contained $58 \% \mathbf{3 7 b}, 26 \%$ cis $-\left[\mathrm{PtCl}_{2}(\mathrm{dppp})\right]$ and $16 \%\left[\mathrm{Pt}(\mathrm{dppp})_{2}\right] \mathrm{Cl}_{2}$ after $10 \mathrm{~min}$. There was no bisphosphine $\beta$-chloroalkyl complex formed in the reaction with $\mathrm{PPh}_{3}$. Instead, the monophosphine complex with the phosphine cis to the $\beta$-chloroalkyl ligand (38c) was formed, decomposing to form cis- $\left[\mathrm{PtCl}_{2}\left(\mathrm{PPh}_{3}\right)_{2}\right]$ over 4 hours (Scheme 4.14).

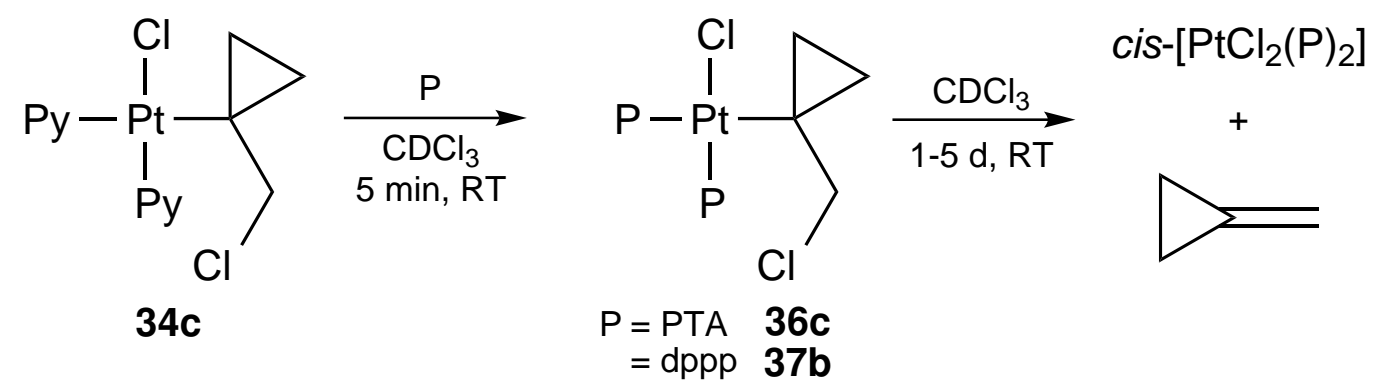

Scheme 4.13. Synthesis of cis- $\left.-\mathrm{Pt}\left(\mathrm{C}\left(\mathrm{CH}_{2}\right)_{2} \mathrm{CH}_{2} \mathrm{Cl}\right) \mathrm{Cl}(\mathrm{P})_{2}\right]$ from cis- $\left[\mathrm{Pt}\left(\mathrm{C}\left(\mathrm{CH}_{2}\right)_{2} \mathrm{CH}_{2} \mathrm{Cl}\right) \mathrm{Cl}(\mathrm{Py})_{2}\right](\mathbf{3 4 b})$.

It appeared that the stability of the $\beta$-chloroalkyl complexes was dependent on the cone angle, $\theta$, of the phosphine ligand. Complexes of the smallest phosphine, PTA $(\theta$ $\left.=115^{\circ}\right)^{185}$ were the most stable. The trans complex $\mathbf{3 6 a}$ was the only $\beta$-chloroalkyl complex with trans phosphines to be formed. For the complexes formed from MCP, the PTA complex 36c was stable for several days longer than the dppp complex $37 \mathbf{b}(\theta=$ $\left.127^{\circ}\right),{ }^{82}$ while no bisphosphine complex was observed with $\operatorname{PPh}_{3}\left(\theta=145^{\circ}\right) .{ }^{82}$ 


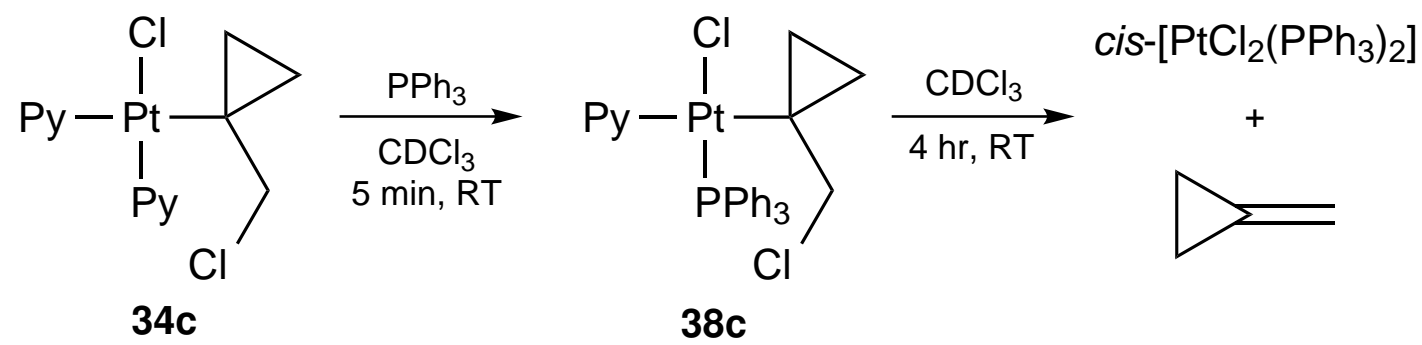

Scheme 4.14. Synthesis of $\left[\mathrm{Pt}\left(\mathrm{C}\left(\mathrm{CH}_{2}\right)_{2} \mathrm{CH}_{2} \mathrm{Cl}\right) \mathrm{Cl}(\mathrm{Py})\left(\mathrm{PPh}_{3}\right)\right](\mathbf{3 8 c})$ from cis- $\left.-\mathrm{Pt}\left(\mathrm{C}\left(\mathrm{CH}_{2}\right)_{2} \mathrm{CH}_{2} \mathrm{Cl}\right) \mathrm{Cl}(\mathrm{Py})_{2}\right](\mathbf{3 4 b})$.

\subsubsection{NMR Characterisation}

For representative NMR spectra, see Figures A.83-A.105. The various NMR spectra of the $\beta$-chloroalkyl complexes were distinctive. The ${ }^{31} \mathrm{P}\left\{{ }^{1} \mathrm{H}\right\}$ NMR spectra of $\mathbf{3 6} \mathbf{b}-\mathbf{3 8 b}$ showed two doublets with ${ }^{2} J_{\mathrm{P}-\mathrm{P}}$ couplings in the range of $14.9-25.9 \mathrm{~Hz}$, typical for cis couplings. The peak due to the phosphorus trans to the $\beta$-chloroalkyl ligand had a low ${ }^{1} J_{\mathrm{Pt}-\mathrm{P}}$ coupling constant of $1522-1684 \mathrm{~Hz}$, with those of the complexes from MCP having values larger by $\sim 30 \mathrm{~Hz}$. This low value was consistent with being trans to a $\sigma$-bound ${ }^{c}$ Pr ring. ${ }^{93,139}$ The ${ }^{1} J_{\mathrm{Pt}-\mathrm{P}}$ coupling constant of the other peak was very large, $3884-4490 \mathrm{~Hz}$, significantly larger than the ${ }^{1} J_{\mathrm{Pt}-\mathrm{P}}$ of the phosphines trans to $\mathrm{Cl}$ in cis$\left[\mathrm{PtCl}_{2}(\mathrm{P})_{2}\right](3350-3674 \mathrm{~Hz}) .{ }^{181,184}$ This difference can be ascribed to the difference in cisinfluence between $\mathrm{Cl}$ and ${ }^{c} \mathrm{Pr}$. While the cis-influence has not been reported for ${ }^{c} \mathrm{Pr}$, it was found that a cis-influence series was approximately the reverse of the corresponding trans-influence series. ${ }^{186}$ The ${ }^{1} J_{\mathrm{Pt}-\mathrm{P}}$ coupling constant for the phosphines cis to $\mathrm{Cl}$ in $\left[\mathrm{PtX}\left(\mathrm{PPh}_{3}\right)_{3}\right]$ was $444 \mathrm{~Hz}$ smaller than that of $\mathrm{Me}$, which has a lower trans-influence than ${ }^{c}$ Pr. ${ }^{139}$ It would therefore be expected that ${ }^{1} J_{\mathrm{Pt}-\mathrm{P}}$ would be significantly higher in cis- $-\left[\mathrm{Pt}\left(\mathrm{C}\left(\mathrm{CH}_{2}\right)_{2} \mathrm{C}\left(\mathrm{CH}_{2}\right)_{2} \mathrm{Cl}\right) \mathrm{Cl}(\mathrm{P})_{2}\right]$ and cis- $-\left[\mathrm{Pt}\left(\mathrm{C}\left(\mathrm{CH}_{2}\right)_{2} \mathrm{CH}_{2} \mathrm{Cl}\right) \mathrm{Cl}(\mathrm{P})_{2}\right]$ than in cis$\left[\mathrm{PtCl}_{2}(\mathrm{P})_{2}\right]$.

For the mono-phosphine complexes $\left[\mathrm{Pt}\left(\mathrm{C}\left(\mathrm{CH}_{2}\right)_{2} \mathrm{C}\left(\mathrm{CH}_{2}\right)_{2} \mathrm{Cl}\right) \mathrm{Cl}(\mathrm{Py})\left(\mathrm{PPh}_{3}\right)\right]$ and $\left[\mathrm{Pt}\left(\mathrm{C}\left(\mathrm{CH}_{2}\right)_{2} \mathrm{CH}_{2} \mathrm{Cl}\right) \mathrm{Cl}(\mathrm{Py})\left(\mathrm{PPh}_{3}\right)\right],{ }^{1} J_{\mathrm{Pt}-\mathrm{P}}$ were 4735 and $4661 \mathrm{~Hz}$, respectively. As these values were more similar to those trans to the chloride than those trans to the $\beta$-chloroalkyl ligands in $\mathbf{3 6 - 3 8}$, it was therefore the pyridine trans to the $\mathrm{Cl}$ that was displaced by the phosphine. 
Table 4.5. Selected NMR Data of $\left[\mathrm{Pt}\left(\mathrm{C}\left(\mathrm{CH}_{2}\right)_{2} \mathrm{CR}_{2} \mathrm{Cl}\right) \mathrm{Cl}(\mathrm{L})_{2}\right] \cdot{ }^{a}$

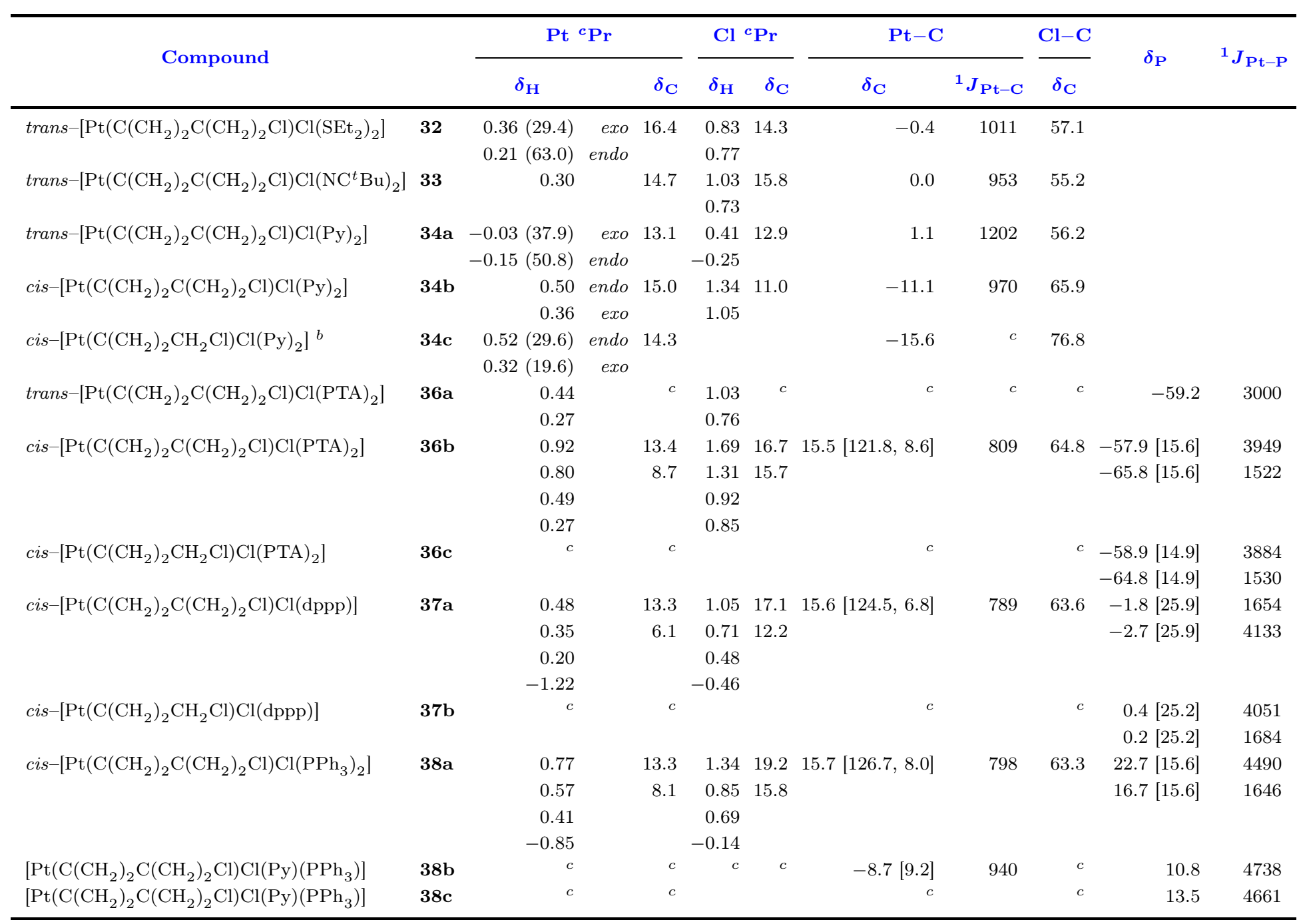

${ }^{a} \delta$ values are given in ppm and $J$ values in $\mathrm{Hz}$. All spectra were measured in $\mathrm{CDCl}_{3}$ at room temperature with $40 \mathrm{mg} / \mathrm{mL}$ sample unless otherwise noted. Values in parentheses are ${ }^{195} \mathrm{Pt}$ couplings, values in square brackets are ${ }^{31} \mathrm{P}$ couplings. ${ }^{b}$ Spectra collected in $d_{6}$-acetone. ${ }^{c}$ NMR data could not be obtained. 
The ${ }^{13} \mathrm{C}\left\{{ }^{1} \mathrm{H}\right\}$ NMR data of the $\beta$-chloroalkyl ligands in $\mathbf{3 2 - 3 8}$ was characteristic of these complexes (Table 4.5). Due to the short lifetimes, ${ }^{13} \mathrm{C}\left\{{ }^{1} \mathrm{H}\right\}$ NMR data could not be obtained for $\mathbf{3 6 a}, \mathbf{3 6 c}, \mathbf{3 7 b}, \mathbf{3 8 b}$ and $\mathbf{3 8 c}$. The $\mathrm{sp}^{3}$ carbons directly bound to the platinum in 32-38 had very large ${ }^{1} J_{\mathrm{Pt}-\mathrm{C}}$ coupling constants $\left({ }^{1} J_{\mathrm{Pt}-\mathrm{C}}=989-1202 \mathrm{~Hz}\right)$, indicative of $\mathrm{Pt}-\mathrm{C} \sigma$-bonds. ${ }^{93,139}$ The magnitude of these coupling constants reflected the trans-influence of the trans ligand, with $\mathrm{Cl}$ and Py approximately the same while the phosphines, with higher trans-influences, had lower ${ }^{1} J_{\mathrm{Pt}-\mathrm{C}} \cdot{ }^{93}$ The nature of the trans ligand also had a significant effect on the chemical shift of the platinum-bound carbon. When trans to $\mathrm{P}$, the chemical shift appeared at $15 \mathrm{ppm}$. In contrast, when trans to $\mathrm{Cl}$, the chemical shift dropped by $15 \mathrm{ppm}$ to $0 \mathrm{ppm}$ and by about $25 \mathrm{ppm}$ to approximately $-11 \mathrm{ppm}$ when trans to Py. While the majority of the NMR data for $\mathbf{3 8 b}$ could not be obtained due to the reactivity of this species, the use of carbon-13 enriched BCP enabled the detection of the peak due to the carbon bound to the platinum. Both the chemical shift $(-8.7 \mathrm{ppm})$ and ${ }^{1} J_{\mathrm{Pt}-\mathrm{C}}(940 \mathrm{~Hz})$ was consistent with the $\beta$-chloroalkyl ligand being trans to Py rather than $\mathrm{PPh}_{3}$, as indicated by the ${ }^{31} \mathrm{P}$ NMR data.

The carbons attached to the chlorines had resonances at $\delta_{\mathrm{C}}=55-66 \mathrm{ppm}$, except for 34c, which had a resonance at $76.8 \mathrm{ppm}$. This was due to the fact that this was a methylene rather than a cyclopropyl carbon. None of these resonances showed ${ }^{2} J_{\mathrm{Pt}-\mathrm{C}}$ couplings. The cyclopropyl methylene carbons appeared at 6-19 ppm, within the typical range for ${ }^{c} \operatorname{Pr}$ carbons.

The ${ }^{1} \mathrm{H}$ NMR resonances of the $\mathrm{CH}_{2}$ protons of the ${ }^{c} \mathrm{Pr}$ ring bound to the $\mathrm{Pt}$ in $32-38$ appeared at low chemical shifts, between -1.22 and $0.92 \mathrm{ppm}$. The protons of the ${ }^{c} \operatorname{Pr}$ ring bound to the $\mathrm{Cl}$ appeared between -0.46 and $1.34 \mathrm{ppm}$, at shifts more typical of organic cyclopropyl protons, except in $\mathbf{3 4 a}$ and the phosphine complexes. For 34a, all of the shifts were lower than in the other complexes, with the $\mathrm{Cl}{ }^{c} \mathrm{Pr}$ protons appearing at 0.41 and $-0.25 \mathrm{ppm}$. In the phosphine complexes, the ${ }^{c} \operatorname{Pr}$ peaks were spread over a wider range than for the other complexes, although the range of the $\mathrm{Pt}{ }^{c} \mathrm{Pr}$ peaks was lower than the $\mathrm{Cl}{ }^{c} \mathrm{Pr}$ peaks. Generally, the resonances appeared as four sharp peaks, each integrating for two protons, corresponding to the exo and endo environments of 


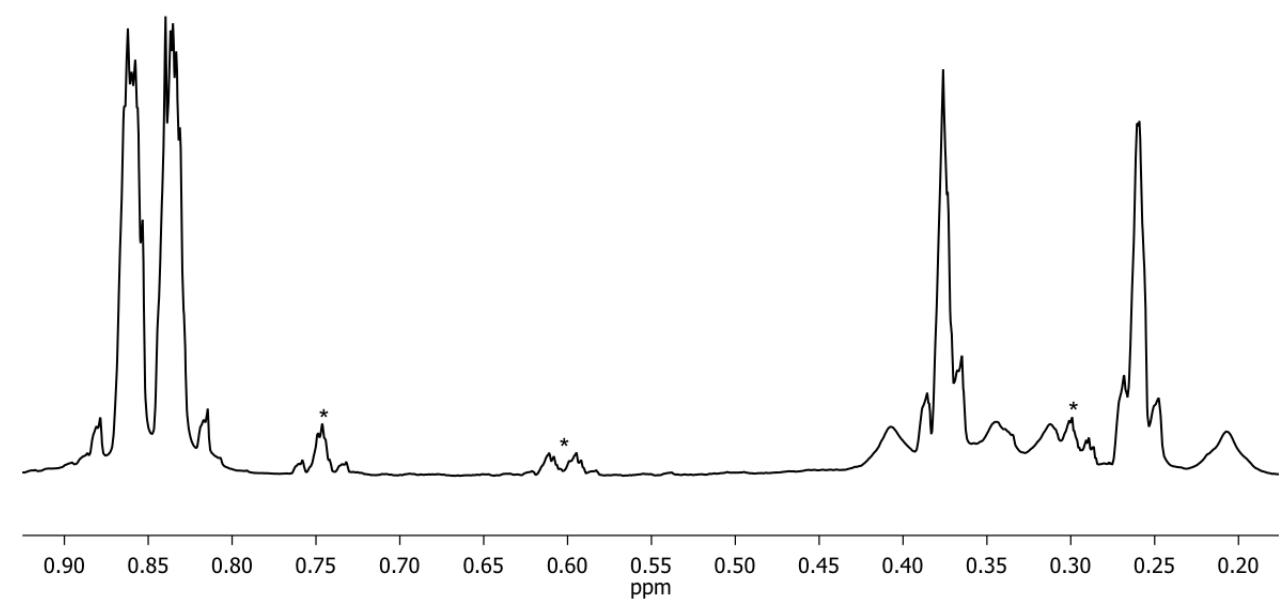

(i)

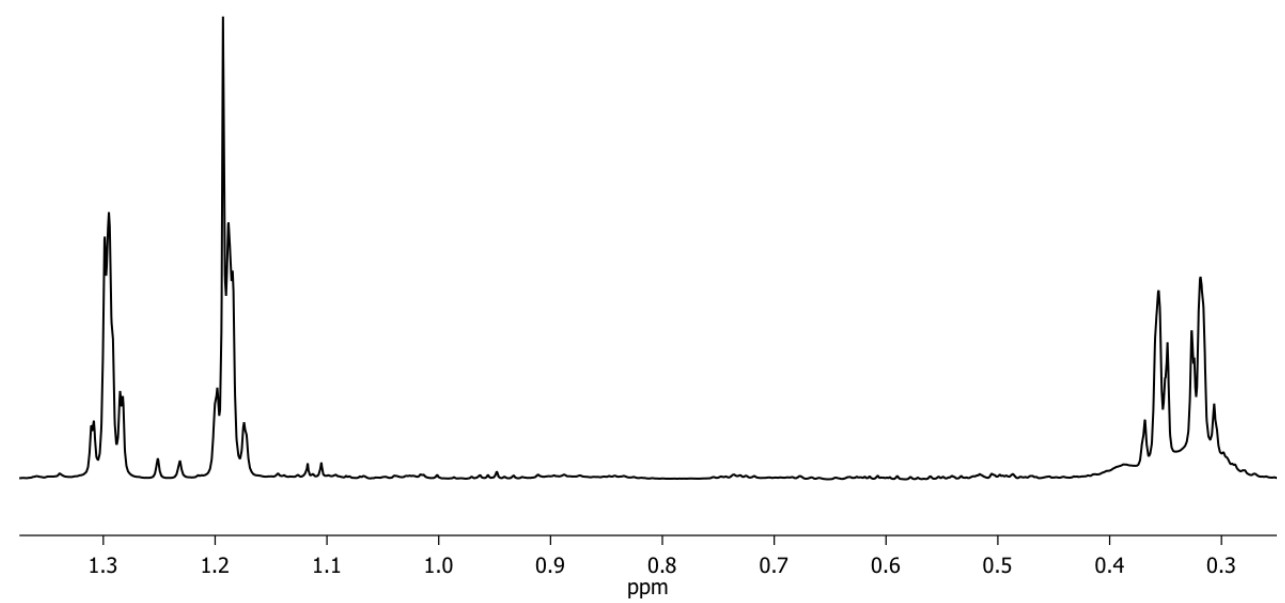

(ii)

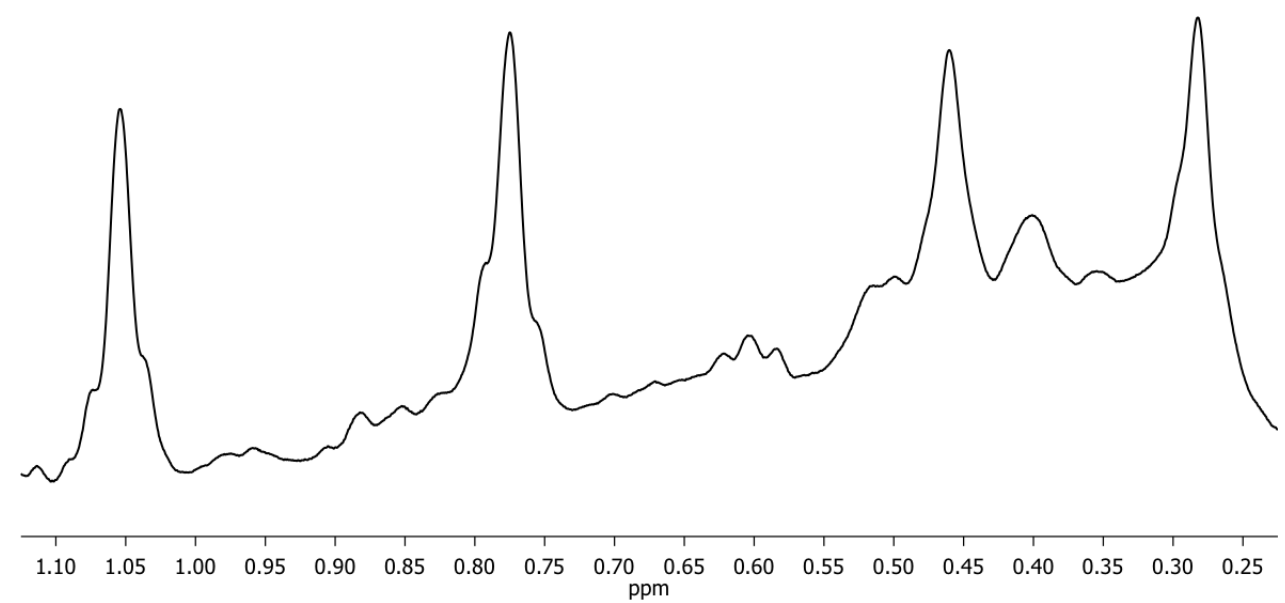

(iii)

Figure 4.3. ${ }^{1} \mathrm{H}$ NMR spectra showing the cyclopropyl peaks for (i) trans- $\left[\mathrm{Pt}\left(\mathrm{C}\left(\mathrm{CH}_{2}\right)_{2} \mathrm{C}\left(\mathrm{CH}_{2}\right)_{2} \mathrm{Cl}\right) \mathrm{Cl}\left(\mathrm{SEt}_{2}\right)_{2}\right]$ (32) (500 MHz, RT, $100 \mathrm{mg} / \mathrm{mL}, \mathrm{CDCl}_{3}$ ), (ii) cis $-\left[\mathrm{Pt}\left(\mathrm{C}\left(\mathrm{CH}_{2}\right)_{2} \mathrm{C}\left(\mathrm{CH}_{2}\right)_{2} \mathrm{Cl}\right) \mathrm{Cl}(\mathrm{Py})_{2}\right]\left(\right.$ 34a) $\left(500 \mathrm{MHz}, \mathrm{RT}, 40 \mathrm{mg} / \mathrm{mL}, \mathrm{CDCl}_{3}\right)$ and (iii) trans $-\left[\mathrm{Pt}\left(\mathrm{C}\left(\mathrm{CH}_{2}\right)_{2} \mathrm{C}\left(\mathrm{CH}_{2}\right)_{2} \mathrm{Cl}\right) \mathrm{Cl}(\mathrm{PTA})_{2}\right]$ (36a) $\left(300 \mathrm{MHz}, \mathrm{RT}, 40 \mathrm{mg} / \mathrm{mL}, \mathrm{CDCl}_{3}\right)$. $*$ signifies peaks belonging to other species. 
the two rings (Figure 4.3). Again, the phosphine complexes were an exception due to the $J_{\mathrm{P}-\mathrm{H}}$ couplings. The peaks of the $\mathrm{Cl}{ }^{c} \mathrm{Pr}$ ring protons did not have ${ }^{195} \mathrm{Pt}$ satellites, while $\mathrm{Pt}{ }^{c} \mathrm{Pr}$ ring protons showed ${ }^{195} \mathrm{Pt}$ coupling, except in $\mathbf{3 3}$ (due to overlap of the peaks), 34b and the phosphine complexes. The endo protons had higher $J_{\mathrm{Pt}-\mathrm{H}}$ coupling constants $(50.8-63.0 \mathrm{~Hz})$ than the exo $(29.4-37.9 \mathrm{~Hz})$. For $34 \mathbf{c}$, the magnitudes of $J_{\mathrm{Pt}-\mathrm{H}}$ were smaller (29.6 and $19.6 \mathrm{~Hz}$ ), although the endo coupling was still larger than the exo coupling. In most cases, the endo/exo geometry of the rings was confirmed by NOESY correlations (Figure 4.4).

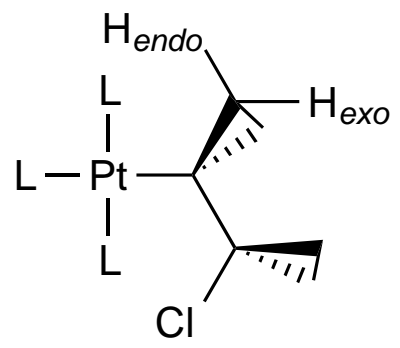

Figure 4.4. Geometry of the endo/exo protons in $\beta$-haloalkyl complexes.

The NMR data of the $\beta$-chloroalkyl complex formed from MCP (34c) was used to determine the mode of insertion into the $\mathrm{Pt}-\mathrm{Cl}$ bond. The ${ }^{1} \mathrm{H}$ NMR data showed a singlet peak at $4.13 \mathrm{ppm}$ with $J_{\mathrm{Pt}-\mathrm{H}}=24.6 \mathrm{~Hz}$ and two sharp peaks at 0.52 and $0.32 \mathrm{ppm}$, with a similar lineshape to the ${ }^{c} \operatorname{Pr} \mathrm{CH}_{2}$ resonances in the complexes from BCP. The cyclopropyl methylene peaks had $J_{\mathrm{Pt}-\mathrm{H}}$ couplings, which were only present in the cyclopropyl ring attached to the metal in the other complexes. The low shifts of the cyclopropyl peaks also indicated that the ${ }^{c} \operatorname{Pr}$ ring was attached to the metal, rather than the methylene. This was supported by the ${ }^{13} \mathrm{C}$ NMR data. There was a peak at $-15.6 \mathrm{ppm}$, with the high field shift indicating that this was the carbon attached to the platinum, although no ${ }^{1} J_{\mathrm{Pt}-\mathrm{C}}$ coupling could be found even after running a $20 \mathrm{hr}{ }^{13} \mathrm{C}$ experiment on the 600 $\mathrm{MHz}$ NMR instrument due to the low solubility of 34c. The corresponding resonance in 34b appeared at $-11.09 \mathrm{ppm}$. There was also a resonance at $76.8 \mathrm{ppm}$ which had an HSQC correlation to the peak in the ${ }^{1} \mathrm{H}$ NMR spectrum at $4.13 \mathrm{ppm}$ due to the carbon attached to the chlorine. The carbon peak was at significantly lower field than that in 34b, which appeared at $65.9 \mathrm{ppm}$. Typically, $\mathrm{sp}^{3}$-cyclopropyl peaks appear at higher field 
than $\mathrm{sp}^{3}$-methylene peaks, indicating that this peak was due to the methylene, and that the cyclopropyl ring was therefore attached to the metal. This was further supported by the ${ }^{31} \mathrm{P}$ NMR spectra of $\mathbf{3 6} \mathbf{c}$ and $\mathbf{3 7 b}$, formed by addition of the phosphines to $\mathbf{3 4 \mathbf { c }}$. When trans to the ${ }^{c} \mathrm{Pr}$ ring in the complexes formed from $\mathrm{BCP}$, the ${ }^{1} J_{\mathrm{Pt}-\mathrm{P}}$ coupling constant was $1522-1654 \mathrm{~Hz}$. In the complexes formed from MCP, ${ }^{1} J_{\mathrm{Pt}-\mathrm{P}}$ was very similar, 1530-1680 Hz. Greater differences would be expected if the methylene was attached to the metal.

Due to the short lifetime of $\mathbf{3 6 a},{ }^{13} \mathrm{C}$ NMR data could not be obtained, even when carbon-13 enriched BCP was used. The ${ }^{1} \mathrm{H}$ NMR spectrum showed the same characteristic sharp peaks as the other $\beta$-chloroalkyl complexes (Figure 4.3). The chemical shifts were in good agreement with those of $\mathbf{3 2 - 3 4 c}$, with peaks at $0.27,0.44,0.76$ and $1.03 \mathrm{ppm}$ (Table 4.5). By analogy, the peaks at 0.27 and $0.44 \mathrm{ppm}$ would correspond to those of the ${ }^{c}$ Pr ring attached to the Pt, while those at 0.76 and $1.03 \mathrm{ppm}$ would correspond to those of the ${ }^{c} \mathrm{Pr}$ ring attached to the $\mathrm{Cl}$. In the ${ }^{31} \mathrm{P}$ NMR spectrum, there was a singlet peak with a ${ }^{1} J_{\mathrm{Pt}-\mathrm{P}}$ coupling constant of $3000 \mathrm{~Hz}$. This indicated that the geometry of the complex was trans, as the cis complexes had two phosphine environments. The coupling constant was in the range expected for two trans phosphines. ${ }^{181}$ It was much smaller than the ${ }^{1} J_{\mathrm{Pt}-\mathrm{P}}$ of phosphines trans to $\mathrm{Cl}$ in cis complexes, typically $\sim 3500 \mathrm{~Hz}$, and $3350 \mathrm{~Hz}$ for cis- $-\left[\mathrm{PtCl}_{2}(\mathrm{PTA})_{2}\right]$ specifically. ${ }^{181,184}$

\subsubsection{Computational Studies}

Computational models were used in order to determine what structural factors led to the formation of a stable $\beta$-chloroalkyl complex. All structures were optimised and frequencies calculated using density functional theory calculations (B3LYP), ${ }^{154-157}$ optimised using the def2-TZVP basis set, ${ }^{158}$ of triple $\zeta$ quality. Complexes with $\beta$-chloroalkyl ligands formed from bicyclopropylidene were determined to be stable experimentally, and a number of these were formed (Section 4.4). Complexes were also formed experimentally from methylenecyclopropane, with the cyclopropyl ring directly bound to the metal. These were unstable, decomposing via a $\beta$-chloride elimination. 
<smiles>N[PH](N)(Cl)CCCl</smiles>

39<smiles>CC(C)(Cl)C[P](N)(N)Cl</smiles>

$40 a$<smiles>CC(C)(CCl)[PH](N)(N)Cl</smiles>

40b<smiles>CC(C)(Cl)C(C)(C)C(N)(N)Cl</smiles>

41<smiles>N[PH](N)(Cl)CC1(Cl)CC1</smiles>

42a<smiles>N[PH](N)(Cl)C1(CCl)CC1</smiles>

$42 b$<smiles>N[PH](N)(Cl)C1(C2(Cl)CC2)CC1</smiles>

33

$$
\mathrm{N}=\mathrm{NC}^{\dagger} \mathrm{Bu} \mathrm{u}_{2}
$$

Figure 4.5. Structures of $\beta$-chloroalkyl complexes.

There were two potential structural factors that could contribute to the unusual stability of the cyclopropyl $\beta$-chloroalkyl complexes. These were the degree of substitution (BCP is tetrasubstituted), and the presence of ${ }^{c} \operatorname{Pr}$ rings. A number of $\beta$-chloroalkyl complexes with varying substituents were optimised. These were trans$\left[\mathrm{Pt}\left(\mathrm{CH}_{2} \mathrm{CH}_{2} \mathrm{Cl}\right) \mathrm{Cl}\left(\mathrm{NC}^{t} \mathrm{Bu}\right)_{2}\right]$ (39), which had no carbon containing substituents on the $\beta$-chloroalkyl ligand, trans $-\left[\mathrm{Pt}\left(\mathrm{CH}_{2} \mathrm{CMe}_{2} \mathrm{Cl}\right) \mathrm{Cl}\left(\mathrm{NC}^{t} \mathrm{Bu}\right)_{2}\right](\mathbf{4 0 a})$, disubstituted with methyl groups on the $\beta$-carbon, trans $-\left[\mathrm{Pt}\left(\mathrm{CMe}_{2} \mathrm{CH}_{2} \mathrm{Cl}\right) \mathrm{Cl}\left(\mathrm{NC}^{t} \mathrm{Bu}\right)_{2}\right](40 \mathrm{~b})$, disubstituted with methyl groups on the $\alpha$-carbon, trans $-\left[\mathrm{Pt}\left(\mathrm{CMe}_{2} \mathrm{CMe}_{2} \mathrm{Cl}\right) \mathrm{Cl}\left(\mathrm{NC}^{t} \mathrm{Bu}\right)_{2}\right]$ (41), tetrasubstituted with methyl groups, trans- $\left[\mathrm{Pt}\left(\mathrm{CH}_{2} \mathrm{C}\left(\mathrm{CH}_{2}\right)_{2} \mathrm{Cl}\right) \mathrm{Cl}\left(\mathrm{NC}^{t} \mathrm{Bu}\right)_{2}\right]$ (42a), substi-

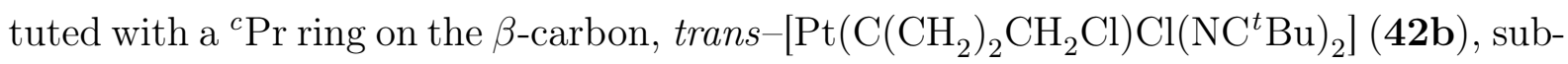

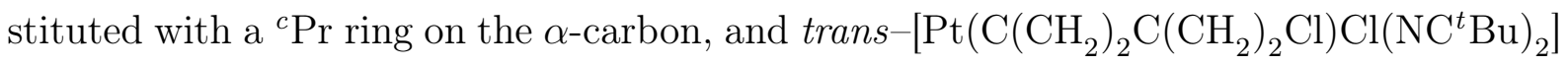
(33), substituted with two ${ }^{c} \operatorname{Pr}$ rings (Figure 4.5). Structures were also optimised for the respective cis- and trans- $\left[\mathrm{PtCl}_{2}(\mathrm{~L})\left(\mathrm{NC}^{t} \mathrm{Bu}\right)\right]$ alkene complexes $\left(\mathrm{L}=\mathrm{C}_{2} \mathrm{H}_{4}(\mathbf{4 3})\right.$, $\mathrm{CH}_{2} \mathrm{CMe}_{2}(44), \mathrm{C}_{2} \mathrm{Me}_{4}(45), \quad \mathrm{MCP}(46), \quad \mathrm{BCP}(47), \quad$ trans $=\mathbf{a}$, cis $\left.=\mathbf{b}\right)$, the free alkenes, $\mathrm{NC}^{t} \mathrm{Bu}$ and trans $-\left[\mathrm{PtCl}_{2}\left(\mathrm{NC}^{t} \mathrm{Bu}\right)_{2}\right]$. 
<smiles>[R]C([R])=C(C)[C@H](C)Cl</smiles>

Scheme 4.15. Formation of $\beta$-chloroalkyl complexes from trans $-\left[\mathrm{PtCl}_{2}\left(\mathrm{NC}^{t} \mathrm{Bu}\right)_{2}\right]$.

Table 4.6. Reaction $\Delta H$ for the Formation of $\beta$-Chloroalkyl Complexes.

\begin{tabular}{|c|c|c|}
\hline \multirow{2}{*}{$\begin{array}{l}\text { Compound } \\
\text { trans }-\left[\mathrm{Pt}\left(\mathrm{CH}_{2} \mathrm{CH}_{2} \mathrm{Cl}\right) \mathrm{Cl}\left(\mathrm{NC}^{t} \mathrm{Bu}\right)_{2}\right]\end{array}$} & \multicolumn{2}{|c|}{$\Delta H\left(\mathrm{~kJ} \mathrm{~mol}^{-1}\right)$} \\
\hline & 39 & 85.1 \\
\hline trans $-\left[\mathrm{Pt}\left(\mathrm{CH}_{2} \mathrm{CMe}_{2} \mathrm{Cl}\right) \mathrm{Cl}\left(\mathrm{NC}^{t} \mathrm{Bu}\right)_{2}\right]$ & $40 a$ & 111.8 \\
\hline trans $-\left[\mathrm{Pt}\left(\mathrm{CMe}_{2} \mathrm{CH}_{2} \mathrm{Cl}\right) \mathrm{Cl}\left(\mathrm{NC}^{t} \mathrm{Bu}\right)_{2}\right]$ & $40 \mathrm{~b}$ & 138.1 \\
\hline trans $-\left[\mathrm{Pt}\left(\mathrm{CMe}_{2} \mathrm{CMe}_{2} \mathrm{Cl}\right) \mathrm{Cl}\left(\mathrm{NC}^{t} \mathrm{Bu}\right)_{2}\right]$ & 41 & 165.4 \\
\hline trans $-\left[\mathrm{Pt}\left(\mathrm{CH}_{2} \mathrm{C}\left(\mathrm{CH}_{2}\right)_{2} \mathrm{Cl}\right) \mathrm{Cl}\left(\mathrm{NC}^{t} \mathrm{Bu}\right)_{2}\right]$ & $42 \mathrm{a}$ & 68.3 \\
\hline trans $-\left[\mathrm{Pt}\left(\mathrm{C}\left(\mathrm{CH}_{2}\right)_{2} \mathrm{CH}_{2} \mathrm{Cl}\right) \mathrm{Cl}\left(\mathrm{NC}^{t} \mathrm{Bu}\right)_{2}\right]$ & $42 \mathrm{~b}$ & 67.0 \\
\hline trans $-\left[\mathrm{Pt}\left(\mathrm{C}\left(\mathrm{CH}_{2}\right)_{2} \mathrm{C}\left(\mathrm{CH}_{2}\right)_{2} \mathrm{Cl}\right) \mathrm{Cl}\left(\mathrm{NC}^{t} \mathrm{Bu}\right)_{2}\right]$ & 33 & 51.5 \\
\hline
\end{tabular}

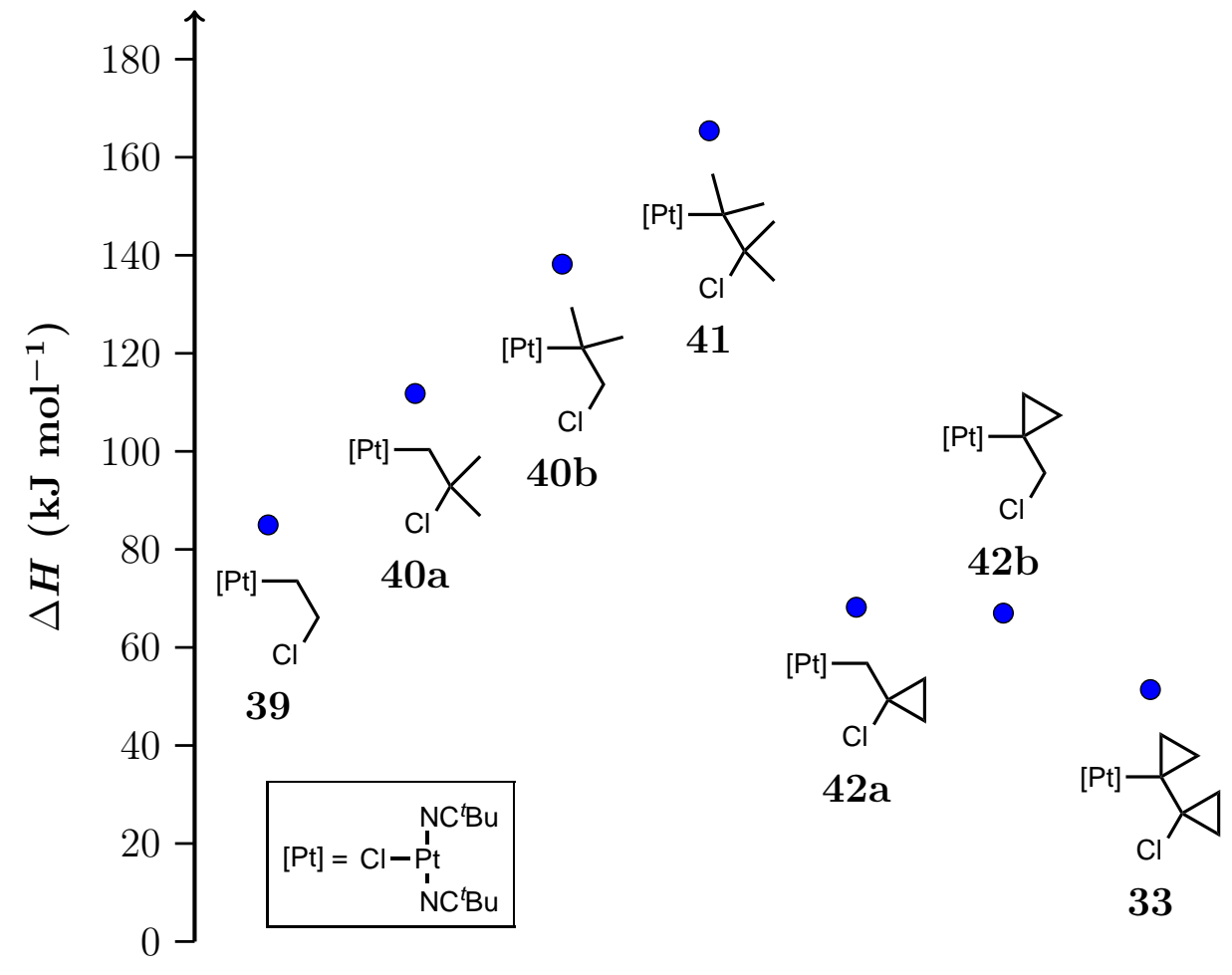

Figure 4.6. Reaction $\Delta H$ for the formation of $\beta$-chloroalkyl complexes From $\left[\mathrm{PtCl}_{2}\left(\mathrm{NC}^{t} \mathrm{Bu}\right)_{2}\right]$. 


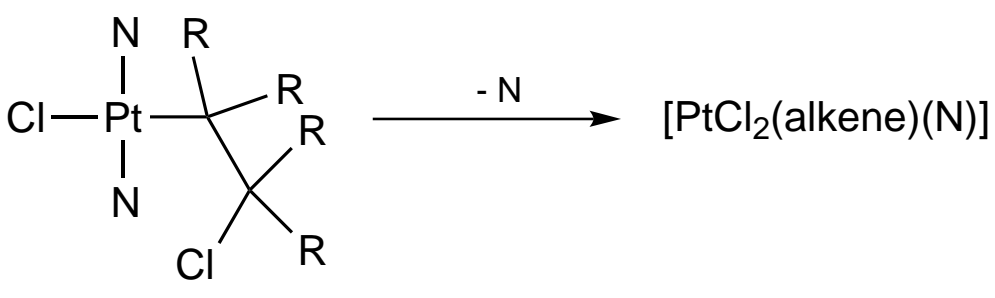

$\mathrm{N}=\mathrm{NC} \mathrm{B}^{\mathrm{B} u}$

Scheme 4.16. Formation of $\left[\mathrm{PtCl}_{2}(\mathrm{~L})\left(\mathrm{NC}^{t} \mathrm{Bu}\right)\right]$ via $\beta$-chloride elimination.

Table 4.7. Reaction $\Delta H$ for the Formation of $\left[\mathrm{PtCl}_{2}(\mathrm{~L})\left(\mathrm{NC}^{t} \mathrm{Bu}\right)\right]$ Through $\beta$-Chloride Elimination.

\begin{tabular}{lllr}
\hline & & \multicolumn{2}{c}{$\Delta \boldsymbol{H}\left(\mathrm{kJ} \mathrm{mol}^{-\mathbf{1}}\right)$} \\
\cline { 3 - 5 } Compound & & trans & cis \\
\hline trans $-\left[\mathrm{Pt}\left(\mathrm{CH}_{2} \mathrm{CH}_{2} \mathrm{Cl}\right) \mathrm{Cl}\left(\mathrm{NC}^{t} \mathrm{Bu}\right)_{2}\right]$ & $\mathbf{3 9}$ & -80.1 & -70.3 \\
trans $-\left[\mathrm{Pt}\left(\mathrm{CH}_{2} \mathrm{CMe}_{2} \mathrm{Cl}\right) \mathrm{Cl}\left(\mathrm{NC}^{t} \mathrm{Bu}\right)_{2}\right]$ & $\mathbf{4 0 a}$ & -88.3 & -72.2 \\
trans $-\left[\mathrm{Pt}\left(\mathrm{CMe}_{2} \mathrm{CH}_{2} \mathrm{Cl}\right) \mathrm{Cl}\left(\mathrm{NC}^{t} \mathrm{Bu}\right)_{2}\right]$ & $\mathbf{4 0 b}$ & -114.5 & -98.5 \\
trans $-\left[\mathrm{Pt}\left(\mathrm{CMe}_{2} \mathrm{CMe}_{2} \mathrm{Cl}\right) \mathrm{Cl}\left(\mathrm{NC}{ }^{t} \mathrm{Bu}\right)_{2}\right]$ & $\mathbf{4 1}$ & -113.2 & -106.0 \\
trans $-\left[\mathrm{Pt}\left(\mathrm{CH}_{2} \mathrm{C}\left(\mathrm{CH}_{2}\right)_{2} \mathrm{Cl}\right) \mathrm{Cl}\left(\mathrm{NC}^{t} \mathrm{Bu}\right)_{2}\right]$ & $\mathbf{4 2 a}$ & -66.5 & -51.2 \\
trans $-\left[\mathrm{Pt}\left(\mathrm{C}\left(\mathrm{CH}_{2}\right)_{2} \mathrm{CH}_{2} \mathrm{Cl}\right) \mathrm{Cl}\left(\mathrm{NC}^{t} \mathrm{Bu}\right)_{2}\right]$ & $\mathbf{4 2 b}$ & -65.2 & -49.9 \\
trans $-\left[\mathrm{Pt}\left(\mathrm{C}\left(\mathrm{CH}_{2}\right)_{2} \mathrm{C}\left(\mathrm{CH}_{2}\right)_{2} \mathrm{Cl}\right) \mathrm{Cl}\left(\mathrm{NC}^{t} \mathrm{Bu}\right)_{2}\right]$ & $\mathbf{3 3}$ & -49.4 & -38.7 \\
\hline
\end{tabular}

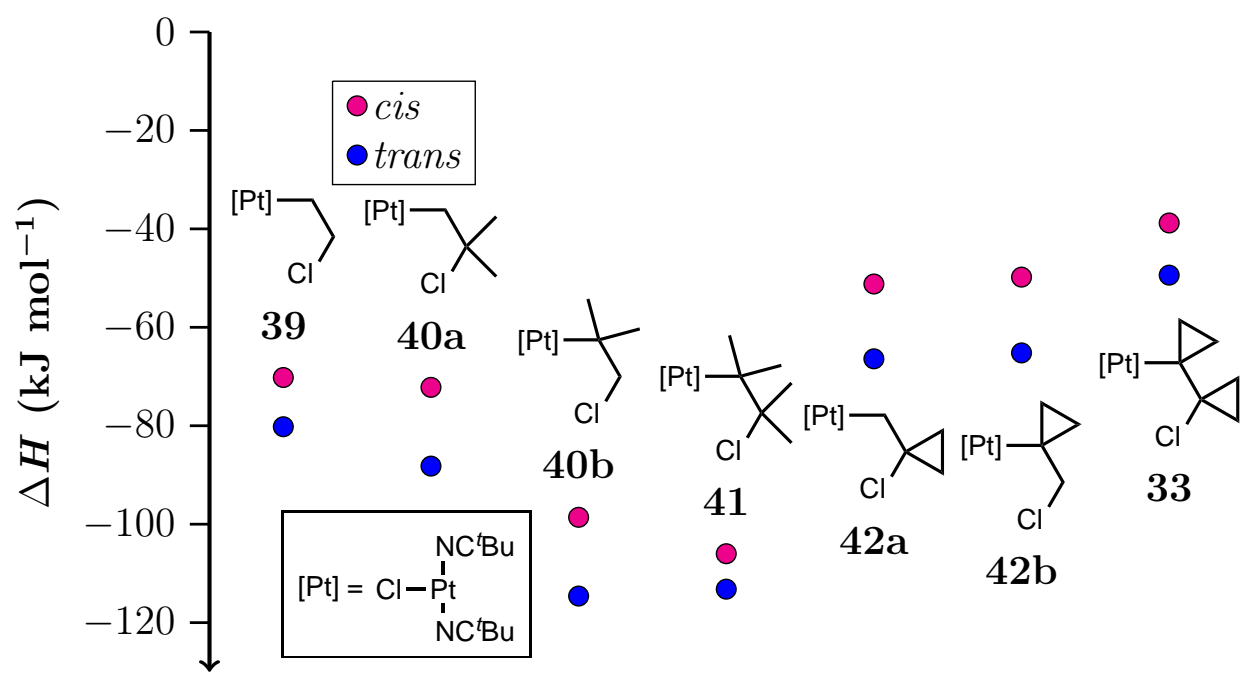

Figure 4.7. Reaction $\Delta H$ for the formation of $\left[\mathrm{PtCl}_{2}(\mathrm{~L})\left(\mathrm{NC}^{t} \mathrm{Bu}\right)\right]$ through $\beta$-chloride elimination. 

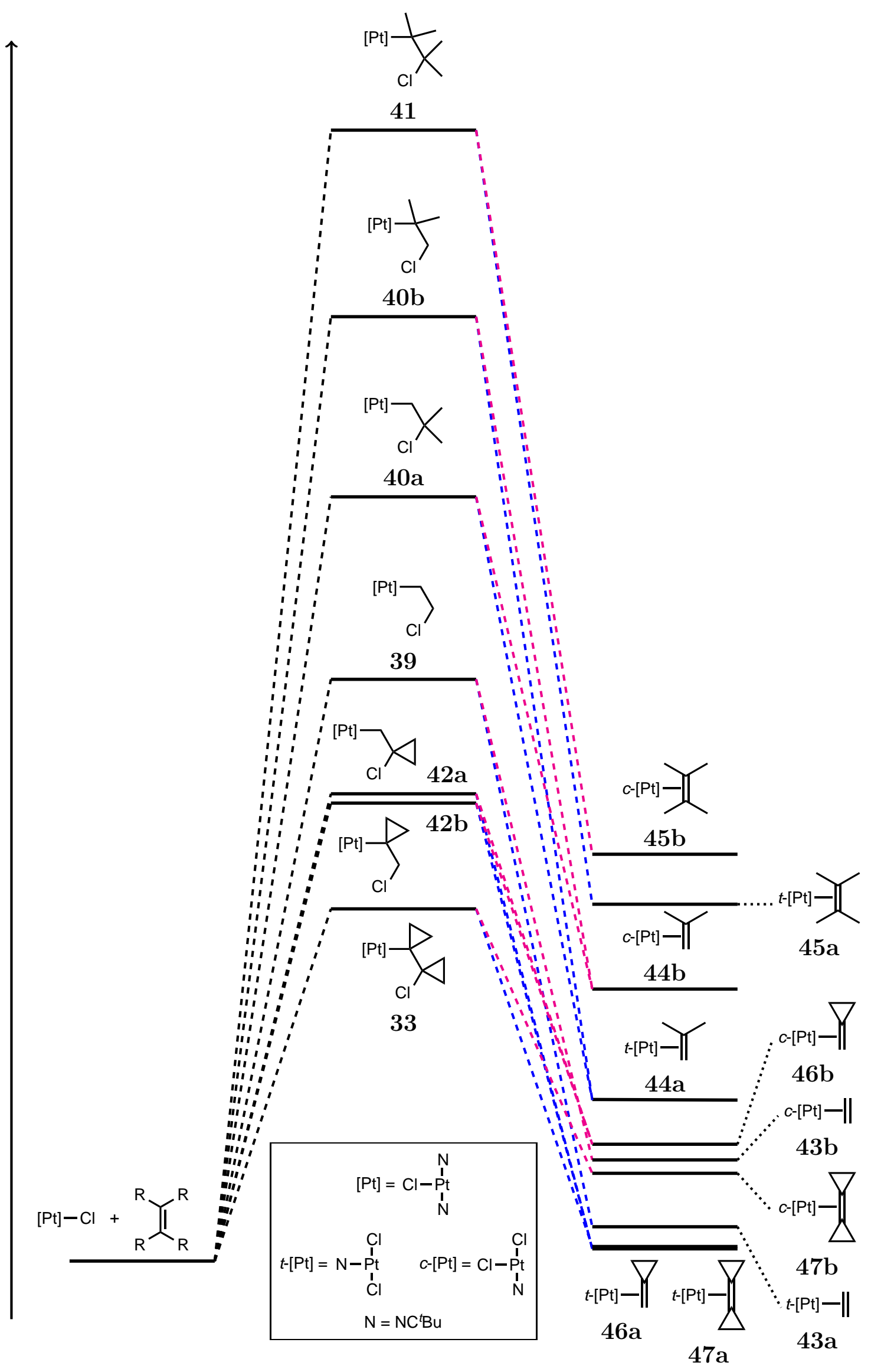

Figure 4.8. Energy diagram for the formation of $\left[\mathrm{PtCl}_{2}(\mathrm{~L})\left(\mathrm{NC}^{t} \mathrm{Bu}\right)\right]$ from $\left[\mathrm{PtCl}_{2}\left(\mathrm{NC}^{t} \mathrm{Bu}\right)_{2}\right]$ via $\beta$-chloroalkyl complexes. 
The reaction $\Delta H$ values for the formation of the $\beta$-chloroalkyl complexes from the addition of the appropriate alkene to trans- $\left[\mathrm{PtCl}_{2}\left(\mathrm{NC}^{t} \mathrm{Bu}\right)_{2}\right]$ were calculated (Scheme 4.15, Table 4.6, Figures 4.6 and 4.8). This reaction was observed experimentally for BCP, but did not occur with MCP. The reaction $\Delta H$ for the decomposition of the $\beta$-chloroalkyl complexs via $\beta$-chloride elimination, forming either the trans or cis alkene complex $\left[\mathrm{PtCl}_{2}(\mathrm{~L})\left(\mathrm{NC}^{t} \mathrm{Bu}\right)\right]$ (Scheme 4.16), was also calculated (Table 4.7, Figures 4.7 and 4.8). The species used in the calculations were isolated molecules in the gas phase, so the absolute values of $\Delta \mathrm{H}$ thus obtained were not necessarily those for the experimental systems. However, the calculated values of reaction $\Delta H$ were considered to be accurate indicators of the trends in stability of the complexes, within the limits of the theoretical description. Transition state structures were not calculated, so no kinetic information was obtained.

The reaction $\Delta H$ for both the formation from trans $-\left[\mathrm{PtCl}_{2}\left(\mathrm{NC}^{t} \mathrm{Bu}\right)_{2}\right]$ and the $\beta$-chloride eliminations indicated that the complexes with cyclopropyl ring substituents were the most stable. In the trans $-\left[\mathrm{PtCl}_{2}\left(\mathrm{NC}^{t} \mathrm{Bu}\right)_{2}\right]$ reaction, the three ${ }^{c} \mathrm{Pr}$ complexes (42a, $\mathbf{4 2 b}$ and $\mathbf{3 3}$ ) had the lowest $\Delta H$ values, $68.3,67.0$ and $51.5 \mathrm{~kJ} \mathrm{~mol}^{-1}$ respectively, indicating that these reactions were the most likely to occur. The difference between the two monosubstituted ${ }^{c} \operatorname{Pr}$ complexes was small, in favour of the $\alpha$-substituted complex by $1.3 \mathrm{~kJ} \mathrm{~mol}^{-1}$. There was a greater difference between the mono- and di-

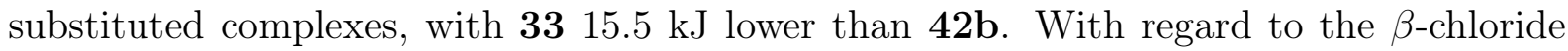
eliminations, the $\Delta H$ values were the highest for the ${ }^{c}$ Pr substituted complexes $(-66.4$ and $-51.2 \mathrm{~kJ} \mathrm{~mol}^{-1}$ for $\mathbf{4 2 a},-65.1$ and $-49.9 \mathrm{~kJ} \mathrm{~mol}^{-1}$ for $\mathbf{4 2} \mathbf{b},-49.4$ and $-38.7 \mathrm{~kJ} \mathrm{~mol}^{-1}$ for 33), indicating that the reactions were less likely to occur and that the $\beta$-chloroalkyl complexes were therefore the most stable. The formation of the trans alkene complexes was more favourable than the cis, with differences of $10.7-15.3 \mathrm{~kJ} \mathrm{~mol}^{-1}$. Again, the dicyclopropyl complex was more stable than either of the monocyclopropyl complexes and the $\alpha$-substituted complex was slightly more stable than the $\beta$-substituted.

The unsubstituted complex 39 was less stable than the cyclopropyl complexes but more stable than the methyl complexes. For the trans $-\left[\mathrm{PtCl}_{2}\left(\mathrm{NC}^{t} \mathrm{Bu}\right)_{2}\right]$ reaction, $\Delta H$ 
was $85.1 \mathrm{~kJ} \mathrm{~mol}^{-1}$, while for the $\beta$-Cl eliminations, $\Delta H$ was -80.1 and $-70.2 \mathrm{~kJ} \mathrm{~mol}^{-1}$ for the trans and cis alkene complexes respectively. The methyl substituted $\beta$-chloroalkyl complexes were the least stable in both the trans $-\left[\mathrm{PtCl}_{2}\left(\mathrm{NC}^{t} \mathrm{Bu}\right)_{2}\right]$ reaction and the $\beta$-chloride eliminations. The tetramethyl complex $4 \mathbf{1}$ had the highest $\Delta H$ for the trans$\left[\mathrm{PtCl}_{2}\left(\mathrm{NC}^{t} \mathrm{Bu}\right)_{2}\right]$ reaction $\left(165.4 \mathrm{~kJ} \mathrm{~mol}^{-1}\right)$, and the lowest for the $\beta$-Cl elimination forming the cis alkene complex $\left(-106.0 \mathrm{~kJ} \mathrm{~mol}^{-1}\right)$, indicating that it was the least stable of all the complexes studied. The $\alpha$-substituted dimethyl complex $40 \mathrm{~b}$ had a slightly lower $\Delta H$ for the trans alkene reaction than 41 (-114.5 v.s. $-113.2 \mathrm{~kJ} \mathrm{~mol}^{-1}$ ), but had a higher $\Delta H$ for the cis alkene reaction $\left(-98.5 \mathrm{~kJ} \mathrm{~mol}^{-1}\right)$ and a lower $\Delta H$ for the dichloride reaction $\left(138.1 \mathrm{~kJ} \mathrm{~mol}^{-1}\right)$. The $\beta$-substituted dimethyl complex 40a was more stable than $40 \mathrm{~b}$, with $\Delta H$ values of $111.8 \mathrm{~kJ} \mathrm{~mol}^{-1}$ for the dichloride, $-88.2 \mathrm{~kJ} \mathrm{~mol}^{-1}$ for the trans alkene and $-72.2 \mathrm{~kJ} \mathrm{~mol}^{-1}$ for the cis alkene reactions. As with the ${ }^{c} \operatorname{Pr}$ substituted complexes, the formation of the trans alkene complex was more favourable than the formation of the cis alkene complex for all three methyl substituted complexes, with differences of $7.2-16.0 \mathrm{~kJ} \mathrm{~mol}{ }^{-1}$.

It was evident from the above data that it was the presence of ${ }^{c} \operatorname{Pr}$ rings rather than simply the degree of substitution which determined the stability of the $\beta$-chloroalkyl complexes. When substituted with methyl groups, the resulting $\beta$-haloalkyl complexes were increasingly unstable with more substitution closer to the metal centre. The opposite trend was observed for ${ }^{c} \operatorname{Pr}$ substitution; it was the complexes with the higher degree of substitution closer to the metal which were more stable. This was in agreement with the experimental observation that complexes formed from BCP were the most stable, while it was the complex with the ${ }^{c} \operatorname{Pr}$ ring in the $\alpha$-position that was formed from MCP. 


\section{Chapter 5}

\section{Conclusion}

Cyclopropyl rings are an important structural motif. They are found in many biologically active molecules, such as the anti-depressant, tranylcypromine, the molecule responsible for Jamaican vomiting sickness, hypoglycine A, and pyrethroids such as allethrin I, used in RAID flyspray (Figure 5.1).

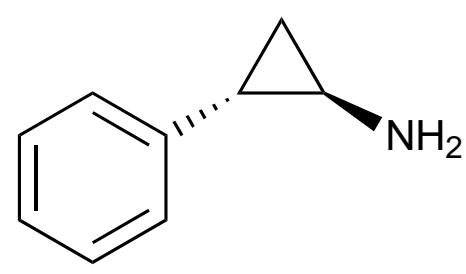

Tranylcypromine

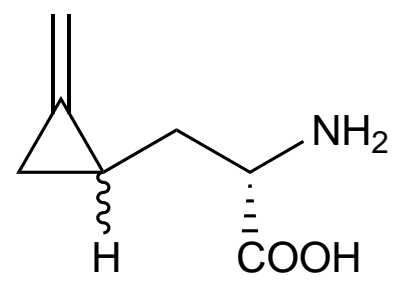

Hypoglycine A<smiles>C=CCC1=C(C)C(OC(=O)C2C(C=C(C)C)C2(C)C)CC1=O</smiles>

Allethrin I

Figure 5.1. Biologically active molecules containing cyclopropyl rings. 
Bicyclopropylidene and methylenecyclopropane, alkenes which contain cyclopropyl rings with exo-cyclic double-bonds, are useful synthetic precursors, enabling the incorporation of one or even two cyclopropyl rings into a carbon skeleton. Both are have reliable syntheses which enable them to be made in appreciable quantities in a relatively short time. Large amounts of work has been done investigating their reactivity and utility as as reagents for organic chemistry. A significant portion of this has involved the use of transition metal catalysts, particularly those of palladium. Two main modes of reactivity with transition metals have been observed; these are additions across the double-bond, as in reactions with Heck-type catalysts (for examples see Schemes 1.6 and 1.21), and ringopening, involving cleavage at either the proximal or the distal ring bonds (for examples see Schemes 1.4 and 1.16). Reactions often involve a combination of the two reactivity modes, such as in the domino-Heck-Diels-Alder reactions of BCP. ${ }^{63,74}$

The isolation of transition metal complexes analogous to the proposed intermediates in these reactions has received comparatively little attention. There is one instance of the isolation of an $\eta^{3}$-allyl complex, which resulted from the addition of $\mathrm{Pd}-\mathrm{Ph}$ across the double bond in a Heck-type reaction. ${ }^{137}$ The coordination of MCP and BCP to form $\eta^{2}$-alkene complexes is a likely first step before any reaction takes place. A small handful of such complexes have been isolated, with $\mathrm{Ni},{ }^{60} \mathrm{Pt},{ }^{61} \mathrm{Co}^{58,59}$ and $\mathrm{Rh}^{61}$ for MCP, and $\mathrm{Ti}^{58}$ and $\mathrm{Co}^{58,59}$ for $\mathrm{BCP}$.

The objective of this research was to investigate the reactivity of MCP and BCP with platinum, with a particular focus on isolating complexes with ligands derived from these alkenes. The majority of the transition metal chemistry done with these alkenes had involved palladium, while very little work was done with platinum. However, catalytically significant palladium species are transient and therefore difficult to characterise. In contrast, platinum species tend to be more stable, making platinum a useful model for palladium systems. Platinum also has an NMR-active isotope which assists with characterisation.

Initial attempts were made to synthesise homoleptic alkene complexes in order to determine the number of ligands that can coordinate. The typical number of alkene 
ligands in complexes such as $\left[\mathrm{Pt}(\mathrm{nb})_{3}\right]$ is three; ${ }^{16}$ in homoleptic alkyne complexes, the typical number of ligands is two. ${ }^{187}$ In BCP, the presence of the cyclopropyl rings increases the s-character of the double-bond carbon orbitals, making the carbons close to sphybridised. ${ }^{29,32,68}$ This could mean that it would behave more like an alkyne in that only two BCP ligands would coordinate in the homoleptic complex. However, the formation of such complexes was not observed; instead ring-opening reactions occurred.

The synthesis of $\eta^{2}$-alkene complexes was more successful when stabilising auxilliary ligands were used. A range of $\eta^{2}$-BCP and MCP Pt(0) complexes with both mono- and di-phosphine ligands were synthesised, $[\mathrm{Pt}(\mathrm{L})(\mathrm{P}-\mathrm{P})],[\mathrm{Pt}(\mathrm{L})(\mathrm{P}-\mathrm{S})],\left[\mathrm{Pt}\left(\mathrm{C}_{2} \mathrm{H}_{4}\right)(\mathrm{L})\left(\mathrm{PR}_{3}\right)\right]$ and $\left[\mathrm{Pt}(\mathrm{L})_{2}\left(\mathrm{PR}_{3}\right)\right]\left(\mathrm{L}=\eta^{2}-\mathrm{BCP}, \eta^{2}-\mathrm{MCP} ; \mathrm{P}-\mathrm{P}=\right.$ dppp, dcyppe, dbpe, dbpx; $\mathrm{P}-\mathrm{S}$ $\left.={ }^{t} \mathrm{Bu}_{2} \mathrm{PCH}_{2}\left(o-\mathrm{C}_{6} \mathrm{H}_{4}\right) \mathrm{CH}_{2} \mathrm{~S}{ }^{t} \mathrm{Bu} ; \mathrm{PR}_{3}=\mathrm{PPh}_{3}, \mathrm{PCy}_{3}\right)$, produced by the displacement of an alkene ligand, either ethene or norbornene, from a precursor complex. Platinum(II) complexes $\left[\mathrm{PtCl}_{2}(\mathrm{~L})\left(\mathrm{L}^{\prime}\right)\right]\left(\mathrm{L}=\eta^{2}\right.$-BCP, $\eta^{2}$-MCP; $\mathrm{L}^{\prime}=\mathrm{Py}$, DMSO) were also synthesised, again by displacement of a ligand from a precursor, either ethene or DMSO. These complexes are the first examples of late transition metal complexes of bicyclopropylidene as well as the first bis-methylenecyclopropane complexes of platinum. ${ }^{79}$

The coordinated alkenes proved to be reactive, and both of the reactivity modes observed with other transition metals, namely additions across the double-bond and ringopening, also occurred with platinum, supporting the formation of $\eta^{2}$-alkene complexes as a first step in TM-catalysed reactions. The alkene ligands underwent reactions with either protons or in situ hydrides to produce $\eta^{3}$-allyl complexes. Three different allyl structures were observed in the protonation of $[\mathrm{Pt}(\mathrm{L})(\mathrm{P}-\mathrm{P})](\mathrm{P}-\mathrm{P}=\mathrm{dppp}$, dbpx $)$, with the relative ratios dependent on both the phosphine auxiliary ligand and the solvent. These allyl structures were the 2-substituted complexes $\left[\mathrm{Pt}\left(\eta^{3}-\mathrm{CH}_{2} \mathrm{C}^{c} \mathrm{PrCH}_{2}\right)(\mathrm{P}-\mathrm{P})\right]^{+}$and $\left[\mathrm{Pt}\left(\eta^{3}-\mathrm{CH}_{2} \mathrm{CMeCH}_{2}\right)(\mathrm{P}-\mathrm{P})\right]^{+}$, the 1-methyl substituted complexes with the methyl in the anti position $\left[\mathrm{Pt}\left(\eta^{3}-\mathrm{C}\left(\mathrm{CH}_{2}\right)_{2} \mathrm{CHCHMe}\right)(\mathrm{P}-\mathrm{P})\right]^{+}$and $\left[\mathrm{Pt}\left(\eta^{3}-\mathrm{CH}_{2} \mathrm{CHCHMe}\right)(\mathrm{P}-\mathrm{P})\right]^{+}$, and the 1-methyl substituted complexes with the methyl in the syn position.

Only one allyl structure was produced from the $[\mathrm{Pt}(\mathrm{L})(\mathrm{P}-\mathrm{S})]$ complexes, the 1-methyl substituted complexes with the methyl in the anti position 
$\left[\mathrm{Pt}\left(\eta^{3}-\mathrm{C}\left(\mathrm{CH}_{2}\right)_{2} \mathrm{CHCHMe}\right)(\mathrm{P}-\mathrm{C})\right]^{+}$and $\left[\mathrm{Pt}\left(\eta^{3}-\mathrm{CH}_{2} \mathrm{CHCHMe}\right)(\mathrm{P}-\mathrm{C})\right]^{+}$. In this case, the coordinated alkene reacted with a hydride generated by ortho-metallation of the $\mathrm{P}-\mathrm{S}$ ligand. Computational models were used to investigate the formation of these various allyl complexes. It was determined that the activation energies for the various reactions had a larger effect than the relative stabilities of the complexes on the final product. The steric bulk of the auxiliary ligand was found to be more important in determining product distributions than the electronic nature of the ligand.

The proposed mechanism for the formation of these allyl complexes involves the addition of $\mathrm{Pt}-\mathrm{H}$ across the double-bond, followed by cleavage of one of the ring bonds in a cyclopropylmethyl to homoallyl rearrangement. ${ }^{135}$ Similar allyl complexes are likely intermediates in other transition metal catalysed reactions, and undergo subsequent reactions with nucleophiles. ${ }^{38,72,74,137,138}$ It is likely that the allyl complexes synthesised in this work would also be reactive towards nucleophiles and therefore form the same products observed with palladium systems.

The addition of $\mathrm{Pt}-\mathrm{H}$ followed by ring-opening in a cyclopropylmethyl to homoallyl rearrangement can also result in the formation of a 1,3 -diene. ${ }^{38,74}$ With $\mathrm{BCP}$, the diene formed is allylidenecyclopropane, while with MCP it is 1,3-butadiene. Allylidenecyclopropane was produced from $\mathrm{BCP}$ with an number of $\mathrm{Pt}(0)$ and $\mathrm{Pt}(\mathrm{II})$ complexes, while 1,3-butadiene is only formed in the reaction of $\mathrm{MCP}$ with $\left[\mathrm{PtEt}_{2}(\mathrm{COD})\right]$ as the minor antiMarkovnikov product. The Markovnikov addition of $\mathrm{Pt}-\mathrm{H}$ across the MCP double-bond is not followed by ring opening. Instead, complexes with 1-methylcyclopropyl ligands are produced, the first stable examples of such complexes.

As allylidenecyclopropane is itself an alkene with a cyclopropyl ring and an exocyclic double-bond, its coordination chemistry was also explored. Diphosphine complexes $[\mathrm{Pt}(\mathrm{ACP})(\mathrm{P}-\mathrm{P})]\left(\mathrm{P}-\mathrm{P}=\mathrm{Ph}_{2} \mathrm{P}\left(\mathrm{CH}_{2}\right)_{3} \mathrm{PPh}_{2}, \mathrm{Cy}_{2} \mathrm{P}\left(\mathrm{CH}_{2}\right)_{2} \mathrm{PCy}_{2},{ }^{t} \mathrm{Bu}{ }_{2} \mathrm{P}\left(\mathrm{CH}_{2}\right)_{2} \mathrm{P}^{t} \mathrm{Bu}_{2}\right)$ were synthesised in the same manor as the BCP and MCP analogues, and are the first examples of coordinated ACP. Some of the ACP complexes underwent a rearrangement reaction to form $\eta^{2}: \sigma^{2}$-metallacyclopentene complexes, the first instances of the formation of $\eta^{2}: \sigma^{2}$-metallacyclopentene complexes from $\eta^{2}: \pi$-diene complexes, rather than from $\eta^{4}: \pi$ - 
diene complexes. This work is the first exploration of the coordination chemistry of allylidenecyclopropane.

Several instances of addition of $\mathrm{Pt}-\mathrm{Cl}$ across the $\mathrm{BCP}$ double-bond were observed. These were not followed by ring-opening. Instead, the addition products were stable $\beta$-haloalkyl complexes, trans- $-\left[\mathrm{Pt}\left(\mathrm{C}\left(\mathrm{CH}_{2}\right)_{2} \mathrm{C}\left(\mathrm{CH}_{2}\right)_{2} \mathrm{Cl}\right) \mathrm{Cl}(\mathrm{L})_{2}\right]\left(\mathrm{L}=\mathrm{SEt}_{2}, \mathrm{NC}^{t} \mathrm{Bu}, \mathrm{Py}\right)$ and cis- $-\left[\mathrm{Pt}\left(\mathrm{C}\left(\mathrm{CH}_{2}\right)_{2} \mathrm{C}\left(\mathrm{CH}_{2}\right)_{2} \mathrm{Cl}\right) \mathrm{Cl}(\mathrm{Py})_{2}\right]$. No trans complexes were produced from MCP; only cis- $\left[\mathrm{Pt}\left(\mathrm{C}\left(\mathrm{CH}_{2}\right)_{2} \mathrm{CH}_{2} \mathrm{Cl}\right) \mathrm{Cl}(\mathrm{Py})_{2}\right]$ was formed. Phosphine complexes were

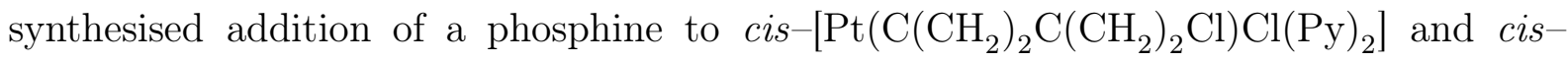
$\left[\mathrm{Pt}\left(\mathrm{C}\left(\mathrm{CH}_{2}\right)_{2} \mathrm{CH}_{2} \mathrm{Cl}\right) \mathrm{Cl}(\mathrm{Py})_{2}\right]$. The addition of a phosphine to trans $\beta$-chloroalkyl complexes resulted in $\beta$-chloride elimination and the formation of either $\left[\mathrm{PtCl}_{2}\left(\mathrm{PR}_{3}\right)_{2}\right]$ or $\left[\mathrm{Pt}(\mathrm{P}-\mathrm{P})_{2}\right] \mathrm{Cl}_{2}$. A short-lived trans $\beta$-chloroalkyl complex formed with PTA, which was the smallest of the phosphines used. The stability and formation rates of the other phosphine complexes were dependent on the size of the phosphine ligand, with smaller phosphines producing more stable complexes.

These $\beta$-chloroalkyl complexes are unusually stable, and are the only reported instances of Pt(II) $\beta$-haloalkyl complexes. These are also the only $\beta$-haloalkyl complexes formed by insertion into an $\mathrm{Pt}-\mathrm{X}$ bond, rather than addition of $\mathrm{X}_{2}$ to an $\eta^{2}$-alkene complex. Computational models of trans- $\left[\mathrm{Pt}\left(\mathrm{CR}_{2} \mathrm{CR}_{2} \mathrm{Cl}\right) \mathrm{Cl}\left(\mathrm{NC}^{t} \mathrm{Bu}\right)_{2}\right]\left(\mathrm{R}=\mathrm{CH}_{2}, \mathrm{Me}, \mathrm{H}\right)$ were used to investigate the stability of complexes with different substitution patterns. When substituted with methyl groups, the resulting $\beta$-chloroalkyl complexes were increasingly unstable with more substitution closer to the metal centre. The opposite trend was observed for cyclopropyl substitution; it was the complexes with the higher degree of substitution closer to the metal that were more stable. This was in agreement with the experimental observations.

The $\beta$-haloalkyl complexes complexes are may have potential in the polymerisation of halogenated monomers such as vinyl chloride. ${ }^{160-163}$ The polymerisation reactions currently involve a radical mechanism, which offers limited control of over the polymer structure and can lead to the formation of defects, affecting the stability of the resulting polymer. A mechanism that involves a $\beta$-haloalkyl intermediate could lead to more control 
over the polymerisation process. However, previous work has been inhibited by very facile $\beta$-chloride elimination reactions. This work has shown that the both the substitution of the $\beta$-haloalkyl ligands and the nature of the auxiliary ligands affects the stability of such complexes, potentially enabling the further development of these polymerisation reactions.

This work has explored the coordination chemistry of bicyclopropylidene and methylenecyclopropane with platinum. Analogous reactivity to other transition metal systems, particularly palladium, was observed. A number of complexes with ligands derived from BCP and MCP were sythesised. These were $\eta^{2}$-alkene, $\eta^{3}$-allyl, 1cycloproylmethyl and $\beta$-chloroalkyl ligands. Such complexes are not only similar to intermediates in various transition metal catalysed reactions, but are also interesting species in their own rights. 


\section{Chapter 6}

\section{Experimental}

\subsection{General Considerations}

All reactions were carried out using de-oxygenated solvents and standard Schlenk techniques under either a nitrogen or argon atmosphere, unless stated otherwise. Starting materials were purchased from Sigma-Aldrich and used without further purification unless stated otherwise. Bicyclopropylidene, ${ }^{67}$ methylenecyclopropane, ${ }^{28}$ $\left[\mathrm{PtCl}_{2}(\mathrm{dppp})\right],{ }^{188} \quad\left[\mathrm{Pt}\left(\mathrm{C}_{2} \mathrm{H}_{4}\right)(\mathrm{dbpx})\right],{ }^{83} \quad\left[\mathrm{Pt}\left(\mathrm{C}_{2} \mathrm{H}_{4}\right)(\mathrm{dbpe})\right],{ }^{83} \quad\left[\mathrm{Pt}\left(\mathrm{C}_{2} \mathrm{H}_{4}\right)_{2}\left(\mathrm{PPh}_{3}\right)\right],{ }^{119}$ $\left[\mathrm{Pt}\left(\mathrm{C}_{2} \mathrm{H}_{4}\right)_{2}\left(\mathrm{PCy}_{3}\right)\right],{ }^{119} \quad\left[\mathrm{Pt}(\mathrm{nb})_{3}\right],{ }^{20} \quad\left[\mathrm{Pt}(\mathrm{COD})_{2}\right],{ }^{20} \quad\left[\mathrm{Pt}\left(\mathrm{C}_{2} \mathrm{H}_{4}\right)_{3}\right],{ }^{20} \quad\left[\mathrm{PtCl}_{2}\left(\mathrm{SEt}_{2}\right)_{2}\right],{ }^{178}$ $\left[\mathrm{PtCl}_{2}(\mathrm{Py})_{2}\right],{ }^{189} \quad\left[\mathrm{PtCl}_{2}(\mathrm{DMSO})_{2}\right],{ }^{190} \quad\left[\mathrm{PtCl}_{2}\left(\mathrm{NC}^{t} \mathrm{Bu}\right)_{2}\right],{ }^{191} \quad\left[\mathrm{PtMe}_{2}(1,5\right.$-hexadiene $\left.)\right],{ }^{192}$ and $\left[\mathrm{PtEt}_{2}(\mathrm{COD})\right]^{83}$ were synthesized according to literature methods. The synthesis of dbpx was via the deprotection of dbpx-borane ${ }^{193}$ using neat diethylamine, while dcyppe was synthesized by the reaction of cyclopentylmagnesium bromide with 1,2bis(dichlorophosphino)ethane. Deuterated solvents were purchased from Sigma-Aldrich and stored under a nitrogen atmosphere.

NMR spectra were measured on Varian Unity Inova $300 \mathrm{MHz}\left(300 \mathrm{MHz}\right.$ for ${ }^{1} \mathrm{H}$, $121 \mathrm{MHz}$ for ${ }^{31} \mathrm{P}, 282 \mathrm{MHz}$ for $\left.{ }^{19} \mathrm{~F}\right)$, Varian Unity Inova $500 \mathrm{MHz}\left(500 \mathrm{MHz}\right.$ for ${ }^{1} \mathrm{H}$, $125 \mathrm{MHz}$ for ${ }^{13} \mathrm{C}$ ) and Varian DirectDrive $600 \mathrm{MHz}\left(600 \mathrm{MHz}\right.$ for ${ }^{1} \mathrm{H}, 150 \mathrm{MHz}$ for $\left.{ }^{13} \mathrm{C}\right)$ NMR spectrometers, with chemical shift values $\delta$ referenced to the residual solvent peaks for ${ }^{1} \mathrm{H}$ and ${ }^{13} \mathrm{C}\left\{{ }^{1} \mathrm{H}\right\}$, to $85 \% \mathrm{H}_{3} \mathrm{PO}_{4}$ for ${ }^{31} \mathrm{P}\left\{{ }^{1} \mathrm{H}\right\}$ and $\mathrm{CFCl}_{3}$ for ${ }^{19} \mathrm{~F}$. NMR yields were reported for compounds unable to be isolated, and obtained by integration of 
the ${ }^{31} \mathrm{P}\left\{{ }^{1} \mathrm{H}\right\}$ or ${ }^{1} \mathrm{H}$ NMR spectra against other species in solution. Elemental analyses were performed by the Campbell Microanalytical Laboratory, University of Otago, New Zealand. Electrospray ionization mass spectra were obtained using a Aglient 6530 Series Q-TOF mass spectrometer or performed by the GlycoSyn QC laboratory at Industrial Research Limited using a Waters Q-TOF Premier Tandem mass spectrometer. Calculated NMR spectra were obtained from gNMR spectral simulation program, version 5.0.6.0, written by P. H. M. Budzelaar, IvorySoft 2006. X-ray diffraction data were collected by the X-ray Crystallograpy Laboratory at the University of Canterbury on a Bruker SMART CCD diffractometer using Mo K $\alpha$ radiation. Data were reduced using Bruker SAINT software. Absorption correction was performed using the SADABS program. The structures were solved using OLEX2 running SHELXS97 and SHELXL97. ${ }^{194,195}$ The positions of all hydrogen atoms were calculated during refinement. Calculations were performed using the Gaussian 09 Revision B.01 program ${ }^{196,197}$ and were performed on the Victoria University of Wellington School of Chemical and Physical Sciences' Heisenberg cluster, consisting of eight processing nodes with two $2.53 \mathrm{GHz}$ Xeon X3440 quad-core processors per node and 1 GB of memory per core.

\subsection{Chapter Two Experimental}

\section{Synthesis of Cyclopropanecarboxylic-carboxyl- ${ }^{13} \mathrm{C}\left\{{ }^{1} \mathrm{H}\right\}$ Acid ${ }^{88}$}

Magnesium turnings $(1.7 \mathrm{~g}, 0.070 \mathrm{~mol})$ was placed in a 2-neck $100 \mathrm{~mL}$ RB flask equipped with a double surface condenser and a dropping funnel and dry stirred overnight. THF (25 mL) was added and bromocyclopropane $(5.0 \mathrm{~g}, 0.413 \mathrm{~mol})$ placed in the dropping funnel. The Mg was activated with 1,2-dibromoethane and heat, and the bromocyclopropane slowly added and the solution stirred for 30 min. Barium carbonate (7.1 g, $0.036 \mathrm{~mol}, 70 \%{ }^{13} \mathrm{C}$ ) was placed in a 2-neck $100 \mathrm{~mL}$ RB flask equipt with a dropping funnel and a drying tube filled with silica gel attached to a glass tube that vented into a $250 \mathrm{~mL}$ flask fitted with a balloon to regulate pressure. This flask was filled with $140 \mathrm{~mL}$ of THF and cooled to $-78^{\circ} \mathrm{C}$ in a dry ice/acetone bath. $\mathrm{H}_{2} \mathrm{SO}_{4}$ (conc.) was slowly added 
onto the $\mathrm{BaCO}_{3}$ while stirring vigorously, with the mouth of the bubbling tube kept above the level of the THF. The $\mathrm{BaCO}_{3}$ was heated to ensure complete reaction. The ${ }^{c} \mathrm{PrMgBr}$ solution was added to the solution of $\mathrm{CO}_{2}$, and the reaction allowed to warm to room temperature. The reaction mixture was cooled in ice, quenched with $\mathrm{H}_{2} \mathrm{SO}_{4}(25 \mathrm{~mL}$, $4 \mathrm{~mol} \mathrm{~L}^{-1}$ ), stirred overnight and filtered. The solution was reduced to $\sim 50 \mathrm{~mL}$ then continuously extracted into $\mathrm{Et}_{2} \mathrm{O}$ for $48 \mathrm{hrs}$. The ether solution was distilled by heating in an oil bath up to $110^{\circ} \mathrm{C}$, adding $5 \mathrm{~mL} \mathrm{CH}_{2} \mathrm{Cl}_{2}$ and continuing until the temperature started to drop. The residue was then distilled under water pump pressure, with the product distilling at $80{ }^{\circ} \mathrm{C}(745 \mathrm{mg}, 19 \%) .{ }^{1} \mathrm{H} \mathrm{NMR}\left(\delta, \mathrm{C}_{6} \mathrm{D}_{6}, 500 \mathrm{MHz}\right): 1.60(\mathrm{tt}$, 8.0, $4.4 \mathrm{~Hz}, 1 \mathrm{H}, \mathrm{CH}), 1.06\left(\mathrm{~m}, 2 \mathrm{H}, \mathrm{CH}_{2}\right), 0.93\left(\mathrm{~m}, 2 \mathrm{H}, \mathrm{CH}_{2}\right) \cdot{ }^{13} \mathrm{C}\left\{{ }^{1} \mathrm{H}\right\} \operatorname{NMR}\left(\delta, \mathrm{C}_{6} \mathrm{D}_{6}\right.$, $125 \mathrm{MHz}): 181.5(\mathrm{~s}, \mathrm{COOH}), 13.0(\mathrm{~s}, \mathrm{CH}), 12.9\left(\mathrm{~d},{ }^{1} J_{\mathrm{C}-\mathrm{C}}=74.4 \mathrm{~Hz}, \mathrm{CH}\right), 9.3\left(\mathrm{~s}, \mathrm{CH}_{2}\right)$.

\section{Synthesis of $\left[\mathrm{Pt}\left(\mathrm{C}_{2} \mathrm{H}_{4}\right)(\mathrm{dppp})\right]$}

$\left[\mathrm{PtCl}_{2}(\mathrm{dppp})\right](0.455 \mathrm{~g}, 0.67 \mathrm{mmol})$ was suspended in ethanol $(12.6 \mathrm{~mL})$ under a nitrogen atmosphere. The solution was saturated with ethene and a solution of $\mathrm{NaBH}_{4}(2.08 \mathrm{mmol}$, $10.4 \mathrm{~mL}, 2 \mathrm{M}$ ) in ethanol was added dropwise. The solution was stirred under a flow of ethene for 2 hrs. The supernatant liquid was removed and the pale yellow precipitate washed with water $(3 \times 6 \mathrm{~mL})$ and ethanol $(3 \times 6 \mathrm{~mL})$. Benzene $(5 \mathrm{~mL})$ was added and the solution dried in vacuo to remove water. The product was a yellow crystalline solid (368 mg, $0.58 \mathrm{mmol}, 86 \%)$. ${ }^{1} \mathrm{H} \mathrm{NMR}\left(\delta, \mathrm{C}_{6} \mathrm{D}_{6}, 500 \mathrm{MHz}\right): 7.71\left(\mathrm{~m}, 8 \mathrm{H}, o-\mathrm{C}_{6} \mathrm{H}_{5}\right)$, $7.03\left(\mathrm{~m}, 12 \mathrm{H}, m\right.$ - and $\left.p-\mathrm{C}_{6} \mathrm{H}_{5}\right), 2.68\left(\mathrm{~d}, 2.7, J_{\mathrm{Pt}-\mathrm{H}}=60.0 \mathrm{~Hz}, 4 \mathrm{H},=\mathrm{CH}_{2}\right), 2.19(\mathrm{~m}, 4 \mathrm{H}$, $\left.\mathrm{P}-\mathrm{CH}_{2}\right), 1.68\left(\mathrm{~m}, 2 \mathrm{H}, \mathrm{CH}_{2}\right) .{ }^{13} \mathrm{C}\left\{{ }^{1} \mathrm{H}\right\} \operatorname{NMR}\left(\delta, \mathrm{C}_{6} \mathrm{D}_{6}, 125 \mathrm{MHz}\right): 138.7\left(\mathrm{~m}, i-\mathrm{C}_{6} \mathrm{H}_{5}\right)$, $133.1\left(\mathrm{~m}, o-\mathrm{C}_{6} \mathrm{H}_{5}\right), 129.4\left(\mathrm{~s}, p-\mathrm{C}_{6} \mathrm{H}_{5}\right), 128.3\left(\mathrm{~s}, m-\mathrm{C}_{6} \mathrm{H}_{5}\right), 31.9\left(\mathrm{t}, 25.5,{ }^{1} J_{\mathrm{Pt}-\mathrm{C}}=216.0 \mathrm{~Hz}\right.$, $\left.=\mathrm{CH}_{2}\right), 28.9\left(\mathrm{dd}, 14.5,13.3 \mathrm{~Hz}, \mathrm{P}-\mathrm{CH}_{2}\right), 21.0\left(\mathrm{t}, 3.8 \mathrm{~Hz}, \mathrm{CH}_{2}\right) \cdot{ }^{31} \mathrm{P}\left\{{ }^{1} \mathrm{H}\right\} \operatorname{NMR}\left(\delta, \mathrm{C}_{6} \mathrm{D}_{6}\right.$, $121 \mathrm{MHz}): 13.8\left(\mathrm{~s},{ }^{1} J_{\mathrm{Pt}-\mathrm{P}}=3340 \mathrm{~Hz}\right)$.

\section{Synthesis of $\left[\mathrm{PtCl}_{2}(\mathrm{dcyppe})\right]$}

1,2-Bis(dicyclopentylphosphino)ethane $(278 \mathrm{mg}, 0.76 \mathrm{mmol})$ was placed in a $50 \mathrm{~mL} \mathrm{2-}$ necked round bottom flask fitted with a reflux condenser. $\mathrm{K}_{2}\left[\mathrm{PtCl}_{4}\right](314 \mathrm{mg}, 0.76 \mathrm{mmol})$ 
was added, followed by $\mathrm{EtOH}(10 \mathrm{~mL})$ and c. $\mathrm{HCl}(7 \mathrm{~mL})$. The solution was refluxed overnight, before filtration of the white solid and washing with $\mathrm{H}_{2} \mathrm{O}(2 \times 5 \mathrm{~mL})$ and EtOH $(2 \times 5 \mathrm{~mL})$. The isolated solid is $\left[\mathrm{PtCl}_{2}(\right.$ dcyppe $\left.)\right](400 \mathrm{mg}, 0.63 \mathrm{mmol}, 83 \%) .{ }^{1} \mathrm{H}$ $\operatorname{NMR}\left(\delta, \mathrm{CDCl}_{3}, 500 \mathrm{MHz}\right): 2.64(\mathrm{~m}, 4 \mathrm{H}, \mathrm{P}-\mathrm{CH}), 2.15\left(\mathrm{~m}, 4 \mathrm{H}, \mathrm{CH}_{2}\right), 1.92\left(\mathrm{~m}, 8 \mathrm{H}, \mathrm{CH}_{2}\right)$, 1.82-1.59(m, 24H, P- $\mathrm{CH}_{2}$ and $\left.\mathrm{CH}_{2}, 125 \mathrm{MHz}\right) .{ }^{13} \mathrm{C}\left\{{ }^{1} \mathrm{H}\right\} \operatorname{NMR}\left(\delta, \mathrm{CDCl}_{3}\right): 36.8(\mathrm{~d}$, $37.8 \mathrm{~Hz}, \mathrm{P}-\mathrm{CH}), 29.7\left(\mathrm{~d}, 1.5 \mathrm{~Hz}, \mathrm{CH}_{2}\right), 29.4\left(\mathrm{~s}, \mathrm{CH}_{2}\right), 26.3\left(\mathrm{~d}, 10.1 \mathrm{~Hz}, \mathrm{CH}_{2}\right), 25.3(\mathrm{~d}$, $\left.11.6 \mathrm{~Hz}, \mathrm{CH}_{2}\right), 22.3\left(\mathrm{dd}, 36.0,7.8 \mathrm{~Hz}, \mathrm{P}-\mathrm{CH}_{2}\right) .{ }^{31} \mathrm{P}\left\{{ }^{1} \mathrm{H}\right\} \operatorname{NMR}\left(\delta, \mathrm{CDCl}_{3}, 121 \mathrm{MHz}\right)$ : $59.2\left(\mathrm{~s},{ }^{1} J_{\mathrm{Pt}-\mathrm{P}}=3570 \mathrm{~Hz}\right)$.

\section{Synthesis of $\left[\operatorname{Pt}\left(\mathrm{C}_{2} \mathrm{H}_{4}\right)(\right.$ dcyppe $\left.)\right]$}

Mercury (10.2 g, $0.051 \mathrm{~mol}$ ) was placed in a Schlenk tube and small pieces of sodium (88 mg, $3.8 \mathrm{mmol}$ ) slowly added. When the dissolution was complete, THF (10 mL) was added and the liquid saturated with ethene. [ $\mathrm{PtCl}_{2}$ (dcyppe)] (248 mg, $\left.0.39 \mathrm{mmol}\right)$ was added and the reaction stirred for $2 \mathrm{hr}$. The solution was run through a $1 \mathrm{~cm}$ Celite column followed by a $1 \mathrm{~cm}$ alumina column and the amalgam was washed with THF $(2 \times$ $10 \mathrm{~mL}$ ). The solvent was removed in vacuo yielding a brown solid (116 mg, $0.20 \mathrm{mmol}$, $51 \%) .{ }^{1} \mathrm{H} \operatorname{NMR}\left(\delta, \mathrm{C}_{6} \mathrm{H}_{6}, 500 \mathrm{MHz}\right): 2.38\left(\mathrm{t}, 1.8, J_{\mathrm{Pt}-\mathrm{H}}=58.0 \mathrm{~Hz}, 4 \mathrm{H},=\mathrm{CH}_{2}\right), 1.97(\mathrm{~m}$, $4 \mathrm{H}, \mathrm{P}-\mathrm{CH}), 1.80\left(\mathrm{~m}, 8 \mathrm{H}, \mathrm{CH}_{2}\right), 1.66-1.50\left(\mathrm{~m}, 12 \mathrm{H}, \mathrm{CH}_{2}\right), 1.50-1.32\left(\mathrm{~m}, 16 \mathrm{H}, \mathrm{P}-\mathrm{CH}_{2}\right.$ and $\left.\mathrm{CH}_{2}\right) .{ }^{13} \mathrm{C}\left\{{ }^{1} \mathrm{H}\right\} \operatorname{NMR}\left(\delta, \mathrm{C}_{6} \mathrm{H}_{6}, 125 \mathrm{MHz}\right): 39.3\left(\mathrm{t}, 12.9, J_{\mathrm{Pt}-\mathrm{C}}=49.9 \mathrm{~Hz}, \mathrm{P}-\mathrm{CH}\right), 31.1(\mathrm{t}$, $\left.4.6, J_{\mathrm{Pt}-\mathrm{C}}=15.2 \mathrm{~Hz}, \mathrm{CH}_{2}\right), 30.5\left(\mathrm{t}, 2.9, J_{\mathrm{Pt}-\mathrm{C}}=22.1 \mathrm{~Hz}, \mathrm{CH}_{2}\right), 28.7\left(\mathrm{t}, 21.1, J_{\mathrm{Pt}-\mathrm{C}}=\right.$ $\left.17.3 \mathrm{~Hz}, \mathrm{P}-\mathrm{CH}_{2}\right), 26.4\left(\mathrm{t}, 4.5 \mathrm{~Hz}, \mathrm{CH}_{2}\right), 23.2\left(\mathrm{t}, 15.1,{ }^{1} J_{\mathrm{Pt}-\mathrm{C}}=227.4 \mathrm{~Hz},=\mathrm{CH}_{2}\right) .{ }^{31} \mathrm{P}\left\{{ }^{1} \mathrm{H}\right\}$ $\operatorname{NMR}\left(\delta, \mathrm{C}_{6} \mathrm{H}_{6}, 121 \mathrm{MHz}\right): 75.4\left(\mathrm{~s},{ }^{1} J_{\mathrm{Pt}-\mathrm{P}}=3170 \mathrm{~Hz}\right)$.

\section{Synthesis of $[\operatorname{Pt}(\mathrm{BCP})(\mathrm{dppp})] 1 \mathrm{a}$}

$\left[\mathrm{Pt}\left(\mathrm{C}_{2} \mathrm{H}_{4}\right)(\mathrm{dppp})\right](0.162 \mathrm{~g}, 0.28 \mathrm{mmol})$ was dissolved in toluene $(3.5 \mathrm{~mL})$. Bicyclopropylidene $(0.052 \mathrm{~mL}, 0.56 \mathrm{mmol})$ was added, and the solution stirred for $30 \mathrm{~min}$. The solvent was removed in vacuo, yielding an off-white solid ([Pt(BCP)(dppp)], $158 \mathrm{mg}, 0.23 \mathrm{mmol}$, $82 \%)$. Crystals of $[\mathrm{Pt}(\mathrm{BCP})(\mathrm{dppp})]$ were grown by slow recrystallization from hot toluene. ${ }^{1} \mathrm{H} \operatorname{NMR}\left(\delta, \mathrm{C}_{6} \mathrm{D}_{6}, 500 \mathrm{MHz}\right): 7.57\left(\mathrm{~m}, 8 \mathrm{H}, o-\mathrm{C}_{6} \mathrm{H}_{5}\right), 7.04\left(\mathrm{~m}, 8 \mathrm{H}, m-\mathrm{C}_{6} \mathrm{H}_{5}\right), 6.98(\mathrm{~m}, 4 \mathrm{H}, p$ - 
$\left.\mathrm{C}_{6} \mathrm{H}_{5}\right), 2.13\left(\mathrm{~m}, 4 \mathrm{H}, \mathrm{P}-\mathrm{CH}_{2}\right), 1.51\left(\mathrm{~m}, 2 \mathrm{H}, \mathrm{CH}_{2}\right), 1.29\left(\mathrm{~m}, J_{\mathrm{Pt}-\mathrm{H}}=66.0 \mathrm{~Hz}, 4 \mathrm{H},{ }^{c}\right.$ Pr-endo $)$, $1.18\left(\mathrm{~d}, 4.4, J_{\mathrm{Pt}-\mathrm{H}}=37.3 \mathrm{~Hz}, 4 \mathrm{H},{ }^{c} \operatorname{Pr}-\right.$ exo $) .{ }^{13} \mathrm{C}\left\{{ }^{1} \mathrm{H}\right\} \operatorname{NMR}\left(\delta, \mathrm{C}_{6} \mathrm{D}_{6}, 150 \mathrm{MHz}\right): 136.8(\mathrm{~m}$, $\left.i-\mathrm{C}_{6} \mathrm{H}_{5}\right), 132.9\left(\mathrm{~m}, o-\mathrm{C}_{6} \mathrm{H}_{5}\right), 129.5\left(\mathrm{~s}, p-\mathrm{C}_{6} \mathrm{H}_{5}\right), 128.4\left(\mathrm{~s}, m-\mathrm{C}_{6} \mathrm{H}_{5}\right), 34.3\left(\mathrm{~m}, J_{\mathrm{P}-\mathrm{C}}=73.3\right.$, $\left.-9.1, J_{\mathrm{P}-\mathrm{P}}=24.5,{ }^{1} J_{\mathrm{Pt}-\mathrm{C}}=409.4 \mathrm{~Hz},=\mathrm{CR}_{2}\right), 28.5\left(\mathrm{~m}, \mathrm{P}-\mathrm{CH}_{2}\right), 20.9\left(\mathrm{~m}, \mathrm{CH}_{2}\right), 8.8(\mathrm{~s}$, $\left.J_{\mathrm{Pt}-\mathrm{C}}=23.1 \mathrm{~Hz},{ }^{c} \mathrm{Pr}\right) .{ }^{31} \mathrm{P}\left\{{ }^{1} \mathrm{H}\right\} \operatorname{NMR}\left(\delta, \mathrm{C}_{6} \mathrm{D}_{6}, 121 \mathrm{MHz}\right): 9.3\left(\mathrm{~s},{ }^{1} J_{\mathrm{Pt}-\mathrm{P}}=2932 \mathrm{~Hz}\right)$. $m / z=[\mathrm{M}+\mathrm{H}]^{+}$calcd for $\mathrm{C}_{33} \mathrm{H}_{35} \mathrm{P}_{2}{ }^{194} \mathrm{Pt}$ 687.1841; found 687.1849. Anal. Calcd for $\mathrm{C}_{33} \mathrm{H}_{34} \mathrm{P}_{2} \mathrm{Pt}$ : C 57.64; H 4.98. Found: C 57.76; H 4.96.

\section{Synthesis of $[\mathrm{Pt}(\mathrm{BCP})($ dcyppe $)] 1 \mathrm{~b}$}

$\left[\mathrm{Pt}\left(\mathrm{C}_{2} \mathrm{H}_{4}\right)\right.$ (dcyppe)] (20 mg, $\left.0.034 \mathrm{mmol}\right)$ was dissolved in $\mathrm{C}_{6} \mathrm{D}_{6}(0.5 \mathrm{~mL})$ and placed in an NMR tube. BCP $(3.2 \mu \mathrm{L}, 0.034 \mathrm{mmol})$ was added and the reaction left overnight. Solution contains $91 \%\left[\mathrm{Pt}(\mathrm{BCP})(\right.$ dcyppe) $]$ by ${ }^{31} \mathrm{P}\left\{{ }^{1} \mathrm{H}\right\} \operatorname{NMR} .{ }^{1} \mathrm{H} \operatorname{NMR}\left(\delta, \mathrm{C}_{6} \mathrm{D}_{6}, 500 \mathrm{MHz}\right)$ : $1.90(\mathrm{~m}, 4 \mathrm{H}, \mathrm{P}-\mathrm{CH}), 1.73\left(\mathrm{~m}, 4 \mathrm{H}, \mathrm{CH}_{2}\right), 1.63-1.53\left(\mathrm{~m}, 18 \mathrm{H}, \mathrm{CH}_{2}, \mathrm{P}-\mathrm{CH}_{2}\right.$ and $\left.{ }^{c} \mathrm{Pr}\right), 1.50-$ $1.40\left(\mathrm{~m}, 12 \mathrm{H}, \mathrm{CH}_{2}\right.$ and $\left.{ }^{c} \mathrm{Pr}\right), 1.40-1.30\left(\mathrm{~m}, 10 \mathrm{H}, \mathrm{CH}_{2}\right.$ and $\left.\mathrm{P}-\mathrm{CH}_{2}\right) .{ }^{13} \mathrm{C}\left\{{ }^{1} \mathrm{H}\right\} \mathrm{NMR}(\delta$, $\left.\mathrm{C}_{6} \mathrm{D}_{6}, 125 \mathrm{MHz}\right): 39.1\left(\mathrm{dd}, 14.5,12.1, J_{\mathrm{Pt}-\mathrm{C}}=63.0 \mathrm{~Hz}, \mathrm{P}-\mathrm{CH}\right), 33.8\left(\mathrm{~m}, J_{\mathrm{P}-\mathrm{C}}=66.8,7.0\right.$, $\left.J_{\mathrm{P}-\mathrm{P}}=-59.7,{ }^{1} J_{\mathrm{Pt}-\mathrm{C}}=424.6 \mathrm{~Hz},=\mathrm{CR}_{2}\right), 30.4\left(\mathrm{t}, 2.3, J_{\mathrm{Pt}-\mathrm{C}}=19.6 \mathrm{~Hz}, \mathrm{CH}_{2}\right), 30.0(\mathrm{t}, 7.5$, $\left.J_{\mathrm{Pt}-\mathrm{C}}=11.6 \mathrm{~Hz}, \mathrm{CH}_{2}\right), 28.0\left(\mathrm{t}, 41.6, J_{\mathrm{Pt}-\mathrm{C}}=14.8 \mathrm{~Hz}, \mathrm{P}-\mathrm{CH}_{2}\right), 26.2\left(\mathrm{t}, 4.6, \mathrm{CH}_{2}\right), 10.4(\mathrm{~s}$, $\left.J_{\mathrm{Pt}-\mathrm{C}}=23.1 \mathrm{~Hz},{ }^{c} \mathrm{Pr}\right) .{ }^{31} \mathrm{P}\left\{{ }^{1} \mathrm{H}\right\} \operatorname{NMR}\left(\delta, \mathrm{C}_{6} \mathrm{D}_{6}, 121 \mathrm{MHz}\right): 70.8\left(\mathrm{~s},{ }^{1} J_{\mathrm{Pt}-\mathrm{P}}=2731 \mathrm{~Hz}\right)$.

\section{Synthesis of $[\operatorname{Pt}(\mathrm{BCP})(\mathrm{dbpe})] 1 \mathrm{c}$}

$\left[\mathrm{Pt}\left(\mathrm{C}_{2} \mathrm{H}_{4}\right)(\mathrm{dbpe})\right](20 \mathrm{mg}, 0.034 \mathrm{mmol})$ was dissolved in $\mathrm{C}_{6} \mathrm{D}_{6}(0.5 \mathrm{~mL})$ and placed in an NMR tube. BCP $(3.2 \mu \mathrm{L}, 0.034 \mathrm{mmol})$ was added and the reaction heated at $60^{\circ} \mathrm{C}$ for 7 days. Solution contains $80 \%[\mathrm{Pt}(\mathrm{BCP})(\mathrm{dbpe})]$ by ${ }^{31} \mathrm{P}\left\{{ }^{1} \mathrm{H}\right\} \operatorname{NMR} .{ }^{1} \mathrm{H} \operatorname{NMR}\left(\delta, \mathrm{C}_{6} \mathrm{D}_{6}\right.$, $500 \mathrm{MHz}): 1.57\left(\mathrm{~m}, 4 \mathrm{H},{ }^{c} \mathrm{Pr}\right), 1.31\left(\mathrm{~m}, 8 \mathrm{H}, \mathrm{P}-\mathrm{CH}_{2}\right.$ and $\left.{ }^{c} \mathrm{Pr}\right), 1.06\left(\mathrm{~d}, 12.0 \mathrm{~Hz}, 36 \mathrm{H},{ }^{t} \mathrm{Bu}\right)$. ${ }^{13} \mathrm{C}\left\{{ }^{1} \mathrm{H}\right\} \operatorname{NMR}\left(\delta, \mathrm{C}_{6} \mathrm{D}_{6}, 125 \mathrm{MHz}\right): 35.1\left(\mathrm{t}, 9.3, J_{\mathrm{Pt}-\mathrm{C}}=49.7 \mathrm{~Hz}, \mathrm{P}-\mathrm{CR}_{3}\right), 31.8\left(\mathrm{~m}, J_{\mathrm{P}-\mathrm{C}}\right.$

$\left.=70.5,4.1, J_{\mathrm{P}-\mathrm{P}}=59.5,{ }^{1} J_{\mathrm{Pt}-\mathrm{C}}=428.91 \mathrm{~Hz},=\mathrm{CR}_{2}\right), 29.9\left(\mathrm{t}, 3.5, J_{\mathrm{Pt}-\mathrm{C}}=15.9 \mathrm{~Hz}, \mathrm{CH}_{3}\right)$, $26.0\left(\mathrm{t}, 5.1, J_{\mathrm{Pt}-\mathrm{C}}=33.7 \mathrm{~Hz}, \mathrm{P}-\mathrm{CH}_{2}\right), 9.9\left(\mathrm{~s}, J_{\mathrm{Pt}-\mathrm{C}}=23.7 \mathrm{~Hz},{ }^{c} \mathrm{Pr}\right) .{ }^{31} \mathrm{P}\left\{{ }^{1} \mathrm{H}\right\} \mathrm{NMR}(\delta$, $\left.\mathrm{C}_{6} \mathrm{D}_{6}, 121 \mathrm{MHz}\right): 97.4\left(\mathrm{~s},{ }^{1} J_{\mathrm{Pt}-\mathrm{P}}=2798 \mathrm{~Hz}\right)$. 


\section{Synthesis of $[\operatorname{Pt}(B C P)(d b p x)] 1 d$}

$\left[\mathrm{Pt}\left(\mathrm{C}_{2} \mathrm{H}_{4}\right)(\mathrm{dbpx})\right](51 \mathrm{mg}, 0.083 \mathrm{mmol})$ was dissolved in $\mathrm{C}_{6} \mathrm{D}_{6}(0.5 \mathrm{~mL})$ and placed in an NMR tube. BCP $(13 \mu \mathrm{L}, 0.14 \mathrm{mmol})$ was added and the reaction heated at $60^{\circ} \mathrm{C}$ for 6 days. Solution contains 98\% $[\mathrm{Pt}(\mathrm{BCP})(\mathrm{dbpx})]$ by ${ }^{31} \mathrm{P}\left\{{ }^{1} \mathrm{H}\right\}$ NMR. ${ }^{1} \mathrm{H}$ NMR $(\delta$, $\left.\mathrm{C}_{6} \mathrm{D}_{6}, 500 \mathrm{MHz}\right):$ 7.14(m, 2H, o- $\left.\mathrm{C}_{6} \mathrm{H}_{4}\right), 6.94\left(\mathrm{~m}, 2 \mathrm{H}, m-\mathrm{C}_{6} \mathrm{H}_{4}\right), 3.44\left(\mathrm{~m}, 4 \mathrm{H}, \mathrm{P}-\mathrm{CH}_{2}\right)$, $1.34\left(\mathrm{~m}, J_{\mathrm{Pt}-\mathrm{H}}=61.2 \mathrm{~Hz}, 4 \mathrm{H},{ }^{c} \operatorname{Pr}-\right.$ endo $), 1.19\left(\mathrm{~d}, 12.5 \mathrm{~Hz}, 36 \mathrm{H},{ }^{t} \mathrm{Bu}\right), 0.99\left(\mathrm{~d}, 4.0, J_{\mathrm{Pt}-\mathrm{H}}\right.$ $=32.0 \mathrm{~Hz}, 4 \mathrm{H},{ }^{c} \operatorname{Pr}-$ exo $) \cdot{ }^{13} \mathrm{C}\left\{{ }^{1} \mathrm{H}\right\} \operatorname{NMR}\left(\delta, \mathrm{C}_{6} \mathrm{D}_{6}, 125 \mathrm{MHz}\right): 138.3\left(\mathrm{~s}, i-\mathrm{C}_{6} \mathrm{H}_{4}\right), 133.1(\mathrm{~s}$, $\left.o-\mathrm{C}_{6} \mathrm{H}_{4}\right), 126.1\left(\mathrm{~s}, m-\mathrm{C}_{6} \mathrm{H}_{4}\right), 37.3\left(\mathrm{~m}, \mathrm{P}-\mathrm{CR}_{3}\right), 32.0\left(\mathrm{~m}, \mathrm{P}-\mathrm{CH}_{2}\right), 30.2\left(\mathrm{~m}, \mathrm{CH}_{3}\right), 29.3(\mathrm{~m}$, $\left.J_{\mathrm{P}-\mathrm{C}}=78.1,-4.2, J_{\mathrm{P}-\mathrm{P}}=21.6,{ }^{1} J_{\mathrm{Pt}-\mathrm{C}}=456.3 \mathrm{~Hz},=\mathrm{CR}_{2}\right), 9.9\left(\mathrm{~s}, J_{\mathrm{Pt}-\mathrm{C}}=22.5 \mathrm{~Hz},{ }^{c} \mathrm{Pr}\right)$. ${ }^{31} \mathrm{P}\left\{{ }^{1} \mathrm{H}\right\} \operatorname{NMR}\left(\delta, \mathrm{C}_{6} \mathrm{D}_{6}, 121 \mathrm{MHz}\right): 43.3\left(\mathrm{~s},{ }^{1} J_{\mathrm{Pt}-\mathrm{P}}=2983 \mathrm{~Hz}\right)$.

\section{Synthesis of $[\operatorname{Pt}(\mathrm{MCP})(\mathrm{dppp})] 2 \mathrm{a}$}

$\left.\operatorname{Pt}\left(\mathrm{C}_{2} \mathrm{H}_{4}\right)(\mathrm{dppp})\right]$ (87 $\left.\mathrm{mg}, 0.14 \mathrm{mmol}\right)$ was dissolved in toluene $(1 \mathrm{~mL})$. A large excess of methylenecyclopropane was added, and the solution stirred for $30 \mathrm{~min}$. The solvent was removed in vacuo, yielding an off-white solid ([Pt(MCP)(dppp)], $79 \mathrm{mg}, 0.13 \mathrm{mmol}$, 92\%). ${ }^{1} \mathrm{H} \operatorname{NMR}\left(\delta, \mathrm{C}_{6} \mathrm{D}_{6}, 500 \mathrm{MHz}\right): 7.77\left(\mathrm{t}, 9 \mathrm{~Hz}, 4 \mathrm{H},{ }_{o}-\mathrm{C}_{6} \mathrm{H}_{4}-\mathrm{P}_{1}\right), 7.51(\mathrm{t}, 8.5 \mathrm{~Hz}$, $\left.4 \mathrm{H}, o-\mathrm{C}_{6} \mathrm{H}_{4}-\mathrm{P}_{2}\right), 7.05\left(\mathrm{~m}, 8 \mathrm{H}, m-\mathrm{C}_{6} \mathrm{H}_{5}\right), 7.00\left(\mathrm{~m}, 4 \mathrm{H}, p-\mathrm{C}_{6} \mathrm{H}_{4}\right), 2.63\left(\mathrm{dd}, J_{\mathrm{P}-\mathrm{H}}=7.7,4.5\right.$, $\left.{ }^{2} J_{\mathrm{Pt}-\mathrm{H}}=65.3 \mathrm{~Hz}, 2 \mathrm{H},=\mathrm{CH}_{2}\right), 2.17\left(\mathrm{~m}, 4 \mathrm{H}, \mathrm{P}-\mathrm{CH}_{2}\right), 1.65\left(\mathrm{~d}, 6.5, J_{\mathrm{Pt}-\mathrm{H}}=33.0 \mathrm{~Hz}, 2 \mathrm{H}\right.$, ${ }^{c} \operatorname{Pr}$-exo $), 1.59\left(\mathrm{~m}, 2 \mathrm{H}, \mathrm{CH}_{2}\right), 1.32\left(\mathrm{~d}, 9.5, J_{\mathrm{Pt}-\mathrm{H}}=82.5 \mathrm{~Hz}, 2 \mathrm{H},{ }^{c} \operatorname{Pr}-\right.$ endo $) .{ }^{13} \mathrm{C}\left\{{ }^{1} \mathrm{H}\right\} \mathrm{NMR}$ $\left(\delta, \mathrm{C}_{6} \mathrm{D}_{6}, 125 \mathrm{MHz}\right): 138.4\left(\mathrm{~m}, i-\mathrm{C}_{6} \mathrm{H}_{4}-\mathrm{P}_{1}\right), 136.9\left(\mathrm{~m}, i-\mathrm{C}_{6} \mathrm{H}_{4}-\mathrm{P}_{2}\right)$, 133.2(m, o- $\left.\mathrm{C}_{6} \mathrm{H}_{4}-\mathrm{P}_{1}\right)$, $132.8\left(\mathrm{~m}, o-\mathrm{C}_{6} \mathrm{H}_{4}-\mathrm{P}_{2}\right), 129.4\left(\mathrm{~m}, p-\mathrm{C}_{6} \mathrm{H}_{4}\right), 128.4\left(\mathrm{~m}, m-\mathrm{C}_{6} \mathrm{H}_{5}\right), 42.7\left(\mathrm{dd}, J_{\mathrm{P}-\mathrm{C}}=57.3,5.0\right.$, $\left.{ }^{1} J_{\mathrm{Pt}-\mathrm{C}}=455.4 \mathrm{~Hz},=\mathrm{CR}_{2}\right), 28.8\left(\mathrm{~m}, \mathrm{P}-\mathrm{CH}_{2}\right), 25.3\left(\mathrm{dd}, J_{\mathrm{P}-\mathrm{C}}=36.4,4.9,{ }^{1} J_{\mathrm{Pt}-\mathrm{C}}=173.4 \mathrm{~Hz}\right.$, $\left.=\mathrm{CH}_{2}\right), 21.0\left(\mathrm{~m}, \mathrm{CH}_{2}\right), 10.1\left(\mathrm{~d}, J_{\mathrm{P}-\mathrm{C}}=3.8, J_{\mathrm{Pt}-\mathrm{C}}=25.9 \mathrm{~Hz},{ }^{c} \mathrm{Pr}\right) .{ }^{31} \mathrm{P}\left\{{ }^{1} \mathrm{H}\right\} \mathrm{NMR}\left(\delta, \mathrm{C}_{6} \mathrm{D}_{6}\right.$, $121 \mathrm{MHz}): 11.8\left(\mathrm{AB},{ }^{2} J_{\mathrm{Pt}-\mathrm{P}}=41.5,{ }^{1} J_{\mathrm{Pt}-\mathrm{P}}=3275 \mathrm{~Hz}, \mathrm{P}_{2}\right.$ trans $\left.=\mathrm{CH}_{2}\right), 11.4\left(\mathrm{AB},{ }^{2} J_{\mathrm{Pt}-\mathrm{P}}\right.$ $=41.5,{ }^{1} J_{\mathrm{Pt}-\mathrm{P}}=2975 \mathrm{~Hz}, \mathrm{P}_{1}$ trans $\left.=\mathrm{CR}_{2}\right) \cdot m / z=[\mathrm{M}+\mathrm{H}]^{+}$calcd for $\mathrm{C}_{31} \mathrm{H}_{33} \mathrm{P}_{2}{ }^{194} \mathrm{Pt}$ 661.1684; found 661.1678. Anal. Calcd for $\mathrm{C}_{31} \mathrm{H}_{32} \mathrm{P}_{2} \mathrm{Pt}$ : C 56.28; H 4.87. Found: C 56.47; H 4.86. 


\section{Synthesis of $[\mathrm{Pt}(\mathrm{MCP})($ dcyppe $)] 2 \mathrm{~b}$}

$\left[\mathrm{Pt}\left(\mathrm{C}_{2} \mathrm{H}_{4}\right)\right.$ (dcyppe)] (20 mg, $\left.0.034 \mathrm{mmol}\right)$ was dissolved in $\mathrm{C}_{6} \mathrm{D}_{6}(0.5 \mathrm{~mL})$ and placed in an NMR tube. A large excess of MCP was added and the reaction left at room temperature overnight. Solution contains $100 \%\left[\mathrm{Pt}(\mathrm{MCP})(\right.$ dcyppe) $)$ by ${ }^{31} \mathrm{P}\left\{{ }^{1} \mathrm{H}\right\} \mathrm{NMR} .{ }^{1} \mathrm{H}$ NMR $(\delta$, $\left.\mathrm{C}_{6} \mathrm{D}_{6}, 500 \mathrm{MHz}\right): 2.40\left(\mathrm{dd}, 8.5,4.5,{ }^{2} J_{\mathrm{Pt}-\mathrm{H}}=60.5 \mathrm{~Hz}, 2 \mathrm{H},=\mathrm{CH}_{2}\right), 1.99-1.89(\mathrm{~m}, 6 \mathrm{H}$, $\mathrm{P}-\mathrm{CH}$ and $\left.{ }^{c} \mathrm{Pr}\right), 1.87-1.77\left(\mathrm{~m}, 6 \mathrm{H}, \mathrm{CH}_{2}\right.$ and $\left.{ }^{c} \mathrm{Pr}\right), 1.75-1.68\left(\mathrm{~m}, 4 \mathrm{H}, \mathrm{CH}_{2}\right), 1.6-1.3(\mathrm{~m}$, $28 \mathrm{H}, \mathrm{P}-\mathrm{CH}_{2}$ and $\left.\mathrm{CH}_{2}\right) \cdot{ }^{13} \mathrm{C}\left\{{ }^{1} \mathrm{H}\right\} \operatorname{NMR}\left(\delta, \mathrm{C}_{6} \mathrm{D}_{6}, 125 \mathrm{MHz}\right): 39.3\left(\mathrm{dd}, 21.6,4.2, J_{\mathrm{Pt}-\mathrm{C}}=\right.$ $43.8 \mathrm{~Hz}, \mathrm{P}-\mathrm{CH}), 39.1\left(\mathrm{dd}, 22.5,4.5, J_{\mathrm{Pt}-\mathrm{C}}=53.2 \mathrm{~Hz}, \mathrm{P}-\mathrm{CH}\right), 38.3\left(\mathrm{dd}, 71.0,8.7,{ }^{1} J_{\mathrm{Pt}-\mathrm{C}}\right.$ $\left.=501.0 \mathrm{~Hz},=\mathrm{CR}_{2}\right), 31.0\left(\mathrm{~d}, 8.2, J_{\mathrm{Pt}-\mathrm{C}}=15.7 \mathrm{~Hz}, \mathrm{CH}_{2}\right), 30.6\left(\mathrm{~d}, 5.4, J_{\mathrm{Pt}-\mathrm{C}}=16.7 \mathrm{~Hz}\right.$, $\left.\mathrm{CH}_{2}\right), 30.4\left(\mathrm{~d}, 5.2, J_{\mathrm{Pt}-\mathrm{C}}=22.0 \mathrm{~Hz}, \mathrm{CH}_{2}\right), 30.0\left(\mathrm{~d}, 14.3, J_{\mathrm{Pt}-\mathrm{C}}=10.3 \mathrm{~Hz}, \mathrm{CH}_{2}\right), 28.8(\mathrm{~m}$, $\left.\mathrm{P}-\mathrm{CH}_{2}\right), 27.6\left(\mathrm{~m}, \mathrm{P}-\mathrm{CH}_{2}\right), 26.3\left(\mathrm{~m}, \mathrm{CH}_{2}\right), 22.4\left(\mathrm{dd}, 41.8,5.6,{ }^{1} J_{\mathrm{Pt}-\mathrm{C}}=168.4 \mathrm{~Hz},=\mathrm{CH}_{2}\right)$, $12.3\left(\mathrm{~d}, 3.9, J_{\mathrm{Pt}-\mathrm{C}}=23.4 \mathrm{~Hz},{ }^{c} \mathrm{Pr}\right) .{ }^{31} \mathrm{P}\left\{{ }^{1} \mathrm{H}\right\} \mathrm{NMR}\left(\delta, \mathrm{C}_{6} \mathrm{D}_{6}, 121 \mathrm{MHz}\right): 75.0\left(\mathrm{AB},{ }^{2} J_{\mathrm{Pt}-\mathrm{P}}\right.$ $=62.5,{ }^{1} J_{\mathrm{Pt}-\mathrm{P}}=2751 \mathrm{~Hz}, \mathrm{P}$ trans $\left.=\mathrm{CR}_{2}\right), 70.8\left(\mathrm{AB},{ }^{2} J_{\mathrm{Pt}-\mathrm{P}}=62.5,{ }^{1} J_{\mathrm{Pt}-\mathrm{P}}=3107 \mathrm{~Hz}, \mathrm{P}\right.$ trans $\left.=\mathrm{CH}_{2}\right)$.

\section{Synthesis of $[\operatorname{Pt}(\mathrm{MCP})(\mathrm{dbpe})] 2 \mathrm{c}$}

$\left[\mathrm{Pt}\left(\mathrm{C}_{2} \mathrm{H}_{4}\right)(\mathrm{dbpe})\right](20 \mathrm{mg}, 0.034 \mathrm{mmol})$ was dissolved in $\mathrm{C}_{6} \mathrm{D}_{6}(0.5 \mathrm{~mL})$ and placed in an NMR tube. A large excess of MCP was added and the reaction heated at $40^{\circ} \mathrm{C}$ overnight. Solution contains $99 \%[\mathrm{Pt}(\mathrm{MCP})(\mathrm{dbpe})]$ by ${ }^{31} \mathrm{P}\left\{{ }^{1} \mathrm{H}\right\} \mathrm{NMR} .{ }^{1} \mathrm{H}$ NMR $\left(\delta, \mathrm{C}_{6} \mathrm{D}_{6}, 500 \mathrm{MHz}\right)$ : $2.39\left(\mathrm{dd}, 8.4,4.2,{ }^{2} J_{\mathrm{Pt}-\mathrm{H}}=60.6 \mathrm{~Hz}, 2 \mathrm{H},=\mathrm{CH}_{2}\right), 1.89\left(\mathrm{~d}, 7.2, J_{\mathrm{Pt}-\mathrm{H}}=33.6 \mathrm{~Hz}, 2 \mathrm{H},{ }^{c} \operatorname{Pr}-\right.$ exo $), 1.79\left(\mathrm{~m}, J_{\mathrm{Pt}-\mathrm{H}}=60.0 \mathrm{~Hz}, 2 \mathrm{H},{ }^{c} \mathrm{Pr}\right.$-endo $), 1.30\left(\mathrm{~m}, 4 \mathrm{H}, \mathrm{P}-\mathrm{CH}_{2}\right), 1.10(\mathrm{~d}, 12.0 \mathrm{~Hz}$,

$\left.18 \mathrm{H},{ }^{t} \mathrm{Bu}\right), 1.02\left(\mathrm{~d}, 12.0 \mathrm{~Hz}, 18 \mathrm{H},{ }^{t} \mathrm{Bu}\right) .{ }^{13} \mathrm{C}\left\{{ }^{1} \mathrm{H}\right\} \operatorname{NMR}\left(\delta, \mathrm{C}_{6} \mathrm{D}_{6}, 125 \mathrm{MHz}\right): 36.8(\mathrm{dd}$, $\left.71.9,8.2,{ }^{1} J_{\mathrm{Pt}-\mathrm{C}}=511.4 \mathrm{~Hz},=\mathrm{CR}_{2}\right), 35.0\left(\mathrm{dd}, 12.2,4.1 \mathrm{~Hz}, \mathrm{P}-\mathrm{CR}_{3}\right), 34.9(\mathrm{dd}, 13.4$, $\left.4.6 \mathrm{~Hz}, \mathrm{P}-\mathrm{CR}_{3}\right), 30.3\left(\mathrm{~d}, 6.4, J_{\mathrm{Pt}-\mathrm{C}}=17.7 \mathrm{~Hz}, \mathrm{CH}_{3}\right), 29.9\left(\mathrm{~d}, 7.0, J_{\mathrm{Pt}-\mathrm{C}}=16.2 \mathrm{~Hz}, \mathrm{CH}_{3}\right)$, $26.8\left(\mathrm{dd}, 18.1,12.2, J_{\mathrm{Pt}-\mathrm{C}}=10.4 \mathrm{~Hz}, \mathrm{P}-\mathrm{CH}_{2}\right), 25.3\left(\mathrm{dd}, 16.9,14.6, J_{\mathrm{Pt}-\mathrm{C}}=14.0 \mathrm{~Hz}\right.$, $\left.\mathrm{P}-\mathrm{CH}_{2}\right), 23.5\left(\mathrm{dd}, 42.7,4.7,{ }^{1} J_{\mathrm{Pt}-\mathrm{C}}=171.6 \mathrm{~Hz},=\mathrm{CH}_{2}\right), 11.8\left(\mathrm{~d}, 4.1, J_{\mathrm{Pt}-\mathrm{C}}=24.5 \mathrm{~Hz}\right.$, $\left.{ }^{c} \mathrm{Pr}\right) .{ }^{31} \mathrm{P}\left\{{ }^{1} \mathrm{H}\right\} \operatorname{NMR}\left(\delta, \mathrm{C}_{6} \mathrm{D}_{6}, 121 \mathrm{MHz}\right): 100.8\left(\mathrm{AB},{ }^{2} J_{\mathrm{Pt}-\mathrm{P}}=65.7,{ }^{1} J_{\mathrm{Pt}-\mathrm{P}}=2807 \mathrm{~Hz}, \mathrm{P}\right.$ trans $\left.=\mathrm{CR}_{2}\right), 99.2\left(\mathrm{AB},{ }^{2} J_{\mathrm{Pt}-\mathrm{P}}=65.7,{ }^{1} J_{\mathrm{Pt}-\mathrm{P}}=3167 \mathrm{~Hz}, \mathrm{P}\right.$ trans $\left.=\mathrm{CH}_{2}\right)$. 


\section{Synthesis of $[\operatorname{Pt}(\mathrm{MCP})(\mathrm{dbpx})] 2 \mathrm{~d}$}

$\left[\mathrm{Pt}\left(\mathrm{C}_{2} \mathrm{H}_{4}\right)(\mathrm{dbpx})\right](35 \mathrm{mg}, 0.057 \mathrm{mmol})$ was dissolved in $\mathrm{C}_{6} \mathrm{D}_{6}(0.5 \mathrm{~mL})$ and placed in an NMR tube. A large excess of MCP was added and the reaction heated at $60^{\circ} \mathrm{C}$ overnight. Solution contains 96\% $[\mathrm{Pt}(\mathrm{MCP})(\mathrm{dbpx})]$ by ${ }^{31} \mathrm{P}\left\{{ }^{1} \mathrm{H}\right\} \mathrm{NMR} .{ }^{1} \mathrm{H}$ NMR $\left(\delta, \mathrm{C}_{6} \mathrm{D}_{6}, 500 \mathrm{MHz}\right)$ : $7.15\left(\mathrm{~m}, 2 \mathrm{H}, o-\mathrm{C}_{6} \mathrm{H}_{4}\right), 6.92\left(\mathrm{~m}, 2 \mathrm{H}, m-\mathrm{C}_{6} \mathrm{H}_{4}\right), 3.47\left(\mathrm{~m}, 4 \mathrm{H}, \mathrm{P}-\mathrm{CH}_{2}\right), 2.12\left(\mathrm{t}, 6.5,{ }^{2} J_{\mathrm{Pt}-\mathrm{H}}=\right.$ $\left.56.5 \mathrm{~Hz}, 2 \mathrm{H},=\mathrm{CH}_{2}\right), 1.60\left(\mathrm{~m}, 4 \mathrm{H},{ }^{c} \mathrm{Pr}\right), 1.26\left(\mathrm{~d}, 12.0 \mathrm{~Hz}, 18 \mathrm{H},{ }^{t} \mathrm{Bu}\right), 1.17(\mathrm{~d}, 12.0 \mathrm{~Hz}, 18 \mathrm{H}$, $\left.{ }^{t} \mathrm{Bu}\right) .{ }^{13} \mathrm{C}\left\{{ }^{1} \mathrm{H}\right\} \operatorname{NMR}\left(\delta, \mathrm{C}_{6} \mathrm{D}_{6}, 125 \mathrm{MHz}\right): 138.6\left(\mathrm{~s}, i-\mathrm{C}_{6} \mathrm{H}_{4}\right), 138.5\left(\mathrm{~s}, i-\mathrm{C}_{6} \mathrm{H}_{4}\right), 133.3(\mathrm{~m}, o-$ $\left.\mathrm{C}_{6} \mathrm{H}_{4}\right), 126.0\left(\mathrm{~m}, m-\mathrm{C}_{6} \mathrm{H}_{4}\right), 37.8\left(\mathrm{~m}, \mathrm{P}-\mathrm{CR}_{3}\right), 36.9\left(\mathrm{dd}, 12.9,3.9, J_{\mathrm{Pt}-\mathrm{C}}=45.0 \mathrm{~Hz}, \mathrm{P}-\mathrm{CR}_{3}\right)$, $33.6\left(\mathrm{dd}, 72.5,10.1,{ }^{1} J_{\mathrm{Pt}-\mathrm{C}}=537.6 \mathrm{~Hz},=\mathrm{CR}_{2}\right), 32.5\left(\mathrm{~d}, 8.7 \mathrm{~Hz}, \mathrm{P}-\mathrm{CH}_{2}\right), 32.3(\mathrm{~d}, 5.3 \mathrm{~Hz}$, $\left.\mathrm{P}-\mathrm{CH}_{2}\right), 30.6\left(\mathrm{~d}, 5.3, J_{\mathrm{Pt}-\mathrm{C}}=16.3 \mathrm{~Hz}, \mathrm{CH}_{3}\right), 30.2\left(\mathrm{~d}, 6.7, J_{\mathrm{Pt}-\mathrm{C}}=15.3 \mathrm{~Hz}, \mathrm{CH}_{3}\right), 27.8(\mathrm{dd}$, $\left.39.4,5.3,{ }^{1} J_{\mathrm{Pt}-\mathrm{C}}=164.2 \mathrm{~Hz},=\mathrm{CH}_{2}\right), 11.4\left(\mathrm{~d}, 2.9, J_{\mathrm{Pt}-\mathrm{C}}=25.0 \mathrm{~Hz},{ }^{c} \mathrm{Pr}\right) .{ }^{31} \mathrm{P}\left\{{ }^{1} \mathrm{H}\right\} \mathrm{NMR}$ $\left(\delta, \mathrm{C}_{6} \mathrm{D}_{6}, 121 \mathrm{MHz}\right): 49.3\left(\mathrm{AB},{ }^{2} J_{\mathrm{Pt}-\mathrm{P}}=29.7,{ }^{1} J_{\mathrm{Pt}-\mathrm{P}}=3362 \mathrm{~Hz}, \mathrm{P}\right.$ trans $\left.=\mathrm{CH}_{2}\right), 43.7(\mathrm{AB}$, ${ }^{2} J_{\mathrm{Pt}-\mathrm{P}}=29.7,{ }^{1} J_{\mathrm{Pt}-\mathrm{P}}=3025 \mathrm{~Hz}, \mathrm{P}$ trans $\left.=\mathrm{CR}_{2}\right)$.

\section{Synthesis of $[\mathrm{Pt}(\mathrm{ACP})(\mathrm{dppp})] 3 \mathrm{a}$ and $\left[\mathrm{Pt}\left(\mathrm{CH}_{2} \mathrm{CH}=\mathrm{CHC}\left(\mathrm{CH}_{2}\right)_{2}\right)(\mathrm{dppp})\right] 4 \mathrm{a}$}

A few crystals of $\left[\mathrm{PtMe}_{2}(1,5\right.$-hexadiene $\left.)\right]$ were placed in an $\mathrm{NMR}$ tube and $\mathrm{CDCl}_{3}(0.5 \mathrm{~mL})$ added. BCP (0.2 mL, $18.7 \mathrm{mmol})$ was added and the reaction left for 3 days, after which all of the BCP had reacted to form ACP. $\left[\mathrm{Pt}\left(\mathrm{C}_{2} \mathrm{H}_{4}\right)(\mathrm{dppp})\right]$ (30 mg, $0.047 \mathrm{mmol}$ ) was placed in an NMR tube and $\mathrm{C}_{6} \mathrm{D}_{6}(0.5 \mathrm{~mL})$ added. A solution of $\mathrm{ACP}(0.1 \mathrm{~mL}, 27 \mathrm{~mol} \mathrm{~L}-1$ solution in $\left.\mathrm{CDCl}_{3}\right)$ was added, resulting in the immediate formation of $[\mathrm{Pt}(\mathrm{ACP})(\mathrm{dppp})]$. After several hours, the complex rearranges to form $\left[\mathrm{Pt}\left(\mathrm{CH}_{2} \mathrm{CH}=\mathrm{CHC}\left(\mathrm{CH}_{2}\right)_{2}\right)(\mathrm{dppp})\right]$ 4a. Solution contains $91 \%\left[\mathrm{Pt}\left(\mathrm{CH}_{2} \mathrm{CH}=\mathrm{CHC}\left(\mathrm{CH}_{2}\right)_{2}\right)(\mathrm{dppp})\right]$ by ${ }^{31} \mathrm{P}\left\{{ }^{1} \mathrm{H}\right\} \mathrm{NMR}$ after 24 hr. [Pt(ACP)(dppp)] 3a: ${ }^{1} \mathrm{H}$ NMR $\left(\delta, \mathrm{C}_{6} \mathrm{D}_{6}, 500 \mathrm{MHz}\right): 7.80\left(\mathrm{t}, 8.7 \mathrm{~Hz}, 2 \mathrm{H}, o-\mathrm{C}_{6} \mathrm{H}_{5}\right)$, $7.69\left(\mathrm{t}, 9.0 \mathrm{~Hz}, 2 \mathrm{H}, o-\mathrm{C}_{6} \mathrm{H}_{5}\right), 7.54\left(\mathrm{t}, 6.9 \mathrm{~Hz}, 2 \mathrm{H}, o-\mathrm{C}_{6} \mathrm{H}_{5}\right), 7.38\left(\mathrm{t}, 8.1 \mathrm{~Hz}, 2 \mathrm{H}, o-\mathrm{C}_{6} \mathrm{H}_{5}\right)$, 7.15-6.96(m, $12 \mathrm{H}, m-$ and $\left.p-\mathrm{C}_{6} \mathrm{H}_{5}\right), 6.47(\mathrm{~m}, 1 \mathrm{H},=\mathrm{CHR}), 5.04\left(\mathrm{~m}, 1 \mathrm{H},=\mathrm{CH}_{2}\right), 4.69(\mathrm{~m}$, $\left.1 \mathrm{H},=\mathrm{CH}_{2}\right), 3.78\left(\mathrm{td}, 9.3,3.6,{ }^{2} J_{\mathrm{Pt}-\mathrm{H}}=67.8 \mathrm{~Hz},=\mathrm{CHR}\right), 2.40-1.96\left(\mathrm{~m}, 4 \mathrm{H}, \mathrm{P}-\mathrm{CH}_{2}\right), 1.5-$ 1.3(m, $\left.2 \mathrm{H}, \mathrm{CH}_{2}\right), 1.3-0.8\left(\mathrm{~m}, 4 \mathrm{H},{ }^{c} \mathrm{Pr}\right) .{ }^{31} \mathrm{P}\left\{{ }^{1} \mathrm{H}\right\} \operatorname{NMR}\left(\delta, \mathrm{C}_{6} \mathrm{D}_{6}, 121 \mathrm{MHz}\right): 10.3(\mathrm{AB}$, ${ }^{2} J_{\mathrm{Pt}-\mathrm{P}}=-39.4,{ }^{1} J_{\mathrm{Pt}-\mathrm{P}}=293 \mathrm{~Hz}, \mathrm{P}$ trans $\left.=\mathrm{CHR}\right), 9.7\left(\mathrm{AB},{ }^{2} J_{\mathrm{Pt}-\mathrm{P}}=-39.4,{ }^{1} J_{\mathrm{Pt}-\mathrm{P}}\right.$

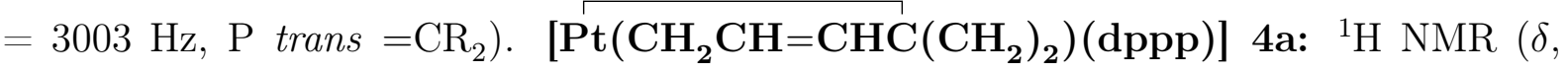


$\left.\mathrm{C}_{6} \mathrm{D}_{6}, 500 \mathrm{MHz}\right): 7.68\left(\mathrm{t}, 8.0 \mathrm{~Hz}, 4 \mathrm{H}, o_{o} \mathrm{C}_{6} \mathrm{H}_{5}\right), 7.58\left(\mathrm{t}, 9.3 \mathrm{~Hz}, 4 \mathrm{H}, o-\mathrm{C}_{6} \mathrm{H}_{5}\right), 7.03(\mathrm{~m}$, $12 \mathrm{H}, m$ - and $\left.p-\mathrm{C}_{6} \mathrm{H}_{5}\right), 6.07\left(\mathrm{dm}, 12.0, J_{\mathrm{Pt}-\mathrm{H}} 97.0 \mathrm{~Hz}, 1 \mathrm{H},=\mathrm{CHCH}_{2}\right), 5.29\left(\mathrm{t}, 5.5, J_{\mathrm{Pt}-\mathrm{H}}\right.$ $\left.=86.5 \mathrm{~Hz}, 1 \mathrm{H},=\mathrm{CH}-{ }^{c} \mathrm{Pr}\right), 2.85\left(\mathrm{~m},{ }^{2} J_{\mathrm{Pt}-\mathrm{H}}=62.0 \mathrm{~Hz}, 2 \mathrm{H}, \mathrm{Pt}-\mathrm{CH}_{2}\right), 2.05(\mathrm{~m}, 4 \mathrm{H}, \mathrm{P}-$ $\mathrm{CH} 2), 1.30\left(\mathrm{~m}, 2 \mathrm{H}, \mathrm{CH}_{2}\right), 0.85\left(\mathrm{~m}, J_{\mathrm{Pt}-\mathrm{H}}=25.0 \mathrm{~Hz}, 2 \mathrm{H},{ }^{c} \operatorname{Pr}-\right.$ exo $), 0.71\left(\mathrm{~d}, 7.5, J_{\mathrm{Pt}-\mathrm{H}}=\right.$ $55.0 \mathrm{~Hz}, 2 \mathrm{H},{ }^{c} \operatorname{Pr}-$ endo $) .{ }^{13} \mathrm{C}\left\{{ }^{1} \mathrm{H}\right\} \operatorname{NMR}\left(\delta, \mathrm{C}_{6} \mathrm{D}_{6}, 125 \mathrm{MHz}\right): 154.3\left(\mathrm{~d}, 9.6 \mathrm{~Hz}, J_{\mathrm{Pt}-\mathrm{C}}=\right.$ $\left.67.6 \mathrm{~Hz},=\mathrm{CH}-{ }^{c} \mathrm{Pr}\right), 134.2\left(\mathrm{~m}, o-\mathrm{C}_{6} \mathrm{H}_{5}\right), 133.8\left(\mathrm{~m}, o-\mathrm{C}_{6} \mathrm{H}_{5}\right), 133.5\left(\mathrm{~m}, i-\mathrm{C}_{6} \mathrm{H}_{5}\right), 132.5(\mathrm{~m}, i-$ $\left.\mathrm{C}_{6} \mathrm{H}_{5}\right), 131.5\left(\mathrm{~m},=\mathrm{CHCH}_{2}\right), 130.1\left(\mathrm{~d}, 1.9 \mathrm{~Hz}, m-\mathrm{C}_{6} \mathrm{H}_{5}\right), 129.9\left(\mathrm{~d}, 1.9 \mathrm{~Hz}, m-\mathrm{C}_{6} \mathrm{H}_{5}\right), 128.6(\mathrm{~s}$, $\left.p-\mathrm{C}_{6} \mathrm{H}_{5}\right), 128.4\left(\mathrm{~s}, \quad p-\mathrm{C}_{6} \mathrm{H}_{5}\right), 39.3\left(\mathrm{dd}, 83.9,4.4,{ }^{1} J_{\mathrm{Pt}-\mathrm{C}}=450.3 \mathrm{~Hz}, \mathrm{Pt}-\mathrm{CH}_{2}\right), 32.3(\mathrm{~m}$, $\left.\mathrm{Pt}-\mathrm{CR}_{3}\right), 30.5\left(\mathrm{~m}, \mathrm{P}-\mathrm{CH}_{2}\right), 27.4\left(\mathrm{~m}, \mathrm{P}-\mathrm{CH}_{2}\right), 20.0\left(\mathrm{~s}, \mathrm{CH}_{2}\right), 16.9\left(\mathrm{~s},{ }^{c} \mathrm{Pr}\right) .{ }^{31} \mathrm{P}\left\{{ }^{1} \mathrm{H}\right\} \mathrm{NMR}$ $\left(\delta, \mathrm{C}_{6} \mathrm{D}_{6}, 121 \mathrm{MHz}\right): 2.2\left(\mathrm{AB},{ }^{2} J_{\mathrm{Pt}-\mathrm{P}}=18.2,{ }^{1} J_{\mathrm{Pt}-\mathrm{P}}=1784 \mathrm{~Hz}\right), 1.7\left(\mathrm{AB},{ }^{2} J_{\mathrm{Pt}-\mathrm{P}}=18.2\right.$, $\left.{ }^{1} J_{\mathrm{Pt}-\mathrm{P}}=1856 \mathrm{~Hz}\right) \cdot m / z=[\mathrm{M}+\mathrm{H}]^{+}$calcd for $\mathrm{C}_{33} \mathrm{H}_{35} \mathrm{P}_{2}{ }^{194} \mathrm{Pt}$ 687.1841; found 687.1848.

\section{Synthesis of $[\mathrm{Pt}(\mathrm{ACP})($ dcyppe $)] 3 \mathrm{~b}$ and $\left[\mathrm{Pt}\left(\mathrm{CH}_{2} \mathrm{CH}=\mathrm{CHC}\left(\mathrm{CH}_{2}\right)_{2}\right)(\operatorname{dcyppe})\right]$} $4 \mathrm{~b}$

$\left[\mathrm{Pt}\left(\mathrm{C}_{2} \mathrm{H}_{4}\right)\right.$ (dcyppe) $](100 \mathrm{mg}, 0.170 \mathrm{mmol})$ was placed in an NMR tube and $\mathrm{C}_{6} \mathrm{D}_{6}(0.5 \mathrm{~mL})$ added. A solution of ACP $\left(0.1 \mathrm{~mL}, 27 \mathrm{~mol} \mathrm{~L}^{-1}\right.$ solution in $\left.\mathrm{CDCl}_{3}\right)$ was added, resulting in the immediate formation of $[\mathrm{Pt}(\mathrm{ACP})($ dcyppe $)]$ and $\left[\longdiv { \mathrm { Pt } ( \mathrm { CH } _ { 2 } \mathrm { CH } = \mathrm { CHC } } ( \mathrm { CH } _ { 2 } ) _ { 2 }\right)($ dcyppe $\left.)\right]$. After $3 \mathrm{hr}$, the only product is $\left[\mathrm{Pt}\left(\mathrm{CH}_{2} \mathrm{CH}=\mathrm{CHC}\left(\mathrm{CH}_{2}\right)_{2}\right)(\mathrm{dcyppe})\right] \mathbf{4 b}$. Solution contains 93\% $\left[\mathrm{Pt}\left(\mathrm{CH}_{2} \mathrm{CH}=\mathrm{CHC}\left(\mathrm{CH}_{2}\right)_{2}\right)(\right.$ dcyppe $\left.)\right]$ by ${ }^{31} \mathrm{P}\left\{{ }^{1} \mathrm{H}\right\}$ NMR. [Pt(ACP)(dcyppe)] 3b: ${ }^{1} \mathrm{H} \operatorname{NMR}\left(\delta, \mathrm{C}_{6} \mathrm{D}_{6}, 500 \mathrm{MHz}\right): 6.1(\mathrm{~m}, 1 \mathrm{H},=\mathrm{CHR}), 4.9\left(\mathrm{~m}, 1 \mathrm{H},=\mathrm{CH}_{2}\right), 4.4(\mathrm{~m}, 1 \mathrm{H}$, $\left.=\mathrm{CH}_{2}\right), 3.4\left(\mathrm{~m},{ }^{2} J_{\mathrm{Pt}-\mathrm{H}}=62.1 \mathrm{~Hz}, 1 \mathrm{H},=\mathrm{CHR}\right), 2.0-1.2\left(\mathrm{~m}, 44 \mathrm{H}, \mathrm{P}-\mathrm{CH}_{2}\right.$, cyp and $\left.{ }^{c} \mathrm{Pr}\right) . \quad{ }^{31} \mathrm{P}\left\{{ }^{1} \mathrm{H}\right\} \quad \mathrm{NMR}\left(\delta, \mathrm{C}_{6} \mathrm{D}_{6}, 121 \mathrm{MHz}\right): \quad 69.8\left(\mathrm{AB},{ }^{2} J_{\mathrm{Pt}-\mathrm{P}}=-57.7,{ }^{1} J_{\mathrm{Pt}-\mathrm{P}}=\right.$ $3153 \mathrm{~Hz}, \mathrm{P}$ trans $=\mathrm{CHR}), 68.3\left(\mathrm{AB},{ }^{2} J_{\mathrm{Pt}-\mathrm{P}}=-57.7,{ }^{1} J_{\mathrm{Pt}-\mathrm{P}}=2771 \mathrm{~Hz}, \mathrm{P}\right.$ trans $\left.=\mathrm{CR}_{2}\right)$. $\left[\mathbf{P t}\left(\mathbf{C H}_{\mathbf{2}} \mathbf{C H}=\mathbf{C H C}\left(\mathbf{C H}_{\mathbf{2}}\right)_{\mathbf{2}}\right)\right.$ (dcyppe) $]$ 4b: ${ }^{1} \mathrm{H}$ NMR $\left(\delta, \mathrm{C}_{6} \mathrm{D}_{6}, 500 \mathrm{MHz}\right): 6.35(\mathrm{~m}$, $\left.J_{\mathrm{Pt}-\mathrm{H}}=92.4 \mathrm{~Hz}, 1 \mathrm{H},=\mathrm{CHCH}_{2}\right), 5.32\left(\mathrm{t}, 6.0, J_{\mathrm{Pt}-\mathrm{H}}=78.0 \mathrm{~Hz}, 1 \mathrm{H},=\mathrm{CH}-{ }^{c} \mathrm{Pr}\right), 3.20(\mathrm{~m}$, $\left.{ }^{2} J_{\mathrm{Pt}-\mathrm{H}}=73.2 \mathrm{~Hz}, 2 \mathrm{H}, \mathrm{Pt}-\mathrm{CH}_{2}\right), 2.10(\mathrm{~m}, 2 \mathrm{H}, \mathrm{P}-\mathrm{CH}), 2.01\left(\mathrm{~m}, 4 \mathrm{H}, \mathrm{P}-\mathrm{CH}\right.$ and $\left.\mathrm{CH}_{2}\right)$, $1.81\left(\mathrm{~m}, 4 \mathrm{H}, \mathrm{CH}_{2}\right), 1.6-1.3\left(\mathrm{~m}, 28 \mathrm{H}, \mathrm{CH}_{2}\right.$ and $\left.{ }^{c} \operatorname{Pr}-e n d o\right), 1.24\left(\mathrm{~m}, 4 \mathrm{H}, \mathrm{P}-\mathrm{CH}_{2}\right.$ and ${ }^{c} \operatorname{Pr}-$ exo $), 1.11\left(\mathrm{~m}, 2 \mathrm{H}, \mathrm{P}-\mathrm{CH}_{2}\right) \cdot{ }^{13} \mathrm{C}\left\{{ }^{1} \mathrm{H}\right\} \operatorname{NMR}\left(\delta, \mathrm{C}_{6} \mathrm{D}_{6}, 125 \mathrm{MHz}\right): 154.0\left(\mathrm{~d}, 10.4, J_{\mathrm{Pt}-\mathrm{C}}=\right.$ 130.6 Hz, $\left.=\mathrm{CH}-{ }^{c} \mathrm{Pr}\right), 132.7\left(\mathrm{dd}, 10.4,4.6 \mathrm{~Hz},=\mathrm{CHCH}_{2}\right), 37.2\left(\mathrm{~d}, 26.0, J_{\mathrm{Pt}-\mathrm{C}}=26.0 \mathrm{~Hz}\right.$, 
$\mathrm{P}-\mathrm{CH}), 36.7\left(\mathrm{~d}, 21.3, J_{\mathrm{Pt}-\mathrm{C}}=19.2 \mathrm{~Hz}, \mathrm{P}-\mathrm{CH}\right), 33.1\left(\mathrm{dd}, 117.9,7.0,{ }^{1} J_{\mathrm{Pt}-\mathrm{C}}=959.0 \mathrm{~Hz}\right.$, $\left.\mathrm{Pt}-\mathrm{CR}_{3}\right), 31.0\left(\mathrm{~d}, 6.4, J_{\mathrm{Pt}-\mathrm{C}}=11.4 \mathrm{~Hz}, \mathrm{CH}_{2}\right), 29.5\left(\mathrm{dd}, 89.5,6.3,{ }^{1} J_{\mathrm{Pt}-\mathrm{C}}=297.1 \mathrm{~Hz}\right.$, $\left.\mathrm{Pt}-\mathrm{CH}_{2}\right), 29.4\left(\mathrm{~m}, \mathrm{CH}_{2}\right), 26.6\left(\mathrm{~d}, 7.0 \mathrm{~Hz}, \mathrm{CH}_{2}\right), 26.4\left(\mathrm{~d}, 8.7 \mathrm{~Hz}, \mathrm{CH}_{2}\right), 25.8(\mathrm{~d}, 9.8 \mathrm{~Hz}$, $\left.\mathrm{CH}_{2}\right), 25.7\left(\mathrm{~d}, 9.3 \mathrm{~Hz}, \mathrm{CH}_{2}\right), 23.4\left(\mathrm{~m}, \mathrm{P}-\mathrm{CH}_{2}\right), 22.6\left(\mathrm{~m}, \mathrm{P}-\mathrm{CH}_{2}\right), 17.8\left(\mathrm{~s},{ }^{c} \mathrm{Pr}\right) .{ }^{31} \mathrm{P}\left\{{ }^{1} \mathrm{H}\right\}$ $\operatorname{NMR}\left(\delta, \mathrm{C}_{6} \mathrm{D}_{6}, 121 \mathrm{MHz}\right): 55.4\left(\mathrm{~s},{ }^{1} J_{\mathrm{Pt}-\mathrm{P}}=1801 \mathrm{~Hz}\right), 52.6\left(\mathrm{~s},{ }^{1} J_{\mathrm{Pt}-\mathrm{P}}=1828 \mathrm{~Hz}\right)$.

\section{Synthesis of $[\operatorname{Pt}(\mathrm{ACP})(\mathrm{dbpe})] 3 \mathrm{c}$}

$\left[\mathrm{Pt}\left(\mathrm{C}_{2} \mathrm{H}_{4}\right)(\mathrm{dbpe})\right](100 \mathrm{mg}, 0.185 \mathrm{mmol})$ was dissolved in $\mathrm{C}_{6} \mathrm{D}_{6}(0.5 \mathrm{~mL})$ and placed in an NMR tube. BCP $(0.02 \mathrm{~mL}, 1.87 \mathrm{mmol})$ was added, and the solution heated at $40{ }^{\circ} \mathrm{C}$ for 13 days. Solution contains $88 \% \operatorname{Pt}(\mathrm{ACP})(\mathrm{dbpe})]$ by ${ }^{31} \mathrm{P}\left\{{ }^{1} \mathrm{H}\right\} \operatorname{NMR} .{ }^{1} \mathrm{H} \operatorname{NMR}\left(\delta, \mathrm{C}_{6} \mathrm{D}_{6}\right.$, $500 \mathrm{MHz}): 6.20(\mathrm{dt}, 16.2,9.6 \mathrm{~Hz}, 1 \mathrm{H},=\mathrm{CHR}), 4.98\left(\mathrm{~m}, 1 \mathrm{H},=\mathrm{CH}_{2}\right), 4.64\left(\mathrm{~m}, 1 \mathrm{H},=\mathrm{CH}_{2}\right)$, $3.43\left(\mathrm{~m},{ }^{2} J_{\mathrm{Pt}-\mathrm{H}}=62.0 \mathrm{~Hz}, 1 \mathrm{H},=\mathrm{CHR}\right), 1.9-1.5\left(\mathrm{~m}, 6 \mathrm{H}, \mathrm{P}-\mathrm{CH}_{2}\right.$ and $\left.{ }^{c} \mathrm{Pr}\right), 1.16(\mathrm{~d}, 12.5 \mathrm{~Hz}$, $\left.9 \mathrm{H},{ }^{t} \mathrm{Bu}\right), 1.15\left(\mathrm{~d}, 12.5 \mathrm{~Hz}, 9 \mathrm{H},{ }^{t} \mathrm{Bu}\right), 1.03\left(\mathrm{~d}, 12.0 \mathrm{~Hz}, 9 \mathrm{H},{ }^{t} \mathrm{Bu}\right), 1.02\left(\mathrm{~d}, 12.5 \mathrm{~Hz}, 9 \mathrm{H},{ }^{t} \mathrm{Bu}\right)$, $1.0\left(\mathrm{~m}, 2 \mathrm{H},{ }^{c} \mathrm{Pr}\right) .{ }^{13} \mathrm{C}\left\{{ }^{1} \mathrm{H}\right\} \mathrm{NMR}\left(\delta, \mathrm{C}_{6} \mathrm{D}_{6}, 125 \mathrm{MHz}\right): 147.5\left(\mathrm{t}, J_{\mathrm{P}-\mathrm{C}}=4.6, J_{\mathrm{P}-\mathrm{P}}=-34.3\right.$, $\left.J_{\mathrm{Pt}-\mathrm{C}}=56.4 \mathrm{~Hz},=\mathrm{CHR}\right), 102.7\left(\mathrm{t}, J_{\mathrm{P}-\mathrm{C}}=8.6, J_{\mathrm{P}-\mathrm{P}}=-25.3, J_{\mathrm{Pt}-\mathrm{C}}=42.9 \mathrm{~Hz},=\mathrm{CH}_{2}\right)$, $44.7\left(\mathrm{dd}, J_{\mathrm{P}-\mathrm{C}}=38.1,2.0, J_{\mathrm{P}-\mathrm{P}}=-57.7,{ }^{1} J_{\mathrm{Pt}-\mathrm{C}}=165.5 \mathrm{~Hz},=\mathrm{CHR}\right), 41.4\left(\mathrm{~m}, J_{\mathrm{P}-\mathrm{C}}=\right.$ $\left.70.3,2.3, J_{\mathrm{P}-\mathrm{P}}=65.8,{ }^{1} J_{\mathrm{Pt}-\mathrm{C}}=533.1 \mathrm{~Hz},=\mathrm{CR}_{2}\right), 36.5\left(\mathrm{dd}, J_{\mathrm{P}-\mathrm{C}}=12.8,4.6, J_{\mathrm{P}-\mathrm{P}}=\right.$ $\left.-27.1, J_{\mathrm{Pt}-\mathrm{C}}=46.8 \mathrm{~Hz}, \mathrm{P}-\mathrm{CR}_{3}\right), 35.8\left(\mathrm{dd}, J_{\mathrm{P}-\mathrm{C}}=11.5,5.1, J_{\mathrm{P}-\mathrm{P}}=-24.3, J_{\mathrm{Pt}-\mathrm{C}}=\right.$ $\left.44.0 \mathrm{~Hz}, \mathrm{P}-\mathrm{CR}_{3}\right), 35.5\left(\mathrm{dd}, J_{\mathrm{P}-\mathrm{C}}=13.2,3.4, J_{\mathrm{P}-\mathrm{P}}=-31.2, J_{\mathrm{Pt}-\mathrm{C}}=53.8 \mathrm{~Hz}, \mathrm{P}-\mathrm{CR}_{3}\right)$, $34.8\left(\mathrm{dd}, J_{\mathrm{P}-\mathrm{C}}=14.5,5.4, J_{\mathrm{P}-\mathrm{P}}=-31.2, J_{\mathrm{Pt}-\mathrm{C}}=60.0 \mathrm{~Hz}, \mathrm{P}-\mathrm{CR}_{3}\right), 30.5-29.5\left(\mathrm{~m}, \mathrm{CH}_{3}\right)$, $26.4\left(\mathrm{t}, 35.8, J_{\mathrm{Pt}-\mathrm{C}}=12.7 \mathrm{~Hz}, \mathrm{P}-\mathrm{CH}_{2}\right), 25.2\left(\mathrm{t}, 18.0, J_{\mathrm{Pt}-\mathrm{C}}=10.4 \mathrm{~Hz}, \mathrm{P}-\mathrm{CH}_{2}\right), 10.6(\mathrm{t}$, $\left.J_{\mathrm{P}-\mathrm{C}}=3.3, J_{\mathrm{P}-\mathrm{P}}=-10.4, J_{\mathrm{Pt}-\mathrm{C}}=17.7 \mathrm{~Hz},{ }^{c} \mathrm{Pr}\right), 9.5\left(\mathrm{t}, J_{\mathrm{P}-\mathrm{C}}=2.0, J_{\mathrm{P}-\mathrm{P}}=-8.9, J_{\mathrm{Pt}-\mathrm{C}}\right.$

$\left.=15.5 \mathrm{~Hz},{ }^{c} \mathrm{Pr}\right) .{ }^{31} \mathrm{P}\left\{{ }^{1} \mathrm{H}\right\} \operatorname{NMR}\left(\delta, \mathrm{C}_{6} \mathrm{D}_{6}, 121 \mathrm{MHz}\right): 96.4\left(\mathrm{AB},{ }^{2} J_{\mathrm{Pt}-\mathrm{P}}=62.2,{ }^{1} J_{\mathrm{Pt}-\mathrm{P}}=\right.$ $2848 \mathrm{~Hz}, \mathrm{P}$ trans $\left.=\mathrm{CR}_{2}\right), 96.4\left(\mathrm{AB},{ }^{2} J_{\mathrm{Pt}-\mathrm{P}}=62.2,{ }^{1} J_{\mathrm{Pt}-\mathrm{P}}=3196 \mathrm{~Hz}, \mathrm{P}\right.$ trans $\left.=\mathrm{CHR}\right)$. $m / z=[\mathrm{M}+\mathrm{H}]^{+}$calcd for $\mathrm{C}_{24} \mathrm{H}_{49} \mathrm{P}_{2}{ }^{194} \mathrm{Pt}$ 593.2936; found 593.2946.

\section{Synthesis of $\left[\mathrm{Pt}(\mathrm{BCP})\left(\mathrm{C}_{2} \mathrm{H}_{4}\right)\left(\mathrm{PPh}_{3}\right)\right] 5 \mathrm{a}$}

$\left[\mathrm{Pt}\left(\mathrm{C}_{2} \mathrm{H}_{4}\right)_{2}\left(\mathrm{PPh}_{3}\right)\right](20 \mathrm{mg}, 0.039 \mathrm{mmol})$ was dissolved in hexane $(2 \mathrm{~mL})$ under an ethene atmosphere. $\mathrm{BCP}(3.6 \mu \mathrm{L}, 0.34 \mathrm{mmol})$ was added, and the reaction stirred for $5 \mathrm{~min}$. 
The solution was cooled to $-78^{\circ} \mathrm{C}$ for an hour, after which the supernatant was decanted off, leaving a white solid ([Pt(BCP) $\left.\left.\left(\mathrm{C}_{2} \mathrm{H}_{4}\right)\left(\mathrm{PPh}_{3}\right)\right], 15 \mathrm{mg}, 0.027 \mathrm{mmol}, 70 \%\right) .{ }^{1} \mathrm{H} \mathrm{NMR}$ $\left(\delta, \mathrm{C}_{6} \mathrm{D}_{6}, 500 \mathrm{MHz}\right): 7.52\left(\mathrm{~m}, 6 \mathrm{H}, o-\mathrm{C}_{6} \mathrm{H}_{5}\right), 7.00\left(\mathrm{~m}, 9 \mathrm{H}, m-\right.$ and $\left.p-\mathrm{C}_{6} \mathrm{H}_{5}\right), 2.71\left(\mathrm{~s},{ }^{2} J_{\mathrm{Pt}-\mathrm{H}}=\right.$ $\left.51.0 \mathrm{~Hz}, 4 \mathrm{H},=\mathrm{CH}_{2}\right), 1.2-0.8\left(\mathrm{brs}, 8 \mathrm{H},{ }^{c} \mathrm{Pr}\right) .{ }^{13} \mathrm{C}\left\{{ }^{1} \mathrm{H}\right\} \mathrm{NMR}\left(\delta, \mathrm{C}_{6} \mathrm{D}_{6}, 125 \mathrm{MHz}\right): 134.6(\mathrm{~d}$, $\left.43.1, J_{\mathrm{Pt}-\mathrm{C}}=25.5 \mathrm{~Hz}, i-\mathrm{C}_{6} \mathrm{H}_{5}\right), 134.2\left(\mathrm{~d}, 12.4, J_{\mathrm{Pt}-\mathrm{C}}=18.2 \mathrm{~Hz}, o-\mathrm{C}_{6} \mathrm{H}_{5}\right), 129.9(\mathrm{~d}, 2.4 \mathrm{~Hz}$, $\left.m-\mathrm{C}_{6} \mathrm{H}_{5}\right), 128.4\left(\mathrm{~s}, p-\mathrm{C}_{6} \mathrm{H}_{5}\right), 54.8\left(\mathrm{~d}, 2.9,{ }^{1} J_{\mathrm{Pt}-\mathrm{C}}=102.2 \mathrm{~Hz},=\mathrm{CH}_{2}\right), 30.2\left(\mathrm{~d}, 16.3,{ }^{1} J_{\mathrm{Pt}-\mathrm{C}}\right.$ $\left.=431.5 \mathrm{~Hz},=\mathrm{CR}_{2}\right), 9.2-6.8\left(\mathrm{brs},{ }^{c} \mathrm{Pr}\right) .{ }^{31} \mathrm{P}\left\{{ }^{1} \mathrm{H}\right\} \mathrm{NMR}\left(\delta, \mathrm{C}_{6} \mathrm{D}_{6}, 121 \mathrm{MHz}\right): 23.2\left(\mathrm{~s},{ }^{1} J_{\mathrm{Pt}-\mathrm{P}}\right.$ $=3094 \mathrm{~Hz})$.

\section{Synthesis of $\left[\mathrm{Pt}(\mathrm{BCP})\left(\mathrm{C}_{2} \mathrm{H}_{4}\right)\left(\mathrm{PCy}_{3}\right)\right] 5 \mathrm{~b}$}

$\left[\mathrm{Pt}\left(\mathrm{C}_{2} \mathrm{H}_{4}\right)_{2}\left(\mathrm{PCy}_{3}\right)\right](63 \mathrm{mg}, 0.12 \mathrm{mmol})$ was dissolved in hexane $(3 \mathrm{~mL})$ under an ethene atmosphere. An excess of BCP $(0.02 \mathrm{~mL}, 1.9 \mathrm{mmol})$ was added, and the solution stirred for $30 \mathrm{~min}$. The solution was reduced to approximately $0.5 \mathrm{~mL}$ and cooled to $-78^{\circ} \mathrm{C}$. After an hour, the supernatant was decanted, leaving a pale yellow solid $\left(\left[\mathrm{Pt}(\mathrm{BCP})\left(\mathrm{C}_{2} \mathrm{H}_{4}\right)\left(\mathrm{PCy}_{3}\right)\right]\right.$, $53 \mathrm{mg}, 0.091 \mathrm{mmol}, 76 \%) .{ }^{1} \mathrm{H} \operatorname{NMR}\left(\delta, \mathrm{C}_{6} \mathrm{D}_{6}, 500 \mathrm{MHz}\right): 2.68\left(\mathrm{~s},{ }^{2} J_{\mathrm{Pt}-\mathrm{H}}=50.0 \mathrm{~Hz}\right.$, $\left.4 \mathrm{H},=\mathrm{CH}_{2}\right), 2.03\left(\mathrm{~d}, 10.0, J_{\mathrm{Pt}-\mathrm{H}}=23.0 \mathrm{~Hz}, 3 \mathrm{H}, \mathrm{P}-\mathrm{CH}\right) 1.86\left(\mathrm{~d}, 12.5 \mathrm{~Hz}, 6 \mathrm{H}, \mathrm{CH}_{2}\right)$, $1.64\left(\mathrm{~d}, 11.0 \mathrm{~Hz}, 6 \mathrm{H}, \mathrm{CH}_{2}\right), 1.54\left(\mathrm{~d}, 12.5 \mathrm{~Hz}, 3 \mathrm{H}, \mathrm{CH}_{2}\right), 1.35\left(\mathrm{qm}, 13.0 \mathrm{~Hz}, 6 \mathrm{H}, \mathrm{CH}_{2}\right)$, 1.17-1.05(m, $11 \mathrm{H}, \mathrm{CH}_{2}$ and $\left.{ }^{c} \mathrm{Pr}\right), 1.02$ (quintt, 13.0, $\left.3.0 \mathrm{~Hz}, 6 \mathrm{H}, \mathrm{CH}_{2}\right) .{ }^{13} \mathrm{C}\left\{{ }^{1} \mathrm{H}\right\} \mathrm{NMR}(\delta$, $\left.\mathrm{C}_{6} \mathrm{D}_{6}, 125 \mathrm{MHz}\right): 50.7\left(\mathrm{~d}, 1.9,{ }^{1} J_{\mathrm{Pt}-\mathrm{C}}=101.8 \mathrm{~Hz},=\mathrm{CH}_{2}\right), 36.5\left(\mathrm{~d}, 20.6, J_{\mathrm{Pt}-\mathrm{C}}=26.0 \mathrm{~Hz}\right.$, $\mathrm{P}-\mathrm{CH}), 30.3\left(\mathrm{~s}, J_{\mathrm{Pt}-\mathrm{C}}=17.8 \mathrm{~Hz}, \mathrm{CH}_{2}\right), 29.1\left(\mathrm{~s},{ }^{1} J_{\mathrm{Pt}-\mathrm{C}}=482.9 \mathrm{~Hz},=\mathrm{CR}_{2}\right), 27.9(\mathrm{~d}, 10.1 \mathrm{~Hz}$, $\left.\mathrm{CH}_{2}\right), 26.8\left(\mathrm{~s}, \mathrm{CH}_{2}\right), 8.3\left(\mathrm{brs}, J_{\mathrm{Pt}-\mathrm{C}}=23.8 \mathrm{~Hz},{ }^{c} \mathrm{Pr}\right) .{ }^{31} \mathrm{P}\left\{{ }^{1} \mathrm{H}\right\} \operatorname{NMR}\left(\delta, \mathrm{C}_{6} \mathrm{D}_{6}, 121 \mathrm{MHz}\right)$ : $25.3\left(\mathrm{~s},{ }^{1} J_{\mathrm{Pt}-\mathrm{P}}=2976 \mathrm{~Hz}\right)$.

\section{Synthesis of $\left[\mathrm{Pt}(\mathrm{MCP})\left(\mathrm{C}_{2} \mathrm{H}_{4}\right)\left(\mathrm{PPh}_{3}\right)\right] \mathbf{6 a}$}

$\left[\mathrm{Pt}\left(\mathrm{C}_{2} \mathrm{H}_{4}\right)_{2}\left(\mathrm{PPh}_{3}\right)\right](10 \mathrm{mg}, 0.019 \mathrm{mmol})$ was dissolved in hexane $(1.5 \mathrm{~mL})$ under an ethene atmosphere. An excess of MCP was added, and the solution flushed with $\mathrm{C}_{2} \mathrm{H}_{4}$ for 5 min. The volume was reduced to $\sim 0.5 \mathrm{~mL}$, and the solution cooled to $-78^{\circ} \mathrm{C}$ for an hour. The supernatant was decanted off, leaving pale white crystals. Solution contains $47 \%$ $\left[\mathrm{Pt}(\mathrm{MCP})\left(\mathrm{C}_{2} \mathrm{H}_{4}\right)\left(\mathrm{PPh}_{3}\right)\right]$ by ${ }^{31} \mathrm{P}\left\{{ }^{1} \mathrm{H}\right\} \mathrm{NMR} .{ }^{1} \mathrm{H} \mathrm{NMR}\left(\delta, \mathrm{C}_{6} \mathrm{D}_{6}, 500 \mathrm{MHz}\right): 7.52(\mathrm{~m}, 6 \mathrm{H}$, 
$\left.o-\mathrm{C}_{6} \mathrm{H}_{5}\right), 7.01\left(\mathrm{~m}, 9 \mathrm{H}, m\right.$ - and $\left.p-\mathrm{C}_{6} \mathrm{H}_{5}\right), 2.61\left(\mathrm{~s},{ }^{2} J_{\mathrm{Pt}-\mathrm{H}}=56.0 \mathrm{~Hz}, 4 \mathrm{H}, \mathrm{C}_{2} \mathrm{H}_{4}=\mathrm{CH}_{2}\right), 2.58(\mathrm{~d}$, $\left.6.5,{ }^{2} J_{\mathrm{Pt}-\mathrm{H}}=61.5 \mathrm{~Hz}, 2 \mathrm{H}, \mathrm{MCP}=\mathrm{CH}_{2}\right), 1.64\left(\mathrm{brd}, 7.5, J_{\mathrm{Pt}-\mathrm{H}}=60.0 \mathrm{~Hz}, 2 \mathrm{H},{ }^{c} \mathrm{Pr}\right), 1.55(\mathrm{~d}$, $\left.5.5, J_{\mathrm{Pt}-\mathrm{H}}=34.0 \mathrm{~Hz}, 2 \mathrm{H},{ }^{c} \mathrm{Pr}\right) .{ }^{31} \mathrm{P}\left\{{ }^{1} \mathrm{H}\right\} \operatorname{NMR}\left(\delta, \mathrm{C}_{6} \mathrm{D}_{6}, 121 \mathrm{MHz}\right): 23.6\left(\mathrm{~s},{ }^{1} J_{\mathrm{Pt}-\mathrm{P}}=\right.$ $3085 \mathrm{~Hz})$.

\section{Synthesis of $\left[\mathrm{Pt}(\mathrm{MCP})\left(\mathrm{C}_{2} \mathrm{H}_{4}\right)\left(\mathrm{PCy}_{3}\right)\right] 6 \mathrm{~b}$}

$\left[\mathrm{Pt}\left(\mathrm{C}_{2} \mathrm{H}_{4}\right)_{2}\left(\mathrm{PCy}_{3}\right)\right](12 \mathrm{mg}, 0.023 \mathrm{mmol})$ was placed in an NMR tube under an ethene atmosphere, and $\mathrm{C}_{6} \mathrm{D}_{6}(0.5 \mathrm{~mL})$ added. An excess of MCP was added, and the solution flushed with $\mathrm{C}_{2} \mathrm{H}_{4}$ for 5 min. Solution contains $94 \%\left[\mathrm{Pt}(\mathrm{MCP})\left(\mathrm{C}_{2} \mathrm{H}_{4}\right)\left(\mathrm{PCy}_{3}\right)\right]$ by ${ }^{31} \mathrm{P}\left\{{ }^{1} \mathrm{H}\right\}$ NMR. In the presence of excess MCP, $\left[\mathrm{Pt}(\mathrm{MCP})_{2}\left(\mathrm{PCy}_{3}\right)\right]$ forms overnight. ${ }^{1} \mathrm{H} \mathrm{NMR}(\delta$, $\left.\mathrm{C}_{6} \mathrm{D}_{6}, 500 \mathrm{MHz}\right): 2.52\left(\mathrm{~d}, 6.3,{ }^{2} J_{\mathrm{Pt}-\mathrm{H}}=61.2 \mathrm{~Hz}, 2 \mathrm{H}, \mathrm{MCP}=\mathrm{CH}_{2}\right), 2.49\left(\mathrm{~s},{ }^{2} J_{\mathrm{Pt}-\mathrm{H}}=\right.$ $\left.48.1 \mathrm{~Hz}, 4 \mathrm{H}, \mathrm{C}_{2} \mathrm{H}_{4}=\mathrm{CH}_{2}\right), 2.20(\mathrm{~m}, 3 \mathrm{H}, \mathrm{P}-\mathrm{CH}), 1.90\left(\mathrm{~d}, 12.0 \mathrm{~Hz}, 6 \mathrm{H}, \mathrm{CH}_{2}\right), 1.7-1.5(\mathrm{~m}$, $\left.9 \mathrm{H}, \mathrm{CH}_{2}\right), 1.5-0.9\left(\mathrm{~m}, 19 \mathrm{H}, \mathrm{CH}_{2}\right.$ and $\left.{ }^{c} \mathrm{Pr}\right) .{ }^{31} \mathrm{P}\left\{{ }^{1} \mathrm{H}\right\} \operatorname{NMR}\left(\delta, \mathrm{C}_{6} \mathrm{D}_{6}, 121 \mathrm{MHz}\right): 28.0(\mathrm{~s}$, $\left.{ }^{1} J_{\mathrm{Pt}-\mathrm{P}}=2978 \mathrm{~Hz}\right)$.

\section{Synthesis of $\left[\mathrm{Pt}(\mathrm{MCP})_{2}\left(\mathrm{PPh}_{3}\right)\right] 7 \mathrm{a}$}

$\left[\mathrm{Pt}\left(\mathrm{C}_{2} \mathrm{H}_{4}\right)_{2}\left(\mathrm{PPh}_{3}\right)\right](70 \mathrm{mg}, 0.14 \mathrm{mmol})$ was suspended in hexane $(5 \mathrm{~mL})$. An excess of MCP was added, and the reaction stirred for $15 \mathrm{~min}$. Hexane was added to dissolve the remaining solid. The solution was cooled to $-78^{\circ} \mathrm{C}$ for an hour, after which the supernatant was decanted off, leaving an off-white solid. Solid was $90 \%\left[\mathrm{Pt}(\mathrm{MCP})_{2}\left(\mathrm{PPh}_{3}\right)\right]$ 7a, $10 \%\left[\mathrm{Pt}(\mathrm{MCP})\left(\mathrm{C}_{2} \mathrm{H}_{4}\right)\left(\mathrm{PPh}_{3}\right)\right]$ 6a. X-ray quality crystals of $\left[\mathrm{Pt}(\mathrm{MCP})_{2}\left(\mathrm{PPh}_{3}\right)\right]$ were grown by recrystallization from hexane containing a few drops of MCP. ${ }^{1} \mathrm{H} \mathrm{NMR}(\delta$, $\left.\mathrm{C}_{6} \mathrm{D}_{6}, 500 \mathrm{MHz}\right): 7.52\left(\mathrm{~m}, 6 \mathrm{H}, o-\mathrm{C}_{6} \mathrm{H}_{5}\right), 7.00\left(\mathrm{~m}, 9 \mathrm{H}, m\right.$ - and $\left.p-\mathrm{C}_{6} \mathrm{H}_{5}\right), 2.39\left(\mathrm{~d}, 4.0,{ }^{2} J_{\mathrm{Pt}-\mathrm{H}}\right.$

$\left.=55.0 \mathrm{~Hz}, 4 \mathrm{H},=\mathrm{CH}_{2}\right), 1.31\left(\mathrm{~m}, 4 \mathrm{H},{ }^{c} \mathrm{Pr}\right) \cdot{ }^{13} \mathrm{C}\left\{{ }^{1} \mathrm{H}\right\} \operatorname{NMR}\left(\delta, \mathrm{C}_{6} \mathrm{D}_{6}, 125 \mathrm{MHz}\right): 138.8(\mathrm{~d}$, $\left.39.1, J_{\mathrm{Pt}-\mathrm{C}}=26.9 \mathrm{~Hz}, i-\mathrm{C}_{6} \mathrm{H}_{5}\right), 134.2\left(\mathrm{~m}, o-\mathrm{C}_{6} \mathrm{H}_{5}\right), 129.8\left(\mathrm{~d}, 2.4 \mathrm{~Hz}, m-\mathrm{C}_{6} \mathrm{H}_{5}\right), 128.4(\mathrm{~s}, p-$ $\left.\mathrm{C}_{6} \mathrm{H}_{5}\right), 54.1\left(\mathrm{~d}, 16.3,{ }^{1} J_{\mathrm{Pt}-\mathrm{C}}=352.9 \mathrm{~Hz},=\mathrm{CR}_{2}\right), 38.9\left(\mathrm{~s},{ }^{1} J_{\mathrm{Pt}-\mathrm{C}}=100.3 \mathrm{~Hz},=\mathrm{CH}_{2}\right), 7.8(\mathrm{~s}$, $\left.J_{\mathrm{Pt}-\mathrm{C}}=24.5 \mathrm{~Hz},{ }^{c} \mathrm{Pr}\right) .{ }^{31} \mathrm{P}\left\{{ }^{1} \mathrm{H}\right\} \operatorname{NMR}\left(\delta, \mathrm{C}_{6} \mathrm{D}_{6}, 121 \mathrm{MHz}\right): 22.3\left(\mathrm{~s},{ }^{1} J_{\mathrm{Pt}-\mathrm{P}}=2932 \mathrm{~Hz}\right)$. 


\section{Synthesis of $\left[\mathrm{Pt}(\mathrm{MCP})_{2}\left(\mathrm{PCy}_{3}\right)\right] 7 \mathrm{~b}$}

$\left[\mathrm{Pt}\left(\mathrm{C}_{2} \mathrm{H}_{4}\right)_{2}\left(\mathrm{PCy}_{3}\right)\right](12 \mathrm{mg}, 0.023 \mathrm{mmol})$ was placed in an NMR tube under an ethene atmosphere, and $\mathrm{C}_{6} \mathrm{D}_{6}(0.5 \mathrm{~mL})$ added. A large excess of MCP was added, and $\mathrm{Ar}$ bubbled through the solution for 5 min. Solution contains $99 \%\left[\mathrm{Pt}(\mathrm{MCP})_{2}\left(\mathrm{PCy}_{3}\right)\right]$ by ${ }^{31} \mathrm{P}\left\{{ }^{1} \mathrm{H}\right\}$ NMR. ${ }^{1} \mathrm{H}$ NMR $\left(\delta, \mathrm{C}_{6} \mathrm{D}_{6}, 500 \mathrm{MHz}\right): 2.27\left(\mathrm{~d}, 6.0,{ }^{2} J_{\mathrm{Pt}-\mathrm{H}}=50.0 \mathrm{~Hz}, 4 \mathrm{H},=\mathrm{CH}_{2}\right)$, $2.21\left(\mathrm{~d}, 8.5, J_{\mathrm{Pt}-\mathrm{H}}=24.0 \mathrm{~Hz}, 3 \mathrm{H}, \mathrm{P}-\mathrm{CH}\right), 1.88\left(\mathrm{~d}, 12.0 \mathrm{~Hz}, 6 \mathrm{H}, \mathrm{CH}_{2}\right), 1.65(\mathrm{dd}, 13.0$, $\left.2.0 \mathrm{~Hz}, 6 \mathrm{H}, \mathrm{CH}_{2}\right), 1.55\left(\mathrm{~d}, 12.0 \mathrm{~Hz}, 3 \mathrm{H}, \mathrm{CH}_{2}\right), 1.47-1.29\left(\mathrm{~m}, 11 \mathrm{H}, \mathrm{CH}_{2}\right.$ and $\left.{ }^{c} \mathrm{Pr}\right), 1.13(\mathrm{~m}$, $\left.6 \mathrm{H}, \mathrm{CH}_{2}\right), 1.03\left(\mathrm{~m}, 6 \mathrm{H}, \mathrm{CH}_{2}\right) \cdot{ }^{13} \mathrm{C}\left\{{ }^{1} \mathrm{H}\right\} \operatorname{NMR}\left(\delta, \mathrm{C}_{6} \mathrm{D}_{6}, 125 \mathrm{MHz}\right): 48.5\left(\mathrm{brd}, 28.3,{ }^{1} J_{\mathrm{Pt}-\mathrm{C}}\right.$ $\left.=385.6 \mathrm{~Hz},=\mathrm{CR}_{2}\right), 36.7\left(\mathrm{~d}, 21.1, J_{\mathrm{Pt}-\mathrm{C}}=26.9 \mathrm{~Hz}, \mathrm{P}-\mathrm{CH}\right), 32.0\left(\mathrm{~m},=\mathrm{CH}_{2}\right), 30.3\left(\mathrm{~s}, J_{\mathrm{Pt}-\mathrm{C}}\right.$ $\left.=18.2 \mathrm{~Hz}, \mathrm{CH}_{2}\right), 28.0\left(\mathrm{~d}, 10.2 \mathrm{~Hz}, \mathrm{CH}_{2}\right), 26.9\left(\mathrm{~s}, \mathrm{CH}_{2}\right), 7.2\left(\mathrm{~s}, J_{\mathrm{Pt}-\mathrm{C}}=25.0 \mathrm{~Hz},{ }^{c} \mathrm{Pr}\right)$. ${ }^{31} \mathrm{P}\left\{{ }^{1} \mathrm{H}\right\} \operatorname{NMR}\left(\delta, \mathrm{C}_{6} \mathrm{D}_{6}\right): 23.2\left(\mathrm{~s},{ }^{1} J_{\mathrm{Pt}-\mathrm{P}}=2695 \mathrm{~Hz}\right)$.

\subsection{Chapter Three Experimental}

Synthesis of $\quad\left[\mathrm{Pt}(\mathrm{BCP})\left({ }^{t} \mathrm{Bu}_{2} \mathrm{PCH}_{2}\left(o-\mathrm{C}_{6} \mathrm{H}_{4}\right) \mathrm{CH}_{2} \mathrm{~S}^{t} \mathrm{Bu}\right)\right] \quad 8 \quad$ and $\left[\mathrm{Pt}\left(\eta^{3}-\mathrm{C}\left(\mathrm{CH}_{2}\right)_{2} \mathrm{CHCHMe}\right)\left(\mathrm{C}_{6} \mathrm{H}_{3}-o-\mathrm{CH}_{2} \mathrm{P}^{t} \mathrm{Bu}_{2}-m-\mathrm{CH}_{2} \mathrm{~S}^{t} \mathrm{Bu}\right)\right]\left(\mathrm{P}\right.$ trans $\left.{ }^{c} \mathrm{Pr}\right)$ $11 \mathrm{a}$ and ( $\mathrm{P}$ trans $\mathrm{Me}) 11 \mathrm{~b}$

$\left[\mathrm{Pt}(\mathrm{nb})\left({ }^{t} \mathrm{Bu}_{2} \mathrm{PCH}_{2}\left(o-\mathrm{C}_{6} \mathrm{H}_{4}\right) \mathrm{CH}_{2} \mathrm{~S}^{t} \mathrm{Bu}\right)\right] \quad(30 \mathrm{mg}, \quad 0.048 \mathrm{mmol})$ was placed in a NMR tube and $\mathrm{C}_{6} \mathrm{D}_{6}(0.5 \mathrm{~mL})$ added. Carbon-13 enriched $\mathrm{BCP}(0.08 \mathrm{~mL}$ of a $0.62 \mathrm{mmol} / \mathrm{mL} \sin$ in $\mathrm{C}_{6} \mathrm{D}_{6}, 0.050 \mathrm{mmol}, 1.03$ eq.) was added, resulting in the immediate formation of $\left[\mathrm{Pt}(\mathrm{BCP})\left({ }^{t} \mathrm{Bu}_{2} \mathrm{PCH}_{2}\left(o-\mathrm{C}_{6} \mathrm{H}_{4}\right) \mathrm{CH}_{2} \mathrm{~S}^{t} \mathrm{Bu}\right)\right]$ 8. After an hour, $\left[\mathrm{Pt}\left(\eta^{3}-\mathrm{C}\left(\mathrm{CH}_{2}\right)_{2} \mathrm{CHCHMe}\right)\left(\mathrm{C}_{6} \mathrm{H}_{3}-o-\mathrm{CH}_{2} \mathrm{P}^{t} \mathrm{Bu}_{2}-m-\mathrm{CH}_{2} \mathrm{~S}^{t} \mathrm{Bu}\right)\right] \quad\left(\mathrm{P}\right.$ trans $\left.{ }^{c} \mathrm{Pr}\right)$ 11a and $\left[\mathrm{Pt}\left(\eta^{3}-\mathrm{C}\left(\mathrm{CH}_{2}\right)_{2} \mathrm{CHCHMe}\right)\left(\mathrm{C}_{6} \mathrm{H}_{3}-o-\mathrm{CH}_{2} \mathrm{P}^{t} \mathrm{Bu}_{2}-m-\mathrm{CH}_{2} \mathrm{~S}{ }^{t} \mathrm{Bu}\right)\right](\mathrm{P}$ trans $\mathrm{Me}) \mathbf{1 1 b}$ begin to form, reaching 98\% completion by ${ }^{31} \mathrm{P}\left\{{ }^{1} \mathrm{H}\right\}$ NMR after 8 days $(85 \% \mathbf{1 1 a}, 15 \% \mathbf{1 1 b})$. $\left[\mathbf{P t}(\mathbf{B C P})\left({ }^{t} \mathbf{B u}_{\mathbf{2}} \mathbf{P C H}_{\mathbf{2}}\left(\boldsymbol{o}-\mathbf{C}_{\mathbf{6}} \mathbf{H}_{\mathbf{4}}\right) \mathbf{C H}_{\mathbf{2}} \mathbf{S}{ }^{t} \mathbf{B u}\right)\right]$ 8: ${ }^{1} \mathrm{H}$ NMR $\left(\delta, \mathrm{C}_{6} \mathrm{D}_{6}, 600 \mathrm{MHz}\right): 7.10(\mathrm{~d}$, $\left.7.6 \mathrm{~Hz}, 1 \mathrm{H}, o-\mathrm{C}_{6} \mathrm{H}_{4}\right), 7.06\left(\mathrm{~d}, 7.3 \mathrm{~Hz}, 1 \mathrm{H}, o-\mathrm{C}_{6} \mathrm{H}_{4}\right), 7.01\left(\mathrm{t}, 7.4 \mathrm{~Hz}, 1 \mathrm{H}, m-\mathrm{C}_{6} \mathrm{H}_{4}\right), 6.95((\mathrm{t}$, $\left.7.3 \mathrm{~Hz}, 1 \mathrm{H}, m-\mathrm{C}_{6} \mathrm{H}_{4}\right), 4.11\left(\mathrm{~s}, J_{\mathrm{Pt}-\mathrm{H}}=28.5 \mathrm{~Hz}, 2 \mathrm{H}, \mathrm{S}-\mathrm{CH}_{2}\right), 3.23\left(\mathrm{~d}, 8.5, J_{\mathrm{Pt}-\mathrm{H}}=17.0 \mathrm{~Hz}\right.$, $\left.2 \mathrm{H}, \mathrm{P}-\mathrm{CH}_{2}\right), 1.22\left(\mathrm{~s}, 9 \mathrm{H}, \mathrm{S}{ }^{t} \mathrm{Bu}\right), 1.16\left(\mathrm{~d}, 12.7 \mathrm{~Hz}, 18 \mathrm{H}, \mathrm{P}{ }^{t} \mathrm{Bu}\right)$. Data for ${ }^{c} \mathrm{Pr}$ protons could not be obtained. ${ }^{13} \mathrm{C}\left\{{ }^{1} \mathrm{H}\right\} \operatorname{NMR}\left(\delta, \mathrm{C}_{6} \mathrm{D}_{6}, 150 \mathrm{MHz}\right): 138.5\left(\mathrm{~s}, \mathrm{~S} i-\mathrm{C}_{6} \mathrm{H}_{4}\right), 136.1(\mathrm{~d}$, 
$\left.2.9 \mathrm{~Hz}, \mathrm{P} i-\mathrm{C}_{6} \mathrm{H}_{4}\right), 131.9\left(\mathrm{~d}, 2.3 \mathrm{~Hz}, \mathrm{P}{ }_{o}-\mathrm{C}_{6} \mathrm{H}_{4}\right), 131.2\left(\mathrm{~d}, 3.5 \mathrm{~Hz}, \mathrm{~S} o-\mathrm{C}_{6} \mathrm{H}_{4}\right), 127.2(\mathrm{~d}$, $\left.1.8 \mathrm{~Hz}, \mathrm{P} m-\mathrm{C}_{6} \mathrm{H}_{4}\right), 127.0\left(\mathrm{~d}, 2.3 \mathrm{~Hz}, \mathrm{~S} m-\mathrm{C}_{6} \mathrm{H}_{4}\right), 49.6\left(\mathrm{~d}, 4.0 \mathrm{~Hz}, \mathrm{~S}-\mathrm{CR}_{3}\right), 38.5(\mathrm{~d}, 2.9$, $\left.J_{\mathrm{Pt}-\mathrm{C}}=32.3 \mathrm{~Hz}, \mathrm{~S}-\mathrm{CH}_{2}\right), 36.2\left(\mathrm{~d}, 14.4, J_{\mathrm{Pt}-\mathrm{C}}=55.5 \mathrm{~Hz}, \mathrm{P}-\mathrm{CR}_{3}\right), 29.9(\mathrm{~d}, 6.4 \mathrm{~Hz}, \mathrm{P}$ $\left.\mathrm{CH}_{3}\right), 29.8\left(\mathrm{~s}, J_{\mathrm{Pt}-\mathrm{C}}=12.8 \mathrm{~Hz}, \mathrm{~S} \mathrm{CH} \mathrm{CH}_{3}\right), 28.4\left(\mathrm{~d}, 4.6 \mathrm{~Hz}, \mathrm{P}-\mathrm{CH}_{2}\right), 28.2\left(\mathrm{~d}, 78.0,{ }^{1} J_{\mathrm{Pt}-\mathrm{C}}\right.$ $=579.0 \mathrm{~Hz},=\mathrm{CR}_{2}$ trans $\left.\mathrm{P}\right), 25.2\left(\mathrm{~d}, 5.2,{ }^{1} J_{\mathrm{Pt}-\mathrm{C}}=656.6 \mathrm{~Hz},=\mathrm{CR}_{2}\right.$ trans $\left.\mathrm{S}\right), 9.0($ brs, $\left.{ }^{c} \mathrm{Pr}\right), 8.7\left(\mathrm{brs},{ }^{c} \mathrm{Pr}\right) . \quad{ }^{31} \mathrm{P}\left\{{ }^{1} \mathrm{H}\right\} \operatorname{NMR}\left(\delta, \mathrm{C}_{6} \mathrm{D}_{6}, 121 \mathrm{MHz}\right): 54.9\left(\mathrm{~s},{ }^{1} J_{\mathrm{Pt}-\mathrm{P}}=3383 \mathrm{~Hz}\right)$. $\left[\mathrm{Pt}\left(\eta^{3}-\mathrm{C}\left(\mathrm{CH}_{2}\right)_{2} \mathrm{CHCHMe}\right)\left(\mathrm{C}_{6} \mathrm{H}_{3}-o-\mathrm{CH}_{2} \mathrm{P}^{t} \mathrm{Bu}_{2}-m-\mathrm{CH}_{2} \mathrm{~S}^{t} \mathrm{Bu}\right)\right]\left(\mathrm{P}\right.$ trans $\left.{ }^{c} \mathrm{Pr}\right)$ 11a: ${ }^{1} \mathrm{H}$ NMR $\left(\delta, \mathrm{C}_{6} \mathrm{D}_{6}, 500 \mathrm{MHz}\right): 7.52\left(\mathrm{t}, 4.5, J_{\mathrm{Pt}-\mathrm{H}}=59.5 \mathrm{~Hz}, 1 \mathrm{H}, \mathrm{Ar}-\mathrm{H}\right), 7.10(\mathrm{~d}$, $4.5 \mathrm{~Hz}, 2 \mathrm{H}, \mathrm{Ar}-\mathrm{H}), 4.85\left(\mathrm{t}, 13.5, J_{\mathrm{Pt}-\mathrm{H}}=13.0 \mathrm{~Hz}, 1 \mathrm{H}, \mathrm{CHMe}\right), 4.54\left(\mathrm{~d}, 8.0, J_{\mathrm{Pt}-\mathrm{H}}=\right.$ $39.0 \mathrm{~Hz}, 1 \mathrm{H}, \mathrm{CH}), 3.80\left(\mathrm{~d}, 12.5, J_{\mathrm{Pt}-\mathrm{H}}=22.0 \mathrm{~Hz}, 2 \mathrm{H}, \mathrm{S}-\mathrm{CH}_{2}\right), 3.55\left(\mathrm{dd}, 17.0,10.0, J_{\mathrm{Pt}-\mathrm{H}}\right.$ $\left.=29.0 \mathrm{~Hz}, 1 \mathrm{H}, \mathrm{P}-\mathrm{CH}_{2}\right), 3.26\left(\mathrm{dd}, 17.0,8.0, J_{\mathrm{Pt}-\mathrm{H}}=8.0 \mathrm{~Hz}, 1 \mathrm{H}, \mathrm{P}-\mathrm{CH}_{2}\right), 1.63(\mathrm{~d}, 6.5 \mathrm{~Hz}$, $\left.3 \mathrm{H}, \mathrm{CH}_{3}\right), 1.56\left(\mathrm{~m}, 2 \mathrm{H},{ }^{c} \mathrm{Pr}\right), 1.29\left(\mathrm{~s}, 9 \mathrm{H}, \mathrm{S}{ }^{t} \mathrm{Bu}\right), 1.26\left(\mathrm{~m}, 2 \mathrm{H},{ }^{c} \mathrm{Pr}\right), 1.15(\mathrm{~d}, 13.0 \mathrm{~Hz}, 9 \mathrm{H}$, $\left.\mathrm{P}{ }^{t} \mathrm{Bu}\right), 1.08\left(\mathrm{~d}, 13.0 \mathrm{~Hz}, 9 \mathrm{H}, \mathrm{P}{ }^{t} \mathrm{Bu}\right) .{ }^{13} \mathrm{C}\left\{{ }^{1} \mathrm{H}\right\} \operatorname{NMR}\left(\delta, \mathrm{C}_{6} \mathrm{D}_{6}, 125 \mathrm{MHz}\right): 153.9(\mathrm{~d}$, $\left.2.4,{ }^{1} J_{\mathrm{Pt}-\mathrm{C}}=1192.1, \mathrm{Pt}-\mathrm{C}\right), 151.4\left(\mathrm{~d}, 15.3, J_{\mathrm{Pt}-\mathrm{C}}=72.0 \mathrm{~Hz}, \mathrm{P} i-\mathrm{C}_{6} \mathrm{H}_{4}\right), 136.9(\mathrm{~d}, 2.9$, $\left.J_{\mathrm{Pt}-\mathrm{C}}=48.9 \mathrm{~Hz}, \mathrm{Ar}\right), 131.7\left(\mathrm{~d}, 12.4, J_{\mathrm{Pt}-\mathrm{C}}=59.5 \mathrm{~Hz}, \mathrm{~S} i-\mathrm{C}_{6} \mathrm{H}_{4}\right), 126.6\left(\mathrm{~s}, J_{\mathrm{Pt}-\mathrm{C}}=\right.$ $9.3 \mathrm{~Hz}, \mathrm{Ar}), 126.3(\mathrm{~s}, \mathrm{Ar}), 98.6\left(\mathrm{~d}, 4.3,{ }^{1} J_{\mathrm{Pt}-\mathrm{C}}=21.1 \mathrm{~Hz}, \mathrm{CH}\right), 74.1\left(\mathrm{~s},{ }^{1} J_{\mathrm{Pt}-\mathrm{C}}=32.6 \mathrm{~Hz}\right.$, CHMe $), 53.5\left(\mathrm{~d}, 76.3,{ }^{1} J_{\mathrm{Pt}-\mathrm{C}}=447.4 \mathrm{~Hz}, \mathrm{C}\left(\mathrm{CH}_{2}\right)_{2}\right), 42.4\left(\mathrm{~s}, \mathrm{~S}-\mathrm{CR}_{3}\right), 35.7\left(\mathrm{~s}, J_{\mathrm{Pt}-\mathrm{C}}=\right.$ $\left.13.8 \mathrm{~Hz}, \mathrm{~S}-\mathrm{CH}_{2}\right), 35.4\left(\mathrm{~d}, 18.2, J_{\mathrm{Pt}-\mathrm{C}}=31.7 \mathrm{~Hz}, \mathrm{P}-\mathrm{CR}_{3}\right), 34.3\left(\mathrm{~d}, 21.1, J_{\mathrm{Pt}-\mathrm{C}}=52.3 \mathrm{~Hz}\right.$, $\left.\mathrm{P}-\mathrm{CR}_{3}\right), 31.4\left(\mathrm{~d}, 33.6, J_{\mathrm{Pt}-\mathrm{C}}=89.4 \mathrm{~Hz}, \mathrm{P}-\mathrm{CH}_{2}\right), 30.9\left(\mathrm{~s}, \mathrm{~S} \mathrm{CH}_{3}\right), 29.4\left(\mathrm{~d}, 4.7, \mathrm{P} \mathrm{CH}_{3}\right)$, $29.3\left(\mathrm{~d}, 5.2, \mathrm{P} \mathrm{CH}_{3}\right), 17.3\left(\mathrm{~s}, J_{\mathrm{Pt}-\mathrm{C}}=27.9 \mathrm{~Hz}, \mathrm{CH}_{3}\right), 7.7\left(\mathrm{~d}, 4.3, J_{\mathrm{Pt}-\mathrm{H}}=25.9 \mathrm{~Hz},{ }^{c} \mathrm{Pr}\right)$, $3.7\left(\mathrm{brs}, J_{\mathrm{Pt}-\mathrm{H}}=18.0 \mathrm{~Hz},{ }^{c} \mathrm{Pr}\right) .{ }^{31} \mathrm{P}\left\{{ }^{1} \mathrm{H}\right\} \operatorname{NMR}\left(\delta, \mathrm{C}_{6} \mathrm{D}_{6}, 121 \mathrm{MHz}\right): 82.0\left(\mathrm{~s},{ }^{1} J_{\mathrm{Pt}-\mathrm{P}}=\right.$ $3141 \mathrm{~Hz}) . \quad\left[\mathrm{Pt}\left(\eta^{3}-\mathrm{C}\left(\mathrm{CH}_{2}\right)_{2} \mathrm{CHCHMe}\right)\left(\mathrm{C}_{6} \mathrm{H}_{3}-o-\mathrm{CH}_{2} \mathrm{P}^{t} \mathrm{Bu}_{2}-m-\mathrm{CH}_{2} \mathrm{~S}^{t} \mathrm{Bu}\right)\right]$ (P trans Me) 11b: ${ }^{1} \mathrm{H}$ NMR $\left(\delta, \mathrm{C}_{6} \mathrm{D}_{6}, 600 \mathrm{MHz}\right): 8.45\left(\mathrm{dd}, 6.4,2.3 J_{\mathrm{Pt}-\mathrm{H}}=46.7 \mathrm{~Hz}\right.$, $1 \mathrm{H}, \mathrm{Ar}-\mathrm{H}), 7.10(\mathrm{~d}, 4.7 \mathrm{~Hz}, 2 \mathrm{H}, \mathrm{Ar}-\mathrm{H}), 4.82\left(\mathrm{~d}, 7.5, J_{\mathrm{Pt}-\mathrm{H}}=41.6 \mathrm{~Hz}, 1 \mathrm{H}, \mathrm{CH}\right), 4.57(\mathrm{~m}$, $1 \mathrm{H}, \mathrm{CHMe}), 3.82\left(\mathrm{~d}, 19.3, J_{\mathrm{Pt}-\mathrm{H}}=30.7 \mathrm{~Hz}, 2 \mathrm{H}, \mathrm{S}-\mathrm{CH}_{2}\right), 3.66(\mathrm{dd}, 17.0,9.6 \mathrm{~Hz}, 1 \mathrm{H}$, $\left.\mathrm{P}-\mathrm{CH}_{2}\right), 3.33\left(\mathrm{dd}, 17.0,8.8 \mathrm{~Hz}, 1 \mathrm{H}, \mathrm{P}-\mathrm{CH}_{2}\right), 1.65\left(\mathrm{dd}, 6.4,4.7 \mathrm{~Hz}, 3 \mathrm{H}, \mathrm{CH}_{3}\right), 1.38(\mathrm{~m}$, $\left.2 \mathrm{H},{ }^{c} \mathrm{Pr}\right), 1.29\left(\mathrm{~s}, 9 \mathrm{H}, \mathrm{S}{ }^{t} \mathrm{Bu}\right), 1.26\left(\mathrm{~m}, 1 \mathrm{H},{ }^{c} \mathrm{Pr}\right), 1.16\left(\mathrm{~d}, 13.6 \mathrm{~Hz}, 9 \mathrm{H}, \mathrm{P}{ }^{t} \mathrm{Bu}\right), 1.12(\mathrm{~d}$, $\left.13.6 \mathrm{~Hz}, 9 \mathrm{H}, \mathrm{P}{ }^{t} \mathrm{Bu}\right), 1.1\left(\mathrm{~m}, 1 \mathrm{H},{ }^{c} \mathrm{Pr}\right) .{ }^{13} \mathrm{C}\left\{{ }^{1} \mathrm{H}\right\} \operatorname{NMR}\left(\delta, \mathrm{C}_{6} \mathrm{D}_{6}, 150 \mathrm{MHz}\right): 159.9(\mathrm{~d}, 2.8$, $\left.{ }^{1} J_{\mathrm{Pt}-\mathrm{C}}=1043.3, \mathrm{Pt}-\mathrm{C}\right), 150.5\left(\mathrm{~d}, 13.3, \mathrm{P} i-\mathrm{C}_{6} \mathrm{H}_{4}\right), 142.7\left(\mathrm{~d}, 2.8, J_{\mathrm{Pt}-\mathrm{C}}=41.7 \mathrm{~Hz}, \mathrm{Ar}\right)$, 
131.8(d, 17.3, $\left.J_{\mathrm{Pt}-\mathrm{C}}=60.0 \mathrm{~Hz}, \mathrm{~S} i-\mathrm{C}_{6} \mathrm{H}_{4}\right), 126.2\left(\mathrm{~s}, J_{\mathrm{Pt}-\mathrm{C}}=7.1 \mathrm{~Hz}, \mathrm{Ar}\right), 126.1(\mathrm{~s}, \mathrm{Ar})$, $102.8\left(\mathrm{brs},{ }^{1} J_{\mathrm{Pt}-\mathrm{C}}=7.1 \mathrm{~Hz}, \mathrm{CH}\right), 84.3\left(\mathrm{~d}, 30.1,{ }^{1} J_{\mathrm{Pt}-\mathrm{C}}=130.6 \mathrm{~Hz}, \mathrm{CHMe}\right), 48.1\left(\mathrm{~s},{ }^{1} J_{\mathrm{Pt}-\mathrm{C}}\right.$ $\left.=202.3 \mathrm{~Hz}, \mathrm{C}\left(\mathrm{CH}_{2}\right)_{2}\right), 42.3\left(\mathrm{~s}, \mathrm{~S}-\mathrm{CR}_{3}\right), 36.1\left(\mathrm{~d}, 23.2, J_{\mathrm{Pt}-\mathrm{C}}=63.9 \mathrm{~Hz}, \mathrm{P}-\mathrm{CR}_{3}\right), 35.9(\mathrm{~s}$, $\left.J_{\mathrm{Pt}-\mathrm{C}}=12.2 \mathrm{~Hz}, \mathrm{~S}-\mathrm{CH}_{2}\right), 34.3\left(\mathrm{~d}, 23.7, J_{\mathrm{Pt}-\mathrm{C}}=54.8 \mathrm{~Hz}, \mathrm{P}-\mathrm{CR}_{3}\right), 33.0\left(\mathrm{~d}, 35.3, J_{\mathrm{Pt}-\mathrm{C}}\right.$ $\left.=80.8 \mathrm{~Hz}, \mathrm{P}-\mathrm{CH}_{2}\right), 30.9\left(\mathrm{~s}, \mathrm{~S} \mathrm{CH}_{3}\right), 29.2\left(\mathrm{~d}, 4.1, J_{\mathrm{Pt}-\mathrm{C}}=14.0 \mathrm{~Hz}, \mathrm{P} \mathrm{CH}_{3}\right), 28.7(\mathrm{~d}, 4.6$, $\left.J_{\mathrm{Pt}-\mathrm{C}}=19.6 \mathrm{~Hz}, \mathrm{P} \mathrm{CH} \mathrm{CH}_{3}\right), 16.8\left(\mathrm{~d}, 4.6, J_{\mathrm{Pt}-\mathrm{C}}=41.6 \mathrm{~Hz}, \mathrm{CH}_{3}\right), 9.0\left(\mathrm{~s}, J_{\mathrm{Pt}-\mathrm{H}}=15.0 \mathrm{~Hz}\right.$, $\left.{ }^{c} \operatorname{Pr}\right) 6.6\left(\mathrm{~s},{ }^{c} \mathrm{Pr}\right) .{ }^{31} \mathrm{P}\left\{{ }^{1} \mathrm{H}\right\} \operatorname{NMR}\left(\delta, \mathrm{C}_{6} \mathrm{D}_{6}, 121 \mathrm{MHz}\right): 80.1\left(\mathrm{~s},{ }^{1} J_{\mathrm{Pt}-\mathrm{P}}=3893 \mathrm{~Hz}\right) \cdot \mathrm{m} / z=$ $\left[\mathrm{M}^{+}\right.$calcd for $\mathrm{C}_{26} \mathrm{H}_{43} \mathrm{P}^{194} \mathrm{PtS} 613.2468$; found 613.2473 .

Synthesis of $\quad\left[\mathrm{Pt}(\mathrm{MCP})\left({ }^{t} \mathrm{Bu}_{2} \mathrm{PCH}_{2}\left(o-\mathrm{C}_{6} \mathrm{H}_{4}\right) \mathrm{CH}_{2} \mathrm{~S}^{t} \mathrm{Bu}\right)\right] \quad 9 \quad$ and $\left[\mathrm{Pt}\left(\eta^{3}-\mathrm{CH}_{2} \mathrm{CHCHMe}\right)\left(\mathrm{C}_{6} \mathrm{H}_{3}-o-\mathrm{CH}_{2} \mathrm{P}^{t} \mathrm{Bu}_{2}-m-\mathrm{CH}_{2} \mathrm{~S}^{t} \mathrm{Bu}\right)\right](\mathrm{P}$ trans $\mathrm{Me}) 12 \mathrm{a}$ and ( $\mathrm{P}$ trans $\left.\mathrm{CH}_{2}\right)$ 12b

$\left[\mathrm{Pt}(\mathrm{nb})\left({ }^{t} \mathrm{Bu}_{2} \mathrm{PCH}_{2}\left(o-\mathrm{C}_{6} \mathrm{H}_{4}\right) \mathrm{CH}_{2} \mathrm{~S}^{t} \mathrm{Bu}\right)\right](35 \mathrm{mg}, 0.056 \mathrm{mmol})$ was placed in a $\mathrm{NMR}$ tube and $\mathrm{C}_{6} \mathrm{D}_{6}(0.5 \mathrm{~mL})$ added. $\mathrm{MCP}(0.16 \mathrm{~mL}$ of a $0.37 \mathrm{mmol} / \mathrm{mL}$ sh in $\mathrm{C}_{6} \mathrm{D}_{6}, 0.059 \mathrm{mmol}, 1.06$ eq.) was added, resulting in the immediate formation of $\left[\mathrm{Pt}(\mathrm{MCP})\left({ }^{t} \mathrm{Bu}_{2} \mathrm{PCH}_{2}\left(o-\mathrm{C}_{6} \mathrm{H}_{4}\right) \mathrm{CH}_{2} \mathrm{~S}{ }^{t} \mathrm{Bu}\right)\right]\left(\mathrm{S}\right.$ trans $\left.{ }^{c} \mathrm{Pr}\right) \mathbf{9 a}$ and $\left[\mathrm{Pt}(\mathrm{MCP})\left({ }^{t} \mathrm{Bu}_{2} \mathrm{PCH}_{2}\left(o_{-}\right.\right.\right.$ $\left.\left.\left.\mathrm{C}_{6} \mathrm{H}_{4}\right) \mathrm{CH}_{2} \mathrm{~S}^{t} \mathrm{Bu}\right)\right]\left(\mathrm{P}\right.$ trans $\left.{ }^{c} \mathrm{Pr}\right) \mathbf{9 b}\left(62 \% \mathbf{9 a}, 38 \% \mathbf{9 b}, 80 \%\right.$ completion by $\left.{ }^{31} \mathrm{P}\left\{{ }^{1} \mathrm{H}\right\} \mathrm{NMR}\right)$. Overnight, $\left[\mathrm{Pt}\left(\eta^{3}-\mathrm{CH}_{2} \mathrm{CHCHMe}\right)\left(\mathrm{C}_{6} \mathrm{H}_{3}-o-\mathrm{CH}_{2} \mathrm{P}^{t} \mathrm{Bu}_{2}-m-\mathrm{CH}_{2} \mathrm{~S}^{t} \mathrm{Bu}\right)\right]$ ( $\mathrm{P}$ trans $\left.\mathrm{Me}\right) \mathbf{1 2 a}$ and $\left[\mathrm{Pt}\left(\eta^{3}-\mathrm{CH}_{2} \mathrm{CHCHMe}\right)\left(\mathrm{C}_{6} \mathrm{H}_{3}-o-\mathrm{CH}_{2} \mathrm{P}^{t} \mathrm{Bu}_{2}-m-\mathrm{CH}_{2} \mathrm{~S}^{t} \mathrm{Bu}\right)\right]\left(\mathrm{P}\right.$ trans $\left.\mathrm{CH}_{2}\right)$ 12b began to form, reaching $95 \%$ completion by ${ }^{31} \mathrm{P}\left\{{ }^{1} \mathrm{H}\right\}$ NMR after 21 days $(63 \% \mathbf{1 2 a}, 37 \% \mathbf{1 2} \mathbf{b})$. $\left[\mathrm{Pt}(\mathrm{MCP})\left({ }^{t} \mathrm{Bu}_{2} \mathrm{PCH}_{2}\left(o-\mathrm{C}_{6} \mathrm{H}_{4}\right) \mathrm{CH}_{2} \mathrm{~S}^{t} \mathrm{Bu}\right)\right]\left(\mathrm{S}\right.$ trans $\left.{ }^{c} \mathrm{Pr}\right)$ 9a: ${ }^{1} \mathrm{H} \operatorname{NMR}\left(\delta, \mathrm{C}_{6} \mathrm{D}_{6}\right.$, $600 \mathrm{MHz}): 7.12\left(\mathrm{~d}, 7.3 \mathrm{~Hz}, 2 \mathrm{H}, o-\mathrm{C}_{6} \mathrm{H}_{4}\right), 7.03\left(\mathrm{t}, 7.3 \mathrm{~Hz}, 1 \mathrm{H}, m-\mathrm{C}_{6} \mathrm{H}_{4}\right), 6.97((\mathrm{t}, 6.1 \mathrm{~Hz}$, $\left.1 \mathrm{H}, m-\mathrm{C}_{6} \mathrm{H}_{4}\right), 4.19\left(\mathrm{~s}, J_{\mathrm{Pt}-\mathrm{H}}=26.8 \mathrm{~Hz}, 2 \mathrm{H}, \mathrm{S}-\mathrm{CH}_{2}\right), 3.27\left(\mathrm{~d}, 8.4, J_{\mathrm{Pt}-\mathrm{H}}=14.4 \mathrm{~Hz}, 2 \mathrm{H}\right.$, $\left.\mathrm{P}-\mathrm{CH}_{2}\right), 2.05\left(\mathrm{~d}, 8.2, J_{\mathrm{Pt}-\mathrm{H}}=52.7 \mathrm{~Hz}, 2 \mathrm{H},=\mathrm{CH}_{2}\right), 1.45\left(\mathrm{brs}, 2 \mathrm{H},{ }^{c} \mathrm{Pr}\right), 1.37(\mathrm{brs}, 2 \mathrm{H}$, $\left.{ }^{c} \mathrm{Pr}\right), 1.34\left(\mathrm{~s}, 9 \mathrm{H}, \mathrm{S}{ }^{t} \mathrm{Bu}\right), 1.25\left(\mathrm{~d}, 12.3 \mathrm{~Hz}, 9 \mathrm{H}, \mathrm{P}{ }^{t} \mathrm{Bu}\right), 1.17\left(\mathrm{~d}, 12.6 \mathrm{~Hz}, 9 \mathrm{H}, \mathrm{P}{ }^{t} \mathrm{Bu}\right)$. ${ }^{13} \mathrm{C}\left\{{ }^{1} \mathrm{H}\right\} \operatorname{NMR}\left(\delta, \mathrm{C}_{6} \mathrm{D}_{6}, 150 \mathrm{MHz}\right): 138.9\left(\mathrm{~s}, \mathrm{~S} i-\mathrm{C}_{6} \mathrm{H}_{4}\right), 136.6\left(\mathrm{~d}, 3.5 \mathrm{~Hz}, \mathrm{P} i-\mathrm{C}_{6} \mathrm{H}_{4}\right)$, 132.0(d, $\left.2.3 \mathrm{~Hz}, \mathrm{P} o-\mathrm{C}_{6} \mathrm{H}_{4}\right), 131.4\left(\mathrm{~d}, 4.1 \mathrm{~Hz}, \mathrm{~S} o-\mathrm{C}_{6} \mathrm{H}_{4}\right), 127.1\left(\mathrm{~d}, 1.2 \mathrm{~Hz}, m-\mathrm{C}_{6} \mathrm{H}_{4}\right)$, $126.9\left(\mathrm{~d}, 2.3 \mathrm{~Hz}, m-\mathrm{C}_{6} \mathrm{H}_{4}\right), 50.5\left(\mathrm{~d}, 4.0 \mathrm{~Hz}, \mathrm{~S}-\mathrm{CR}_{3}\right), 38.8\left(\mathrm{~d}, 2.3, J_{\mathrm{Pt}-\mathrm{C}}=31.1 \mathrm{~Hz}\right.$, $\left.\mathrm{S}-\mathrm{CH}_{2}\right), 37.2\left(\mathrm{~d}, 13.9, J_{\mathrm{Pt}-\mathrm{C}}=52.6 \mathrm{~Hz}, \mathrm{P}-\mathrm{CR}_{3}\right), 30.1\left(\mathrm{~s}, J_{\mathrm{Pt}-\mathrm{C}}=14.5 \mathrm{~Hz}, \mathrm{~S} \mathrm{CH}_{3}\right)$, 
$29.8\left(\mathrm{brd}, 6.9, J_{\mathrm{Pt}-\mathrm{C}}=29.6 \mathrm{~Hz}, \mathrm{P} \mathrm{CH}_{3}\right), 28.9\left(\mathrm{~d}, 5.2 \mathrm{~Hz}, \mathrm{P}-\mathrm{CH}_{2}\right), 26.3\left(\mathrm{~d}, 38.7,{ }^{1} J_{\mathrm{Pt}-\mathrm{C}}\right.$ $\left.=145.1 \mathrm{~Hz},=\mathrm{CH}_{2}\right), 10.5\left(\mathrm{~d}, 1.7, J_{\mathrm{Pt}-\mathrm{C}}=30.1 \mathrm{~Hz},{ }^{c} \mathrm{Pr}\right)$. Data for $\mathrm{MCP}=\mathrm{CR}_{2}$ carbon could not be obtained. ${ }^{31} \mathrm{P}\left\{{ }^{1} \mathrm{H}\right\} \operatorname{NMR}\left(\delta, \mathrm{C}_{6} \mathrm{D}_{6}, 121 \mathrm{MHz}\right): 58.8\left(\mathrm{~s},{ }^{1} J_{\mathrm{Pt}-\mathrm{P}}=3870 \mathrm{~Hz}\right)$. $\left[\mathrm{Pt}(\mathrm{MCP})\left({ }^{t} \mathrm{Bu}_{2} \mathrm{PCH}_{2}\left({ }_{o}-\mathrm{C}_{6} \mathrm{H}_{4}\right) \mathrm{CH}_{2} \mathrm{~S}^{t} \mathrm{Bu}\right)\right]\left(\mathrm{P}\right.$ trans $\left.{ }^{c} \mathrm{Pr}\right)$ 9b: ${ }^{1} \mathrm{H} \operatorname{NMR}\left(\delta, \mathrm{C}_{6} \mathrm{D}_{6}\right.$, $600 \mathrm{MHz}): 7.14\left(\mathrm{~d}, 7.5 \mathrm{~Hz}, 1 \mathrm{H}, o-\mathrm{C}_{6} \mathrm{H}_{4}\right), 7.10\left(\mathrm{~d}, 7.5 \mathrm{~Hz}, 1 \mathrm{H}, o-\mathrm{C}_{6} \mathrm{H}_{4}\right), 7.01(\mathrm{t}, 6.6 \mathrm{~Hz}$, $\left.1 \mathrm{H}, m-\mathrm{C}_{6} \mathrm{H}_{4}\right), 6.96\left(\left(\mathrm{t}, 6.1 \mathrm{~Hz}, 1 \mathrm{H}, m-\mathrm{C}_{6} \mathrm{H}_{4}\right), 4.20\left(\mathrm{~s}, J_{\mathrm{Pt}-\mathrm{H}}=31.4 \mathrm{~Hz}, 2 \mathrm{H}, \mathrm{S}-\mathrm{CH}_{2}\right)\right.$, $3.27\left(\mathrm{~d}, 8.4, J_{\mathrm{Pt}-\mathrm{H}}=18.8 \mathrm{~Hz}, 2 \mathrm{H}, \mathrm{P}-\mathrm{CH}_{2}\right), 2.38\left(\mathrm{~d}, 4.2, J_{\mathrm{Pt}-\mathrm{H}}=82.1 \mathrm{~Hz}, 2 \mathrm{H},=\mathrm{CH}_{2}\right)$, 1.59(m, 2H, $\left.{ }^{c} \mathrm{Pr}\right), 1.50\left(\mathrm{~m}, 2 \mathrm{H},{ }^{c} \mathrm{Pr}\right), 1.29\left(\mathrm{~d}, 12.3 \mathrm{~Hz}, 9 \mathrm{H}, \mathrm{P}^{t} \mathrm{Bu}\right), 1.26(\mathrm{~d}, 12.0 \mathrm{~Hz}, 9 \mathrm{H}$, $\left.\mathrm{P}{ }^{t} \mathrm{Bu}\right), 1.21\left(\mathrm{~s}, 9 \mathrm{H}, \mathrm{S}{ }^{t} \mathrm{Bu}\right) .{ }^{13} \mathrm{C}\left\{{ }^{1} \mathrm{H}\right\} \operatorname{NMR}\left(\delta, \mathrm{C}_{6} \mathrm{D}_{6}, 150 \mathrm{MHz}\right): 138.9\left(\mathrm{~s}, \mathrm{~S} i-\mathrm{C}_{6} \mathrm{H}_{4}\right)$, 136.5(d, $\left.2.9 \mathrm{~Hz}, \mathrm{P} i-\mathrm{C}_{6} \mathrm{H}_{4}\right), 132.2\left(\mathrm{~d}, 1.7 \mathrm{~Hz}, \mathrm{P}{ }_{o}-\mathrm{C}_{6} \mathrm{H}_{4}\right), 131.4\left(\mathrm{~d}, 4.0 \mathrm{~Hz}, \mathrm{~S} o-\mathrm{C}_{6} \mathrm{H}_{4}\right)$, 127.0(brs, $\left.m-\mathrm{C}_{6} \mathrm{H}_{4}\right), 127.0\left(\mathrm{~d}, 2.3 \mathrm{~Hz}, m-\mathrm{C}_{6} \mathrm{H}_{4}\right), 49.2\left(\mathrm{~d}, 4.7 \mathrm{~Hz}, \mathrm{~S}-\mathrm{CR}_{3}\right), 39.5(\mathrm{~d}, 4.1$, $\left.J_{\mathrm{Pt}-\mathrm{C}}=34.1 \mathrm{~Hz}, \mathrm{~S}-\mathrm{CH}_{2}\right), 36.1\left(\mathrm{~d}, 15.1, J_{\mathrm{Pt}-\mathrm{C}}=63.0 \mathrm{~Hz}, \mathrm{P}-\mathrm{CR}_{3}\right), 30.3(\mathrm{brd}, 5.2 \mathrm{~Hz}$, $\left.J_{\mathrm{Pt}-\mathrm{C}}=16.3 \mathrm{~Hz}, \mathrm{P} \mathrm{CH}_{3}\right), 29.4\left(\mathrm{~s}, J_{\mathrm{Pt}-\mathrm{C}}=13.8 \mathrm{~Hz}, \mathrm{~S} \mathrm{CH} \mathrm{CH}_{3}\right), 28.9\left(\mathrm{~d}, 1.5 \mathrm{~Hz}, \mathrm{P}-\mathrm{CH}_{2}\right)$, $25.7\left(\mathrm{~d}, 5.7,{ }^{1} J_{\mathrm{Pt}-\mathrm{C}}=270.6 \mathrm{~Hz},=\mathrm{CH}_{2}\right), 10.0\left(\mathrm{~s}, J_{\mathrm{Pt}-\mathrm{C}}=24.8 \mathrm{~Hz},{ }^{c} \mathrm{Pr}\right)$. Data for MCP $=\mathrm{CR}_{2}$ carbon could not be obtained. ${ }^{31} \mathrm{P}\left\{{ }^{1} \mathrm{H}\right\} \operatorname{NMR}\left(\delta, \mathrm{C}_{6} \mathrm{D}_{6}, 121 \mathrm{MHz}\right): 55.3\left(\mathrm{~s},{ }^{1} J_{\mathrm{Pt}-\mathrm{P}}\right.$ $=3483 \mathrm{~Hz}) \cdot\left[\mathrm{Pt}\left(\eta^{3}-\mathrm{CH}_{2} \mathbf{C H C H M e}\right)\left(\mathrm{C}_{6} \mathbf{H}_{3}-o-\mathrm{CH}_{2} \mathbf{P}^{t} \mathbf{B u}_{2}-m-\mathrm{CH}_{2} \mathrm{~S}^{t} \mathbf{B u}\right)\right](\mathbf{P}$ trans Me) 12a: ${ }^{1} \mathrm{H} \operatorname{NMR}\left(\delta, \mathrm{C}_{6} \mathrm{D}_{6}, 600 \mathrm{MHz}\right): 8.49\left(\mathrm{t}, 7.3, J_{\mathrm{Pt}-\mathrm{H}}=55.2 \mathrm{~Hz}, 1 \mathrm{H}, \mathrm{Ar}-\mathrm{H}\right), 7.1(\mathrm{~m}$, $2 \mathrm{H}, \mathrm{Ar}-\mathrm{H}), 4.61\left(\mathrm{dt}, 13.3,7.7, J_{\mathrm{Pt}-\mathrm{H}}=41.9 \mathrm{~Hz}, 1 \mathrm{H}, \mathrm{CH}\right), 4.34(\mathrm{~m}, 1 \mathrm{H}, \mathrm{CHMe}), 3.83(\mathrm{~m}$, $\left.2 \mathrm{H}, \mathrm{S}-\mathrm{CH}_{2}\right), 3.58\left(\mathrm{dt}, 7.6,1.2 \mathrm{~Hz}, 1 \mathrm{H}, \mathrm{CH}_{2}\right.$ syn), 3.57(dd, 16.7, 9.1, J $\mathrm{Pt}-\mathrm{H}=42.5 \mathrm{~Hz}$, $\left.1 \mathrm{H}, \mathrm{P}-\mathrm{CH}_{2}\right), 3.42\left(\mathrm{~d}, 9.1, J_{\mathrm{Pt}-\mathrm{H}}=15.4 \mathrm{~Hz}, 1 \mathrm{H}, \mathrm{P}-\mathrm{CH}_{2}\right), 2.27\left(\mathrm{~d}, 13.2, J_{\mathrm{Pt}-\mathrm{H}}=38.1 \mathrm{~Hz}\right.$, $1 \mathrm{H}, \mathrm{CH}_{2}$ anti), $1.39\left(\mathrm{dd}, 6.4,5.6 \mathrm{~Hz}, 3 \mathrm{H}, \mathrm{CH}_{3}\right), 1.29\left(\mathrm{~s}, 9 \mathrm{H}, \mathrm{S}{ }^{t} \mathrm{Bu}\right), 1.16(\mathrm{~d}, 13.5 \mathrm{~Hz}, 9 \mathrm{H}$, $\left.\mathrm{P}{ }^{t} \mathrm{Bu}\right), 1.09\left(\mathrm{~d}, 13.5 \mathrm{~Hz}, 9 \mathrm{H}, \mathrm{P}{ }^{t} \mathrm{Bu}\right) .{ }^{13} \mathrm{C}\left\{{ }^{1} \mathrm{H}\right\} \mathrm{NMR}\left(\delta, \mathrm{C}_{6} \mathrm{D}_{6}, 150 \mathrm{MHz}\right): 158.4(\mathrm{~d}, 2.3$, $\left.{ }^{1} J_{\mathrm{Pt}-\mathrm{C}}=1142.7, \mathrm{Pt}-\mathrm{C}\right), 151.0\left(\mathrm{~d}, 14.4, J_{\mathrm{Pt}-\mathrm{C}}=80.3 \mathrm{~Hz}, \mathrm{P} i-\mathrm{C}_{6} \mathrm{H}_{4}\right), 142.7\left(\mathrm{~d}, 3.2, J_{\mathrm{Pt}-\mathrm{C}}\right.$ $=52.1 \mathrm{~Hz}, \mathrm{Ar}), 131.9\left(\mathrm{~d}, 12.7, J_{\mathrm{Pt}-\mathrm{C}}=56.0 \mathrm{~Hz}, \mathrm{~S} i-\mathrm{C}_{6} \mathrm{H}_{4}\right), 126.5(\mathrm{~s}, \mathrm{Ar}), 126.2\left(\mathrm{~s}, J_{\mathrm{Pt}-\mathrm{C}}=\right.$ $8.7 \mathrm{~Hz}, \mathrm{Ar}), 108.2\left(\mathrm{~d}, 2.4,{ }^{1} J_{\mathrm{Pt}-\mathrm{C}}=8.4 \mathrm{~Hz}, \mathrm{CH}\right), 73.4\left(\mathrm{~d}, 37.0,{ }^{1} J_{\mathrm{Pt}-\mathrm{C}}=173.4 \mathrm{~Hz}, \mathrm{CHMe}\right)$, $42.5\left(\mathrm{~s},{ }^{1} J_{\mathrm{Pt}-\mathrm{C}}=52.0 \mathrm{~Hz}, \mathrm{CH}_{2}\right), 42.3\left(\mathrm{~s}, \mathrm{~S}-\mathrm{CR}_{3}\right), 35.9\left(\mathrm{~s}, J_{\mathrm{Pt}-\mathrm{C}}=13.8 \mathrm{~Hz}, \mathrm{~S}-\mathrm{CH}_{2}\right)$, $34.6\left(\mathrm{~d}, 22.5, J_{\mathrm{Pt}-\mathrm{C}}=54.3 \mathrm{~Hz}, \mathrm{P}-\mathrm{CR}_{3}\right), 34.1\left(\mathrm{~d}, 23.2, J_{\mathrm{Pt}-\mathrm{C}}=43.8 \mathrm{~Hz}, \mathrm{P}-\mathrm{CR}_{3}\right), 32.0(\mathrm{~d}$, 34.7, $\left.J_{\mathrm{Pt}-\mathrm{C}}=82.6 \mathrm{~Hz}, \mathrm{P}-\mathrm{CH}_{2}\right), 30.9\left(\mathrm{~s}, \mathrm{~S} \mathrm{CH}_{3}\right), 29.3\left(\mathrm{~d}, 1.7, \mathrm{P} \mathrm{CH}_{3}\right), 29.3\left(\mathrm{~d}, 1.7, \mathrm{P} \mathrm{CH}_{3}\right)$, $15.3\left(\mathrm{~d}, 5.2, J_{\mathrm{Pt}-\mathrm{C}}=39.9 \mathrm{~Hz}, \mathrm{CH}_{3}\right) .{ }^{31} \mathrm{P}\left\{{ }^{1} \mathrm{H}\right\} \mathrm{NMR}\left(\delta, \mathrm{C}_{6} \mathrm{D}_{6}, 121 \mathrm{MHz}\right): 84.1\left(\mathrm{~s},{ }^{1} J_{\mathrm{Pt}-\mathrm{P}}\right.$ 
$=3560 \mathrm{~Hz}) \cdot\left[\mathrm{Pt}\left(\eta^{3}-\mathrm{CH}_{2} \mathbf{C H C H M e}\right)\left(\mathrm{C}_{6} \mathbf{H}_{3}-\boldsymbol{o}-\mathrm{CH}_{2} \mathbf{P}^{t} \mathbf{B u}_{2}-m-\mathbf{C H}_{2} \mathbf{S}^{t} \mathbf{B u}\right)\right](\mathbf{P}$ trans $\left.\mathrm{CH}_{2}\right)$ 12b: ${ }^{1} \mathrm{H} \operatorname{NMR}\left(\delta, \mathrm{C}_{6} \mathrm{D}_{6}, 600 \mathrm{MHz}\right): 8.51\left(\mathrm{~d}, 7.0, J_{\mathrm{Pt}-\mathrm{H}}=58.3 \mathrm{~Hz}, 1 \mathrm{H}\right.$, Ar-H), 7.1(m, 2H, Ar-H), 4.61(dt, 13.3, 7.7, $\left.J_{\mathrm{Pt}-\mathrm{H}}=41.9 \mathrm{~Hz}, 1 \mathrm{H}, \mathrm{CH}\right), 4.39$ (quint, $5.1 \mathrm{~Hz}, 1 \mathrm{H}$, CHMe), 3.83(m, 2H, S- $\left.\mathrm{CH}_{2}\right), 3.6\left(\mathrm{~m}, 1 \mathrm{H}, \mathrm{CH}_{2}\right.$ syn $), 3.51\left(\mathrm{dd}, 9.1,2.1, J_{\mathrm{Pt}-\mathrm{H}}=20.0 \mathrm{~Hz}\right.$, $\left.1 \mathrm{H}, \mathrm{P}-\mathrm{CH}_{2}\right), 3.39\left(\mathrm{~d}, 9.1, J_{\mathrm{Pt}-\mathrm{H}}=14.6 \mathrm{~Hz}, 1 \mathrm{H}, \mathrm{P}-\mathrm{CH}_{2}\right), 2.92(\mathrm{ddd}, 12.9,9.7,2.1 \mathrm{~Hz}, 1 \mathrm{H}$, $\mathrm{CH}_{2}$ anti), $1.29\left(\mathrm{~d}, 11.8 \mathrm{~Hz}, 3 \mathrm{H}, \mathrm{CH}_{3}\right), 1.29\left(\mathrm{~s}, 9 \mathrm{H}, \mathrm{S}{ }^{t} \mathrm{Bu}\right), 1.15\left(\mathrm{~d}, 13.5 \mathrm{~Hz}, 9 \mathrm{H}, \mathrm{P}{ }^{t} \mathrm{Bu}\right)$, $1.07\left(\mathrm{~d}, 13.5 \mathrm{~Hz}, 9 \mathrm{H}, \mathrm{P}{ }^{t} \mathrm{Bu}\right) .{ }^{13} \mathrm{C}\left\{{ }^{1} \mathrm{H}\right\} \operatorname{NMR}\left(\delta, \mathrm{C}_{6} \mathrm{D}_{6}, 150 \mathrm{MHz}\right): 155.5\left(\mathrm{~d}, 2.4,{ }^{1} J_{\mathrm{Pt}-\mathrm{C}}=\right.$ 1132.8, Pt-C), 151.1(d, 14.5, $\left.J_{\mathrm{Pt}-\mathrm{C}}=81.0 \mathrm{~Hz}, \mathrm{P} i-\mathrm{C}_{6} \mathrm{H}_{4}\right), 144.5\left(\mathrm{~d}, 4.0, J_{\mathrm{Pt}-\mathrm{C}}=58.4 \mathrm{~Hz}\right.$, $\mathrm{Ar}), 131.8\left(\mathrm{~d}, 12.8, J_{\mathrm{Pt}-\mathrm{C}}=55.3 \mathrm{~Hz}, \mathrm{~S} i-\mathrm{C}_{6} \mathrm{H}_{4}\right), 126.3\left(\mathrm{~s}, J_{\mathrm{Pt}-\mathrm{C}}=7.5 \mathrm{~Hz}, \mathrm{Ar}\right), 126.0(\mathrm{~s}$, $\mathrm{Ar}), 108.7\left(\mathrm{~d}, 3.4,{ }^{1} J_{\mathrm{Pt}-\mathrm{C}}=11.0 \mathrm{~Hz}, \mathrm{CH}\right), 62.5\left(\mathrm{~s},{ }^{1} J_{\mathrm{Pt}-\mathrm{C}}=48.6 \mathrm{~Hz}, \mathrm{CHMe}\right), 53.1(\mathrm{~d}, 40.4$, $\left.{ }^{1} J_{\mathrm{Pt}-\mathrm{C}}=182.6 \mathrm{~Hz}, \mathrm{CH}_{2}\right), 42.4\left(\mathrm{~s}, \mathrm{~S}-\mathrm{CR}_{3}\right), 35.8\left(\mathrm{~s}, J_{\mathrm{Pt}-\mathrm{C}}=13.8 \mathrm{~Hz}, \mathrm{~S}-\mathrm{CH}_{2}\right), 34.8(\mathrm{~d}, 13.8$, $\left.J_{\mathrm{Pt}-\mathrm{C}}=40.6 \mathrm{~Hz}, \mathrm{P}-\mathrm{CR}_{3}\right), 34.7\left(\mathrm{~d}, 16.1, J_{\mathrm{Pt}-\mathrm{C}}=59.0 \mathrm{~Hz}, \mathrm{P}-\mathrm{CR}_{3}\right), 32.2\left(\mathrm{~d}, 34.6, J_{\mathrm{Pt}-\mathrm{C}}=\right.$ $\left.82.0 \mathrm{~Hz}, \mathrm{P}-\mathrm{CH}_{2}\right), 30.9\left(\mathrm{~s}, \mathrm{~S} \mathrm{CH}{ }_{3}\right), 29.4\left(\mathrm{~d}, 5.2, \mathrm{P} \mathrm{CH}_{3}\right), 29.4\left(\mathrm{~d}, 4.6, \mathrm{P} \mathrm{CH}_{3}\right), 15.6\left(\mathrm{~s}, J_{\mathrm{Pt}-\mathrm{C}}\right.$ $\left.=26.6 \mathrm{~Hz}, \mathrm{CH}_{3}\right) .{ }^{31} \mathrm{P}\left\{{ }^{1} \mathrm{H}\right\} \operatorname{NMR}\left(\delta, \mathrm{C}_{6} \mathrm{D}_{6}, 121 \mathrm{MHz}\right): 82.0\left(\mathrm{~s},{ }^{1} J_{\mathrm{Pt}-\mathrm{P}}=3590 \mathrm{~Hz}\right) . \mathrm{m} / z$ $=[\mathrm{M}+\mathrm{H}]^{+}$calcd for $\mathrm{C}_{24} \mathrm{H}_{42} \mathrm{P}^{194} \mathrm{PtS}$ 583.2299; found 583.2344.

\section{Synthesis of $\left[\mathrm{Pt}(\mathrm{MCP})_{2}\left({ }^{t} \mathrm{Bu}_{2} \mathrm{PCH}_{2}\left(o-\mathrm{C}_{6} \mathrm{H}_{4}\right) \mathrm{CH}_{2} \mathrm{~S}^{t} \mathrm{Bu}\right)\right] 10$}

$\left[\mathrm{Pt}(\mathrm{nb})\left({ }^{t} \mathrm{Bu}_{2} \mathrm{PCH}_{2}\left(o-\mathrm{C}_{6} \mathrm{H}_{4}\right) \mathrm{CH}_{2} \mathrm{~S}^{t} \mathrm{Bu}\right)\right](12 \mathrm{mg}, 0.019 \mathrm{mmol})$ was placed in a NMR tube and $\mathrm{C}_{6} \mathrm{D}_{6}(0.5 \mathrm{~mL})$ added. A large excess of MCP was added, resulting in the immediate formation of $\mathbf{9 a}, \mathbf{9 b}$ and $\left[\mathrm{Pt}(\mathrm{MCP})_{2}\left({ }^{t} \mathrm{Bu}_{2} \mathrm{PCH}_{2}\left(o-\mathrm{C}_{6} \mathrm{H}_{4}\right) \mathrm{CH}_{2} \mathrm{~S}^{t} \mathrm{Bu}\right)\right] \mathbf{1 0}(40 \% \mathbf{9 a}, 24 \% \mathbf{9 b}$, $36 \% \mathbf{1 0}$, quantitative by $\left.{ }^{31} \mathrm{P}\left\{{ }^{1} \mathrm{H}\right\} \mathrm{NMR}\right)$. After an hour, $\mathbf{1 2} \mathbf{a}$ and $\mathbf{1 2} \mathbf{b}$ began to form. All of the $\mathbf{1 0}$ had reacted after 13 days, and the formation of $\mathbf{1 2 a}$ and $\mathbf{1 2 b}$ had reached $91 \%$ completion by ${ }^{31} \mathrm{P}\left\{{ }^{1} \mathrm{H}\right\} \mathrm{NMR}$ after 21 days $(63 \% \mathbf{1 2 a}, 37 \% \mathbf{1 2 b}) .{ }^{1} \mathrm{H} \operatorname{NMR}(\delta$, $\left.\mathrm{C}_{6} \mathrm{D}_{6}, 600 \mathrm{MHz}\right): 7.1\left(\mathrm{~m}, 2 \mathrm{H}, o-\mathrm{C}_{6} \mathrm{H}_{4}\right), 6.89\left(\mathrm{t}, 7.4 \mathrm{~Hz}, 1 \mathrm{H}, m-\mathrm{C}_{6} \mathrm{H}_{4}\right), 6.79((\mathrm{t}, 7.5 \mathrm{~Hz}, 1 \mathrm{H}$, $\left.m-\mathrm{C}_{6} \mathrm{H}_{4}\right), 4.29\left(\mathrm{dd}, 10.9,5.3 \mathrm{~Hz}, 2 \mathrm{H}, \mathrm{P}-\mathrm{CH}_{2}\right), 4.24\left(\mathrm{~m}, 2 \mathrm{H}, \mathrm{P}-\mathrm{CH}_{2}\right), 3.96\left(\mathrm{~d}, 9.4, J_{\mathrm{Pt}-\mathrm{H}}\right.$ $\left.=32.6 \mathrm{~Hz}, 2 \mathrm{H}, \mathrm{S}-\mathrm{CH}_{2}\right), 2.49\left(\mathrm{~d}, 6.4, J_{\mathrm{Pt}-\mathrm{H}}=48.1 \mathrm{~Hz}, 4 \mathrm{H},=\mathrm{CH}_{2}\right), 1.26\left(\mathrm{~s}, 9 \mathrm{H}, \mathrm{S}{ }^{t} \mathrm{Bu}\right)$, 1.23(d, $\left.12.3 \mathrm{~Hz}, 18 \mathrm{H}, \mathrm{P}^{t} \mathrm{Bu}\right)$. Data for ${ }^{c}$ Pr protons could not be obtained. ${ }^{13} \mathrm{C}\left\{{ }^{1} \mathrm{H}\right\} \mathrm{NMR}$ $\left(\delta, \mathrm{C}_{6} \mathrm{D}_{6}, 150 \mathrm{MHz}\right): 142.0\left(\mathrm{~s}, \mathrm{~S} i-\mathrm{C}_{6} \mathrm{H}_{4}\right), 136.4\left(\mathrm{~d}, 5.8 \mathrm{~Hz}, \mathrm{P} i-\mathrm{C}_{6} \mathrm{H}_{4}\right), 131.9(\mathrm{~d}, 7.5 \mathrm{~Hz}, \mathrm{Ar})$, 130.9(s, Ar), 126.8(s, Ar), 48.7(brd, $\left.25.7 \mathrm{~Hz},{ }^{1} J_{\mathrm{Pt}-\mathrm{C}}=381.9 \mathrm{~Hz},=\mathrm{CR}_{2}\right), 42.6\left(\mathrm{~s}, \mathrm{~S}-\mathrm{CR}_{3}\right)$, 
$37.8\left(\mathrm{~d}, 14.5, J_{\mathrm{Pt}-\mathrm{C}}=28.8 \mathrm{~Hz}, \mathrm{~S}-\mathrm{CH}_{2}\right), 35.7\left(\mathrm{brs},{ }^{1} J_{\mathrm{Pt}-\mathrm{C}}=100.6 \mathrm{~Hz},=\mathrm{CH}_{2}\right), 30.9(\mathrm{~s}, \mathrm{~S}$ $\left.\mathrm{CH}_{3}\right), 30.5\left(\mathrm{~d}, 4.0 \mathrm{~Hz}, \mathrm{P} \mathrm{CH}_{3}\right), 26.5\left(\mathrm{~d}, 18.5 \mathrm{~Hz}, J_{\mathrm{Pt}-\mathrm{C}}=30.0 \mathrm{~Hz}, \mathrm{P}-\mathrm{CH}_{2}\right), 7.2\left(\mathrm{~s}, J_{\mathrm{Pt}-\mathrm{C}}=\right.$ $\left.25.4 \mathrm{~Hz},{ }^{c} \mathrm{Pr}\right)$. Data for $\mathrm{P}-\mathrm{CR}_{3}$ carbons could not be obtained. ${ }^{31} \mathrm{P}\left\{{ }^{1} \mathrm{H}\right\} \operatorname{NMR}\left(\delta, \mathrm{C}_{6} \mathrm{D}_{6}\right.$, $121 \mathrm{MHz}): 40.6\left(\mathrm{~s},{ }^{1} J_{\mathrm{Pt}-\mathrm{P}}=2661 \mathrm{~Hz}\right)$.

\section{Synthesis of $\left[\mathrm{Pt}\left(\eta^{3}-\mathrm{C}\left(\mathrm{CH}_{2}\right)_{2} \mathrm{CHCHMe}\right)(\mathrm{dppp})\right]\left[\mathrm{HC}\left(\mathrm{SO}_{2} \mathrm{CF}_{3}\right)_{2}\right]$ (anti $\left.\mathrm{Me}\right)$} $13 \mathrm{a}\left[\mathrm{HC}\left(\mathrm{SO}_{2} \mathrm{CF}_{3}\right)_{2}\right]$ and $\left[\mathrm{Pt}\left(\eta^{3}-\mathrm{C}\left(\mathrm{CH}_{2}\right)_{2} \mathrm{CHCHMe}\right)(\mathrm{dppp})\right]\left[\mathrm{HC}\left(\mathrm{SO}_{2} \mathrm{CF}_{3}\right)_{2}\right]$ $(\operatorname{syn} \mathrm{Me}) 13 \mathrm{~b}\left[\mathrm{HC}\left(\mathrm{SO}_{2} \mathrm{CF}_{3}\right)_{2}\right]$

$\left[\mathrm{Pt}\left(\mathrm{C}_{2} \mathrm{H}_{4}\right)(\mathrm{dppp})\right](30 \mathrm{mg}, 0.047 \mathrm{mmol})$ was placed in an NMR tube and $\mathrm{C}_{6} \mathrm{D}_{6}(0.5 \mathrm{~mL})$ added. Carbon-13 enriched BCP $\left(0.08 \mathrm{~mL}\right.$ of a $0.62 \mathrm{mmol} / \mathrm{mL} \sin$ in $\mathrm{C}_{6} \mathrm{D}_{6}, 0.050 \mathrm{mmol}$, 1.06 eq.) was added, resulting in the immediate formation of $\left[\mathrm{Pt}\left({ }^{13} \mathrm{BCP}\right)(\mathrm{dppp})\right]$. After 30 min, the solution was dried in vacuo and a solution of $\mathrm{H}_{2} \mathrm{C}\left(\mathrm{SO}_{2} \mathrm{CF}_{3}\right)_{2}(13 \mathrm{mg}, 0.047 \mathrm{mmol})$ in $d_{6}$-acetone $(0.5 \mathrm{~mL})$ added. Two new complexes, $\mathbf{1 3} \mathbf{a}\left[\mathrm{HC}\left(\mathrm{SO}_{2} \mathrm{CF}_{3}\right)_{2}\right]$ and $\mathbf{1 4 a}$ were formed immediately in a 75:25 ratio by ${ }^{31} \mathrm{P}\left\{{ }^{1} \mathrm{H}\right\}$ NMR. Overnight, 14a converted completely to $\mathbf{1 4 b}$, while $\mathbf{1 3 a}\left[\mathrm{HC}\left(\mathrm{SO}_{2} \mathrm{CF}_{3}\right)_{2}\right]$ began to form $\mathbf{1 3 b}\left[\mathrm{HC}\left(\mathrm{SO}_{2} \mathrm{CF}_{3}\right)_{2}\right]$, stabilising at 27:73 anti:syn after 2 months. $\left[\mathbf{P t}\left(\eta^{3}-\mathbf{C}\left(\mathbf{C H}_{\mathbf{2}}\right)_{\mathbf{2}} \mathbf{C H C H M e}\right)(\mathbf{d p p p})\right]\left[\mathbf{H C}\left(\mathbf{S O}_{\mathbf{2}} \mathbf{C F}_{\mathbf{3}}\right)_{\mathbf{2}}\right]$ (anti $\mathrm{Me}) \mathbf{1 3} \mathrm{a}\left[\mathbf{H C}\left(\mathbf{S O}_{\mathbf{2}} \mathbf{C F}_{\mathbf{3}}\right)_{\mathbf{2}}\right]:{ }^{1} \mathrm{H} \operatorname{NMR}\left(\delta, d_{6}\right.$-acetone, $\left.600 \mathrm{MHz}\right): 7.9-7.3(\mathrm{~m}, 20 \mathrm{H}$, Ar-H), 5.40(d, 8.2, J $\left.J_{\mathrm{Pt}-\mathrm{H}}=54.0 \mathrm{~Hz}, 1 \mathrm{H}, \mathrm{CH}\right), 4.93(\mathrm{~m}, 1 \mathrm{H}, \mathrm{CHMe}), 3.80\left(\mathrm{~s}, 1 \mathrm{H}, \mathrm{CHS}_{2}\right)$, $3.3-2.9\left(\mathrm{~m}, 4 \mathrm{H}, \mathrm{P}-\mathrm{CH}_{2}\right), 2.3\left(\mathrm{~m}, 2 \mathrm{H}, \mathrm{CH}_{2}\right), 1.21\left(\mathrm{~m}, 1 \mathrm{H},{ }^{c} \mathrm{Pr}\right), 0.88\left(\mathrm{~m}, 3 \mathrm{H}, \mathrm{CH}_{3}\right), 0.86(\mathrm{~m}$, $\left.1 \mathrm{H},{ }^{c} \mathrm{Pr}\right), 0.37\left(\mathrm{~m}, 2 \mathrm{H},{ }^{c} \mathrm{Pr}\right) \cdot{ }^{13} \mathrm{C}\left\{{ }^{1} \mathrm{H}\right\} \operatorname{NMR}\left(\delta, d_{6}\right.$-acetone, $\left.150 \mathrm{MHz}\right): 134-129(\mathrm{~m}, \mathrm{Ar})$, $122.1\left(\mathrm{q},{ }^{1} J_{\mathrm{F}-\mathrm{C}}=325.4 \mathrm{~Hz}, \mathrm{CF}_{3}\right), 104.2(\mathrm{dd}, 3.4,1.7, \mathrm{CH}), 91.2\left(\mathrm{~d}, 22.6,{ }^{1} J_{\mathrm{Pt}-\mathrm{C}}=65.9 \mathrm{~Hz}\right.$, CHMe), 66.7(d, 54.3, $\left.{ }^{1} J_{\mathrm{Pt}-\mathrm{C}}=252.6 \mathrm{~Hz}, \mathrm{C}\left(\mathrm{CH}_{2}\right)_{2}\right), 55.4\left(\mathrm{~m}, \mathrm{CHS}_{2}\right), 26.3(\mathrm{dd}, 37.0,4.1$, $\left.J_{\mathrm{Pt}-\mathrm{C}}=35.8 \mathrm{~Hz}, \mathrm{P}-\mathrm{CH}_{2}\right), 25.4\left(\mathrm{dd}, 34.7,2.3, J_{\mathrm{Pt}-\mathrm{C}}=17.2 \mathrm{~Hz}, \mathrm{P}-\mathrm{CH}_{2}\right), 19.4\left(\mathrm{~s}, J_{\mathrm{Pt}-\mathrm{C}}=\right.$ $\left.17.3 \mathrm{~Hz}, \mathrm{CH}_{2}\right), 15.5\left(\mathrm{~d}, 4.1, J_{\mathrm{Pt}-\mathrm{C}}=33.2, \mathrm{CH}_{3}\right), 8.1\left(\mathrm{~d}, 4.0, J_{\mathrm{Pt}-\mathrm{C}}=16.8 \mathrm{~Hz},{ }^{c} \mathrm{Pr}\right), 4.4(\mathrm{~s}$, $\left.J_{\mathrm{Pt}-\mathrm{C}}=15.6 \mathrm{~Hz},{ }^{c} \mathrm{Pr}\right) .{ }^{31} \mathrm{P}\left\{{ }^{1} \mathrm{H}\right\} \mathrm{NMR}\left(\delta, d_{6}\right.$-acetone, $\left.121 \mathrm{MHz}\right): 1.4\left(\mathrm{~d}, 21.2,{ }^{1} J_{\mathrm{Pt}-\mathrm{P}}=\right.$ $3852 \mathrm{~Hz}, \mathrm{P}$ trans $\mathrm{CHMe}),-2.8\left(\mathrm{~d}, 21.2,{ }^{1} J_{\mathrm{Pt}-\mathrm{P}}=3259 \mathrm{~Hz}, \mathrm{P}\right.$ trans $\left.{ }^{c} \mathrm{Pr}\right) .{ }^{19} \mathrm{~F} \operatorname{NMR}\left(\delta, d_{6^{-}}\right.$ acetone, $282 \mathrm{MHz})$ : $-81.5(\mathrm{brs})$. [Pt $\left.\left(\eta^{3}-\mathbf{C}\left(\mathbf{C H}_{2}\right)_{\mathbf{2}} \mathbf{C H C H M e}\right)(\mathrm{dppp})\right]\left[\mathbf{H C}\left(\mathrm{SO}_{\mathbf{2}} \mathbf{C F}_{3}\right)_{2}\right]$ $(\operatorname{syn} \mathrm{Me}) \mathbf{1 3 b}\left[\mathbf{H C}\left(\mathrm{SO}_{\mathbf{2}} \mathbf{C F}_{\mathbf{3}}\right)_{\mathbf{2}}\right]$ : ${ }^{1} \mathrm{H} \mathrm{NMR}\left(\delta, d_{6}\right.$-acetone, $\left.600 \mathrm{MHz}\right): 7.9-7.3(\mathrm{~m}, 20 \mathrm{H}$, Ar-H), 5.39(d, 12.5, $\left.J_{\mathrm{Pt}-\mathrm{H}}=51.0 \mathrm{~Hz}, 1 \mathrm{H}, \mathrm{CH}\right), 4.14(\mathrm{~m}, 1 \mathrm{H}, \mathrm{CHMe}), 3.80\left(\mathrm{~s}, 1 \mathrm{H}, \mathrm{CHS}_{2}\right)$, 
$3.3-2.9\left(\mathrm{~m}, 4 \mathrm{H}, \mathrm{P}-\mathrm{CH}_{2}\right), 2.3\left(\mathrm{~m}, 2 \mathrm{H}, \mathrm{CH}_{2}\right), 1.38\left(\mathrm{~m}, 3 \mathrm{H}, \mathrm{CH}_{3}\right), 1.22\left(\mathrm{~m}, 1 \mathrm{H},{ }^{c} \mathrm{Pr}\right), 0.65(\mathrm{~m}$, $\left.1 \mathrm{H},{ }^{c} \mathrm{Pr}\right), 0.39\left(\mathrm{~m}, 1 \mathrm{H},{ }^{c} \mathrm{Pr}\right), 0.14\left(\mathrm{~m}, 1 \mathrm{H},{ }^{c} \mathrm{Pr}\right) .{ }^{13} \mathrm{C}\left\{{ }^{1} \mathrm{H}\right\} \mathrm{NMR}\left(\delta, d_{6}\right.$-acetone, $\left.150 \mathrm{MHz}\right)$ : 134-129(m, Ar), 122.1(q, $\left.{ }^{1} J_{\mathrm{F}-\mathrm{C}}=325.4 \mathrm{~Hz}, \mathrm{CF}_{3}\right), 11.6(\mathrm{dd}, 4.1,1.8, \mathrm{CH}), 92.6(\mathrm{~d}, 21.9$, $\left.{ }^{1} J_{\mathrm{Pt}-\mathrm{C}}=29.0 \mathrm{~Hz}, \mathrm{CHMe}\right), 67.1\left(\mathrm{~d}, 53.2,{ }^{1} J_{\mathrm{Pt}-\mathrm{C}}=269.3 \mathrm{~Hz}, \mathrm{C}\left(\mathrm{CH}_{2}\right)_{2}\right), 55.4\left(\mathrm{~m}, \mathrm{CHS}_{2}\right)$, $27.2\left(\mathrm{dd}, 34.7,2.9, \mathrm{P}-\mathrm{CH}_{2}\right), 25.9\left(\mathrm{dd}, 37.0,3.5, \mathrm{P}-\mathrm{CH}_{2}\right), 19.7\left(\mathrm{~s}, J_{\mathrm{Pt}-\mathrm{C}}=13.8 \mathrm{~Hz}, \mathrm{CH}_{2}\right)$, $15.9\left(\mathrm{~d}, 2.4, \mathrm{CH}_{3}\right), 8.6\left(\mathrm{~d}, 4.0, J_{\mathrm{Pt}-\mathrm{C}}=20.8 \mathrm{~Hz},{ }^{c} \mathrm{Pr}\right), 5.7\left(\mathrm{~s},{ }^{c} \mathrm{Pr}\right) .{ }^{31} \mathrm{P}\left\{{ }^{1} \mathrm{H}\right\} \operatorname{NMR}\left(\delta, d_{6^{-}}\right.$ acetone, $121 \mathrm{MHz}): 1.0\left(\mathrm{~d}, 20.8,{ }^{1} J_{\mathrm{Pt}-\mathrm{P}}=4042 \mathrm{~Hz}\right.$, P trans $\left.\mathrm{CHMe}\right),-0.41\left(\mathrm{~d}, 20.8,{ }^{1} J_{\mathrm{Pt}-\mathrm{P}}\right.$ $=3267 \mathrm{~Hz}, \mathrm{P}$ trans $\left.{ }^{c} \mathrm{Pr}\right) .{ }^{19} \mathrm{~F} \operatorname{NMR}\left(\delta, d_{6}\right.$-acetone, $\left.282 \mathrm{MHz}\right):-81.5(\mathrm{brs}) \cdot \mathrm{m} / z=\left[\mathrm{M}^{+}\right.$ calcd for $\mathrm{C}_{33} \mathrm{H}_{35} \mathrm{P}_{2}{ }^{194} \mathrm{Pt} 683.1767$; found 683.1813 .

Synthesis of $\quad\left[\mathrm{Pt}\left(\eta^{3}-\mathrm{CH}_{2} \mathrm{CMeCH}_{2}\right)(\mathrm{dppp})\right]\left[\mathrm{PhC}\left(\mathrm{SO}_{2} \mathrm{CF}_{3}\right)_{2}\right]$ 15[PhC $\left.\left(\mathrm{SO}_{2} \mathrm{CF}_{3}\right)_{2}\right],\left[\mathrm{Pt}\left(\eta^{3}-\mathrm{CH}_{2} \mathrm{CHCHMe}\right)(\mathrm{dppp})\right]\left[\mathrm{PhC}\left(\mathrm{SO}_{2} \mathrm{CF}_{3}\right)_{2}\right]$ (anti Me) $16 \mathrm{a}\left[\mathrm{PhC}\left(\mathrm{SO}_{2} \mathrm{CF}_{3}\right)_{2}\right]$ and $\left[\mathrm{Pt}\left(\eta^{3}-\mathrm{CH}_{2} \mathrm{CHCHMe}\right)(\mathrm{dppp})\right]\left[\mathrm{PhC}\left(\mathrm{SO}_{2} \mathrm{CF}_{3}\right)_{2}\right]$ (syn Me) $16 \mathrm{~b}\left[\mathrm{PhC}\left(\mathrm{SO}_{2} \mathrm{CF}_{3}\right)_{2}\right]$

$\left[\mathrm{Pt}\left(\mathrm{C}_{2} \mathrm{H}_{4}\right)(\mathrm{dppp})\right](30 \mathrm{mg}, 0.047 \mathrm{mmol})$ was placed in an NMR tube and $\mathrm{C}_{6} \mathrm{D}_{6}$ $(0.25 \mathrm{~mL})$ added. $\mathrm{MCP}\left(0.25 \mathrm{~mL}\right.$ of a $0.37 \mathrm{mmol} / \mathrm{mL} \operatorname{sh}$ in $\mathrm{C}_{6} \mathrm{D}_{6}, 0.093 \mathrm{mmol}$, 2 eq.) was added, resulting in the immediate formation of $[\mathrm{Pt}(\mathrm{MCP})(\mathrm{dppp})]$. After $30 \mathrm{~min}$, the solution was dried in vacuo and a solution of $\mathrm{H}_{2} \mathrm{C}\left(\mathrm{SO}_{2} \mathrm{CF}_{3}\right)_{2}(13 \mathrm{mg}$, $0.047 \mathrm{mmol})$ in $d_{6}$-acetone $(0.5 \mathrm{~mL})$ added. Two new complexes, $15\left[\mathrm{PhC}\left(\mathrm{SO}_{2} \mathrm{CF}_{3}\right)_{2}\right]$ and $\mathbf{1 6 a}\left[\mathrm{PhC}\left(\mathrm{SO}_{2} \mathrm{CF}_{3}\right)_{2}\right]$ were formed immediately in a 68:32 ratio by ${ }^{31} \mathrm{P}\left\{{ }^{1} \mathrm{H}\right\}$ NMR. Overnight, $\mathbf{1 6 a}\left[\mathrm{PhC}\left(\mathrm{SO}_{2} \mathrm{CF}_{3}\right)_{2}\right]$ began to form $\mathbf{1 6} \mathbf{b}\left[\mathrm{PhC}\left(\mathrm{SO}_{2} \mathrm{CF}_{3}\right)_{2}\right]$, stabilising at 16:84 anti:syn after 8 days. $\left.\mathbf{P t}\left(\eta^{\mathbf{3}}-\mathbf{C H}_{\mathbf{2}} \mathbf{C M e C H} \mathbf{C H}_{\mathbf{2}}\right)(\mathbf{d p p p})\right]\left[\mathbf{P h C}\left(\mathbf{S O}_{\mathbf{2}} \mathbf{C F}_{\mathbf{3}}\right)_{\mathbf{2}}\right]$ 15[PhC( $\left.\left.\mathbf{S O}_{\mathbf{2}} \mathbf{C F}_{\mathbf{3}}\right)_{\mathbf{2}}\right]:{ }^{1} \mathrm{H} \mathrm{NMR}\left(\delta, d_{6}\right.$-acetone, $\left.600 \mathrm{MHz}\right):$ 7.7-7.1(m, 25H, Ar-H), 3.56(brs, $2 \mathrm{H}, \mathrm{CH}_{2}$ syn) $, 3.2-2.9\left(\mathrm{~m}, 6 \mathrm{H}, \mathrm{P}-\mathrm{CH}_{2}\right.$ and $\left.\mathrm{CH}_{2}\right), 2.96\left(\mathrm{~d}, 8.5, J_{\mathrm{Pt}-\mathrm{H}}=32.0 \mathrm{~Hz}\right.$, $2 \mathrm{H}, \mathrm{CH}_{2}$ anti $), 1.96\left(\mathrm{~s}, J_{\mathrm{Pt}-\mathrm{H}}=58.4 \mathrm{~Hz}, 3 \mathrm{H}, \mathrm{CH}_{3}\right) .{ }^{13} \mathrm{C}\left\{{ }^{1} \mathrm{H}\right\} \mathrm{NMR}\left(\delta, d_{6}\right.$-acetone, $150 \mathrm{MHz}): \quad 136.1(\mathrm{~s}, \mathrm{Ph}), 135.9\left(\mathrm{t}, 3.2,{ }^{1} J_{\mathrm{Pt}-\mathrm{C}}=24.8 \mathrm{~Hz}, \mathrm{CR}_{2} \mathrm{Me}\right), 134-129(\mathrm{~m}, \mathrm{Ar})$, 127.8(s, Ph), 127.7(s, Ph), 123.0(q, $\left.{ }^{1} J_{\mathrm{F}-\mathrm{C}}=328.9 \mathrm{~Hz}, \mathrm{CF}_{3}\right), 66.4\left(\mathrm{~m}, J_{\mathrm{P}-\mathrm{C}}=27.5,1.8\right.$, $\left.J_{\mathrm{P}-\mathrm{P}}=24.6,{ }^{1} J_{\mathrm{Pt}-\mathrm{C}}=85.0 \mathrm{~Hz}, \mathrm{CH}_{2}\right), 71.5\left(\mathrm{sept}, J_{\mathrm{F}-\mathrm{C}}=3.2, \mathrm{CS}_{2}\right), 25.6\left(\mathrm{~m}, \mathrm{P}-\mathrm{CH}_{2}\right)$, $24.8\left(\mathrm{~s}, J_{\mathrm{Pt}-\mathrm{C}}=30.0, \mathrm{CH}_{3}\right), 20.1\left(\mathrm{~s}, J_{\mathrm{Pt}-\mathrm{C}}=15.0 \mathrm{~Hz}, \mathrm{CH}_{2}\right) .{ }^{31} \mathrm{P}\left\{{ }^{1} \mathrm{H}\right\} \mathrm{NMR}\left(\delta, d_{6}\right.$-acetone, 
$121 \mathrm{MHz}): 0.1\left(\mathrm{~s},{ }^{1} J_{\mathrm{Pt}-\mathrm{P}}=3521 \mathrm{~Hz}\right) .{ }^{19} \mathrm{~F} \mathrm{NMR}\left(\delta, d_{6}\right.$-acetone, $\left.282 \mathrm{MHz}\right):-78.72(\mathrm{~s})$. $\left[\mathrm{Pt}\left(\eta^{3}-\mathrm{CH}_{2} \mathrm{CHCHMe}\right)(\mathrm{dppp})\right]\left[\mathrm{PhC}\left(\mathrm{SO}_{2} \mathrm{CF}_{3}\right)_{2}\right]($ anti $\mathrm{Me}) 16 \mathrm{a}\left[\mathrm{PhC}\left(\mathrm{SO}_{2} \mathrm{CF}_{3}\right)_{2}\right]$ : ${ }^{1} \mathrm{H}$ NMR $\left(\delta, d_{6^{-}}\right.$acetone, $\left.600 \mathrm{MHz}\right): 7.7-7.1(\mathrm{~m}, 25 \mathrm{H}, \mathrm{Ar}-\mathrm{H}), 5.32\left(\mathrm{dt}, 14.1,7.6, J_{\mathrm{Pt}-\mathrm{H}}=\right.$ $53.4 \mathrm{~Hz}, 1 \mathrm{H}, \mathrm{CH}), 4.62(\mathrm{t}, 6.2,1 \mathrm{H}, \mathrm{CHMe}), 3.94\left(\mathrm{~m}, 1 \mathrm{H}, \mathrm{CH}_{2}\right.$ syn), 3.2-2.9(m, 5H, $\mathrm{P}-\mathrm{CH}_{2}$ and $\mathrm{CH}_{2}$ anti $), 2.3-2.2\left(\mathrm{~m}, 2 \mathrm{H}, \mathrm{CH}_{2}\right), 0.80\left(\mathrm{~m}, 3 \mathrm{H}, \mathrm{CH}_{3}\right) .{ }^{13} \mathrm{C}\left\{{ }^{1} \mathrm{H}\right\} \operatorname{NMR}\left(\delta, d_{6}\right.$-acetone, $150 \mathrm{MHz}): 136.1(\mathrm{~s}, \mathrm{Ph}), 134.4-129.5(\mathrm{~m}, \mathrm{Ar}), 127.8(\mathrm{~s}, \mathrm{Ph}), 127.7(\mathrm{~s}, \mathrm{Ph}), 123.0\left(\mathrm{q},{ }^{1} J_{\mathrm{F}-\mathrm{C}}\right.$ $\left.=328.9 \mathrm{~Hz}, \mathrm{CF}_{3}\right), 113.9\left(\mathrm{t}, 3.2,{ }^{1} J_{\mathrm{Pt}-\mathrm{C}}=16.5 \mathrm{~Hz}, \mathrm{CH}\right), 83.4\left(\mathrm{~m},{ }^{1} J_{\mathrm{Pt}-\mathrm{C}}=83.7 \mathrm{~Hz}\right.$, CHMe $), 60.2\left(\mathrm{~m},{ }^{1} J_{\mathrm{Pt}-\mathrm{C}}=88.0 \mathrm{~Hz}, \mathrm{CH}_{2}\right), 71.5\left(\mathrm{sept}, J_{\mathrm{F}-\mathrm{C}}=3.2, \mathrm{CS}_{2}\right), 25.6\left(\mathrm{~m}, \mathrm{P}-\mathrm{CH}_{2}\right)$, $19.7\left(\mathrm{~s}, J_{\mathrm{Pt}-\mathrm{C}}=16.8 \mathrm{~Hz}, \mathrm{CH}_{2}\right), 14.1\left(\mathrm{dd}, 2.8,1.1, J_{\mathrm{Pt}-\mathrm{C}}=23.1, \mathrm{CH}_{3}\right) .{ }^{31} \mathrm{P}\left\{{ }^{1} \mathrm{H}\right\} \mathrm{NMR}$ $\left(\delta, d_{6}\right.$-acetone, $\left.121 \mathrm{MHz}\right):-1.2\left(\mathrm{AB},{ }^{2} J_{\mathrm{Pt}-\mathrm{P}}=23.0,{ }^{1} J_{\mathrm{Pt}-\mathrm{P}}=3569 \mathrm{~Hz}, \mathrm{P}\right.$ trans $\left.\mathrm{CH}_{2}\right)$, $-1.2\left(\mathrm{AB},{ }^{2} J_{\mathrm{Pt}-\mathrm{P}}=23.0,{ }^{1} J_{\mathrm{Pt}-\mathrm{P}}=3625 \mathrm{~Hz}, \mathrm{P}\right.$ trans $\left.\mathrm{CHMe}\right) .{ }^{19} \mathrm{~F} \mathrm{NMR}\left(\delta, d_{6}\right.$-acetone, $282 \mathrm{MHz}):-78.72(\mathrm{~s}) \cdot\left[\mathbf{P t}\left(\eta^{\mathbf{3}}-\mathrm{CH}_{\mathbf{2}} \mathrm{CHCHMe}\right)(\mathrm{dppp})\right]\left[\mathrm{PhC}\left(\mathrm{SO}_{\mathbf{2}} \mathrm{CF}_{\mathbf{3}}\right)_{2}\right]($ syn $\mathrm{Me})$ 16b[PhC $\left.\left(\mathbf{S O}_{\mathbf{2}} \mathbf{C F}_{\mathbf{3}}\right)_{\mathbf{2}}\right]:{ }^{1} \mathrm{H} \mathrm{NMR}\left(\delta, d_{6}\right.$-acetone, $\left.600 \mathrm{MHz}\right): 7.7-7.1(\mathrm{~m}, 25 \mathrm{H}, \mathrm{Ar}-\mathrm{H})$, $5.23\left(\mathrm{td}, 12.7,7.3, J_{\mathrm{Pt}-\mathrm{H}}=51.5 \mathrm{~Hz}, 1 \mathrm{H}, \mathrm{CH}\right), 3.68(\mathrm{~m}, 1 \mathrm{H}, \mathrm{CHMe}), 3.59\left(\mathrm{~m}, 1 \mathrm{H}, \mathrm{CH}_{2}\right.$ syn), $3.2-2.9\left(\mathrm{~m}, 4 \mathrm{H}, \mathrm{P}-\mathrm{CH}_{2}\right), 2.54\left(\mathrm{ddd}, 12.7,10.0,2.7,1 \mathrm{H}, \mathrm{CH}_{2}\right.$ anti $), 2.3-2.1\left(\mathrm{~m}, 2 \mathrm{H}, \mathrm{CH}_{2}\right)$, 1.29(m, 3H, $\left.\mathrm{CH}_{3}\right) .{ }^{13} \mathrm{C}\left\{{ }^{1} \mathrm{H}\right\} \operatorname{NMR}\left(\delta, d_{6}\right.$-acetone, $\left.150 \mathrm{MHz}\right): 136.1(\mathrm{~s}, \mathrm{Ph}), 134-129(\mathrm{~m}$, $\mathrm{Ar}), 127.8(\mathrm{~s}, \mathrm{Ph}), 127.7(\mathrm{~s}, \mathrm{Ph}), 123.0\left(\mathrm{q},{ }^{1} J_{\mathrm{F}-\mathrm{C}}=328.9 \mathrm{~Hz}, \mathrm{CF}_{3}\right), 119.3\left(\mathrm{t}, 3.5,{ }^{1} J_{\mathrm{Pt}-\mathrm{C}}=\right.$ $26.6 \mathrm{~Hz}, \mathrm{CH}), 84.3\left(\mathrm{~d}, 27.2,{ }^{1} J_{\mathrm{Pt}-\mathrm{C}}=54.4 \mathrm{~Hz}, \mathrm{CHMe}\right), 62.3\left(\mathrm{~d}, 27.8,{ }^{1} J_{\mathrm{Pt}-\mathrm{C}}=100.1 \mathrm{~Hz}\right.$, $\left.\mathrm{CH}_{2}\right), 71.5\left(\mathrm{sept}, J_{\mathrm{F}-\mathrm{C}}=3.2, \mathrm{CS}_{2}\right), 26.9\left(\mathrm{dd}, 35.8,3.5, J_{\mathrm{Pt}-\mathrm{C}}=19.6 \mathrm{~Hz}, \mathrm{P}-\mathrm{CH}_{2}\right), 25.6(\mathrm{~m}$, $\left.\mathrm{P}-\mathrm{CH}_{2}\right), 19.9\left(\mathrm{~s}, J_{\mathrm{Pt}-\mathrm{C}}=13.8 \mathrm{~Hz}, \mathrm{CH}_{2}\right), 15.9\left(\mathrm{~d}, 2.9, J_{\mathrm{Pt}-\mathrm{C}}=3.8, \mathrm{CH}_{3}\right) .{ }^{31} \mathrm{P}\left\{{ }^{1} \mathrm{H}\right\} \mathrm{NMR}$

$\left(\delta, d_{6}\right.$-acetone, $\left.121 \mathrm{MHz}\right): 1.4\left(\mathrm{AB},{ }^{2} J_{\mathrm{Pt}-\mathrm{P}}=22.0,{ }^{1} J_{\mathrm{Pt}-\mathrm{P}}=3670 \mathrm{~Hz}, \mathrm{P}\right.$ trans $\left.\mathrm{CH}_{2}\right)$, $-1.8\left(\mathrm{AB},{ }^{2} J_{\mathrm{Pt}-\mathrm{P}}=22.0,{ }^{1} J_{\mathrm{Pt}-\mathrm{P}}=3693 \mathrm{~Hz}, \mathrm{P}\right.$ trans $\left.\mathrm{CHMe}\right) .{ }^{19} \mathrm{~F} \mathrm{NMR}\left(\delta, d_{6}\right.$-acetone, $282 \mathrm{MHz}):-78.72(\mathrm{~s})$.

\section{Synthesis of $\left[\mathrm{Pt}\left(\eta^{3}-\mathrm{CH}_{2} \mathrm{C}^{c} \mathrm{PrCH}_{2}\right)(\mathrm{dbpx})\right]\left[\mathrm{HC}\left(\mathrm{SO}_{2} \mathrm{CF}_{3}\right)_{2}\right] 17\left[\mathrm{HC}\left(\mathrm{SO}_{2} \mathrm{CF}_{3}\right)_{2}\right]$}

$\left[\mathrm{Pt}\left(\mathrm{C}_{2} \mathrm{H}_{4}\right)(\mathrm{dbpx})\right](30 \mathrm{mg}, 0.049 \mathrm{mmol})$ was placed in an NMR tube and $\mathrm{C}_{6} \mathrm{D}_{6}(0.5 \mathrm{~mL})$ added. Carbon-13 enriched BCP $\left(0.24 \mathrm{~mL}\right.$ of a $0.62 \mathrm{mmol} / \mathrm{mL}$ sh in $\mathrm{C}_{6} \mathrm{D}_{6}, 0.14 \mathrm{mmol}$, 3 eq.) was added, and the solution heated at $60{ }^{\circ} \mathrm{C}$ for 3 days, forming $\left[\mathrm{Pt}\left({ }^{13} \mathrm{BCP}\right)(\mathrm{dbpx})\right]$ in an $90 \%$ yield by ${ }^{31} \mathrm{P}\left\{{ }^{1} \mathrm{H}\right\}$ NMR. The solution was dried in vacuo and a solution of 
$\mathrm{H}_{2} \mathrm{C}\left(\mathrm{SO}_{2} \mathrm{CF}_{3}\right)_{2}(14 \mathrm{mg}, 0.049 \mathrm{mmol})$ in $d_{6}$-acetone $(0.5 \mathrm{~mL})$ added, resulting in the immediate formation of $\left[\mathrm{Pt}\left(\eta^{3}-\mathrm{CH}_{2} \mathrm{C}^{c} \mathrm{PrCH}_{2}\right)(\mathrm{dbpx})\right]\left[\mathrm{HC}\left(\mathrm{SO}_{2} \mathrm{CF}_{3}\right)_{2}\right] .{ }^{1} \mathrm{H} \mathrm{NMR}\left(\delta, d_{6^{-}}\right.$ acetone, $600 \mathrm{MHz})$ : 7.60(brs, $\left.2 \mathrm{H}, o-\mathrm{C}_{6} \mathrm{H}_{4}\right), 7.28$ (brs, $\left.2 \mathrm{H}, m-\mathrm{C}_{6} \mathrm{H}_{4}\right), 4.81$ (brs, $2 \mathrm{H}, \mathrm{CH}_{2}$ syn), 4.2(br, 4H, P- $\left.\mathrm{CH}_{2}\right), 3.86\left(\mathrm{brs}, 1 \mathrm{H}, \mathrm{CHS}_{2}\right), 2.74\left(\mathrm{~d}, 8.1, J_{\mathrm{Pt}-\mathrm{H}}=41.3 \mathrm{~Hz}, \mathrm{CH}_{2}\right.$ anti), 1.44(brm, 37H, ${ }^{t} \mathrm{Bu}$ and $\left.\mathrm{CH}\right), 0.93\left(\mathrm{brm}, 2 \mathrm{H},{ }^{c} \mathrm{Pr}\right), 0.87\left(\mathrm{brm}, 2 \mathrm{H},{ }^{c} \mathrm{Pr}\right) .{ }^{13} \mathrm{C}\left\{{ }^{1} \mathrm{H}\right\} \mathrm{NMR}$ $\left(\delta, d_{6}\right.$-acetone, $\left.125 \mathrm{MHz}\right): 136.4\left(\mathrm{brs}, i-\mathrm{C}_{6} \mathrm{H}_{4}\right), 134.2\left(\mathrm{brs}, o-\mathrm{C}_{6} \mathrm{H}_{4}\right), 128.0\left(\mathrm{~s}, m-\mathrm{C}_{6} \mathrm{H}_{4}\right)$, $126.4\left(\mathrm{~s},{ }^{1} J_{\mathrm{Pt}-\mathrm{C}}=44.5 \mathrm{~Hz}, \mathrm{CR}_{2}{ }^{c} \mathrm{Pr}\right), 122.2\left(\mathrm{q},{ }^{1} J_{\mathrm{F}-\mathrm{C}}=325.4 \mathrm{~Hz}, \mathrm{CF}_{3}\right), 59.1\left(\mathrm{~m}, J_{\mathrm{P}-\mathrm{C}}=\right.$ $\left.30.2,-2.1, J_{\mathrm{P}-\mathrm{P}}=11.2,{ }^{1} J_{\mathrm{Pt}-\mathrm{C}}=79.8 \mathrm{~Hz}, \mathrm{CH}_{2}\right), 55.3\left(\mathrm{sept}, J_{\mathrm{F}-\mathrm{C}}=1.2 \mathrm{~Hz}, \mathrm{CS}_{2}\right), 40.2(\mathrm{brs}$, $\left.\mathrm{P}-\mathrm{CH}_{2}\right), 39.4\left(\right.$ brs, $\left.\mathrm{P}-\mathrm{CR}_{3}\right), 30.8\left(\right.$ brs, $\left.\mathrm{CH}_{3}\right), 15.6\left(\mathrm{~s}, J_{\mathrm{Pt}-\mathrm{C}}=24.9 \mathrm{~Hz}, \mathrm{CH}\right), 8.9$ (brs, $\left.{ }^{c} \mathrm{Pr}\right)$. ${ }^{31} \mathrm{P}\left\{{ }^{1} \mathrm{H}\right\} \operatorname{NMR}\left(\delta, d_{6}\right.$-acetone, $\left.121 \mathrm{MHz}\right): 33.9\left(\mathrm{brs},{ }^{1} J_{\mathrm{Pt}-\mathrm{P}}=3632 \mathrm{~Hz}\right), 32.1\left(\mathrm{brs},{ }^{1} J_{\mathrm{Pt}-\mathrm{P}}\right.$ $=3647 \mathrm{~Hz}) \cdot{ }^{19} \mathrm{~F} \operatorname{NMR}\left(\delta, d_{6^{-}}\right.$acetone, $\left.282 \mathrm{MHz}\right):-81.6(\mathrm{brs}) . \quad \mathrm{m} / z=\left[\mathrm{M}^{+}\right.$calcd for $\mathrm{C}_{30} \mathrm{H}_{53} \mathrm{P}_{2}^{194} \mathrm{Pt} 670.3268$; found 670.3256 .

\section{Synthesis of $\quad\left[\mathrm{Pt}\left(\eta^{3}-\mathrm{CH}_{2} \mathrm{CMeCH}_{2}\right)(\mathrm{dbpx})\right]\left[\mathrm{HC}\left(\mathrm{SO}_{2} \mathrm{CF}_{3}\right)_{2}\right]$ $18 \mathrm{a}\left[\mathrm{HC}\left(\mathrm{SO}_{2} \mathrm{CF}_{3}\right)_{2}\right]$ and $\quad\left[\mathrm{Pt}\left(\eta^{3}-\mathrm{CH}_{2} \mathrm{CHCHMe}\right)(\mathrm{dbpx})\right]\left[\mathrm{HC}\left(\mathrm{SO}_{2} \mathrm{CF}_{3}\right)_{2}\right]$ $18 \mathrm{~b}\left[\mathrm{HC}\left(\mathrm{SO}_{2} \mathrm{CF}_{3}\right)_{2}\right]$}

$\left[\mathrm{Pt}\left(\mathrm{C}_{2} \mathrm{H}_{4}\right)(\mathrm{dbpx})\right](30 \mathrm{mg}, 0.049 \mathrm{mmol})$ was placed in an NMR tube and $\mathrm{C}_{6} \mathrm{D}_{6}(0.5 \mathrm{~mL})$ added. $\mathrm{MCP}\left(0.08 \mathrm{~mL}\right.$ of a $1.85 \mathrm{mmol} / \mathrm{mL}$ sh in $\mathrm{C}_{6} \mathrm{D}_{6}, 0.14 \mathrm{mmol}, 3$ eq.) was added, and the solution heated at $60^{\circ} \mathrm{C}$ for 4 days, forming $[\operatorname{Pt}(\mathrm{MCP})(\mathrm{dbpx})]$ in an $83 \%$ yield by ${ }^{31} \mathrm{P}\left\{{ }^{1} \mathrm{H}\right\}$ NMR. The solution was dried in vacuo and a solution of $\mathrm{H}_{2} \mathrm{C}\left(\mathrm{SO}_{2} \mathrm{CF}_{3}\right)_{2}(14 \mathrm{mg}, 0.049 \mathrm{mmol})$ in $d_{6}$-acetone $(0.5 \mathrm{~mL})$ added, resulting in the immediate formation of $\left[\mathrm{Pt}\left(\eta^{3}-\mathrm{CH}_{2} \mathrm{CMeCH}_{2}\right)(\mathrm{dbpx})\right]\left[\mathrm{HC}\left(\mathrm{SO}_{2} \mathrm{CF}_{3}\right)_{2}\right]$ and $\left[\mathrm{Pt}\left(\eta^{3}-\mathrm{CH}_{2} \mathrm{CHCHMe}\right)(\mathrm{dbpx})\right]\left[\mathrm{HC}\left(\mathrm{SO}_{2} \mathrm{CF}_{3}\right)_{2}\right]$ in a $58: 42$ ratio. $\quad\left[\mathbf{P t}\left(\eta^{\mathbf{3}} \mathbf{-}\right.\right.$ $\left.\left.\mathrm{CH}_{2} \mathrm{CMeCH}_{2}\right)(\mathrm{dbpx})\right]\left[\mathrm{HC}\left(\mathrm{SO}_{2} \mathrm{CF}_{3}\right)_{2}\right] \quad 18 \mathrm{a}\left[\mathrm{HC}\left(\mathrm{SO}_{2} \mathrm{CF}_{3}\right)_{2}\right]: \quad{ }^{1} \mathrm{H} \quad \mathrm{NMR} \quad\left(\delta, d_{6^{-}}\right.$ acetone, $600 \mathrm{MHz})$ : 7.60(brs, 2H, o- $\left.\mathrm{C}_{6} \mathrm{H}_{4}\right), 7.28\left(\mathrm{brs}, 2 \mathrm{H}, m-\mathrm{C}_{6} \mathrm{H}_{4}\right), 4.88\left(\mathrm{brs}, 2 \mathrm{H}, \mathrm{CH}_{2}\right.$ syn), 4.2(br, $\left.4 \mathrm{H}, \mathrm{P}-\mathrm{CH}_{2}\right), 3.77\left(\mathrm{~s}, 1 \mathrm{H}, \mathrm{CHS}_{2}\right), 2.80\left(\mathrm{~d}, 8.4, J_{\mathrm{Pt}-\mathrm{H}}=39.4 \mathrm{~Hz}, \mathrm{CH}_{2}\right.$ anti), 1.45(brm, 39H, ${ }^{t} \mathrm{Bu}$ and $\left.\mathrm{CH}_{3}\right) .{ }^{13} \mathrm{C}\left\{{ }^{1} \mathrm{H}\right\} \operatorname{NMR}\left(\delta, d_{6}\right.$-acetone, $\left.150 \mathrm{MHz}\right):$ 136.4(brs, $\left.i-\mathrm{C}_{6} \mathrm{H}_{4}\right), 134.2\left(\mathrm{brs}, o-\mathrm{C}_{6} \mathrm{H}_{4}\right), 128.1\left(\mathrm{~s}, m-\mathrm{C}_{6} \mathrm{H}_{4}\right), 127.9\left(\mathrm{~m},{ }^{1} J_{\mathrm{Pt}-\mathrm{C}}=56.7 \mathrm{~Hz}, \mathrm{CR}_{2} \mathrm{Me}\right)$, $122.2\left(\mathrm{q},{ }^{1} J_{\mathrm{F}-\mathrm{C}}=326.0 \mathrm{~Hz}, \mathrm{CF}_{3}\right), 63.3\left(\mathrm{~m}, \mathrm{CH}_{2}\right), 55.3\left(\mathrm{~m}, \mathrm{CS}_{2}\right), 40.7\left(\mathrm{brs}, \mathrm{P}-\mathrm{CR}_{3}\right)$, 
40.2(brs, $\left.\mathrm{P}-\mathrm{CH}_{2}\right), 30.8\left(\right.$ brs, $\left.\mathrm{CH}_{3}\right), 21.6\left(\mathrm{~s}, J_{\mathrm{Pt}-\mathrm{C}}=28.4 \mathrm{~Hz}, \mathrm{CH}\right) .{ }^{31} \mathrm{P}\left\{{ }^{1} \mathrm{H}\right\} \operatorname{NMR}\left(\delta, d_{6^{-}}\right.$ acetone, $121 \mathrm{MHz})$ : 33.9(brs, $\left.{ }^{1} J_{\mathrm{Pt}-\mathrm{P}}=3572 \mathrm{~Hz}\right), 32.4\left(\mathrm{brs},{ }^{1} J_{\mathrm{Pt}-\mathrm{P}}=3641 \mathrm{~Hz}\right) .{ }^{19} \mathrm{~F} \mathrm{NMR}$ $\left(\delta, d_{6}\right.$-acetone, $\left.282 \mathrm{MHz}\right):-81.81(\mathrm{~s}) \cdot\left[\mathbf{P t}\left(\eta^{\mathbf{3}}-\mathbf{C H}_{\mathbf{2}} \mathbf{C H C H M e}\right)(\mathbf{d b p x})\right]\left[\mathbf{H C}\left(\mathbf{S O}_{\mathbf{2}} \mathbf{C F}_{\mathbf{3}}\right)_{\mathbf{2}}\right]$ $\mathbf{1 8 b}\left[\mathbf{H C}\left(\mathbf{S O}_{\mathbf{2}} \mathbf{C F}_{\mathbf{3}}\right)_{\mathbf{2}}\right]:{ }^{1} \mathrm{H} \mathrm{NMR}\left(\delta, d_{6}\right.$-acetone, $\left.600 \mathrm{MHz}\right): 7.60\left(\mathrm{~m}, 2 \mathrm{H}, o-\mathrm{C}_{6} \mathrm{H}_{4}\right), 7.28(\mathrm{~m}$, $\left.2 \mathrm{H}, m-\mathrm{C}_{6} \mathrm{H}_{4}\right), 6.28(\mathrm{brs}, 1 \mathrm{H}, \mathrm{CHMe}), 5.04\left(\mathrm{dt}, 12.2,7.5 \mathrm{~Hz}, J_{\mathrm{Pt}-\mathrm{H}}=51.9 \mathrm{~Hz}, 1 \mathrm{H}, \mathrm{CH}\right)$, 4.53(m, $1 \mathrm{H}, \mathrm{CH}_{2}$ syn), 4.2(br, 4H, $\left.\mathrm{P}-\mathrm{CH}_{2}\right), 3.77$ (brs, $\left.1 \mathrm{H}, \mathrm{CHS}_{2}\right), 2.86(\mathrm{ddd}, 11.1,10.0$, 2.2, $J_{\mathrm{Pt}-\mathrm{H}}=34.4 \mathrm{~Hz}, \mathrm{CH}_{2}$ anti $), 1.45\left(\mathrm{brm}, 39 \mathrm{H},{ }^{t} \mathrm{Bu}\right.$ and $\left.\mathrm{CH}_{3}\right) .{ }^{13} \mathrm{C}\left\{{ }^{1} \mathrm{H}\right\} \operatorname{NMR}\left(\delta, d_{6^{-}}\right.$ acetone, $150 \mathrm{MHz})$ : 136.4(brs, $\left.i-\mathrm{C}_{6} \mathrm{H}_{4}\right), 134.1\left(\mathrm{brs}, o-\mathrm{C}_{6} \mathrm{H}_{4}\right), 128.1\left(\mathrm{~s}, m-\mathrm{C}_{6} \mathrm{H}_{4}\right), 122.2(\mathrm{q}$, $\left.{ }^{1} J_{\mathrm{F}-\mathrm{C}}=326.0 \mathrm{~Hz}, \mathrm{CF}_{3}\right), 106.8(\mathrm{brs}, \mathrm{CH}), 84.6\left(\mathrm{brd}, 22.0,{ }^{1} J_{\mathrm{Pt}-\mathrm{C}}=63.7 \mathrm{~Hz}, \mathrm{CHMe}\right)$, 55.3(m, $\left.\mathrm{CS}_{2}\right), 51.7\left(\mathrm{brd}, 32.4,{ }^{1} J_{\mathrm{Pt}-\mathrm{C}}=106.9 \mathrm{~Hz}, \mathrm{CH}_{2}\right), 40.1\left(\mathrm{brs}, \mathrm{P}-\mathrm{CH}_{2}\right), 39.4($ brs, $\left.\mathrm{P}-\mathrm{CR}_{3}\right), 30.9\left(\mathrm{dd}, 13.9,3.5 \mathrm{~Hz}, \mathrm{CH}_{3}\right), 30.3\left(\mathrm{~d}, 2.9, J_{\mathrm{Pt}-\mathrm{C}}=15 \mathrm{~Hz}, \mathrm{CH}_{3}\right), 16.5\left(\mathrm{brs}, J_{\mathrm{Pt}-\mathrm{C}}\right.$ $=14.5 \mathrm{~Hz}, \mathrm{CH}) .{ }^{31} \mathrm{P}\left\{{ }^{1} \mathrm{H}\right\} \operatorname{NMR}\left(\delta, d_{6}\right.$-acetone, $\left.121 \mathrm{MHz}\right): 36.9\left(\mathrm{~d},{ }^{1} J_{\mathrm{Pt}-\mathrm{P}}=3844 \mathrm{~Hz}\right)$. ${ }^{19} \mathrm{~F} \operatorname{NMR}\left(\delta, d_{6}\right.$-acetone, $\left.282 \mathrm{MHz}\right):-81.81(\mathrm{~s}) . m / z=\left[\mathrm{M}^{+}\right.$calcd for $\mathrm{C}_{28} \mathrm{H}_{51} \mathrm{P}_{2}{ }^{194} \mathrm{Pt}$ 643.3093; found 643.3089.

\subsection{Chapter Four Experimental}

\section{Synthesis of $\left[\operatorname{PtEt}\left(\mathrm{C}\left(\mathrm{CH}_{2}\right)_{2} \mathrm{CH}_{3}\right)(\mathrm{COD})\right] 27 \mathrm{a}$ and $\left[\mathrm{Pt}\left(\mathrm{C}\left(\mathrm{CH}_{2}\right)_{2} \mathrm{CH}_{3}\right)_{2}(\mathrm{COD})\right] 27 \mathrm{~b}$}

$\left[\mathrm{PtEt}_{2}(\mathrm{COD})\right]$ (20 mg, $\left.0.055 \mathrm{mmol}\right)$ was placed in an NMR tube and MCP $(0.51 \mathrm{~mL}$ of

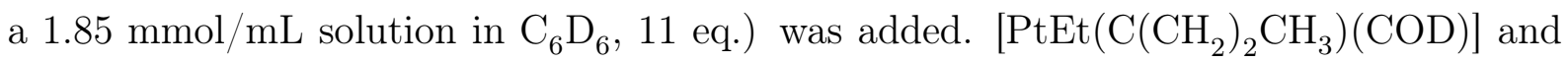
$\left[\mathrm{Pt}\left(\mathrm{C}\left(\mathrm{CH}_{2}\right)_{2} \mathrm{CH}_{3}\right)_{2}(\mathrm{COD})\right]$ began to form after two hours, ending in a 15:85 ratio by ${ }^{1} \mathrm{H}$ NMR after 30 days. $\left[\operatorname{PtEt}\left(\mathbf{C}\left(\mathbf{C H}_{\mathbf{2}}\right)_{\mathbf{2}} \mathbf{C H}_{\mathbf{3}}\right)(\mathbf{C O D})\right] \mathbf{2 7 a :}{ }^{1} \mathrm{H} \mathrm{NMR}\left(\delta, \mathrm{C}_{6} \mathrm{D}_{6}, 600 \mathrm{MHz}\right)$ : $4.82\left(\mathrm{brs}, J_{\mathrm{Pt}-\mathrm{H}}=33.8 \mathrm{~Hz}, 2 \mathrm{H},=\mathrm{CH}\right), 4.64\left(\mathrm{brs}, J_{\mathrm{Pt}-\mathrm{H}}=34.4 \mathrm{~Hz}, 2 \mathrm{H},=\mathrm{CH}\right), 1.96(\mathrm{q}, 7.8$, $\left.J_{\mathrm{Pt}-\mathrm{H}}=91.8 \mathrm{~Hz}, 2 \mathrm{H}, \mathrm{Et} \mathrm{CH}_{2}\right), 1.85-1.75\left(\mathrm{~m}, 8 \mathrm{H}, \mathrm{COD} \mathrm{CH}_{2}\right), 1.51\left(\mathrm{t}, 7.7, J_{\mathrm{Pt}-\mathrm{H}}=74.4 \mathrm{~Hz}\right.$, $3 \mathrm{H}$, Et $\left.\mathrm{CH}_{3}\right), 1.35\left(\mathrm{~s}, J_{\mathrm{Pt}-\mathrm{H}}=55.9 \mathrm{~Hz}, 3 \mathrm{H}, \mathrm{MCP} \mathrm{CH}_{3}\right), 0.73\left(\mathrm{~m}, J_{\mathrm{Pt}-\mathrm{H}}=66.2 \mathrm{~Hz}, 2 \mathrm{H}\right.$, $\left.{ }^{c} \mathrm{Pr}\right), 0.42\left(\mathrm{~m}, J_{\mathrm{Pt}-\mathrm{H}}=46.5 \mathrm{~Hz}, 2 \mathrm{H},{ }^{c} \mathrm{Pr}\right) .{ }^{13} \mathrm{C}\left\{{ }^{1} \mathrm{H}\right\} \operatorname{NMR}\left(\delta, \mathrm{C}_{6} \mathrm{D}_{6} / d_{6}\right.$-acetone, $\left.150 \mathrm{MHz}\right)$ : $101.8\left(\mathrm{~s}, J_{\mathrm{Pt}-\mathrm{C}}=46.7 \mathrm{~Hz},=\mathrm{CH}\right), 98.9\left(\mathrm{~s}, J_{\mathrm{Pt}-\mathrm{C}}=54.2 \mathrm{~Hz},=\mathrm{CH}\right), 31.2\left(\mathrm{~s}, J_{\mathrm{Pt}-\mathrm{C}}=21.3 \mathrm{~Hz}\right.$, MCP $\left.\mathrm{CH}_{3}\right), 29.8\left(\mathrm{~s}, \mathrm{COD} \mathrm{CH}_{2}\right), 29.3\left(\mathrm{~s}, \mathrm{COD} \mathrm{CH}_{2}\right), 21.8\left(\mathrm{~s}, J_{\mathrm{Pt}-\mathrm{C}}=854.8 \mathrm{~Hz}, \mathrm{Et} \mathrm{CH}_{2}\right)$, 
$17.4\left(\mathrm{~s}, J_{\mathrm{Pt}-\mathrm{C}}=1160.6 \mathrm{~Hz}, \mathrm{MCP} \mathrm{Pt}-\mathrm{C}\right), 16.4\left(\mathrm{~s}, J_{\mathrm{Pt}-\mathrm{C}}=35.2 \mathrm{~Hz}, \mathrm{Et} \mathrm{CH}_{3}\right), 14.9\left(\mathrm{~s},{ }^{c} \mathrm{Pr}\right)$. $\left[\operatorname{Pt}\left(\mathbf{C}\left(\mathbf{C H}_{\mathbf{2}}\right)_{\mathbf{2}} \mathbf{C H}_{\mathbf{3}}\right)_{\mathbf{2}}(\mathbf{C O D})\right] \mathbf{2 7 b}:{ }^{1} \mathrm{H} \mathrm{NMR}\left(\delta, \mathrm{C}_{6} \mathrm{D}_{6}, 600 \mathrm{MHz}\right): 4.82\left(\mathrm{brs}, J_{\mathrm{Pt}-\mathrm{H}}=\right.$ $33.8 \mathrm{~Hz}, 4 \mathrm{H},=\mathrm{CH}), 1.85-1.75\left(\mathrm{~m}, 8 \mathrm{H}, \mathrm{COD} \mathrm{CH}_{2}\right), 1.41\left(\mathrm{~s}, J_{\mathrm{Pt}-\mathrm{H}}=53.5 \mathrm{~Hz}, 3 \mathrm{H}, \mathrm{MCP}\right.$ $\left.\mathrm{CH}_{3}\right), 0.86\left(\mathrm{t}, 4.2, J_{\mathrm{Pt}-\mathrm{H}}=66.2 \mathrm{~Hz}, 2 \mathrm{H},{ }^{c} \mathrm{Pr}\right), 0.41\left(\mathrm{~m}, J_{\mathrm{Pt}-\mathrm{H}}=44.4 \mathrm{~Hz}, 2 \mathrm{H},{ }^{c} \mathrm{Pr}\right) .{ }^{13} \mathrm{C}\left\{{ }^{1} \mathrm{H}\right\}$ $\operatorname{NMR}\left(\delta, \mathrm{C}_{6} \mathrm{D}_{6} / d_{6}\right.$-acetone, $\left.150 \mathrm{MHz}\right): 102.0\left(\mathrm{~s}, J_{\mathrm{Pt}-\mathrm{C}}=43.7 \mathrm{~Hz},=\mathrm{CH}\right), 31.5\left(\mathrm{~s}, J_{\mathrm{Pt}-\mathrm{C}}=\right.$ $\left.21.3 \mathrm{~Hz}, \mathrm{MCP} \mathrm{CH}_{3}\right), 29.3\left(\mathrm{~s}, \mathrm{COD} \mathrm{CH}_{2}\right), 17.2\left(\mathrm{~s}, J_{\mathrm{Pt}-\mathrm{C}}=1178.5 \mathrm{~Hz}, \mathrm{MCP} \mathrm{Pt}-\mathrm{C}\right), 15.9(\mathrm{~s}$, $\left.{ }^{c} \operatorname{Pr}\right)$.

\section{Synthesis of trans- $\left[\mathrm{PtCl}_{2}(\mathrm{BCP})(\mathrm{Py})\right] 28$}

$\left[\mathrm{Pt}_{2} \mathrm{Cl}_{4}\left(\mathrm{C}_{2} \mathrm{H}_{4}\right)_{2}\right](50 \mathrm{mg}, 0.085 \mathrm{mmol})$ was placed in an NMR tube and $\mathrm{CDCl}_{3}(0.5 \mathrm{~mL})$ added. Pyridine $(14 \mu \mathrm{L}, 0.085 \mathrm{mmol})$ and carbon-13 enriched BCP $(0.14 \mathrm{~mL}$ of a $0.62 \mathrm{mmol} / \mathrm{mL}$ sh in $\mathrm{C}_{6} \mathrm{D}_{6}, 0.085 \mathrm{mmol}, 1$ eq.) were added, resulting in the immediate formation of trans $-\left[\mathrm{PtCl}_{2}(\mathrm{BCP})(\mathrm{Py})\right]$. Reaction is quantitative by ${ }^{1} \mathrm{H} \mathrm{NMR} .{ }^{1} \mathrm{H} \mathrm{NMR}(\delta$, $\left.\mathrm{CDCl}_{3}, 300 \mathrm{MHz}\right): 8.92(\mathrm{dd}, 6.6,1.3,2 \mathrm{H}, o-\mathrm{H} \mathrm{Py}), 7.89(\mathrm{tt}, 7.8,1.5,1 \mathrm{H}, p-\mathrm{H} \mathrm{Py}), 7.47(\mathrm{td}$, $6.6,1.5,2 \mathrm{H}, m-\mathrm{H} \mathrm{Py}), 1.58\left(\mathrm{t}, 7.0, J_{\mathrm{Pt}-\mathrm{H}}=45.8 \mathrm{~Hz}, 4 \mathrm{H},{ }^{c} \mathrm{Pr}-\right.$ endo $), 1.12\left(\mathrm{t}, 7.5, J_{\mathrm{Pt}-\mathrm{H}}\right.$ $=29.9 \mathrm{~Hz}, 4 \mathrm{H},{ }^{c} \operatorname{Pr}-$ exo $) \cdot{ }^{13} \mathrm{C}\left\{{ }^{1} \mathrm{H}\right\} \operatorname{NMR}\left(\delta, \mathrm{C}_{6} \mathrm{D}_{6} / \mathrm{CDCl}_{3}, 150 \mathrm{MHz}\right): 151.6(\mathrm{~s}, o-\mathrm{C} \mathrm{Py})$, 140.1(s, $p$-C Py), 125.5(s, m-C Py), 75.3(s, $\left.{ }^{1} J_{\mathrm{Pt}-\mathrm{C}}=248.5 \mathrm{~Hz},=\mathrm{CR}_{2}\right), 10.6\left(\mathrm{~s},{ }^{c} \mathrm{Pr}\right) . \mathrm{m} / z$ $=[\mathrm{M}+\mathrm{H}]^{+}$calcd for $\mathrm{C}_{11} \mathrm{H}_{14} \mathrm{Cl}_{2} \mathrm{~N}^{194} \mathrm{Pt}$ 424.0130; found 424.0136.

\section{Synthesis of trans-[PtCl $2(\mathrm{MCP})(\mathrm{Py})] 29$}

$\left[\mathrm{Pt}_{2} \mathrm{Cl}_{4}\left(\mathrm{C}_{2} \mathrm{H}_{4}\right)_{2}\right](50 \mathrm{mg}, 0.085 \mathrm{mmol})$ was placed in an $\mathrm{NMR}$ tube and $\mathrm{CDCl}_{3}(0.5 \mathrm{~mL})$ added. Pyridine $(14 \mu \mathrm{L}, 0.085 \mathrm{mmol})$ and $\mathrm{MCP}(0.09 \mathrm{~mL}$ of a $0.92 \mathrm{mmol} / \mathrm{mL}$ sln in $\mathrm{CDCl}_{3}, 0.085 \mathrm{mmol}, 1$ eq.) were added, resulting in the immediate formation of trans$\left[\mathrm{PtCl}_{2}(\mathrm{MCP})(\mathrm{Py})\right]$. Reaction is quantitative by ${ }^{1} \mathrm{H}$ NMR. ${ }^{1} \mathrm{H} \mathrm{NMR}\left(\delta, \mathrm{CDCl}_{3}, 300 \mathrm{MHz}\right)$ : $8.92\left(\mathrm{~d}, 5.2, J_{\mathrm{Pt}-\mathrm{H}}=33.6 \mathrm{~Hz}, 2 \mathrm{H}, o-\mathrm{H} \mathrm{Py}\right), 7.93(\mathrm{t}, 7.6,1 \mathrm{H}, p-\mathrm{H} \mathrm{Py}), 7.51(\mathrm{t}, 7.0,2 \mathrm{H}$, $m$-H Py), 5.02(brs, $\left.2 \mathrm{H},=\mathrm{CH}_{2}\right), 1.63\left(\mathrm{brs}, 2 \mathrm{H},{ }^{c} \mathrm{Pr}\right), 1.32\left(\mathrm{brs}, 2 \mathrm{H},{ }^{c} \mathrm{Pr}\right) .{ }^{13} \mathrm{C}\left\{{ }^{1} \mathrm{H}\right\} \operatorname{NMR}(\delta$, $\left.\mathrm{CDCl}_{3}, 150 \mathrm{MHz}\right):$ 151.6(s, o-C Py), 140.2(s, p-C Py), 125.5(s, m-C Py), 91.6(brs, = $\mathrm{CR}_{2}$ ), $59.8\left(\mathrm{brs},=\mathrm{CH}_{2}\right), 10.2\left(\mathrm{~s},{ }^{c} \mathrm{Pr}\right) . \quad m / z=[\mathrm{M}-\mathrm{Cl}]^{+}$calcd for $\mathrm{C}_{9} \mathrm{H}_{11} \mathrm{ClN}^{194} \mathrm{Pt} 358.0185$; found 358.0179 . 


\section{Synthesis of $c i s-\left[\mathrm{PtCl}_{2}(\mathrm{BCP})(\mathrm{DMSO})\right] 30$}

cis- $-\left[\mathrm{PtCl}_{2}(\mathrm{DMSO})_{2}\right](10 \mathrm{mg}, 0.024 \mathrm{mmol})$ was placed in an NMR tube and $\mathrm{CDCl}_{3}$ $(0.5 \mathrm{~mL})$ added. $\mathrm{BCP}\left(0.04 \mathrm{~mL}\right.$ of a $0.62 \mathrm{mmol} / \mathrm{mL}$ solution in $\left.\mathrm{C}_{6} \mathrm{D}_{6}, 0.024 \mathrm{mmol}\right)$ was added, resulting in the formation of $c i s-\left[\mathrm{PtCl}_{2}(\mathrm{BCP})(\mathrm{DMSO})\right]$ after $1 \mathrm{hr}$. Due to the limited solubility of cis- $\left[\mathrm{PtCl}_{2}(\mathrm{DMSO})_{2}\right]$ in $\mathrm{CDCl}_{3}$, a yield could not be obtained. ${ }^{1} \mathrm{H}$ $\operatorname{NMR}\left(\delta, \mathrm{CDCl}_{3}, 600 \mathrm{MHz}\right): 3.53\left(\mathrm{~s}, J_{\mathrm{Pt}-\mathrm{H}}=21.2 \mathrm{~Hz}, 3 \mathrm{H}, \mathrm{S}-\mathrm{CH}_{3}\right), 1.25\left(\mathrm{~m}, 4 \mathrm{H},{ }^{c} \mathrm{Pr}\right)$, $0.85\left(\mathrm{~m}, 4 \mathrm{H},{ }^{c} \mathrm{Pr}\right) .{ }^{13} \mathrm{C}\left\{{ }^{1} \mathrm{H}\right\} \operatorname{NMR}\left(\delta, \mathrm{C}_{6} \mathrm{D}_{6} / \mathrm{CDCl}_{3}, 150 \mathrm{MHz}\right): 82.2\left(\mathrm{~s},{ }^{1} J_{\mathrm{Pt}-\mathrm{C}}=251.8 \mathrm{~Hz}\right.$, $\left.=\mathrm{CR}_{2}\right), 44.6\left(\mathrm{~s}, \mathrm{~S}-\mathrm{CH}_{3}\right), 12.5\left(\mathrm{~s},{ }^{c} \mathrm{Pr}\right), 11.5\left(\mathrm{~s},{ }^{c} \mathrm{Pr}\right)$.

\section{Synthesis of cis-[PtCl $(\mathrm{MCP})(\mathrm{DMSO})] 31$}

cis- $\left[\mathrm{PtCl}_{2}(\mathrm{DMSO})_{2}\right](20 \mathrm{mg}, 0.047 \mathrm{mmol})$ was placed in an NMR tube and $\mathrm{CDCl}_{3}$ $(0.5 \mathrm{~mL})$ added. $\mathrm{MCP}\left(0.05 \mathrm{~mL}\right.$ of a $0.92 \mathrm{mmol} / \mathrm{mL}$ solution in $\left.\mathrm{CDCl}_{3}, 0.046 \mathrm{mmol}\right)$ was added, resulting in the immediate formation of $c i s-\left[\mathrm{PtCl}_{2}(\mathrm{MCP})(\mathrm{DMSO})\right]$. Due to the limited solubility of cis- $\left[\mathrm{PtCl}_{2}(\mathrm{DMSO})_{2}\right]$ in $\mathrm{CDCl}_{3}$, a yield could not be obtained. ${ }^{1} \mathrm{H} \mathrm{NMR}\left(\delta, \mathrm{CDCl}_{3}, 600 \mathrm{MHz}\right): 4.81\left(\mathrm{~s}, J_{\mathrm{Pt}-\mathrm{H}}=67.5 \mathrm{~Hz}, 1 \mathrm{H},=\mathrm{CH}_{2}\right), 4.64\left(\mathrm{~s}, J_{\mathrm{Pt}-\mathrm{H}}=\right.$ $\left.63.1 \mathrm{~Hz}, 1 \mathrm{H},=\mathrm{CH}_{2}\right), 3.59\left(\mathrm{~s}, J_{\mathrm{Pt}-\mathrm{H}}=16.5 \mathrm{~Hz}, 3 \mathrm{H}, \mathrm{S}-\mathrm{CH}_{3}\right), 3.45\left(\mathrm{~s}, J_{\mathrm{Pt}-\mathrm{H}}=14.8 \mathrm{~Hz}, 3 \mathrm{H}\right.$, $\left.\mathrm{S}-\mathrm{CH}_{3}\right), 1.88\left(\mathrm{dt}, 12.0,8.3,1 \mathrm{H},{ }^{c} \mathrm{Pr}\right), 1.55\left(\mathrm{dt}, 12.0,8.3,1 \mathrm{H},{ }^{c} \mathrm{Pr}\right), 1.38(\mathrm{dt}, 9.4,8.0,1 \mathrm{H}$, $\left.{ }^{c} \mathrm{Pr}\right), 1.28\left(\mathrm{td}, 9.4,8.0,1 \mathrm{H},{ }^{c} \mathrm{Pr}\right) .{ }^{13} \mathrm{C}\left\{{ }^{1} \mathrm{H}\right\} \mathrm{NMR}\left(\delta, \mathrm{CDCl}_{3}, 150 \mathrm{MHz}\right): 97.3\left(\mathrm{~s},{ }^{1} J_{\mathrm{Pt}-\mathrm{C}}=\right.$ $\left.277.5 \mathrm{~Hz},=\mathrm{CR}_{2}\right), 67.5\left(\mathrm{~s},{ }^{1} J_{\mathrm{Pt}-\mathrm{C}}=141.0 \mathrm{~Hz},=\mathrm{CH}_{2}\right), 45.5\left(\mathrm{~s},{ }^{1} J_{\mathrm{Pt}-\mathrm{C}}=47.9 \mathrm{~Hz}, \mathrm{~S}-\mathrm{CH}_{3}\right)$, $44.2\left(\mathrm{~s},{ }^{1} J_{\mathrm{Pt}-\mathrm{C}}=44.0 \mathrm{~Hz}, \mathrm{~S}-\mathrm{CH}_{3}\right), 12.6\left(\mathrm{~s},{ }^{c} \mathrm{Pr}\right), 11.0\left(\mathrm{~s},{ }^{c} \mathrm{Pr}\right)$.

\section{Synthesis of trans- $\left[\mathrm{Pt}\left(\mathrm{C}\left(\mathrm{CH}_{2}\right)_{2} \mathrm{C}\left(\mathrm{CH}_{2}\right)_{2} \mathrm{Cl}\right) \mathrm{Cl}\left(\mathrm{SEt}_{2}\right)_{2}\right] 32$}

$\left[\mathrm{PtCl}_{2}\left(\mathrm{SEt}_{2}\right)_{2}\right] \quad(50 \mathrm{mg}, 0.11 \mathrm{mmol})$ was placed in an NMR tube and $\mathrm{CDCl}_{3}$ $(0.5 \mathrm{~mL})$ added. BCP $(0.05 \mathrm{~mL}, 0.53 \mathrm{mmol})$ was added. After 2 days, trans$\mathrm{Pt}\left(\mathrm{C}\left(\mathrm{CH}_{2}\right)_{2} \mathrm{C}\left(\mathrm{CH}_{2}\right)_{2} \mathrm{Cl}\right) \mathrm{Cl}\left(\mathrm{SEt}_{2}\right)_{2}$ ] formed. Reaction is quantitative by ${ }^{1} \mathrm{H} \mathrm{NMR} .{ }^{1} \mathrm{H}$ $\operatorname{NMR}\left(\delta, \mathrm{CDCl}_{3}, 500 \mathrm{MHz}\right): 3.3-2.9\left(\right.$ brs, $\left.8 \mathrm{H}, \mathrm{S}-\mathrm{CH}_{2}\right), 1.37\left(\mathrm{t}, 15 \mathrm{~Hz}, 12 \mathrm{H}, \mathrm{CH}_{3}\right), 0.83(\mathrm{t}$, $\left.7.0 \mathrm{~Hz}, 2 \mathrm{H}, \mathrm{Cl}{ }^{c} \mathrm{Pr}\right), 0.77\left(\mathrm{t}, 7.0 \mathrm{~Hz}, 2 \mathrm{H}, \mathrm{Cl}{ }^{c} \mathrm{Pr}\right), 0.36\left(\mathrm{t}, 5.0, J_{\mathrm{Pt}-\mathrm{H}}=29.4 \mathrm{~Hz}, 2 \mathrm{H}, \mathrm{Pt}\right.$ ${ }^{c} \operatorname{Pr}$-exo $), 0.21\left(\mathrm{t}, 5.0, J_{\mathrm{Pt}-\mathrm{H}}=63.0 \mathrm{~Hz}, 2 \mathrm{H}, \mathrm{Pt}{ }^{c} \operatorname{Pr}-\right.$ endo $) .{ }^{13} \mathrm{C}\left\{{ }^{1} \mathrm{H}\right\} \mathrm{NMR}\left(\delta, \mathrm{CDCl}_{3}\right.$, $125 \mathrm{MHz}): 57.1(\mathrm{~s}, \mathrm{Cl}-\mathrm{C}), 32.2\left(\mathrm{~s}, J_{\mathrm{Pt}-\mathrm{C}}=17.7 \mathrm{~Hz}, \mathrm{~S}-\mathrm{CH}_{2}\right), 16.4\left(\mathrm{~s}, \mathrm{Pt}{ }^{c} \mathrm{Pr}\right), 14.3(\mathrm{~s}, \mathrm{Cl}$ 
$\left.{ }^{c} \operatorname{Pr}\right), 13.4\left(\mathrm{~s}, J_{\mathrm{Pt}-\mathrm{C}}=32.9 \mathrm{~Hz}, \mathrm{CH}_{3}\right),-0.4\left(\mathrm{~s}, J_{\mathrm{Pt}-\mathrm{C}}=1011 \mathrm{~Hz}, \mathrm{Pt}-\mathrm{C}\right) \cdot m / z=[\mathrm{M}-\mathrm{Cl}]^{+}$ calcd for $\mathrm{C}_{14} \mathrm{H}_{28} \mathrm{Cl}^{194} \mathrm{PtS}_{2}$ 489.0948; found 489.0949.

\section{Synthesis of trans $-\left[\mathrm{Pt}\left(\mathrm{C}\left(\mathrm{CH}_{2}\right)_{2} \mathrm{C}\left(\mathrm{CH}_{2}\right)_{2} \mathrm{Cl}\right) \mathrm{Cl}\left(\mathrm{NC}^{t} \mathrm{Bu}\right)_{2}\right] 33$}

trans $-\left[\mathrm{PtCl}_{2}\left(\mathrm{NC}^{t} \mathrm{Bu}\right)_{2}\right](10 \mathrm{mg}, 0.026 \mathrm{mmol})$ was was placed in an $\mathrm{NMR}$ tube and $\mathrm{CDCl}_{3}$ $(0.5 \mathrm{~mL})$ added. BCP $(2.4 \mu \mathrm{L}, 0.026 \mathrm{mmol})$ was added, resulting in the formation of trans $-\left[\mathrm{Pt}\left(\mathrm{C}\left(\mathrm{CH}_{2}\right)_{2} \mathrm{C}\left(\mathrm{CH}_{2}\right)_{2} \mathrm{Cl}\right) \mathrm{Cl}\left(\mathrm{NC}^{t} \mathrm{Bu}\right)_{2}\right]$ after 2 days. Reaction is quantitative by ${ }^{1} \mathrm{H}$ NMR. ${ }^{1} \mathrm{H} \mathrm{NMR}\left(\delta, \mathrm{CDCl}_{3}, 500 \mathrm{MHz}\right): 1.44\left(\mathrm{~s}, 18 \mathrm{H},{ }^{t} \mathrm{Bu}\right), 1.03\left(\mathrm{t}, 6.3 \mathrm{~Hz}, 2 \mathrm{H}, \mathrm{Cl}{ }^{c} \mathrm{Pr}\right)$, $0.73\left(\mathrm{t}, 6.3 \mathrm{~Hz}, 2 \mathrm{H}, \mathrm{Cl}{ }^{c} \mathrm{Pr}\right), 0.30\left(\mathrm{~m}, 4 \mathrm{H}, \mathrm{Pt}{ }^{c} \mathrm{Pr}\right) .{ }^{13} \mathrm{C}\left\{{ }^{1} \mathrm{H}\right\} \operatorname{NMR}\left(\delta, \mathrm{CDCl}_{3}, 125 \mathrm{MHz}\right)$ : $122.1\left(\mathrm{~s}, J_{\mathrm{Pt}-\mathrm{C}}=349 \mathrm{~Hz}, \mathrm{~N} \equiv \mathrm{C}\right), 55.2(\mathrm{~s}, \mathrm{Cl}-\mathrm{C}), 30.2\left(\mathrm{~s}, \mathrm{CR}_{3}\right), 27.9(\mathrm{~s}, \mathrm{Me}), 15.8\left(\mathrm{~s}, \mathrm{Cl}{ }^{c} \mathrm{Pr}\right)$, 14.7(s, Pt $\left.{ }^{c} \mathrm{Pr}\right), 0.0\left(\mathrm{~s}, J_{\mathrm{Pt}-\mathrm{C}}=953 \mathrm{~Hz}, \mathrm{Pt}-\mathrm{C}\right)$.

\section{Synthesis of trans-[Pt $\left.\left(\mathrm{C}\left(\mathrm{CH}_{2}\right)_{2} \mathrm{C}\left(\mathrm{CH}_{2}\right)_{2} \mathrm{Cl}\right) \mathrm{Cl}(\mathrm{Py})_{2}\right] 34 \mathrm{a}$}

trans $-\left[\mathrm{PtCl}_{2}(\mathrm{Py})_{2}\right](20 \mathrm{mg}, 0.047 \mathrm{mmol})$ was placed in an NMR tube and $\mathrm{CDCl}_{3}$ $(0.5 \mathrm{~mL})$ added. $\mathrm{BCP}(4.4 \mu \mathrm{L}, 0.047 \mathrm{mmol})$ was added. Overnight, trans$\left[\mathrm{Pt}\left(\mathrm{C}\left(\mathrm{CH}_{2}\right)_{2} \mathrm{C}\left(\mathrm{CH}_{2}\right)_{2} \mathrm{Cl}\right) \mathrm{Cl}(\mathrm{Py})_{2}\right]$ forms, ending up as $30 \%$ of the species in solution. ${ }^{1} \mathrm{H} \mathrm{NMR}\left(\delta, \mathrm{CDCl}_{3}, 600 \mathrm{MHz}\right): 9.04\left(\mathrm{dd}, 6.6,1.2, J_{\mathrm{Pt}-\mathrm{H}}=39.7 \mathrm{~Hz}, 4 \mathrm{H}, o-\mathrm{Py}\right), 7.41(\mathrm{tt}$, 7.9, $1.6 \mathrm{~Hz}, 2 \mathrm{H}, p-\mathrm{Py}), 6.98(\mathrm{td}, 6.6,0.9 \mathrm{~Hz}, 4 \mathrm{H}, m-\mathrm{Py}), 0.41\left(\mathrm{t}, 6.4 \mathrm{~Hz}, 2 \mathrm{H}, \mathrm{Cl}{ }^{c} \mathrm{Pr}-\right.$ exo $),-0.03\left(\mathrm{td}, 4.1,1.2, J_{\mathrm{Pt}-\mathrm{H}}=37.9 \mathrm{~Hz}, 2 \mathrm{H}, \operatorname{Pt}{ }^{c} \operatorname{Pr}-\right.$ exo $),-0.15\left(\mathrm{t}, 4.1,1.2, J_{\mathrm{Pt}-\mathrm{H}}=\right.$ $50.8 \mathrm{~Hz}, 2 \mathrm{H}, \mathrm{Pt}{ }^{c} \operatorname{Pr}-$ endo $),-0.25\left(\mathrm{t}, 6.4 \mathrm{~Hz}, 2 \mathrm{H}, \mathrm{Cl}{ }^{c} \operatorname{Pr}-e n d o\right) .{ }^{13} \mathrm{C}\left\{{ }^{1} \mathrm{H}\right\} \operatorname{NMR}\left(\delta, \mathrm{CDCl}_{3}\right.$, $150 \mathrm{MHz}): 153.7(\mathrm{~s}, o-\mathrm{Py}), 136.7(\mathrm{~s}, p-\mathrm{Py}), 124.9(\mathrm{~s}, m-\mathrm{Py}), 56.2(\mathrm{~s}, \mathrm{Cl}-\mathrm{C}), 13.1\left(\mathrm{~s}, \mathrm{Pt}{ }^{c} \mathrm{Pr}\right)$, $12.9\left(\mathrm{~s}, \mathrm{Cl}{ }^{c} \mathrm{Pr}\right), 1.1\left(\mathrm{~s}, J_{\mathrm{Pt}-\mathrm{C}}=1202 \mathrm{~Hz}, \mathrm{Pt}-\mathrm{C}\right)$.

\section{Synthesis of $c i s-\left[\mathrm{Pt}\left(\mathrm{C}\left(\mathrm{CH}_{2}\right)_{2} \mathrm{C}\left(\mathrm{CH}_{2}\right)_{2} \mathrm{Cl}\right) \mathrm{Cl}(\mathrm{Py})_{2}\right] 34 \mathrm{~b}$}

$\left[\mathrm{Pt}_{2} \mathrm{Cl}_{4}\left(\mathrm{C}_{2} \mathrm{H}_{4}\right)_{2}\right](20 \mathrm{mg}, 0.034 \mathrm{mmol})$ was placed in an $\mathrm{NMR}$ tube and $\mathrm{CDCl}_{3}(0.5 \mathrm{~mL})$ added. Pyridine $(11 \mu \mathrm{L}, 0.137 \mathrm{mmol}, 4$ eq.) and $\mathrm{BCP}(6.4 \mu \mathrm{L}, 0.068 \mathrm{mmol}, 2$ eq.) were added, resulting in the immediate formation of paritally soluble yellow cis$\left[\mathrm{Pt}\left(\mathrm{C}\left(\mathrm{CH}_{2}\right)_{2} \mathrm{C}\left(\mathrm{CH}_{2}\right)_{2} \mathrm{Cl}\right) \mathrm{Cl}(\mathrm{Py})_{2}\right]$. Reaction is quantitative by ${ }^{1} \mathrm{H} \mathrm{NMR}$. ${ }^{1} \mathrm{H} \mathrm{NMR}(\delta$, $\left.\mathrm{CDCl}_{3}, 500 \mathrm{MHz}\right): 9.46(\mathrm{~d}, 6.0 \mathrm{~Hz}, 2 \mathrm{H}, o-\mathrm{H}$ cis-Py), 8.87(d, $5.0 \mathrm{~Hz}, 2 \mathrm{H}, o-\mathrm{H}$ trans-Py), 
8.28(t, $8.0 \mathrm{~Hz}, 1 \mathrm{H}, p-\mathrm{H}$ cis-Py), 7.83(t, $7.5 \mathrm{~Hz}, 2 \mathrm{H}, m-\mathrm{H}$ cis-Py), 7.62(t, 8.0 Hz, 1H, $p-\mathrm{H}$ trans-Py), 7.18(t, $6.5 \mathrm{~Hz}, 2 \mathrm{H}, m-\mathrm{H}$ trans-Py), 1.34(t, $6.5 \mathrm{~Hz}, 2 \mathrm{H}, \mathrm{Cl}{ }^{c} \operatorname{Pr}-$ endo $), 1.05(\mathrm{t}$, $6.5 \mathrm{~Hz}, 2 \mathrm{H}, \mathrm{Cl}{ }^{c} \operatorname{Pr}-$ exo $), 0.50\left(\mathrm{t}, 4.8 \mathrm{~Hz}, 2 \mathrm{H}, \mathrm{Pt}{ }^{c} \operatorname{Pr}-\right.$ endo $), 0.36\left(\mathrm{t}, 4.8 \mathrm{~Hz}, 2 \mathrm{H}, \mathrm{Pt}{ }^{c} \mathrm{Pr}-\right.$ exo). ${ }^{13} \mathrm{C}\left\{{ }^{1} \mathrm{H}\right\} \operatorname{NMR}\left(\delta, \mathrm{CDCl}_{3}, 125 \mathrm{MHz}\right): 151.3(\mathrm{~s}$, o-C trans-Py), 146.5(s, o-C cis-Py), 144.4(s, p-C cis-Py), 136.5(s, p-C trans-Py), 126.1(s, m-C cis-Py), 124.5(s, m-C transPy), 65.9(s, Cl-C), 15.0(s, Pt $\left.{ }^{c} \operatorname{Pr}\right), 11.1\left(\mathrm{~s}, \mathrm{Cl}{ }^{c} \mathrm{Pr}\right),-11.1\left(\mathrm{~s}, J_{\mathrm{Pt}-\mathrm{C}}=970 \mathrm{~Hz}, \mathrm{Pt}-\mathrm{C}\right)$. $m / z=[\mathrm{M}-\mathrm{Cl}]^{+}$calcd for $\mathrm{C}_{16} \mathrm{H}_{18} \mathrm{ClN}_{2}{ }^{194} \mathrm{Pt} 467.0785$; found 467.0791 .

\section{Synthesis of $c i s-\left[\mathrm{Pt}\left(\mathrm{C}\left(\mathrm{CH}_{2}\right)_{2} \mathrm{CH}_{2} \mathrm{Cl}\right) \mathrm{Cl}(\mathrm{Py})_{2}\right] 34 \mathrm{c}$}

$\left[\mathrm{Pt}_{2} \mathrm{Cl}_{4}\left(\mathrm{C}_{2} \mathrm{H}_{4}\right)_{2}\right](20 \mathrm{mg}, 0.034 \mathrm{mmol})$ was placed in an NMR tube and $d_{6}$-acetone $(0.5 \mathrm{~mL})$ added. Pyridine $(11 \mu \mathrm{L}, 0.137 \mathrm{mmol}, 4$ eq. $)$ and $\mathrm{MCP}(0.07 \mathrm{~mL}$ of a $0.92 \mathrm{mmol} / \mathrm{mL}$ solution in $\mathrm{CDCl}_{3}, 0.068 \mathrm{mmol}, 2$ eq.) were added, resulting in the immediate formation of sparingly soluble yellow cis- $\left.-\mathrm{Pt}\left(\mathrm{C}\left(\mathrm{CH}_{2}\right)_{2} \mathrm{CH}_{2} \mathrm{Cl}\right) \mathrm{Cl}(\mathrm{Py})_{2}\right]$. Reaction is quantitative by ${ }^{1} \mathrm{H}$ NMR. ${ }^{1} \mathrm{H}$ NMR $\left(\delta, d_{6}\right.$-acetone, $\left.600 \mathrm{MHz}\right): 9.50\left(\mathrm{~d}, 5.6, J_{\mathrm{Pt}-\mathrm{H}}=81.9 \mathrm{~Hz}, 2 \mathrm{H}, o-\mathrm{H}\right.$ cis-Py), 8.91(dt, 4.7, $1.8 \mathrm{~Hz}, 2 \mathrm{H}, o-\mathrm{H}$ trans-Py), 8.54(td, 7.7, $1.4 \mathrm{~Hz}, 1 \mathrm{H}, p-\mathrm{H}$ cis-Py), 8.08(t, $6.9 \mathrm{~Hz}, 2 \mathrm{H}, m-\mathrm{H}$ cis-Py), 7.82(tt, 7.6, $1.8 \mathrm{~Hz}, 1 \mathrm{H}$, p-H trans-Py), 7.31(ddd, 7.6, $5.0,1.4 \mathrm{~Hz}, 2 \mathrm{H}, m-\mathrm{H}$ trans-Py), 4.13(s, $\left.J_{\mathrm{Pt}-\mathrm{H}}=24.6 \mathrm{~Hz}, 2 \mathrm{H}, \mathrm{Cl}-\mathrm{CH}_{2}\right), 0.52(\mathrm{td}, 5.0$, $1.5, J_{\mathrm{Pt}-\mathrm{H}}=29.6 \mathrm{~Hz}, 2 \mathrm{H}, \mathrm{Pt}{ }^{c} \operatorname{Pr}-$ endo $), 0.32\left(\mathrm{td}, 5.0,1.5, J_{\mathrm{Pt}-\mathrm{H}}=19.6 \mathrm{~Hz}, 2 \mathrm{H}, \mathrm{Pt}{ }^{c} \operatorname{Pr}-\right.$ exo). ${ }^{13} \mathrm{C}\left\{{ }^{1} \mathrm{H}\right\} \operatorname{NMR}\left(\delta, d_{6}\right.$-acetone, $\left.150 \mathrm{MHz}\right): 153.5(\mathrm{~s}, o-\mathrm{C}$ trans-Py), 151.1(s, o-C cis-Py), 138.8(s, p-C trans-Py), 136.3(s, p-C cis-Py), 126.4(s, m-C trans-Py), 124.0(s, $m$-C cis-Py), 76.8(s, Cl-C), 14.3(s, Pt $\left.{ }^{c} \mathrm{Pr}\right),-15.6(\mathrm{~s}, \mathrm{Pt}-\mathrm{C}) . m / z=[\mathrm{M}-\mathrm{Cl}]^{+}$calcd for $\mathrm{C}_{14} \mathrm{H}_{16} \mathrm{ClN}_{2}^{194} \mathrm{Pt} 437.0597$; found 437.0601.

\section{Synthesis of $\left[\operatorname{Pt}(\operatorname{dppp})_{2}\right] \mathrm{Cl}_{2} 35 \mathrm{a}$}

$\left[\mathrm{PtCl}_{2}\left(\mathrm{SEt}_{2}\right)_{2}\right](50 \mathrm{mg}, 0.11 \mathrm{mmol})$ was placed in an $\mathrm{NMR}$ tube and $\mathrm{CDCl}_{3}(0.5 \mathrm{~mL})$ added. BCP $(0.05 \mathrm{~mL}, 0.54 \mathrm{mmol})$ was added, resulting in the formation of trans$\left[\mathrm{Pt}\left(\mathrm{C}\left(\mathrm{CH}_{2}\right)_{2} \mathrm{C}\left(\mathrm{CH}_{2}\right)_{2} \mathrm{Cl}\right) \mathrm{Cl}\left(\mathrm{SEt}_{2}\right)_{2}\right](\mathbf{3 2})$ after 5 days. The solution was frozen in liquid $\mathrm{N}_{2}$, and a solution of dppp (90 mg, $\left.0.22 \mathrm{mmol}\right)$ in $\mathrm{CDCl}_{3}(0.5 \mathrm{~mL})$ added. X-ray quality crystals of $\left[\mathrm{Pt}(\mathrm{dppp})_{2}\right] \mathrm{Cl}_{2}$ formed as the solution warmed to RT. 


\section{Synthesis of trans $-\left[\mathrm{Pt}\left(\mathrm{C}\left(\mathrm{CH}_{2}\right)_{2} \mathrm{C}\left(\mathrm{CH}_{2}\right)_{2} \mathrm{Cl}\right) \mathrm{Cl}(\mathrm{PTA})_{2}\right] 36 \mathrm{a}$}

$\left[\mathrm{PtCl}_{2}\left(\mathrm{SEt}_{2}\right)_{2}\right] \quad(50 \mathrm{mg}, \quad 0.11 \mathrm{mmol})$ was placed in an $\mathrm{NMR}$ tube and $\mathrm{CDCl}_{3}$ $(0.5 \mathrm{~mL})$ added. BCP $(0.05 \mathrm{~mL}, 0.53 \mathrm{mmol})$ was added. After 2 days, trans$\left.\mathrm{Pt}\left(\mathrm{C}\left(\mathrm{CH}_{2}\right)_{2} \mathrm{C}\left(\mathrm{CH}_{2}\right)_{2} \mathrm{Cl}\right) \mathrm{Cl}\left(\mathrm{SEt}_{2}\right)_{2}\right]$ formed and the solvent was removed in vacuo. PTA (40 mg, $0.25 \mathrm{mmol})$ was dissolved in $\mathrm{CDCl}_{3}(0.5 \mathrm{~mL})$ and added to the NMR tube., resulting in the immediate formation of trans $-\left[\mathrm{Pt}\left(\mathrm{C}\left(\mathrm{CH}_{2}\right)_{2} \mathrm{C}\left(\mathrm{CH}_{2}\right)_{2} \mathrm{Cl}\right) \mathrm{Cl}(\mathrm{PTA})_{2}\right]$. After $\sim 1 \mathrm{hr}$, the complex had decomposed to form cis- $\left[\mathrm{PtCl}_{2}(\mathrm{PTA})_{2}\right]$ and $\mathrm{BCP}$. Due to the insolubility of $c i s-\left[\mathrm{PtCl}_{2}(\mathrm{PTA})_{2}\right]$, a yield was not obtained. ${ }^{1} \mathrm{H} \mathrm{NMR}\left(\delta, \mathrm{CDCl}_{3}\right.$, $600 \mathrm{MHz}): 4.45\left(\mathrm{~m}, 12 \mathrm{H}, \mathrm{N}-\mathrm{CH}_{2}\right), 4.31\left(\mathrm{dd}, 47.4,14.4,12 \mathrm{H}, \mathrm{P}-\mathrm{CH}_{2}\right), 1.03(\mathrm{t}, 6.0 \mathrm{~Hz}, 2 \mathrm{H}$, $\left.\mathrm{Cl}{ }^{c} \mathrm{Pr}\right), 0.76\left(\mathrm{t}, 6.0 \mathrm{~Hz}, 2 \mathrm{H}, \mathrm{Cl}{ }^{c} \mathrm{Pr}\right), 0.44\left(\mathrm{~s}, 2 \mathrm{H}, \mathrm{Pt}{ }^{c} \mathrm{Pr}\right), 0.27\left(\mathrm{~s}, 2 \mathrm{H}, \mathrm{Pt}{ }^{c} \mathrm{Pr}\right) .{ }^{31} \mathrm{P}\left\{{ }^{1} \mathrm{H}\right\}$ $\operatorname{NMR}\left(\delta, \mathrm{CDCl}_{3}, 121 \mathrm{MHz}\right):-59.2\left(\mathrm{~s},{ }^{1} J_{\mathrm{Pt}-\mathrm{P}}=3000 \mathrm{~Hz}\right)$.

\section{Synthesis of $c i s-\left[\mathrm{Pt}\left(\mathrm{C}\left(\mathrm{CH}_{2}\right)_{2} \mathrm{C}\left(\mathrm{CH}_{2}\right)_{2} \mathrm{Cl}\right) \mathrm{Cl}(\mathrm{PTA})_{2}\right] 36 \mathrm{~b}$}

$\left[\mathrm{Pt}_{2} \mathrm{Cl}_{4}\left(\mathrm{C}_{2} \mathrm{H}_{4}\right)_{2}\right](30 \mathrm{mg}, 0.051 \mathrm{mmol})$ was placed in an $\mathrm{NMR}$ tube and $\mathrm{CDCl}_{3}(0.3 \mathrm{~mL})$ added. Pyridine $(16.5 \mu \mathrm{L}, 0.21 \mathrm{mmol}, 4$ eq. $)$ and $\mathrm{BCP}(0.25 \mathrm{~mL}$ of a $0.62 \mathrm{mmol} / \mathrm{mL}$ solution in $\mathrm{C}_{6} \mathrm{D}_{6}, 0.153 \mathrm{mmol}, 3$ eq.) were added, resulting in the immediate formation of cis- $-\left[\mathrm{Pt}\left(\mathrm{C}\left(\mathrm{CH}_{2}\right)_{2} \mathrm{C}\left(\mathrm{CH}_{2}\right)_{2} \mathrm{Cl}\right) \mathrm{Cl}(\mathrm{Py})_{2}\right]$. The solvent was removed in vacuo and $\mathrm{PTA}$ (48 mg of a sample containing $10 \%$ PTA oxide, $\sim 6$ eq. $)$ in $\mathrm{CDCl}_{3}(0.5 \mathrm{~mL})$ added. A large amount of cis- $\left[\mathrm{PtCl}_{2}(\mathrm{PTA})_{2}\right]$ was formed, as well as cis- $\left.-\mathrm{Pt}\left(\mathrm{C}\left(\mathrm{CH}_{2}\right)_{2} \mathrm{C}\left(\mathrm{CH}_{2}\right)_{2} \mathrm{Cl}\right) \mathrm{Cl}(\mathrm{PTA})_{2}\right]$. Relative amounts could not be calculated due to the insolubility of cis- $\left[\mathrm{PtCl}_{2}(\mathrm{PTA})_{2}\right] .{ }^{1} \mathrm{H}$ $\operatorname{NMR}\left(\delta, \mathrm{CDCl}_{3}, 600 \mathrm{MHz}\right): 4.7-4.1\left(\mathrm{~m}, 24 \mathrm{H}, \mathrm{N}-\mathrm{CH}_{2}\right.$ and $\left.\mathrm{P}-\mathrm{CH}_{2}\right), 1.69(\mathrm{dt}, 11.2,6.7 \mathrm{~Hz}$, $\left.1 \mathrm{H}, \mathrm{Cl}{ }^{c} \mathrm{Pr}\right), 1.31\left(\mathrm{dt}, 10.2,7.1 \mathrm{~Hz}, 1 \mathrm{H}, \mathrm{Cl}{ }^{c} \mathrm{Pr}\right), 0.92\left(\mathrm{~m}, 2 \mathrm{H}, \mathrm{Cl}{ }^{c} \mathrm{Pr}\right.$ and $\left.\mathrm{Pt}{ }^{c} \mathrm{Pr}\right), 0.85(\mathrm{dt}$, 10.9, 6.2 Hz, $\left.1 \mathrm{H}, \mathrm{Cl}{ }^{c} \mathrm{Pr}\right), 0.80\left(\mathrm{~m}, 1 \mathrm{H}, \mathrm{Pt}{ }^{c} \mathrm{Pr}\right), 0.49\left(\mathrm{~m}, 1 \mathrm{H}, \mathrm{Pt}{ }^{c} \mathrm{Pr}\right), 0.27\left(\mathrm{~m}, 1 \mathrm{H}, \mathrm{Pt}{ }^{c} \mathrm{Pr}\right)$. ${ }^{13} \mathrm{C}\left\{{ }^{1} \mathrm{H}\right\} \operatorname{NMR}\left(\delta, \mathrm{CDCl}_{3}, 150 \mathrm{MHz}\right): 72.8\left(\mathrm{~m}, \mathrm{~N}-\mathrm{CH}_{2}\right), 72.2\left(\mathrm{~d}, 9.2 \mathrm{~Hz}, \mathrm{~N}-\mathrm{CH}_{2}\right), 64.8(\mathrm{~s}$, $\mathrm{Cl}-\mathrm{C}), 53.5\left(\mathrm{dd}, 23.3,2.4 \mathrm{~Hz}, \mathrm{P}-\mathrm{CH}_{2}\right), 51.9\left(\mathrm{~d}, 14.7 \mathrm{~Hz}, \mathrm{P}-\mathrm{CH}_{2}\right), 16.7\left(\mathrm{~s}, \mathrm{Cl}{ }^{c} \mathrm{Pr}\right), 15.7(\mathrm{~s}$, $\left.\mathrm{Cl}^{c} \mathrm{Pr}\right), 15.5\left(\mathrm{dd}, 121.8,8.6,{ }^{1} J_{\mathrm{Pt}-\mathrm{C}}=809.1 \mathrm{~Hz}, \mathrm{Pt}-\mathrm{C}\right), 13.4\left(\mathrm{~s}, \mathrm{Pt}{ }^{c} \mathrm{Pr}\right), 8.7(\mathrm{~d}, 3.7 \mathrm{~Hz}, \mathrm{Pt}$ $\left.{ }^{c} \mathrm{Pr}\right) .{ }^{31} \mathrm{P}\left\{{ }^{1} \mathrm{H}\right\} \operatorname{NMR}\left(\delta, \mathrm{CDCl}_{3}, 121 \mathrm{MHz}\right):-57.9\left(\mathrm{~d}, 15.6,{ }^{1} J_{\mathrm{Pt}-\mathrm{P}}=3949 \mathrm{~Hz}\right.$, trans $\left.\mathrm{Cl}\right)$, $-65.8\left(\mathrm{~d}, 15.6,{ }^{1} J_{\mathrm{Pt}-\mathrm{P}}=1522 \mathrm{~Hz}, J_{\mathrm{P}-\mathrm{C}}=121.5 \mathrm{~Hz}\right.$, trans $\left.{ }^{c} \mathrm{Pr}\right) . m / z=[\mathrm{M}+\mathrm{K}]^{+}$calcd for $\mathrm{C}_{18} \mathrm{H}_{32} \mathrm{Cl}_{2} \mathrm{KN}_{6} \mathrm{P}_{2}{ }^{194} \mathrm{Pt}$ 699.0804; found 699.0784. 


\section{Synthesis of cis- $\left[\mathrm{Pt}\left(\mathrm{C}\left(\mathrm{CH}_{2}\right)_{2} \mathrm{CH}_{2} \mathrm{Cl}\right) \mathrm{Cl}(\mathrm{PTA})_{2}\right] 36 \mathrm{c}$}

$\left[\mathrm{Pt}_{2} \mathrm{Cl}_{4}\left(\mathrm{C}_{2} \mathrm{H}_{4}\right)_{2}\right](30 \mathrm{mg}, 0.051 \mathrm{mmol})$ was placed in an NMR tube and MCP $(0.17 \mathrm{~mL}$ of a $0.92 \mathrm{mmol} / \mathrm{mL}$ solution in $\mathrm{CDCl}_{3}, 0.153 \mathrm{mmol}, 3$ eq.) and pyridine (16.5 $\mu \mathrm{L}, 0.21 \mathrm{mmol}$, 4 eq.) added, resulting in the immediate formation of cis $-\left[\mathrm{Pt}\left(\mathrm{C}\left(\mathrm{CH}_{2}\right)_{2} \mathrm{CH}_{2} \mathrm{Cl}\right) \mathrm{Cl}(\mathrm{Py})_{2}\right]$. PTA (48 mg of a sample containing $10 \%$ PTA oxide, $\sim 6$ eq.) in $\mathrm{CDCl}_{3}(0.3 \mathrm{~mL}$ ) was added. A large amount of cis $-\left[\mathrm{PtCl}_{2}(\mathrm{PTA})_{2}\right]$ was formed, as well as cis$\left[\mathrm{Pt}\left(\mathrm{C}\left(\mathrm{CH}_{2}\right)_{2} \mathrm{CH}_{2} \mathrm{Cl}\right) \mathrm{Cl}(\mathrm{PTA})_{2}\right]$ (50\% of species in solution). After 5 days, all of the cis- $-\left[\mathrm{Pt}\left(\mathrm{C}\left(\mathrm{CH}_{2}\right)_{2} \mathrm{CH}_{2} \mathrm{Cl}\right) \mathrm{Cl}(\mathrm{PTA})_{2}\right]$ had decomposed to form cis- $\left[\mathrm{PtCl}_{2}(\mathrm{PTA})_{2}\right] .{ }^{31} \mathrm{P}\left\{{ }^{1} \mathrm{H}\right\}$ $\operatorname{NMR}\left(\delta, \mathrm{CDCl}_{3}, 121 \mathrm{MHz}\right):-58.9\left(\mathrm{~d}, 14.9,{ }^{1} J_{\mathrm{Pt}-\mathrm{P}}=3884 \mathrm{~Hz}\right.$, trans $\left.\mathrm{Cl}\right),-65.8(\mathrm{~d}, 14.9$, ${ }^{1} J_{\mathrm{Pt}-\mathrm{P}}=1530 \mathrm{~Hz}$, trans $\left.{ }^{c} \mathrm{Pr}\right)$.

\section{Synthesis of cis- $\left[\mathrm{Pt}\left(\mathrm{C}\left(\mathrm{CH}_{2}\right)_{2} \mathrm{C}\left(\mathrm{CH}_{2}\right)_{2} \mathrm{Cl}\right) \mathrm{Cl}(\mathrm{dppp})\right] 37 \mathrm{a}$}

$\left[\mathrm{Pt}_{2} \mathrm{Cl}_{4}\left(\mathrm{C}_{2} \mathrm{H}_{4}\right)_{2}\right](30 \mathrm{mg}, 0.051 \mathrm{mmol})$ was placed in an $\mathrm{NMR}$ tube and $\mathrm{CDCl}_{3}(0.3 \mathrm{~mL})$ added. Pyridine $(16.5 \mu \mathrm{L}, 0.21 \mathrm{mmol}, 4$ eq. $)$ and $\mathrm{BCP}(0.25 \mathrm{~mL}$ of a $0.62 \mathrm{mmol} / \mathrm{mL}$ solution in $\mathrm{C}_{6} \mathrm{D}_{6}, 0.153 \mathrm{mmol}, 3$ eq.) were added, resulting in the immediate formation of cis- $-\left[\mathrm{Pt}\left(\mathrm{C}\left(\mathrm{CH}_{2}\right)_{2} \mathrm{C}\left(\mathrm{CH}_{2}\right)_{2} \mathrm{Cl}\right) \mathrm{Cl}(\mathrm{Py})_{2}\right]$. The solvent was removed in vacuo and dppp (42 mg, $0.102 \mathrm{mmol})$ in $\mathrm{CDCl}_{3}(0.5 \mathrm{~mL})$ added. cis- $\left.\mathrm{Pt}\left(\mathrm{C}\left(\mathrm{CH}_{2}\right)_{2} \mathrm{C}\left(\mathrm{CH}_{2}\right)_{2} \mathrm{Cl}\right) \mathrm{Cl}(\mathrm{dppp})\right]$ (85\%) and $c i s-\left[\mathrm{PtCl}_{2}(\mathrm{dppp})\right](11 \%)$ formed immediately. ${ }^{1} \mathrm{H} \mathrm{NMR}\left(\delta, \mathrm{CDCl}_{3}, 600 \mathrm{MHz}\right)$ : 7.86(t, 8.4 Hz, 4H, Ar), 7.53(t, 9.0 Hz, 4H, Ar), 7.37(m, 4H, Ar), 7.2(m, 8H, Ar), 4.47(brs, 1H, $\left.\mathrm{P}-\mathrm{CH}_{2}\right), 3.41\left(\mathrm{t}, 13.8 \mathrm{~Hz}, 1 \mathrm{H}, \mathrm{P}-\mathrm{CH}_{2}\right), 2.51\left(\mathrm{~m}, 2 \mathrm{H}, \mathrm{P}-\mathrm{CH}_{2}\right), 2.28\left(\mathrm{~m}, 1 \mathrm{H}, \mathrm{CH}_{2}\right)$, 1.05(m, $2 \mathrm{H}, \mathrm{CH}_{2}$ and $\left.\mathrm{Cl}{ }^{c} \mathrm{Pr}\right), 0.71\left(\mathrm{~m}, 1 \mathrm{H}, \mathrm{Cl}{ }^{c} \mathrm{Pr}\right), 0.48\left(\mathrm{~m}, 2 \mathrm{H}, \mathrm{Cl}{ }^{c} \mathrm{Pr}\right.$ and $\left.\mathrm{Pt}{ }^{c} \mathrm{Pr}\right)$, 0.35(m, 1H, Pt $\left.{ }^{c} \mathrm{Pr}\right), 0.20\left(\mathrm{~m}, 1 \mathrm{H}, \mathrm{Pt}{ }^{c} \mathrm{Pr}\right),-0.46\left(\mathrm{~m}, 1 \mathrm{H}, \mathrm{Cl}{ }^{c} \mathrm{Pr}\right),-1.22(\mathrm{~m}, 1 \mathrm{H}, \mathrm{Pt}$ $\left.{ }^{c} \operatorname{Pr}\right) .{ }^{13} \mathrm{C}\left\{{ }^{1} \mathrm{H}\right\} \operatorname{NMR}\left(\delta, \mathrm{CDCl}_{3}, 150 \mathrm{MHz}\right): 134.3(\mathrm{~d}, 10.0 \mathrm{~Hz}, \mathrm{Ar}), 133.5(\mathrm{~d}, 9.6 \mathrm{~Hz}, \mathrm{Ar})$, 132.9(d, 10.0 Hz, Ar), 130.6(d, $13.8 \mathrm{~Hz}, \mathrm{Ar}), 128.8(\mathrm{~m}, \mathrm{Ar}), 128.5(\mathrm{~d}, 9.5 \mathrm{~Hz}, \mathrm{Ar}), 128.1(\mathrm{~d}$, 11.2 Hz, Ar), 127.0(d, 10.6 Hz, Ar), 63.6(s, Cl-C), 28.5(dd, 39.3, $\left.5.9 \mathrm{~Hz}, \mathrm{P}-\mathrm{CH}_{2}\right), 22.8(\mathrm{~d}$, $\left.29.2 \mathrm{~Hz}, \mathrm{P}-\mathrm{CH}_{2}\right), 18.8\left(\mathrm{~m}, \mathrm{CH}_{2}\right), 17.1\left(\mathrm{~s}, \mathrm{Cl}{ }^{c} \mathrm{Pr}\right), 15.6\left(\mathrm{dd}, 124.5,6.8,{ }^{1} J_{\mathrm{Pt}-\mathrm{C}}=789.4 \mathrm{~Hz}\right.$, $\mathrm{Pt}-\mathrm{C}), 13.3\left(\mathrm{~s}, \mathrm{Pt}{ }^{c} \mathrm{Pr}\right), 12.2\left(\mathrm{~s}, \mathrm{Cl}{ }^{c} \mathrm{Pr}\right), 6.1\left(\mathrm{~d}, 3.2 \mathrm{~Hz}, \mathrm{Pt}{ }^{c} \mathrm{Pr}\right) .{ }^{31} \mathrm{P}\left\{{ }^{1} \mathrm{H}\right\} \operatorname{NMR}\left(\delta, \mathrm{CDCl}_{3}\right.$, $121 \mathrm{MHz}):-1.8\left(\mathrm{~d}, 25.9,{ }^{1} J_{\mathrm{Pt}-\mathrm{P}}=1654 \mathrm{~Hz}\right.$, trans $\left.{ }^{c} \mathrm{Pr}\right),-2.7\left(\mathrm{~d}, 25.9,{ }^{1} J_{\mathrm{Pt}-\mathrm{P}}=4133 \mathrm{~Hz}\right.$, trans $\mathrm{Cl})$. 


\section{Synthesis of cis- $\left[\mathrm{Pt}\left(\mathrm{C}\left(\mathrm{CH}_{2}\right)_{2} \mathrm{CH}_{2} \mathrm{Cl}\right) \mathrm{Cl}(\mathrm{dppp})\right] 37 \mathrm{~b}$}

$\left[\mathrm{Pt}_{2} \mathrm{Cl}_{4}\left(\mathrm{C}_{2} \mathrm{H}_{4}\right)_{2}\right] \quad(30 \mathrm{mg}, 0.051 \mathrm{mmol})$ was placed in an NMR tube and MCP (0.17 $\mathrm{mL}$ of a $0.92 \mathrm{mmol} / \mathrm{mL}$ solution in $\mathrm{CDCl}_{3}, 0.153 \mathrm{mmol}, 3$ eq.) and pyridine (16.5 $\mu \mathrm{L}, 0.21 \mathrm{mmol}, 4$ eq.) added, resulting in the immediate formation of cis$\left[\mathrm{Pt}\left(\mathrm{C}\left(\mathrm{CH}_{2}\right)_{2} \mathrm{CH}_{2} \mathrm{Cl}\right) \mathrm{Cl}(\mathrm{Py})_{2}\right]$. Dppp (42 mg, $\left.0.102 \mathrm{mmol}\right)$ in $\mathrm{CDCl}_{3}(0.3 \mathrm{~mL})$ was added. cis- $\left[\mathrm{Pt}\left(\mathrm{C}\left(\mathrm{CH}_{2}\right)_{2} \mathrm{CH}_{2} \mathrm{Cl}\right) \mathrm{Cl}(\mathrm{dppp})\right](58 \%)$, cis- $\left[\mathrm{PtCl}_{2}(\mathrm{dppp})\right](26 \%)$ and $\left[\mathrm{Pt}(\mathrm{dppp})_{2}\right] \mathrm{Cl}_{2}$ $(16 \%)$ formed immediately. The cis- $\left.\left[\mathrm{Pt}\left(\mathrm{C}_{\left(\mathrm{CH}_{2}\right.}\right)_{2} \mathrm{CH}_{2} \mathrm{Cl}\right) \mathrm{Cl}(\mathrm{dppp})\right]$ decomposed to form cis- $\left[\mathrm{PtCl}_{2}(\mathrm{dppp})\right]$ overnight. ${ }^{31} \mathrm{P}\left\{{ }^{1} \mathrm{H}\right\} \mathrm{NMR}\left(\delta, \mathrm{CDCl}_{3}, 121 \mathrm{MHz}\right): 0.4\left(\mathrm{~d}, 25.2,{ }^{1} J_{\mathrm{Pt}-\mathrm{P}}=\right.$ $4051 \mathrm{~Hz}$, trans $\mathrm{Cl}), 0.2\left(\mathrm{~d}, 25.2,{ }^{1} J_{\mathrm{Pt}-\mathrm{P}}=1684 \mathrm{~Hz}\right.$, trans $\left.{ }^{c} \mathrm{Pr}\right)$.

\section{Synthesis of cis- $\left[\mathrm{Pt}\left(\mathrm{C}\left(\mathrm{CH}_{2}\right)_{2} \mathrm{C}\left(\mathrm{CH}_{2}\right)_{2} \mathrm{Cl}\right) \mathrm{Cl}\left(\mathrm{PPh}_{3}\right)_{2}\right] 38 \mathrm{a}$}

$\left[\mathrm{Pt}_{2} \mathrm{Cl}_{4}\left(\mathrm{C}_{2} \mathrm{H}_{4}\right)_{2}\right](30 \mathrm{mg}, 0.051 \mathrm{mmol})$ was placed in an $\mathrm{NMR}$ tube and $\mathrm{CDCl}_{3}$ (0.3 mL) added. Pyridine $(16.5 \mu \mathrm{L}, 0.21 \mathrm{mmol}, 4$ eq.) and BCP $(0.25 \mathrm{~mL}$ of a $0.62 \mathrm{mmol} / \mathrm{mL}$ solution in $\mathrm{C}_{6} \mathrm{D}_{6}, 0.153 \mathrm{mmol}, 3$ eq.) were added, resulting in the immediate formation of cis- $\left[\mathrm{Pt}\left(\mathrm{C}\left(\mathrm{CH}_{2}\right)_{2} \mathrm{C}\left(\mathrm{CH}_{2}\right)_{2} \mathrm{Cl}\right) \mathrm{Cl}(\mathrm{Py})_{2}\right]$. The solvent was removed in vacuo and $\mathrm{PPh}_{3}(54 \mathrm{mg}, 0.204 \mathrm{mmol})$ in $\mathrm{CDCl}_{3}(0.5 \mathrm{~mL})$ added. $\quad\left[\mathrm{Pt}\left(\mathrm{C}\left(\mathrm{CH}_{2}\right)_{2} \mathrm{C}\left(\mathrm{CH}_{2}\right)_{2} \mathrm{Cl}\right) \mathrm{Cl}(\mathrm{Py})\left(\mathrm{PPh}_{3}\right)\right] \quad(70 \%)$ and cis- $\left[\mathrm{PtCl}_{2}\left(\mathrm{PPh}_{3}\right)_{2}\right]$ $(30 \%)$ formed immediately. After an hour, cis- $\left[\mathrm{Pt}\left(\mathrm{C}\left(\mathrm{CH}_{2}\right)_{2} \mathrm{C}\left(\mathrm{CH}_{2}\right)_{2} \mathrm{Cl}\right) \mathrm{Cl}\left(\mathrm{PPh}_{3}\right)_{2}\right]$ began to form, ending up as $53 \%$ cis- $\left[\mathrm{Pt}\left(\mathrm{C}\left(\mathrm{CH}_{2}\right)_{2} \mathrm{C}\left(\mathrm{CH}_{2}\right)_{2} \mathrm{Cl}\right) \mathrm{Cl}\left(\mathrm{PPh}_{3}\right)_{2}\right], \quad 8.5 \%$ $\left[\mathrm{Pt}\left(\mathrm{C}\left(\mathrm{CH}_{2}\right)_{2} \mathrm{C}\left(\mathrm{CH}_{2}\right)_{2} \mathrm{Cl}\right) \mathrm{Cl}(\mathrm{Py})\left(\mathrm{PPh}_{3}\right)\right](70 \%)$ and $30 \%$ cis- $\left[\mathrm{PtCl}_{2}\left(\mathrm{PPh}_{3}\right)_{2}\right]$ after 4 days.

$\left[\mathbf{P t}\left(\mathbf{C}\left(\mathbf{C H}_{2}\right)_{2} \mathbf{C}\left(\mathbf{C H}_{2}\right)_{2} \mathbf{C l}\right) \mathbf{C l}(\mathbf{P y})\left(\mathbf{P P h}_{3}\right)\right]$ 38b: ${ }^{31} \mathrm{P}\left\{{ }^{1} \mathrm{H}\right\} \operatorname{NMR}\left(\delta, \mathrm{CDCl}_{3}, 121 \mathrm{MHz}\right)$ :

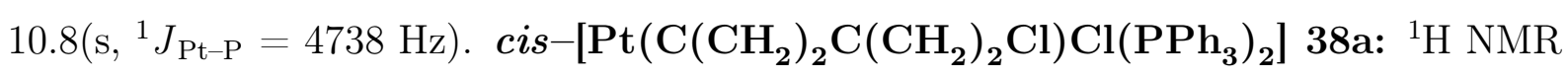
$\left(\delta, \mathrm{CDCl}_{3}, 600 \mathrm{MHz}\right): 8-7(\mathrm{~m}, 8 \mathrm{H}, \mathrm{Ar}), 1.34\left(\mathrm{~m}, 1 \mathrm{H}, \mathrm{Cl}{ }^{c} \mathrm{Pr}\right), 0.85\left(\mathrm{~m}, 1 \mathrm{H}, \mathrm{Cl}{ }^{c} \mathrm{Pr}\right), 0.77(\mathrm{~m}$, $\left.1 \mathrm{H}, \mathrm{Pt}{ }^{c} \mathrm{Pr}\right), 0.69\left(\mathrm{~m}, 1 \mathrm{H}, \mathrm{Cl}{ }^{c} \mathrm{Pr}\right), 0.57\left(\mathrm{~m}, 1 \mathrm{H}, \mathrm{Pt}{ }^{c} \mathrm{Pr}\right),-0.41\left(\mathrm{~m}, 1 \mathrm{H}, \mathrm{Cl}{ }^{c} \mathrm{Pr}\right),-0.85(\mathrm{~m}$, $\left.1 \mathrm{H}, \mathrm{Pt}{ }^{c} \mathrm{Pr}\right) .{ }^{13} \mathrm{C}\left\{{ }^{1} \mathrm{H}\right\} \operatorname{NMR}\left(\delta, \mathrm{CDCl}_{3}, 150 \mathrm{MHz}\right): 134.7(\mathrm{~m}, \mathrm{Ar}), 133.6(\mathrm{~d}, 18.4 \mathrm{~Hz}, \mathrm{Ar})$, 128.9-127.6(m, Ar), 63.3(s, Cl-C), 19.2(s, Cl $\left.{ }^{c} \operatorname{Pr}\right), 15.8\left(\mathrm{~d}, 4.3 \mathrm{Cl}{ }^{c} \operatorname{Pr}\right), 15.7(\mathrm{dd}, 126.7$, 8.0, $\left.{ }^{1} J_{\mathrm{Pt}-\mathrm{C}}=797.7 \mathrm{~Hz}, \mathrm{Pt}-\mathrm{C}\right), 13.3\left(\mathrm{~s}, \mathrm{Pt}{ }^{c} \mathrm{Pr}\right), 8.1\left(\mathrm{~d}, 3.7 \mathrm{~Hz}, \mathrm{Pt}{ }^{c} \mathrm{Pr}\right) .{ }^{31} \mathrm{P}\left\{{ }^{1} \mathrm{H}\right\} \mathrm{NMR}$ $\left(\delta, \mathrm{CDCl}_{3}, 121 \mathrm{MHz}\right): 22.7\left(\mathrm{~d}, 15.6,{ }^{1} J_{\mathrm{Pt}-\mathrm{P}}=1646 \mathrm{~Hz}\right.$, trans $\left.{ }^{c} \mathrm{Pr}\right), 16.7\left(\mathrm{~d}, 15.6,{ }^{1} J_{\mathrm{Pt}-\mathrm{P}}\right.$ $=4490 \mathrm{~Hz}$, trans $\mathrm{Cl}) . \quad m / z=[\mathrm{M}-\mathrm{Cl}]^{+}$calcd for $\mathrm{C}_{42} \mathrm{H}_{38} \mathrm{ClP}_{2}{ }^{194} \mathrm{Pt}$ 835.1783; found 
838.1785 .

\section{Synthesis of cis- $\left.-\mathrm{Pt}\left(\mathrm{C}\left(\mathrm{CH}_{2}\right)_{2} \mathrm{CH}_{2} \mathrm{Cl}\right) \mathrm{Cl}(\mathrm{Py})\left(\mathrm{PPh}_{3}\right)\right] 38 \mathrm{c}$}

$\left[\mathrm{Pt}_{2} \mathrm{Cl}_{4}\left(\mathrm{C}_{2} \mathrm{H}_{4}\right)_{2}\right] \quad(30 \mathrm{mg}, 0.051 \mathrm{mmol})$ was placed in an NMR tube and MCP (0.17 $\mathrm{mL}$ of a $0.92 \mathrm{mmol} / \mathrm{mL}$ solution in $\mathrm{CDCl}_{3}, 0.153 \mathrm{mmol}, 3$ eq.) and pyridine (16.5 $\mu \mathrm{L}, 0.21 \mathrm{mmol}, 4$ eq.) added, resulting in the immediate formation of cis$\left[\mathrm{Pt}\left(\mathrm{C}\left(\mathrm{CH}_{2}\right)_{2} \mathrm{CH}_{2} \mathrm{Cl}\right) \mathrm{Cl}(\mathrm{Py})_{2}\right] . \quad \mathrm{PPh}_{3}(54 \mathrm{mg}, 0.204 \mathrm{mmol})$ in $\mathrm{CDCl}_{3}(0.3 \mathrm{~mL})$ was added. $\left[\mathrm{Pt}\left(\mathrm{C}\left(\mathrm{CH}_{2}\right)_{2} \mathrm{CH}_{2} \mathrm{Cl}\right) \mathrm{Cl}(\mathrm{Py})\left(\mathrm{PPh}_{3}\right)\right](32 \%)$ and cis- $\left[\mathrm{PtCl}_{2}\left(\mathrm{PPh}_{3}\right)_{2}\right](30 \%)$ formed immediately, with the $\left[\mathrm{Pt}\left(\mathrm{C}\left(\mathrm{CH}_{2}\right)_{2} \mathrm{CH}_{2} \mathrm{Cl}\right) \mathrm{Cl}(\mathrm{Py})\left(\mathrm{PPh}_{3}\right)\right]$ decomposing to form cis$\left[\mathrm{PtCl}_{2}\left(\mathrm{PPh}_{3}\right)_{2}\right]$ over 4 hours. ${ }^{31} \mathrm{P}\left\{{ }^{1} \mathrm{H}\right\} \mathrm{NMR}\left(\delta, \mathrm{CDCl}_{3}, 121 \mathrm{MHz}\right): 13.5\left(\mathrm{~s},{ }^{1} J_{\mathrm{Pt}-\mathrm{P}}=\right.$ $4661 \mathrm{~Hz}$ ). 


\section{Appendix A}

\section{NMR Spectra}

\section{A.1 Chapter Two}

\section{$[\operatorname{Pt}(\mathrm{BCP})(\mathrm{dppp})](1 \mathrm{a})$}

${ }^{1} \mathrm{H}$ NMR spectrum - Figures A.1 and A.2, pages 162 and 163 ${ }^{13} \mathrm{C}\left\{{ }^{1} \mathrm{H}\right\}$ NMR spectrum - Figures A.4 and A.5, pages 164 and 165

${ }^{31} \mathrm{P}\left\{{ }^{1} \mathrm{H}\right\}$ NMR spectrum - Figure A.3, page 163

\section{$[\mathrm{Pt}(\mathrm{MCP})(\mathrm{dppp})](2 \mathrm{a})$}

${ }^{1} \mathrm{H}$ NMR spectrum - Figures A.6 and A.7, pages 166 and 167 ${ }^{13} \mathrm{C}\left\{{ }^{1} \mathrm{H}\right\}$ NMR spectrum - Figures A.8-A.10, pages $168-170$ ${ }^{31} \mathrm{P}\left\{{ }^{1} \mathrm{H}\right\}$ NMR spectrum - Figure A.11, page 170

\section{$\left[\mathrm{Pt}\left(\mathrm{CH}_{2} \mathrm{CH}=\mathrm{CHC}\left(\mathrm{CH}_{2}\right)_{2}\right)(\mathrm{dppp})\right](4 \mathrm{a})$}

${ }^{1}$ H NMR spectrum - Figures A.12-A.14, pages 171-173

${ }^{13} \mathrm{C}\left\{{ }^{1} \mathrm{H}\right\}$ NMR spectrum - Figures A.16-A.19, pages $174-177$

${ }^{31} \mathrm{P}\left\{{ }^{1} \mathrm{H}\right\}$ NMR spectrum - Figure A.15, page 173 

$\left[\mathrm{Pt}(\mathrm{MCP})_{2}\left(\mathrm{PPh}_{3}\right)\right](7 \mathrm{a})$

${ }^{1} \mathrm{H}$ NMR spectrum - Figures A.20 and A.21, pages 178 and 179

${ }^{13} \mathrm{C}\left\{{ }^{1} \mathrm{H}\right\}$ NMR spectrum - Figures A.22-A.24, pages $180-182$

${ }^{31} \mathrm{P}\left\{{ }^{1} \mathrm{H}\right\}$ NMR spectrum - Figure A.25, page 182 

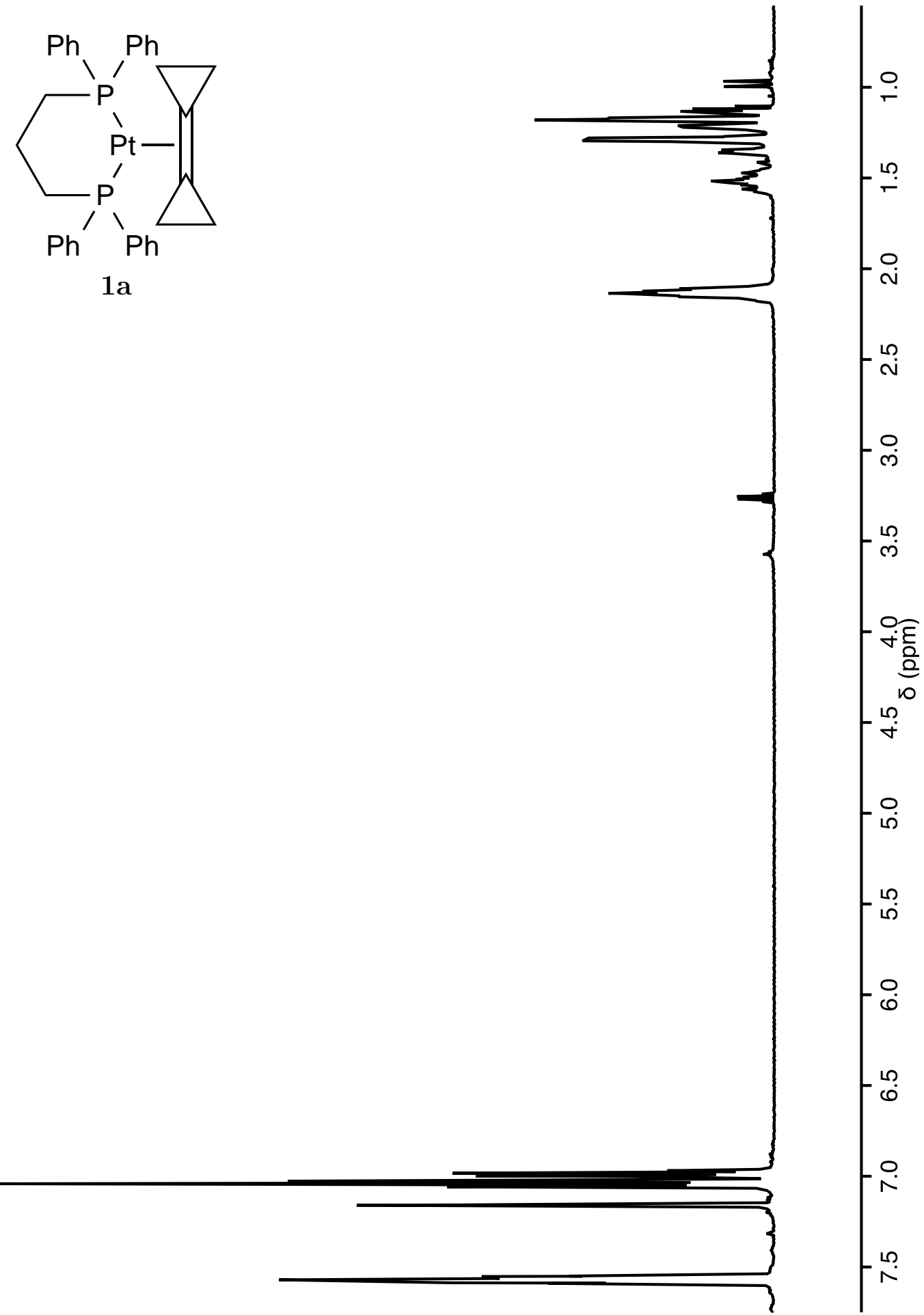

Figure A.1. ${ }^{1} \mathrm{H}$ NMR spectrum of $[\mathrm{Pt}(\mathrm{BCP})(\mathrm{dppp})]$ (1a) $(600 \mathrm{MHz}, \mathrm{RT}, 40 \mathrm{mg} / \mathrm{mL}$, $\mathrm{C}_{6} \mathrm{D}_{6}$ ). 

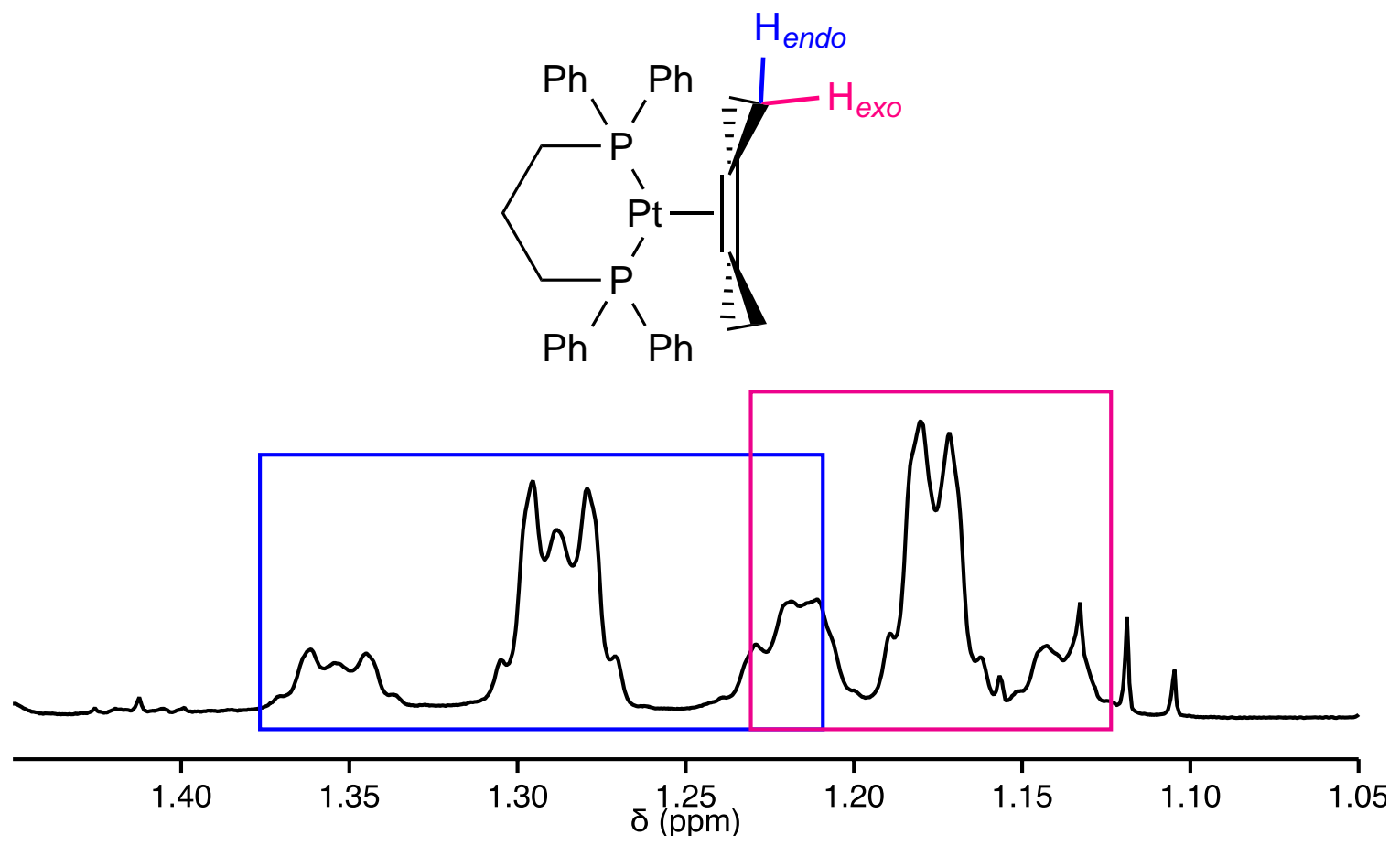

Figure A.2. Expanded ${ }^{1} \mathrm{H}$ NMR spectrum of $[\mathrm{Pt}(\mathrm{BCP})(\mathrm{dppp})]$ (1a) (600 MHz, RT, $\left.40 \mathrm{mg} / \mathrm{mL}, \mathrm{C}_{6} \mathrm{D}_{6}\right)$.

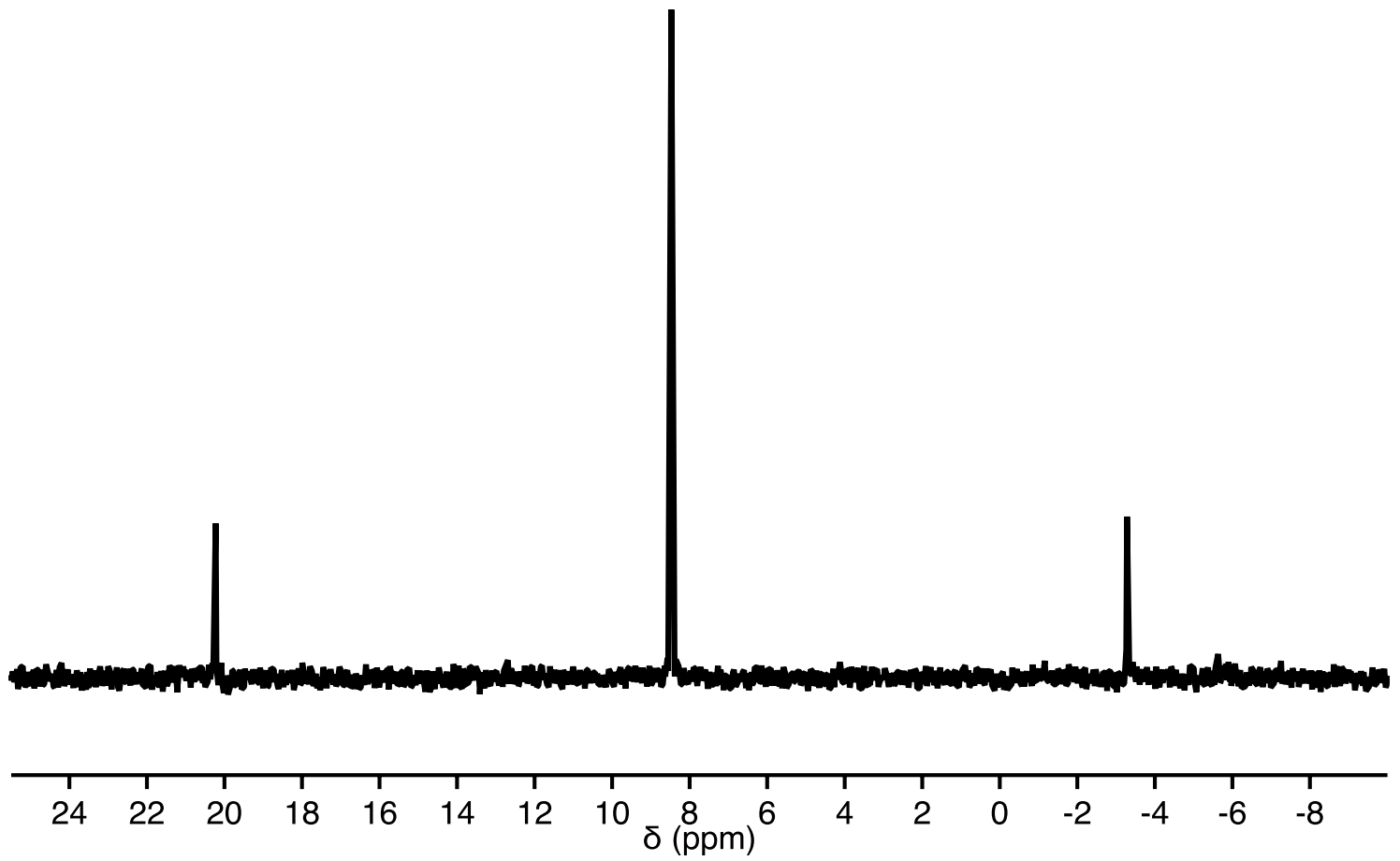

Figure A.3. ${ }^{31} \mathrm{P}\left\{{ }^{1} \mathrm{H}\right\}$ NMR spectrum of $[\mathrm{Pt}(\mathrm{BCP})(\mathrm{dppp})](\mathbf{1 a})(121 \mathrm{MHz}, \mathrm{RT}$, $\left.40 \mathrm{mg} / \mathrm{mL}, \mathrm{C}_{6} \mathrm{D}_{6}\right)$. 

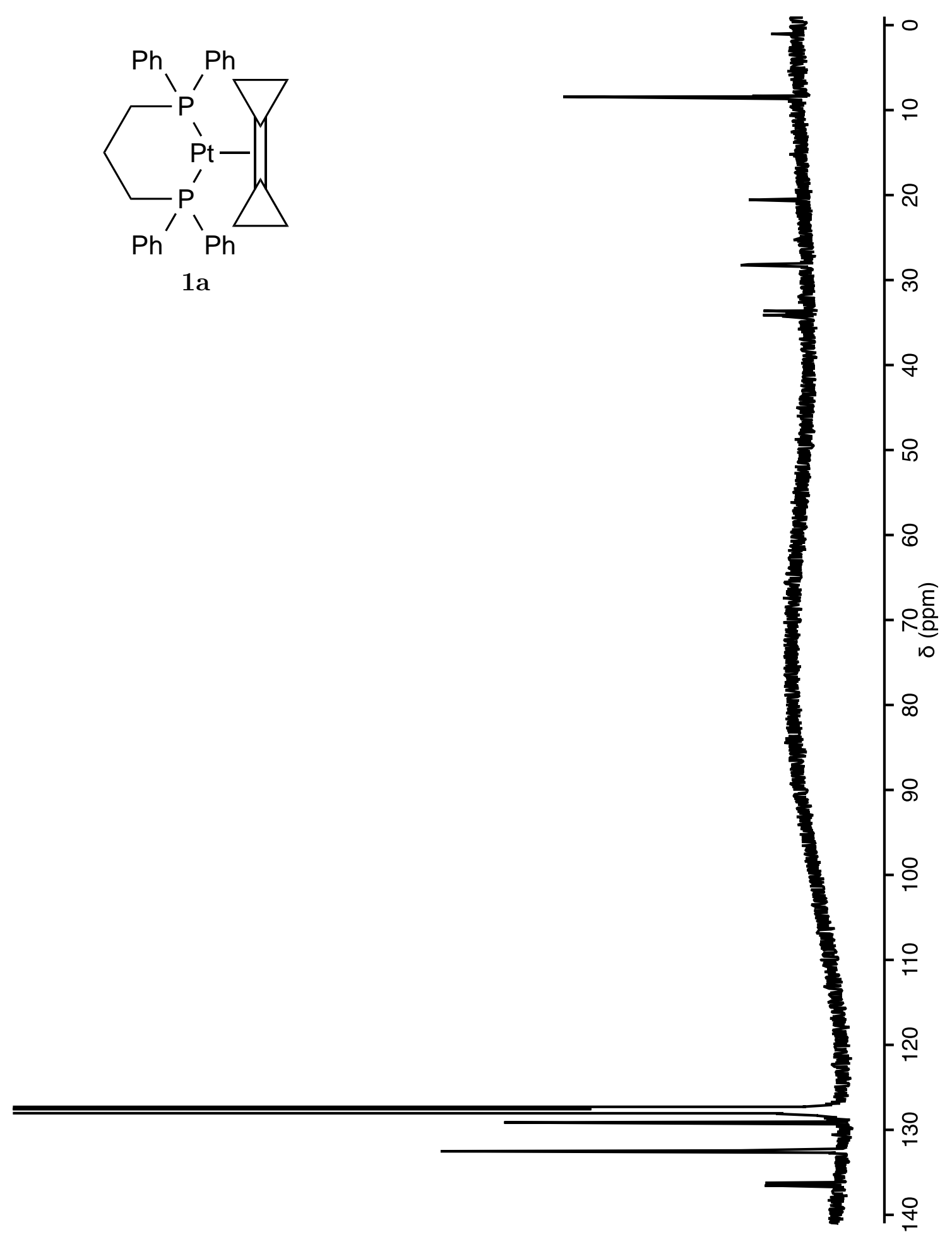

Figure A.4. ${ }^{13} \mathrm{C}\left\{{ }^{1} \mathrm{H}\right\}$ NMR spectrum of $[\mathrm{Pt}(\mathrm{BCP})(\mathrm{dppp})]$ (1a) (150 MHz, RT, $40 \mathrm{mg} / \mathrm{mL}, \mathrm{C}_{6} \mathrm{D}_{6}$ ). 

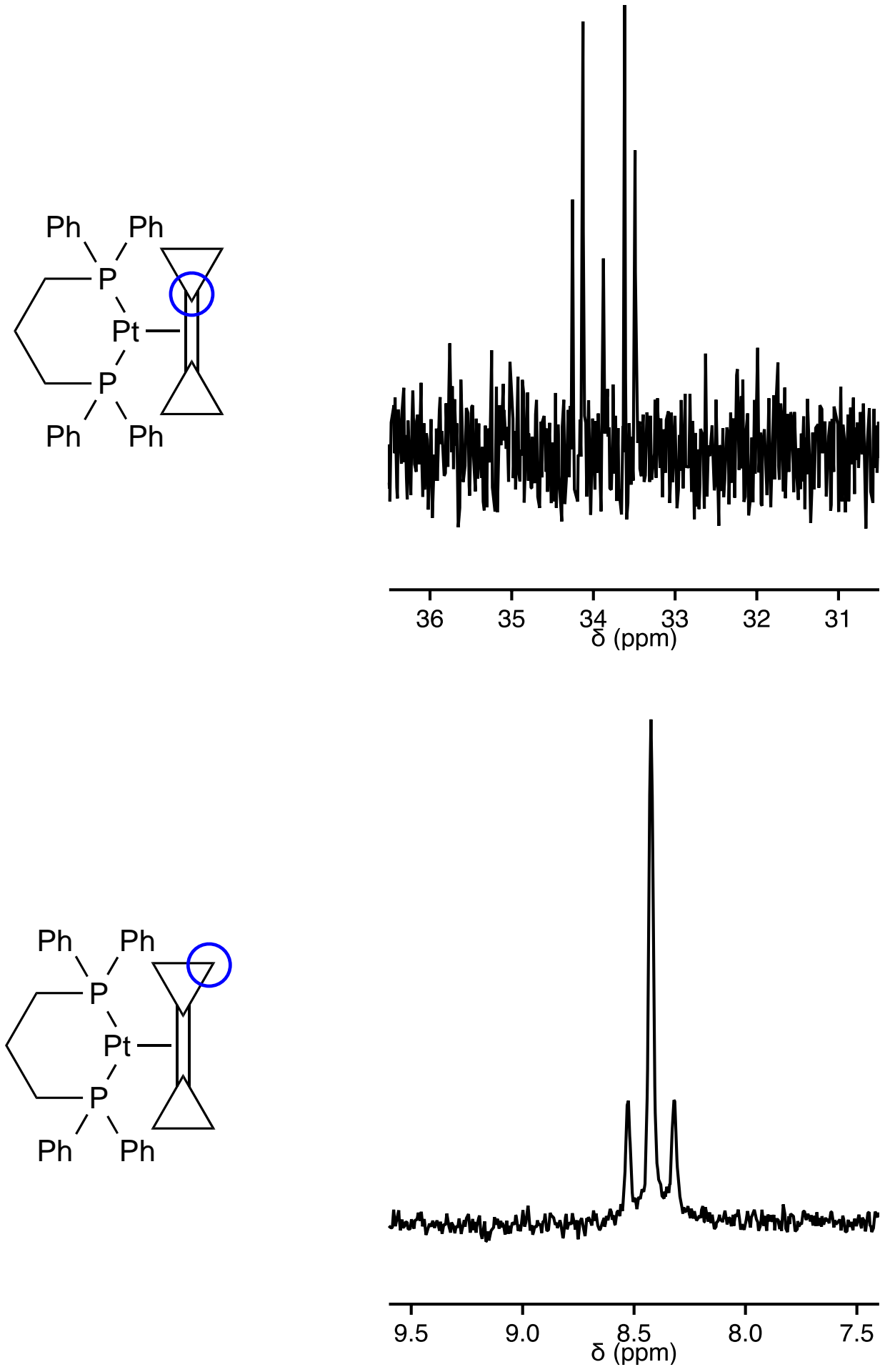

Figure A.5. Expanded ${ }^{13} \mathrm{C}\left\{{ }^{1} \mathrm{H}\right\}$ NMR spectrum of $[\mathrm{Pt}(\mathrm{BCP})(\mathrm{dppp})](\mathbf{1 a})(150 \mathrm{MHz}$, $\mathrm{RT}, 40 \mathrm{mg} / \mathrm{mL}, \mathrm{C}_{6} \mathrm{D}_{6}$ ). 

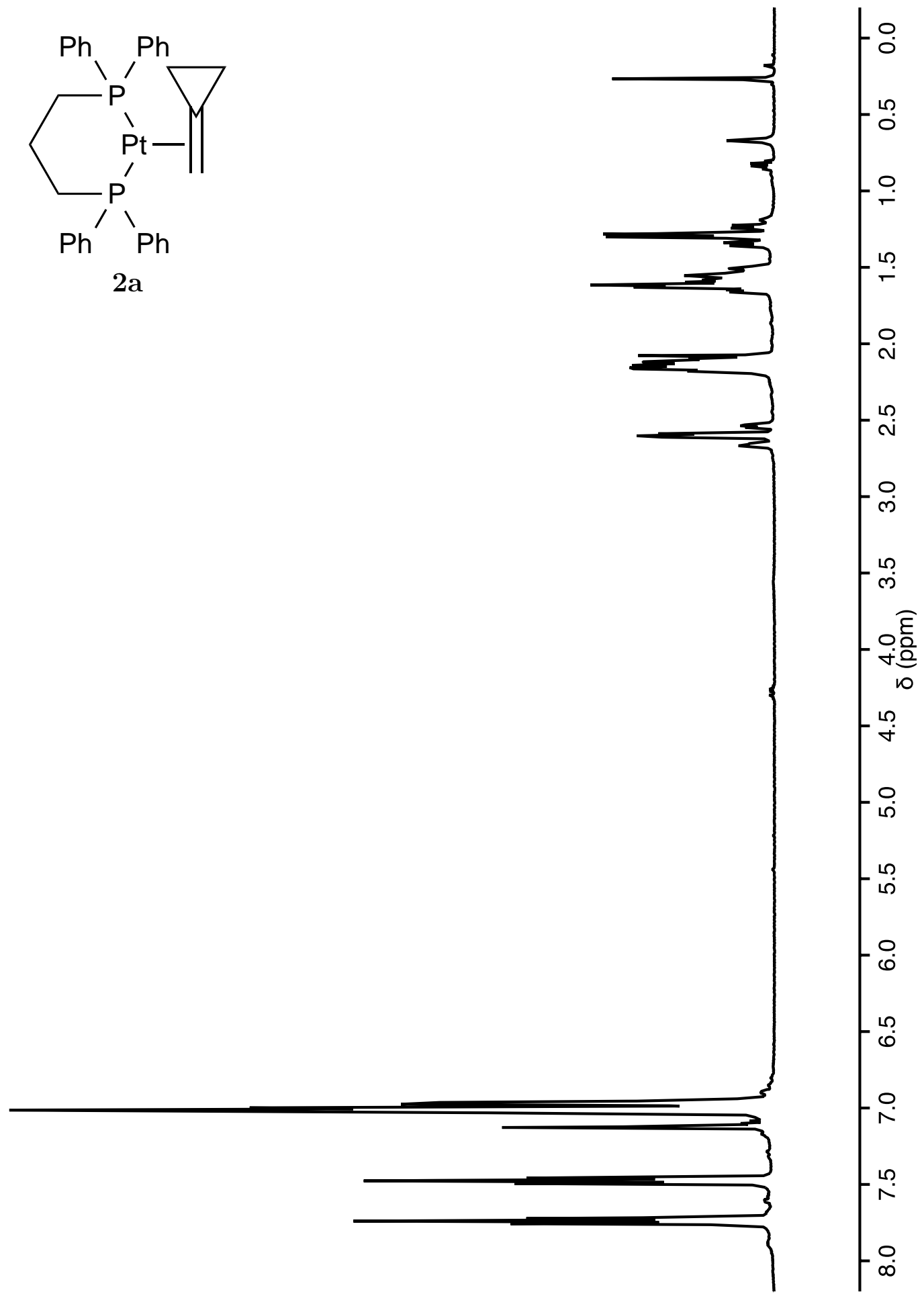

Figure A.6. ${ }^{1} \mathrm{H}$ NMR spectrum of $[\mathrm{Pt}(\mathrm{MCP})(\mathrm{dppp})]$ (2a) $(500 \mathrm{MHz}, \mathrm{RT}, 40 \mathrm{mg} / \mathrm{mL}$, $\mathrm{C}_{6} \mathrm{D}_{6}$ ). 

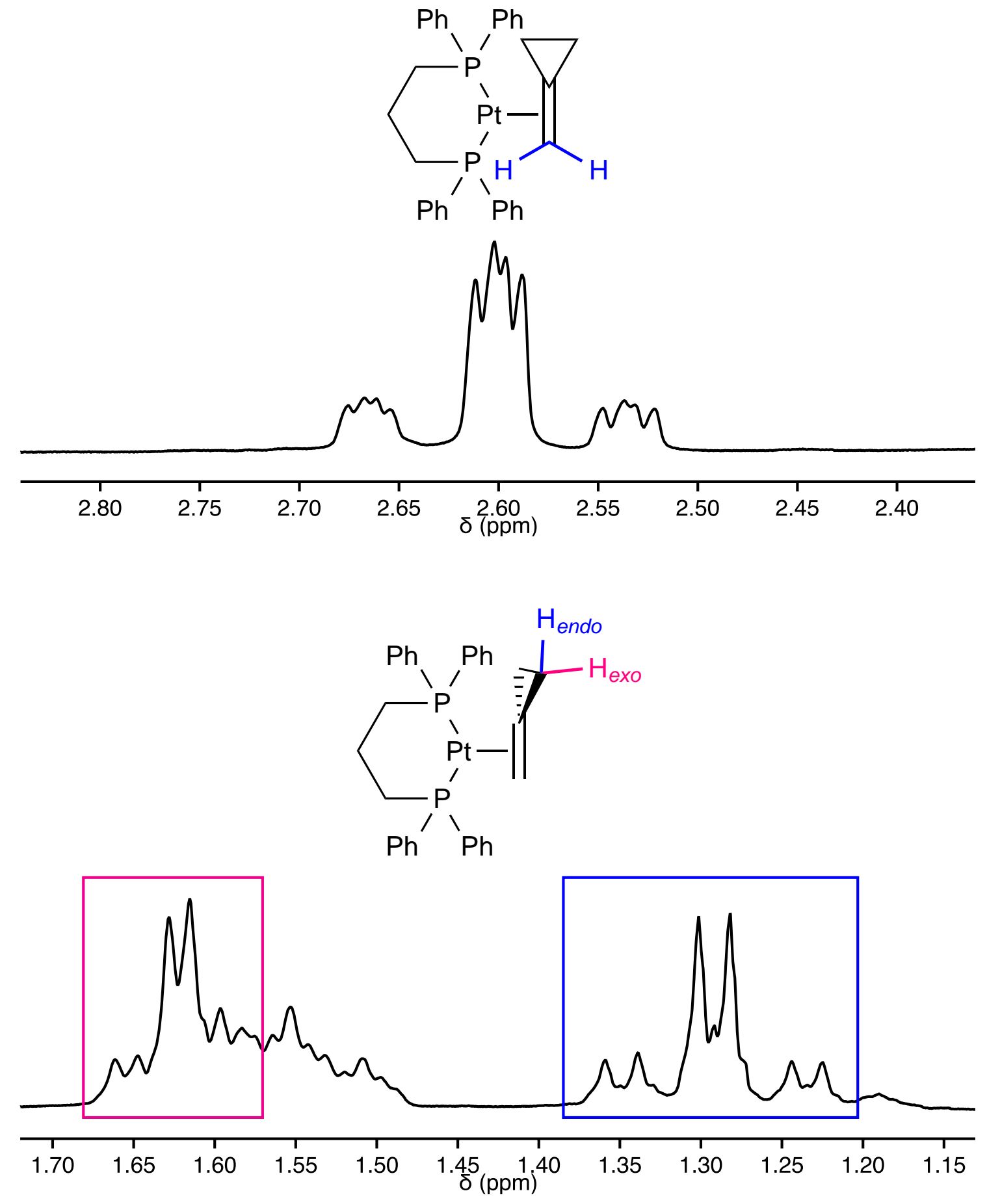

Figure A.7. Expanded ${ }^{1} \mathrm{H}$ NMR spectrum of $[\mathrm{Pt}(\mathrm{MCP})(\mathrm{dppp})]$ (2a) (500 MHz, RT, $40 \mathrm{mg} / \mathrm{mL}, \mathrm{C}_{6} \mathrm{D}_{6}$ ). 

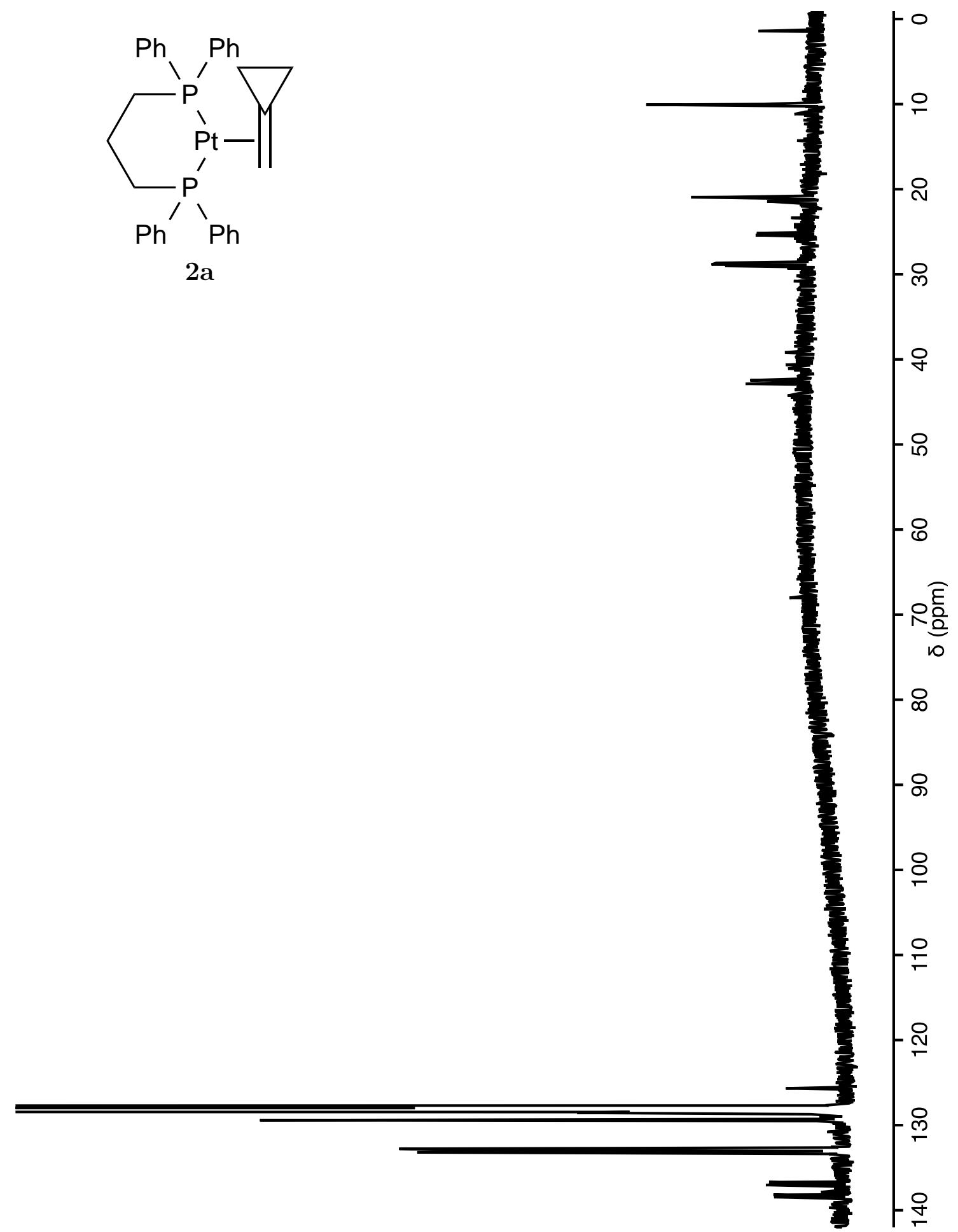

Figure A.8. ${ }^{13} \mathrm{C}\left\{{ }^{1} \mathrm{H}\right\}$ NMR spectrum of $[\mathrm{Pt}(\mathrm{MCP})(\mathrm{dppp})](\mathbf{2 a})(125 \mathrm{MHz}, \mathrm{RT}$, $\left.40 \mathrm{mg} / \mathrm{mL}, \mathrm{C}_{6} \mathrm{D}_{6}\right)$. 

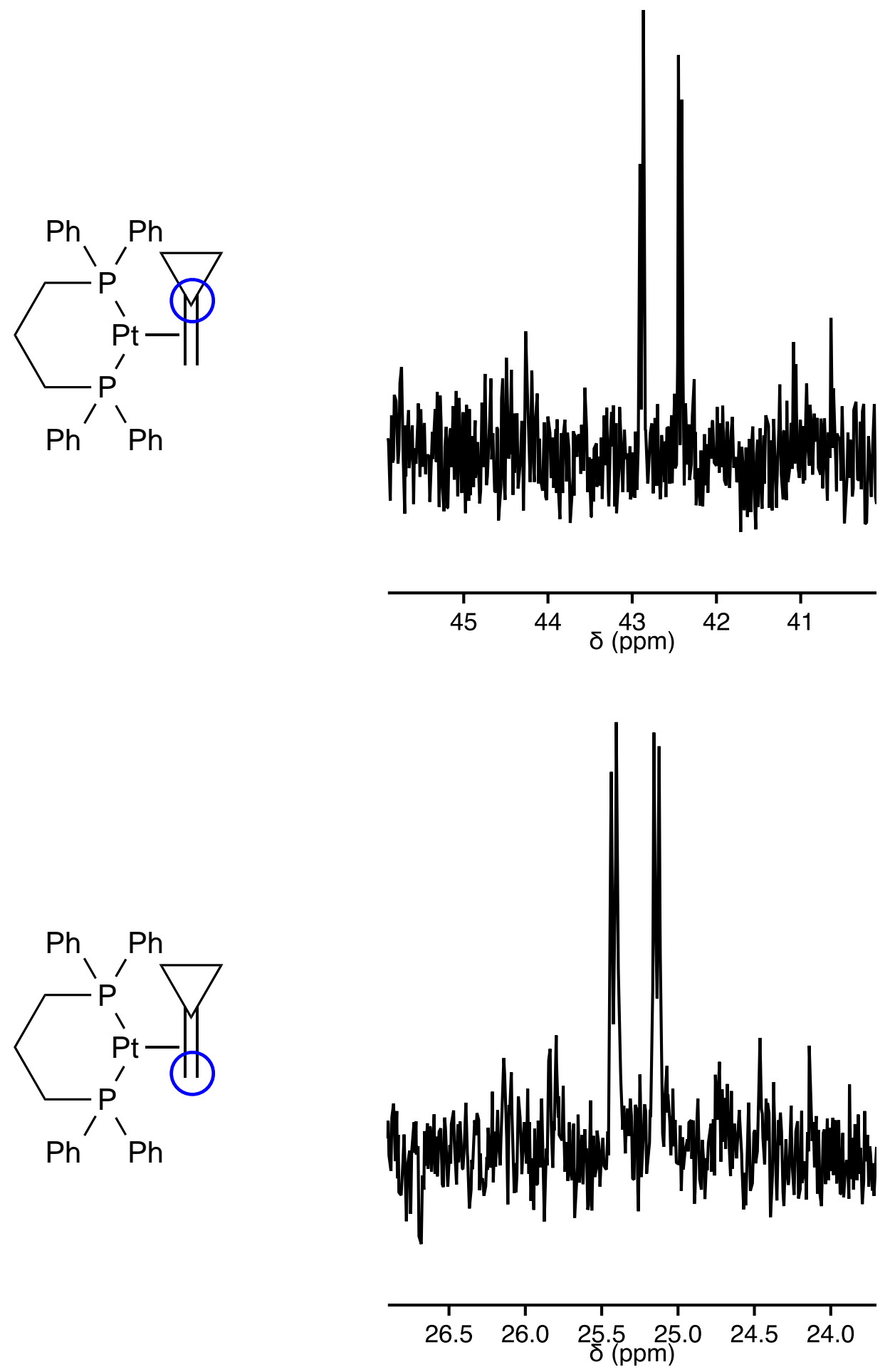

Figure A.9. Expanded ${ }^{13} \mathrm{C}\left\{{ }^{1} \mathrm{H}\right\}$ NMR spectrum of $[\mathrm{Pt}(\mathrm{MCP})(\mathrm{dppp})]$ (2a) (125 MHz, $\left.\mathrm{RT}, 40 \mathrm{mg} / \mathrm{mL}, \mathrm{C}_{6} \mathrm{D}_{6}\right)$. 

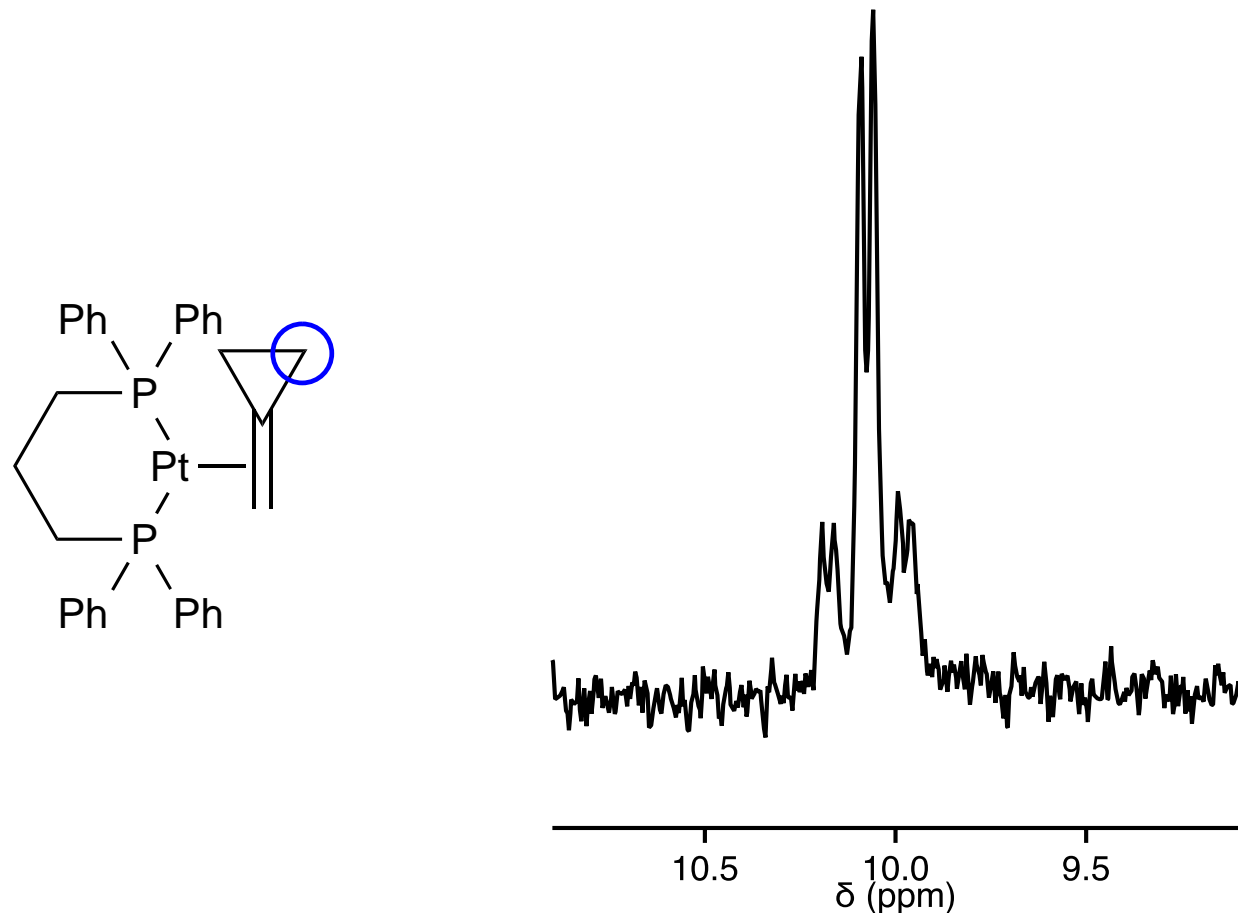

Figure A.10. Expanded ${ }^{13} \mathrm{C}\left\{{ }^{1} \mathrm{H}\right\}$ NMR spectrum of $[\mathrm{Pt}(\mathrm{MCP})(\mathrm{dppp})](\mathbf{2 a})(125 \mathrm{MHz}$, $\mathrm{RT}, 40 \mathrm{mg} / \mathrm{mL}, \mathrm{C}_{6} \mathrm{D}_{6}$ ).

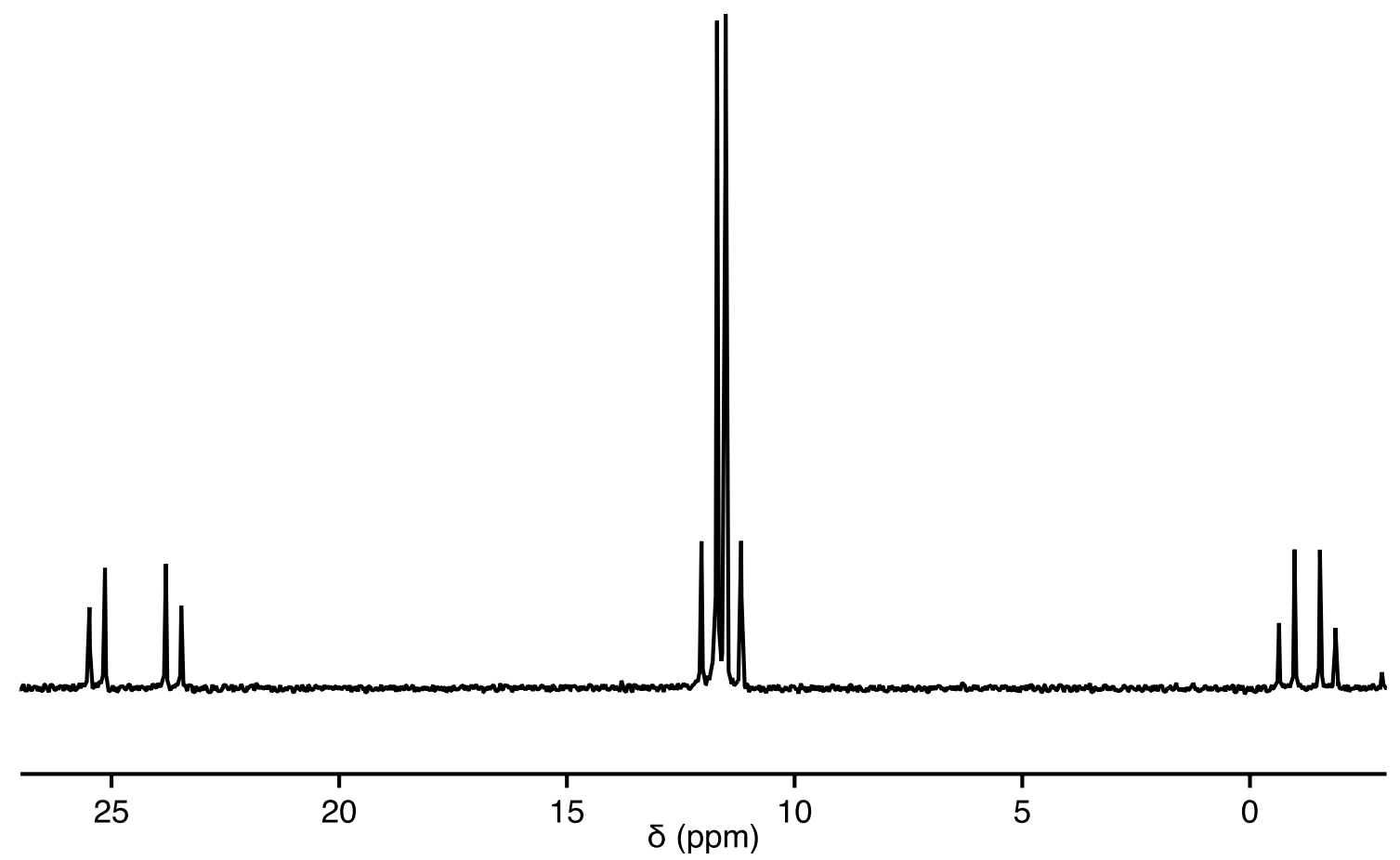

Figure A.11. ${ }^{31} \mathrm{P}\left\{{ }^{1} \mathrm{H}\right\}$ NMR spectrum of $[\mathrm{Pt}(\mathrm{MCP})(\mathrm{dppp})](\mathbf{2 a})(121 \mathrm{MHz}, \mathrm{RT}$, $40 \mathrm{mg} / \mathrm{mL}, \mathrm{C}_{6} \mathrm{D}_{6}$ ). 

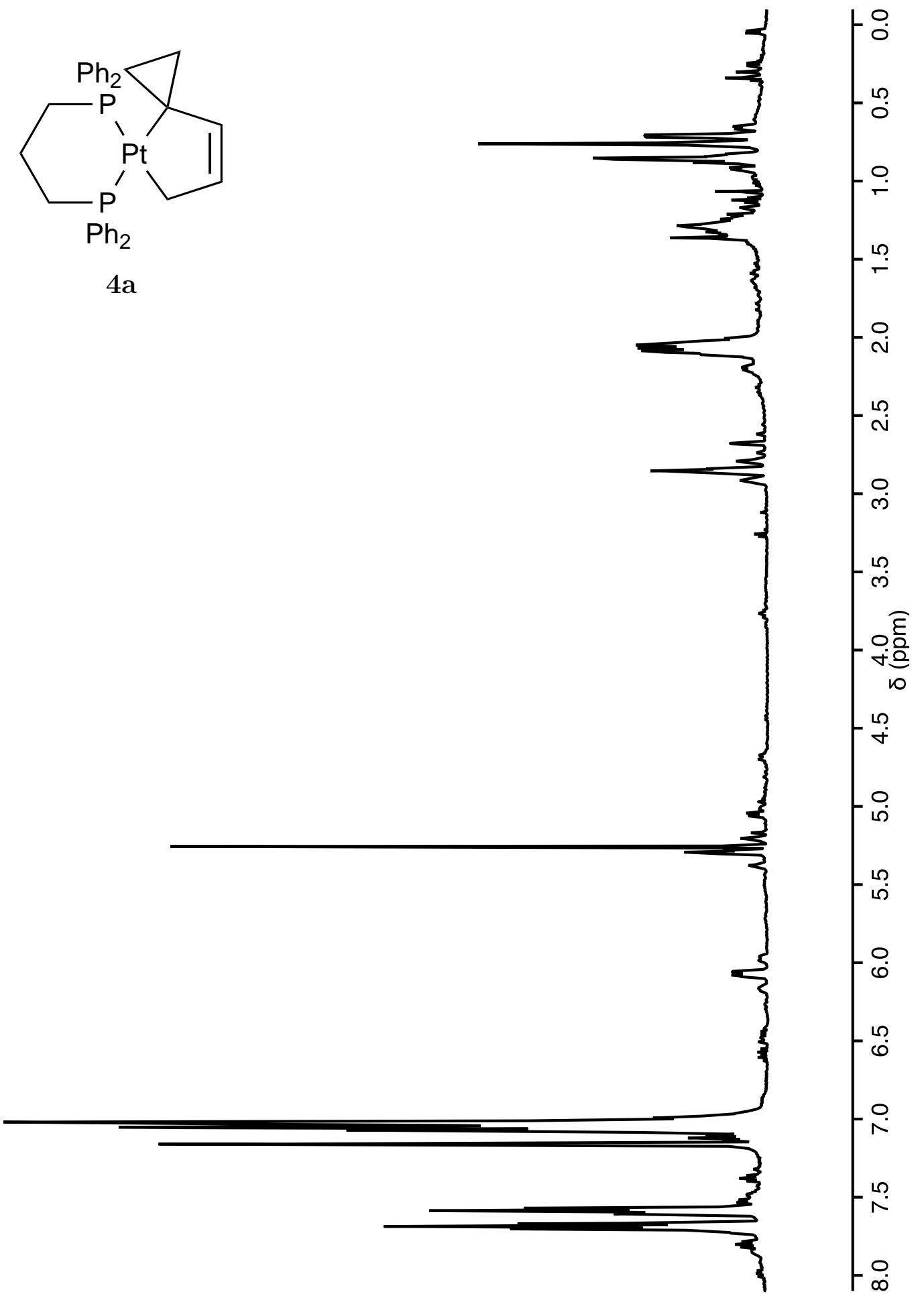

Figure A.12. ${ }^{1} \mathrm{H}$ NMR spectrum of $\left[\mathrm{Pt}\left(\mathrm{CH}_{2} \mathrm{CH}=\mathrm{CHC}\left(\mathrm{CH}_{2}\right)_{2}\right)(\mathrm{dppp})\right](4 \mathbf{a})(500 \mathrm{MHz}$, $\mathrm{RT}, 40 \mathrm{mg} / \mathrm{mL}, \mathrm{C}_{6} \mathrm{D}_{6}$ ). 

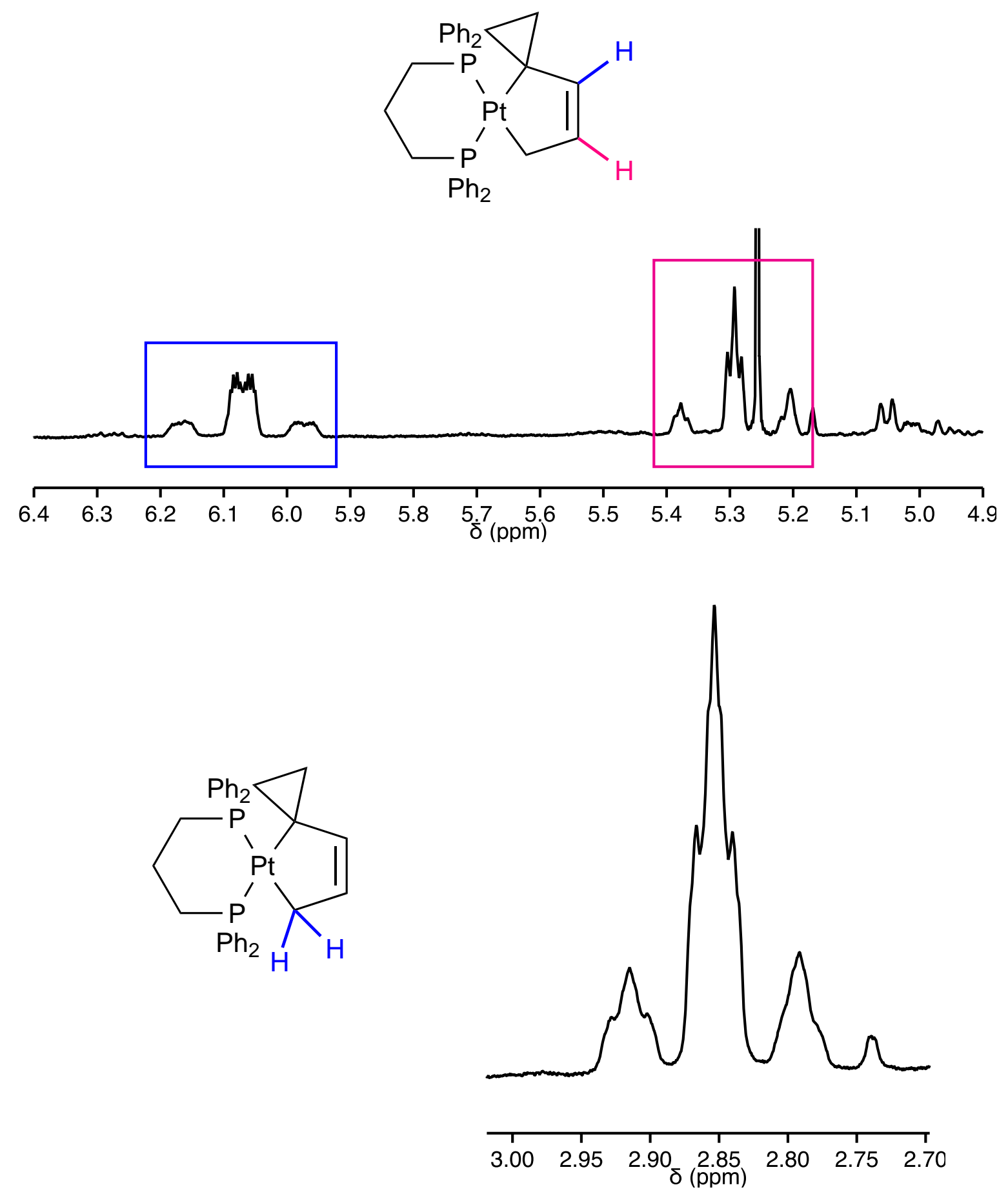

Figure A.13. Expanded ${ }^{1} \mathrm{H}$ NMR spectrum of $\left[{\mathrm{Pt}\left(\mathrm{CH}_{2} \mathrm{CH}=\mathrm{CHC}\right.}_{\left.\left(\mathrm{CH}_{2}\right)_{2}\right)}(\mathrm{dppp})\right]$ (4a) (500 MHz, RT, $40 \mathrm{mg} / \mathrm{mL}, \mathrm{C}_{6} \mathrm{D}_{6}$ ). 


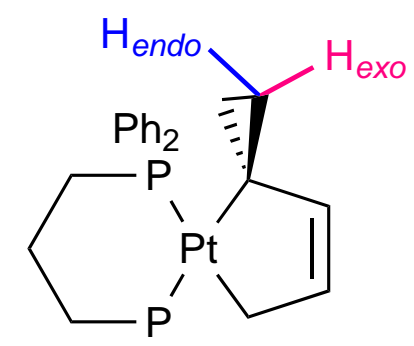

$\mathrm{Ph}_{2}$

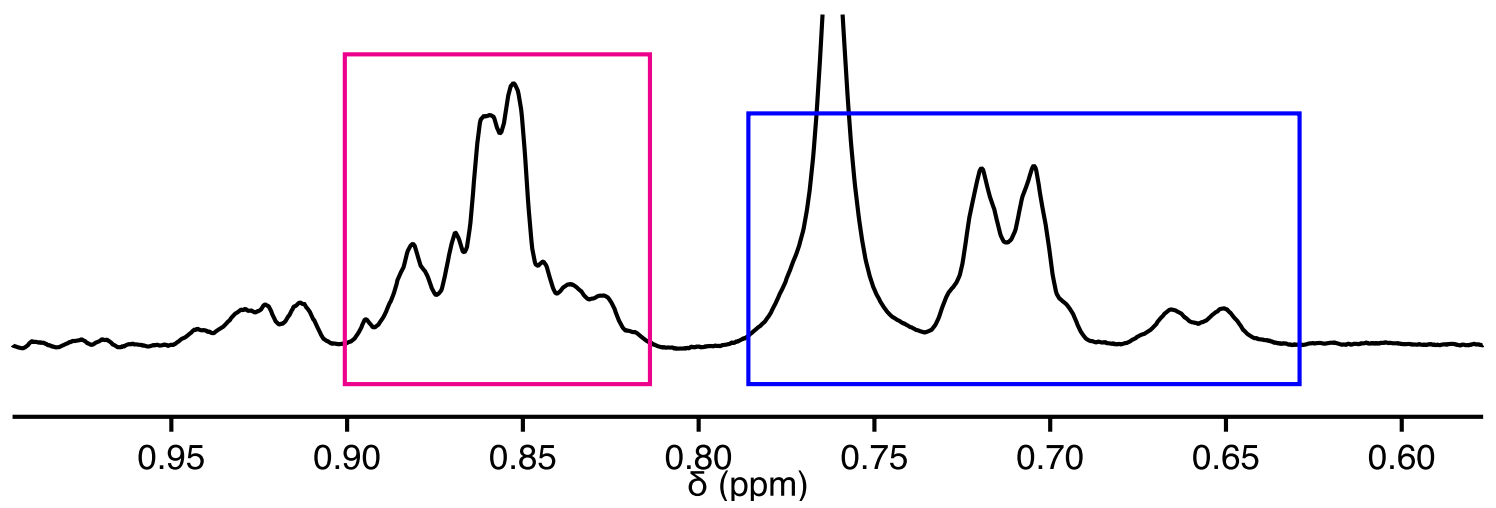

Figure A.14. Expanded ${ }^{1} \mathrm{H}$ NMR spectrum of $\left[\mathrm{Pt}\left(\mathrm{CH}_{2} \mathrm{CH}=\mathrm{CHC}\left(\mathrm{CH}_{2}\right)_{2}\right)(\mathrm{dppp})\right](\mathbf{4 a})$ $\left(500 \mathrm{MHz}, \mathrm{RT}, 40 \mathrm{mg} / \mathrm{mL}, \mathrm{C}_{6} \mathrm{D}_{6}\right.$ ).
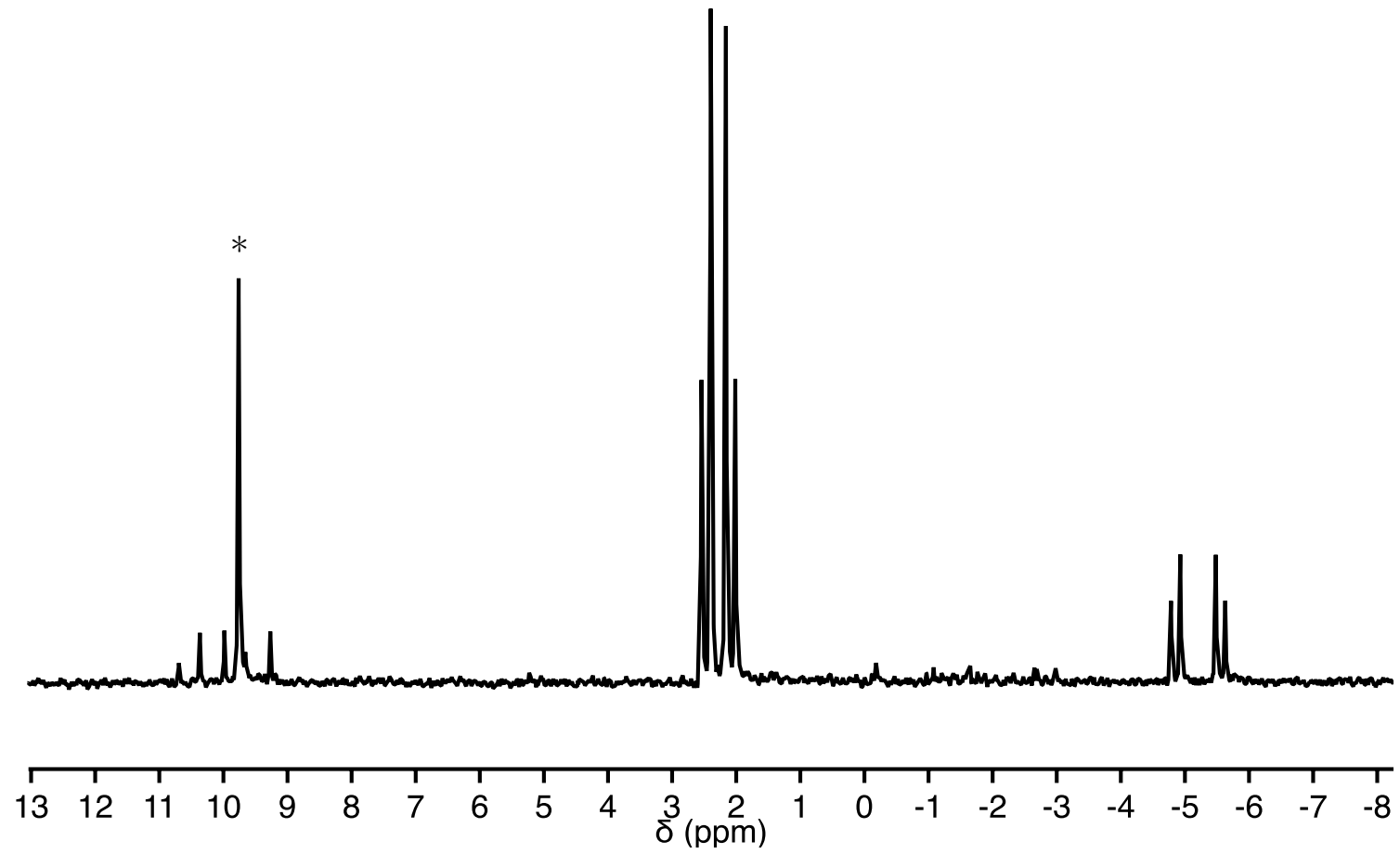

Figure A.15. ${ }^{31} \mathrm{P}\left\{{ }^{1} \mathrm{H}\right\}$ NMR spectrum of $\left[\mathrm{Pt}\left(\mathrm{CH}_{2} \mathrm{CH}=\mathrm{CHC}\left(\mathrm{CH}_{2}\right)_{2}\right)(\mathrm{dppp})\right]($ (4a) $\left(121 \mathrm{MHz}, \mathrm{RT}, 40 \mathrm{mg} / \mathrm{mL}, \mathrm{C}_{6} \mathrm{D}_{6}\right) .{ }^{*}$ signifies peaks belonging to other species. 

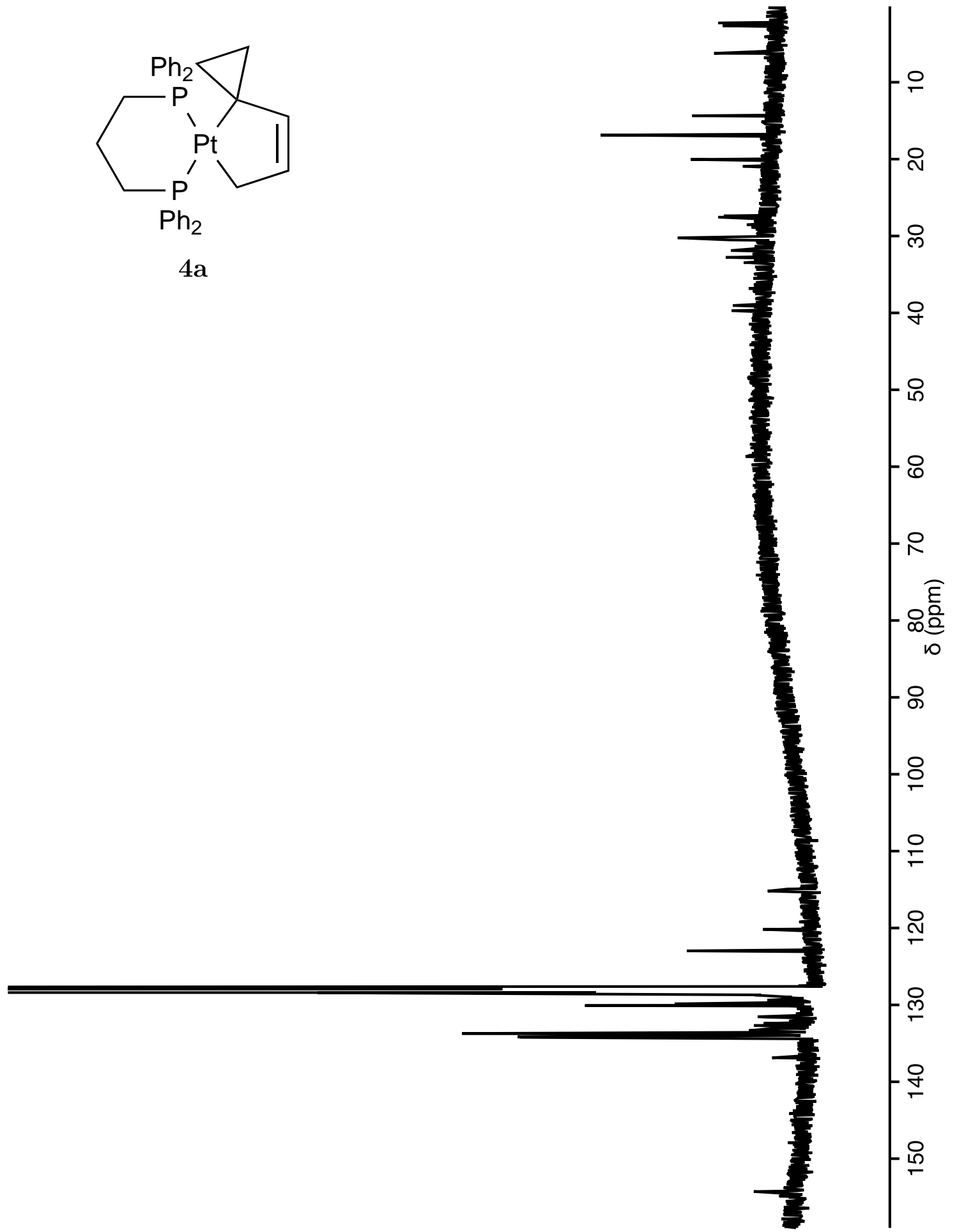

Figure A.16. ${ }^{13} \mathrm{C}\left\{{ }^{1} \mathrm{H}\right\}$ NMR spectrum of $\left[\mathrm{Pt}\left(\mathrm{CH}_{2} \mathrm{CH}=\mathrm{CHC}\left(\mathrm{CH}_{2}\right)_{2}\right)(\mathrm{dppp})\right]$ (4a) (125 MHz, RT, $40 \mathrm{mg} / \mathrm{mL}, \mathrm{C}_{6} \mathrm{D}_{6}$ ). 

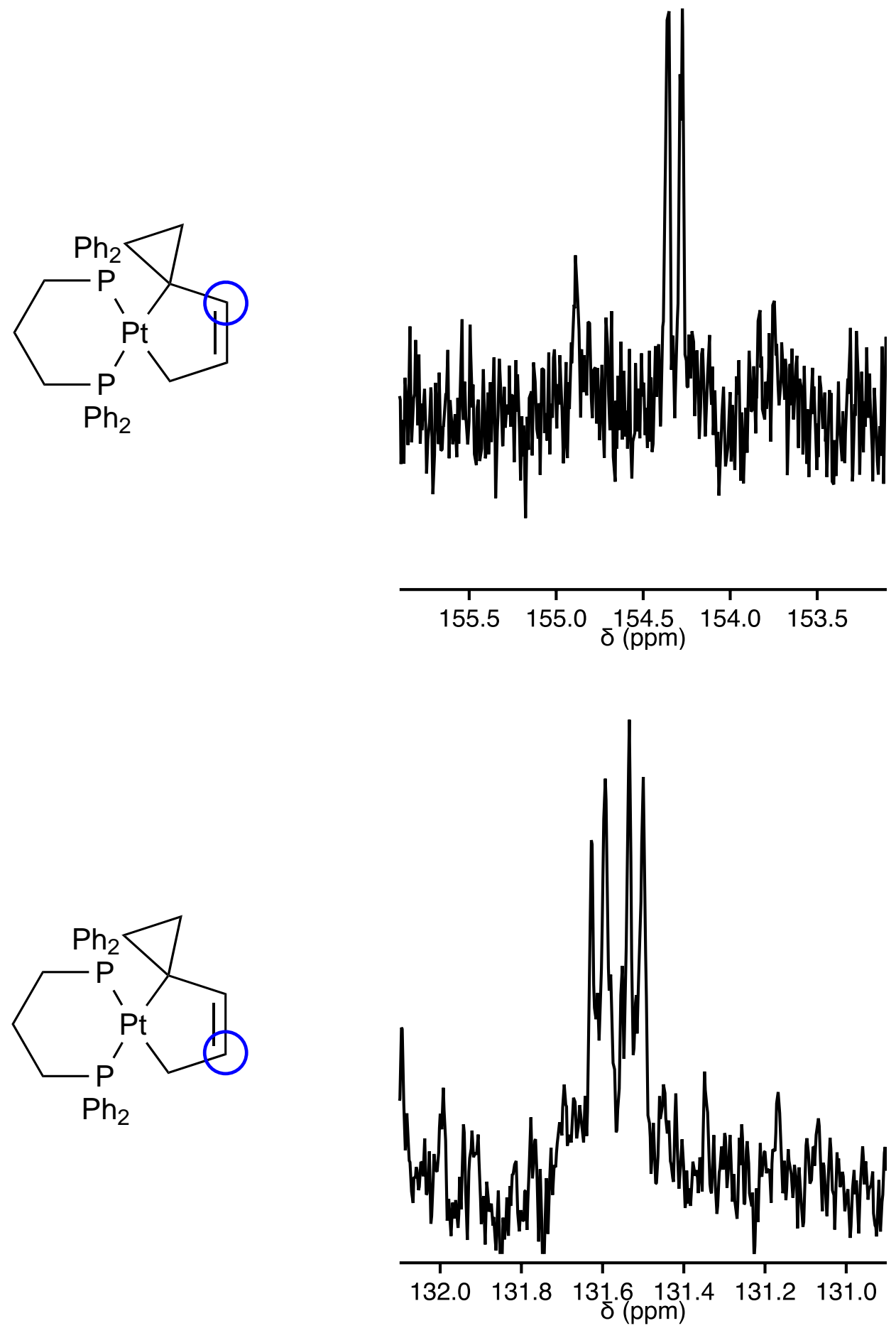

Figure A.17. Expanded ${ }^{13} \mathrm{C}\left\{{ }^{1} \mathrm{H}\right\}$ NMR spectrum of $\left[\mathrm{Pt}\left(\mathrm{CH}_{2} \mathrm{CH}=\mathrm{CHC}\left(\mathrm{CH}_{2}\right)_{2}\right)(\mathrm{dppp})\right]$ (4a) $\left(125 \mathrm{MHz}, \mathrm{RT}, 40 \mathrm{mg} / \mathrm{mL}, \mathrm{C}_{6} \mathrm{D}_{6}\right)$. 

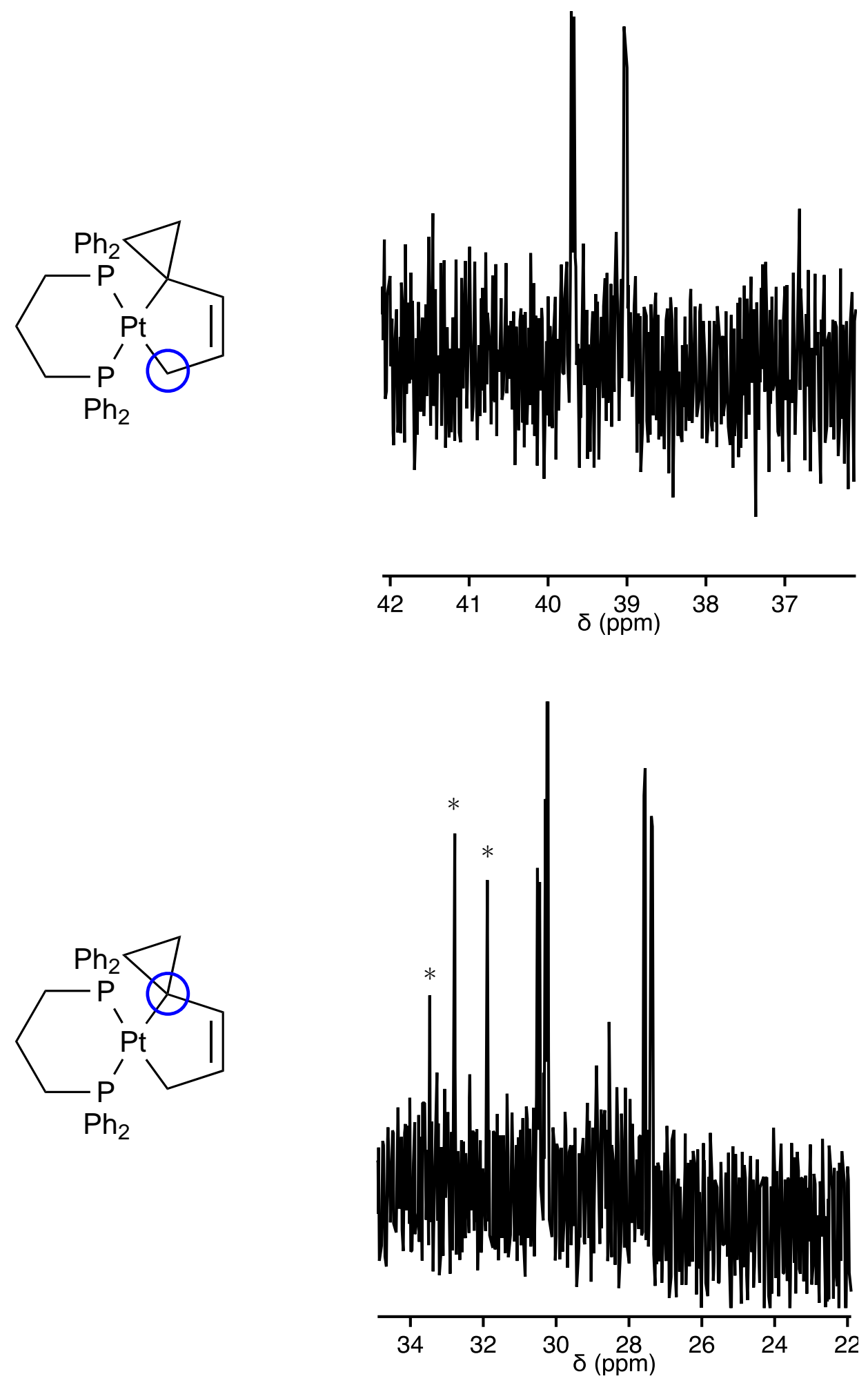

Figure A.18. Expanded ${ }^{13} \mathrm{C}\left\{{ }^{1} \mathrm{H}\right\}$ NMR spectrum of $\left[\mathrm{Pt}\left(\mathrm{CH}_{2} \mathrm{CH}=\mathrm{CHC}\left(\mathrm{CH}_{2}\right)_{2}\right)(\mathrm{dppp})\right]$ (4a) $\left(125 \mathrm{MHz}, \mathrm{RT}, 40 \mathrm{mg} / \mathrm{mL}, \mathrm{C}_{6} \mathrm{D}_{6}\right)$.* signifies peaks belonging to other species 


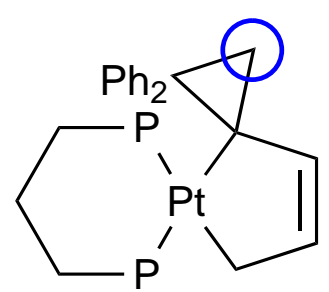

$\mathrm{Ph}_{2}$

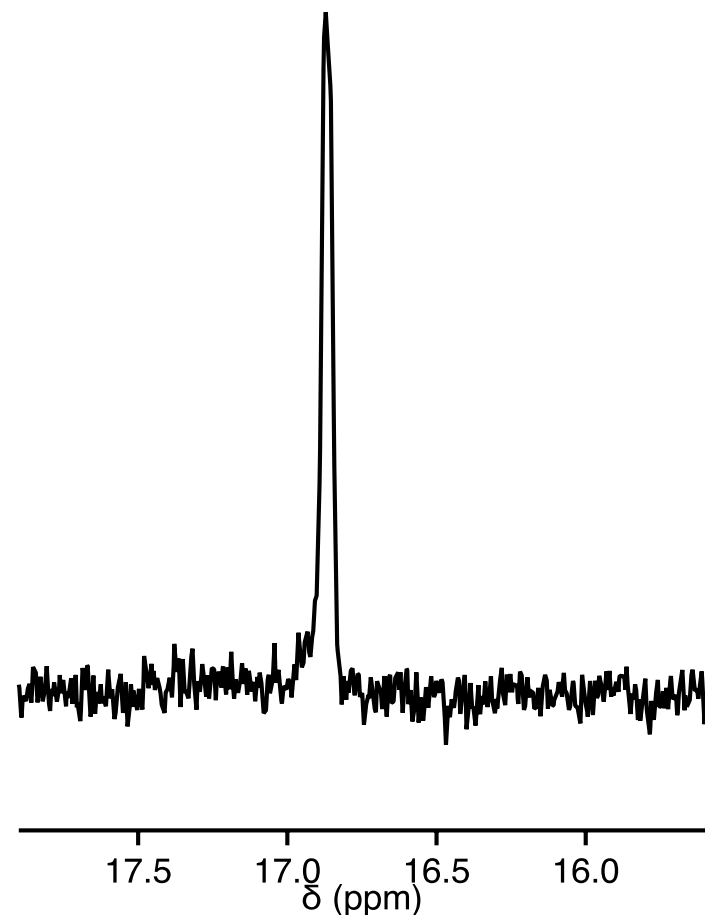

Figure A.19. Expanded ${ }^{13} \mathrm{C}\left\{{ }^{1} \mathrm{H}\right\}$ NMR spectrum of $\left.\left.\left[\stackrel{\mathrm{Pt}\left(\mathrm{CH}_{2} \mathrm{CH}=\mathrm{CHC}\right.}{\mathrm{CH}_{2}}\right)_{2}\right)(\mathrm{dppp})\right]$ (4a) $\left(125 \mathrm{MHz}, \mathrm{RT}, 40 \mathrm{mg} / \mathrm{mL}, \mathrm{C}_{6} \mathrm{D}_{6}\right)$. 


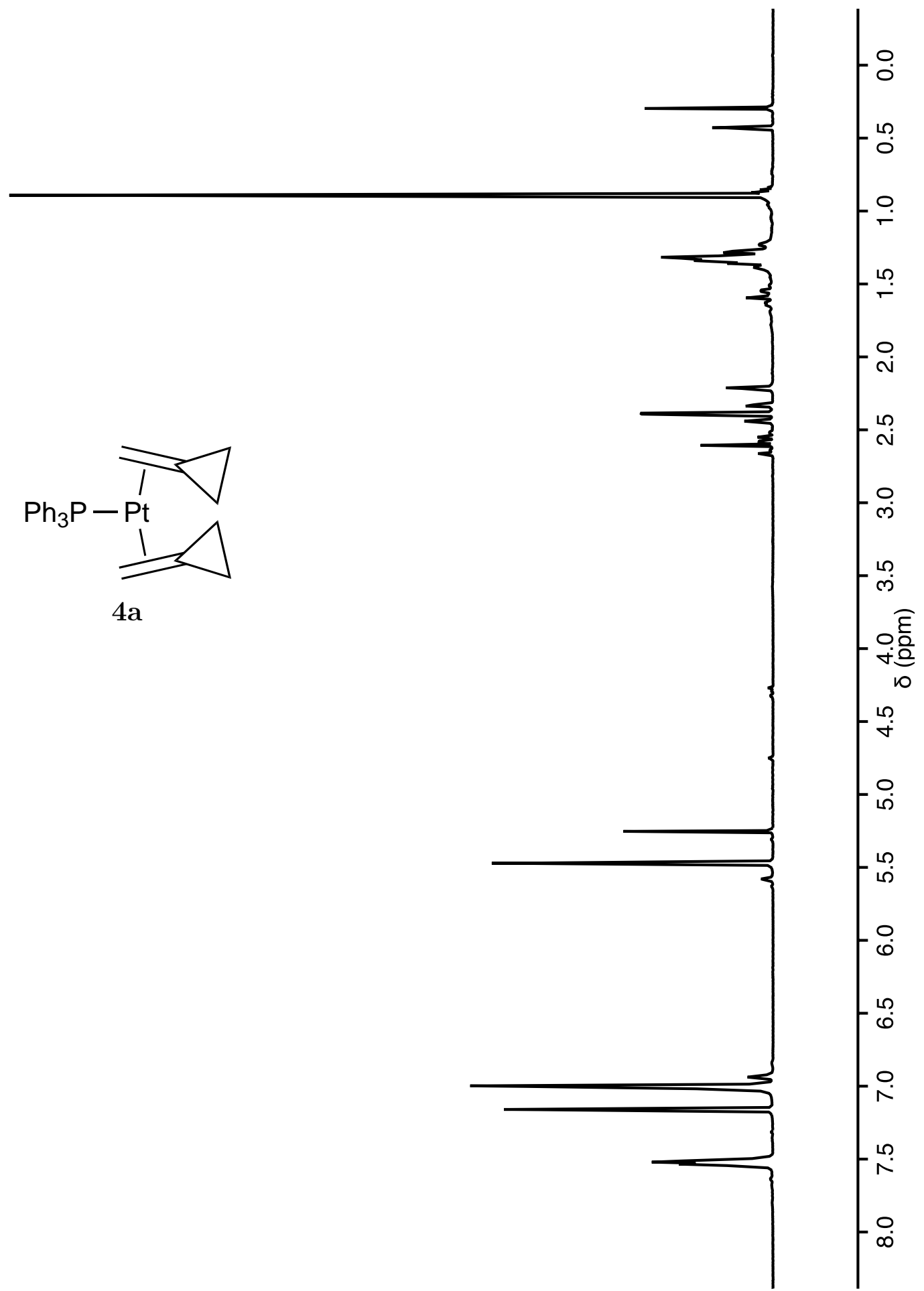

Figure A.20. ${ }^{1} \mathrm{H}$ NMR spectrum of $\left[\mathrm{Pt}(\mathrm{MCP})_{2}\left(\mathrm{PPh}_{3}\right)\right](\mathbf{7 a})(500 \mathrm{MHz}, \mathrm{RT}$, $\left.40 \mathrm{mg} / \mathrm{mL}, \mathrm{C}_{6} \mathrm{D}_{6}\right)$. 

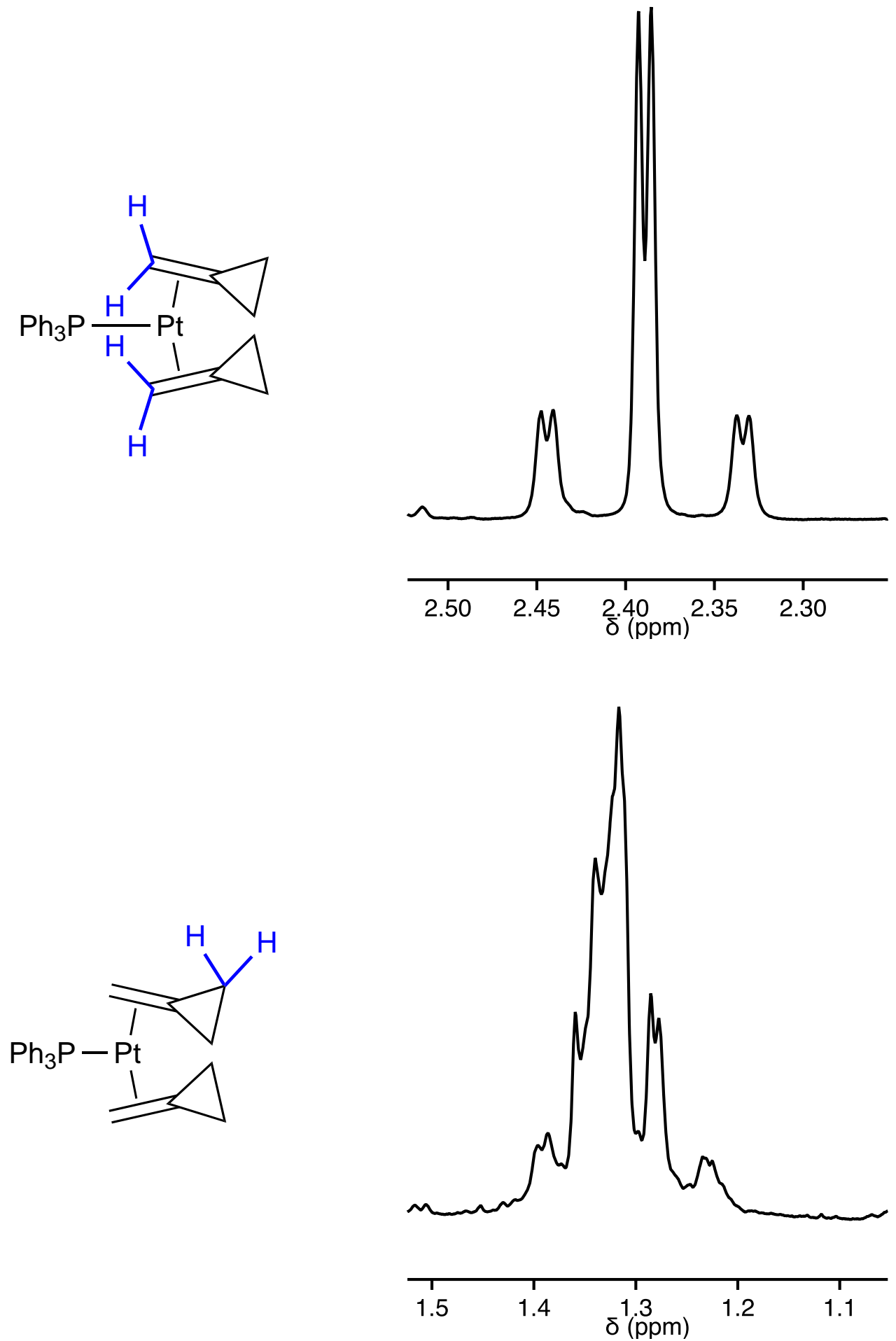

Figure A.21. Expanded ${ }^{1} \mathrm{H}$ NMR spectrum of $\left[\mathrm{Pt}(\mathrm{MCP})_{2}\left(\mathrm{PPh}_{3}\right)\right](\mathbf{7 a})(500 \mathrm{MHz}, \mathrm{RT}$, $40 \mathrm{mg} / \mathrm{mL}, \mathrm{C}_{6} \mathrm{D}_{6}$ ). 


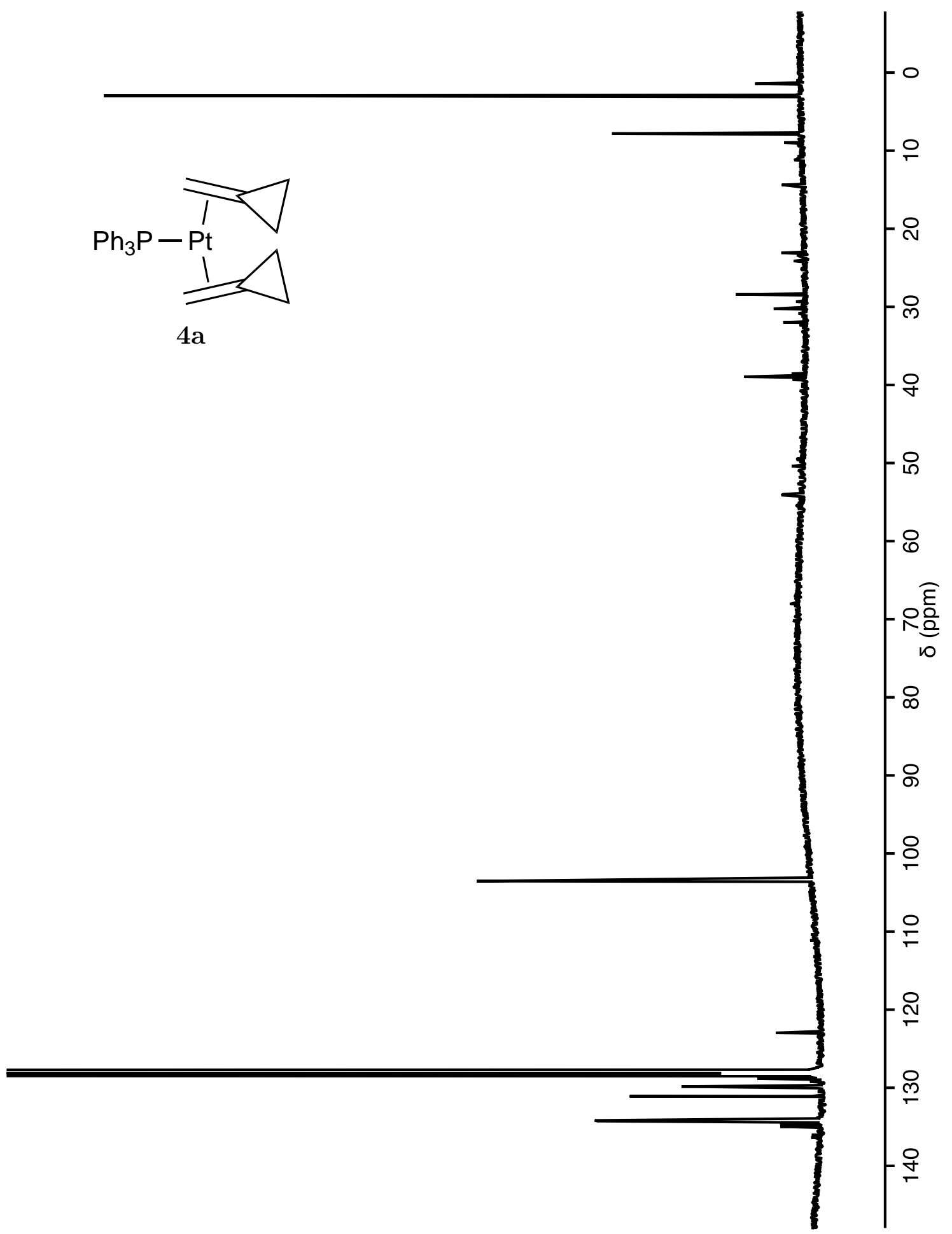

Figure A.22. ${ }^{13} \mathrm{C}\left\{{ }^{1} \mathrm{H}\right\}$ NMR spectrum of $\left[\mathrm{Pt}(\mathrm{MCP})_{2}\left(\mathrm{PPh}_{3}\right)\right]$ (7a) $(125 \mathrm{MHz}, \mathrm{RT}$, $\left.40 \mathrm{mg} / \mathrm{mL}, \mathrm{C}_{6} \mathrm{D}_{6}\right)$. 

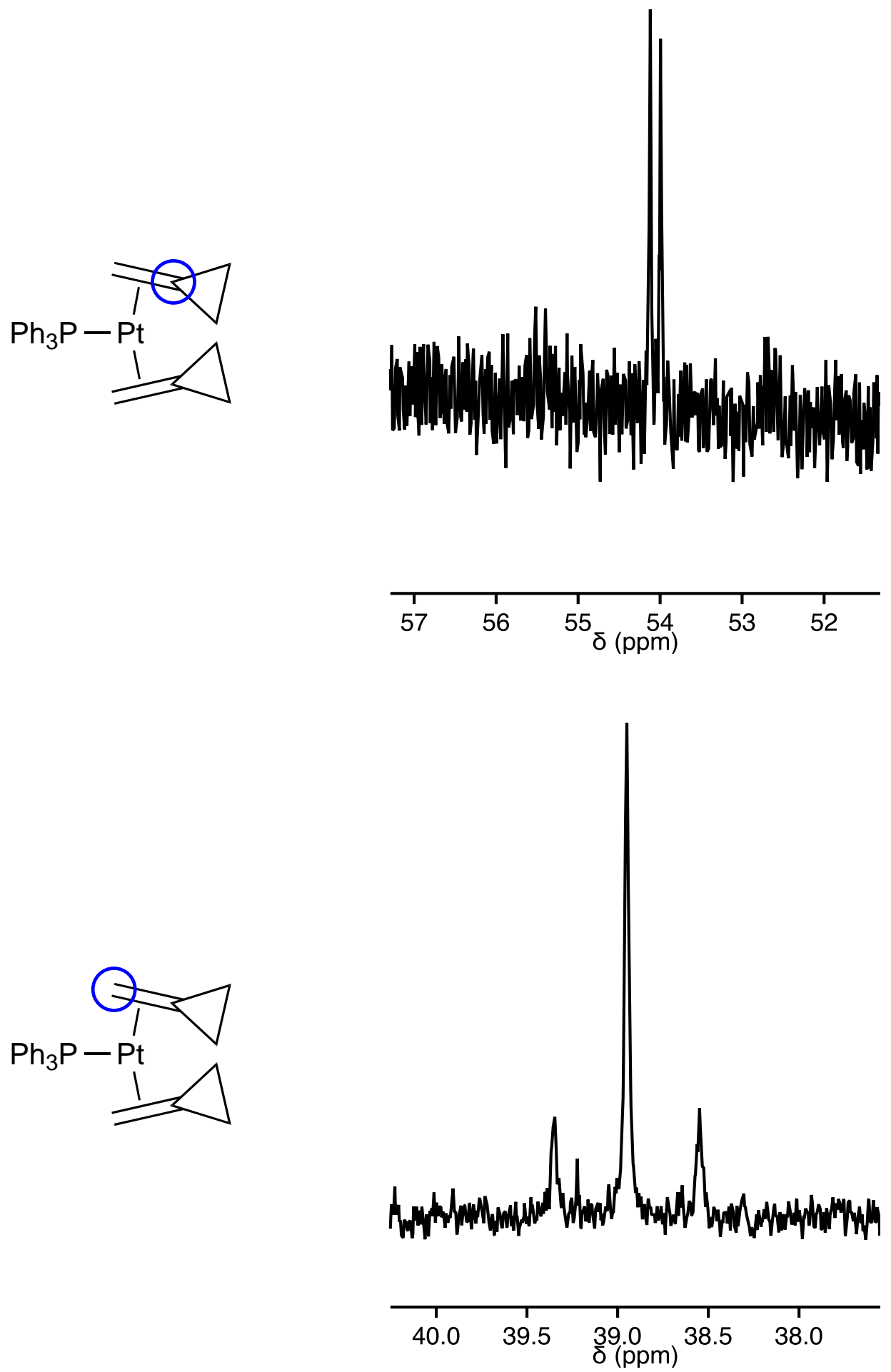

Figure A.23. Expanded ${ }^{13} \mathrm{C}\left\{{ }^{1} \mathrm{H}\right\}$ NMR spectrum of $\left[\mathrm{Pt}(\mathrm{MCP})_{2}\left(\mathrm{PPh}_{3}\right)\right](\mathbf{7 a})$ $\left(125 \mathrm{MHz}, \mathrm{RT}, 40 \mathrm{mg} / \mathrm{mL}, \mathrm{C}_{6} \mathrm{D}_{6}\right.$ ). 

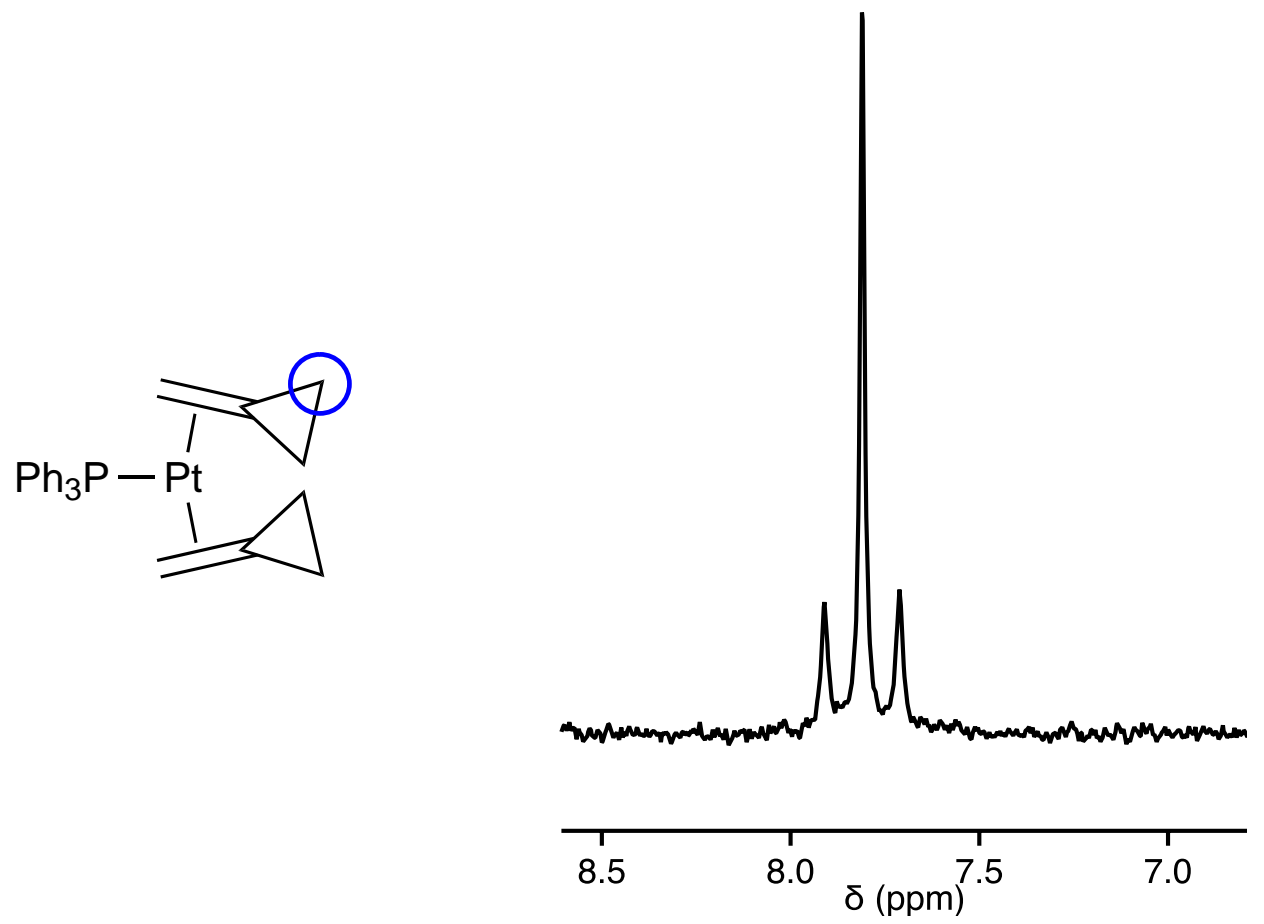

Figure A.24. Expanded ${ }^{13} \mathrm{C}\left\{{ }^{1} \mathrm{H}\right\}$ NMR spectrum of $\left[\mathrm{Pt}(\mathrm{MCP})_{2}\left(\mathrm{PPh}_{3}\right)\right](\mathbf{7 a})$ $\left(125 \mathrm{MHz}, \mathrm{RT}, 40 \mathrm{mg} / \mathrm{mL}, \mathrm{C}_{6} \mathrm{D}_{6}\right)$.

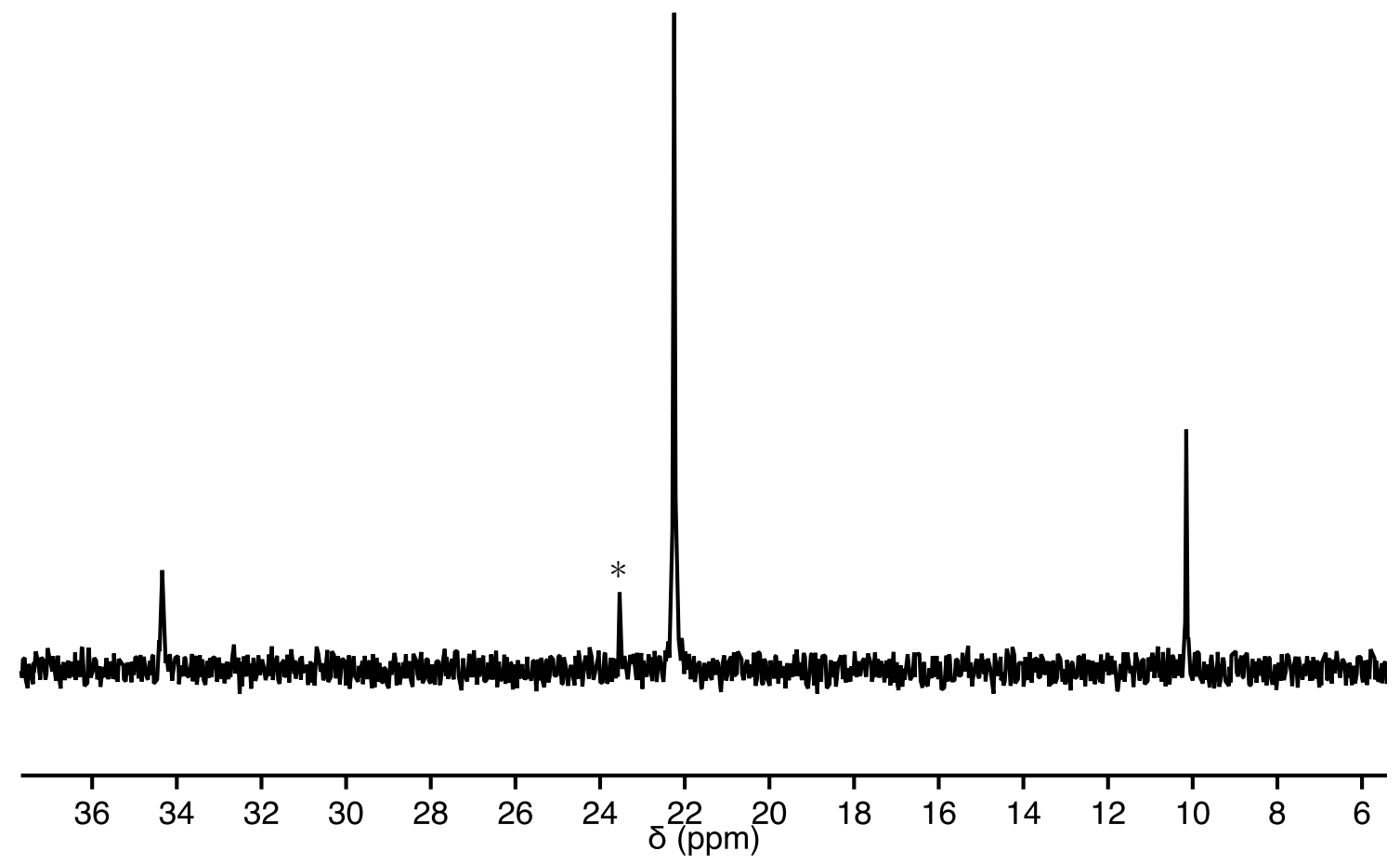

Figure A.25. ${ }^{31} \mathrm{P}\left\{{ }^{1} \mathrm{H}\right\}$ NMR spectrum of $\left[\mathrm{Pt}(\mathrm{MCP})_{2}\left(\mathrm{PPh}_{3}\right)\right]$ (7a) (121 MHz, RT, $\left.40 \mathrm{mg} / \mathrm{mL}, \mathrm{C}_{6} \mathrm{D}_{6}\right)$. ${ }^{*}$ signifies peaks belonging to other species. 


\section{A.2 Chapter Three}

$\left[\mathrm{Pt}\left(\eta^{3}-\mathrm{C}\left(\mathrm{CH}_{2}\right)_{2} \mathrm{CHCHMe}\right)\left(\mathrm{C}_{6} \mathrm{H}_{3}-o-\mathrm{CH}_{2} \mathrm{P}^{t} \mathrm{Bu}_{2}-m-\mathrm{CH}_{2} \mathrm{~S}^{t} \mathrm{Bu}\right)\right] \quad(11 \mathrm{a}$ and 11b)

${ }^{1} \mathrm{H}$ NMR spectrum - Figures A.26 and A.27, pages 185 and 186 ${ }^{13} \mathrm{C}\left\{{ }^{1} \mathrm{H}\right\}$ NMR spectrum - Figures A.28-A.31, pages $187-190$ HMBC spectrum - Figures A.32 and A.33, pages 191 and 192 COSY spectrum - Figure A.34, page 192 ${ }^{31} \mathrm{P}\left\{{ }^{1} \mathrm{H}\right\}$ NMR spectrum - Figure A.35, page 193

$\left[\mathrm{Pt}\left(\eta^{3}-\mathrm{C}\left(\mathrm{CH}_{2}\right)_{2} \mathrm{CHCHMe}\right)(\mathrm{dppp})\right]\left[\mathrm{HC}\left(\mathrm{SO}_{2} \mathrm{CF}_{3}\right)_{2}\right] \quad($ anti $\quad \mathrm{Me})$ $\left(13 \mathrm{a}\left[\mathrm{HC}\left(\mathrm{SO}_{2} \mathrm{CF}_{3}\right)_{2}\right]\right)$ and $\left[\mathrm{Pt}\left(\eta^{3}-\mathrm{C}\left(\mathrm{CH}_{2}\right)_{2} \mathrm{CHCHMe}\right)(\mathrm{dppp})\right]\left[\mathrm{HC}\left(\mathrm{SO}_{2} \mathrm{CF}_{3}\right)_{2}\right] \quad($ syn $\mathrm{Me})$ $\left(13 \mathrm{~b}\left[\mathrm{HC}\left(\mathrm{SO}_{2} \mathrm{CF}_{3}\right)_{2}\right]\right)$

${ }^{1} \mathrm{H}$ NMR spectra - Figures A.36-A.39, pages 194-197 ${ }^{13} \mathrm{C}\left\{{ }^{1} \mathrm{H}\right\}$ NMR spectrum - Figures A.40-A.43, pages $198-201$ HMBC spectrum - Figures A.44 and A.45, pages 202 and 203 COSY spectrum - Figure A.46, page 203 ${ }^{31} \mathrm{P}\left\{{ }^{1} \mathrm{H}\right\}$ NMR spectra - Figures A.47 and A.48, pages 204 and 205 

$\left[\mathrm{Pt}\left(\eta^{3}-\mathrm{CH}_{2} \mathrm{CMeCH}_{2}\right)(\mathrm{dppp})\right]\left[\mathrm{PhC}\left(\mathrm{SO}_{2} \mathrm{CF}_{3}\right)_{2}\right]\left(15\left[\mathrm{PhC}\left(\mathrm{SO}_{2} \mathrm{CF}_{3}\right)_{2}\right]\right)$, $\left[\mathrm{Pt}\left(\eta^{3}-\mathrm{CH}_{2} \mathrm{CHCHMe}\right)(\mathrm{dppp})\right]\left[\mathrm{PhC}\left(\mathrm{SO}_{2} \mathrm{CF}_{3}\right)_{2}\right]$

$\left(\begin{array}{llll}\text { anti } & \mathrm{Me}) & \left(16 \mathrm{a}\left[\mathrm{PhC}\left(\mathrm{SO}_{2} \mathrm{CF}_{3}\right)_{2}\right]\right) \quad \text { and }\end{array}\right.$

$\left[\mathrm{Pt}\left(\eta^{3}-\mathrm{CH}_{2} \mathrm{CHCHMe}\right)(\mathrm{dppp})\right]\left[\mathrm{PhC}\left(\mathrm{SO}_{2} \mathrm{CF}_{3}\right)_{2}\right] \quad($ syn $\quad \mathrm{Me})$ $\left(16 \mathrm{~b}\left[\mathrm{PhC}\left(\mathrm{SO}_{2} \mathrm{CF}_{3}\right)_{2}\right]\right)$

${ }^{1} \mathrm{H}$ NMR spectra - Figures A.49-A.54, pages 206-211

${ }^{13} \mathrm{C}\left\{{ }^{1} \mathrm{H}\right\}$ NMR spectrum - Figures A.55-A.62, pages 212-219

HMBC spectrum - Figures A.63, A.64, A.66 and A.67, pages 220- 223

COSY spectrum - Figures A.65 and A.68, pages 221 and 223

${ }^{31} \mathrm{P}\left\{{ }^{1} \mathrm{H}\right\}$ NMR spectra - Figures A.69 and A.70, pages 224 and 225 



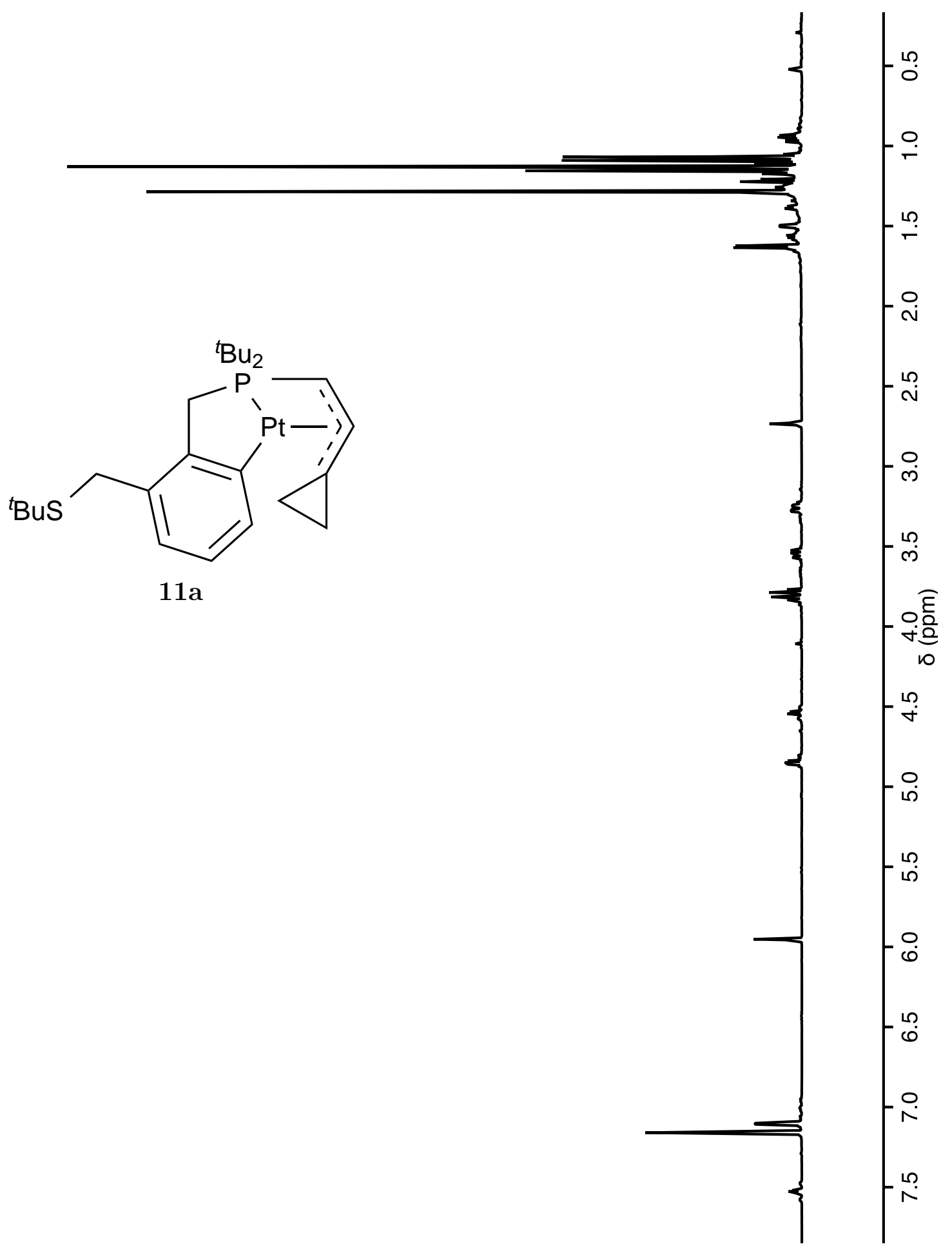

Figure A.26. ${ }^{1} \mathrm{H}$ NMR spectrum of $\left[\mathrm{Pt}\left(\eta^{3}-\mathrm{C}\left(\mathrm{CH}_{2}\right)_{2} \mathrm{CHCHMe}\right)\left(\mathrm{C}_{6} \mathrm{H}_{3}-o-\mathrm{CH}_{2} \mathrm{P}^{t} \mathrm{Bu}_{2}-m-\mathrm{CH}_{2} \mathrm{~S}^{t} \mathrm{Bu}\right)\right]$ (11a) (600 MHz, RT, $\left.40 \mathrm{mg} / \mathrm{mL}, \mathrm{C}_{6} \mathrm{D}_{6}\right)$. 

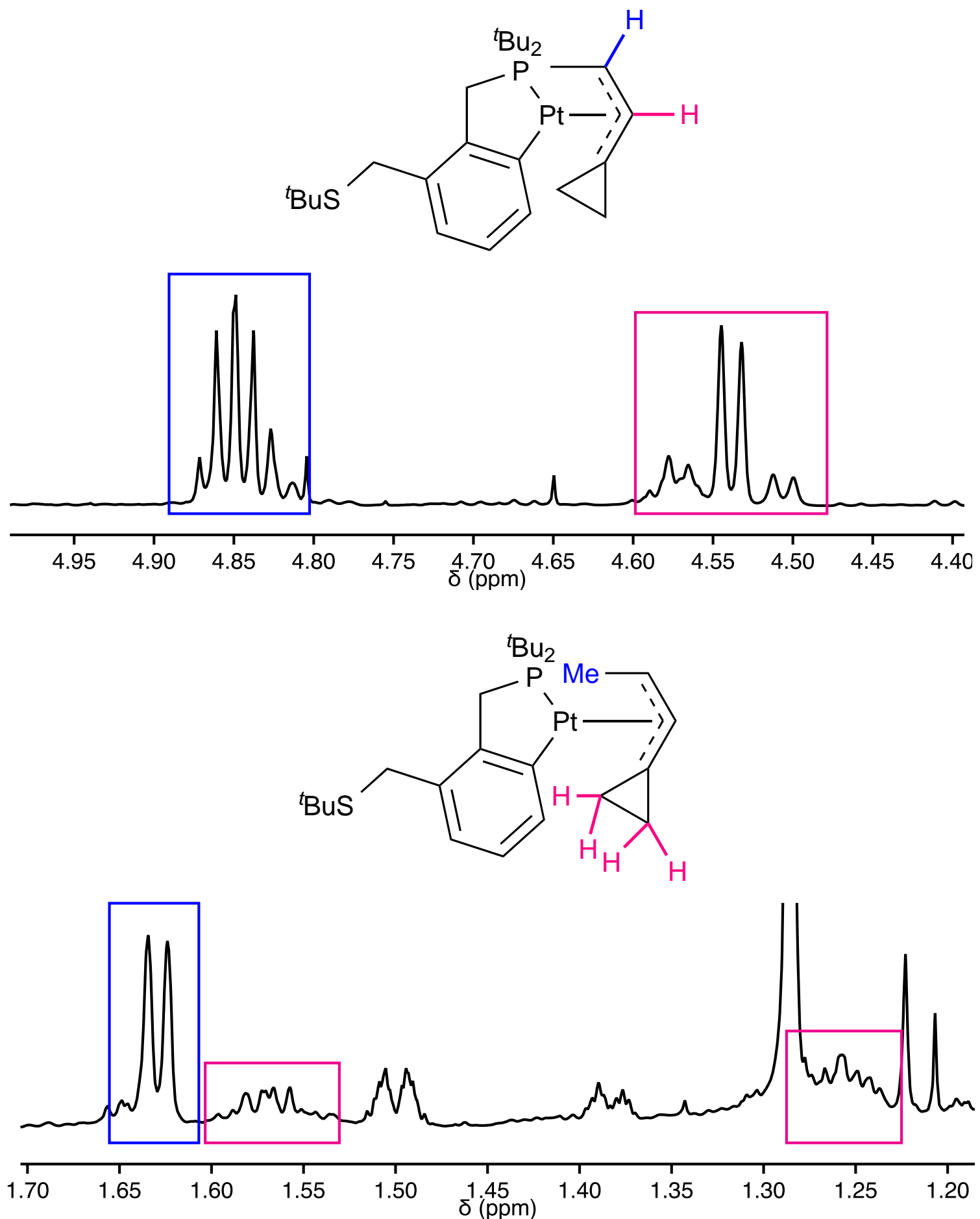

Figure A.27. Expanded ${ }^{1} \mathrm{H}$ NMR spectrum of $\left[\mathrm{Pt}\left(\eta^{3}-\mathrm{C}\left(\mathrm{CH}_{2}\right)_{2} \mathrm{CHCHMe}\right)\left(\mathrm{C}_{6} \mathrm{H}_{3}-o-\mathrm{CH}_{2} \mathrm{P}^{t} \mathrm{Bu}_{2}-m-\mathrm{CH}_{2} \mathrm{~S}{ }^{t} \mathrm{Bu}\right)\right](\mathbf{1 1 a})(600 \mathrm{MHz}, \mathrm{RT}$, $40 \mathrm{mg} / \mathrm{mL}, \mathrm{C}_{6} \mathrm{D}_{6}$ ). 


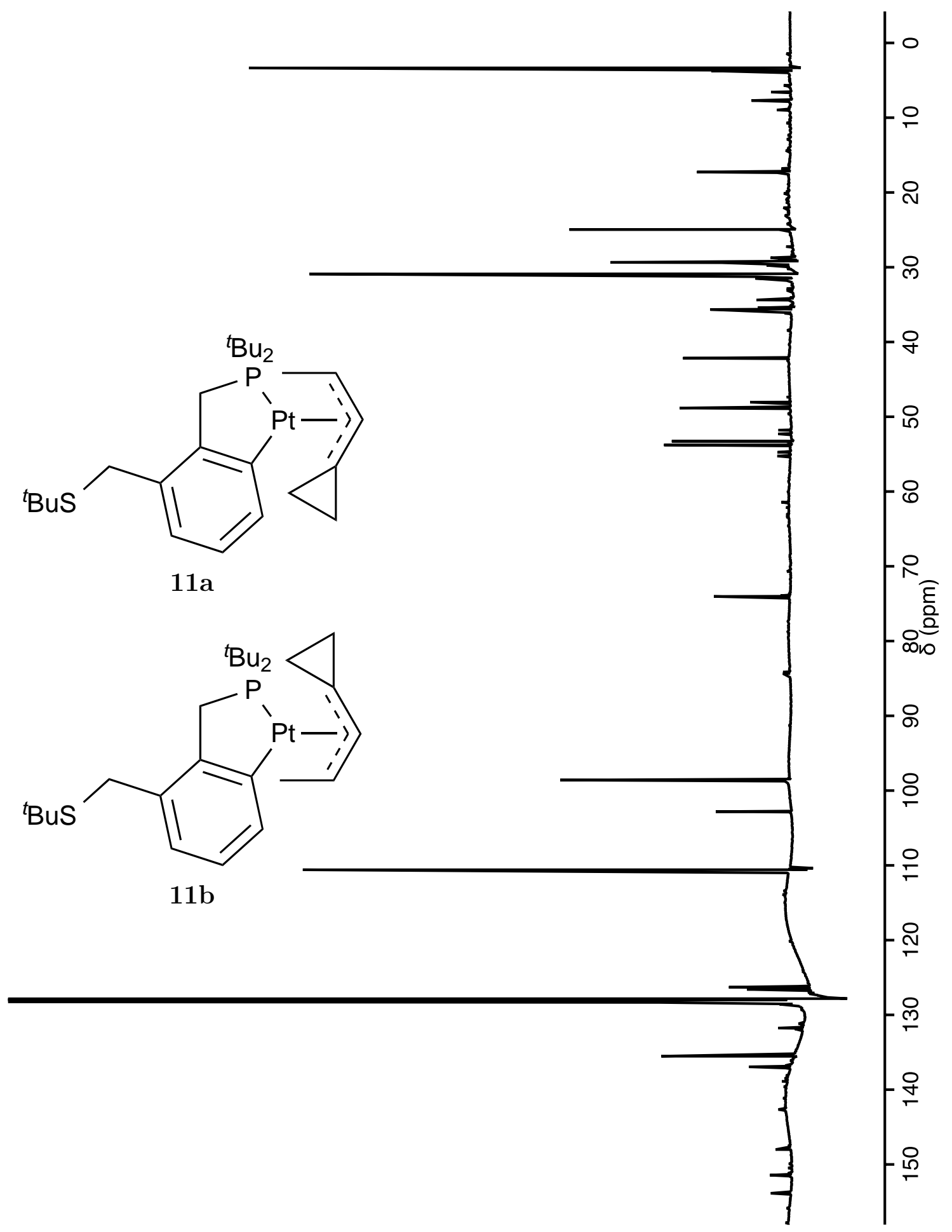

Figure A.28. ${ }^{13} \mathrm{C}\left\{{ }^{1} \mathrm{H}\right\}$ NMR spectrum of carbon-13 enriched $\left[\mathrm{Pt}\left(\eta^{3}-\mathrm{C}\left(\mathrm{CH}_{2}\right)_{2} \mathrm{CHCHMe}\right)\left(\mathrm{C}_{6} \mathrm{H}_{3}-o-\mathrm{CH}_{2} \mathrm{P}^{t} \mathrm{Bu}_{2}-m-\mathrm{CH}_{2} \mathrm{~S}^{t} \mathrm{Bu}\right)\right](\mathbf{1 1 a}$ and $\mathbf{1 1 b})(150 \mathrm{MHz}$, $\left.\mathrm{RT}, 40 \mathrm{mg} / \mathrm{mL}, \mathrm{C}_{6} \mathrm{D}_{6}\right)$. 

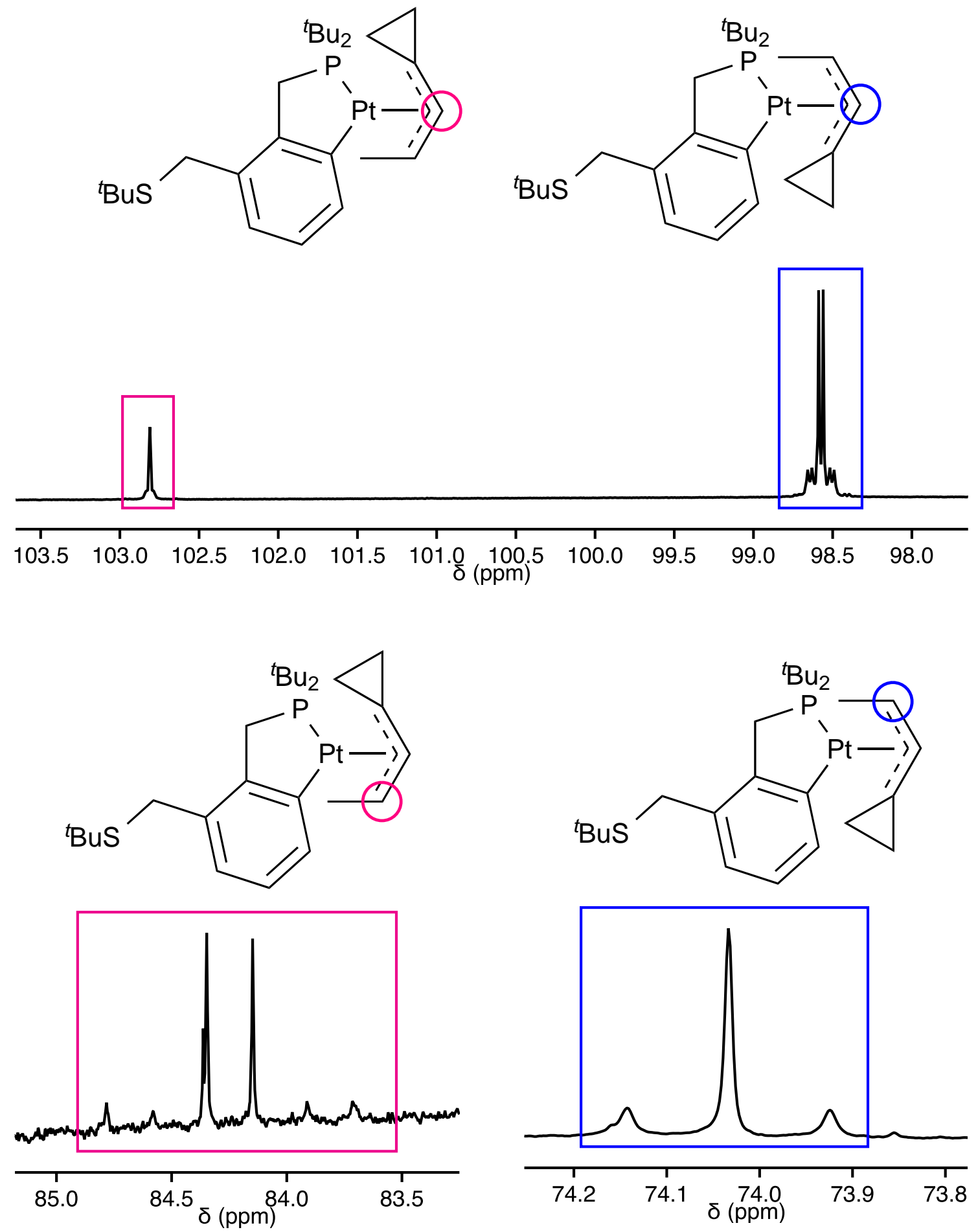

Figure A.29. Expanded ${ }^{13} \mathrm{C}\left\{{ }^{1} \mathrm{H}\right\}$ NMR spectrum of carbon-13 enriched $\left[\mathrm{Pt}\left(\eta^{3}-\mathrm{C}\left(\mathrm{CH}_{2}\right)_{2} \mathrm{CHCHMe}\right)\left(\mathrm{C}_{6} \mathrm{H}_{3}-o-\mathrm{CH}_{2} \mathrm{P}^{t} \mathrm{Bu}_{2}-m-\mathrm{CH}_{2} \mathrm{~S}^{t} \mathrm{Bu}\right)\right](\mathbf{1 1 a}$ and $\mathbf{1 1 b})(150 \mathrm{MHz}$, $\left.\mathrm{RT}, 40 \mathrm{mg} / \mathrm{mL}, \mathrm{C}_{6} \mathrm{D}_{6}\right)$. 

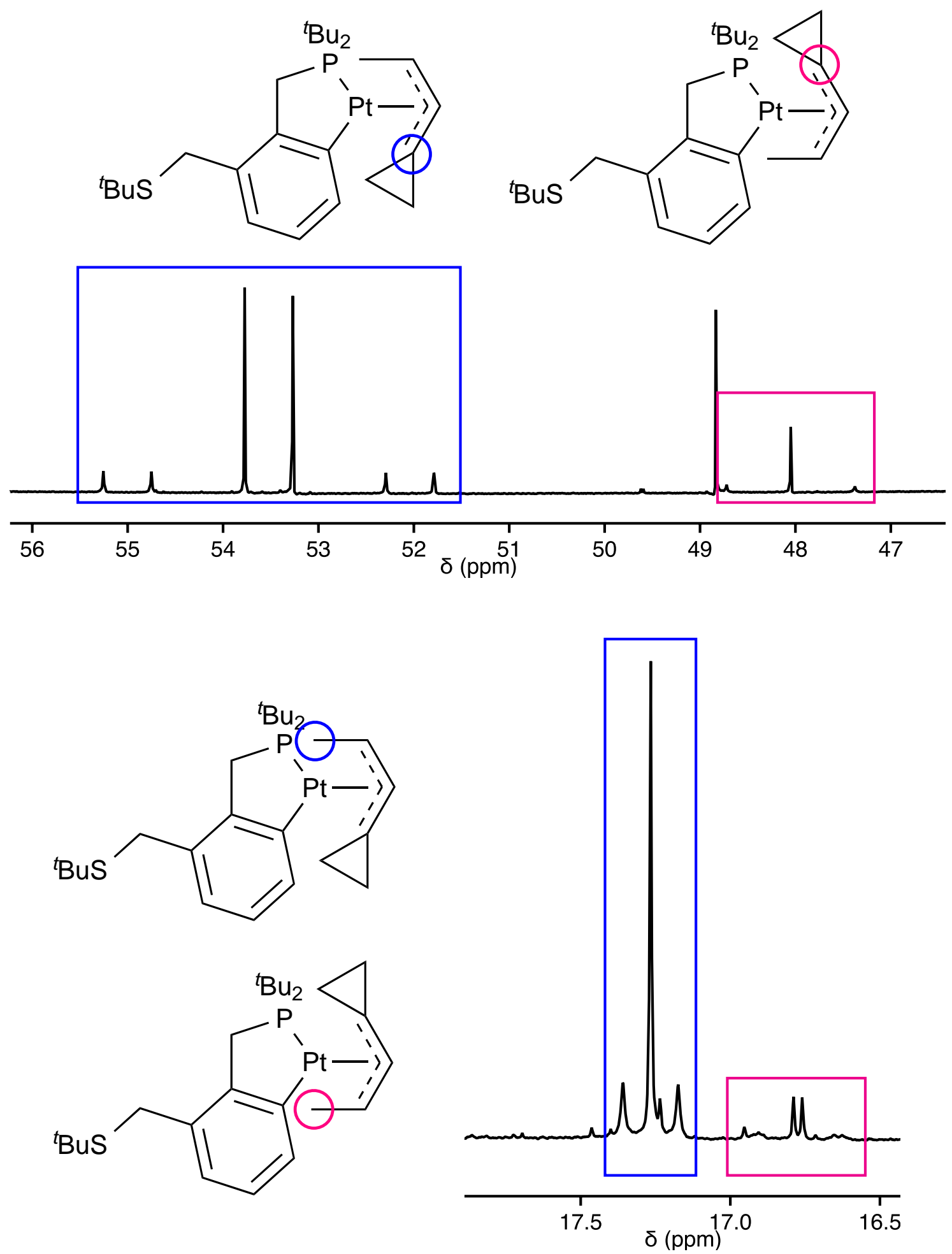

Figure A.30. Expanded ${ }^{13} \mathrm{C}\left\{{ }^{1} \mathrm{H}\right\}$ NMR spectrum of carbon- 13 enriched $\left[\mathrm{Pt}\left(\eta^{3}-\mathrm{C}\left(\mathrm{CH}_{2}\right)_{2} \mathrm{CHCHMe}\right)\left(\mathrm{C}_{6} \mathrm{H}_{3}-o-\mathrm{CH}_{2} \mathrm{P}^{t} \mathrm{Bu}_{2}-m-\mathrm{CH}_{2} \mathrm{~S}^{t} \mathrm{Bu}\right)\right](\mathbf{1 1 a}$ and 11b) $(150 \mathrm{MHz}$, $\mathrm{RT}, 40 \mathrm{mg} / \mathrm{mL}, \mathrm{C}_{6} \mathrm{D}_{6}$ ). 

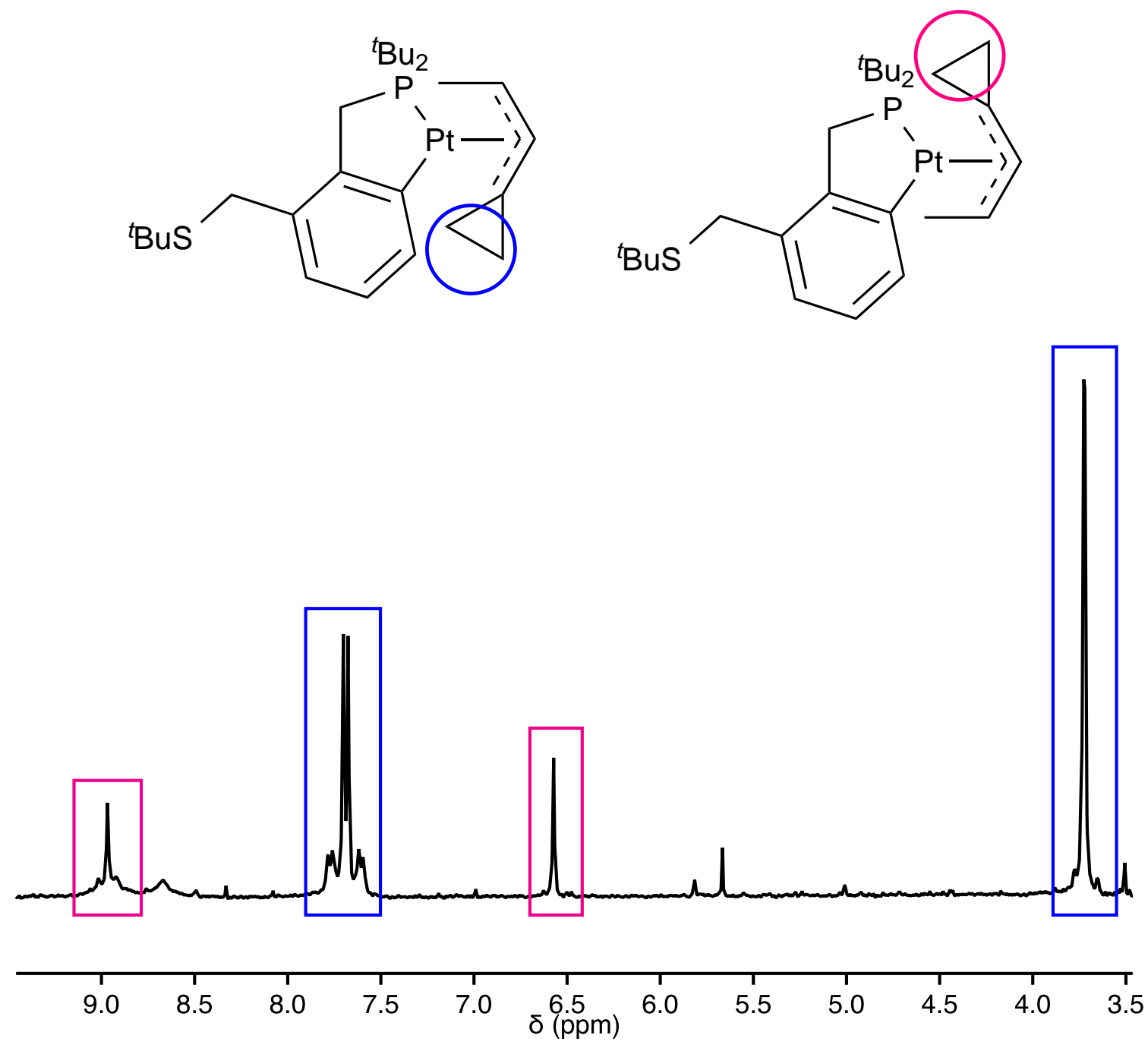

Figure A.31. Expanded ${ }^{13} \mathrm{C}\left\{{ }^{1} \mathrm{H}\right\}$ NMR spectrum of carbon- 13 enriched $\left[\mathrm{Pt}\left(\eta^{3}-\mathrm{C}\left(\mathrm{CH}_{2}\right)_{2} \mathrm{CHCHMe}\right)\left(\mathrm{C}_{6} \mathrm{H}_{3}-o-\mathrm{CH}_{2} \mathrm{P}^{t} \mathrm{Bu}_{2}-m-\mathrm{CH}_{2} \mathrm{~S}{ }^{t} \mathrm{Bu}\right)\right](\mathbf{1 1 a}$ and $\mathbf{1 1 b})(150 \mathrm{MHz}$, $\mathrm{RT}, 40 \mathrm{mg} / \mathrm{mL}, \mathrm{C}_{6} \mathrm{D}_{6}$ ). 
(mdd) HQ

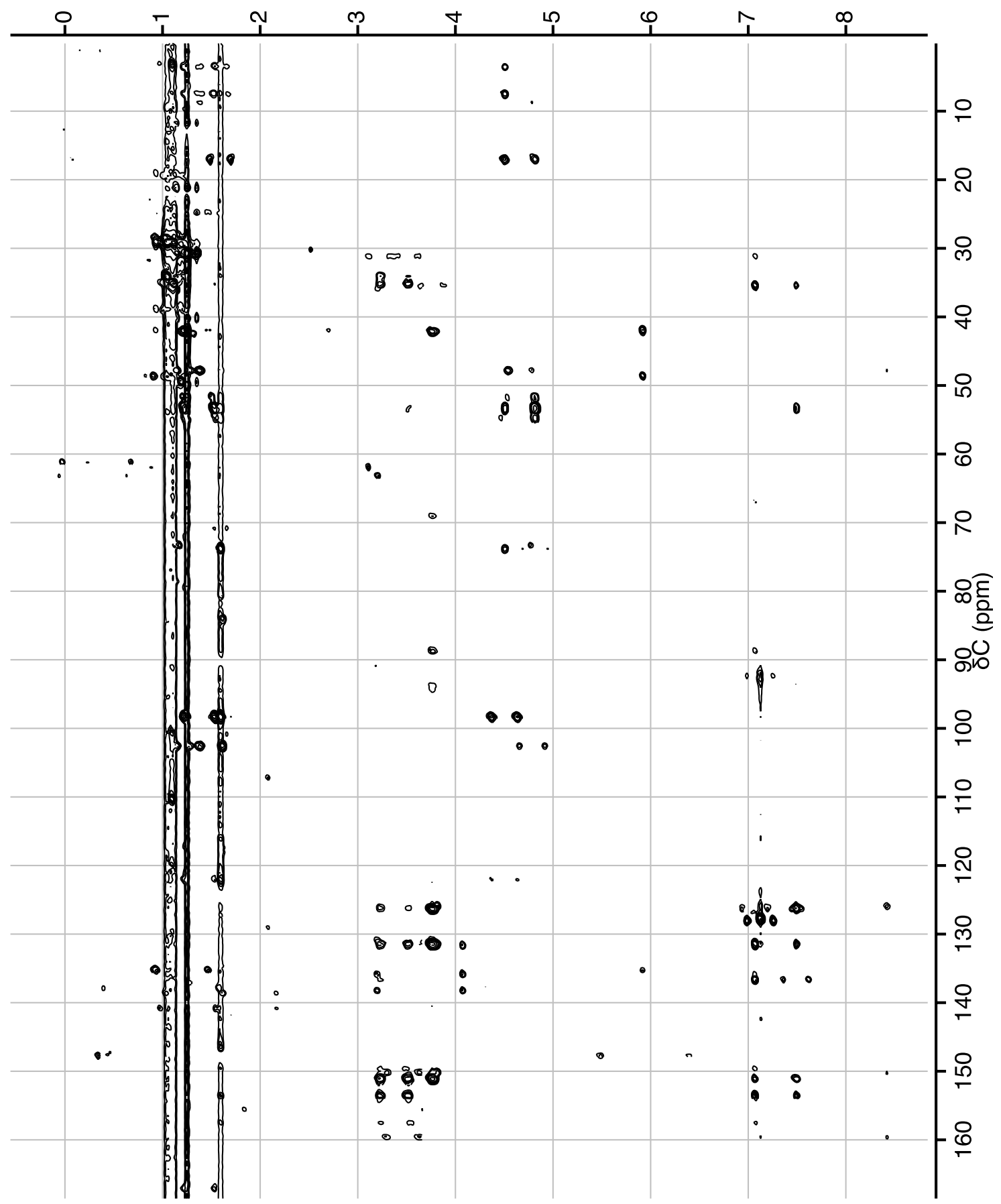

Figure A.32. HMBC spectrum of carbon-13 enriched

$\left[\mathrm{Pt}\left(\eta^{3}-\mathrm{C}\left(\mathrm{CH}_{2}\right)_{2} \mathrm{CHCHMe}\right)\left(\mathrm{C}_{6} \mathrm{H}_{3}-o-\mathrm{CH}_{2} \mathrm{P}^{t} \mathrm{Bu}_{2}-m-\mathrm{CH}_{2} \mathrm{~S}{ }^{t} \mathrm{Bu}\right)\right](\mathbf{1 1 a}$ and 11b)

$\left(600 / 150 \mathrm{MHz}, \mathrm{RT}, 40 \mathrm{mg} / \mathrm{mL}, \mathrm{C}_{6} \mathrm{D}_{6}\right)$. Some residual one bond coupling is present. 


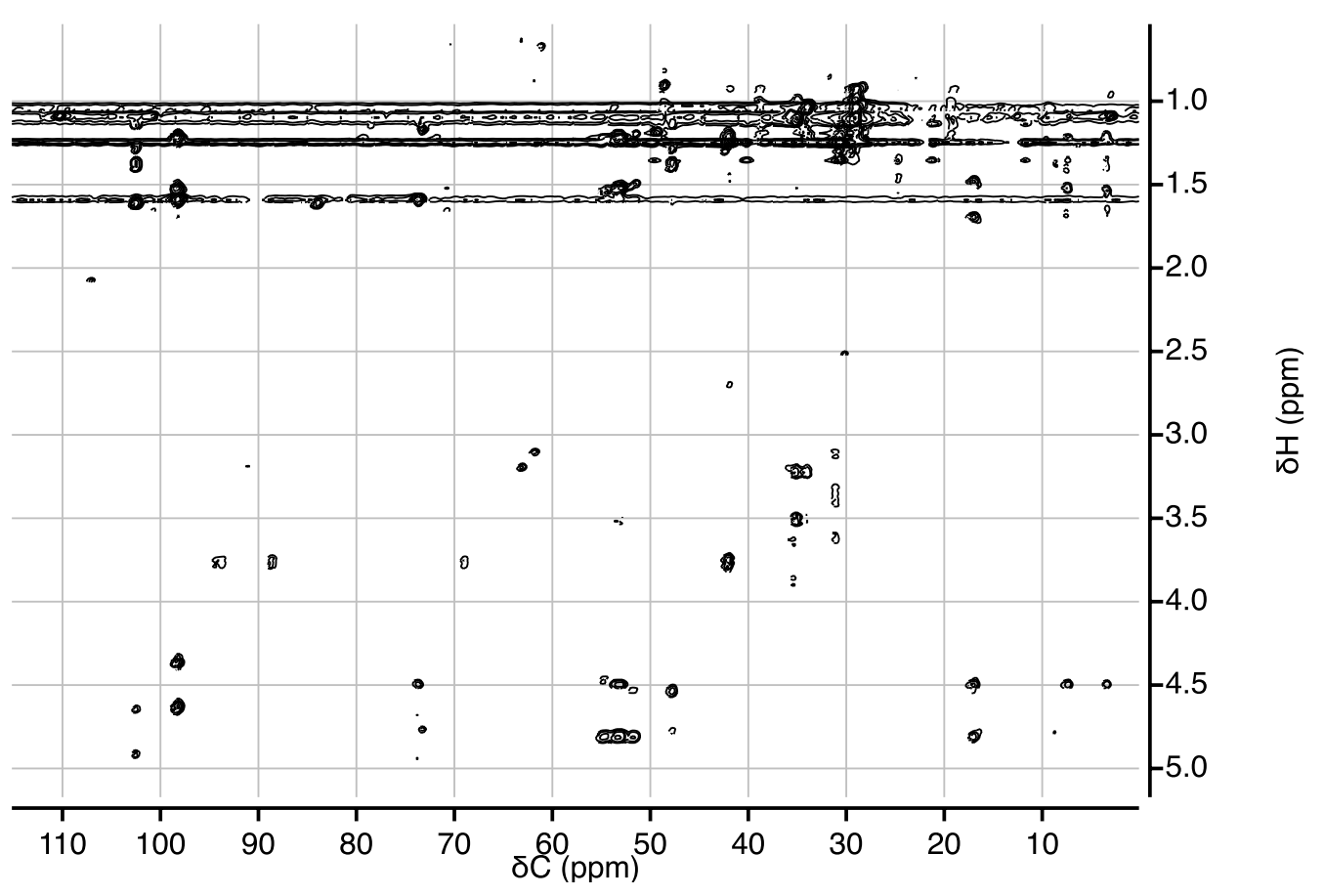

Figure A.33. Expanded HMBC spectrum of carbon-13 enriched $\left[\mathrm{Pt}\left(\eta^{3}-\mathrm{C}\left(\mathrm{CH}_{2}\right)_{2} \mathrm{CHCHMe}\right)\left(\mathrm{C}_{6} \mathrm{H}_{3}-o-\mathrm{CH}_{2} \mathrm{P}^{t} \mathrm{Bu}_{2}-m-\mathrm{CH}_{2} \mathrm{~S}^{t} \mathrm{Bu}\right)\right]$ (11a and 11b) $\left(600 / 150 \mathrm{MHz}, \mathrm{RT}, 40 \mathrm{mg} / \mathrm{mL}, \mathrm{C}_{6} \mathrm{D}_{6}\right)$. Some residual one bond coupling is present.

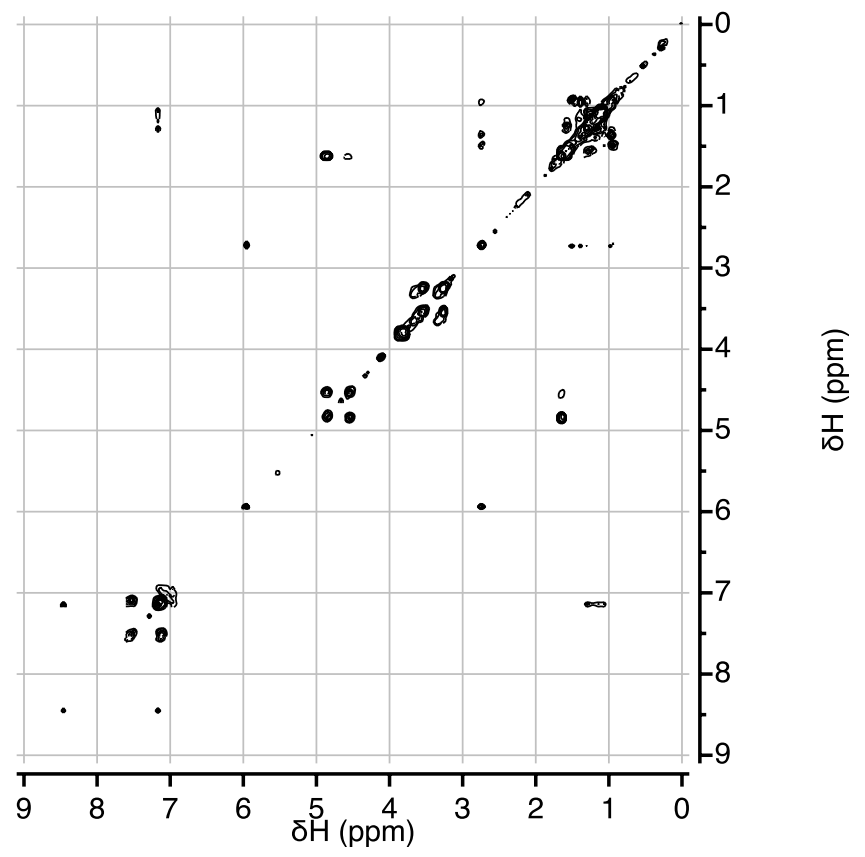

Figure A.34. COSY spectrum of $\left[\mathrm{Pt}\left(\eta^{3}-\mathrm{C}\left(\mathrm{CH}_{2}\right)_{2} \mathrm{CHCHMe}\right)\left(\mathrm{C}_{6} \mathrm{H}_{3}-o-\mathrm{CH}_{2} \mathrm{P}^{t} \mathrm{Bu}_{2}-m-\mathrm{CH}_{2} \mathrm{~S}^{t} \mathrm{Bu}\right)\right](\mathbf{1 1 a}$ and 11b) $(600 \mathrm{MHz}$, $\left.\mathrm{RT}, 40 \mathrm{mg} / \mathrm{mL}, \mathrm{C}_{6} \mathrm{D}_{6}\right)$. 

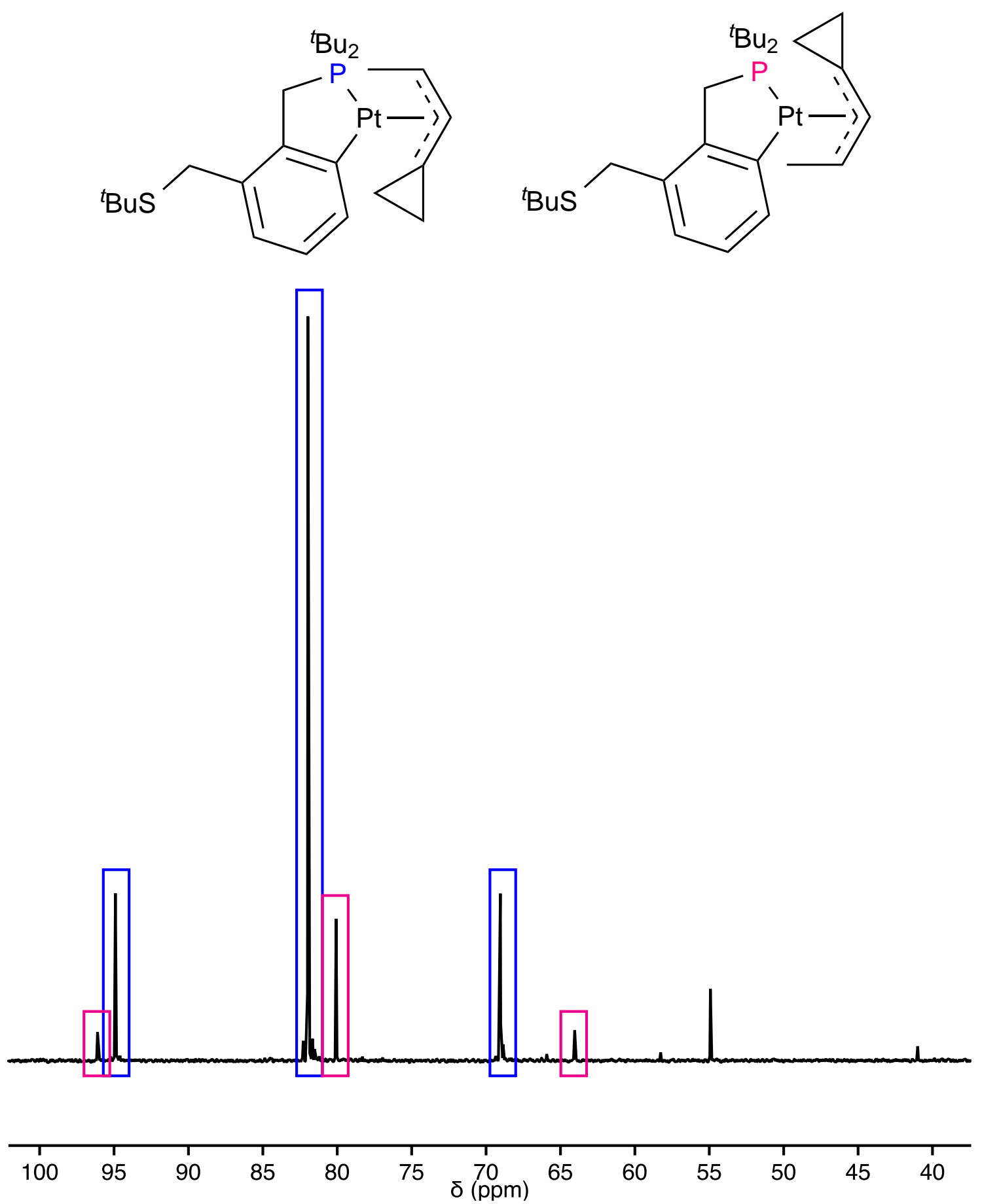

Figure A.35. ${ }^{31} \mathrm{P}\left\{{ }^{1} \mathrm{H}\right\}$ NMR spectrum of

$\left[\mathrm{Pt}\left(\eta^{3}-\mathrm{C}\left(\mathrm{CH}_{2}\right)_{2} \mathrm{CHCHMe}\right)\left(\mathrm{C}_{6} \mathrm{H}_{3}-{ }^{o-} \mathrm{CH}_{2} \mathrm{P}^{t} \mathrm{Bu}_{2}-m-\mathrm{CH}_{2} \mathrm{~S}^{t} \mathrm{Bu}\right)\right](\mathbf{1 1 a}$ and $\mathbf{1 1 b})(121 \mathrm{MHz}$, $\left.\mathrm{RT}, 40 \mathrm{mg} / \mathrm{mL}, \mathrm{C}_{6} \mathrm{D}_{6}\right)$. 

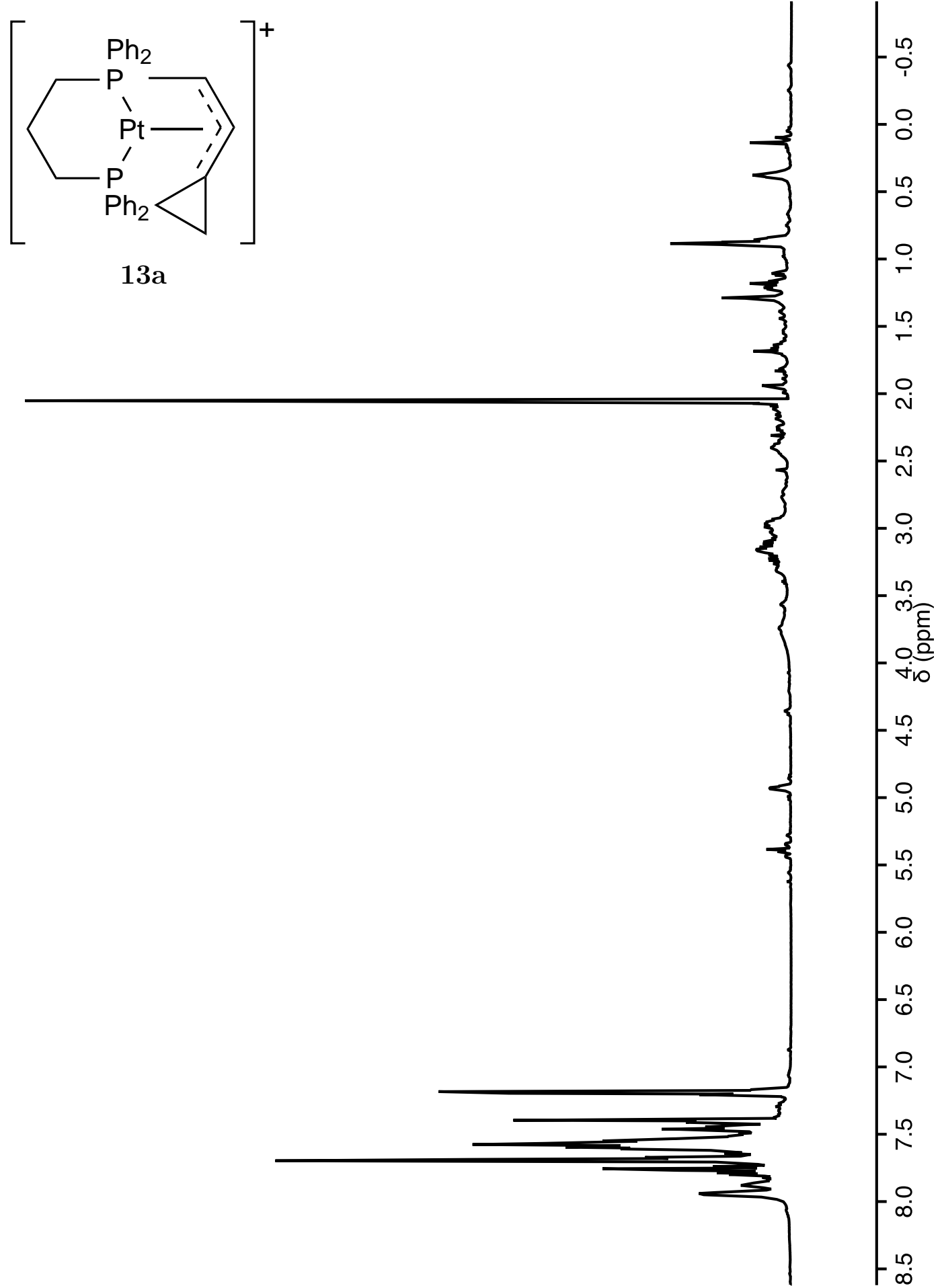

Figure A.36. ${ }^{1} \mathrm{H}$ NMR spectrum of $\left[\mathrm{Pt}\left(\eta^{3}-\mathrm{C}\left(\mathrm{CH}_{2}\right)_{2} \mathrm{CHCHMe}\right)(\mathrm{dppp})\right]\left[\mathrm{HC}\left(\mathrm{SO}_{2} \mathrm{CF}_{3}\right)_{2}\right]$ (anti $\mathrm{Me})\left(\mathbf{1 3 a}\left[\mathrm{HC}\left(\mathrm{SO}_{2} \mathrm{CF}_{3}\right)_{2}\right]\right)\left(600 \mathrm{MHz}, \mathrm{RT}, 40 \mathrm{mg} / \mathrm{mL}, d_{6}\right.$-acetone). 

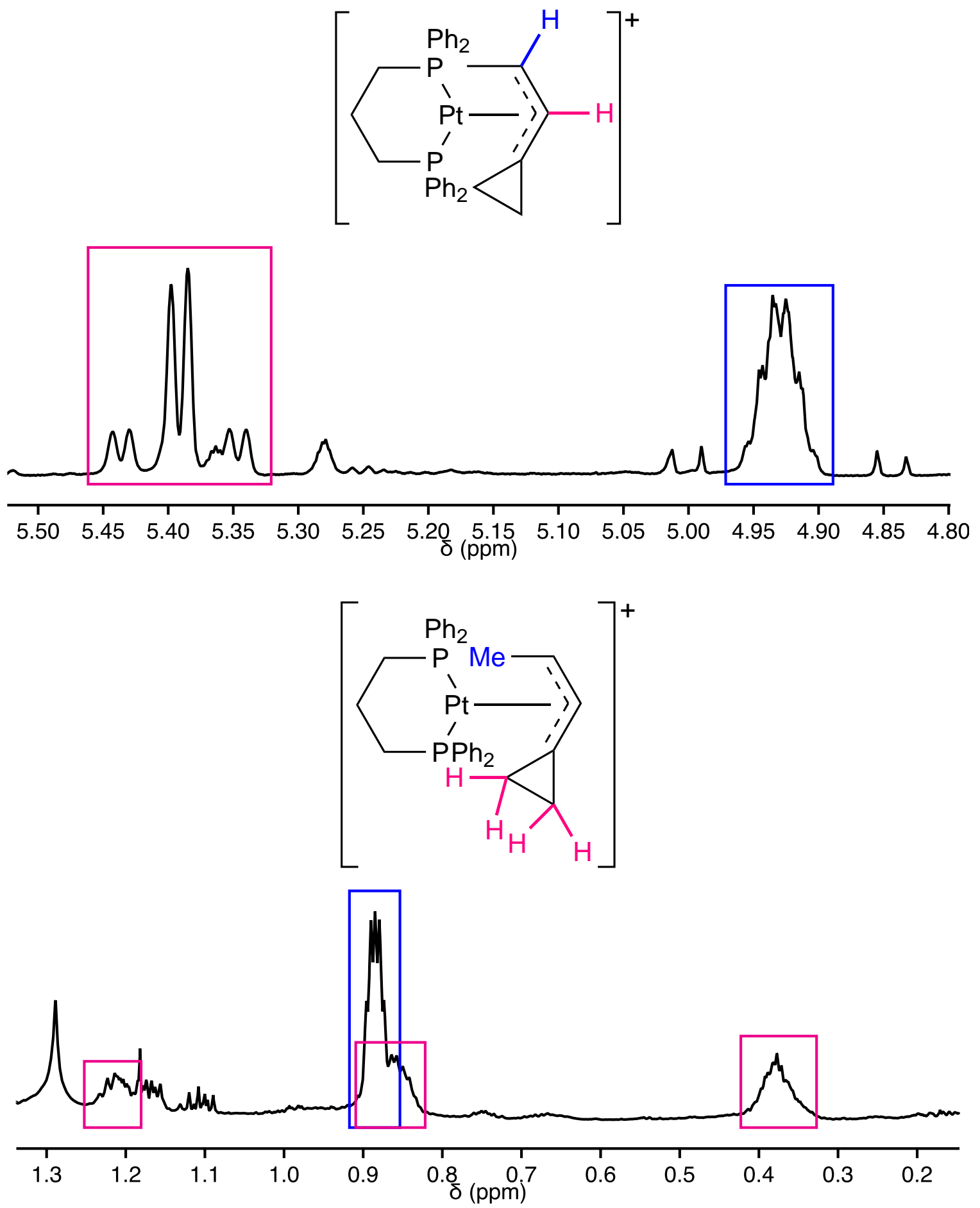

Figure A.37. Expanded ${ }^{1} \mathrm{H}$ NMR spectrum of $\left[\mathrm{Pt}\left(\eta^{3}-\mathrm{C}\left(\mathrm{CH}_{2}\right)_{2} \mathrm{CHCHMe}\right)(\mathrm{dppp})\right]\left[\mathrm{HC}\left(\mathrm{SO}_{2} \mathrm{CF}_{3}\right)_{2}\right]($ anti $\mathrm{Me})\left(\mathbf{1 3 a}\left[\mathrm{HC}\left(\mathrm{SO}_{2} \mathrm{CF}_{3}\right)_{2}\right]\right)$ (600 MHz, RT, $40 \mathrm{mg} / \mathrm{mL}, d_{6}$-acetone). 


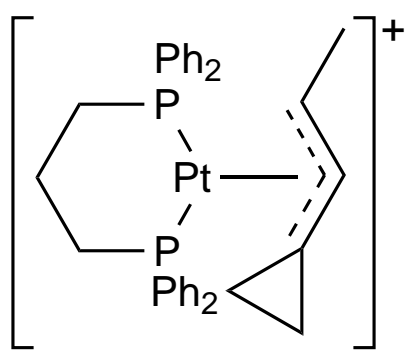

13b

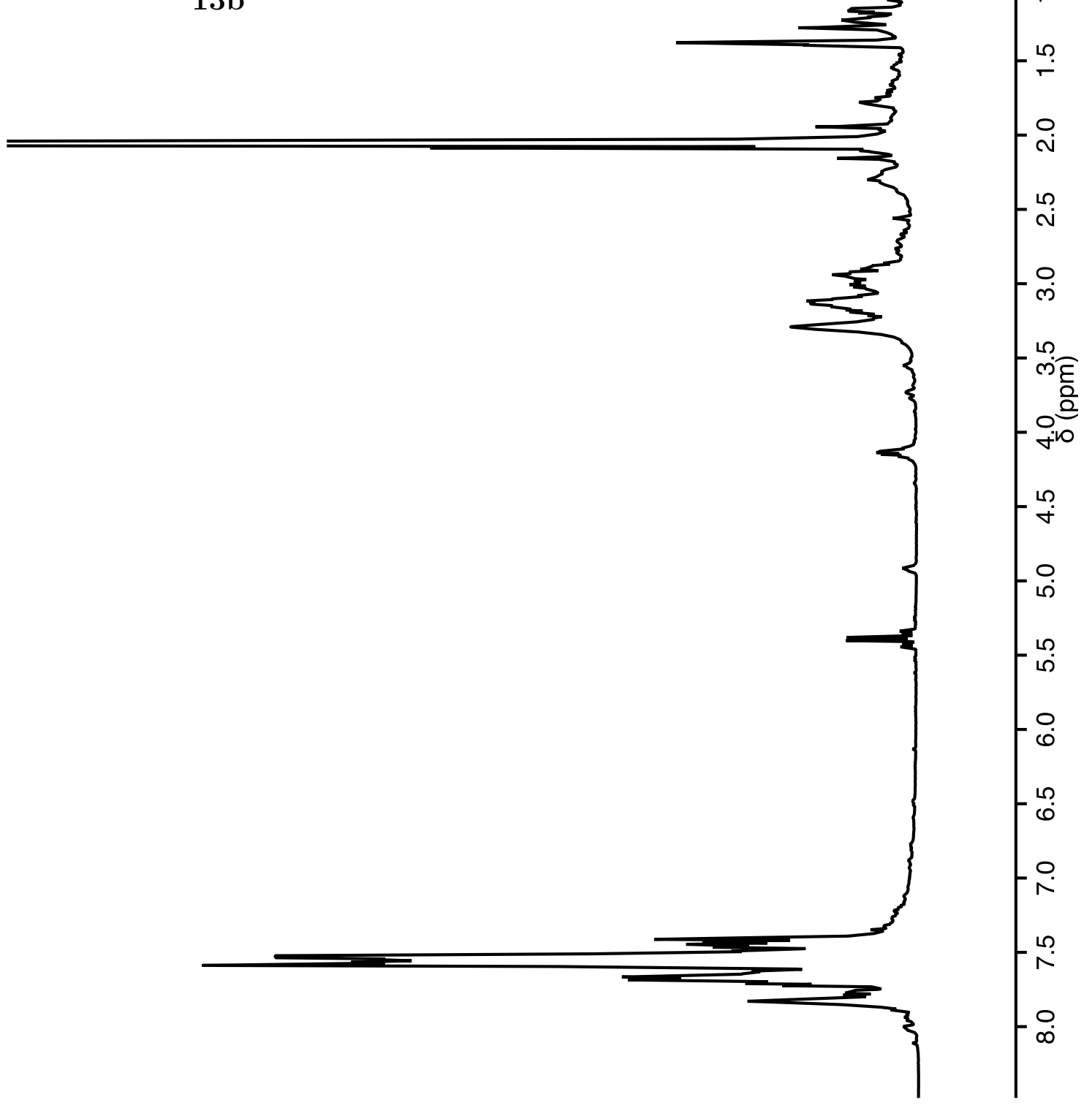

Figure A.38. ${ }^{1} \mathrm{H}$ NMR spectrum of $\left[\mathrm{Pt}\left(\eta^{3}-\mathrm{C}\left(\mathrm{CH}_{2}\right)_{2} \mathrm{CHCHMe}\right)(\mathrm{dppp})\right]\left[\mathrm{HC}\left(\mathrm{SO}_{2} \mathrm{CF}_{3}\right)_{2}\right]$ $(\operatorname{syn} \mathrm{Me})\left(\mathbf{1 3 b}\left[\mathrm{HC}\left(\mathrm{SO}_{2} \mathrm{CF}_{3}\right)_{2}\right]\right)\left(600 \mathrm{MHz}, \mathrm{RT}, 40 \mathrm{mg} / \mathrm{mL}, d_{6}\right.$-acetone). 

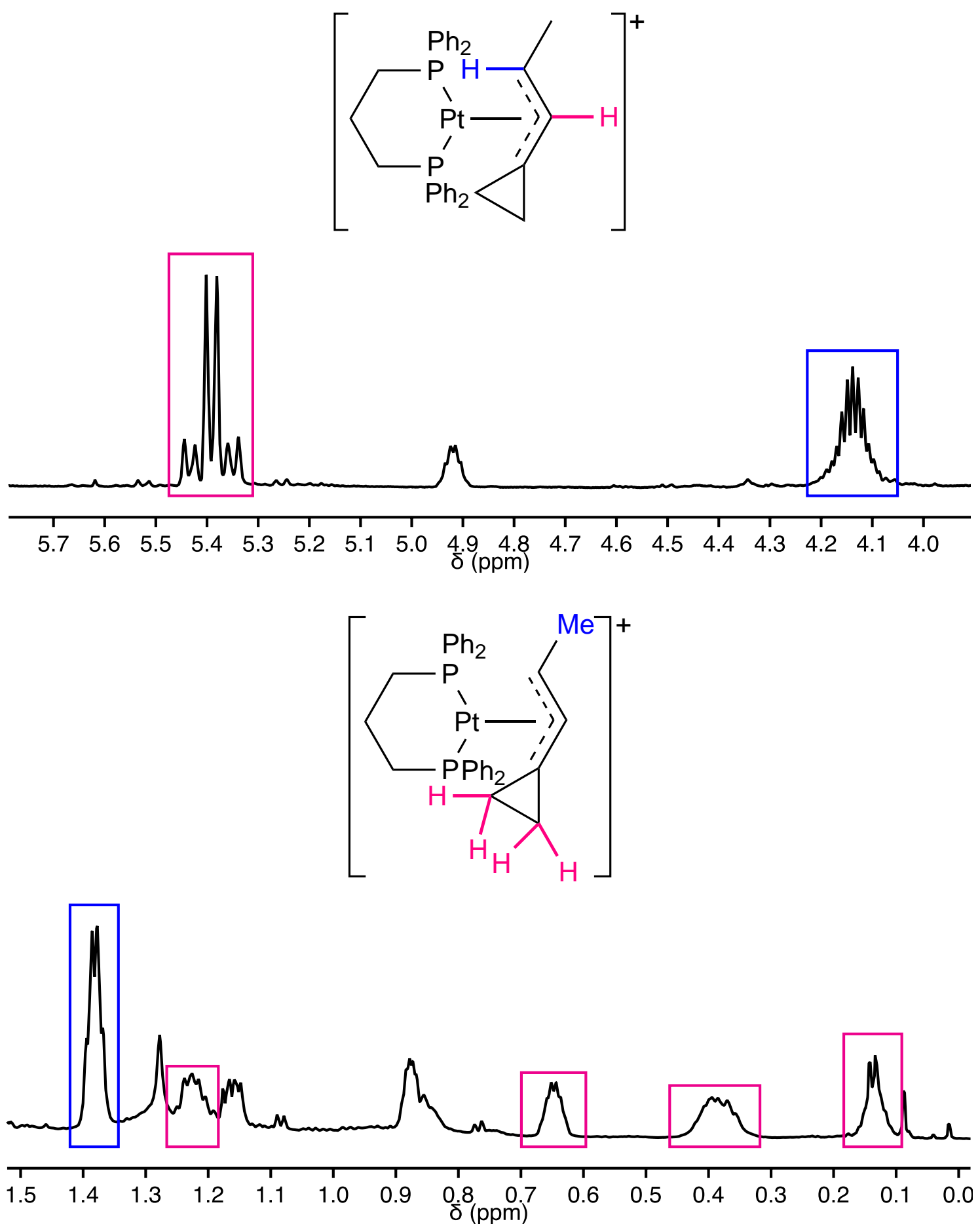

Figure A.39. Expanded ${ }^{1} \mathrm{H}$ NMR spectrum of

$\left[\mathrm{Pt}\left(\eta^{3}-\mathrm{C}\left(\mathrm{CH}_{2}\right)_{2} \mathrm{CHCHMe}\right)(\mathrm{dppp})\right]\left[\mathrm{HC}\left(\mathrm{SO}_{2} \mathrm{CF}_{3}\right)_{2}\right](\operatorname{syn} \mathrm{Me})\left(\mathbf{1 3 b}\left[\mathrm{HC}\left(\mathrm{SO}_{2} \mathrm{CF}_{3}\right)_{2}\right]\right)$ (600 MHz, RT, $40 \mathrm{mg} / \mathrm{mL}, d_{6}$-acetone). 


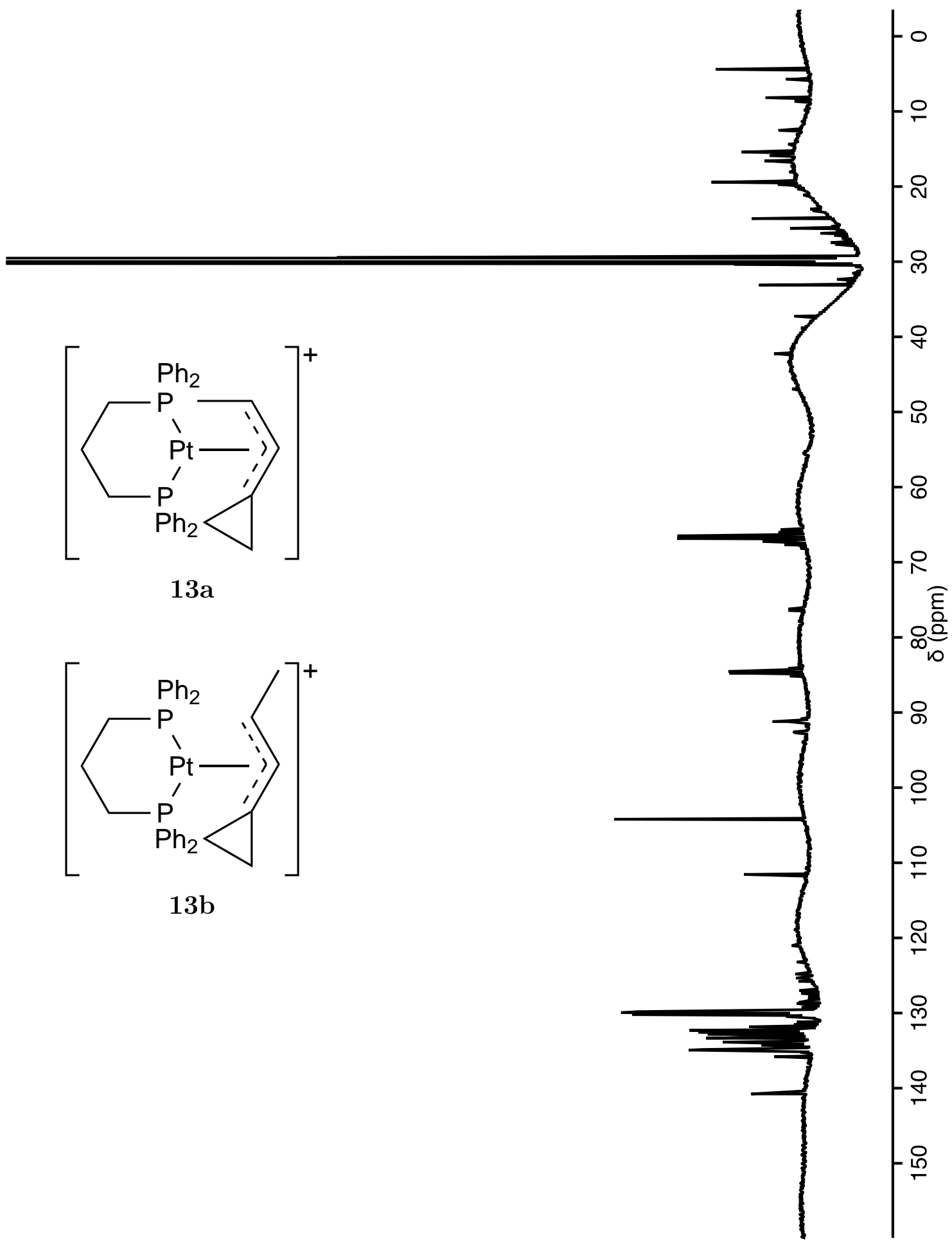

Figure A.40. ${ }^{13} \mathrm{C}\left\{{ }^{1} \mathrm{H}\right\}$ NMR spectrum of carbon-13 enriched $\left[\mathrm{Pt}\left(\eta^{3}-\mathrm{C}\left(\mathrm{CH}_{2}\right)_{2} \mathrm{CHCHMe}\right)(\mathrm{dppp})\right]\left[\mathrm{HC}\left(\mathrm{SO}_{2} \mathrm{CF}_{3}\right)_{2}\right]\left(\mathbf{1 3 a}\left[\mathrm{HC}\left(\mathrm{SO}_{2} \mathrm{CF}_{3}\right)_{2}\right]\right.$ and $\left.13 \mathrm{~b}\left[\mathrm{HC}\left(\mathrm{SO}_{2} \mathrm{CF}_{3}\right)_{2}\right]\right)\left(150 \mathrm{MHz}, \mathrm{RT}, 40 \mathrm{mg} / \mathrm{mL}, d_{6}\right.$-acetone). 

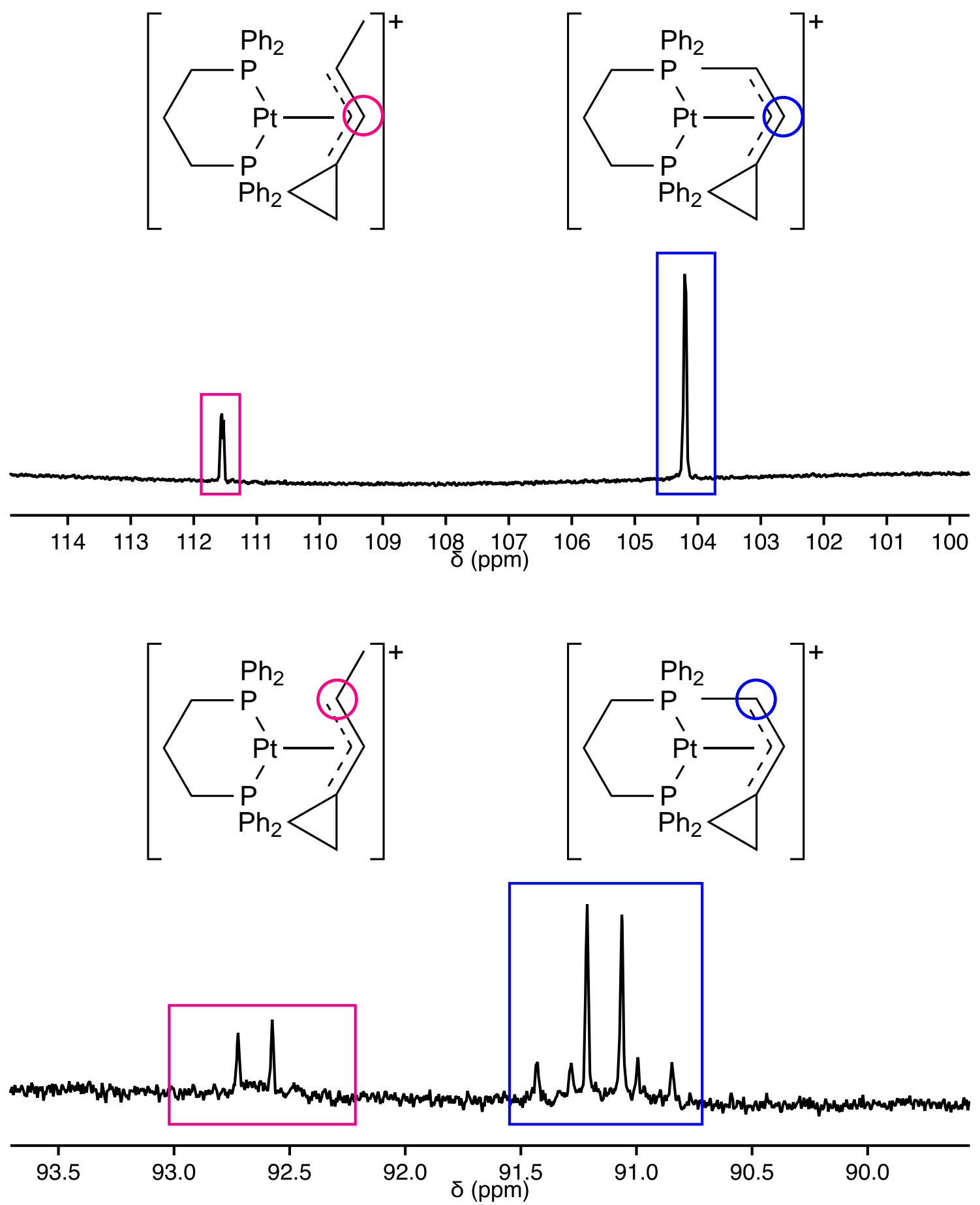

Figure A.41. Expanded ${ }^{13} \mathrm{C}\left\{{ }^{1} \mathrm{H}\right\}$ NMR spectrum of carbon- 13 enriched $\left[\mathrm{Pt}\left(\eta^{3}-\mathrm{C}\left(\mathrm{CH}_{2}\right)_{2} \mathrm{CHCHMe}\right)(\mathrm{dppp})\right]\left[\mathrm{HC}\left(\mathrm{SO}_{2} \mathrm{CF}_{3}\right)_{2}\right]\left(\mathbf{1 3 a}\left[\mathrm{HC}\left(\mathrm{SO}_{2} \mathrm{CF}_{3}\right)_{2}\right]\right.$ and $\left.13 \mathrm{~b}\left[\mathrm{HC}\left(\mathrm{SO}_{2} \mathrm{CF}_{3}\right)_{2}\right]\right)\left(150 \mathrm{MHz}, \mathrm{RT}, 40 \mathrm{mg} / \mathrm{mL}, d_{6}\right.$-acetone). 

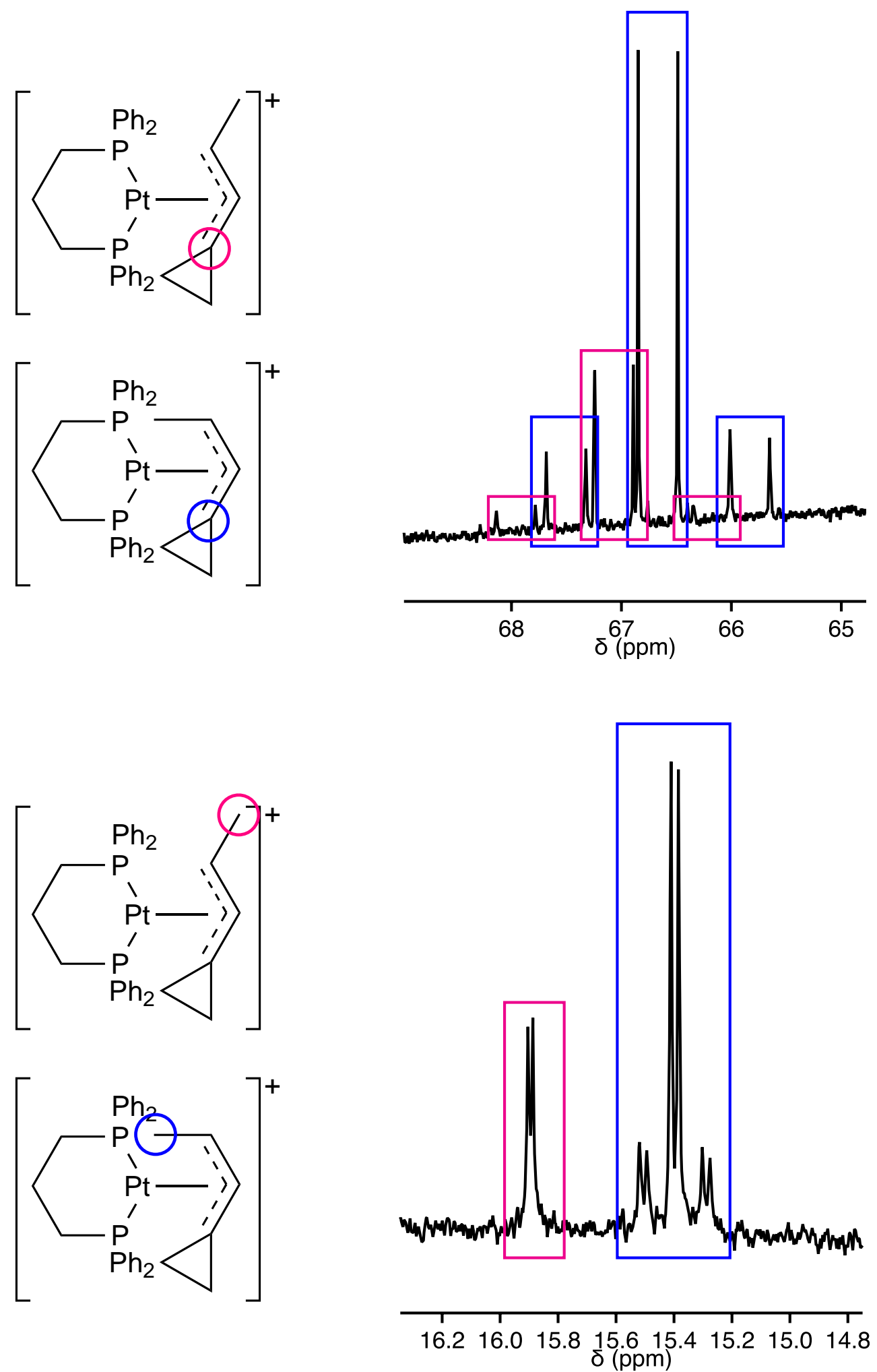

Figure A.42. Expanded ${ }^{13} \mathrm{C}\left\{{ }^{1} \mathrm{H}\right\}$ NMR spectrum of carbon- 13 enriched $\left[\mathrm{Pt}\left(\eta^{3}-\mathrm{C}\left(\mathrm{CH}_{2}\right)_{2} \mathrm{CHCHMe}\right)(\mathrm{dppp})\right]\left[\mathrm{HC}\left(\mathrm{SO}_{2} \mathrm{CF}_{3}\right)_{2}\right]\left(\mathbf{1 3 a}\left[\mathrm{HC}\left(\mathrm{SO}_{2} \mathrm{CF}_{3}\right)_{2}\right]\right.$ and $\left.13 \mathrm{~b}\left[\mathrm{HC}\left(\mathrm{SO}_{2} \mathrm{CF}_{3}\right)_{2}\right]\right)\left(150 \mathrm{MHz}, \mathrm{RT}, 40 \mathrm{mg} / \mathrm{mL}, d_{6}\right.$-acetone). 

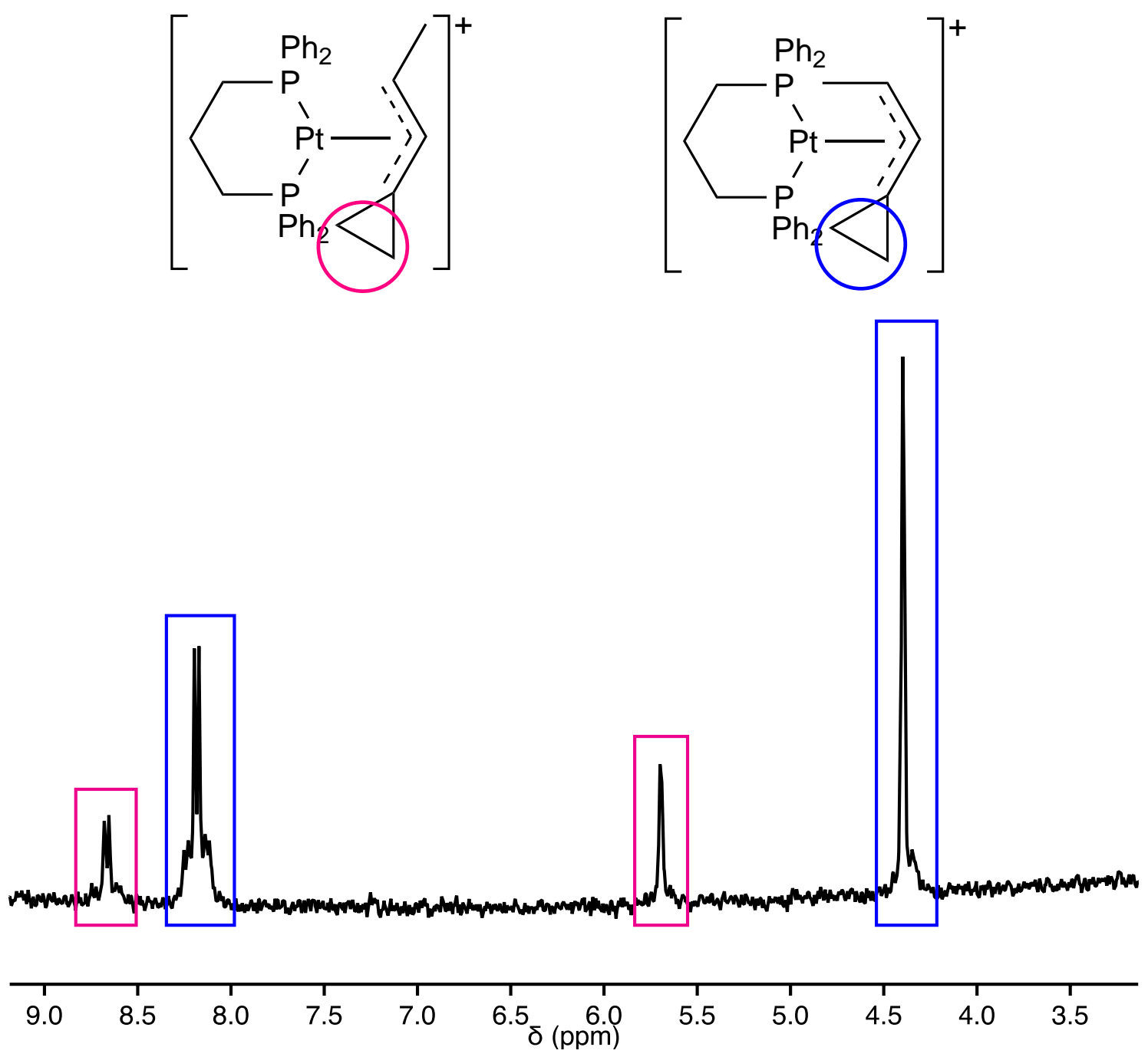

Figure A.43. Expanded ${ }^{13} \mathrm{C}\left\{{ }^{1} \mathrm{H}\right\}$ NMR spectrum of carbon- 13 enriched $\left[\mathrm{Pt}\left(\eta^{3}-\mathrm{C}\left(\mathrm{CH}_{2}\right)_{2} \mathrm{CHCHMe}\right)(\mathrm{dppp})\right]\left[\mathrm{HC}\left(\mathrm{SO}_{2} \mathrm{CF}_{3}\right)_{2}\right]\left(\mathbf{1 3 a}\left[\mathrm{HC}\left(\mathrm{SO}_{2} \mathrm{CF}_{3}\right)_{2}\right]\right.$ and $\left.13 \mathrm{~b}\left[\mathrm{HC}\left(\mathrm{SO}_{2} \mathrm{CF}_{3}\right)_{2}\right]\right)\left(150 \mathrm{MHz}, \mathrm{RT}, 40 \mathrm{mg} / \mathrm{mL}, d_{6}\right.$-acetone). 
(mdd) HQ

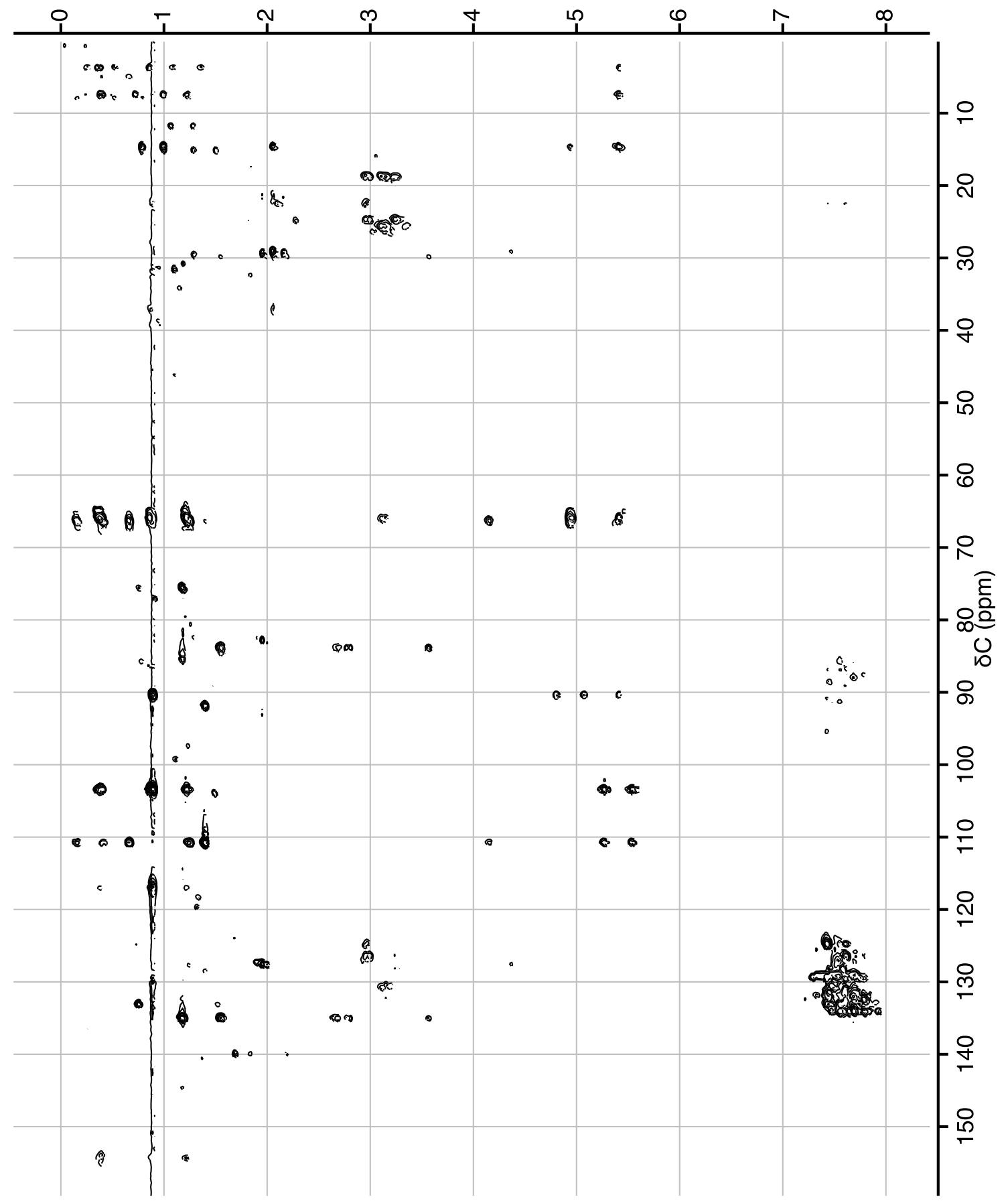

Figure A.44. HMBC spectrum of carbon-13 enriched

$\left[\mathrm{Pt}\left(\eta^{3}-\mathrm{C}\left(\mathrm{CH}_{2}\right)_{2} \mathrm{CHCHMe}\right)(\mathrm{dppp})\right]\left[\mathrm{HC}\left(\mathrm{SO}_{2} \mathrm{CF}_{3}\right)_{2}\right]\left(\mathbf{1 3 a}\left[\mathrm{HC}\left(\mathrm{SO}_{2} \mathrm{CF}_{3}\right)_{2}\right]\right.$ and

$\left.13 \mathrm{~b}\left[\mathrm{HC}\left(\mathrm{SO}_{2} \mathrm{CF}_{3}\right)_{2}\right]\right)\left(600 / 150 \mathrm{MHz}, \mathrm{RT}, 40 \mathrm{mg} / \mathrm{mL}, d_{6}\right.$-acetone). Some residual one bond coupling is present. 


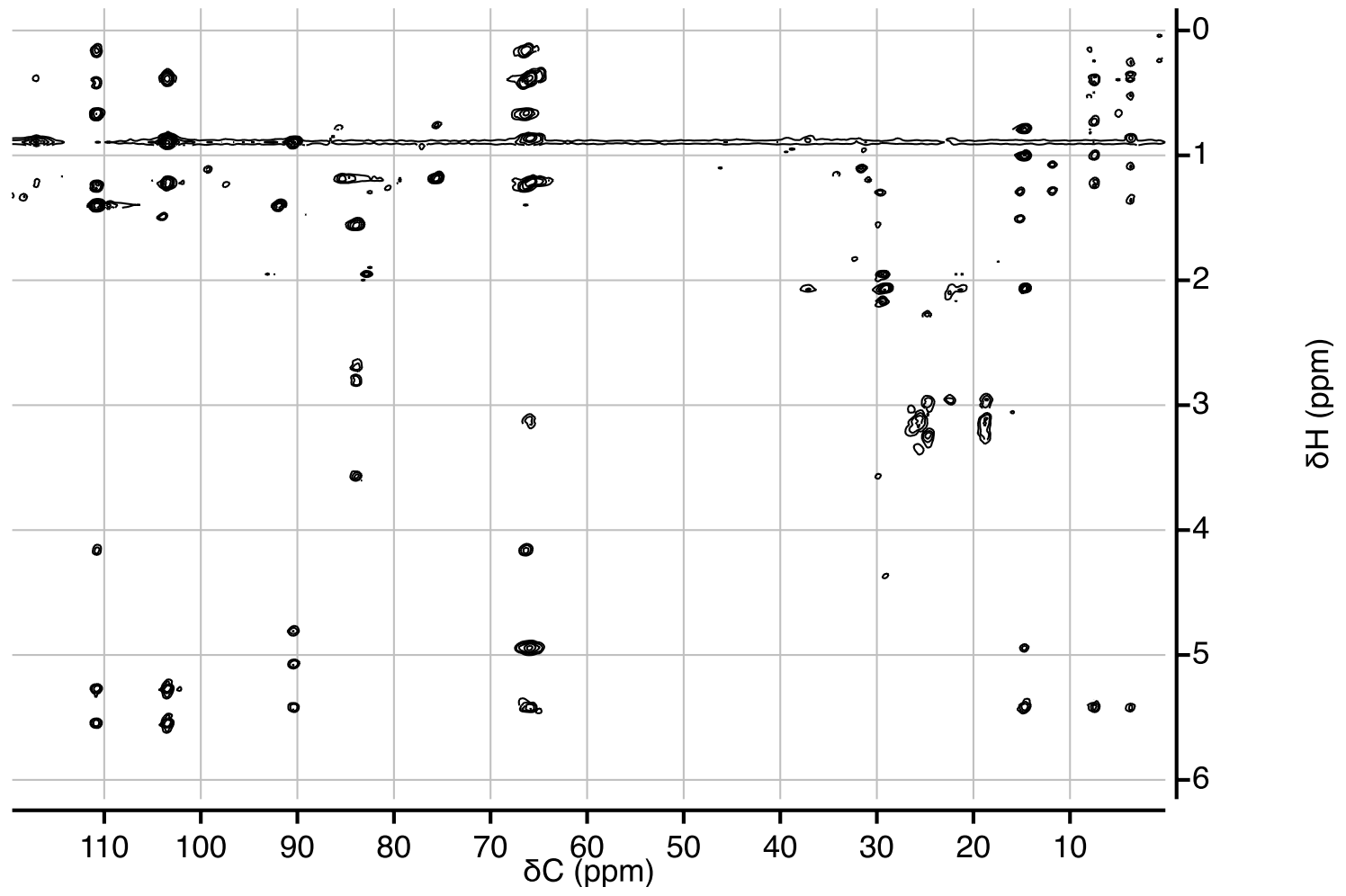

Figure A.45. Expanded HMBC spectrum of carbon-13 enriched $\left[\mathrm{Pt}\left(\eta^{3}-\mathrm{C}\left(\mathrm{CH}_{2}\right)_{2} \mathrm{CHCHMe}\right)(\mathrm{dppp})\right]\left[\mathrm{HC}\left(\mathrm{SO}_{2} \mathrm{CF}_{3}\right)_{2}\right]\left(\mathbf{1 3 a}\left[\mathrm{HC}\left(\mathrm{SO}_{2} \mathrm{CF}_{3}\right)_{2}\right]\right.$ and $\left.13 \mathrm{~b}\left[\mathrm{HC}\left(\mathrm{SO}_{2} \mathrm{CF}_{3}\right)_{2}\right]\right)\left(600 / 150 \mathrm{MHz}, \mathrm{RT}, 40 \mathrm{mg} / \mathrm{mL}, d_{6}\right.$-acetone). Some residual one bond coupling is present.

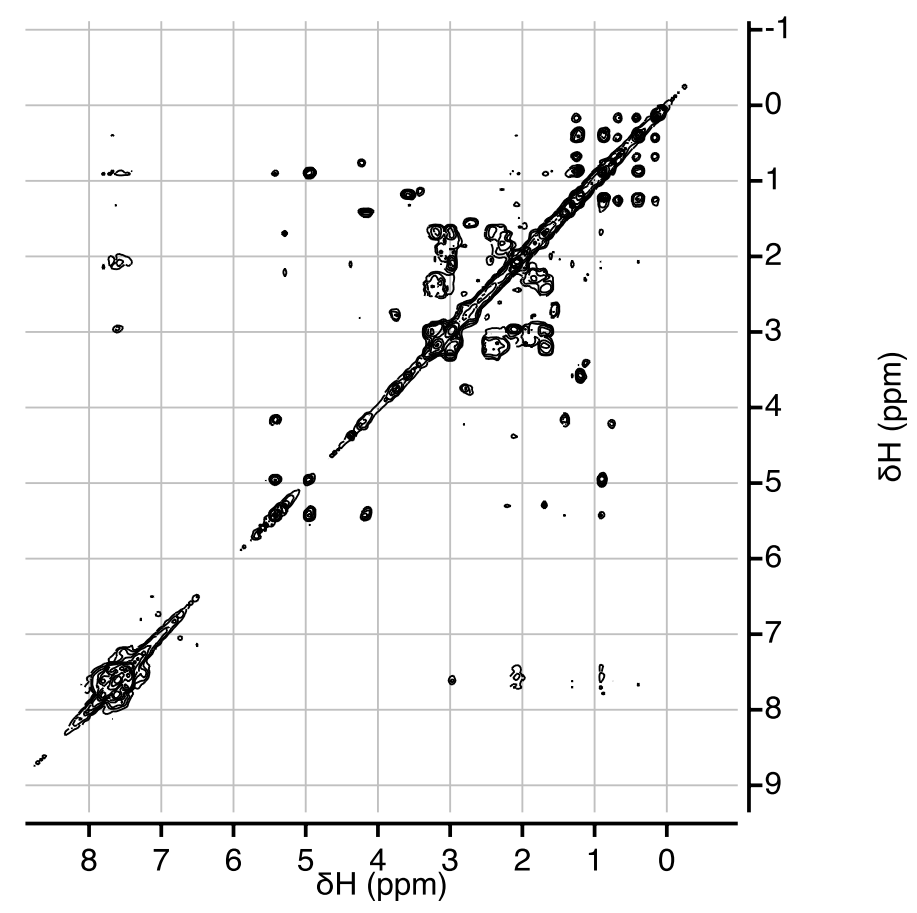

Figure A.46. COSY spectrum of carbon-13 enriched $\left[\mathrm{Pt}\left(\eta^{3}-\mathrm{C}\left(\mathrm{CH}_{2}\right)_{2} \mathrm{CHCHMe}\right)(\mathrm{dppp})\right]\left[\mathrm{HC}\left(\mathrm{SO}_{2} \mathrm{CF}_{3}\right)_{2}\right]\left(\mathbf{1 3 a}\left[\mathrm{HC}\left(\mathrm{SO}_{2} \mathrm{CF}_{3}\right)_{2}\right]\right)(150 \mathrm{MHz}, \mathrm{RT}$, $40 \mathrm{mg} / \mathrm{mL}, d_{6}$-acetone). 

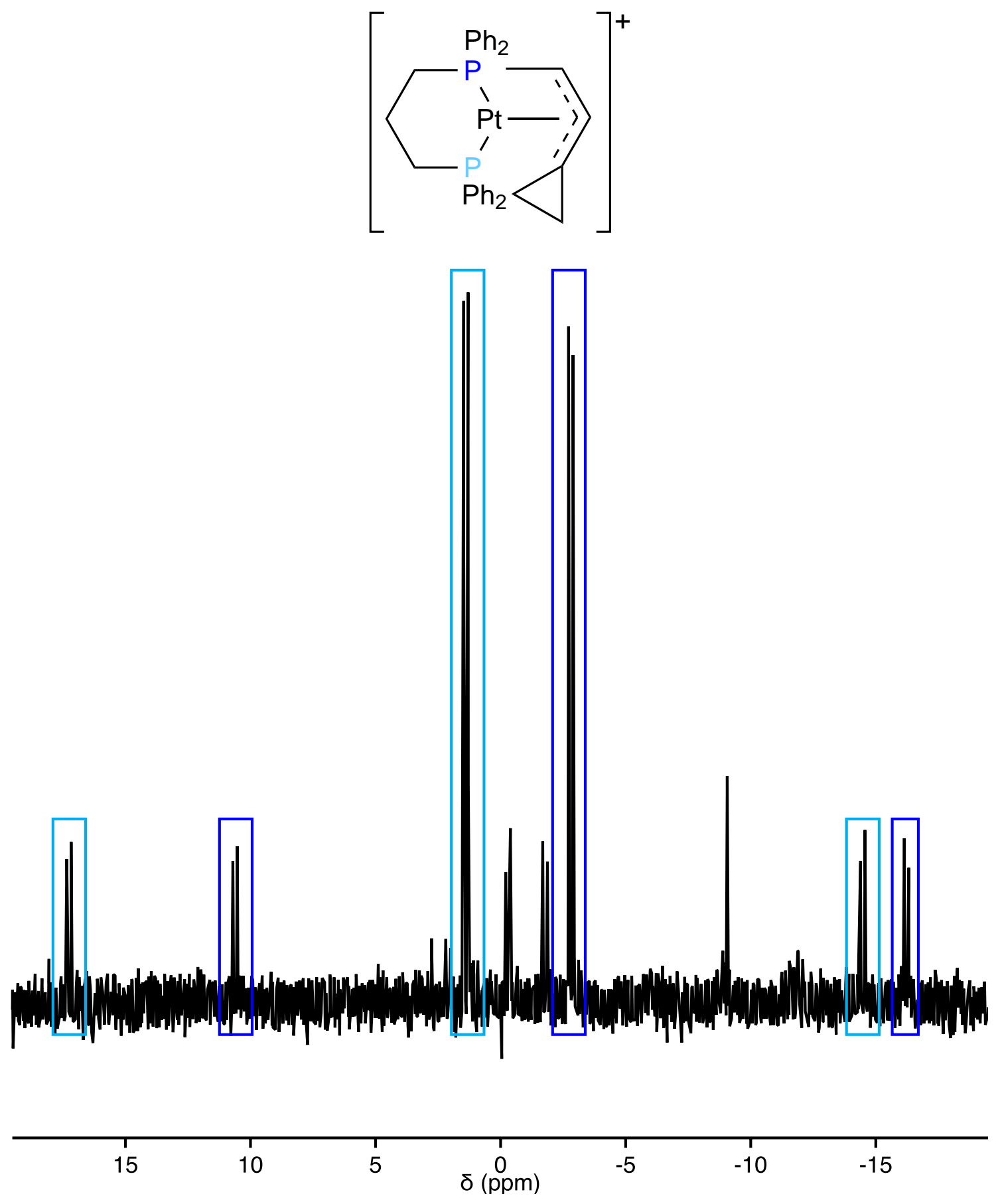

Figure A.47. ${ }^{31} \mathrm{P}\left\{{ }^{1} \mathrm{H}\right\}$ NMR spectrum of

$\left[\mathrm{Pt}\left(\eta^{3}-\mathrm{C}\left(\mathrm{CH}_{2}\right)_{2} \mathrm{CHCHMe}\right)(\mathrm{dppp})\right]\left[\mathrm{HC}\left(\mathrm{SO}_{2} \mathrm{CF}_{3}\right)_{2}\right]\left(\mathbf{1 3 a}\left[\mathrm{HC}\left(\mathrm{SO}_{2} \mathrm{CF}_{3}\right)_{2}\right]\right)(121 \mathrm{MHz}, \mathrm{RT}$, $40 \mathrm{mg} / \mathrm{mL}, d_{6}$-acetone). 

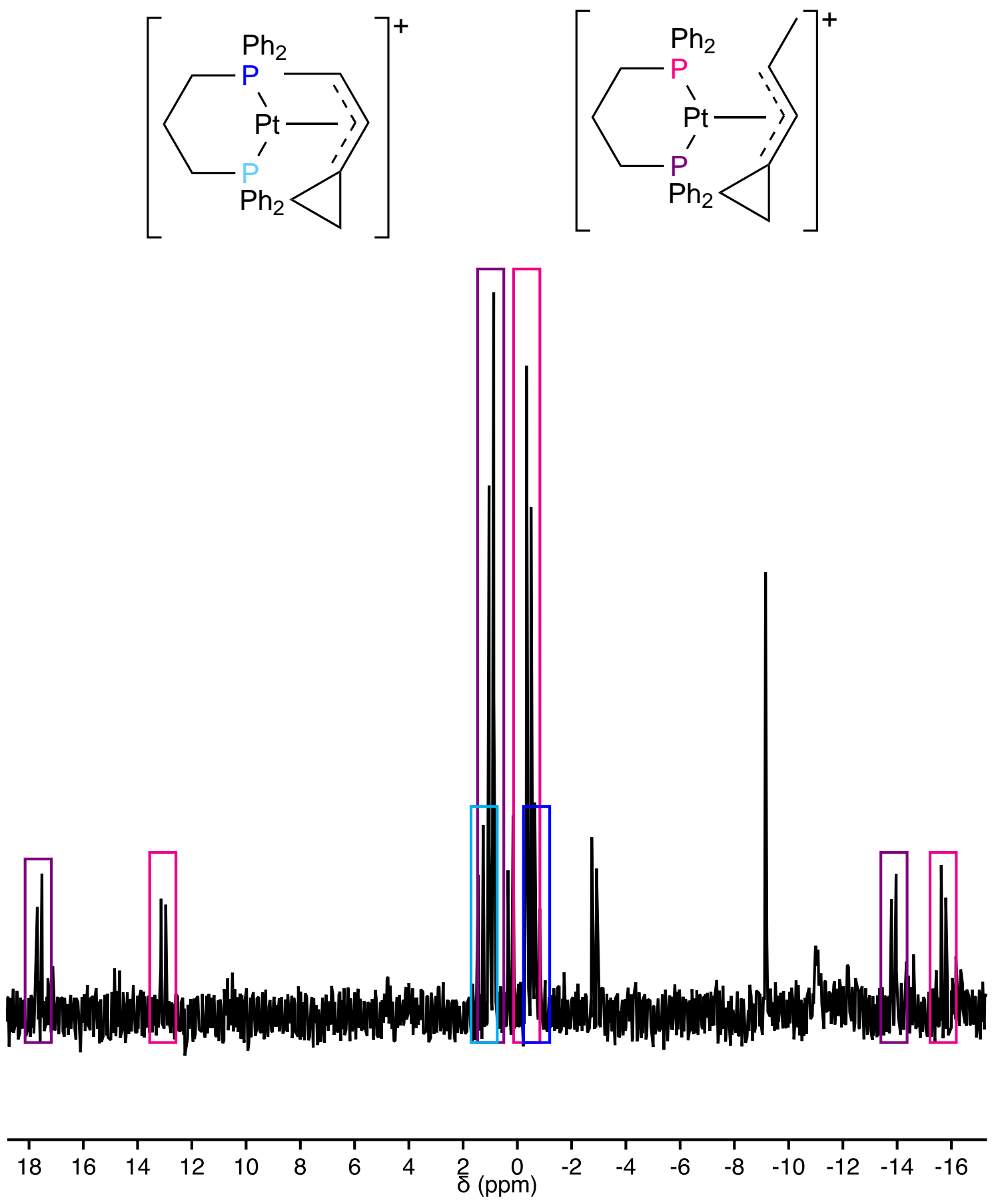

Figure A.48. ${ }^{31} \mathrm{P}\left\{{ }^{1} \mathrm{H}\right\}$ NMR spectrum of $\left[\mathrm{Pt}\left(\eta^{3}-\mathrm{C}\left(\mathrm{CH}_{2}\right)_{2} \mathrm{CHCHMe}\right)(\mathrm{dppp})\right]\left[\mathrm{HC}\left(\mathrm{SO}_{2} \mathrm{CF}_{3}\right)_{2}\right]\left(\mathbf{1 3 a}\left[\mathrm{HC}\left(\mathrm{SO}_{2} \mathrm{CF}_{3}\right)_{2}\right]\right.$ and $\left.\mathbf{1 3 b}\left[\mathrm{HC}\left(\mathrm{SO}_{2} \mathrm{CF}_{3}\right)_{2}\right]\right)$ (121 MHz, RT, $40 \mathrm{mg} / \mathrm{mL}, d_{6}$-acetone). 

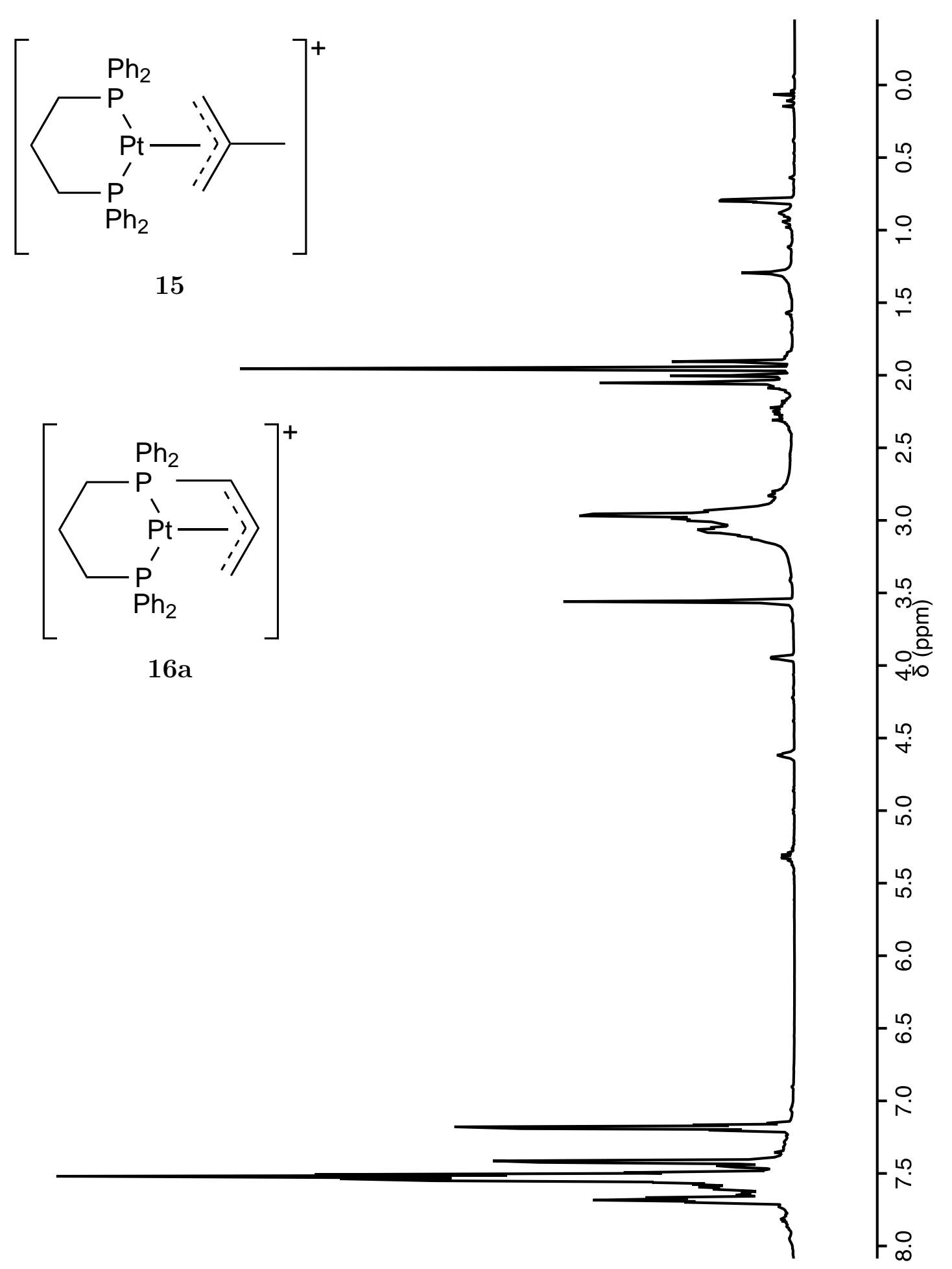

Figure A.49. ${ }^{1} \mathrm{H}$ NMR spectrum of $\left[\mathrm{Pt}\left(\eta^{3}-\mathrm{CH}_{2} \mathrm{CMeCH}_{2}\right)(\operatorname{dppp})\right]\left[\mathrm{PhC}\left(\mathrm{SO}_{2} \mathrm{CF}_{3}\right)_{2}\right]$ $\left(\mathbf{1 5}\left[\mathrm{PhC}\left(\mathrm{SO}_{2} \mathrm{CF}_{3}\right)_{2}\right]\right)$ and $\left[\mathrm{Pt}\left(\eta^{3}-\mathrm{CH}_{2} \mathrm{CHCHMe}\right)(\operatorname{dppp})\right]\left[\mathrm{PhC}\left(\mathrm{SO}_{2} \mathrm{CF}_{3}\right)_{2}\right]$ (anti $\left.\mathrm{Me}\right)$ $\left(\mathbf{1 6 a}\left[\mathrm{PhC}\left(\mathrm{SO}_{2} \mathrm{CF}_{3}\right)_{2}\right]\right)$. (600 MHz, RT, $40 \mathrm{mg} / \mathrm{mL}, d_{6}$-acetone). 

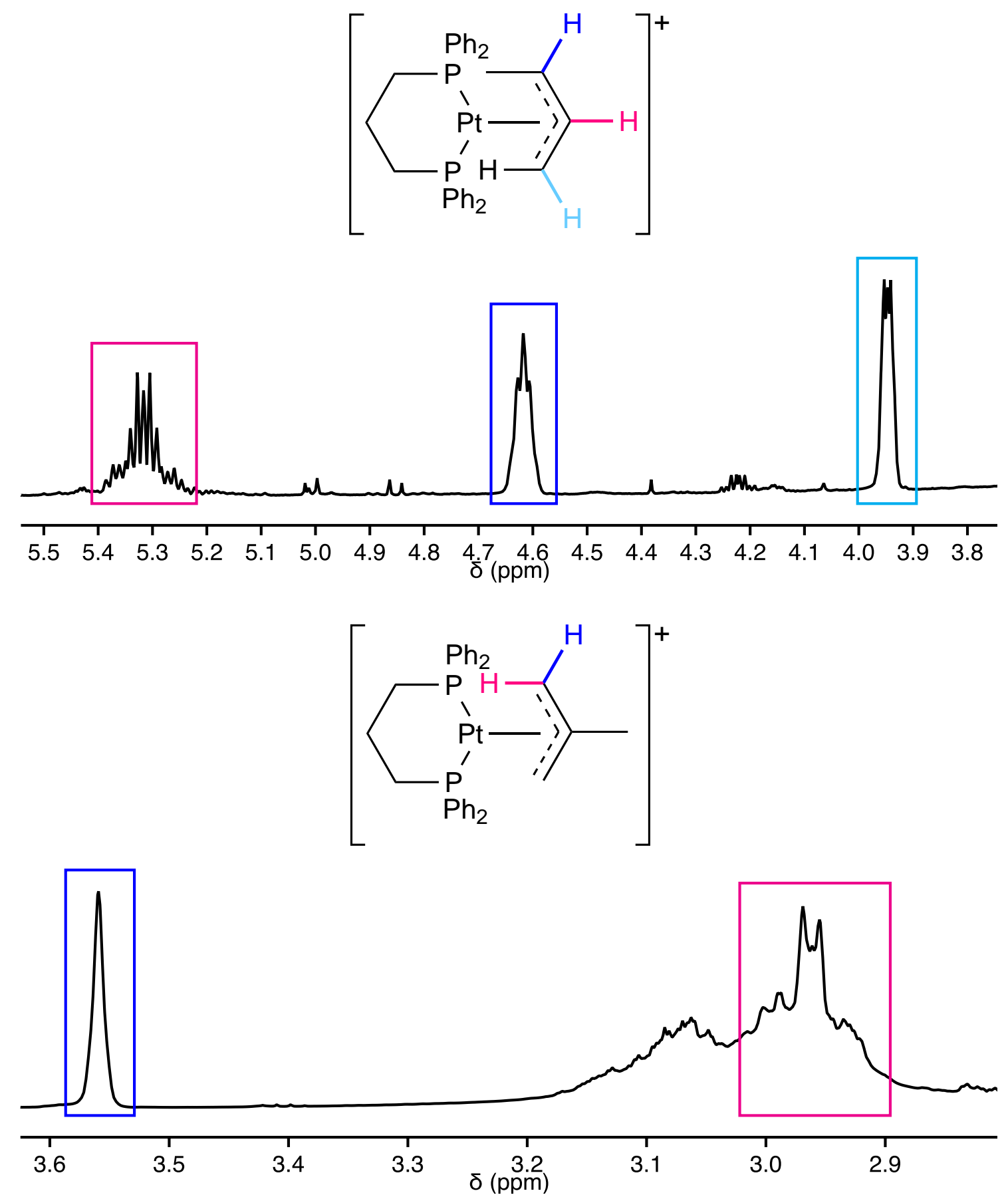

Figure A.50. Expanded ${ }^{1} \mathrm{H}$ NMR spectrum of

$\left[\mathrm{Pt}\left(\eta^{3}-\mathrm{CH}_{2} \mathrm{CMeCH}_{2}\right)(\mathrm{dppp})\right]\left[\mathrm{PhC}\left(\mathrm{SO}_{2} \mathrm{CF}_{3}\right)_{2}\right]\left(\mathbf{1 5}\left[\mathrm{PhC}\left(\mathrm{SO}_{2} \mathrm{CF}_{3}\right)_{2}\right]\right)$ and $\left[\mathrm{Pt}\left(\eta^{3}-\mathrm{CH}_{2} \mathrm{CHCHMe}\right)(\mathrm{dppp})\right]\left[\mathrm{PhC}\left(\mathrm{SO}_{2} \mathrm{CF}_{3}\right)_{2}\right]$ (anti $\left.\mathrm{Me}\right)\left(\mathbf{1 6 a}\left[\mathrm{PhC}\left(\mathrm{SO}_{2} \mathrm{CF}_{3}\right)_{2}\right]\right)$. (600 MHz, RT, $40 \mathrm{mg} / \mathrm{mL}, d_{6}$-acetone). 

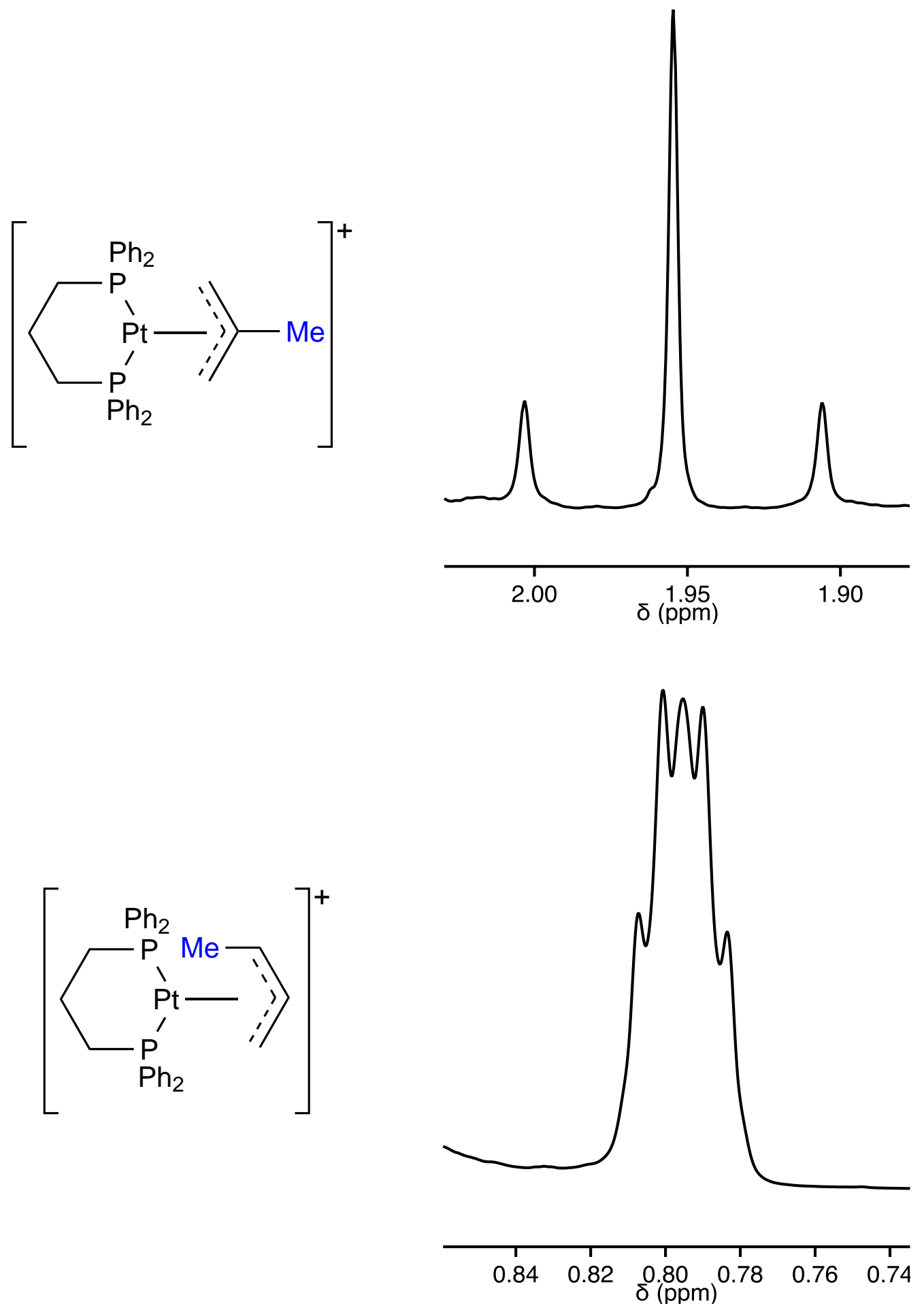

Figure A.51. Expanded ${ }^{1} \mathrm{H}$ NMR spectrum of $\left[\mathrm{Pt}\left(\eta^{3}-\mathrm{CH}_{2} \mathrm{CMeCH}_{2}\right)(\mathrm{dppp})\right]\left[\mathrm{PhC}\left(\mathrm{SO}_{2} \mathrm{CF}_{3}\right)_{2}\right]\left(\mathbf{1 5}\left[\mathrm{PhC}\left(\mathrm{SO}_{2} \mathrm{CF}_{3}\right)_{2}\right]\right)$ and $\left[\mathrm{Pt}\left(\eta^{3}-\mathrm{CH}_{2} \mathrm{CHCHMe}\right)(\mathrm{dppp})\right]\left[\mathrm{PhC}\left(\mathrm{SO}_{2} \mathrm{CF}_{3}\right)_{2}\right]$ (anti $\left.\mathrm{Me}\right)\left(\mathbf{1 6 a}\left[\mathrm{PhC}\left(\mathrm{SO}_{2} \mathrm{CF}_{3}\right)_{2}\right]\right)$. (600 MHz, RT, $40 \mathrm{mg} / \mathrm{mL}, d_{6}$-acetone). 


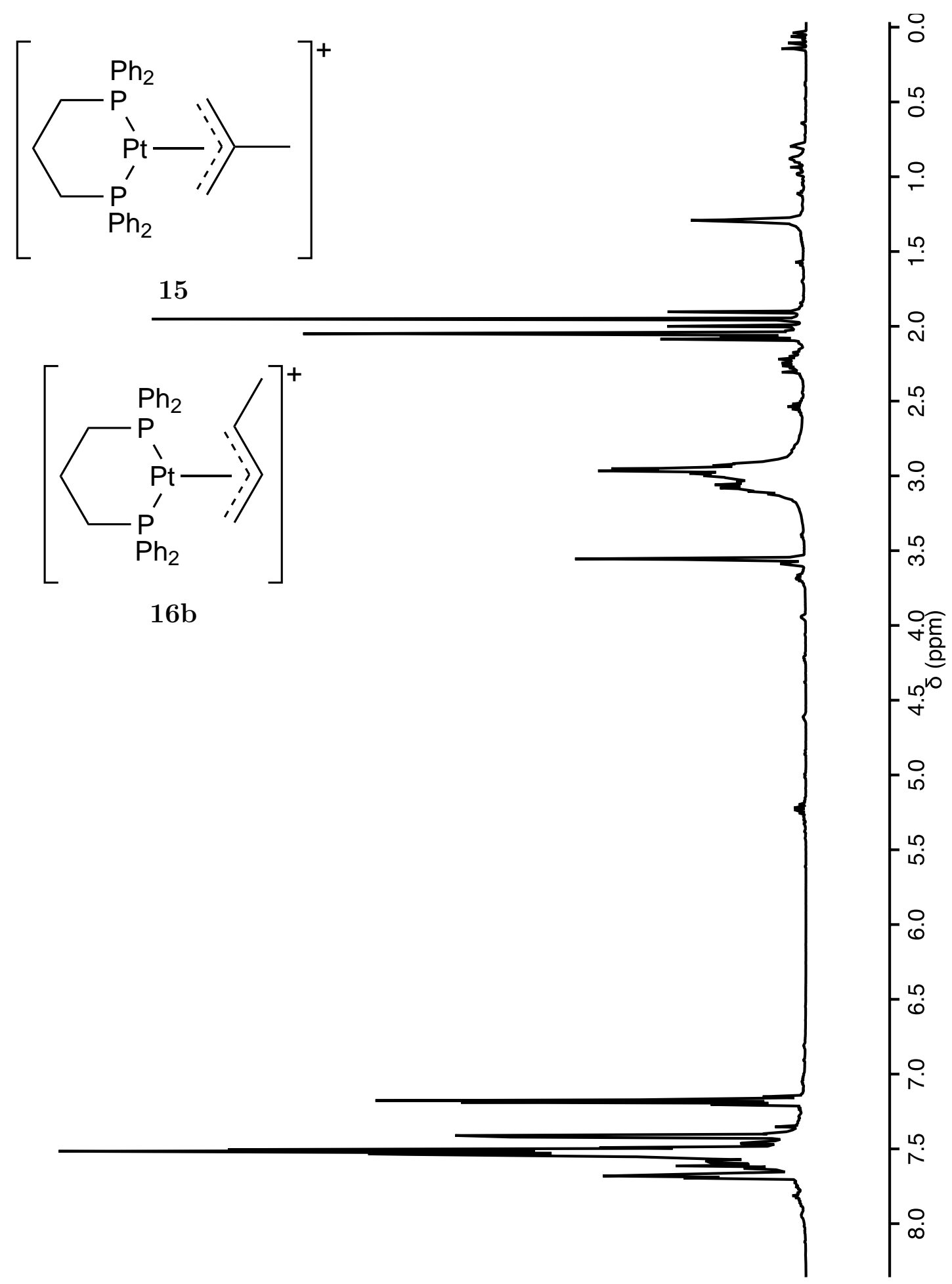

Figure A.52. ${ }^{1} \mathrm{H}$ NMR spectrum of $\left[\mathrm{Pt}\left(\eta^{3}-\mathrm{CH}_{2} \mathrm{CMeCH}_{2}\right)(\mathrm{dppp})\right]\left[\mathrm{PhC}\left(\mathrm{SO}_{2} \mathrm{CF}_{3}\right)_{2}\right]$ $\left(\mathbf{1 5}\left[\mathrm{PhC}\left(\mathrm{SO}_{2} \mathrm{CF}_{3}\right)_{2}\right]\right)$ and $\left[\mathrm{Pt}\left(\eta^{3}-\mathrm{CH}_{2} \mathrm{CHCHMe}\right)(\mathrm{dppp})\right]\left[\mathrm{PhC}\left(\mathrm{SO}_{2} \mathrm{CF}_{3}\right)_{2}\right]$ (syn $\left.\mathrm{Me}\right)$ $\left(\mathbf{1 6 b}\left[\mathrm{PhC}\left(\mathrm{SO}_{2} \mathrm{CF}_{3}\right)_{2}\right]\right)$. (600 MHz, RT, $40 \mathrm{mg} / \mathrm{mL}, d_{6}$-acetone). 

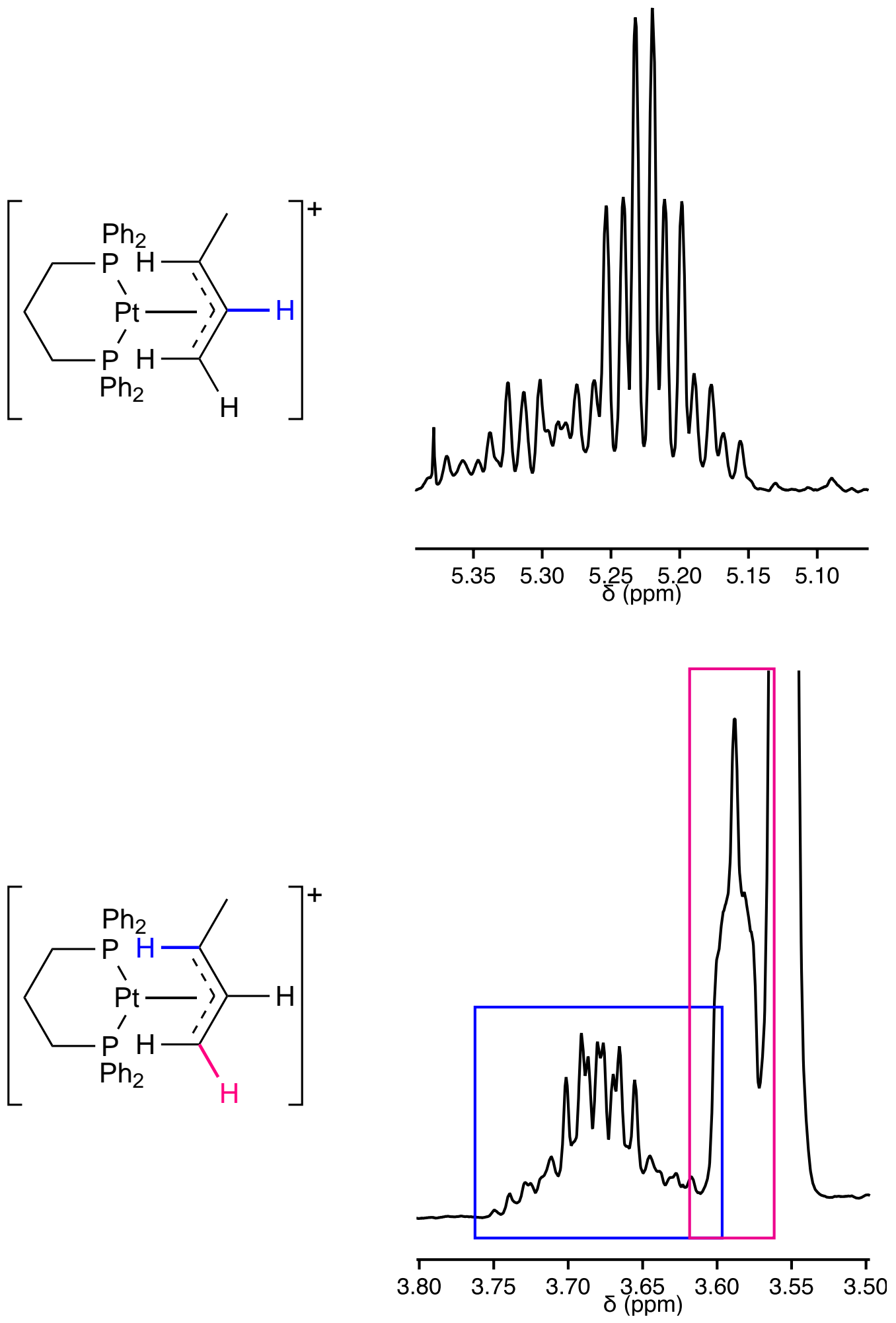

Figure A.53. Expanded ${ }^{1} \mathrm{H}$ NMR spectrum of $\left[\mathrm{Pt}\left(\eta^{3}-\mathrm{CH}_{2} \mathrm{CMeCH}_{2}\right)(\mathrm{dppp})\right]\left[\mathrm{PhC}\left(\mathrm{SO}_{2} \mathrm{CF}_{3}\right)_{2}\right]\left(\mathbf{1 5}\left[\mathrm{PhC}\left(\mathrm{SO}_{2} \mathrm{CF}_{3}\right)_{2}\right]\right)$ and $\left[\mathrm{Pt}\left(\eta^{3}-\mathrm{CH}_{2} \mathrm{CHCHMe}\right)(\mathrm{dppp})\right]\left[\mathrm{PhC}\left(\mathrm{SO}_{2} \mathrm{CF}_{3}\right)_{2}\right]($ syn $\mathrm{Me})\left(\mathbf{1 6 b}\left[\mathrm{PhC}\left(\mathrm{SO}_{2} \mathrm{CF}_{3}\right)_{2}\right]\right)$. (600 MHz, RT, $40 \mathrm{mg} / \mathrm{mL}, d_{6}$-acetone). 

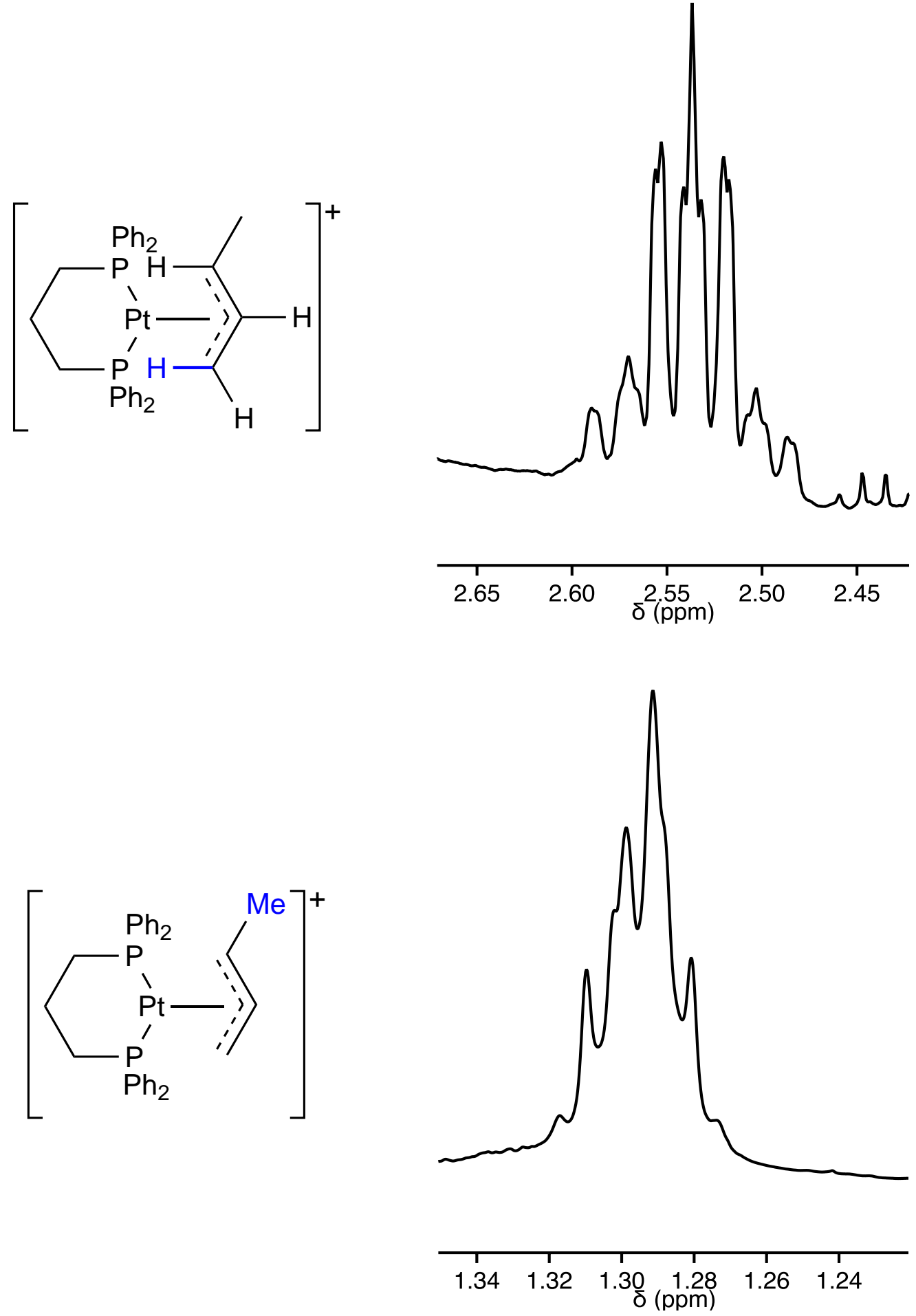

Figure A.54. Expanded ${ }^{1} \mathrm{H}$ NMR spectrum of $\left[\mathrm{Pt}\left(\eta^{3}-\mathrm{CH}_{2} \mathrm{CMeCH}_{2}\right)(\mathrm{dppp})\right]\left[\mathrm{PhC}\left(\mathrm{SO}_{2} \mathrm{CF}_{3}\right)_{2}\right]\left(\mathbf{1 5}\left[\mathrm{PhC}\left(\mathrm{SO}_{2} \mathrm{CF}_{3}\right)_{2}\right]\right)$ and $\left[\mathrm{Pt}\left(\eta^{3}-\mathrm{CH}_{2} \mathrm{CHCHMe}\right)(\mathrm{dppp})\right]\left[\mathrm{PhC}\left(\mathrm{SO}_{2} \mathrm{CF}_{3}\right)_{2}\right]$ ( syn $\left.\mathrm{Me}\right)\left(\mathbf{1 6 b}\left[\mathrm{PhC}\left(\mathrm{SO}_{2} \mathrm{CF}_{3}\right)_{2}\right]\right)$. (600 MHz, RT, $40 \mathrm{mg} / \mathrm{mL}, d_{6}$-acetone). 


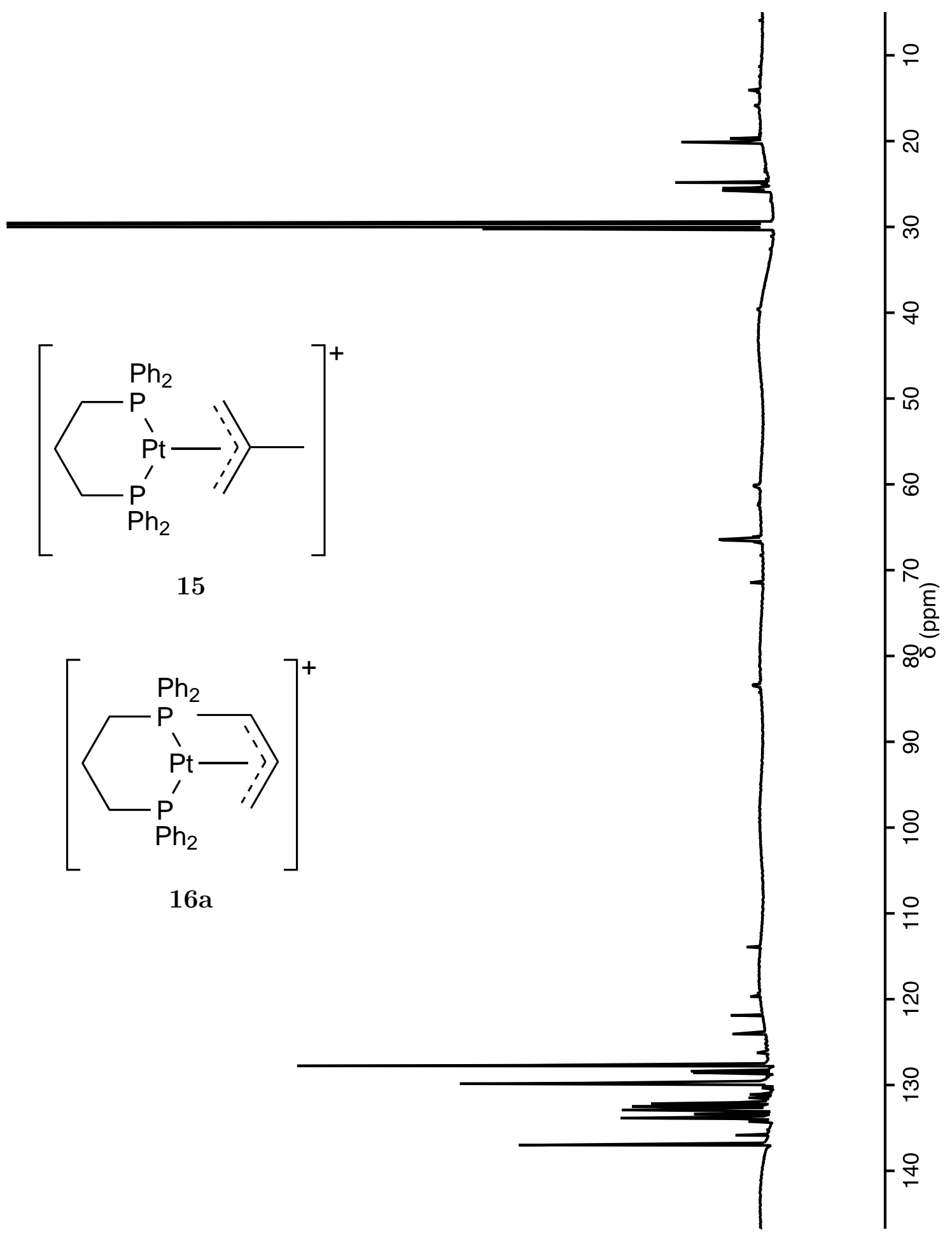

Figure A.55. ${ }^{13} \mathrm{C}\left\{{ }^{1} \mathrm{H}\right\}$ NMR spectrum of $\left[\mathrm{Pt}\left(\eta^{3}-\mathrm{CH}_{2} \mathrm{CMeCH}_{2}\right)(\mathrm{dppp})\right]\left[\mathrm{PhC}\left(\mathrm{SO}_{2} \mathrm{CF}_{3}\right)_{2}\right]$ $\left(\mathbf{1 5}\left[\mathrm{PhC}\left(\mathrm{SO}_{2} \mathrm{CF}_{3}\right)_{2}\right]\right)$ and $\left[\mathrm{Pt}\left(\eta^{3}-\mathrm{CH}_{2} \mathrm{CHCHMe}\right)(\mathrm{dppp})\right]\left[\mathrm{PhC}\left(\mathrm{SO}_{2} \mathrm{CF}_{3}\right)_{2}\right]$ (anti $\left.\mathrm{Me}\right)$ $\left(\mathbf{1 6 a}\left[\mathrm{PhC}\left(\mathrm{SO}_{2} \mathrm{CF}_{3}\right)_{2}\right]\right)$. (150 MHz, RT, $40 \mathrm{mg} / \mathrm{mL}, d_{6}$-acetone). 

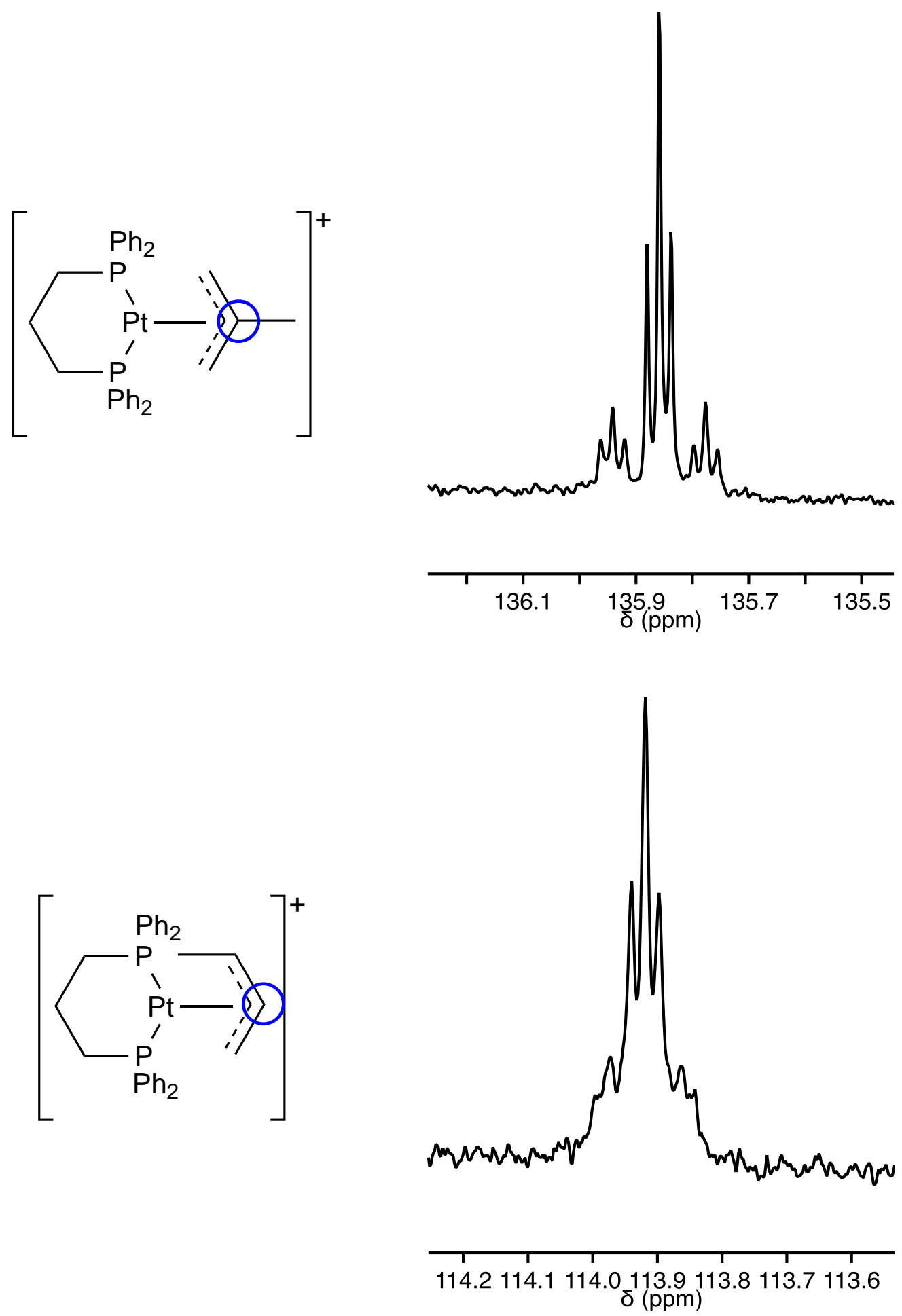

Figure A.56. Expanded ${ }^{13} \mathrm{C}\left\{{ }^{1} \mathrm{H}\right\}$ NMR spectrum of

$\left[\mathrm{Pt}\left(\eta^{3}-\mathrm{CH}_{2} \mathrm{CMeCH}_{2}\right)(\mathrm{dppp})\right]\left[\mathrm{PhC}\left(\mathrm{SO}_{2} \mathrm{CF}_{3}\right)_{2}\right]\left(\mathbf{1 5}\left[\mathrm{PhC}\left(\mathrm{SO}_{2} \mathrm{CF}_{3}\right)_{2}\right]\right)$ and $\left[\mathrm{Pt}\left(\eta^{3}-\mathrm{CH}_{2} \mathrm{CHCHMe}\right)(\mathrm{dppp})\right]\left[\mathrm{PhC}\left(\mathrm{SO}_{2} \mathrm{CF}_{3}\right)_{2}\right]$ (anti $\left.\mathrm{Me}\right)\left(\mathbf{1 6 a}\left[\mathrm{PhC}\left(\mathrm{SO}_{2} \mathrm{CF}_{3}\right)_{2}\right]\right)$. (150 MHz, RT, $40 \mathrm{mg} / \mathrm{mL}, d_{6}$-acetone). 

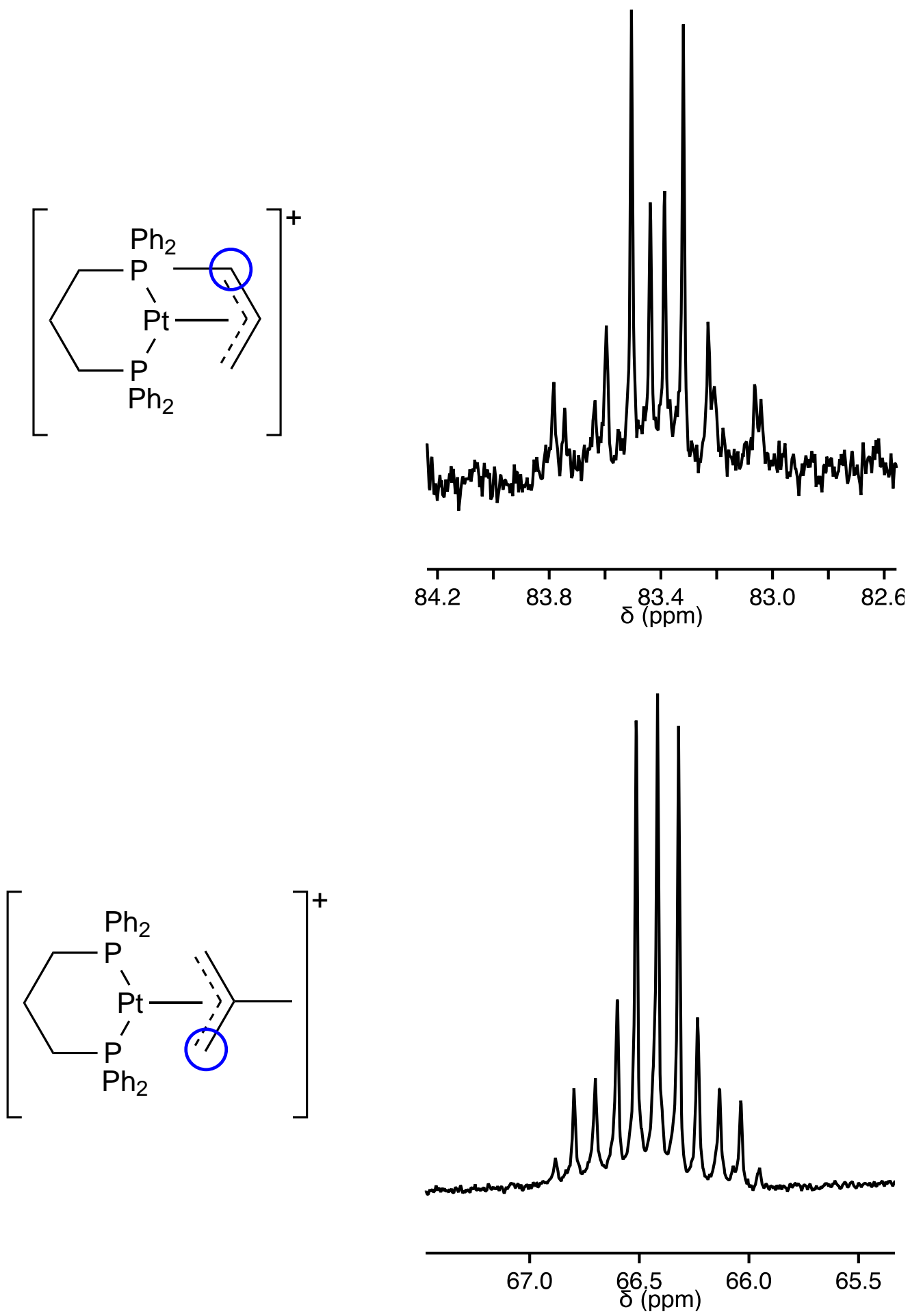

Figure A.57. Expanded ${ }^{13} \mathrm{C}\left\{{ }^{1} \mathrm{H}\right\}$ NMR spectrum of $\left[\mathrm{Pt}\left(\eta^{3}-\mathrm{CH}_{2} \mathrm{CMeCH}_{2}\right)(\mathrm{dppp})\right]\left[\mathrm{PhC}\left(\mathrm{SO}_{2} \mathrm{CF}_{3}\right)_{2}\right]\left(\mathbf{1 5}\left[\mathrm{PhC}\left(\mathrm{SO}_{2} \mathrm{CF}_{3}\right)_{2}\right]\right)$ and $\left[\mathrm{Pt}\left(\eta^{3}-\mathrm{CH}_{2} \mathrm{CHCHMe}\right)(\mathrm{dppp})\right]\left[\mathrm{PhC}\left(\mathrm{SO}_{2} \mathrm{CF}_{3}\right)_{2}\right]$ (anti $\left.\mathrm{Me}\right)\left(\mathbf{1 6 a}\left[\mathrm{PhC}\left(\mathrm{SO}_{2} \mathrm{CF}_{3}\right)_{2}\right]\right)$. (150 MHz, RT, $40 \mathrm{mg} / \mathrm{mL}, d_{6}$-acetone). 

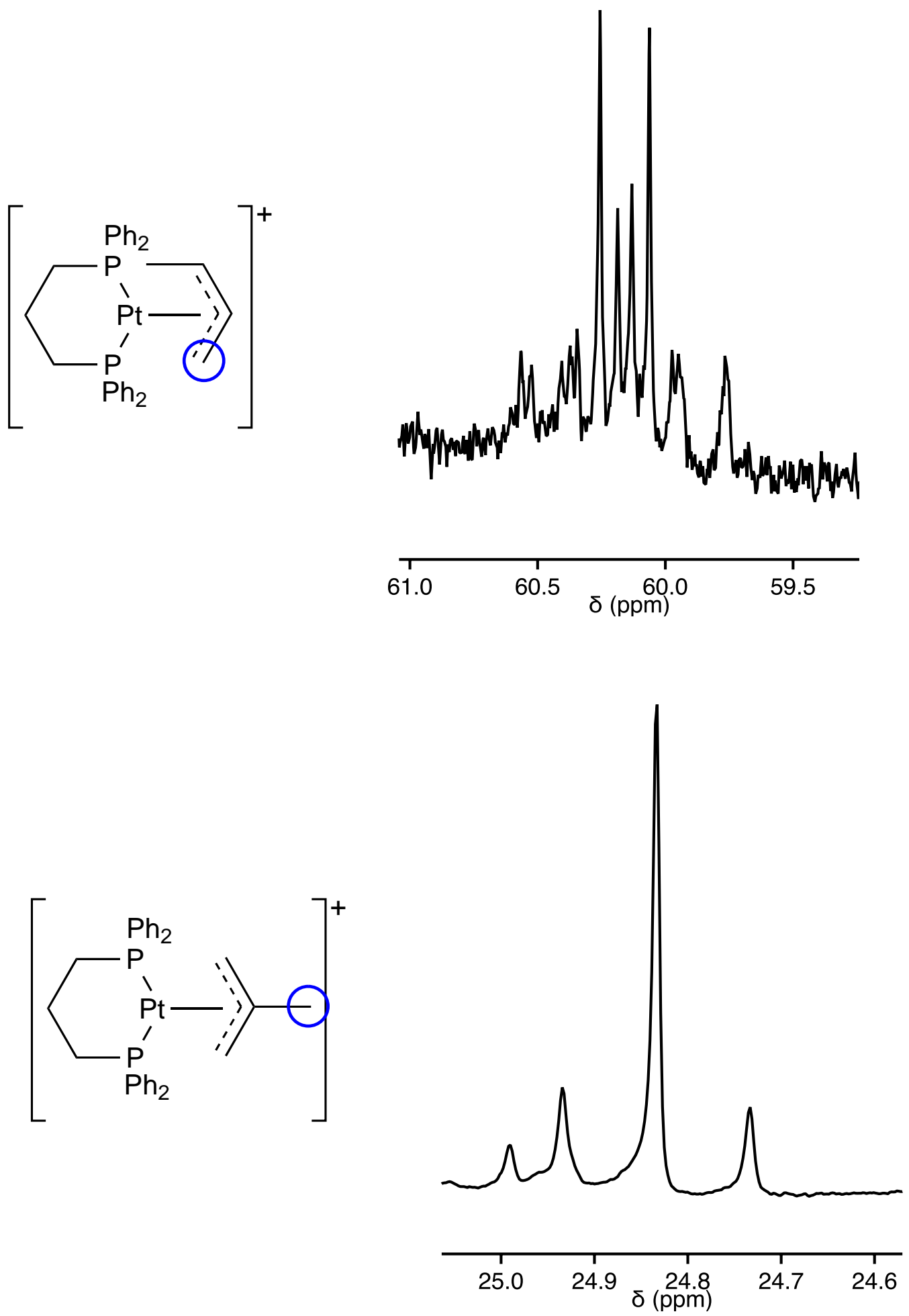

Figure A.58. Expanded ${ }^{13} \mathrm{C}\left\{{ }^{1} \mathrm{H}\right\}$ NMR spectrum of $\left[\mathrm{Pt}\left(\eta^{3}-\mathrm{CH}_{2} \mathrm{CMeCH}_{2}\right)(\mathrm{dppp})\right]\left[\mathrm{PhC}\left(\mathrm{SO}_{2} \mathrm{CF}_{3}\right)_{2}\right]\left(\mathbf{1 5}\left[\mathrm{PhC}\left(\mathrm{SO}_{2} \mathrm{CF}_{3}\right)_{2}\right]\right)$ and $\left[\mathrm{Pt}\left(\eta^{3}-\mathrm{CH}_{2} \mathrm{CHCHMe}\right)(\mathrm{dppp})\right]\left[\mathrm{PhC}\left(\mathrm{SO}_{2} \mathrm{CF}_{3}\right)_{2}\right]$ (anti $\left.\mathrm{Me}\right)\left(\mathbf{1 6 a}\left[\mathrm{PhC}\left(\mathrm{SO}_{2} \mathrm{CF}_{3}\right)_{2}\right]\right)$. (150 MHz, RT, $40 \mathrm{mg} / \mathrm{mL}, d_{6}$-acetone). 

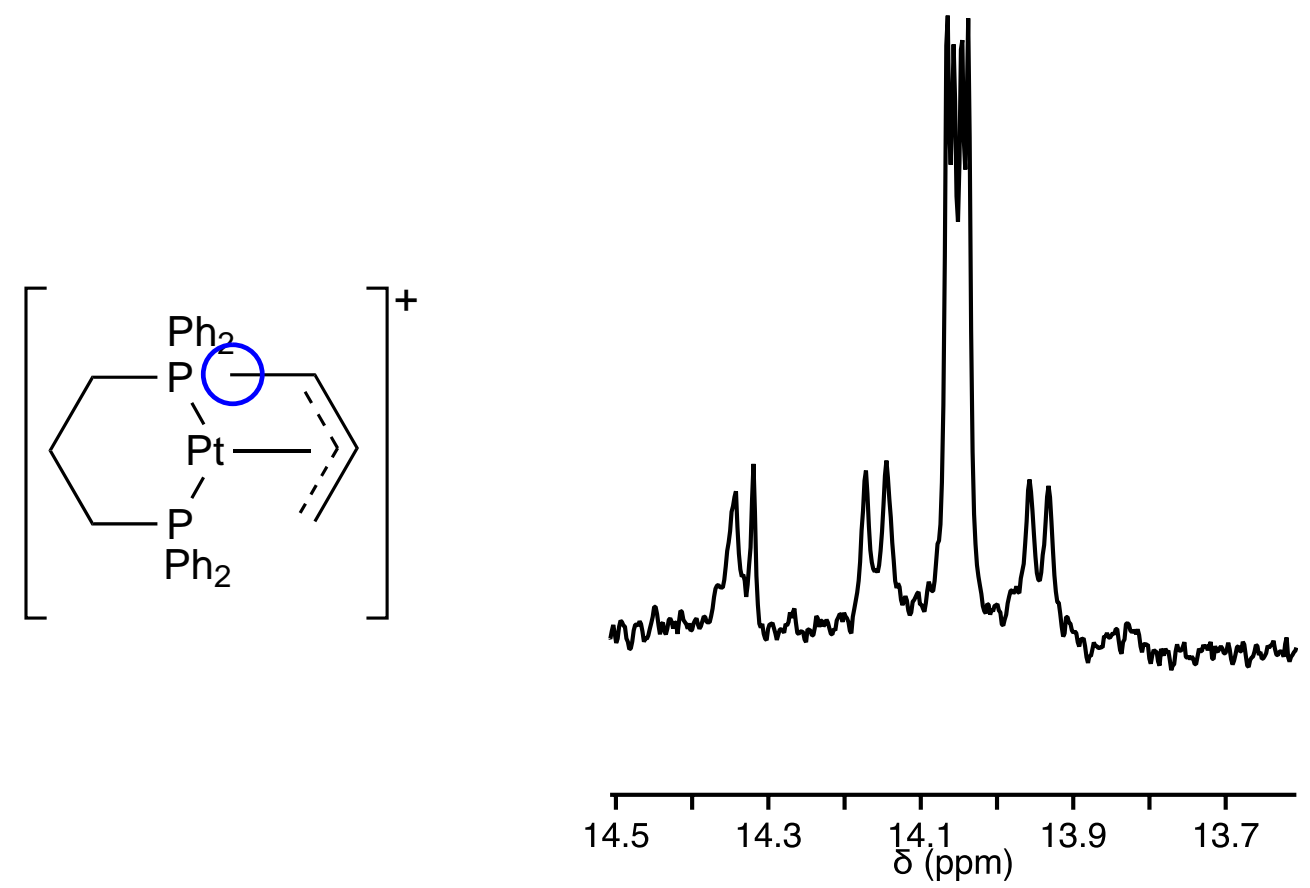

Figure A.59. Expanded ${ }^{13} \mathrm{C}\left\{{ }^{1} \mathrm{H}\right\}$ NMR spectrum of $\left[\mathrm{Pt}\left(\eta^{3}-\mathrm{CH}_{2} \mathrm{CMeCH}_{2}\right)(\mathrm{dppp})\right]\left[\mathrm{PhC}\left(\mathrm{SO}_{2} \mathrm{CF}_{3}\right)_{2}\right]\left(\mathbf{1 5}\left[\mathrm{PhC}\left(\mathrm{SO}_{2} \mathrm{CF}_{3}\right)_{2}\right]\right)$ and $\left[\mathrm{Pt}\left(\eta^{3}-\mathrm{CH}_{2} \mathrm{CHCHMe}\right)(\mathrm{dppp})\right]\left[\mathrm{PhC}\left(\mathrm{SO}_{2} \mathrm{CF}_{3}\right)_{2}\right]($ anti $\mathrm{Me})\left(\mathbf{1 6 a}\left[\mathrm{PhC}\left(\mathrm{SO}_{2} \mathrm{CF}_{3}\right)_{2}\right]\right)$. (150 MHz, RT, $40 \mathrm{mg} / \mathrm{mL}, d_{6}$-acetone). 


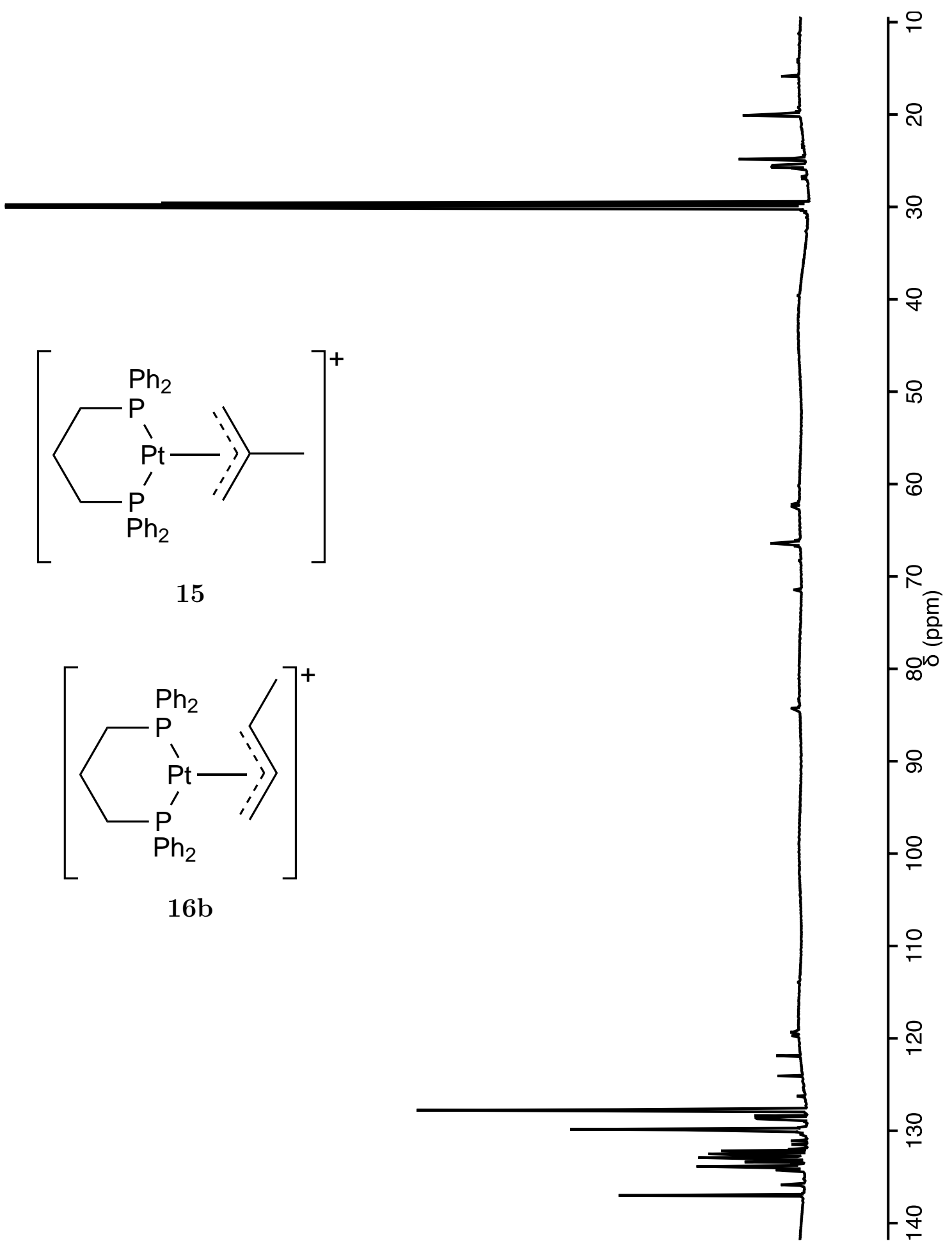

Figure A.60. ${ }^{13} \mathrm{C}\left\{{ }^{1} \mathrm{H}\right\} \mathrm{NMR}$ spectrum of $\left[\mathrm{Pt}\left(\eta^{3}-\mathrm{CH}_{2} \mathrm{CMeCH}_{2}\right)(\mathrm{dppp})\right]\left[\mathrm{PhC}\left(\mathrm{SO}_{2} \mathrm{CF}_{3}\right)_{2}\right]$ $\left(\mathbf{1 5}\left[\mathrm{PhC}\left(\mathrm{SO}_{2} \mathrm{CF}_{3}\right)_{2}\right]\right)$ and $\left[\mathrm{Pt}\left(\eta^{3}-\mathrm{CH}_{2} \mathrm{CHCHMe}\right)(\mathrm{dppp})\right]\left[\mathrm{PhC}\left(\mathrm{SO}_{2} \mathrm{CF}_{3}\right)_{2}\right]$ (syn $\left.\mathrm{Me}\right)$ $\left(\mathbf{1 6 b}\left[\mathrm{PhC}\left(\mathrm{SO}_{2} \mathrm{CF}_{3}\right)_{2}\right]\right)$. (150 MHz, RT, $40 \mathrm{mg} / \mathrm{mL}, d_{6}$-acetone). 

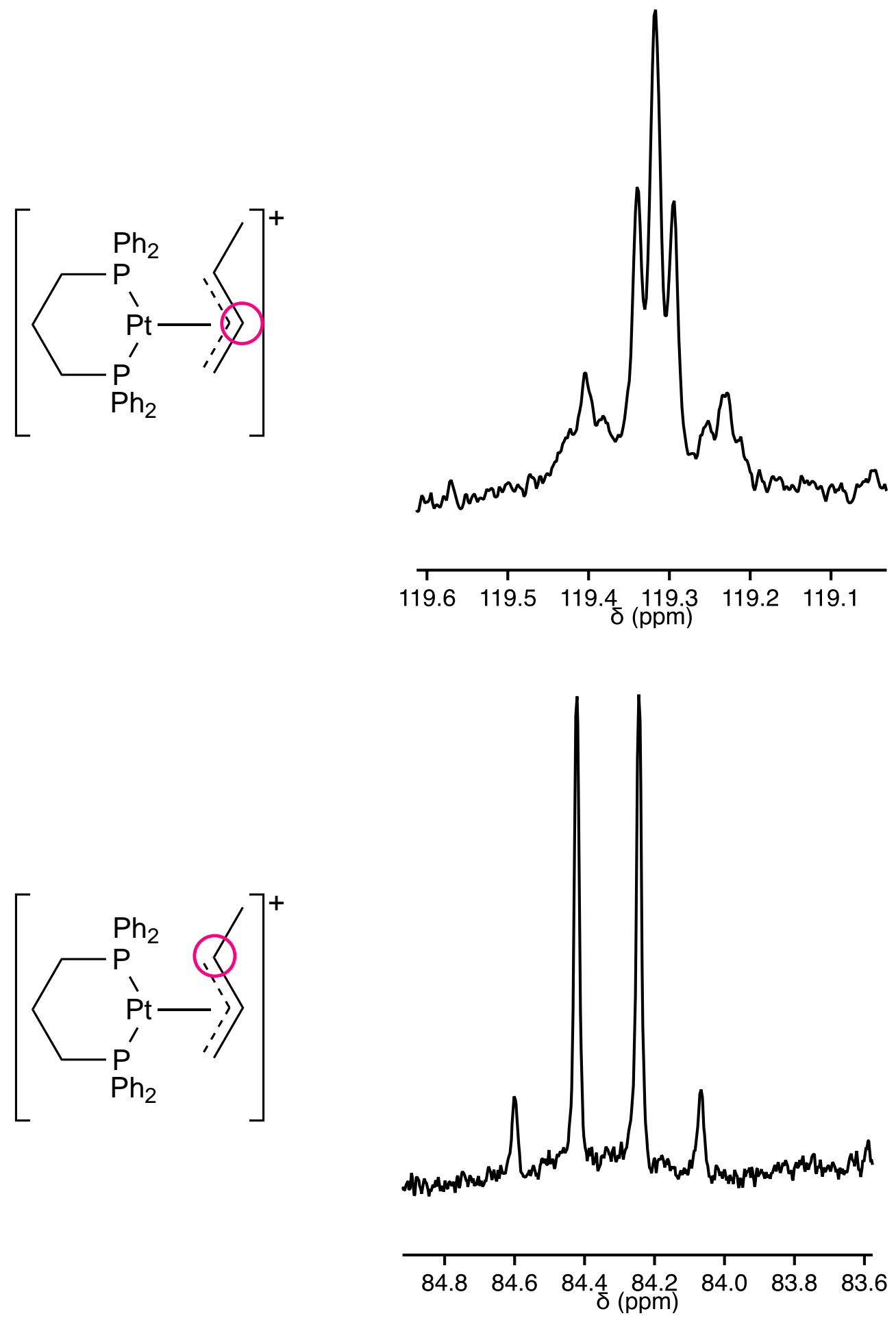

Figure A.61. Expanded ${ }^{13} \mathrm{C}\left\{{ }^{1} \mathrm{H}\right\}$ NMR spectrum of $\left[\mathrm{Pt}\left(\eta^{3}-\mathrm{CH}_{2} \mathrm{CMeCH}_{2}\right)(\mathrm{dppp})\right]\left[\mathrm{PhC}\left(\mathrm{SO}_{2} \mathrm{CF}_{3}\right)_{2}\right]\left(\mathbf{1 5}\left[\mathrm{PhC}\left(\mathrm{SO}_{2} \mathrm{CF}_{3}\right)_{2}\right]\right)$ and $\left[\mathrm{Pt}\left(\eta^{3}-\mathrm{CH}_{2} \mathrm{CHCHMe}\right)(\mathrm{dppp})\right]\left[\mathrm{PhC}\left(\mathrm{SO}_{2} \mathrm{CF}_{3}\right)_{2}\right]$ ( syn $\left.\mathrm{Me}\right)\left(\mathbf{1 6 b}\left[\mathrm{PhC}\left(\mathrm{SO}_{2} \mathrm{CF}_{3}\right)_{2}\right]\right)$. (150 MHz, RT, $40 \mathrm{mg} / \mathrm{mL}, d_{6}$-acetone). 

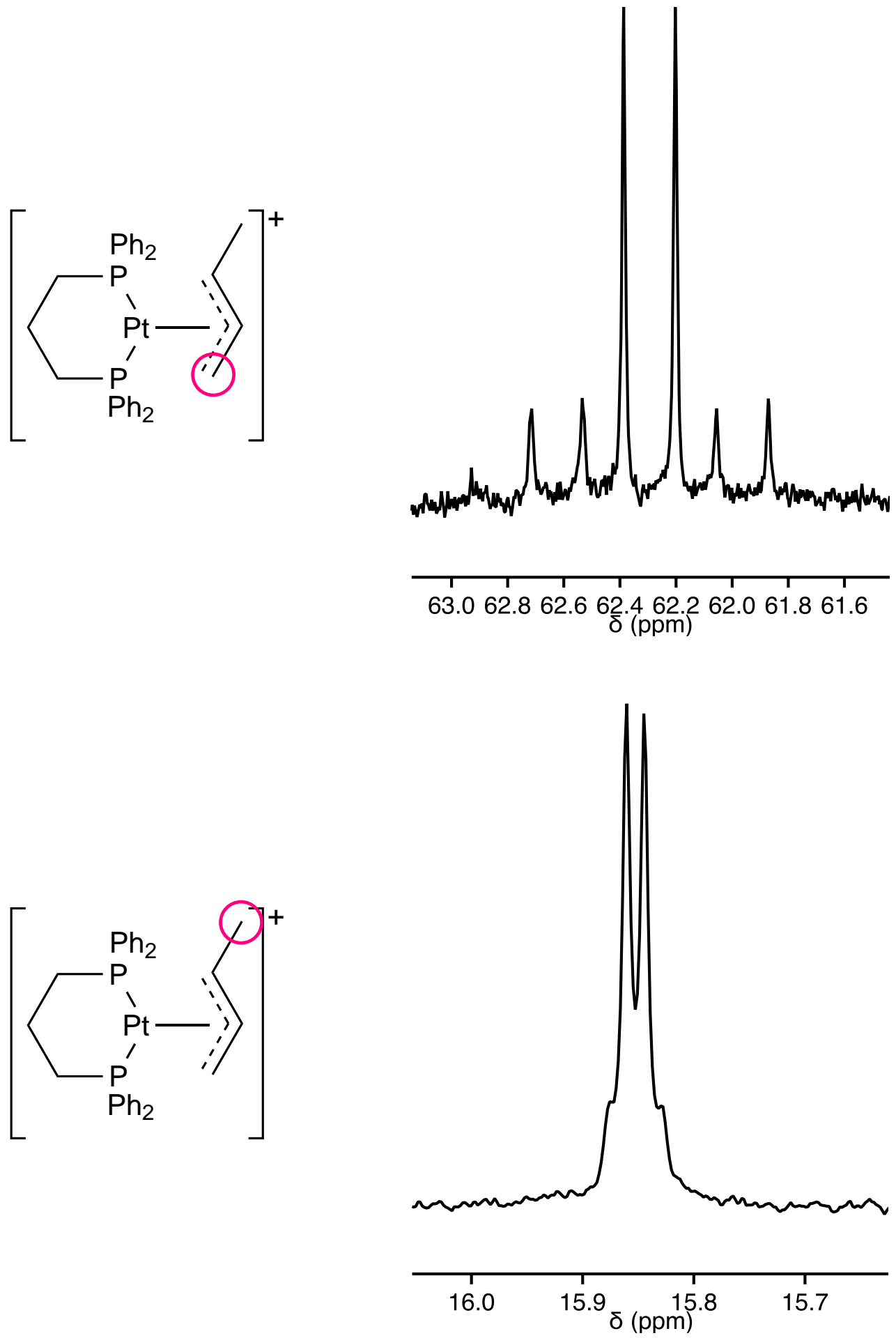

Figure A.62. Expanded ${ }^{13} \mathrm{C}\left\{{ }^{1} \mathrm{H}\right\}$ NMR spectrum of

$\left[\mathrm{Pt}\left(\eta^{3}-\mathrm{CH}_{2} \mathrm{CMeCH}_{2}\right)(\mathrm{dppp})\right]\left[\mathrm{PhC}\left(\mathrm{SO}_{2} \mathrm{CF}_{3}\right)_{2}\right]\left(\mathbf{1 5}\left[\mathrm{PhC}\left(\mathrm{SO}_{2} \mathrm{CF}_{3}\right)_{2}\right]\right)$ and $\left[\mathrm{Pt}\left(\eta^{3}-\mathrm{CH}_{2} \mathrm{CHCHMe}\right)(\mathrm{dppp})\right]\left[\mathrm{PhC}\left(\mathrm{SO}_{2} \mathrm{CF}_{3}\right)_{2}\right]$ ( syn $\left.\mathrm{Me}\right)\left(\mathbf{1 6 b}\left[\mathrm{PhC}\left(\mathrm{SO}_{2} \mathrm{CF}_{3}\right)_{2}\right]\right)$. (150 MHz, RT, $40 \mathrm{mg} / \mathrm{mL}, d_{6}$-acetone). 
(mdd) HQ

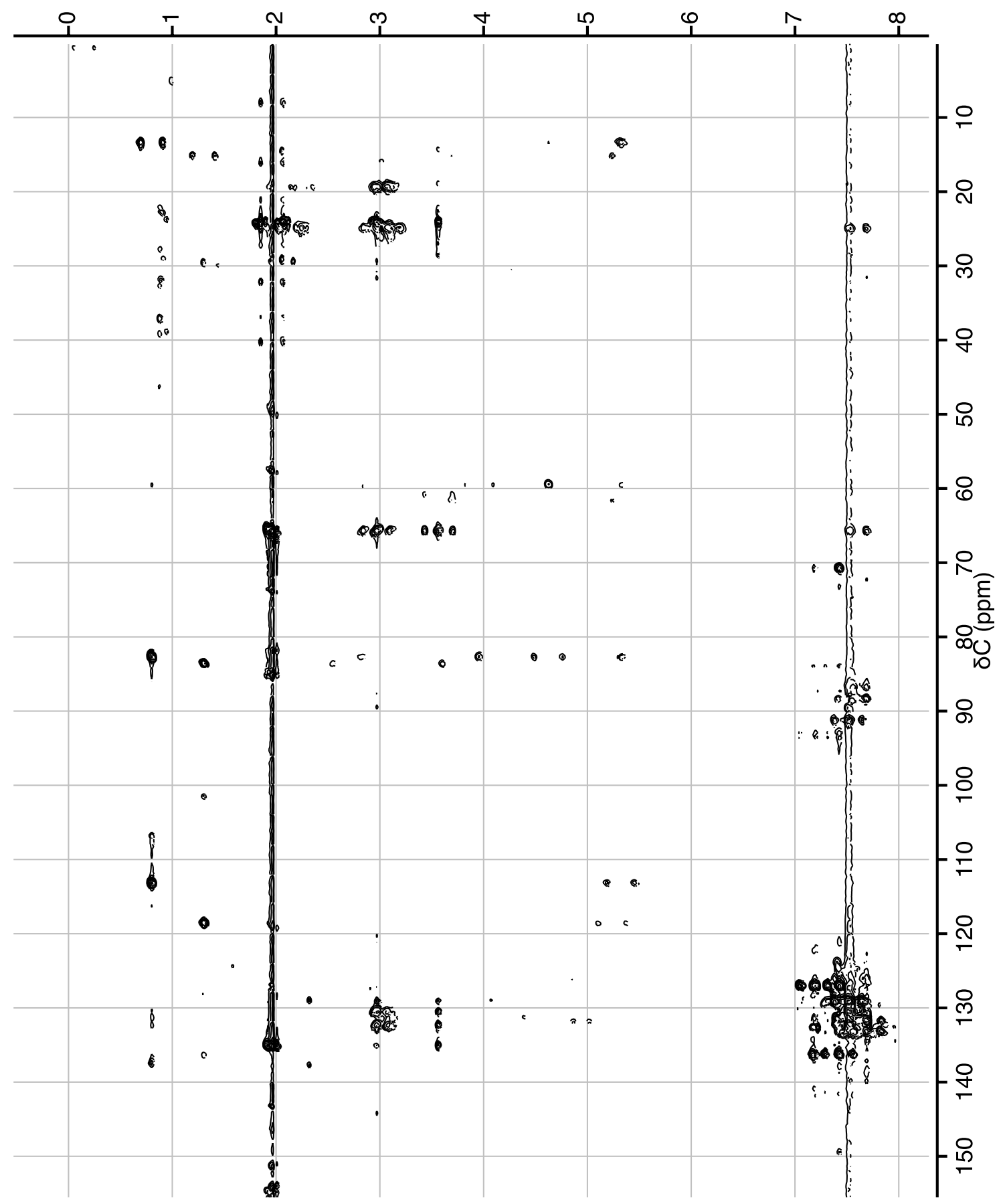

Figure A.63. $\mathrm{HMBC}$ spectrum of $\left[\mathrm{Pt}\left(\eta^{3}-\mathrm{CH}_{2} \mathrm{CMeCH}_{2}\right)(\mathrm{dppp})\right]\left[\mathrm{PhC}\left(\mathrm{SO}_{2} \mathrm{CF}_{3}\right)_{2}\right]$ $\left(\mathbf{1 5}\left[\mathrm{PhC}\left(\mathrm{SO}_{2} \mathrm{CF}_{3}\right)_{2}\right]\right)$ and $\left[\mathrm{Pt}\left(\eta^{3}-\mathrm{CH}_{2} \mathrm{CHCHMe}\right)(\operatorname{dppp})\right]\left[\mathrm{PhC}\left(\mathrm{SO}_{2} \mathrm{CF}_{3}\right)_{2}\right]$ (anti $\left.\mathrm{Me}\right)$ $\left(\mathbf{1 6 a}\left[\mathrm{PhC}\left(\mathrm{SO}_{2} \mathrm{CF}_{3}\right)_{2}\right]\right)$. (600/150 MHz, RT, $40 \mathrm{mg} / \mathrm{mL}, d_{6}$-acetone). Some residual one bond coupling is present. 


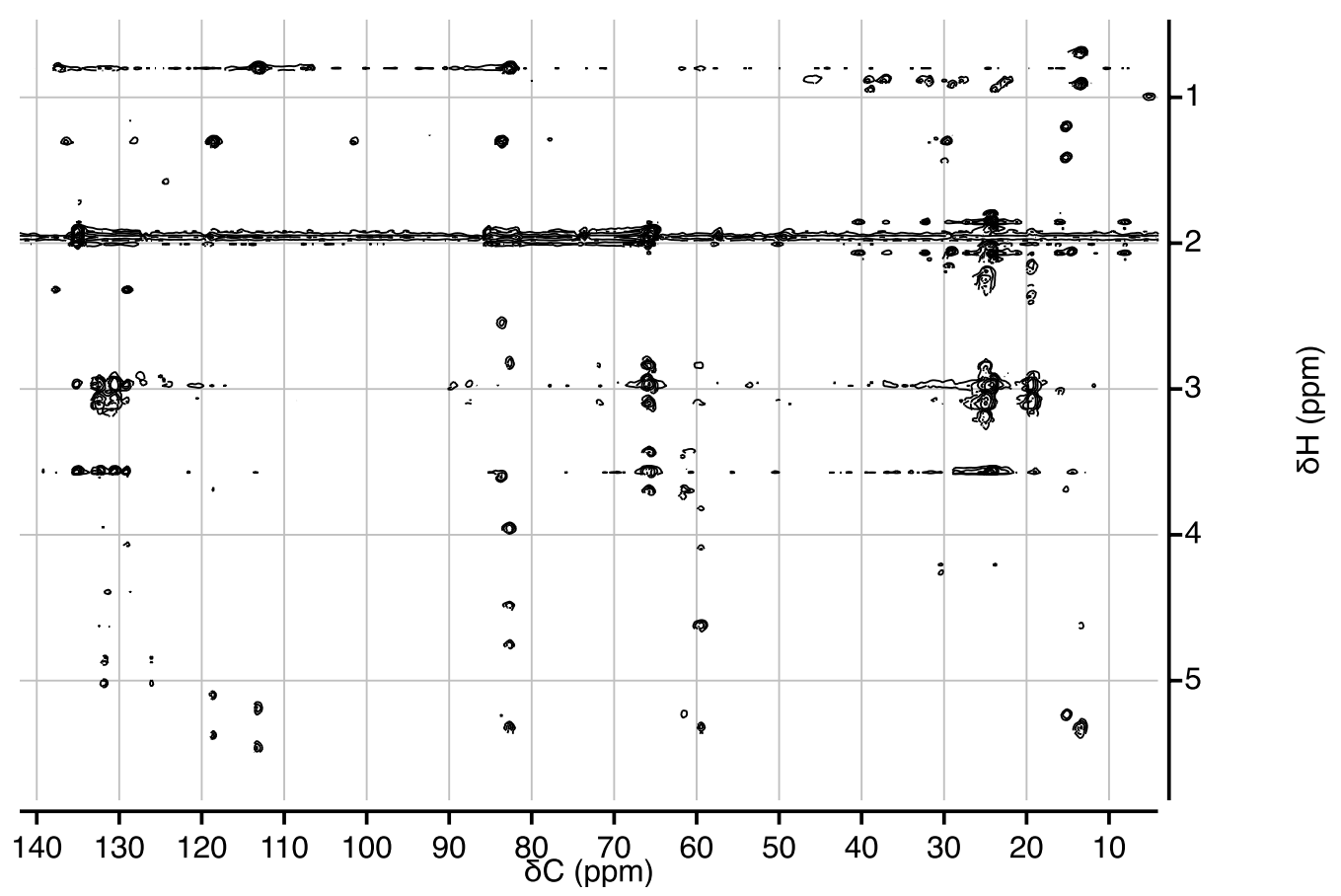

Figure A.64. Expanded HMBC spectrum of $\left[\mathrm{Pt}\left(\eta^{3}-\mathrm{CH}_{2} \mathrm{CMeCH}_{2}\right)(\mathrm{dppp})\right]\left[\mathrm{PhC}\left(\mathrm{SO}_{2} \mathrm{CF}_{3}\right)_{2}\right]\left(\mathbf{1 5}\left[\mathrm{PhC}\left(\mathrm{SO}_{2} \mathrm{CF}_{3}\right)_{2}\right]\right)$ and $\left[\mathrm{Pt}\left(\eta^{3}-\mathrm{CH}_{2} \mathrm{CHCHMe}\right)(\mathrm{dppp})\right]\left[\mathrm{PhC}\left(\mathrm{SO}_{2} \mathrm{CF}_{3}\right)_{2}\right]$ (anti $\left.\mathrm{Me}\right)\left(\mathbf{1 6 a}\left[\mathrm{PhC}\left(\mathrm{SO}_{2} \mathrm{CF}_{3}\right)_{2}\right]\right)$. (150 MHz, RT, $40 \mathrm{mg} / \mathrm{mL}, d_{6}$-acetone). Some residual one bond coupling is present.

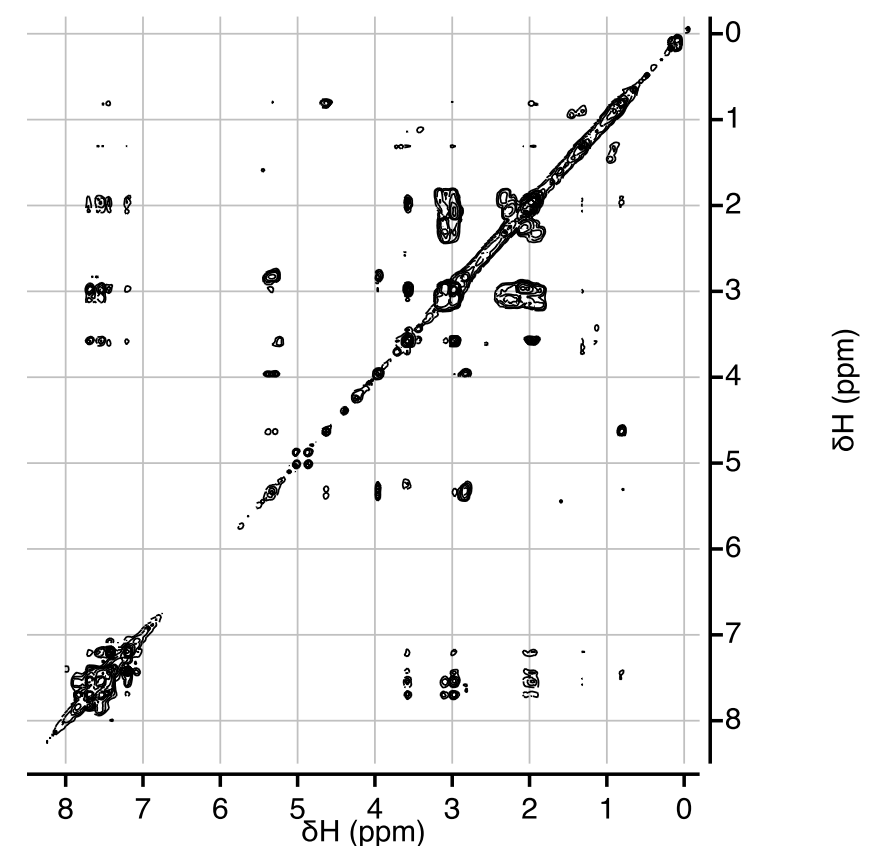

Figure A.65. COSY spectrum of carbon-13 enriched $\left[\mathrm{Pt}\left(\eta^{3}-\mathrm{CH}_{2} \mathrm{CMeCH}_{2}\right)(\mathrm{dppp})\right]\left[\mathrm{PhC}\left(\mathrm{SO}_{2} \mathrm{CF}_{3}\right)_{2}\right]\left(\mathbf{1 5}\left[\mathrm{PhC}\left(\mathrm{SO}_{2} \mathrm{CF}_{3}\right)_{2}\right]\right)$ and $\left[\mathrm{Pt}\left(\eta^{3}-\mathrm{CH}_{2} \mathrm{CHCHMe}\right)(\mathrm{dppp})\right]\left[\mathrm{PhC}\left(\mathrm{SO}_{2} \mathrm{CF}_{3}\right)_{2}\right]$ (anti $\left.\mathrm{Me}\right)\left(\mathbf{1 6 a}\left[\mathrm{PhC}\left(\mathrm{SO}_{2} \mathrm{CF}_{3}\right)_{2}\right]\right)$. (150 MHz, RT, $40 \mathrm{mg} / \mathrm{mL}, d_{6}$-acetone). 


\section{(mdd) HQ}

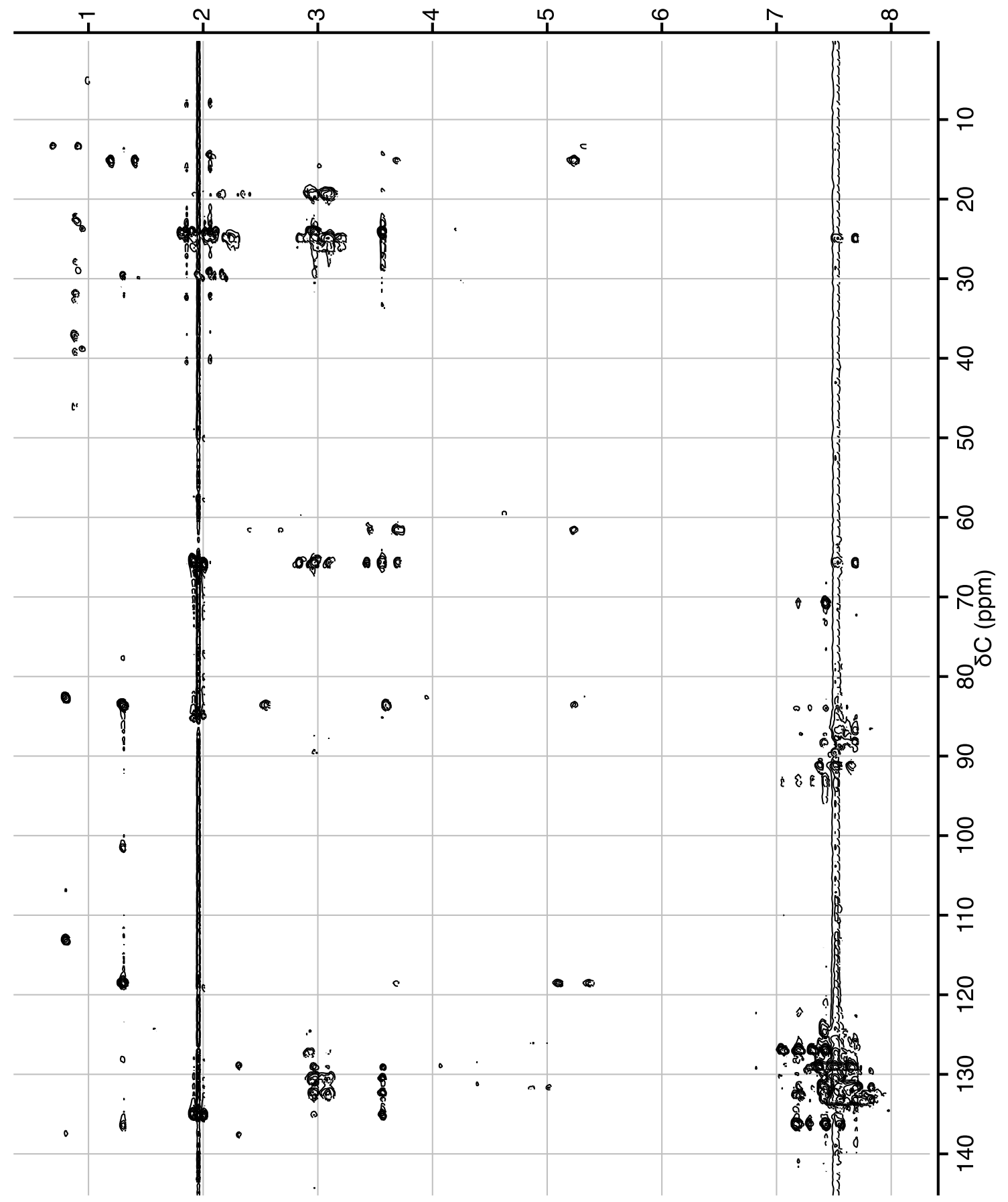

Figure A.66. $\mathrm{HMBC}$ spectrum of $\left[\mathrm{Pt}\left(\eta^{3}-\mathrm{CH}_{2} \mathrm{CMeCH}_{2}\right)(\mathrm{dppp})\right]\left[\mathrm{PhC}\left(\mathrm{SO}_{2} \mathrm{CF}_{3}\right)_{2}\right]$ $\left(\mathbf{1 5}\left[\mathrm{PhC}\left(\mathrm{SO}_{2} \mathrm{CF}_{3}\right)_{2}\right]\right)$ and $\left[\mathrm{Pt}\left(\eta^{3}-\mathrm{CH}_{2} \mathrm{CHCHMe}\right)(\mathrm{dppp})\right]\left[\mathrm{PhC}\left(\mathrm{SO}_{2} \mathrm{CF}_{3}\right)_{2}\right]($ syn $\mathrm{Me})$ $\left(\mathbf{1 6 b}\left[\mathrm{PhC}\left(\mathrm{SO}_{2} \mathrm{CF}_{3}\right)_{2}\right]\right)$. (600/150 MHz, RT, $40 \mathrm{mg} / \mathrm{mL}, d_{6}$-acetone). Some residual one bond coupling is present. 


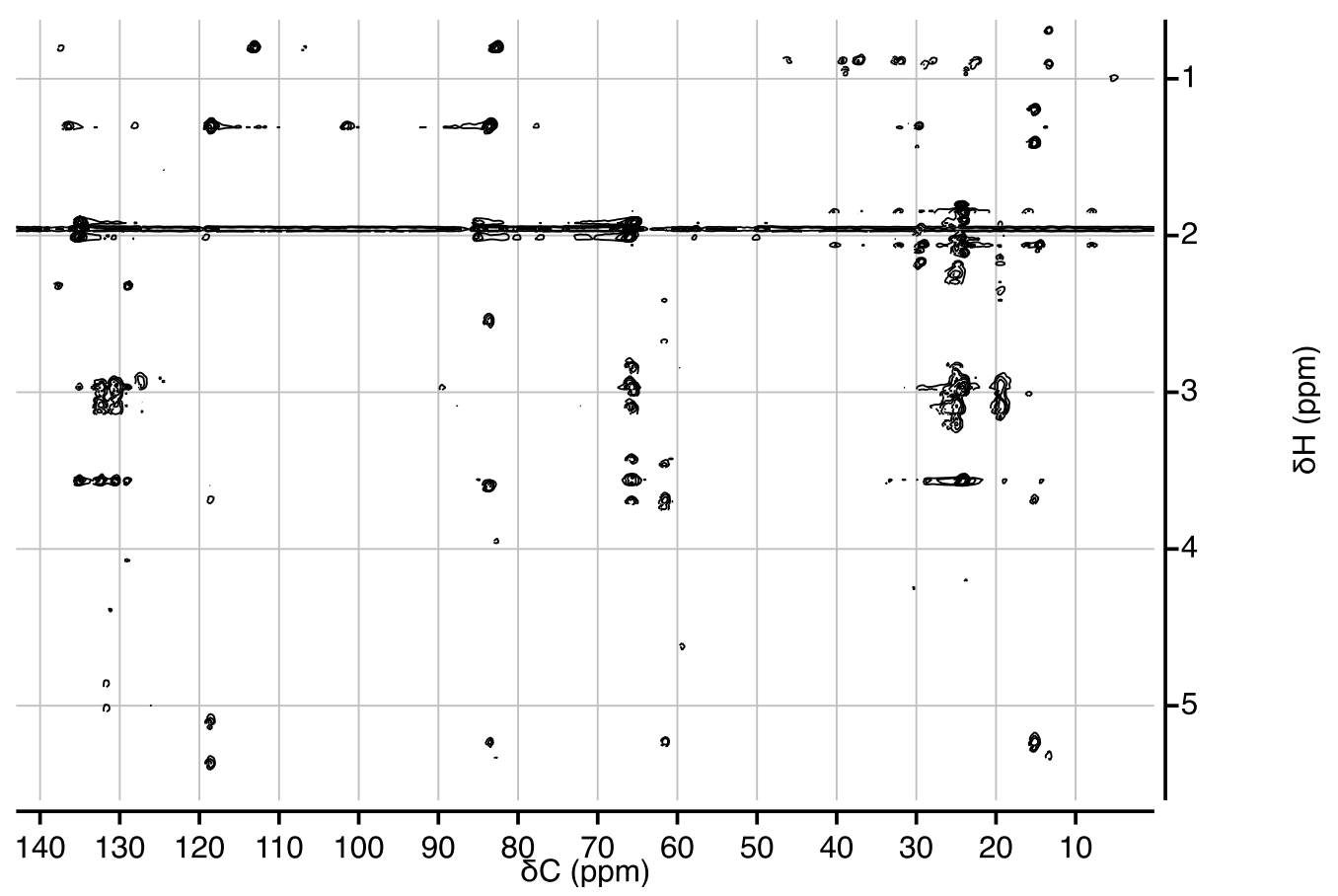

Figure A.67. Expanded HMBC spectrum of $\left[\mathrm{Pt}\left(\eta^{3}-\mathrm{CH}_{2} \mathrm{CMeCH}_{2}\right)(\mathrm{dppp})\right]\left[\mathrm{PhC}\left(\mathrm{SO}_{2} \mathrm{CF}_{3}\right)_{2}\right]\left(\mathbf{1 5}\left[\mathrm{PhC}\left(\mathrm{SO}_{2} \mathrm{CF}_{3}\right)_{2}\right]\right)$ and $\left[\mathrm{Pt}\left(\eta^{3}-\mathrm{CH}_{2} \mathrm{CHCHMe}\right)(\mathrm{dppp})\right]\left[\mathrm{PhC}\left(\mathrm{SO}_{2} \mathrm{CF}_{3}\right)_{2}\right]$ ( syn $\left.\mathrm{Me}\right)\left(\mathbf{1 6 b}\left[\mathrm{PhC}\left(\mathrm{SO}_{2} \mathrm{CF}_{3}\right)_{2}\right]\right)$. (150 MHz, RT, $40 \mathrm{mg} / \mathrm{mL}, d_{6}$-acetone). Some residual one bond coupling is present.

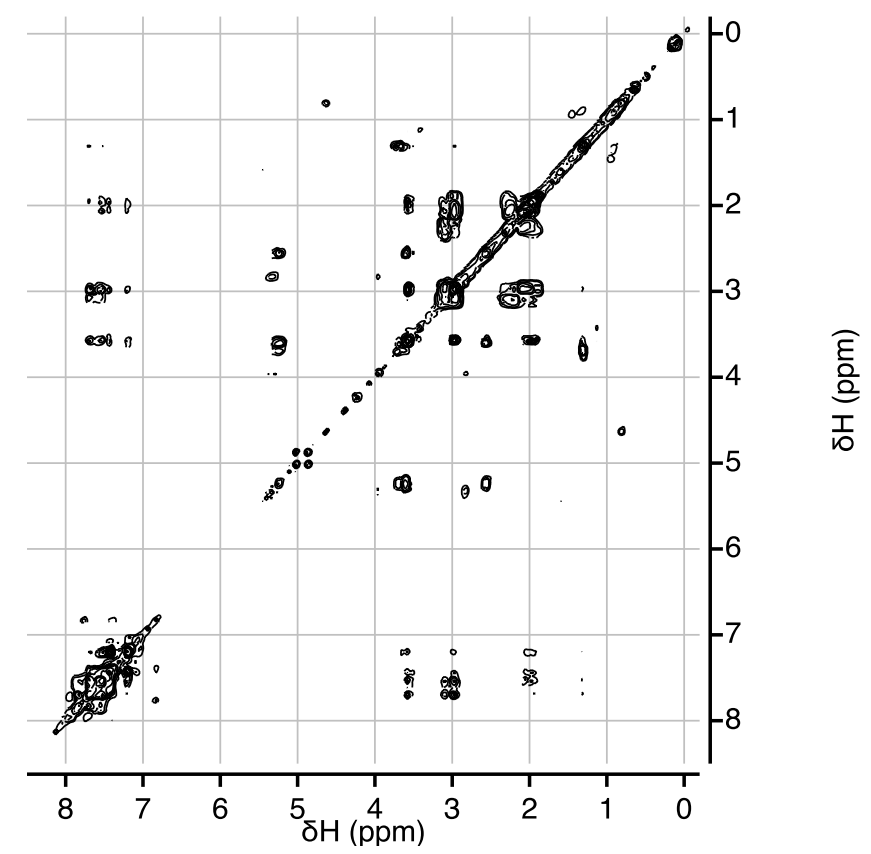

Figure A.68. COSY spectrum of carbon-13 enriched[$\left[\mathrm{Pt}\left(\eta^{3}-\mathrm{CH}_{2} \mathrm{CMeCH}_{2}\right)(\mathrm{dppp})\right]\left[\mathrm{PhC}\left(\mathrm{SO}_{2} \mathrm{CF}_{3}\right)_{2}\right]\left(\mathbf{1 5}\left[\mathrm{PhC}\left(\mathrm{SO}_{2} \mathrm{CF}_{3}\right)_{2}\right]\right)$ and $\left[\mathrm{Pt}\left(\eta^{3}-\mathrm{CH}_{2} \mathrm{CHCHMe}\right)(\mathrm{dppp})\right]\left[\mathrm{PhC}\left(\mathrm{SO}_{2} \mathrm{CF}_{3}\right)_{2}\right]$ ( syn $\left.\mathrm{Me}\right)\left(\mathbf{1 6 b}\left[\mathrm{PhC}\left(\mathrm{SO}_{2} \mathrm{CF}_{3}\right)_{2}\right]\right)$. (150 MHz, RT, $40 \mathrm{mg} / \mathrm{mL}, d_{6}$-acetone). 

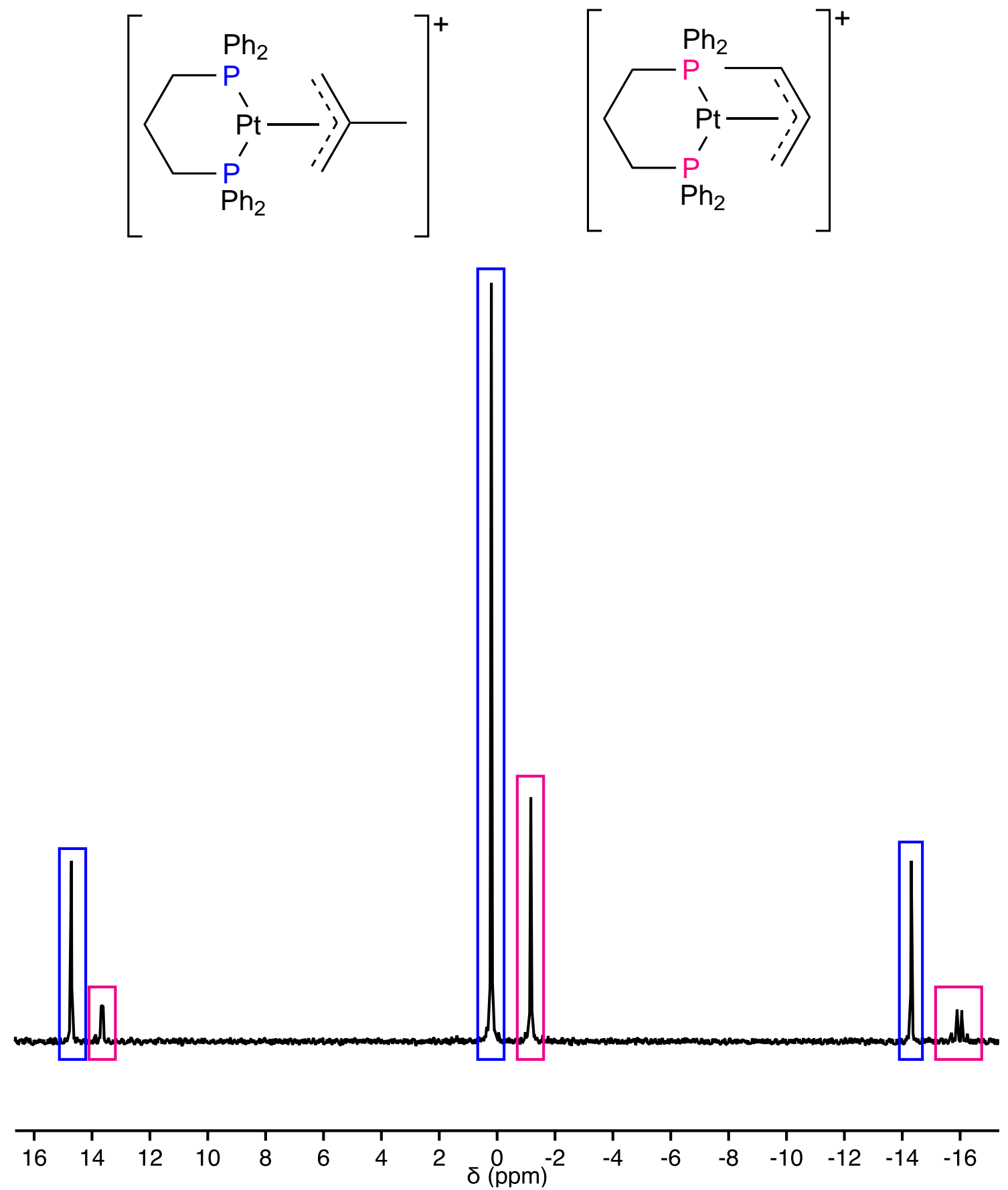

Figure A.69. ${ }^{31} \mathrm{P}\left\{{ }^{1} \mathrm{H}\right\}$ NMR spectrum of $\left[\mathrm{Pt}\left(\eta^{3}-\mathrm{CH}_{2} \mathrm{CMeCH}_{2}\right)(\mathrm{dppp})\right]\left[\mathrm{PhC}\left(\mathrm{SO}_{2} \mathrm{CF}_{3}\right)_{2}\right]$ $\left(\mathbf{1 5}\left[\mathrm{PhC}\left(\mathrm{SO}_{2} \mathrm{CF}_{3}\right)_{2}\right]\right)$ and $\left[\mathrm{Pt}\left(\eta^{3}-\mathrm{CH}_{2} \mathrm{CHCHMe}\right)(\mathrm{dppp})\right]\left[\mathrm{PhC}\left(\mathrm{SO}_{2} \mathrm{CF}_{3}\right)_{2}\right]$ (anti $\left.\mathrm{Me}\right)$ $\left(\mathbf{1 6 a}\left[\mathrm{PhC}\left(\mathrm{SO}_{2} \mathrm{CF}_{3}\right)_{2}\right]\right)$. (150 MHz, RT, $40 \mathrm{mg} / \mathrm{mL}, d_{6}$-acetone). 

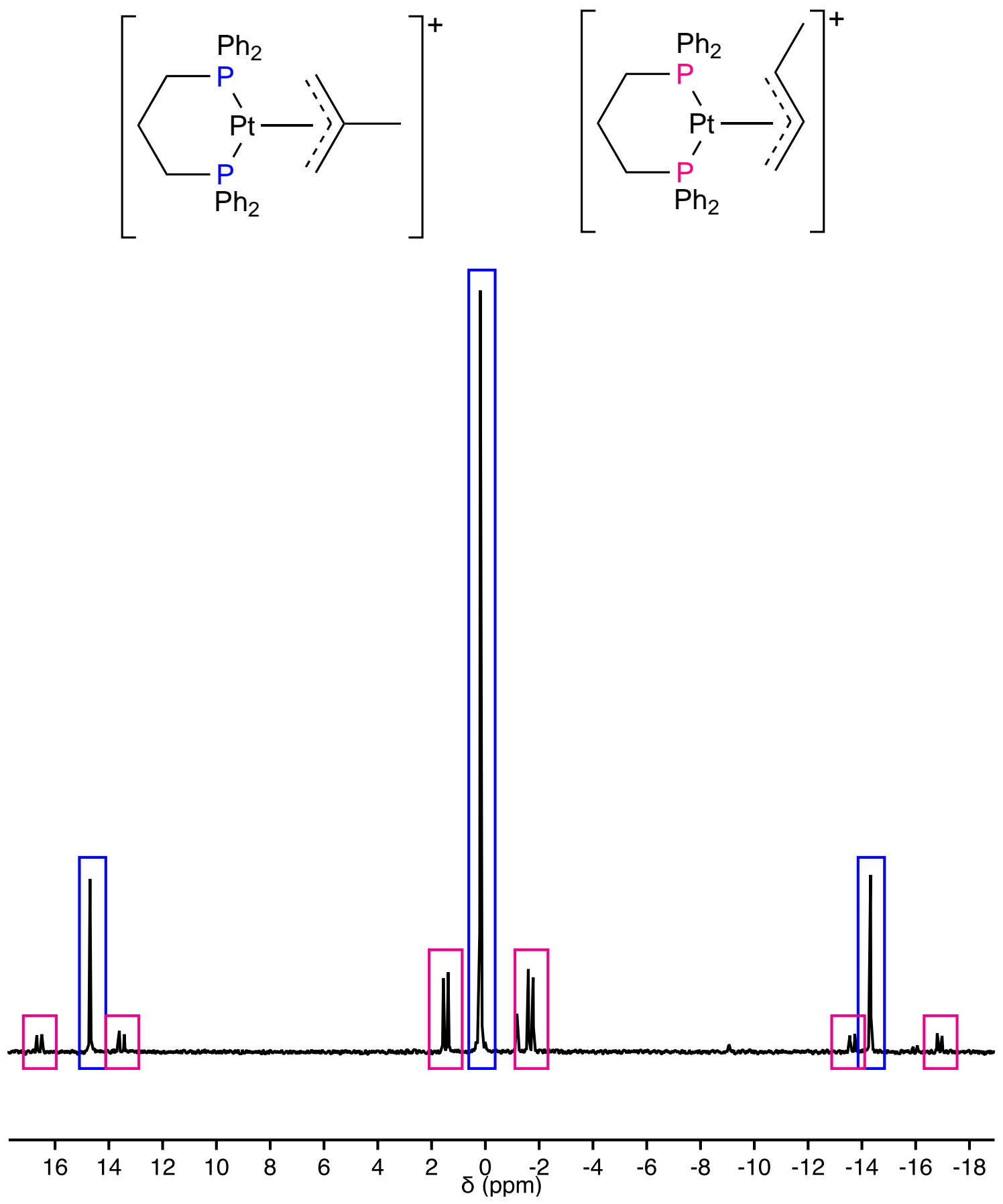

Figure A.70. ${ }^{31} \mathrm{P}\left\{{ }^{1} \mathrm{H}\right\} \mathrm{NMR}$ spectrum of $\left[\mathrm{Pt}\left(\eta^{3}-\mathrm{CH}_{2} \mathrm{CMeCH}_{2}\right)(\mathrm{dppp})\right]\left[\mathrm{PhC}\left(\mathrm{SO}_{2} \mathrm{CF}_{3}\right)_{2}\right]$ $\left(\mathbf{1 5}\left[\mathrm{PhC}\left(\mathrm{SO}_{2} \mathrm{CF}_{3}\right)_{2}\right]\right)$ and $\left[\mathrm{Pt}\left(\eta^{3}-\mathrm{CH}_{2} \mathrm{CHCHMe}\right)(\mathrm{dppp})\right]\left[\mathrm{PhC}\left(\mathrm{SO}_{2} \mathrm{CF}_{3}\right)_{2}\right]$ (syn $\left.\mathrm{Me}\right)$ $\left(\mathbf{1 6 b}\left[\mathrm{PhC}\left(\mathrm{SO}_{2} \mathrm{CF}_{3}\right)_{2}\right]\right)$. (150 MHz, RT, $40 \mathrm{mg} / \mathrm{mL}, d_{6}$-acetone). 


\section{A.3 Chapter Four}

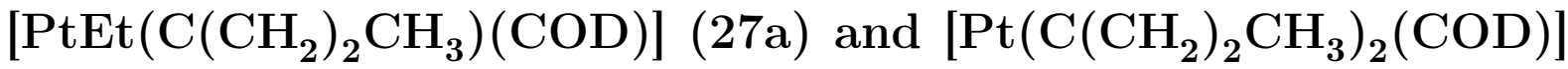

$(27 \mathrm{~b})$

${ }^{1} \mathrm{H}$ NMR spectrum - Figures A.71 and A.72, pages 228 and 229 ${ }^{13} \mathrm{C}\left\{{ }^{1} \mathrm{H}\right\}$ NMR spectrum - Figures A.73-A.75, pages $230-232$ HMBC spectrum - Figures A.76 and A.77, pages 233 and 234 COSY spectrum - Figure A.78, pages 234

\section{Trans $-\left[\mathrm{PtCl}_{2}(\mathrm{BCP})(\mathrm{Py})\right](28)$}

${ }^{1}$ H NMR spectrum - Figures A.79 and A.80, pages 235 and 236 ${ }^{13} \mathrm{C}\left\{{ }^{1} \mathrm{H}\right\}$ NMR spectrum - Figures A.81 and A.82, pages 237 and 238

\section{Trans- $\left[\mathrm{Pt}\left(\mathrm{C}\left(\mathrm{CH}_{2}\right)_{2} \mathrm{C}\left(\mathrm{CH}_{2}\right)_{2} \mathrm{Cl}\right) \mathrm{Cl}\left(\mathrm{SEt}_{2}\right)_{2}\right](32)$}

${ }^{1} \mathrm{H}$ NMR spectrum - Figures A.83 and A.84, pages 239 and 240 ${ }^{13} \mathrm{C}\left\{{ }^{1} \mathrm{H}\right\}$ NMR spectrum - Figures A.85 and A.86, pages 241 and 242 HMBC spectrum - Figures A.87 and A.88, pages 243 and 244 COSY spectrum - Figure A.89, pages 244

Cis- $\left[\mathrm{Pt}\left(\mathrm{C}\left(\mathrm{CH}_{2}\right)_{2} \mathrm{C}\left(\mathrm{CH}_{2}\right)_{2} \mathrm{Cl}\right) \mathrm{Cl}(\mathrm{Py})_{2}\right](34 \mathrm{~b})$

${ }^{1} \mathrm{H}$ NMR spectrum - Figures A.90 and A.91, pages 245 and 246 ${ }^{13} \mathrm{C}\left\{{ }^{1} \mathrm{H}\right\}$ NMR spectrum - Figures A.92 and A.93, pages 247 and 248 HMBC spectrum - Figures A.94 and A.95, pages 249 and 250 COSY spectrum - Figure A.96, pages 250 



\section{$C i s-\left[\mathrm{Pt}\left(\mathrm{C}\left(\mathrm{CH}_{2}\right)_{2} \mathrm{C}\left(\mathrm{CH}_{2}\right)_{2} \mathrm{Cl}\right) \mathrm{Cl}(\mathrm{dppp})\right](37 \mathrm{a})$}

${ }^{1} \mathrm{H}$ NMR spectrum - Figures A.97 and A.98, pages 251 and 252 ${ }^{13} \mathrm{C}\left\{{ }^{1} \mathrm{H}\right\}$ NMR spectrum - Figures A.99-A.101, pages 253-255

HMBC spectrum - Figures A.102 and A.103, pages 256 and 257 COSY spectrum - Figure A.104, pages 257

${ }^{31} \mathrm{P}\left\{{ }^{1} \mathrm{H}\right\}$ NMR spectrum - Figure A.105, page 258 


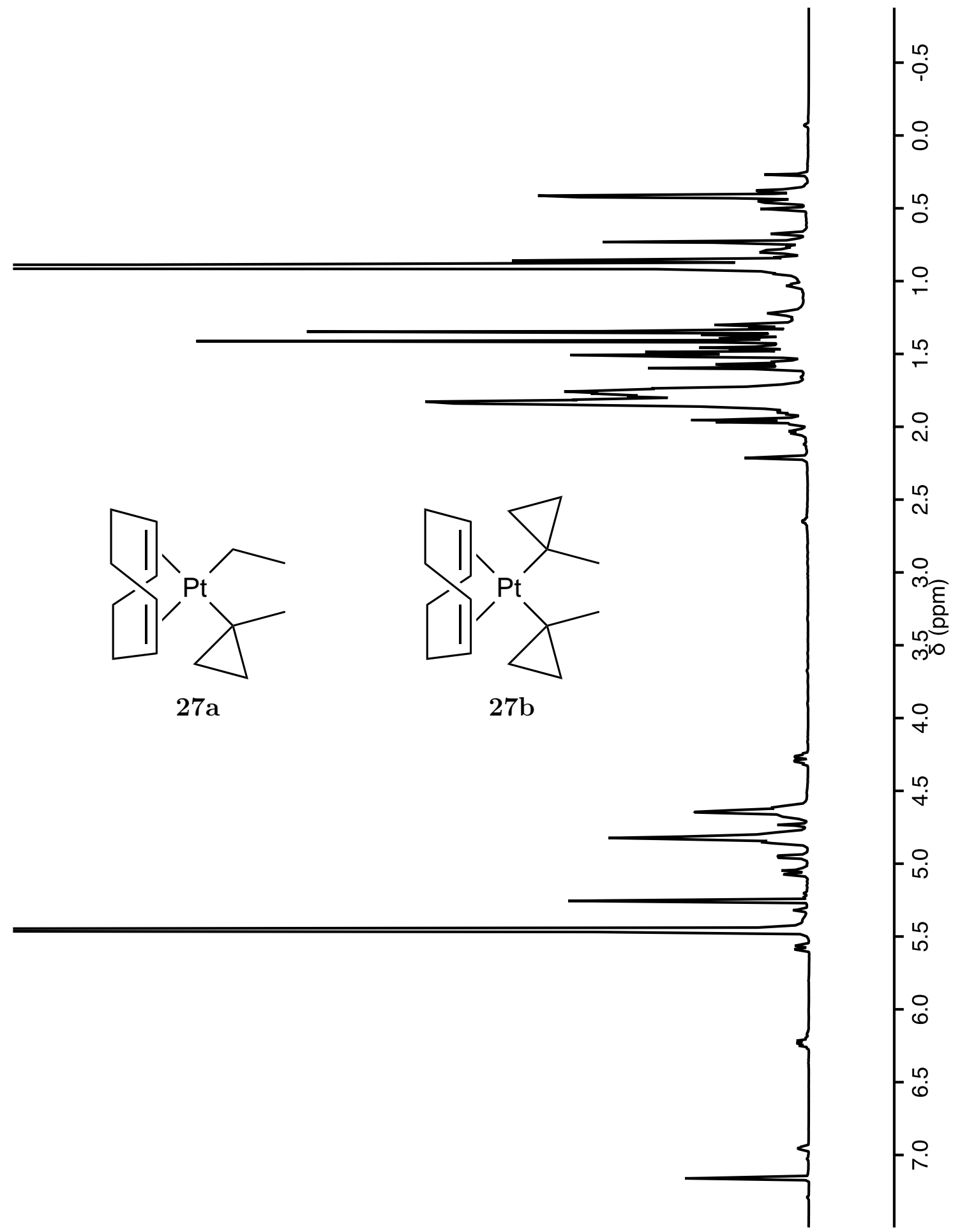

Figure A.71. ${ }^{1} \mathrm{H}$ NMR spectrum of $\left[\mathrm{PtEt}\left(\mathrm{C}\left(\mathrm{CH}_{2}\right)_{2} \mathrm{CH}_{3}\right)(\mathrm{COD})\right](\mathbf{2 7 a})$ and $\left[\mathrm{Pt}\left(\mathrm{C}\left(\mathrm{CH}_{2}\right)_{2} \mathrm{CH}_{3}\right)_{2}(\mathrm{COD})\right](\mathbf{2 7 b})\left(600 \mathrm{MHz}, \mathrm{RT}, 40 \mathrm{mg} / \mathrm{mL}, \mathrm{C}_{6} \mathrm{D}_{6}\right)$. 

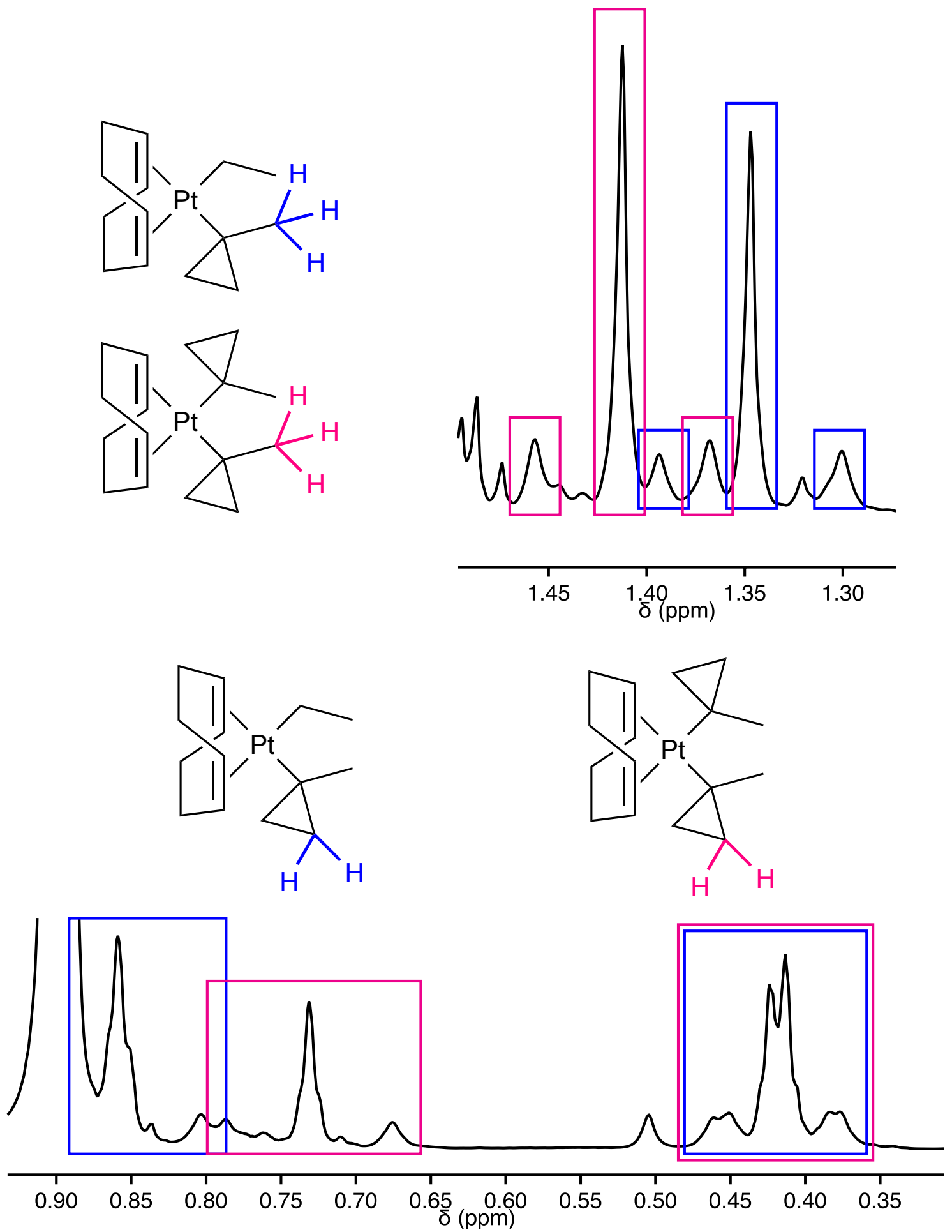

Figure A.72. Expanded ${ }^{1} \mathrm{H}$ NMR spectrum of $\left[\mathrm{PtEt}\left(\mathrm{C}\left(\mathrm{CH}_{2}\right)_{2} \mathrm{CH}_{3}\right)(\mathrm{COD})\right](\mathbf{2 7 a})$ and $\left[\mathrm{Pt}\left(\mathrm{C}\left(\mathrm{CH}_{2}\right)_{2} \mathrm{CH}_{3}\right)_{2}(\mathrm{COD})\right](\mathbf{2 7 b})\left(600 \mathrm{MHz}, \mathrm{RT}, 40 \mathrm{mg} / \mathrm{mL}, \mathrm{C}_{6} \mathrm{D}_{6}\right)$. 


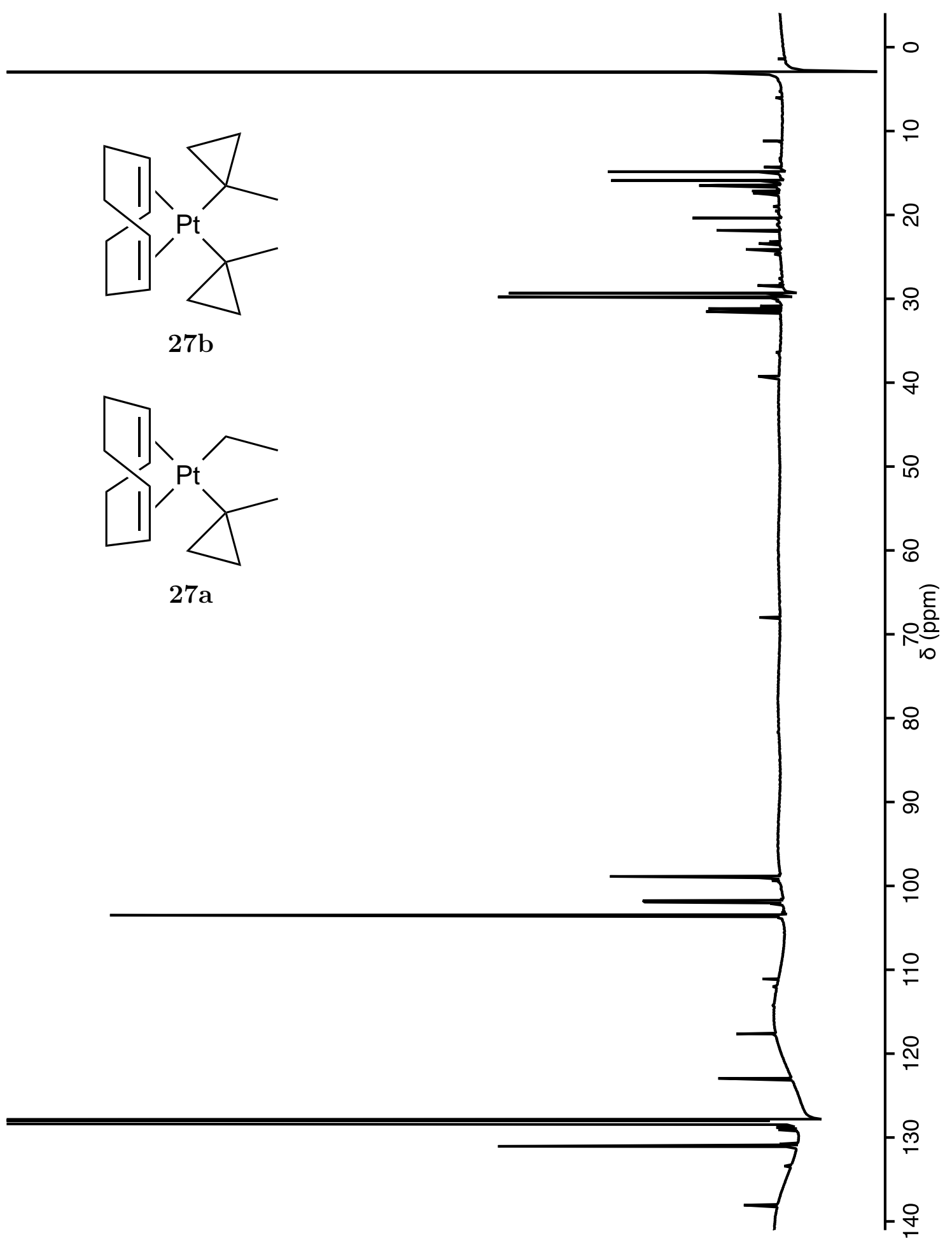

Figure A.73. ${ }^{13} \mathrm{C}\left\{{ }^{1} \mathrm{H}\right\}$ NMR spectrum of $\left[\mathrm{PtEt}\left(\mathrm{C}\left(\mathrm{CH}_{2}\right)_{2} \mathrm{CH}_{3}\right)(\mathrm{COD})\right](\mathbf{2 7 a})$ and $\left[\mathrm{Pt}\left(\mathrm{C}\left(\mathrm{CH}_{2}\right)_{2} \mathrm{CH}_{3}\right)_{2}(\mathrm{COD})\right](\mathbf{2 7 b})\left(150 \mathrm{MHz}, \mathrm{RT}, 40 \mathrm{mg} / \mathrm{mL}, \mathrm{C}_{6} \mathrm{D}_{6}\right)$. 

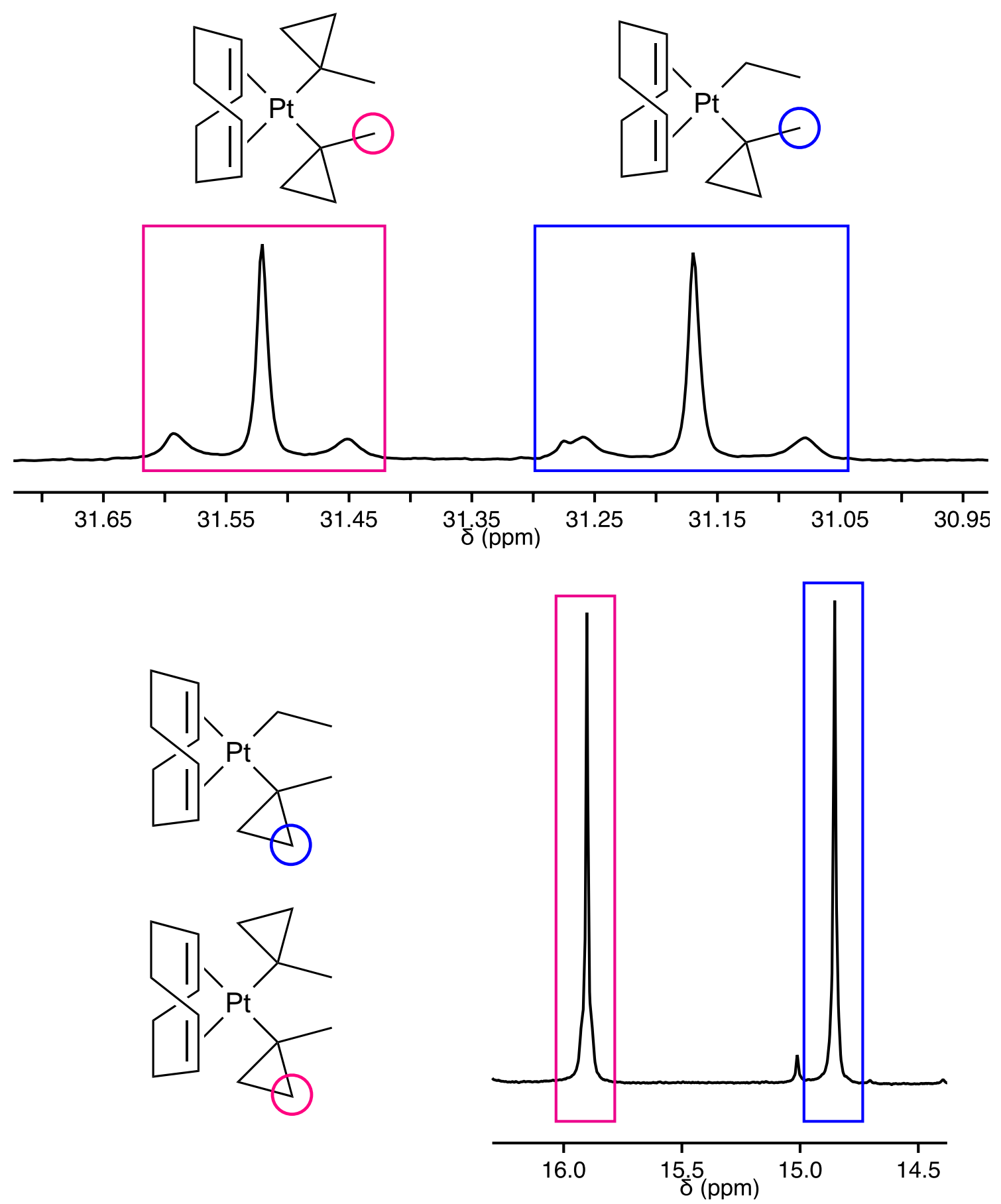

Figure A.74. Expanded ${ }^{13} \mathrm{C}\left\{{ }^{1} \mathrm{H}\right\}$ NMR spectrum of $\left[\mathrm{PtEt}\left(\mathrm{C}\left(\mathrm{CH}_{2}\right)_{2} \mathrm{CH}_{3}\right)(\mathrm{COD})\right](\mathbf{2 7 a})$ and $\left[\mathrm{Pt}\left(\mathrm{C}\left(\mathrm{CH}_{2}\right)_{2} \mathrm{CH}_{3}\right)_{2}(\mathrm{COD})\right](\mathbf{2 7 b})\left(150 \mathrm{MHz}, \mathrm{RT}, 40 \mathrm{mg} / \mathrm{mL}, \mathrm{C}_{6} \mathrm{D}_{6}\right)$. 


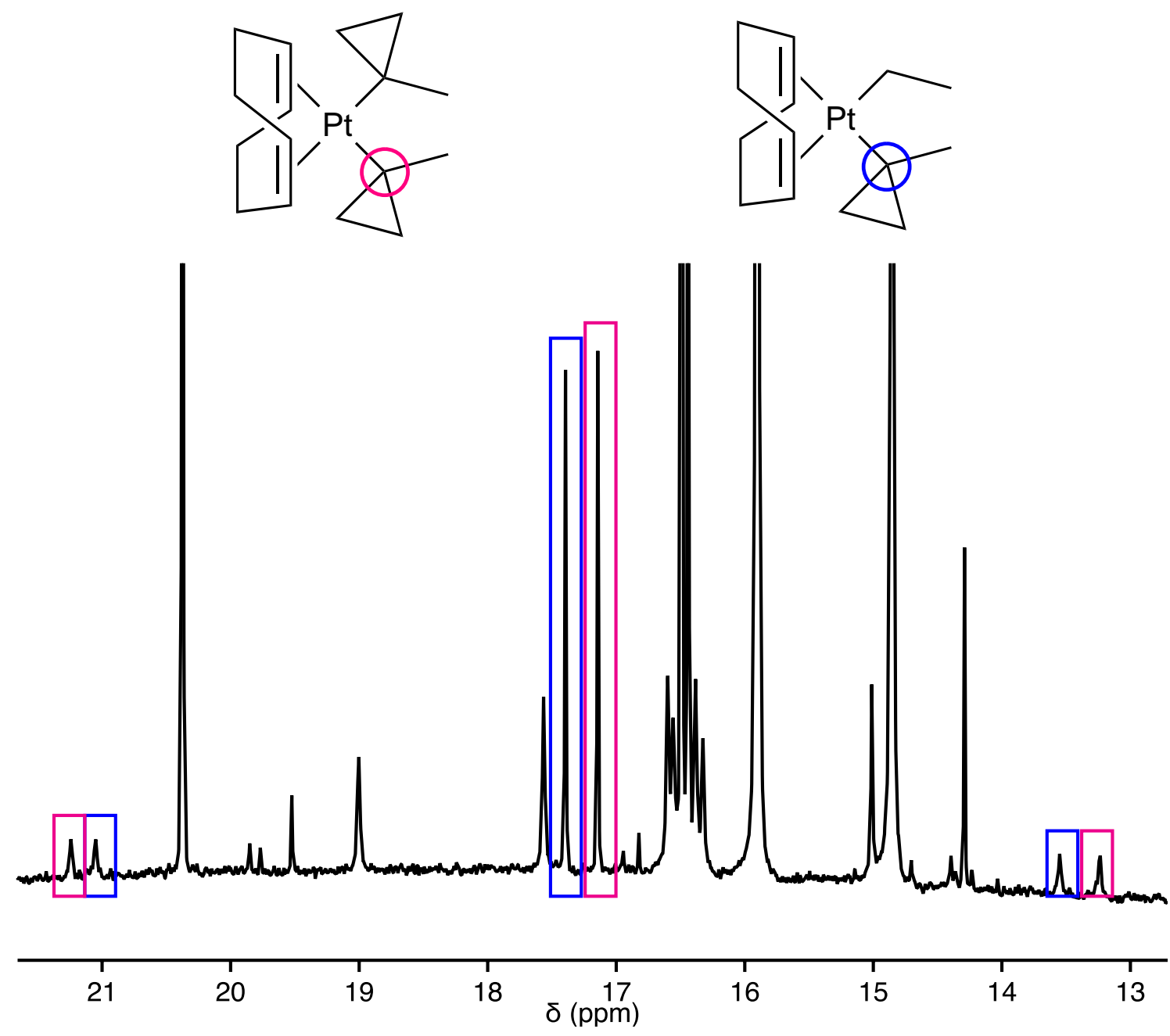

Figure A.75. Expanded ${ }^{13} \mathrm{C}\left\{{ }^{1} \mathrm{H}\right\}$ NMR spectrum of $\left[\mathrm{PtEt}\left(\mathrm{C}\left(\mathrm{CH}_{2}\right)_{2} \mathrm{CH}_{3}\right)(\mathrm{COD})\right](\mathbf{2 7 a})$ and $\left[\mathrm{Pt}\left(\mathrm{C}\left(\mathrm{CH}_{2}\right)_{2} \mathrm{CH}_{3}\right)_{2}(\mathrm{COD})\right](\mathbf{2 7 b})\left(150 \mathrm{MHz}, \mathrm{RT}, 40 \mathrm{mg} / \mathrm{mL}, \mathrm{C}_{6} \mathrm{D}_{6}\right)$. 


\section{(udd) HQ}

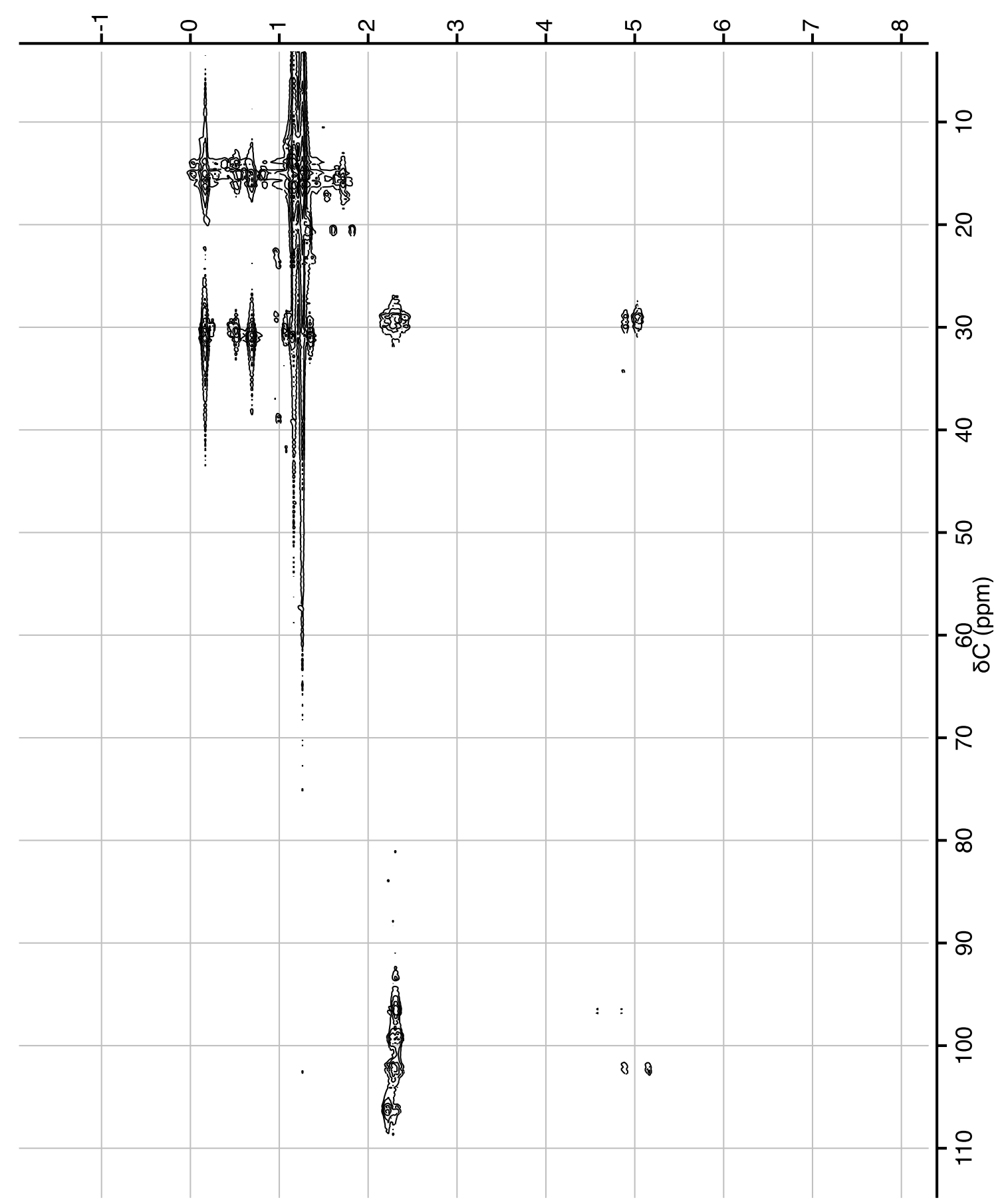

Figure A.76. HMBC spectrum of $\left[\mathrm{PtEt}\left(\mathrm{C}\left(\mathrm{CH}_{2}\right)_{2} \mathrm{CH}_{3}\right)(\mathrm{COD})\right](\mathbf{2 7 a})$ and $\left[\mathrm{Pt}\left(\mathrm{C}\left(\mathrm{CH}_{2}\right)_{2} \mathrm{CH}_{3}\right)_{2}(\mathrm{COD})\right](\mathbf{2 7 b})\left(600 / 150 \mathrm{MHz}, \mathrm{RT}, 40 \mathrm{mg} / \mathrm{mL}, \mathrm{C}_{6} \mathrm{D}_{6}\right)$. Some residual one bond coupling is present. 


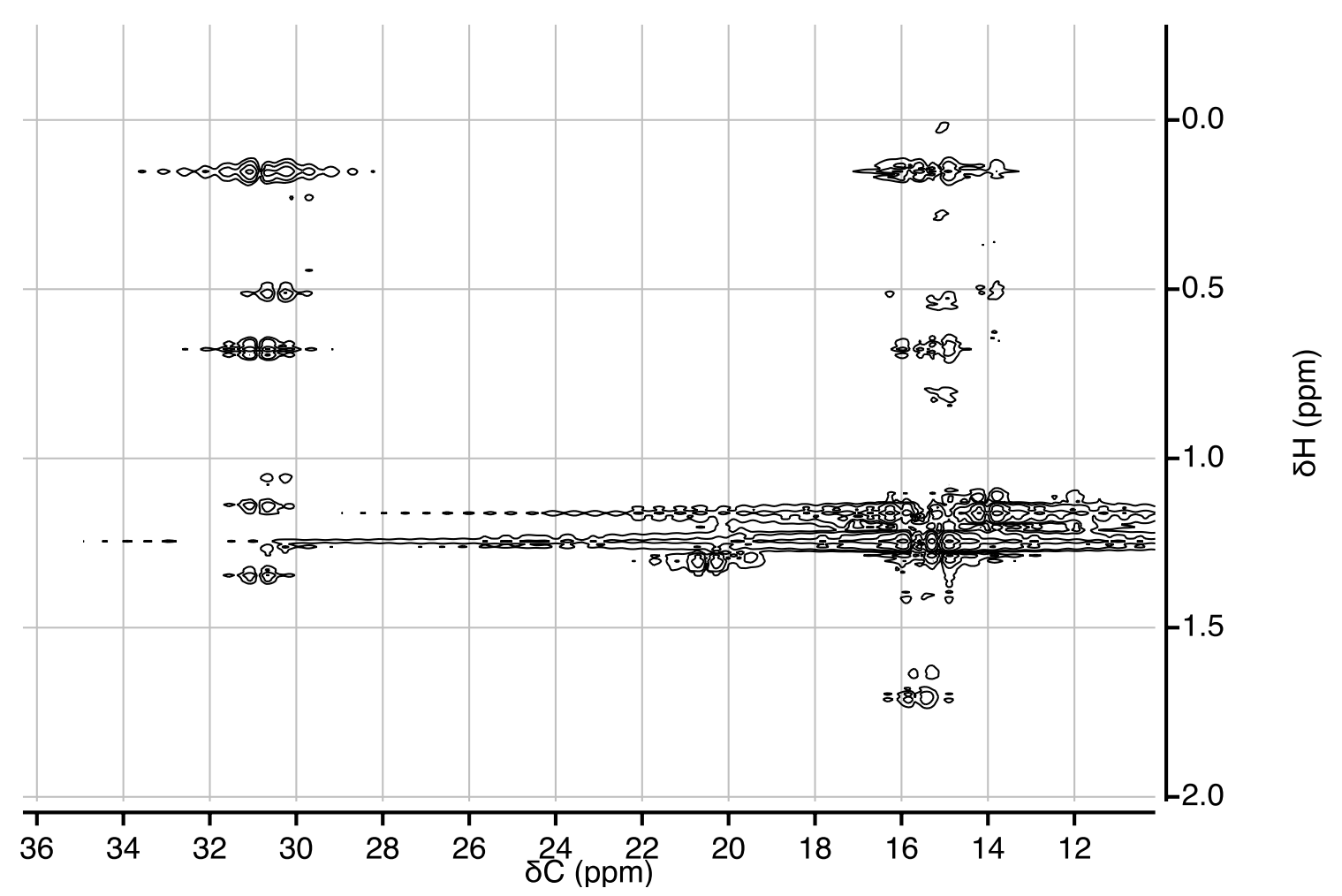

Figure A.77. Expanded HMBC spectrum of $\left[\mathrm{PtEt}\left(\mathrm{C}\left(\mathrm{CH}_{2}\right)_{2} \mathrm{CH}_{3}\right)(\mathrm{COD})\right](\mathbf{2 7 a})$ and $\left[\mathrm{Pt}\left(\mathrm{C}\left(\mathrm{CH}_{2}\right)_{2} \mathrm{CH}_{3}\right)_{2}(\mathrm{COD})\right](\mathbf{2 7 b})\left(600 / 150 \mathrm{MHz}, \mathrm{RT}, 40 \mathrm{mg} / \mathrm{mL}, \mathrm{C}_{6} \mathrm{D}_{6}\right)$. Some residual one bond coupling is present.

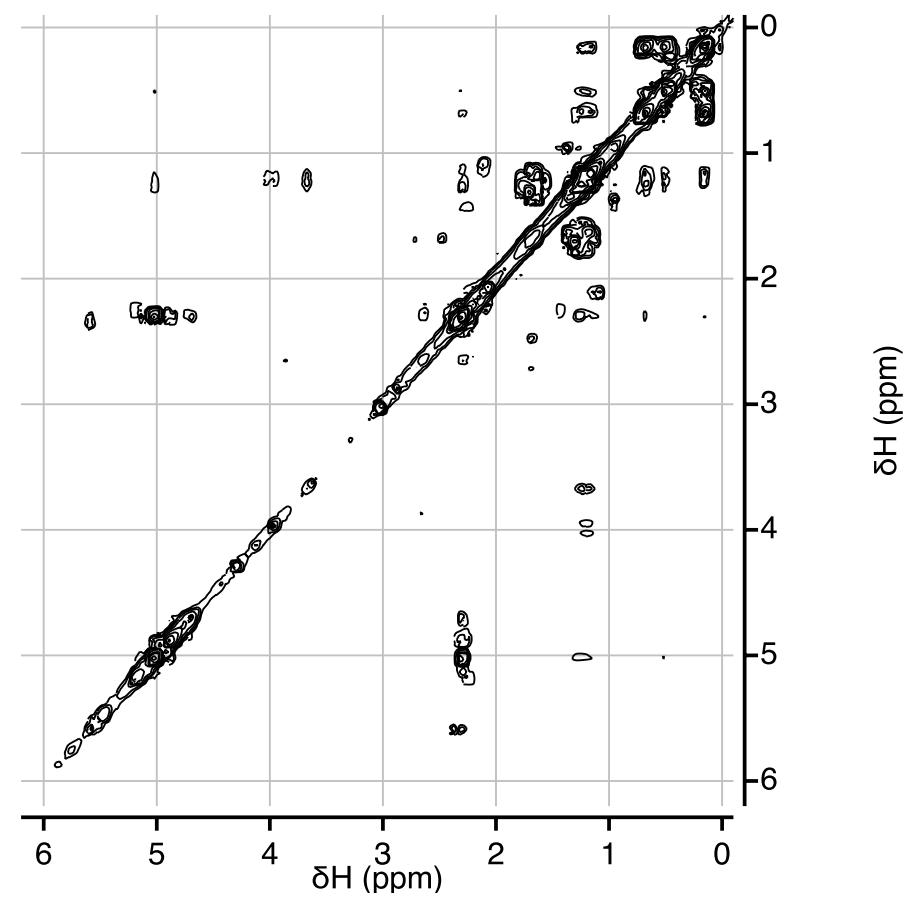

Figure A.78. COSY spectrum of $\left[\mathrm{PtEt}\left(\mathrm{C}\left(\mathrm{CH}_{2}\right)_{2} \mathrm{CH}_{3}\right)(\mathrm{COD})\right](\mathbf{2 7 a})$ and $\left[\mathrm{Pt}\left(\mathrm{C}\left(\mathrm{CH}_{2}\right)_{2} \mathrm{CH}_{3}\right)_{2}(\mathrm{COD})\right](\mathbf{2 7 b})\left(600 \mathrm{MHz}, \mathrm{RT}, 40 \mathrm{mg} / \mathrm{mL}, \mathrm{C}_{6} \mathrm{D}_{6}\right)$. 


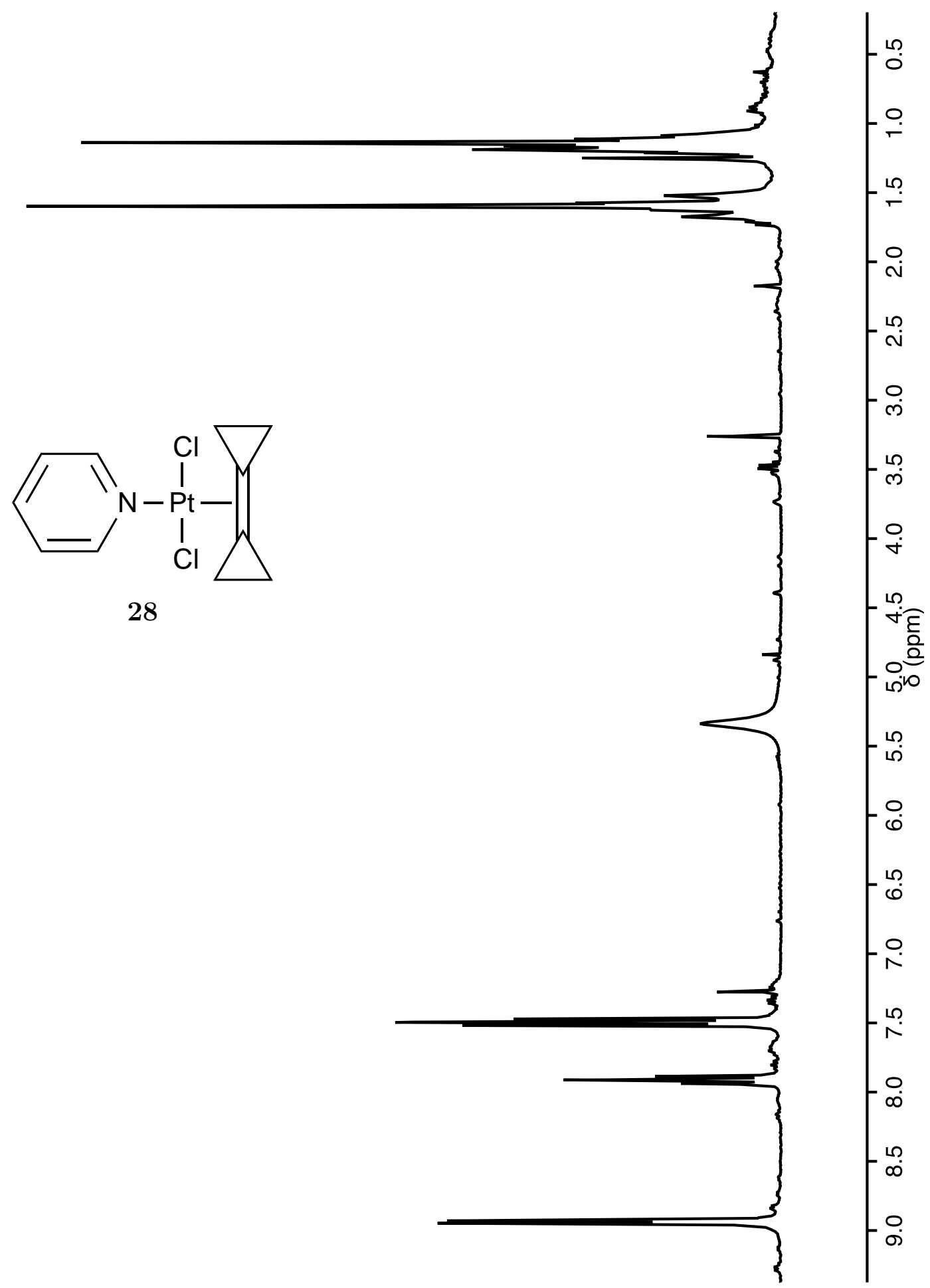

Figure A.79. ${ }^{1} \mathrm{H}$ NMR spectrum of trans $-\left[\mathrm{PtCl}_{2}(\mathrm{BCP})(\mathrm{Py})\right](\mathbf{2 8})(300 \mathrm{MHz}, \mathrm{RT}$, $100 \mathrm{mg} / \mathrm{mL}, \mathrm{CDCl}_{3}$ ). 

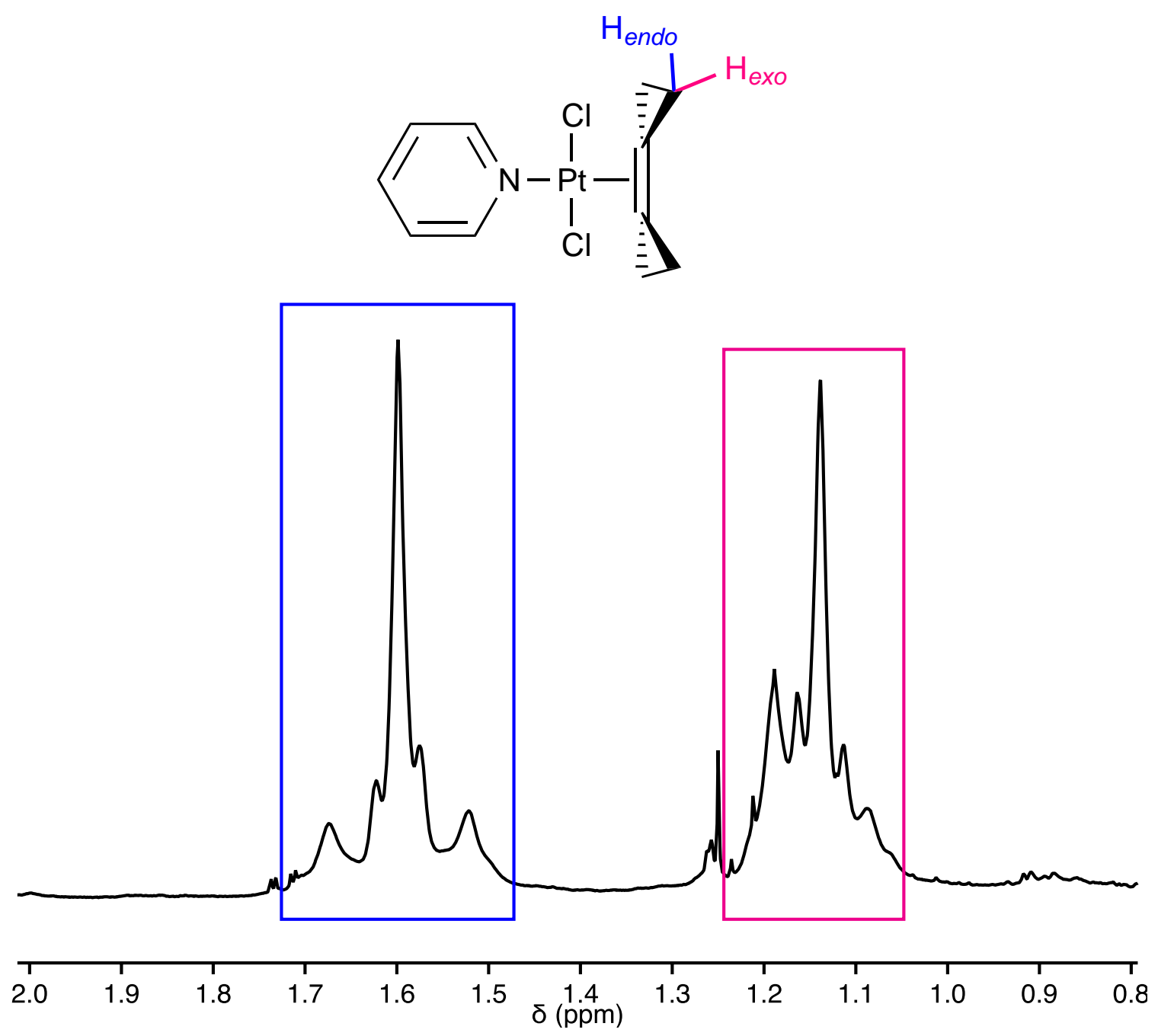

Figure A.80. Expanded ${ }^{1} \mathrm{H}$ NMR spectrum of trans- $-\left[\mathrm{PtCl}_{2}(\mathrm{BCP})(\mathrm{Py})\right](\mathbf{2 8})$ (300 MHz, RT, $100 \mathrm{mg} / \mathrm{mL}, \mathrm{CDCl}_{3}$ ). 


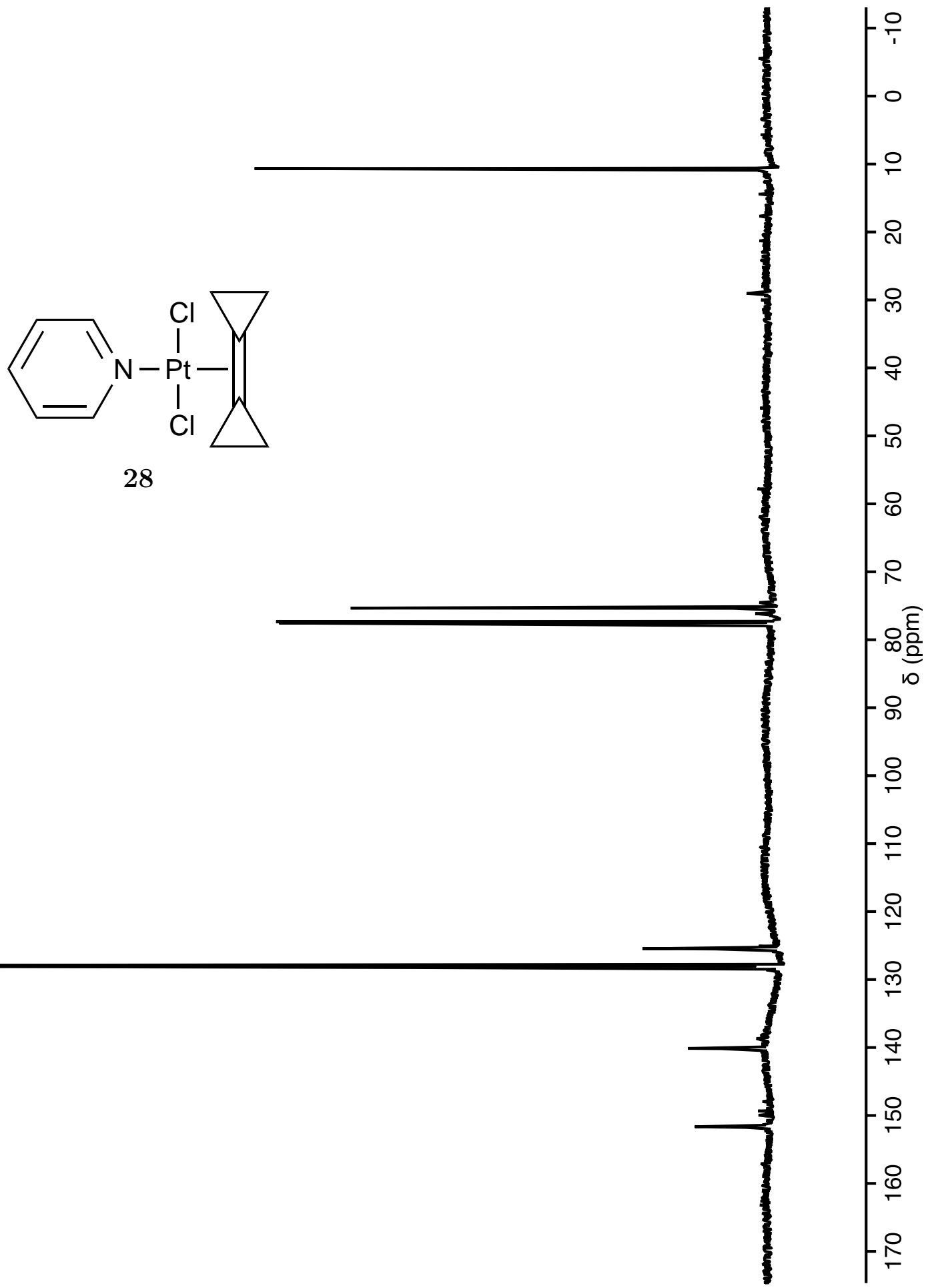

Figure A.81. ${ }^{13} \mathrm{C}\left\{{ }^{1} \mathrm{H}\right\}$ NMR spectrum of carbon- 13 enriched trans $-\left[\mathrm{PtCl}_{2}(\mathrm{BCP})(\mathrm{Py})\right]$ (28) $\left(150 \mathrm{MHz}, \mathrm{RT}, 100 \mathrm{mg} / \mathrm{mL}, \mathrm{CDCl}_{3}\right)$. 

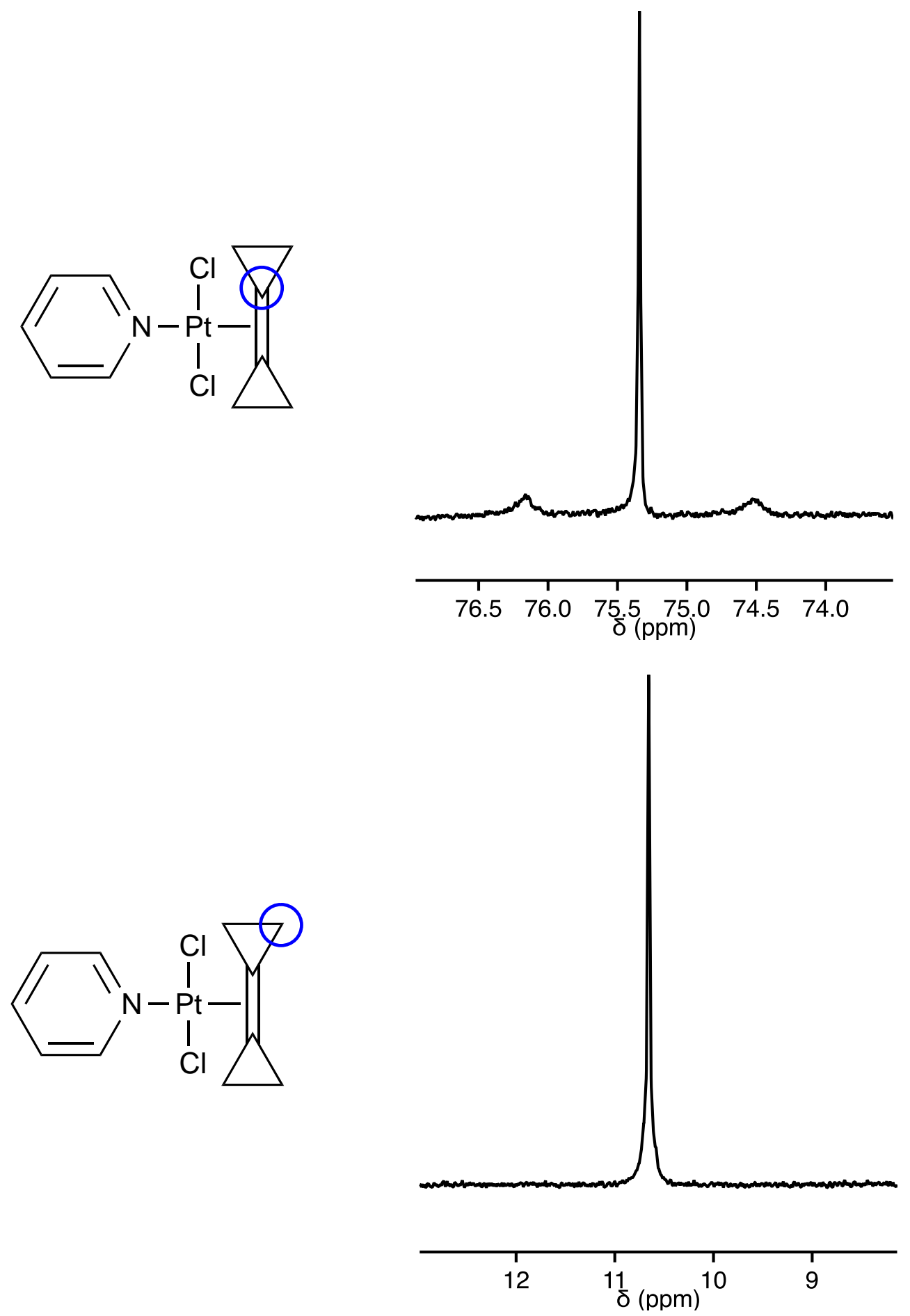

Figure A.82. Expanded ${ }^{13} \mathrm{C}\left\{{ }^{1} \mathrm{H}\right\}$ NMR spectrum of carbon-13 enriched trans $-\left[\mathrm{PtCl}_{2}(\mathrm{BCP})(\mathrm{Py})\right](\mathbf{2 8})\left(150 \mathrm{MHz}, \mathrm{RT}, 100 \mathrm{mg} / \mathrm{mL}, \mathrm{CDCl}_{3}\right)$. 


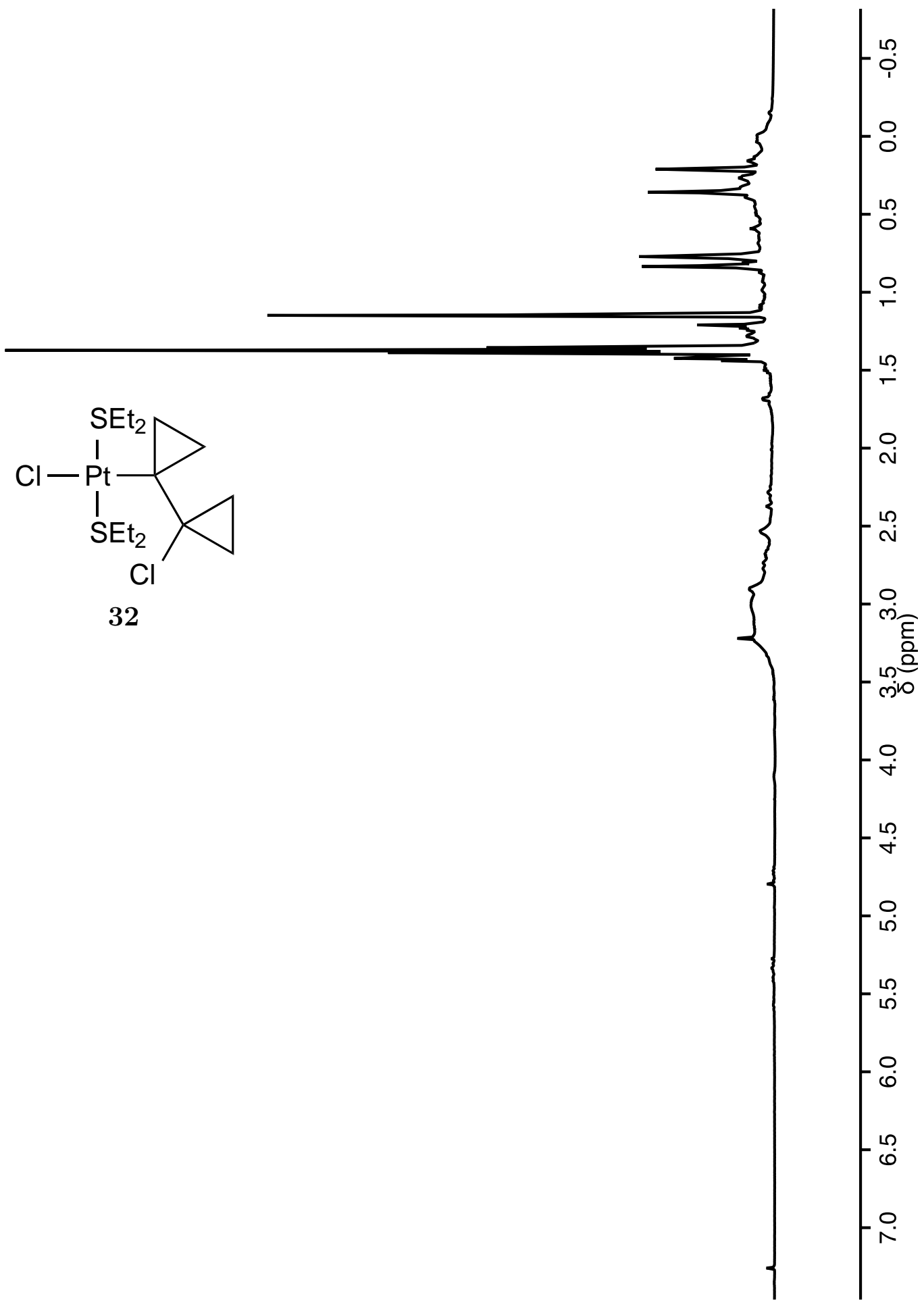

Figure A.83. ${ }^{1} \mathrm{H}$ NMR spectrum of trans $-\left[\mathrm{Pt}\left(\mathrm{C}\left(\mathrm{CH}_{2}\right)_{2} \mathrm{C}\left(\mathrm{CH}_{2}\right)_{2} \mathrm{Cl}\right) \mathrm{Cl}\left(\mathrm{SEt}_{2}\right)_{2}\right](\mathbf{3 2})$ $\left(500 \mathrm{MHz}, \mathrm{RT}, 100 \mathrm{mg} / \mathrm{mL}, \mathrm{CDCl}_{3}\right)$. 

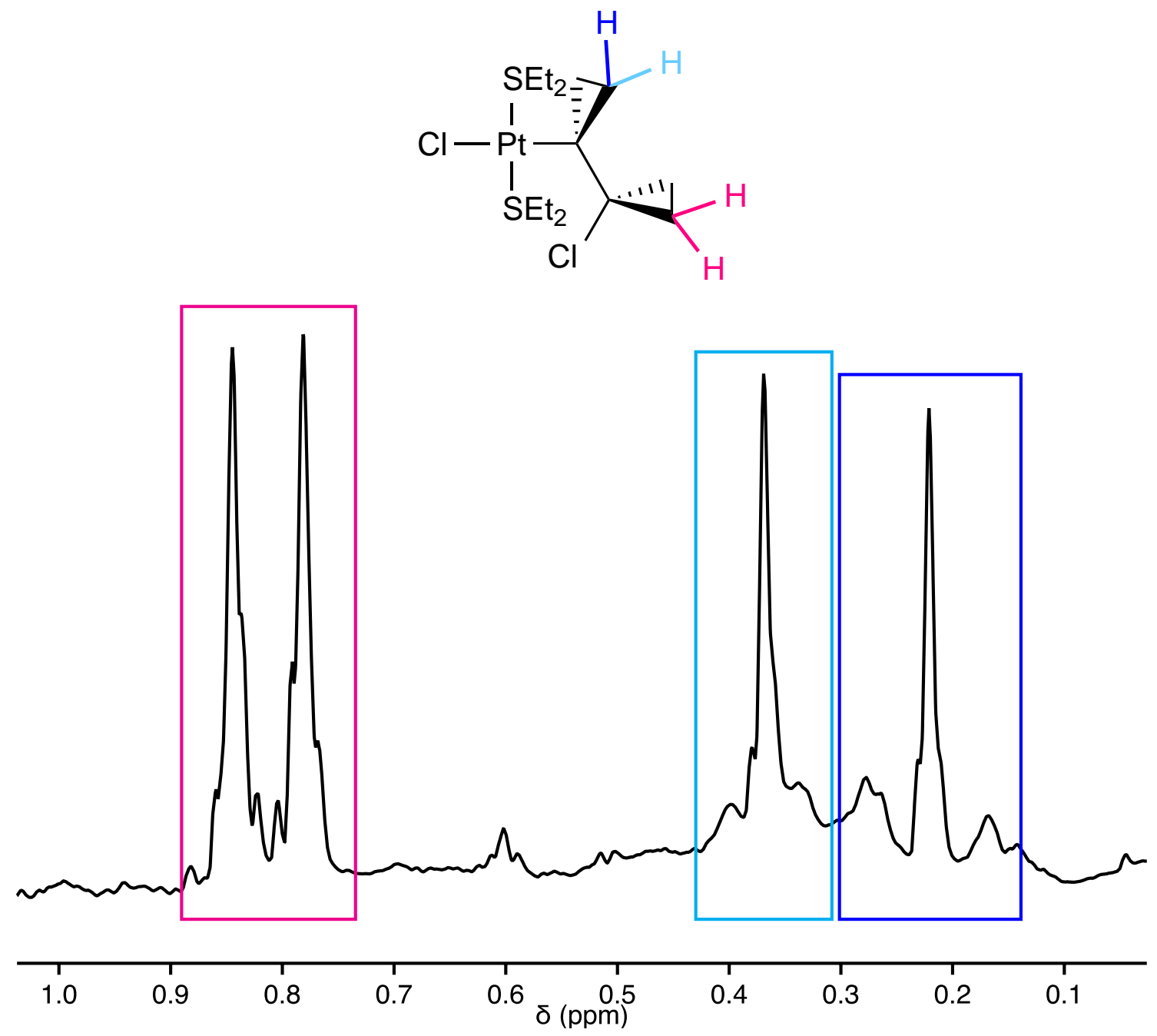

Figure A.84. Expanded ${ }^{1} \mathrm{H}$ NMR spectrum of trans- $\left[\mathrm{Pt}\left(\mathrm{C}\left(\mathrm{CH}_{2}\right)_{2} \mathrm{C}\left(\mathrm{CH}_{2}\right)_{2} \mathrm{Cl}\right) \mathrm{Cl}\left(\mathrm{SEt}_{2}\right)_{2}\right](\mathbf{3 2})\left(500 \mathrm{MHz}, \mathrm{RT}, 100 \mathrm{mg} / \mathrm{mL}, \mathrm{CDCl}_{3}\right)$. 


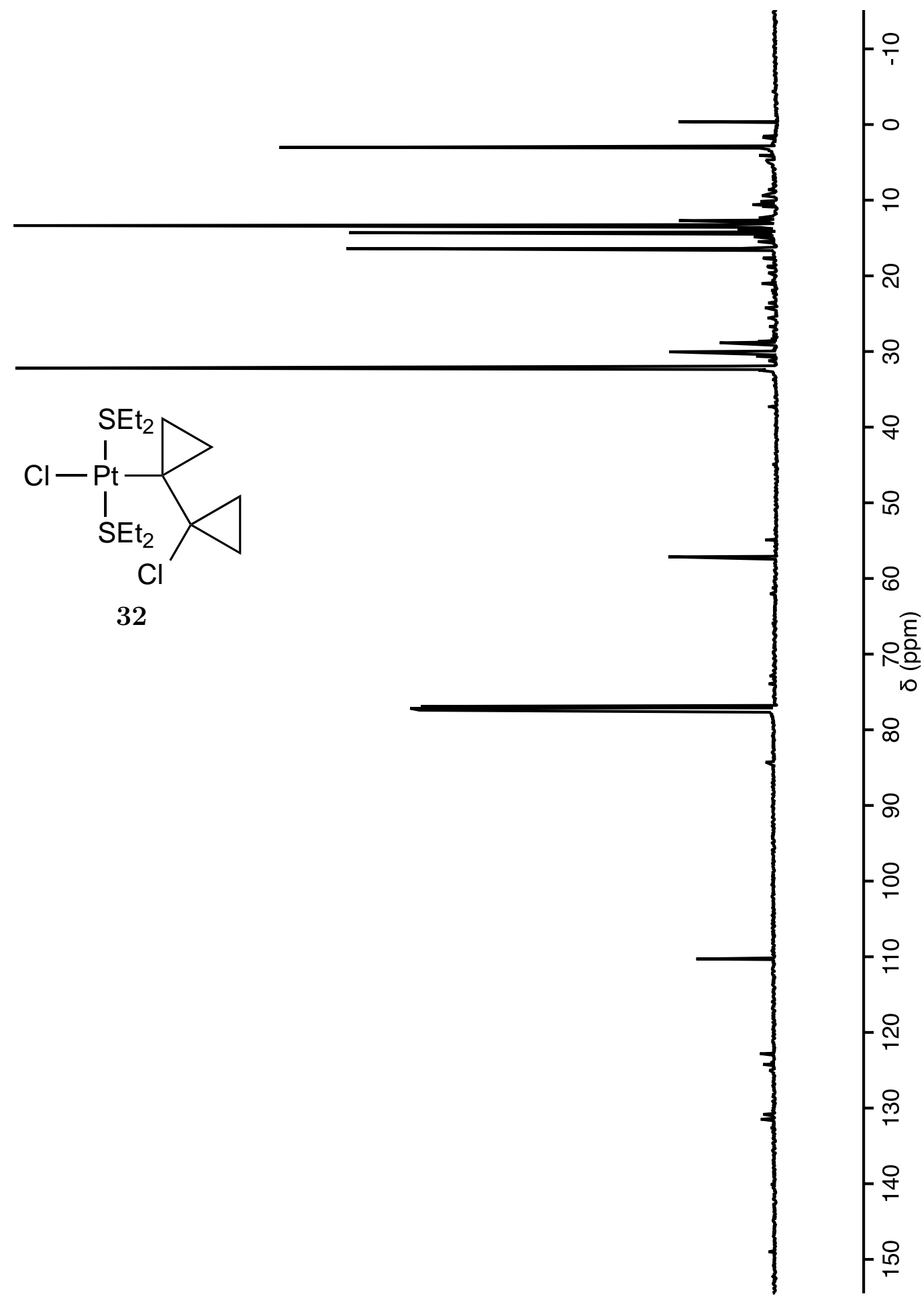

Figure A.85. ${ }^{13} \mathrm{C}\left\{{ }^{1} \mathrm{H}\right\}$ NMR spectrum of trans $-\left[\mathrm{Pt}\left(\mathrm{C}\left(\mathrm{CH}_{2}\right)_{2} \mathrm{C}\left(\mathrm{CH}_{2}\right)_{2} \mathrm{Cl}\right) \mathrm{Cl}\left(\mathrm{SEt}_{2}\right)_{2}\right]$ (32) (125 MHz, RT, $100 \mathrm{mg} / \mathrm{mL}, \mathrm{CDCl}_{3}$ ). 

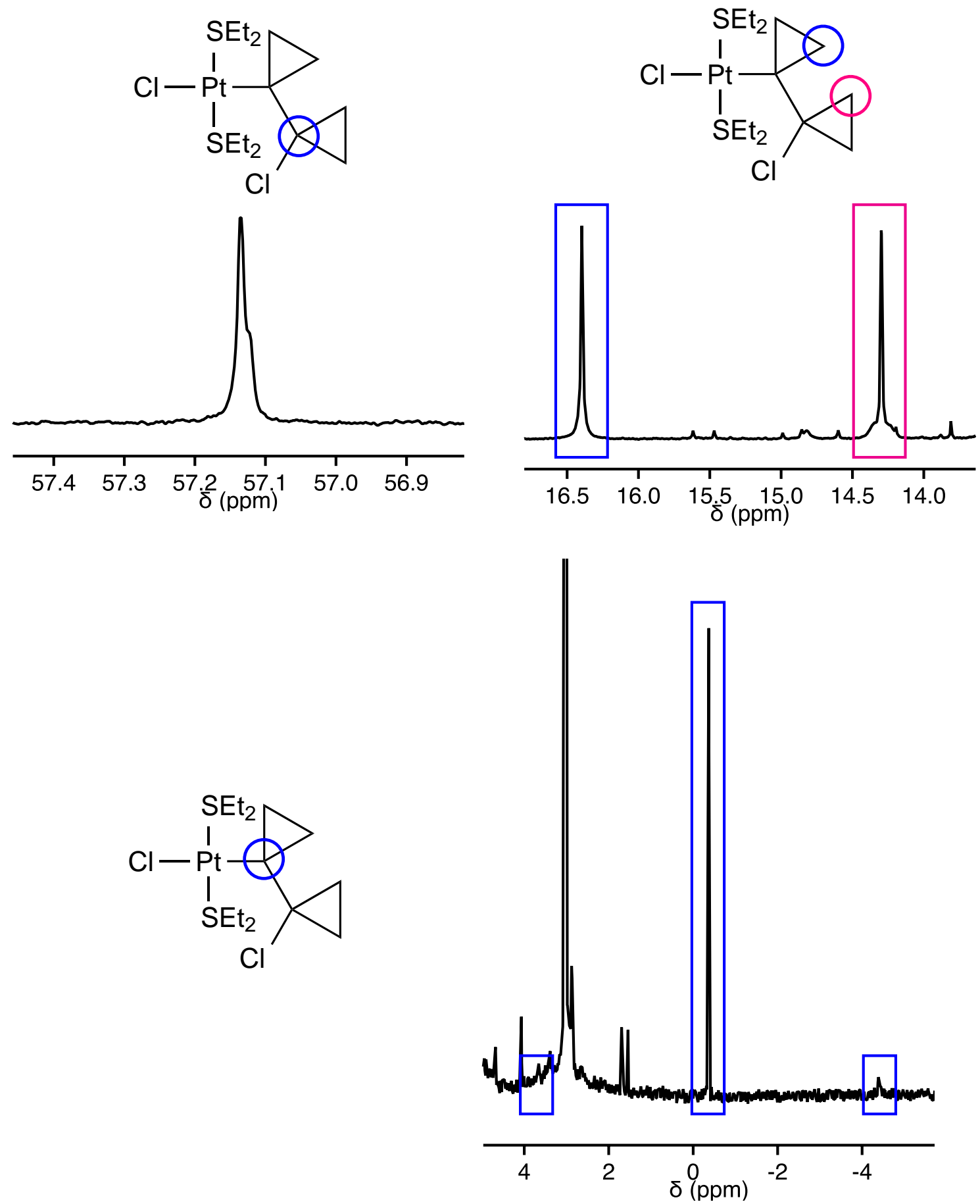

Figure A.86. Expanded ${ }^{13} \mathrm{C}\left\{{ }^{1} \mathrm{H}\right\}$ NMR spectrum of

trans $-\left[\mathrm{Pt}\left(\mathrm{C}\left(\mathrm{CH}_{2}\right)_{2} \mathrm{C}\left(\mathrm{CH}_{2}\right)_{2} \mathrm{Cl}\right) \mathrm{Cl}\left(\mathrm{SEt}_{2}\right)_{2}\right]$ (32) (125 MHz, RT, $\left.100 \mathrm{mg} / \mathrm{mL}, \mathrm{CDCl}_{3}\right)$. 
(mdd) HQ

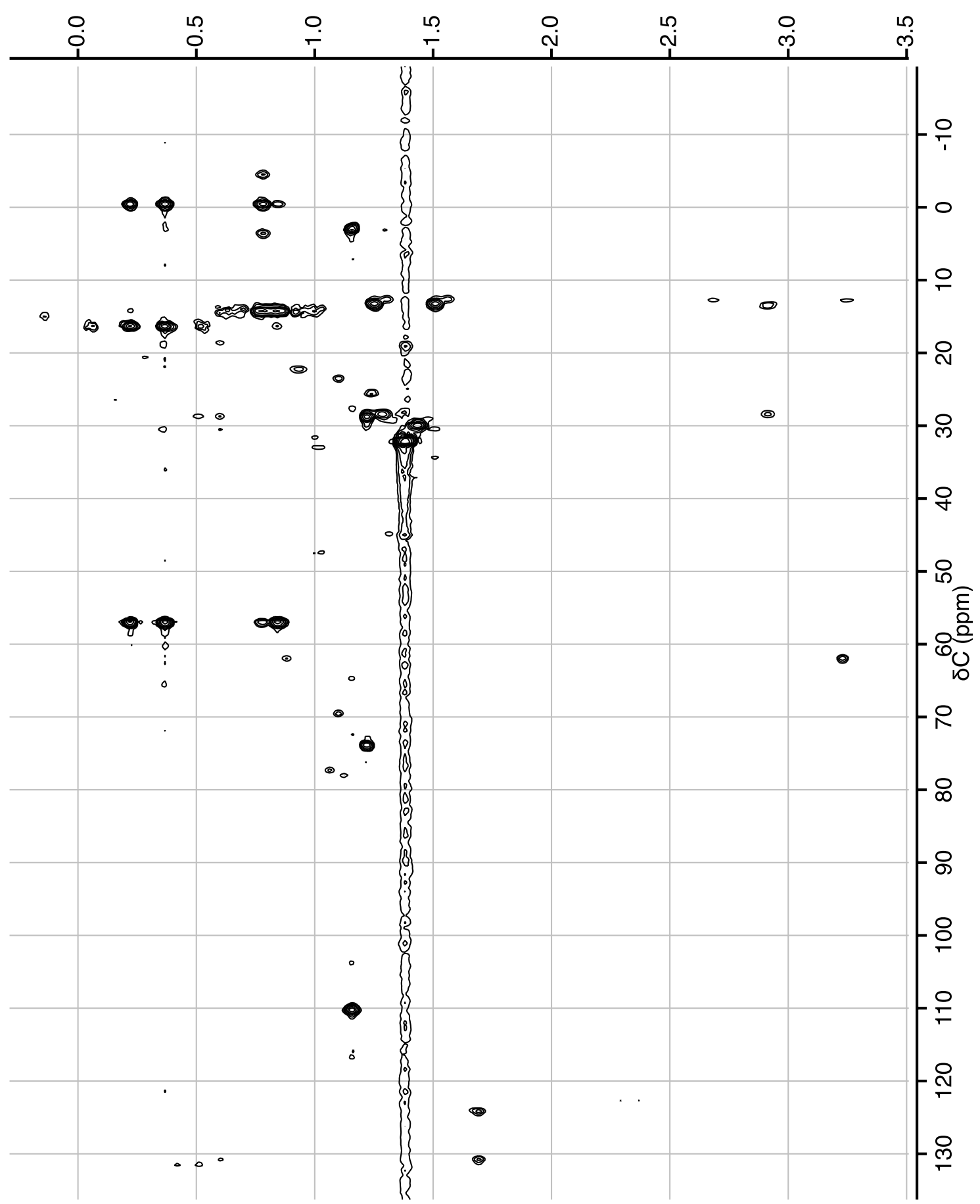

Figure A.87. HMBC spectrum of trans $-\left[\mathrm{Pt}\left(\mathrm{C}\left(\mathrm{CH}_{2}\right)_{2} \mathrm{C}\left(\mathrm{CH}_{2}\right)_{2} \mathrm{Cl}\right) \mathrm{Cl}\left(\mathrm{SEt}_{2}\right)_{2}\right](\mathbf{3 2})$ $\left(500 / 125 \mathrm{MHz}, \mathrm{RT}, 100 \mathrm{mg} / \mathrm{mL}, \mathrm{CDCl}_{3}\right)$. 


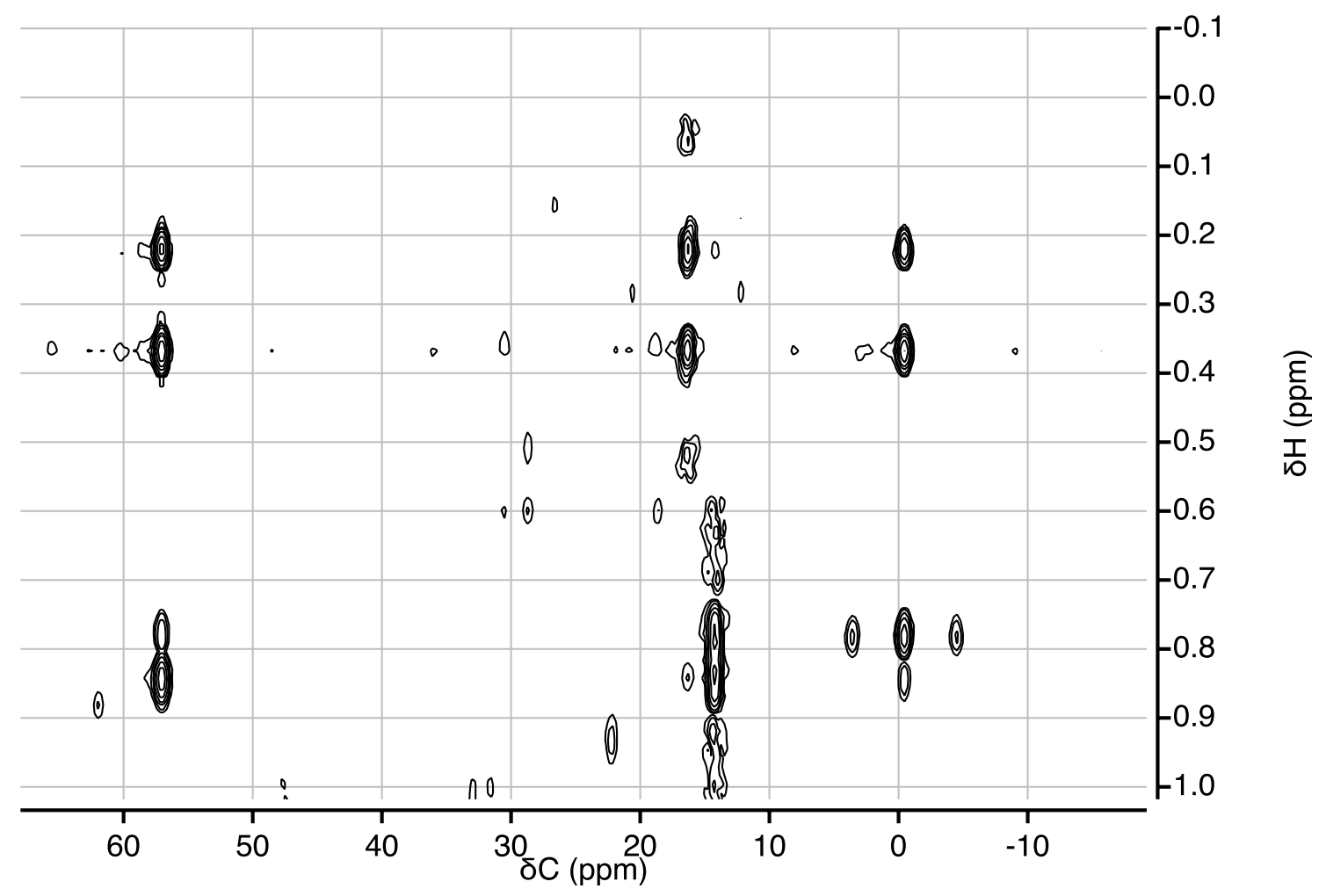

Figure A.88. Expanded HMBC spectrum of trans- $\left.-\mathrm{Pt}\left(\mathrm{C}\left(\mathrm{CH}_{2}\right)_{2} \mathrm{C}\left(\mathrm{CH}_{2}\right)_{2} \mathrm{Cl}\right) \mathrm{Cl}\left(\mathrm{SEt}_{2}\right)_{2}\right]$ (32) $\left(500 / 125 \mathrm{MHz}, \mathrm{RT}, 100 \mathrm{mg} / \mathrm{mL}, \mathrm{CDCl}_{3}\right)$.

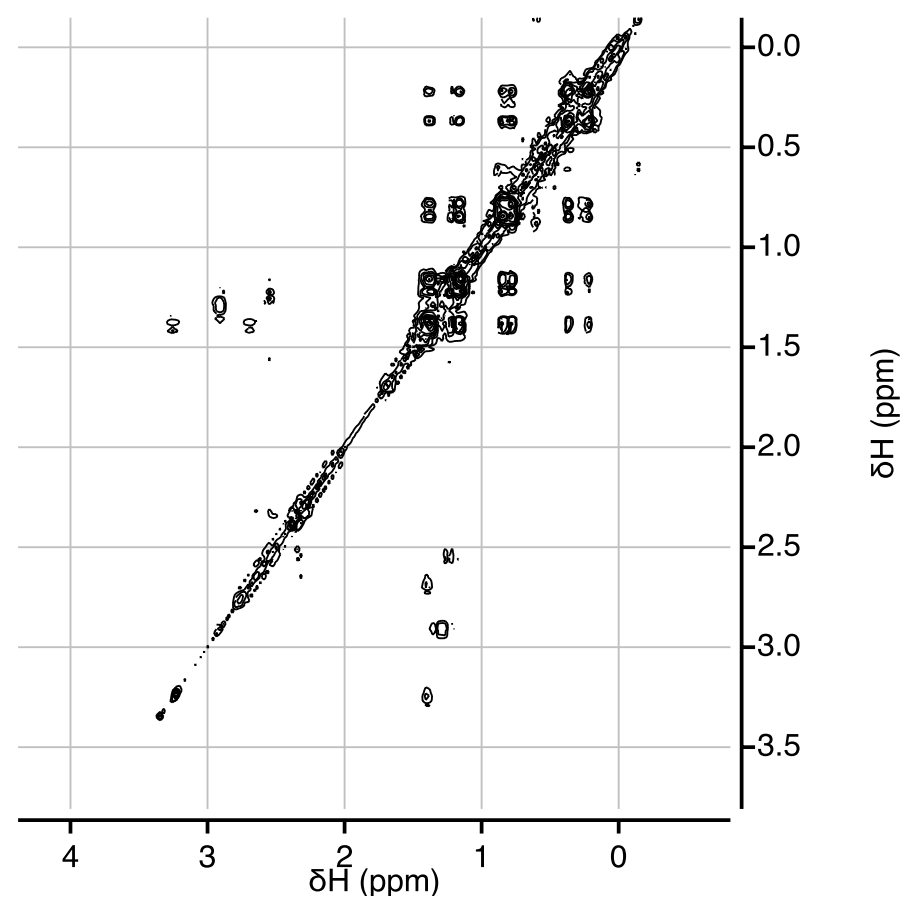

Figure A.89. COSY spectrum of trans- $\left[\mathrm{Pt}\left(\mathrm{C}\left(\mathrm{CH}_{2}\right)_{2} \mathrm{C}\left(\mathrm{CH}_{2}\right)_{2} \mathrm{Cl}\right) \mathrm{Cl}\left(\mathrm{SEt}_{2}\right)_{2}\right](\mathbf{3 2})$ $\left(500 \mathrm{MHz}, \mathrm{RT}, 100 \mathrm{mg} / \mathrm{mL}, \mathrm{CDCl}_{3}\right)$. 


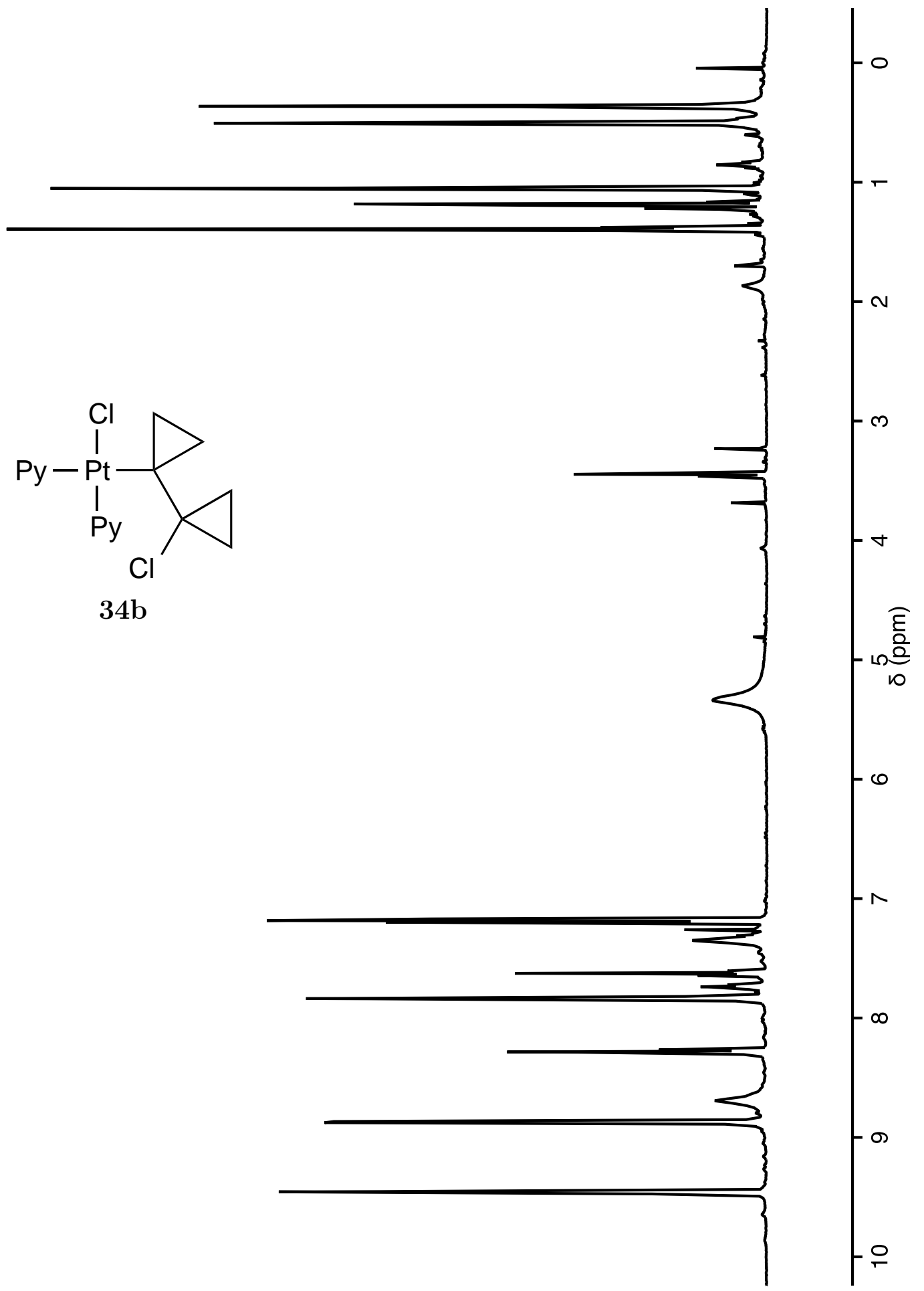

Figure A.90. ${ }^{1} \mathrm{H}$ NMR spectrum of cis- $\left[\mathrm{Pt}\left(\mathrm{C}\left(\mathrm{CH}_{2}\right)_{2} \mathrm{C}\left(\mathrm{CH}_{2}\right)_{2} \mathrm{Cl}\right) \mathrm{Cl}(\mathrm{Py})_{2}\right](\mathbf{3 4 b})$ (500 $\mathrm{MHz}, \mathrm{RT}, 40 \mathrm{mg} / \mathrm{mL}, \mathrm{CDCl}_{3}$ ). 

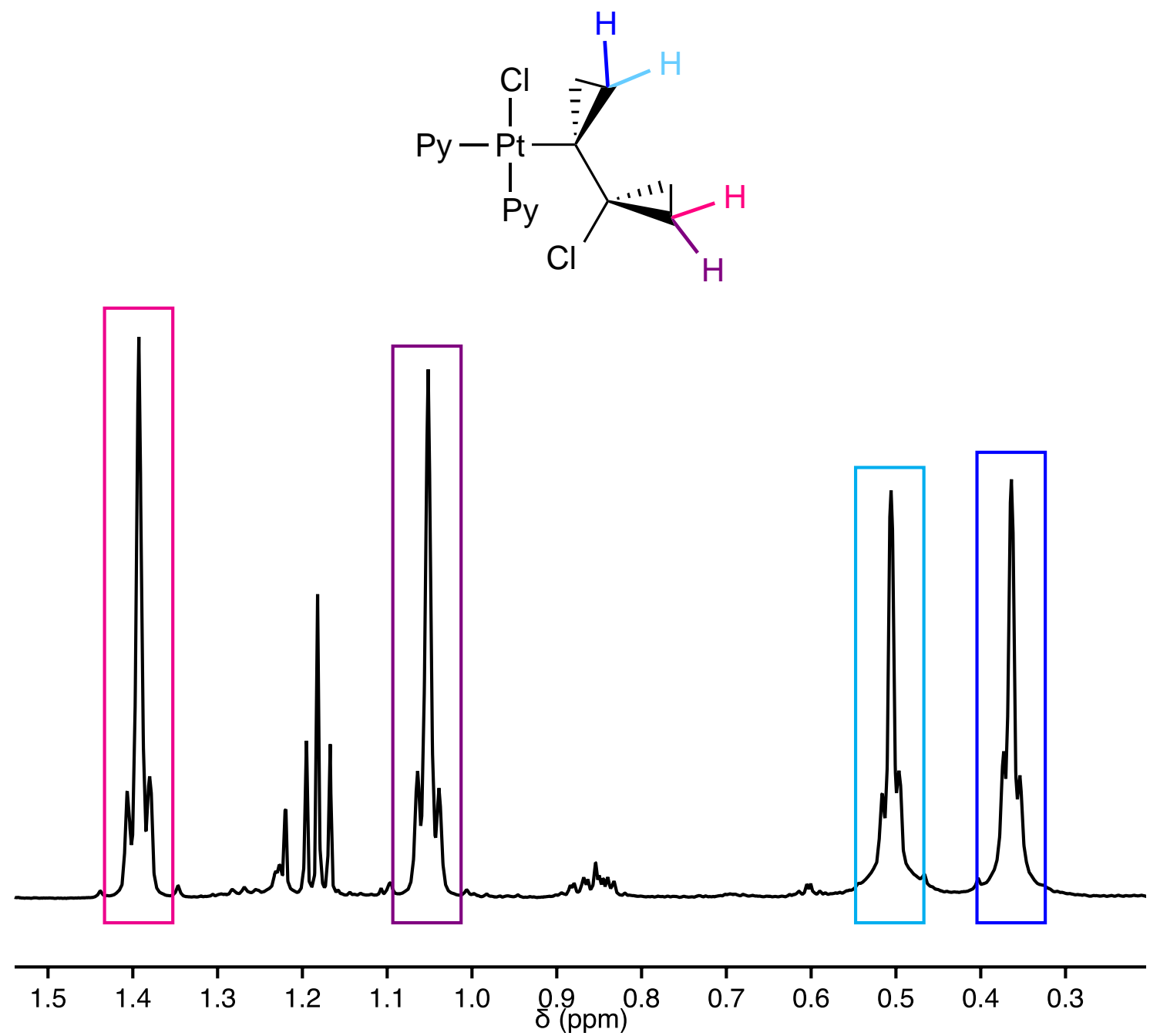

Figure A.91. Expanded ${ }^{1} \mathrm{H}$ NMR spectrum of cis- $\left[\mathrm{Pt}\left(\mathrm{C}\left(\mathrm{CH}_{2}\right)_{2} \mathrm{C}\left(\mathrm{CH}_{2}\right)_{2} \mathrm{Cl}\right) \mathrm{Cl}(\mathrm{Py})_{2}\right]$ (34b) (500 MHz, RT, $40 \mathrm{mg} / \mathrm{mL}, \mathrm{CDCl}_{3}$ ). 


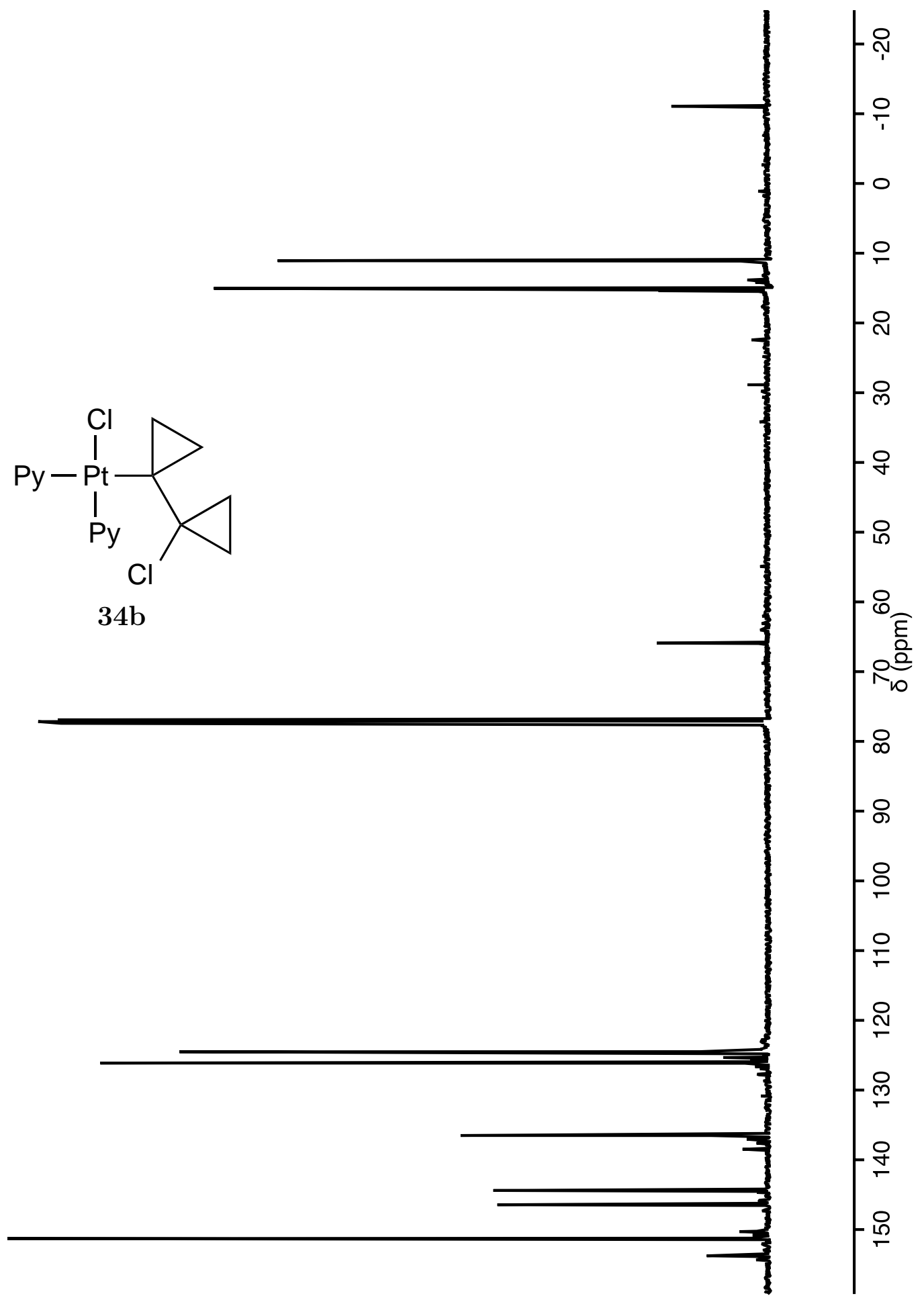

Figure A.92. ${ }^{13} \mathrm{C}\left\{{ }^{1} \mathrm{H}\right\}$ NMR spectrum of cis- $\left[\mathrm{Pt}\left(\mathrm{C}\left(\mathrm{CH}_{2}\right)_{2} \mathrm{C}\left(\mathrm{CH}_{2}\right)_{2} \mathrm{Cl}\right) \mathrm{Cl}(\mathrm{Py})_{2}\right](\mathbf{3 4} \mathbf{b})$ (125 $\mathrm{MHz}, \mathrm{RT}, 40 \mathrm{mg} / \mathrm{mL}, \mathrm{CDCl}_{3}$ ). 

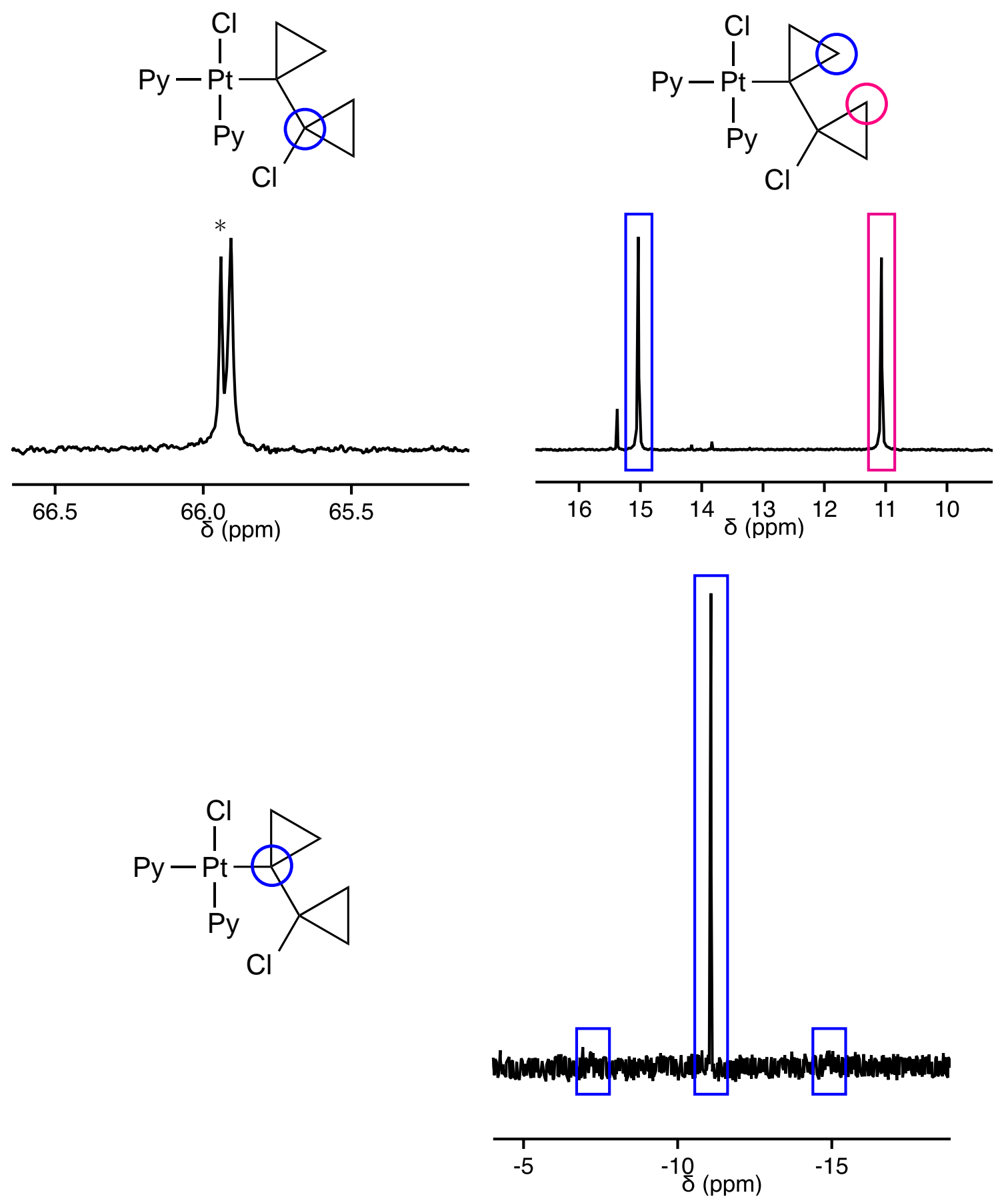

Figure A.93. Expanded ${ }^{13} \mathrm{C}\left\{{ }^{1} \mathrm{H}\right\}$ NMR spectrum of cis- $\left[\mathrm{Pt}\left(\mathrm{C}\left(\mathrm{CH}_{2}\right)_{2} \mathrm{C}\left(\mathrm{CH}_{2}\right)_{2} \mathrm{Cl}\right) \mathrm{Cl}(\mathrm{Py})_{2}\right](\mathbf{3 4 b})(125 \mathrm{MHz}, \mathrm{RT}, 40 \mathrm{mg} / \mathrm{mL}$, $\left.\mathrm{CDCl}_{3}\right) . *$ signifies peaks belonging to other species. 
(udd) HQ

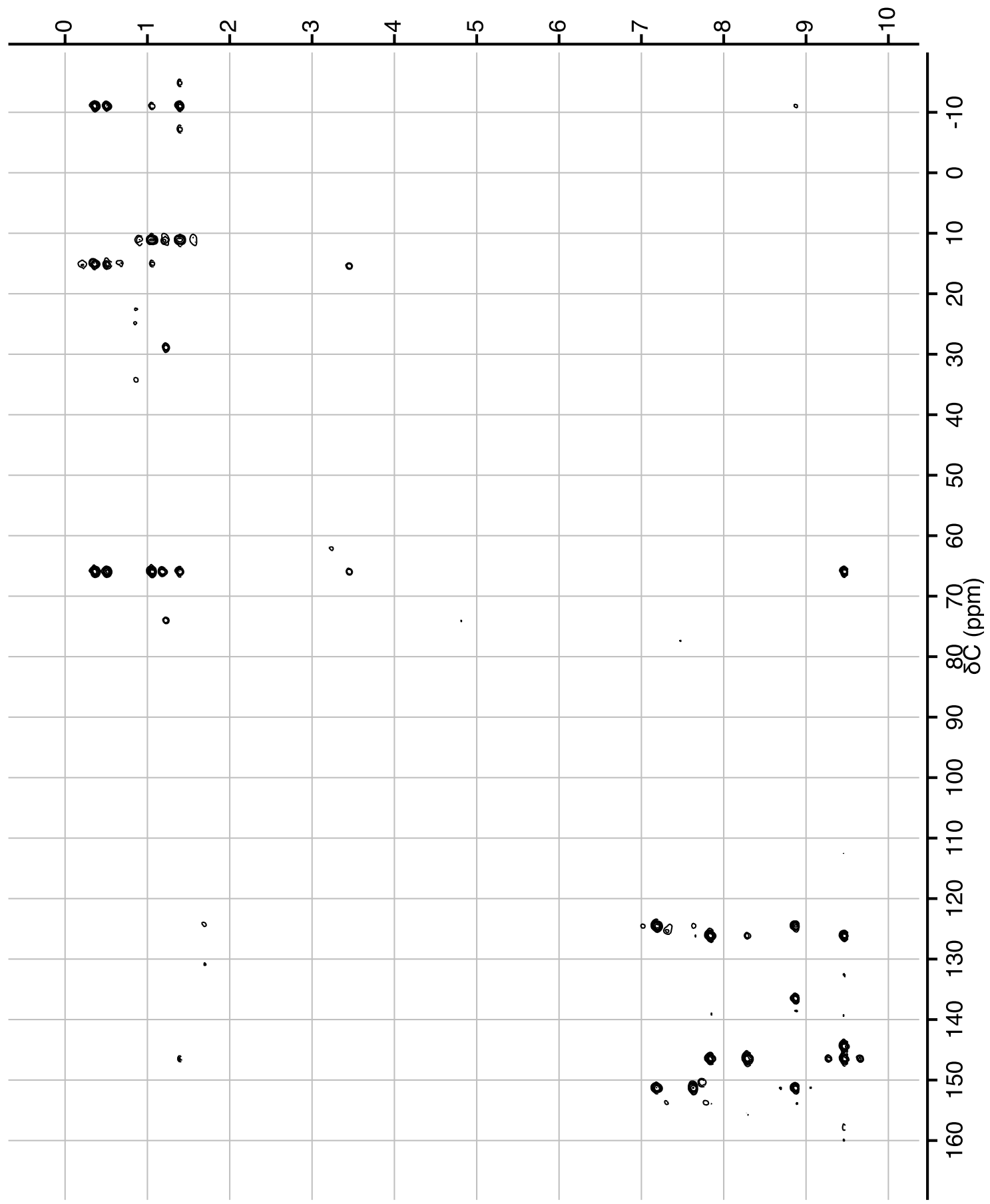

Figure A.94. $\mathrm{HMBC}$ spectrum of cis- $\left[\mathrm{Pt}\left(\mathrm{C}\left(\mathrm{CH}_{2}\right)_{2} \mathrm{C}\left(\mathrm{CH}_{2}\right)_{2} \mathrm{Cl}\right) \mathrm{Cl}(\mathrm{Py})_{2}\right](\mathbf{3 4 b})$ $\left(500 / 125 \mathrm{MHz}, \mathrm{RT}, 40 \mathrm{mg} / \mathrm{mL}, \mathrm{CDCl}_{3}\right)$. 


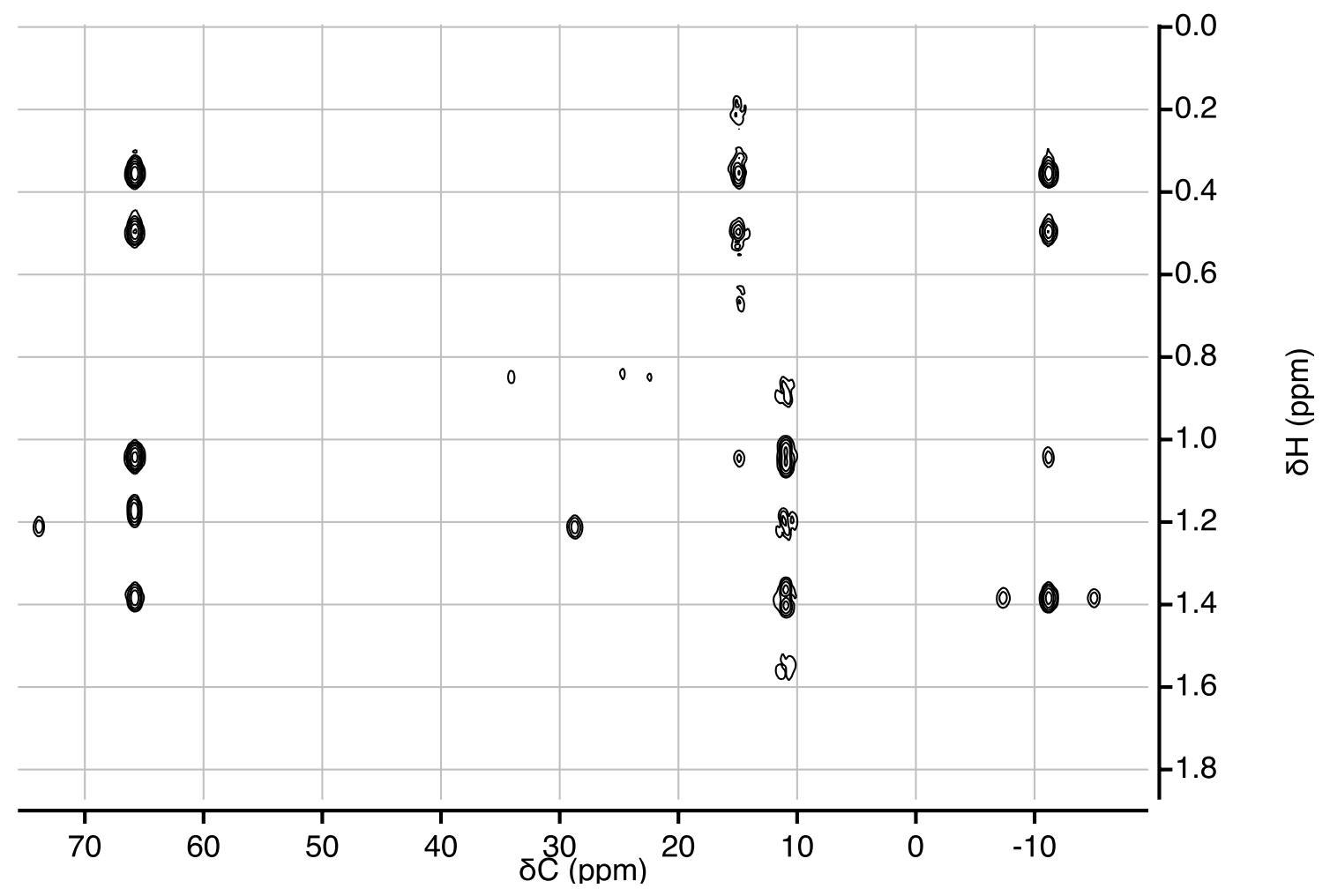

Figure A.95. Expanded HMBC spectrum of cis- $\left[\mathrm{Pt}\left(\mathrm{C}\left(\mathrm{CH}_{2}\right)_{2} \mathrm{C}\left(\mathrm{CH}_{2}\right)_{2} \mathrm{Cl}\right) \mathrm{Cl}(\mathrm{Py})_{2}\right]$ (34b) $\left(500 / 125 \mathrm{MHz}, \mathrm{RT}, 40 \mathrm{mg} / \mathrm{mL}, \mathrm{CDCl}_{3}\right)$.

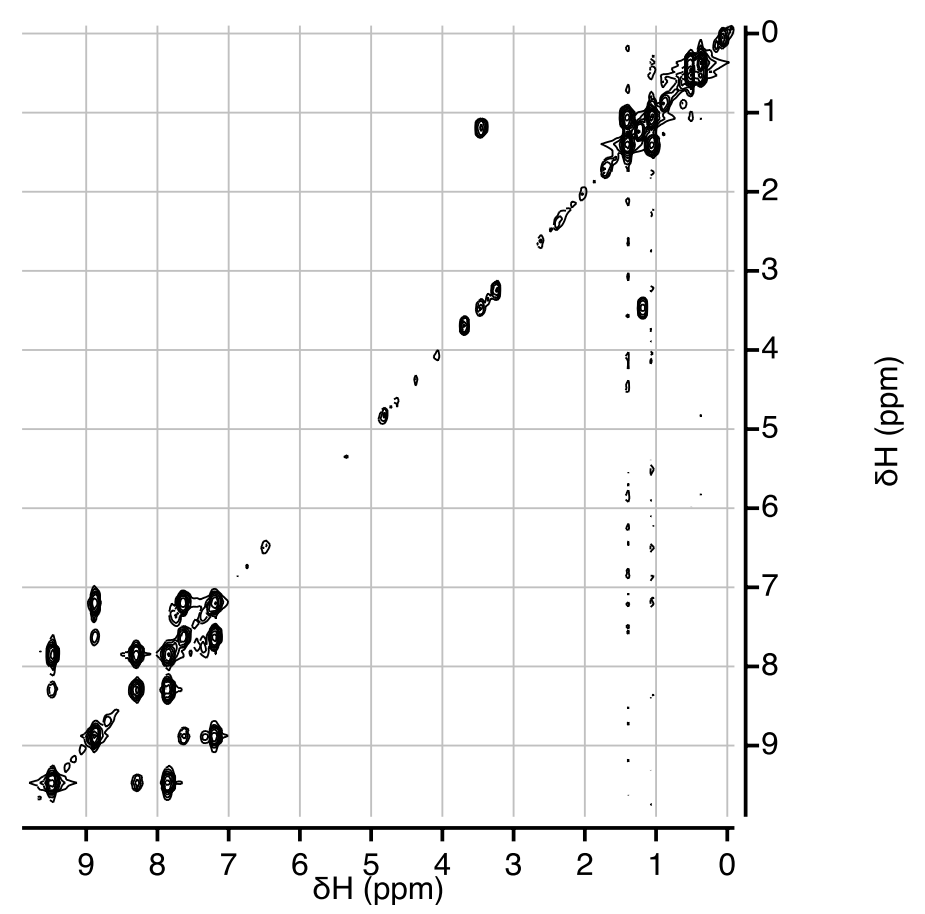

Figure A.96. COSY spectrum of cis $-\left[\mathrm{Pt}\left(\mathrm{C}\left(\mathrm{CH}_{2}\right)_{2} \mathrm{C}\left(\mathrm{CH}_{2}\right)_{2} \mathrm{Cl}\right) \mathrm{Cl}(\mathrm{Py})_{2}\right](\mathbf{3 4 b})$ (500 MHz, RT, $40 \mathrm{mg} / \mathrm{mL}, \mathrm{CDCl}_{3}$ ). 


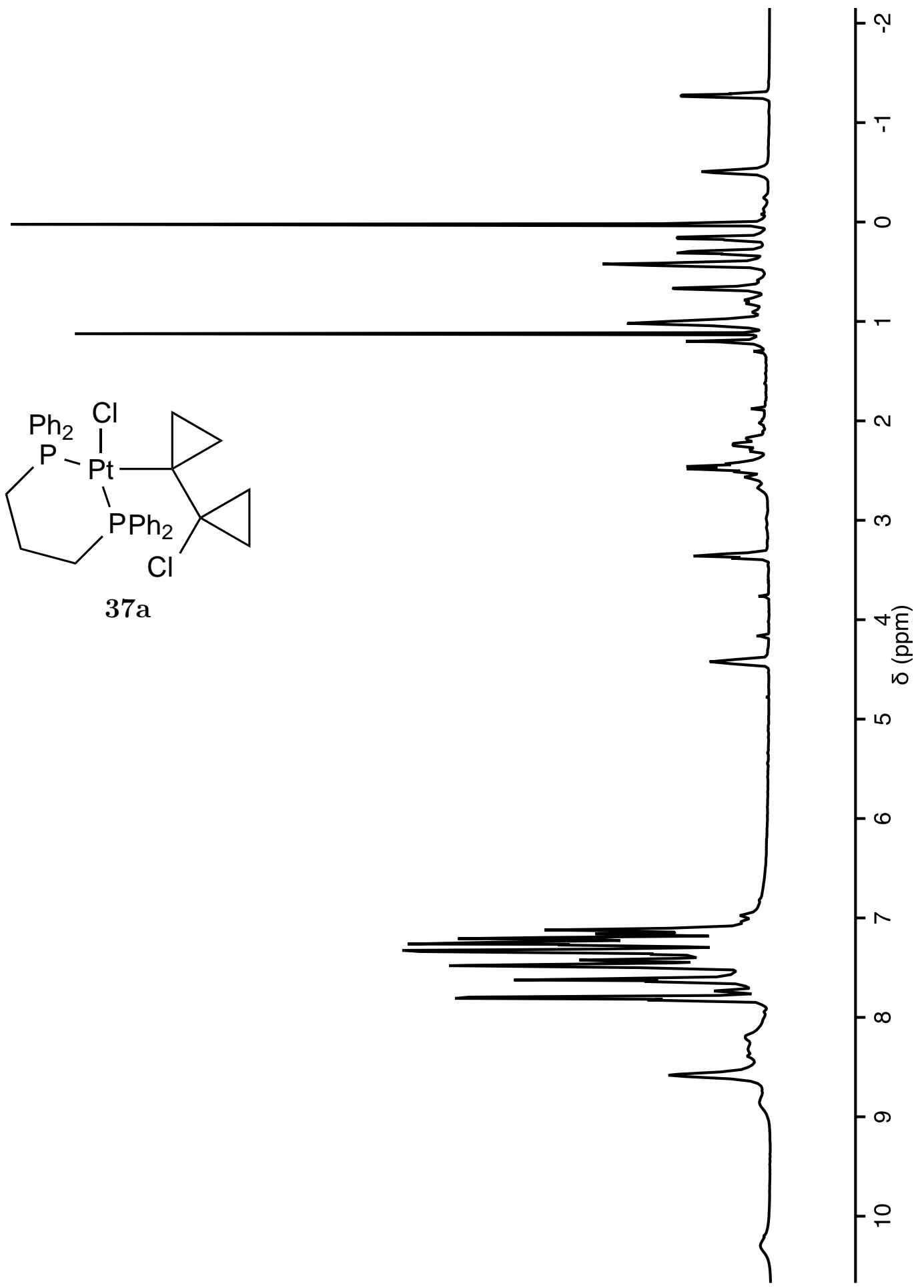

Figure A.97. ${ }^{1} \mathrm{H}$ NMR spectrum of cis- $\left.-\mathrm{Pt}\left(\mathrm{C}\left(\mathrm{CH}_{2}\right)_{2} \mathrm{C}\left(\mathrm{CH}_{2}\right)_{2} \mathrm{Cl}\right) \mathrm{Cl}(\mathrm{dppp})\right](\mathbf{3 7 a})$ (600 MHz, RT, $40 \mathrm{mg} / \mathrm{mL}, \mathrm{CDCl}_{3}$ ). 

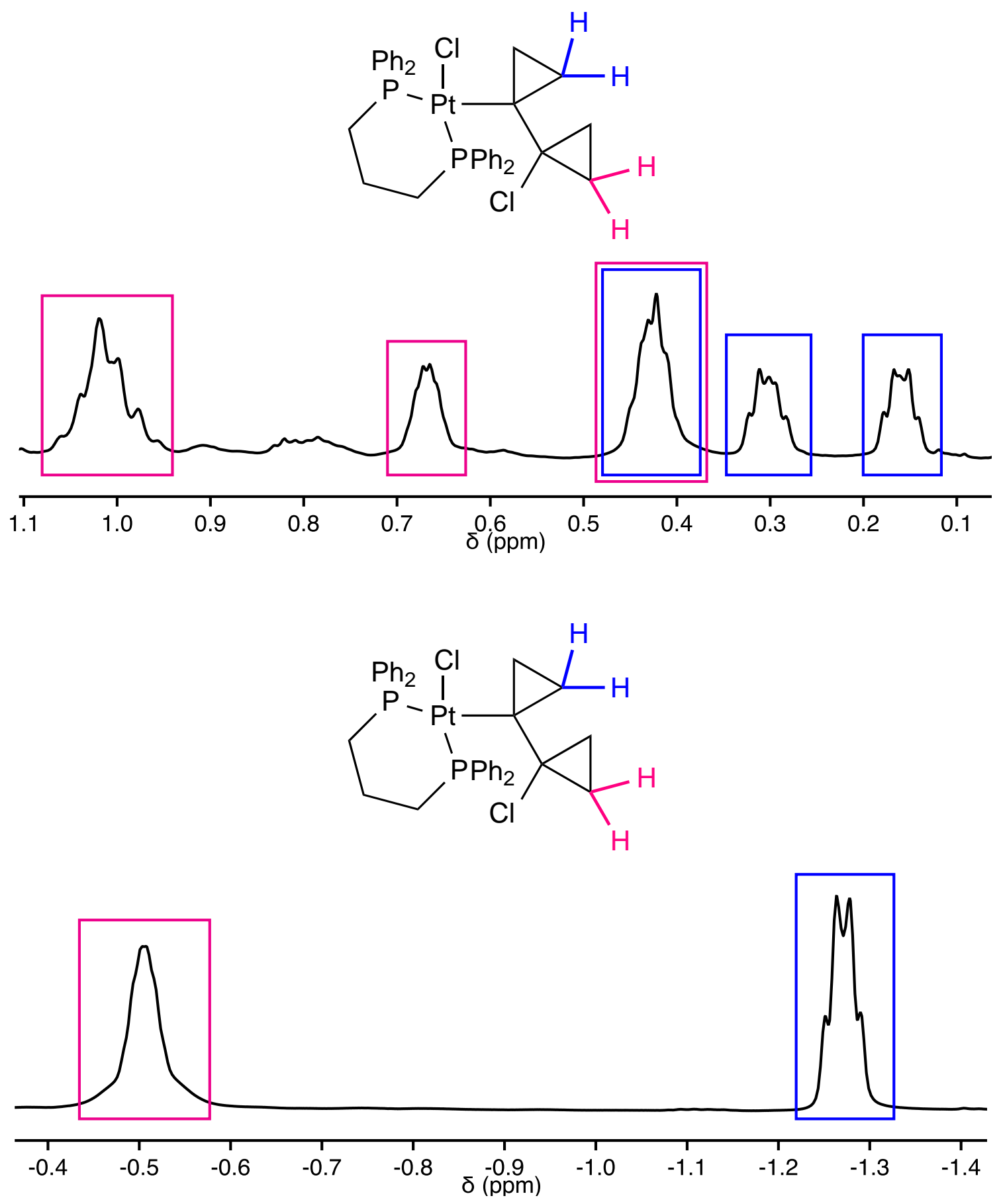

Figure A.98. Expanded ${ }^{1} \mathrm{H}$ NMR spectrum of cis- $\left[\mathrm{Pt}\left(\mathrm{C}\left(\mathrm{CH}_{2}\right)_{2} \mathrm{C}\left(\mathrm{CH}_{2}\right)_{2} \mathrm{Cl}\right) \mathrm{Cl}(\mathrm{dppp})\right]$ (37a) $\left(600 \mathrm{MHz}, \mathrm{RT}, 40 \mathrm{mg} / \mathrm{mL}, \mathrm{CDCl}_{3}\right)$. 

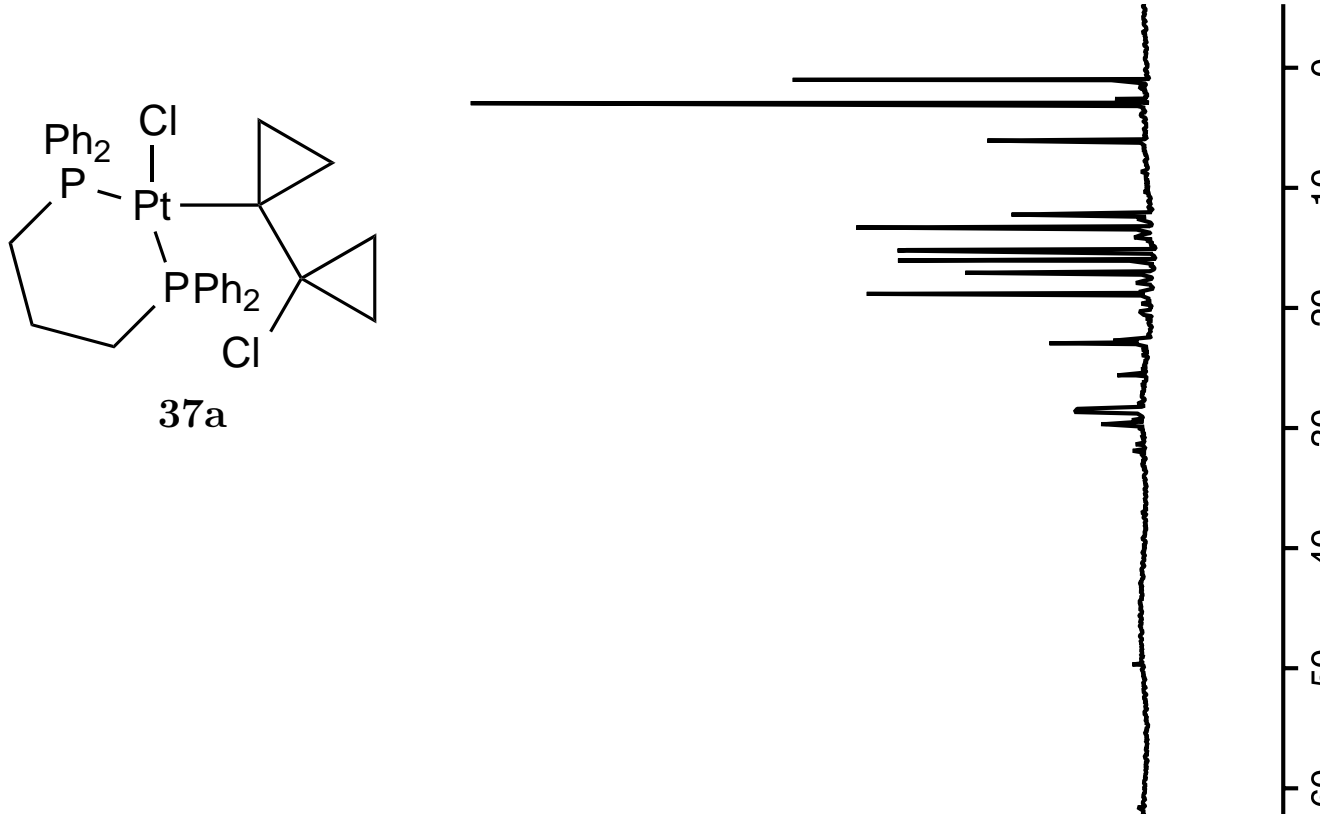

$37 \mathbf{a}$

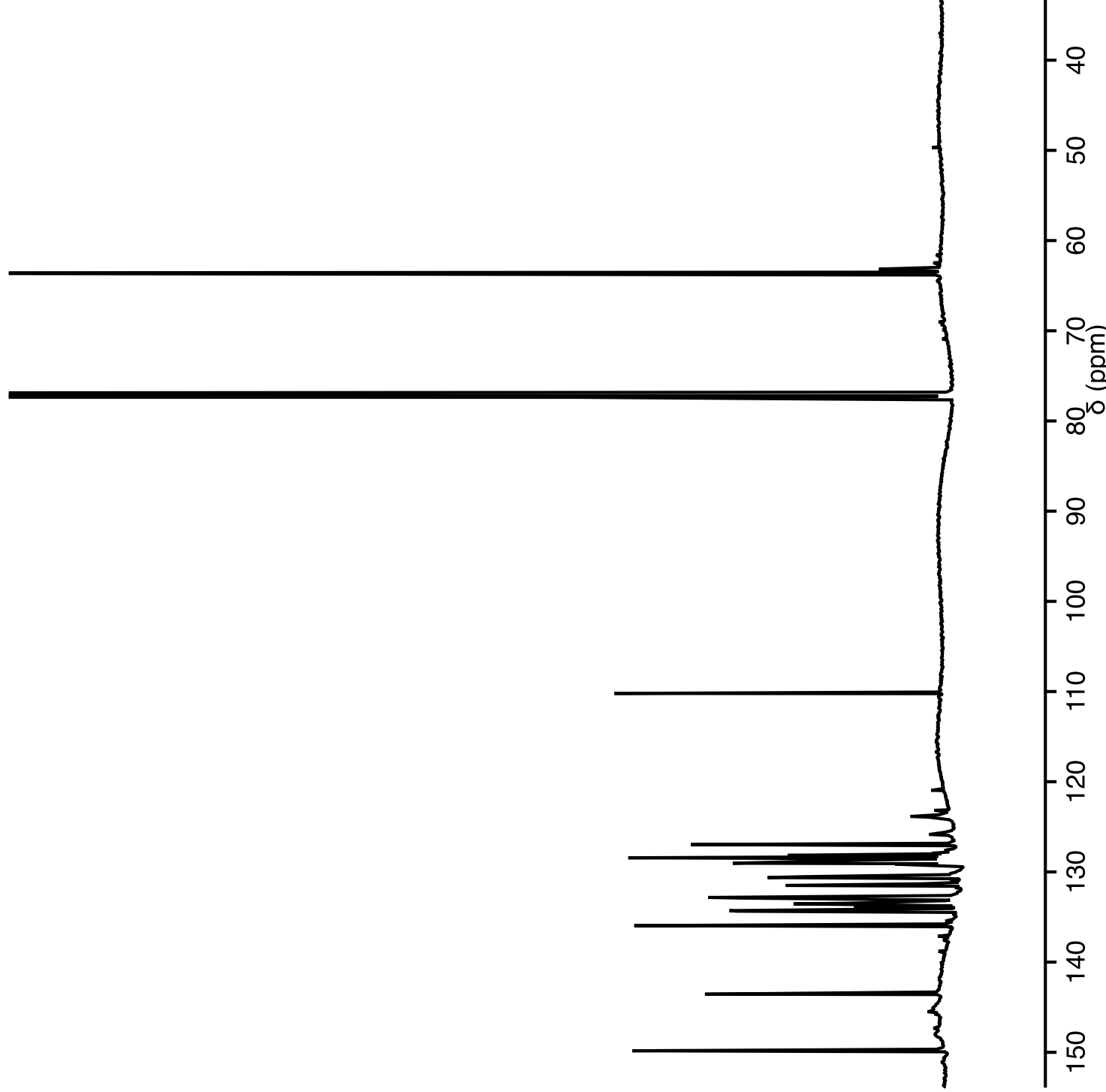

Figure A.99. ${ }^{13} \mathrm{C}\left\{{ }^{1} \mathrm{H}\right\}$ NMR spectrum of carbon-13 enriched cis- $-\left[\mathrm{Pt}\left(\mathrm{C}\left(\mathrm{CH}_{2}\right)_{2} \mathrm{C}\left(\mathrm{CH}_{2}\right)_{2} \mathrm{Cl}\right) \mathrm{Cl}(\mathrm{dppp})\right](\mathbf{3 7 a})$ (150 MHz, RT, $\left.40 \mathrm{mg} / \mathrm{mL}, \mathrm{CDCl}_{3}\right)$. 

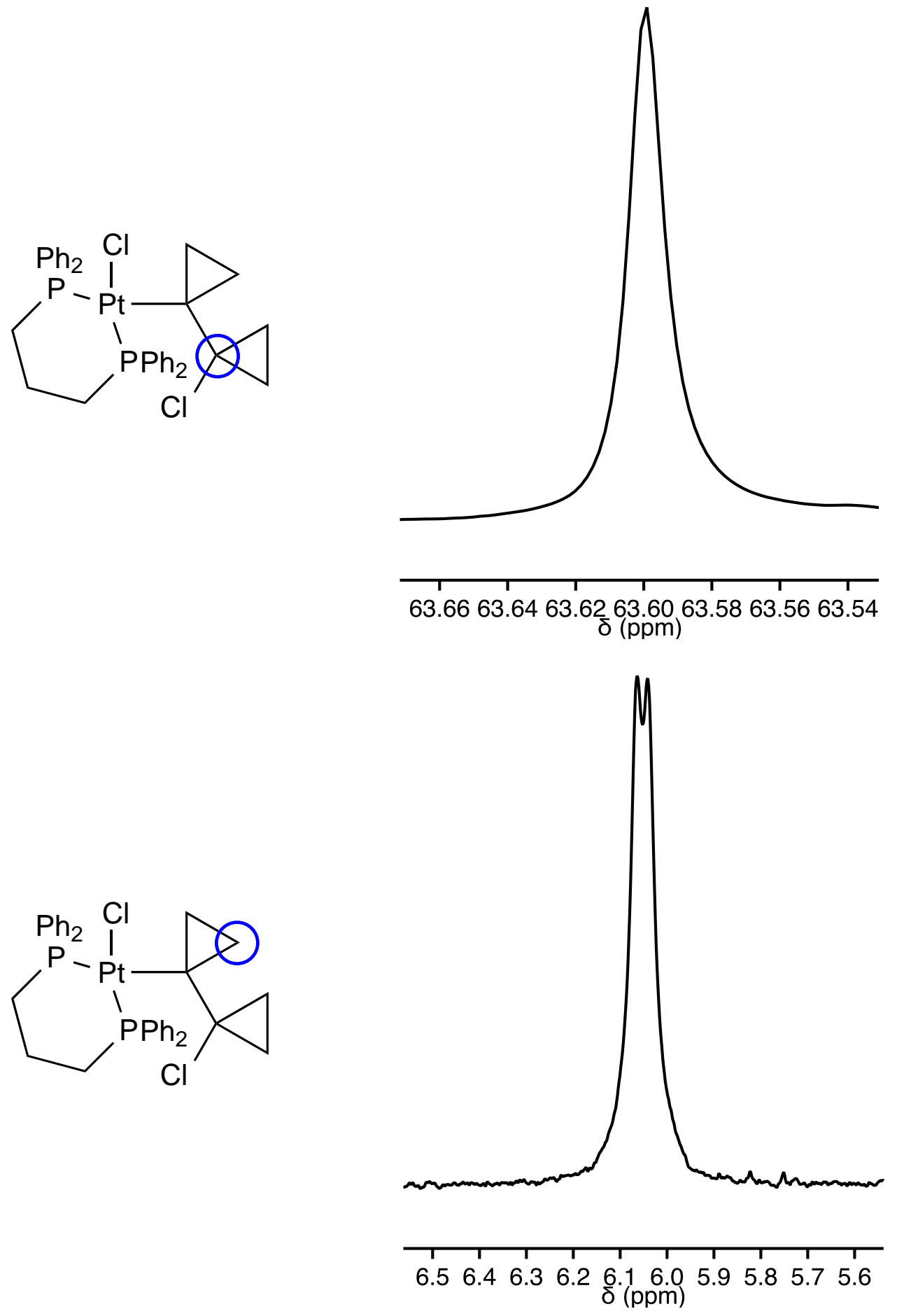

Figure A.100. Expanded ${ }^{13} \mathrm{C}\left\{{ }^{1} \mathrm{H}\right\}$ NMR spectrum of carbon-13 enriched cis-[Pt $\left.\left(\mathrm{C}\left(\mathrm{CH}_{2}\right)_{2} \mathrm{C}\left(\mathrm{CH}_{2}\right)_{2} \mathrm{Cl}\right) \mathrm{Cl}(\mathrm{dppp})\right]$ (37a) (150 MHz, RT, $\left.40 \mathrm{mg} / \mathrm{mL}, \mathrm{CDCl}_{3}\right)$. 

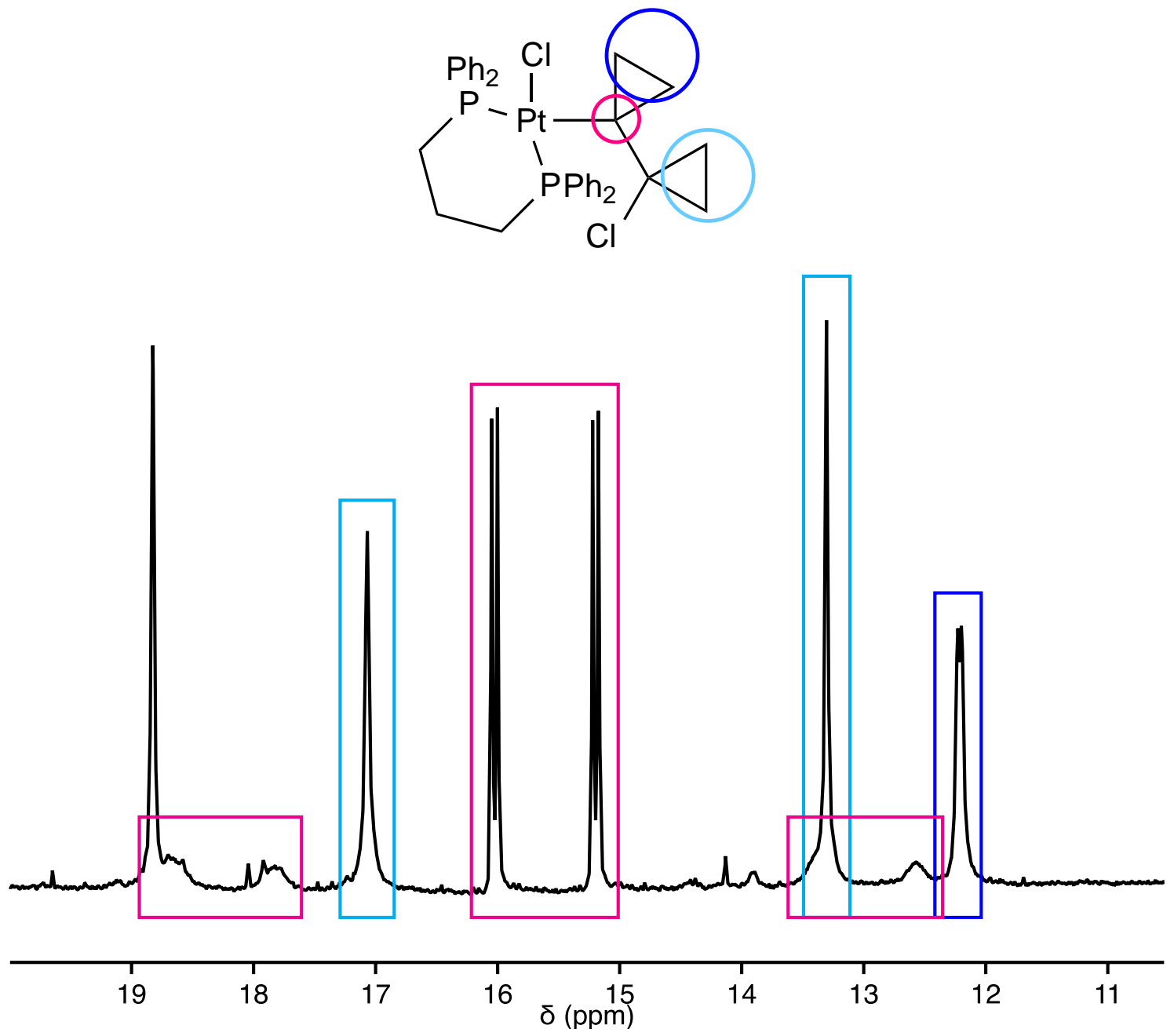

Figure A.101. Expanded ${ }^{13} \mathrm{C}\left\{{ }^{1} \mathrm{H}\right\}$ NMR spectrum of carbon-13 enriched cis- $\left[\mathrm{Pt}\left(\mathrm{C}\left(\mathrm{CH}_{2}\right)_{2} \mathrm{C}\left(\mathrm{CH}_{2}\right)_{2} \mathrm{Cl}\right) \mathrm{Cl}(\mathrm{dppp})\right]$ (37a) $\left(150 \mathrm{MHz}, \mathrm{RT}, 40 \mathrm{mg} / \mathrm{mL}, \mathrm{CDCl}_{3}\right)$. 
(mdd) HQ

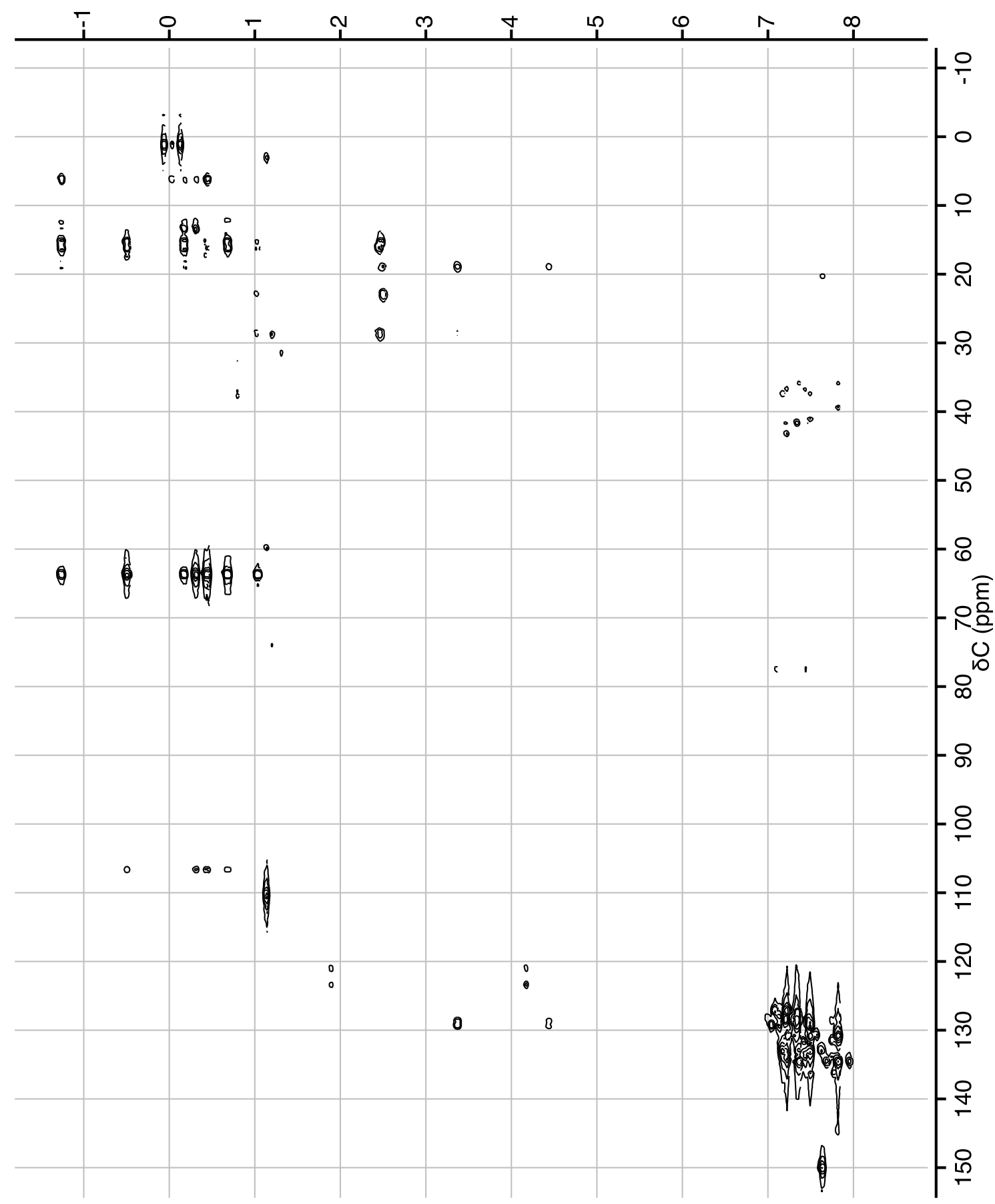

Figure A.102. HMBC spectrum of carbon-13 enriched cis- $\left.-\mathrm{Pt}\left(\mathrm{C}\left(\mathrm{CH}_{2}\right)_{2} \mathrm{C}\left(\mathrm{CH}_{2}\right)_{2} \mathrm{Cl}\right) \mathrm{Cl}(\mathrm{dppp})\right](\mathbf{3 7 a})\left(600 / 150 \mathrm{MHz}, \mathrm{RT}, 40 \mathrm{mg} / \mathrm{mL}, \mathrm{CDCl}_{3}\right)$. Some residual one bond coupling is present. 


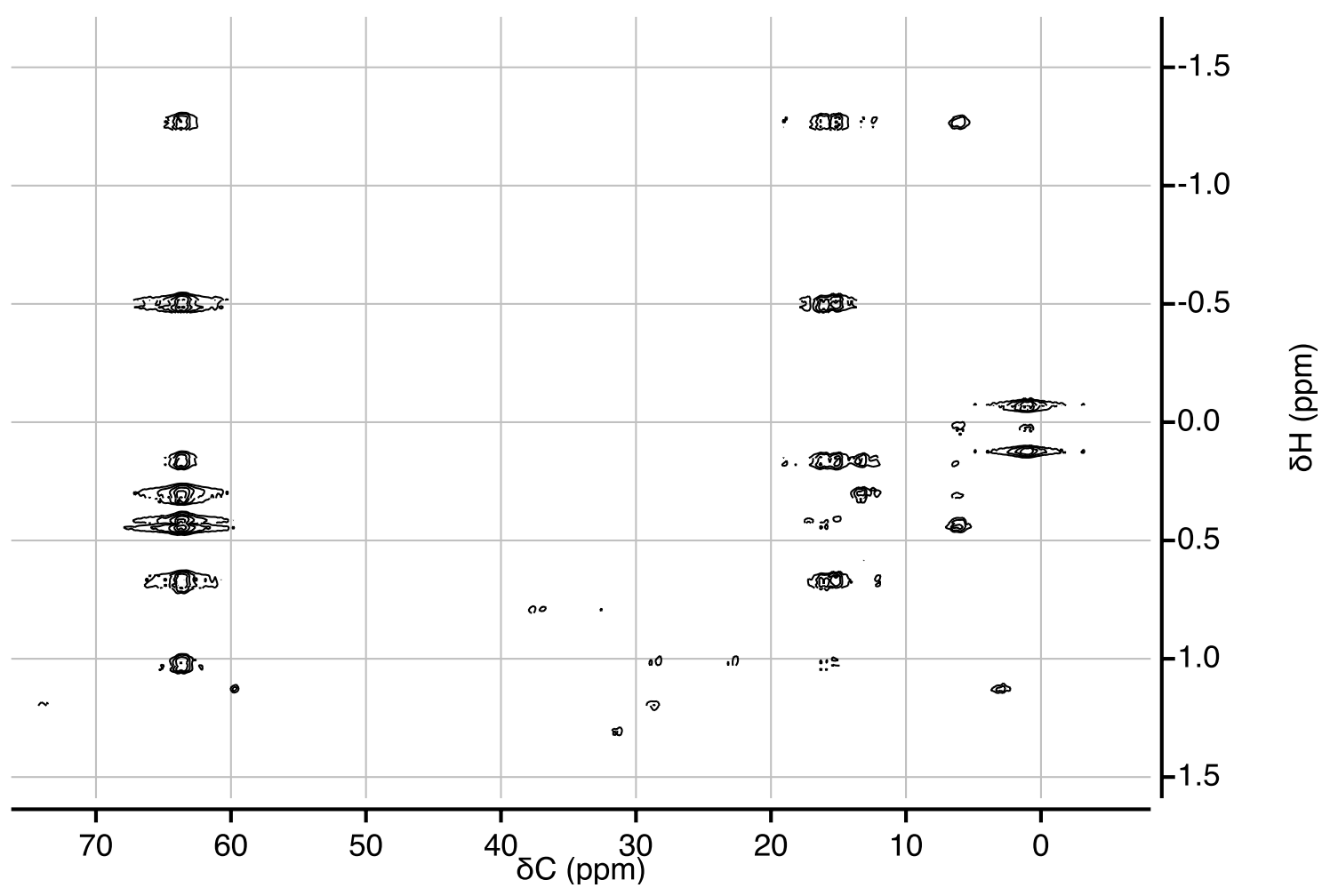

Figure A.103. Expanded HMBC spectrum of carbon-13 enriched cis- $\left.-\mathrm{Pt}\left(\mathrm{C}\left(\mathrm{CH}_{2}\right)_{2} \mathrm{C}\left(\mathrm{CH}_{2}\right)_{2} \mathrm{Cl}\right) \mathrm{Cl}(\mathrm{dppp})\right]$ (37a) $\left(600 / 150 \mathrm{MHz}, \mathrm{RT}, 40 \mathrm{mg} / \mathrm{mL}, \mathrm{CDCl}_{3}\right)$. Some residual one bond coupling is present.

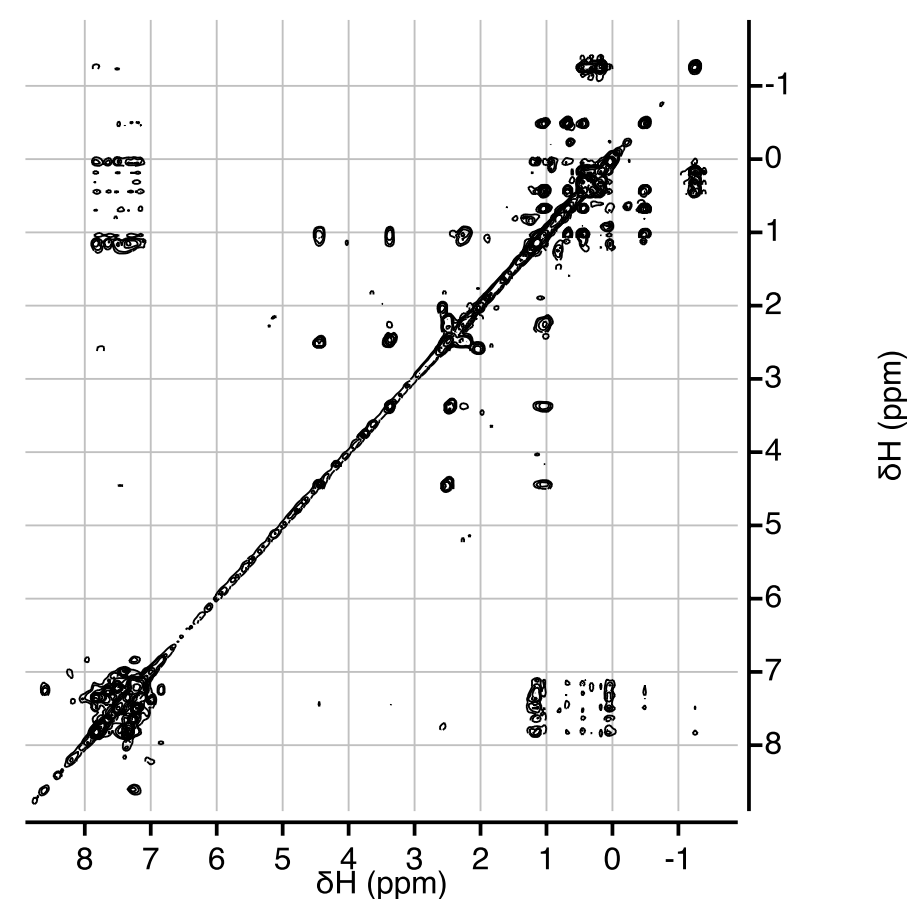

Figure A.104. COSY spectrum of carbon-13 enriched cis- $-\left[\mathrm{Pt}\left(\mathrm{C}\left(\mathrm{CH}_{2}\right)_{2} \mathrm{C}\left(\mathrm{CH}_{2}\right)_{2} \mathrm{Cl}\right) \mathrm{Cl}(\mathrm{dppp})\right](\mathbf{3 7 a})\left(600 \mathrm{MHz}, \mathrm{RT}, 40 \mathrm{mg} / \mathrm{mL}, \mathrm{CDCl}_{3}\right)$. 


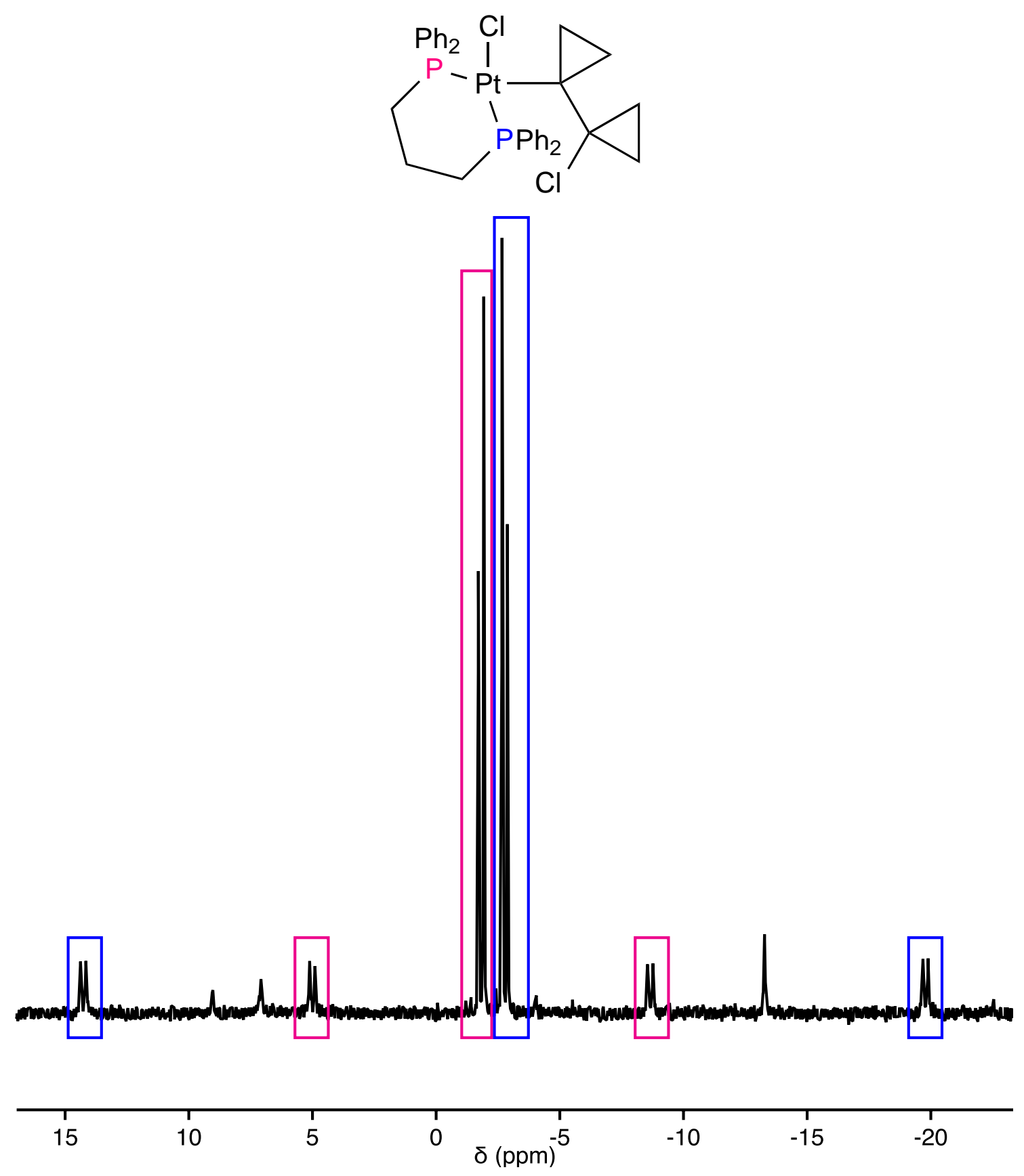

Figure A.105. ${ }^{31} \mathrm{P}\left\{{ }^{1} \mathrm{H}\right\}$ NMR spectrum of cis- $\left[\mathrm{Pt}\left(\mathrm{C}\left(\mathrm{CH}_{2}\right)_{2} \mathrm{C}\left(\mathrm{CH}_{2}\right)_{2} \mathrm{Cl}\right) \mathrm{Cl}(\mathrm{dppp})\right]$ (37a) (150 MHz, RT, $40 \mathrm{mg} / \mathrm{mL}, \mathrm{CDCl}_{3}$ ). 


\section{References}

1. Kurosawa, H.; Ikeda, I. J. Organomet. Chem. 1992, 428, 289-301.

2. Hartley, F. R. Chem. Rev. 1969, 69, 799-844.

3. Wunderlich, J. A.; Mellor, D. P. Acta Crystallogr. 1953, 7, 130.

4. Dewar, M. J. S. Bull. Soc. Chim. Fr. 1951, C71-C79.

5. Chatt, J.; Duncanson, L. A. J. Chem. Soc. 1953, 2939-2947.

6. Frenking, G.; Frohlich, N. Chem. Rev. 2000, 100, 717-774.

7. Mingos, D. M. P. J. Organomet. Chem. 2001, 635, 1-8.

8. Johnson, J. B.; Rovis, T. Angew. Chem., Int. Ed. 2008, 47, 840-871.

9. Tolman, C. A. J. Am. Chem. Soc. 1974, 96, 2780-2789.

10. Fürstner, A.; Davies, P. W. Angew. Chem., Int. Ed. 2007, 46, 3410-3449.

11. Casey, C. P.; Lee, T.-Y.; Tunge, J. A.; Carpenetti, D. W. J. Am. Chem. Soc. 2001, 123, 10762-10763.

12. Casey, C. P.; Tunge, J. A.; Lee, T.-Y.; Fagan, M. A. J. Am. Chem. Soc. 2003, 125, 2641-2651.

13. Stoebenau, E. J.; Jordan, R. F. J. Am. Chem. Soc. 2006, 128, 8162-8175.

14. Joy, J. R.; Orchin, M. J. Am. Chem. Soc. 1959, 81, 310-311.

15. Tolman, C. A. Organometallics 1983, 2, 614-621.

16. Green, M.; Howard, J. A. K.; Spencer, J. L.; Stone, F. G. A. J. Chem. Soc., Dalton Trans. 1977, 271-277.

17. Denning, R. G.; Venanzi, L. M. J. Chem. Soc. 1963, 3241-3247.

18. Garcia, L. M.; Shupack, S. I.; Orchin, M. Inorg. Chem. 1962, 1, 893-896.

19. Chatt, J.; Shaw, B. L.; Williams, A. A. J. Chem. Soc. 1962, 3269-3270.

20. Spencer, J. L. Inorg. Synth. 1979, 19, 213-218.

21. Fitton, P.; McKeon, J. E. Chem. Commun. 1968, 4-6.

22. Otto, S.; Roodt, A.; Elding, L. I. Inorg. Chem. Commun. 2006, 9, 764-766. 
23. Scherer, W.; Eickerling, G.; Shorokhov, D.; Gullo, E.; McGrady, G. S.; Sirsch, P. New J. Chem. 2006, 30, 309-312.

24. Howard, J. A. K. Acta Crystallogr., Sect. B 1982, B38, 2896-2898.

25. Galano, A.; Alvarez-Idaboy, J. R.; Vivier-Bunge, A. Theor. Chem. Acc. 2007, 118, 597-606.

26. Gragson, J. T.; Greenlee, K. W.; Derfer, J. M.; Boord, C. E. J. Am. Chem. Soc. 1953, 75, 3344-3347.

27. Köster, R.; Arora, S.; Binger, P. Angew. Chem., Int. Ed. Engl. 1969, 8, 205-206.

28. Salaun, J.; Champion, J.; Conia, J. M. Org. Synth. 1977, 57, 36-40.

29. Laurie, V. W.; Stigliani, W. M. J. Am. Chem. Soc. 1970, 92, 1485-1488.

30. de Boer, J. S. A. M.; Stam, C. H. Recl. Trav. Chim. Pays-Bas 1993, 112, 635-638.

31. Skancke, A.; Boggs, J. E. J. Mol. Struct. 1978, 50, 173-182.

32. Traetteberg, M.; Simon, A.; Peters, E.-M.; De Meijere, A. J. Mol. Struct. 1984, 118, 333-343.

33. Bieri, G.; Burger, F.; Heilbronner, E.; Maier, J. P. Helv. Chim. Acta 1977, 60, 2213-2233.

34. Bertie, J. E.; Norton, M. G. Can. J. Chem. 1970, 48, 3889-3902.

35. Aihara, J. Bull. Chem. Soc. Jpn. 1980, 53, 3404-3407.

36. Rol, N. C.; Clague, A. D. H. Org. Magn. Res. 1981, 16, 187-194.

37. de Meijere, A.; Kozhushkov, S. Eur. J. Org. Chem. 2000, 3809-3822.

38. Nakamura, I.; Yamamoto, Y. Adv. Synth. Catal. 2002, 344, 111-129.

39. Noyori, R.; Odagi, T.; Takaya, H. J. Am. Chem. Soc. 1970, 92, 5780-5781.

40. Trost, B. M. Angew. Chem., Int. Ed. Engl. 1986, 25, 1-20.

41. Suzuki, T.; Fujimoto, H. Inorg. Chem. 2000, 39, 1113-1119.

42. Yamago, S.; Nakamura, E. J. Chem. Soc., Chem. Commun. 1988, 1112-1113.

43. Lautens, M.; Ren, Y.; Delanghe, P. H. M. J. Am. Chem. Soc. 1994, 116, 8821-8822.

44. Bräse, S.; de Meijere, A. Angew. Chem., Int. Ed. Engl. 1995, 34, 2545-2547.

45. Weintz, H.-J.; Binger, P. Tetrahedron Lett. 1985, 26, 4075-4078.

46. Nakamura, I.; Oh, B. H.; Saito, S.; Yamamoto, Y. Angew. Chem., Int. Ed. 2001, 40, 1298-1300.

47. Oh, B. H.; Nakamura, I.; Saito, S.; Yamamoto, Y. Tetrahedron Lett. 2001, 42, 62036205. 
48. Fournet, G.; Balme, G.; Gore, J. Tetrahedron 1988, 44, 5809-5820.

49. Fournet, G.; Balmea, G.; Barieux, J. J.; Gore, J. Tetrahedron 1988, 44, 5821-5832.

50. Lautens, M.; Meyer, C.; Lorenz, A. J. Am. Chem. Soc. 1996, 118, 10676-10677.

51. Chatani, N.; Takeyasu, T.; Hanafusa, T. Tetrahedron Lett. 1988, 29, 3979-3982.

52. Ishiyama, T.; Momota, S.; Miyaura, N. Synlett 1999, 1790-1792.

53. Suginome, M.; Matsuda, T.; Ito, Y. J. Am. Chem. Soc. 2000, 122, 11015-11016.

54. Barnes, S. G. J. Chem. Soc., Chem. Commun. 1980, 267-268.

55. Noyori, R.; Yamakawa, M.; Takaya, H. Tetrahedron Lett. 1978, 19, 4823-4826.

56. Trost, B. M.; Chan, D. M. T. J. Am. Chem. Soc. 1980, 102, 6359-6361.

57. Fischer, H.; Bidell, W.; Hofmann, J. J. Chem. Soc., Chem. Commun. 1990, 858-859.

58. Foerstner, J.; Kozhushkov, S.; Binger, P.; Wedemann, P.; Noltemeyer, M.; de Meijere, A.; Butenschön, H. Chem. Commun. 1998, 239-240.

59. Kozhushkov, S. I.; Foerstner, J.; Kakoschke, A.; Stellfeldt, D.; Yong, L.; Wartchow, R.; de Meijere, A.; Butenschön, H. Chem. Eur. J. 2006, 12, 5642-5647.

60. Isaeva, L. S.; Peganova, T. A.; Petrovskii, P. V.; Furman, D. B.; Zotova, S. V.; Kudryashev, A. V.; Bragin, O. V. J. Organomet. Chem. 1983, 258, 367-372.

61. Green, M.; Howard, J. A. K.; Hughes, R. P.; Kellett, S. C.; Woodward, P. J. Chem. Soc., Dalton Trans. 1975, 2007-2014.

62. Kashiwagi, T.; Yasuoka, N.; Kasai, N.; Kukudo, M. J. Chem. Soc. D 1969, 317-318.

63. Molander, G. A. Pure Appl. Chem. 2000, 72, 1745-1756.

64. Le Perchec, P.; Conia, J. M. Tetrahedron Lett. 1970, 11, 1587-1588.

65. de Meijere, A. Chem. Ber. 1974, 10\%, 1702-1713.

66. de Meijere, A.; Kozhushkov, S. I.; Spaeth, T.; Zefirov, N. S. J. Org. Chem. 1993, $58,502-505$.

67. de Meijere, A.; Kozhushkov, S.; Spaeth, T. Org. Synth. 2002, 78, 142-151.

68. Gleiter, R.; Haider, R.; Conia, J.-M.; Barnier, J.-P.; De Meijere, A.; Weber, W. J. Chem. Soc., Chem. Commun. 1979, 130-132.

69. Brammer, C. N.; Nelson, D. J.; Li, R. Tetrahedron Lett. 2007, 48, 3237-3241.

70. de Meijere, A. Angew. Chem., Int. Ed. Engl. 1979, 18, 809-826.

71. de Meijere, A.; Erden, I.; Weber, W.; Kaufmann, D. J. Org. Chem. 1988, 53, 152161. 
72. Binger, P.; Kozhushkov, S. I.; Wedemann, P.; de Meijere, A. Eur. J. Org. Chem. 1998, 113-119.

73. Oishi, Y.; Sakamoto, E.; Fujimoto, H. Inorg. Chem. 1996, 35, 231-238.

74. Nüske, H.; Bräse, S.; Kozhushkov, S. I.; Noltemeyer, M.; Es-Sayed, M.; de Meijere, A. Chem. Eur. J. 2002, 8, 2350-2369.

75. Kaufmann, D.; de Meijere, A. Tetrahedron Lett. 1979, 20, 779-782.

76. de Meijere, A.; Nüske, H.; Es-Sayed, M.; Labahn, T.; Schroen, M.; Bräse, S. Angew. Chem., Int. Ed. 1999, 38, 3669-3672.

77. Pohlmann, T.; de Meijere, A. Org. Lett. 2000, 2, 3877-3879.

78. Butenschön, H.; Kettenbach, R. T.; Krüger, C. Angew. Chem., Int. Ed. Engl. 1992, 31, 1066-1068.

79. Hoyte, S. A.; Spencer, J. L. Organometallics 2011, 30, 5415-5423.

80. Blue, E. D.; Davis, A.; Conner, D.; Gunnoe, T. B.; Boyle, P. D.; White, P. S. Journal of the American Chemical Society 2003, 125, 9435-9441.

81. Fanjul, T.; Eastham, G.; Floure, J.; Forrest, S. J. K.; Haddow, M. F.; Hamilton, A.; Pringle, P. G.; Orpen, A. G.; Waugh, M. Dalton Trans. 2012, 42, 100.

82. Tolman, C. A. Chem. Rev. 1977, 77, 313-348.

83. Carr, N.; Mole, L.; Orpen, A. G.; Spencer, J. L. J. Chem. Soc., Dalton Trans. 1992, 2653-2662.

84. Carmichael, D.; Hitchcock, B.; Nixon, J. F.; Pidcock, A. J. Chem. Soc., Chem. Commun. 1988, 1554-1556.

85. Tulip, T. H.; Yamagata, T.; Yoshida, T.; Wilson, R. D.; Ibers, J. A.; Otsuka, S. Inorg. Chem. 1979, 18, 2239-2250.

86. Head, R. A. Inorg. Synth. 1990, 28, 132-135.

87. Rao, C. G. Org. Prep. Proced. Int. 1980, 12, 225-228.

88. Renk, E.; Shafer, P. R.; Graham, W. H.; Mazur, R. H.; Roberts, J. D. J. Am. Chem. Soc. 1961, 83, 1987-1989.

89. Eraker, J.; Roemming, C. Acta Chem. Scand. 1967, 21, 2721-2726.

90. Asker, K. A.; Hitchcock, P. B.; Moulding, R. P.; Seddon, K. R. Inorg. Chem. 1990, 29, 4146-4148.

91. Saito, S.; Tando, K.; Kabuto, C.; Yamamoto, Y. Organometallics 2000, 19, 37403743 .

92. Zhang, K.; Hu, J.; Chan, K. C.; Wong, K. Y.; Yip, H. K. J. Eur. J. Inorg. Chem. 2007, 2007, 384-393. 
93. Appleton, T. G.; Clark, H. C.; Manzer, L. E. Coord. Chem. Rev. 1973, 10, 335-422.

94. Godleski, S. A.; Gundlach, K. B.; Valpey, R. S. Organometallics 1985, 4, 296-302.

95. Nicolaides, A.; Smith, J. M.; Kumar, A.; Barnhart, D. M.; Borden, W. T. Organometallics 1995, 14, 3475-3485.

96. Uddin, J.; Dapprich, S.; Frenking, G.; Yates, B. F. Organometallics 1999, 18, 457465.

97. Yates, B. F. J. Organomet. Chem. 2001, 635, 142-152.

98. Hersh, W. H. J. Chem. Educ. 1997, 74, 1485-1489.

99. Ault, A. J. Chem. Educ. 1970, 47, 812-818.

100. Yasuda, H.; Nakamura, A. Angew. Chem., Int. Ed. Engl. 1987, 26, 723-742.

101. Erker, G.; Krueger, C.; Mueller, G. In Adv. Organomet. Chem.; Elsevier, 1985; Vol. 24, pp 1-39.

102. Mashima, K.; Kaidzu, M.; Nakayama, Y.; Nakamura, A. Organometallics 1997, 16, $1345-1348$.

103. Murakami, M.; Itami, K.; Ito, Y. Organometallics 1999, 18, 1326-1336.

104. Hitchcock, P. B.; Mason, R. Chem. Commun. 1967, 242-243.

105. Hunt, R. L.; Roundhill, D. M.; Wilkinson, G. J. Chem. Soc. A 1967, 982-984.

106. Wakatsuki, Y.; Aoki, K.; Yamazaki, H. J. Chem. Soc., Dalton Trans. 1986, 11931199 .

107. Gausing, W.; Wilke, G. Angew. Chem., Int. Ed. Engl. 1981, 20, 186-187.

108. Roundhill, D. M.; Lawson, D. N.; Wilkinson, G. J. Chem. Soc. A 1968, 845-849.

109. Hughes, R. P.; Rose, P. R.; Rheingold, A. L. Organometallics 1993, 12, 3109-3117.

110. Murakami, M.; Itami, K.; Ito, Y. J. Am. Chem. Soc. 1996, 118, 11672-11673.

111. Bleeke, J. R.; Haile, T.; Chiang, M. Y. Organometallics 1991, 10, 19-21.

112. Bleeke, J. R.; Behm, R. J. Am. Chem. Soc. 1997, 119, 8503-8511.

113. Paneque, M.; Poveda, M. L.; Salazar, V.; Gutierrez-Puebla, E.; Monge, A. Organometallics 2000, 19, 3120-3126.

114. Paneque, M.; Poveda, M. L.; Rendón, N. Eur. J. Inorg. Chem. 2011, 2011, 19-33.

115. Barker, G. K.; Green, M.; Howard, J. A. K.; Spencer, J. L.; Stone, F. G. A. J. Chem. Soc., Dalton Trans. 1978, 1839-1847.

116. Barrau, J.; Rima, G.; El Amraoui, T. Organometallics 1998, 17, 607-614. 
117. Mashima, K.; Sugiyama, H.; Kanehisa, N.; Kai, Y.; Yasuda, H.; Nakamura, A. J. Am. Chem. Soc. 1994, 116, 6977-6978.

118. Zhao, L.; de Meijere, A. Adv. Synth. Catal. 2006, 248, 2484-2492.

119. Harrison, N. C.; Murray, M.; Spencer, J. L.; Stone, F. G. A. J. Chem. Soc., Dalton Trans. 1978, 1337-1342.

120. Van Nes, G. J. H.; Vos, A. Acta Crystallogr., Sect. B 1979, 35, 2593-2601.

121. Howard, J. A. K.; Mitrprachachon, P.; Roy, A. J. Organomet. Chem. 1982, 235, $375-381$.

122. Lentz, D.; Bach, A.; Buschmann, J.; Luger, P.; Messerschmidt, M. Chem. Eur. J. 2004, 10, 5059-5066.

123. Allan, K. M. Unpublished work.

124. Mmongoyo, J. A.; Mgani, Q. A.; Mdachi, S. J. M.; Pogorzelec, P. J.; ColeHamilton, D. J. Eur. J. Lipid Sci. Technol. 2012, 114, 1183-1192.

125. Núñez Magro, A. A.; Eastham, G. R.; Cole-Hamilton, D. J. Dalton Trans. 2009, 4683.

126. Rucklidge, A. J.; Morris, G. E.; Slawin, A. M.; Cole-Hamilton, D. J. Helv. Chim. Acta 2006, 89, 1783-1800.

127. Tooze, R. P.; Eastham, G. R.; Whiston, K.; Wang, X. L. Process for the Carbonylation of Ethylene and Catalyst System for Use Therein, Patent Application, 1996, WO 1996/019434 A1.

128. Eastham, G. R.; Tooze, R. P.; Heaton, B. T.; Iggo, J. A.; Whyman, R.; Zacchini, S. Chem. Commun. 2000, 609-610.

129. Wiester, M. J.; Braunschweig, A. B.; Yoo, H.; Mirkin, C. A. Inorg. Chem. 2010, 49, 7188-7196.

130. Oliveri, C. G.; Gianneschi, N. C.; Nguyen, S. T.; Mirkin, C. A.; Stern, C. L.; Wawrzak, Z.; Pink, M. J. Am. Chem. Soc. 2006, 128, 16286-16296.

131. Rosen, M. S.; Spokoyny, A. M.; Machan, C. W.; Stern, C.; Sarjeant, A.; Mirkin, C. A. Inorg. Chem. 2011, 50, 1411-1419.

132. Spokoyny, A. M.; Machan, C. W.; Clingerman, D. J.; Rosen, M. S.; Wiester, M. J.; Kennedy, R. D.; Stern, C. L.; Sarjeant, A. A.; Mirkin, C. A. Nature Chem. 2011, 3, $590-596$.

133. Carr, N.; Dunne, B. J.; Orpen, A. G.; Spencer, J. L. J. Chem. Soc., Chem. Commun. 1988, 926 .

134. Phillips, R.; Puddephatt, R. J. Organomet. Chem. 1977, 136, C52-C54.

135. Phillips, R. L.; Puddephatt, R. J. J. Chem. Soc., Dalton Trans. 1978, 1736-1739.

136. Noyori, R.; Takaya, H. J. Chem. Soc. D 1969, 525-525. 
137. Nüske, H.; Noltemeyer, M.; de Meijere, A. Angew. Chem., Int. Ed. 2001, 40, 34113413 .

138. Yucel, B.; Arve, L.; de Meijere, A. Tetrahedron 2005, 61, 11355-11373.

139. Jones, N. L.; Ibers, J. A. Organometallics 1982, 1, 326-330.

140. Hahn, C. Chem. Eur. J. 2004, 10, 5888-5899.

141. Clark, H. C.; Kurosawa, H. Inorg. Chem. 1973, 12, 357-362.

142. Kurosawa, H.; Yoshida, G. J. Organomet. Chem. 1976, 120, 297-311.

143. Boag, N. M.; Green, M.; Spencer, J. L.; Stone, F. G. A. J. Chem. Soc., Dalton Trans. 1980, 1200-1207.

144. Sano, M.; Nakamura, Y. J. Chem. Soc., Dalton Trans. 1991, 417-424.

145. Carturan, G.; Belluco, U.; Del Pra, A.; Zanotti, G. Inorg. Chim. Acta 1979, 33, $155-160$.

146. Koppel, I. A.; Koppel, J.; Pihl, V.; Leito, I.; Mishima, M.; Vlasov, V. M.; Yagupolskii, L. M.; Taft, t. 1. R. W. J. Chem. Soc., Perkin Trans. 2 2000, 1125-1133.

147. Kütt, A.; Rodima, T.; Saame, J.; Raamat, E.; Mäemets, V.; Kaljurand, I.; Koppel, I. A.; Garlyauskayte, R. Y.; Yagupolskii, Y. L.; Yagupolskii, L. M.; Bernhardt, E.; Willner, H.; Leito, I. J. Org. Chem. 2011, 76, 391-395.

148. Tsutsumi, H.; Sunada, Y.; Shiota, Y.; Yoshizawa, K.; Nagashima, H. Organometallics 2009, 28, 1988-1991.

149. Cavallo, L.; Macchioni, A.; Zuccaccia, C.; Zuccaccia, D.; Orabona, I.; Ruffo, F. Organometallics 2004, 23, 2137-2145.

150. Cooper, D. G.; Powell, J. Inorg. Chem. 1976, 15, 1959-1968.

151. Chisholm, M. H.; Clark, H. C.; Manzer, L. E.; Stothers, J. B. J. Am. Chem. Soc. 1972, 94, 5087-5089.

152. Fanjul, T.; Eastham, G.; Haddow, M. F.; Hamilton, A.; Pringle, P. G.; Orpen, A. G.; Turner, T. P. W.; Waugh, M. Catal. Sci. Tech. 2012, 2, 937.

153. Fanjul, T.; Eastham, G.; Fey, N.; Hamilton, A.; Orpen, A. G.; Pringle, P. G.; Waugh, M. Organometallics 2010, 29, 2292-2305.

154. Becke, A. D. J. Chem. Phys. 1993, 98, 5648-5652.

155. Lee, C.; Yang, W.; Parr, R. G. Phys. Rev. B 1988, 37, 785-789.

156. Vosko, S. H.; Wilk, L.; Nusair, M. Can. J. Phys. 1980, 58, 1200-1211.

157. Stephens, P. J.; Devlin, F. J.; Chabalowski, C. F.; Frisch, M. J. J. Phys. Chem. 1994, 98, 11623-11627.

158. Weingend, F.; Ahlrichs, R. Phys. Chem. Chem. Phys. 2005, 7, 3297-3305. 
159. Bryndza, H. E. J. Chem. Soc., Chem. Commun. 1985, 1696.

160. Stockland, R. A.; Foley, S. R.; Jordan, R. F. J. Am. Chem. Soc. 2003, 125, 796-809.

161. Stockland, R.; Jordan, R. J. Am. Chem. Soc. 2000, 122, 6315-6316.

162. Foley, S. R.; Stockland, R. A.; Shen, H.; Jordan, R. F. J. Am. Chem. Soc. 2003, 125, 4350-4361.

163. Boone, H. W.; Athey, P. S.; Mullins, M. J.; Philipp, D.; Muller, R.; Goddard, W. A. J. Am. Chem. Soc. 2002, 124, 8790-8791.

164. von Schenck, H.; Strömberg, S.; Zetterberg, K.; Ludwig, M.; Åkermark, B.; Svensson, M. Organometallics 2001, 20, 2813-2819.

165. Philipp, D. M.; Muller, R. P.; Goddard, W. A.; Storer, J.; McAdon, M.; Mullins, M. J. Am. Chem. Soc. 2002, 124, 10198-10210.

166. Zhao, H.; Ariafard, A.; Lin, Z. Organometallics 2006, 25, 812-819.

167. Friedrich, H. B.; Moss, J. R. Adv. Organomet. Chem. 1991, 33, 235-290.

168. Halpern, J.; Jewsbury, R. J. Organomet. Chem. 1979, 181, 223-232.

169. Fanizzi, F.; Maresca, L.; Pacifico, C.; Natile, G.; Lanfranchi, M.; Tiripicchio, A. Eur. J. Inorg. Chem. 1999, 1999, 1351-1358.

170. Deeming, A. J.; Shaw, B. L. J. Chem. Soc. A 1971, 376.

171. Schmidt, E. K. G. J. Organomet. Chem. 1980, 204, 393-403.

172. Burns, R. J.; Bulkowski, P. B.; Stevens, S. C. V.; Baird, M. C. J. Chem. Soc., Dalton Trans. 1974, 415.

173. Churchill, M. R.; Fennessey, J. P. Inorg. Chem. 1967, 6, 1213-1220.

174. Hensley, D. W.; Stewart, R. P., Jr Inorg. Chem. 1978, 17, 905-910.

175. Hughes, R. P.; Sweetser, J. T.; Tawa, M. D.; Williamson, A.; Incarvito, C. D.; Rhatigan, B.; Rheingold, A. L.; Rossi, G. Organometallics 2001, 20, 3800-3810.

176. Hughes, R. P.; Overby, J. S.; Williamson, A.; Lam, K.-C.; Concolino, T. E.; Rheingold, A. L. Organometallics 2000, 19, 5190-5201.

177. King, R. B.; Bond, A. J. Am. Chem. Soc. 1974, 96, 1334-1338.

178. Albrecht, M.; Gossage, R.; Lutz, M.; Spek, A.; van Koten G, Chem. Eur. J. 2000, $6,1431-1445$.

179. Roulet, R.; Barbey, C. Helv. Chim. Acta 1973, 56, 2179-2186.

180. Al-Najjar, I.; Green, M. J. Chem. Soc., Chem. Commun. 1977, 212-213.

181. Al-Najjar, I. M. Inorg. Chim. Acta 1987, 128, 93-104. 
182. Anderson, G. K.; Davies, J. A.; Schoeck, D. J. Inorg. Chim. Acta 1983, 76, L251L252.

183. Anderson, B. G.; Hoyte, S. A.; Spencer, J. L. In press.

184. Darensbourg, D. J.; Decuir, T. J.; Stafford, N. W.; Robertson, J. B.; Draper, J. D.; Reibenspies, J. H.; Kathó, A.; Joó, F. Inorg. Chem. 1997, 36, 4218-4226.

185. Meij, A. M. M.; Otto, S.; Roodt, A. Inorg. Chim. Acta 2005, 358, 1005-1011.

186. Rigamonti, L.; Rusconi, M.; Manassero, C.; Manassero, M.; Pasini, A. Inorg. Chim. Acta 2010, 363, 3498-3505.

187. Boag, N. M.; Green, M.; Grove, D. M.; Howard, J. A. K.; Spencer, J. L.; Stone, F. G. A. J. Chem. Soc., Dalton Trans. 1980, 2170.

188. Slack, D. A.; Baird, M. C. Inorg. Chim. Acta 1977, 24, 277-280.

189. Kauffman, G. B. Inorg. Synth. 1963, 7, 249-253.

190. Price, J.; Williamson, A.; Schramm, R.; Wayland, B. Inorg. Chem. 1971, 11, 12801284 .

191. Fraccarollo, D.; Bertani, R.; Mozzon, M.; Belluco, U.; Michelin, R. A. Inorg. Chim. Acta 1992, 201, 15-22.

192. Vaughan, T. F.; Koedyk, D. J.; Spencer, J. L. Organometallics 2011, 30, 5170-5180.

193. Allan, K. M.; Spencer, J. L. Tetrahedron Lett. 2009, 50, 834-835.

194. Dolomanov, O. V.; Bourhis, L. J.; Gildea, R. J.; Howard, J. A. K.; Puschmann, H. J. J. Appl. Crystallogr. 2009, 42, 339-341.

195. Sheldrick, G. M. Acta Crystallogr., Sect. A 2008, 64, 112-122.

196. Frisch, M. J. et al. Gaussian 09 Revision B.01, Gaussian Inc. Wallingford CT, 2009.

197. Glendening, E. D.; Reed, A. E.; Carpenter, J. E.; Weinhold, F. NBO Version 3.1, E. D. 